


\section{VNiVERSIDAD

CAMPUS DE EXCELENCIA INTERNACIONAL

Título: Análisis de determinantes de la calidad de vida de alumnos con necesidades especificas de apoyo educativo y sin ellas.

\section{Presentado por: Beatriz Ruiz Fernández}

Supervisado por: María Gómez Vela, Ramón Fernández Pulido y María Begoña Orgaz Baz

Este trabajo se ha llevado a cabo con la colaboración del Instituto Universitario de Integración a la Comunidad (INICO)de la Universidad de Salamanca. Asimismo, parte de su estudio ha sido financiado por la Fundación Memoria de D. Samuel Solórzano Barruso, gestionada por la Universidad de Salamanca.

(C) Diseño y Maquetación: Davide Castorina

(C) Gami Editorial

Impreso por Impresión Digital Gami

Avda. Constitución, 24 Bajo, Granada

Tel. $958290610 / 958273090$

www.impresiondigitalgami.com - info@impresiondigitalgami.com

Este libro esta impreso en papel 100\% libre de cloro

Todos los derechos reservados. Esta publicación no puede ser reproducida, ni en todo ni en parte, ni registrada en, o transmitida por, un sistema de recuperación de información, en ninguna forma ni por ningún medio, sea mecánico, fotoquímico, electrónico, magnético, electro óptico, por fotocopia, o cualquier otro, sin el permiso previo por escrito de la editorial. 


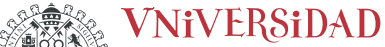

16.0.

CAMPUS DE EXCELENCIA INTERNACIONAL

FACULTAD DE PSICOLOGÍA

Programa de Doctorado en Psicología

Departamento de Personalidad, Evaluación y Tratamiento Psicológico

\title{
Análisis de determinantes de la calidad de vida de alumnos con necesidades específicas de apoyo educativo y sin ellas
}

Autora: Beatriz Ruiz Fernández

\author{
Dirigida por: \\ María Gómez Vela \\ Ramón Fernández Pulido \\ María Begoña Orgaz Baz
}





\title{
Universidad de Salamanca
}

Facultad de Psicología

Programa de Doctorado en Psicología

Departamento de Personalidad, Evaluación y Tratamiento Psicológico

\section{Análisis de Determinantes de la Calidad de Vida de Alumnos con Necesidades Específicas de Apoyo Educativo y sin Ellas}

\author{
Memoria Presentada por la Lda. Beatriz Ruiz Fernández \\ para optar al título de Doctora
}

Fdo. Beatriz Ruiz Fernández

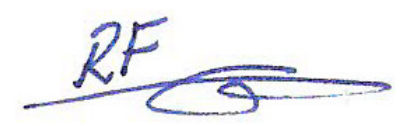

$\mathrm{V}^{\circ} \mathrm{B}^{\circ}$ de los Directores de la Tesis Doctoral

Fdo. María Gómez Vela

Profesora titular

Universidad de Salamanca

Investigadora del INICO

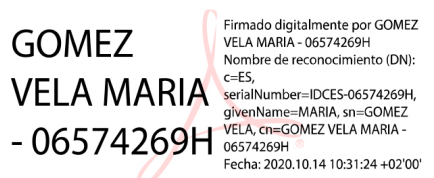

Fdo. Ramón Fernández Pulido

Profesor titular

Universidad de Salamanca

Investigador del INICO

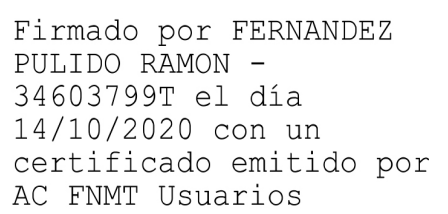

PULIDO RAMON -

34603799T el día

$14 / 10 / 2020$ con un

AC FNMT Usuarios

Fdo. María Begoña Orgaz Baz

Profesora titular

Universidad de Salamanca

Investigadora del INICO

Firmado por ORGAZ

BAZ MARIA BEGOÑA -

$14592505 \mathrm{~V}$ el día

$14 / 10 / 2020$ con un

certificado emitido 

La doctoranda Beatriz Ruiz Fernández y los supervisores de la tesis Prof. María Gómez Vela, Prof. Ramón Fernández Pulido y Prof. María Begoña Orgaz Baz garantizamos, al firmar esta tesis doctoral que el trabajo ha sido realizado por la doctoranda bajo la dirección de los directores de tesis y hasta donde nuestro conocimiento alcanza, en la realización del trabajo se han respetado los derechos de otros autores al ser citados, cuando se han utilizado sus resultados y/o publicaciones.

Salamanca, 14 de octubre de 2020

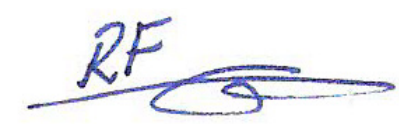

Fdo. Beatriz Ruiz Fernández

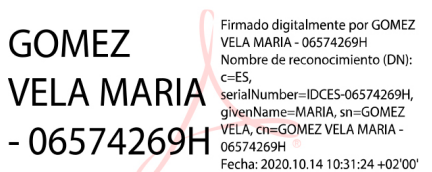

Fdo. María Gómez Vela

Profesora titular

Universidad de Salamanca

Investigadora del INICO

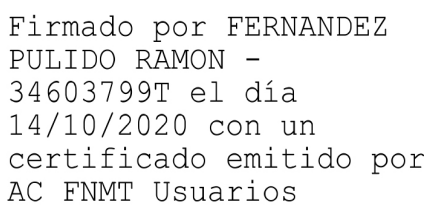

Fdo. Ramón Fernández Pulido

Profesor titular

Universidad de Salamanca

Investigador del INICO

Firmado por ORGAZ

BAZ MARIA BEGOÑA -

$14592505 \mathrm{~V}$ el día

$14 / 10 / 2020$ con un

certificado emitido

Fdo. María Begoña Orgaz Baz

Profesora titular

Universidad de Salamanca

Investigadora del INICO 

INVICTUS

Más allá de la noche que me cubre negra como el abismo insondable, doy gracias a los dioses que pudieran existir por mi alma invicta.

En las azarosas garras de las circunstancias nunca me he lamentado ni he pestañeado.

Sometido a los golpes del destino mi cabeza está ensangrentada, pero erguida. Más allá de este lugar de cólera y lágrimas donde yace el Horror de la Sombra, la amenaza de los años me encuentra, y me encontrará, sin miedo. No importa cuán estrecho sea el portal, cuán cargada de castigos la sentencia, soy el amo de mi destino: soy el capitán de mi alma.

William Ernest Henley (Long John Silver) leído por Nelson Mandela 

Érase una vez un guerro pacífico tan valiente y amoroso, que no existía frontera que le impidiese llegar al corazón de las personas y nutrir sus maravillas. 

A mi Padre,

Quien con amor me enseñó el valor de la educación. 



\section{Presentación general}

El desarrollo de esta tesis doctoral se ha llevado a cabo en la Universidad de Salamanca, con la colaboración económica de la Fundación Memoria de D. Samuel Solórzano Barruso. Esta Fundación convoca anualmente ayudas dirigidas a la financiación de Proyectos de Investigación realizados en Centros de la Universidad de Salamanca. El trabajo de investigación de la presente tesis doctoral ha sido varias veces presentado a dichas convocatorias, siendo concedida su ayuda dos de ellas (convocatorias de 2014 y 2018).

El objetivo general de esta tesis es analizar los resultados personales en calidad de vida, participación en actividades de ocio y resiliencia infantil, así como la relación que se establece entre estas tres variables y el peso de otras variables personales o familiares en dichos resultados, a fin de comprender el papel facilitador o limitador de todas ellas en el bienestar y desarrollo integral de niños en condiciones de vida diversas.

Su investigación se encuadra en la actual concepción sobre Desarrollo Infantil Positivo, desde un enfoque sistémico de interacción dinámica entre el niño y su ambiente. Desde este marco teórico el trabajo analiza la conexión e influencia entre diferentes factores personales y ambientes presentes en el contexto de desarrollo infantil y los resultados personales de bienestar, participación y resiliencia de alumnos de Primaria, con necesidades específicas de apoyo educativo y sin ellas, en entornos escolares ordinarios del sistema educativo español.

En la primera parte de la tesis se presenta de manera pormenorizada este marco teórico de referencia, siendo su objetivo contextualizar el desarrollo empírico de la investigación realizada. En la segunda parte, a través de tres capítulos empíricos, se analizan los resultados personales en calidad de vida, participación en actividades de ocio y tiempo libre y la resiliencia de alumnos de Primaria con necesidades específicas de apoyo educativo y sin ellas, la relación que se establece entre estas tres variables y el peso de otras variables de tipo personal, familiar y escolar en estos 
resultados personales, con la finalidad de comprender el papel facilitador o de obstáculo de todas estas variables en el bienestar y desarrollo infantil integral.

Por último, se exponen las principales conclusiones derivadas de los resultados obtenidos en la parte empírica, las aportaciones científicas realizadas y sus implicaciones para el campo práctico, las limitaciones de la investigación, así como los pasos futuros que deben de guiar esta línea de trabajo. 


\section{INDICE}

INDICE DE FIGURAS - X

INDICE DETABLA XI

PRIMERA PARTE - Justificación Teórica $\quad 1$

CAPITULO 1 - Concepción del Desarrollo Infantil Positivo de Niños 3 en Condiciones Diversas de Vida

Introducción

1.1. Desarrollo Infantil 5

1.1.2. Desarrollo Infantil Positivo 8

1.1.2.1. Desarrollo Positivo como Proceso 8

1.1.2.2. Desarrollo Positivo como Programación Infantil y Juvenil 12

1.2. La Diversidad en la Infancia

1.2.1. La Clasificación Internacional del Funcionamiento, de 15 la Discapacidad y de la Salud, y su Versión para Niños y Jóvenes, (OMS, 2001, 2007)

\subsection{Resultados Personales Significativos en la Infancia 18}

1.3.1. Calidad de Vida Infantil 18

1.3.2. Participación Infantil 20

1.3.3. Resiliencia Infantil 22

1.4. Desarrollo Infantil Positivo Aplicado al Contexto 26 Educativo

1.4.1. Un Modelo de Educación Basado en el Bienestar y Desarrollo Pleno del Niño

1.4.1.1. Educación Inclusiva $\quad 28$

1.4.2. Alumnos con Necesidades Específicas de Apoyo Educativo 29 (NEAE)

1.5. Conclusiones 
2.1. Antecedentes Teóricos del Concepto Calidad de Vida

2.2. Calidad de Vida, Concepto y Definición

2.3. El Modelo de Calidad de Vida de Schalock et al. (2002, 2003)

2.3.1. El Modelo de Calidad de Vida Individual de Schalock et al. (2002, 2003) Aplicado a Población Infantil

2.3.1.1. Conceptualización

2.4. Evaluación de la Calidad de Vida Infantil

2.5. Aplicación del Concepto Calidad de Vida a Población Infantil con NEAE y Sin Ellas

2.5.1. Aplicación del Concepto CV Infantil a Nivel del Microsistema

2.5.2. Aplicación del Concepto CV Infantil a Nivel Mesosistémico

2.5.3. Aplicación del Concepto CV Infantil a Nivel del Macrosistema

2.6. Conclusiones Actividades de Ocio y Tiempo Libre

\section{Introducción}

3.1. Participación en Actividades de Ocio y Tiempo Libre

3.2. Desarrollo Conceptual del Constructo Participación en Actividades Diversas de Ocio y Tiempo Libre

3.2.1. Asistencia y Participación

3.2.2. Raíces Conceptuales de la Participación: Perspectiva Social e Individual

3.3. Factores del Contexto que Afectan a la Participación de los Niños en Actividades de Ocio y Recreo (King et al., 2003) 
3.3.1. Factores que Influyen en la Participación en Actividades de

Ocio y Tiempo Libre

3.3.1.1. Factores Relacionados con el Niño $\quad 95$

3.3.1.1.1. Asistencia: Diversidad y Frecuencia de Participación 95

3.3.1.1.2. Intensidad: Disfrute y Preferencia de Participación 97

3.3.1.2. Factores Relacionados con el Ambiente 98

3.3.1.2.1. Variables del Ambiente Familiar 98

3.3.1.2.2. Variables del Ambiente Comunitario 99

3.3.1.2.2.1. Factores Físicos 99

$\begin{array}{ll}3.3 .1 .2 .2 .2 \text {. Factores Sociales } & 101\end{array}$

3.3.1.2.2.3. Factores Actitudinales $\quad 102$

3.4 Evaluación de la Participación de Niños Con y Sin 104

Discapacidad en Actividades de Ocio y Tiempo Libre

3.5. Participación Infantil en Actividades de Ocio y Calidad 108 deVida

3.6. Conclusiones

CAPITULO 4 - Conceptualización de Resiliencia Infantil 117

$\begin{array}{lr}\text { Introducción } & 119\end{array}$

4.1. Desarrollo Conceptual del Constructo de Resiliencia 121

4.1.1. Antecedentes y Consecuentes de la Resiliencia 123

4.1.1.1. La Adversidad 123

4.1.1.2. La Adaptación Positiva 124

4.1.2. Atributos 125

4.1.2.1. Primera Etapa de Investigación 126

4.1.2.2. Segunda Etapa de Investigación $\quad 127$

$\begin{array}{lr}\text { 4.1.2.2.1. Modelo Compensatorio } & 128\end{array}$

$\begin{array}{lr}\text { 4.1.2.2.2. Modelo de Protección } & 128\end{array}$

$\begin{array}{lr}\text { 4.1.2.2.3. Modelo de Exposición } & 129\end{array}$

$\begin{array}{ll}\text { 4.1.2.3. Tercera Etapa de Investigación } & 130\end{array}$ 
4.1.2.4. Cuarta Etapa de Investigación

4.2. Instrumentos para Medir la Resiliencia Infantil

4.3. Modelo Socio-Ecológico en Resiliencia (Ungar, 2004, 2008, 2011)

4.3.1. Conceptualización Socio-Ecológica de la Resiliencia Infantil

4.3.2. Evaluación Socio-Ecológica de la Resiliencia Infantil y Juvenil

\subsection{Resiliencia Infantil y Discapacidad}

4.5 Resiliencia Infantil y Calidad de Vida

4.6. Conclusiones

156

SEGUNDA PARTE - Desarrollo Empírico

INTRODUCCIÓN PARTE EMPÍRICA

CAPITULO 5 - Adaptación de la CYRM-28 a Población Infantil Española de Alumnos con Necesidades Específicas de Apoyo Educativo y Sin Ellas

\section{Introducción}

\subsection{Planteamiento Inicial}

5.1.1. La Medida de Resiliencia Infantil y Juvenil (CYRM)

5.1.2. La Medida de Resiliencia para Población Infantil con NEAE y Sin Ellas

\subsection{Método}

5.2.1. Procedimiento

5.2.1.1. Etapa I: Permiso Legal de los Autores

5.2.1.2. Etapa II: Adaptación de la CYRM-28 a Contexto Infantil Español

5.2.1.3. Etapa III: Revisión por Grupos Focales

5.2.1.4. Etapa IV: Administración a una Muestra de Alumnos de Primaria 
5.2.3.1. Etapa V: Análisis Estadísticos 185

5.2.3.1.1. Consistencia y Validez de la Medida de Resiliencia 185

$\begin{array}{lr}\text { 5.2.3.1.2. Evidencias de validez externa } & 189\end{array}$

\subsection{Resultados}

189

5.3.1. Análisis Descriptivos 189

5.3.2. Análisis Validez Interna 191

5.3.3. Análisis Validez Externa 201

5.4. Discusión 204

5.5. Conclusiones 209

CAPITULO 6 - Variables Personales y Ambientales Asociadas a los 211 Resultados Personales en Calidad de Vida, Participación y Resiliencia de Alumnos de Primaria con NEAE y Sin Ellas

Introducción

6.1. Planteamiento Inicial 214

6.1.1. Objetivos de Estudio 219

6.1.1.1. Objetivo General $\quad 219$

6.1.1.2. Objetivos Específicos $\quad 219$

\subsection{Método 220}

6.2.1. Participantes 222

6.2.2. Instrumentos 225

6.2.2.1. El Cuestionario de Calidad de Vida Kidscreen-27 (Ravens- 225

Sieberer et al., 2007)

6.2.2.2. La Medida de Resiliencia CYRM-22 (Ruiz et al., en prensa) 226

6.2.2.3. Cuestionario de Participación en Actividades de Ocio y 227

Tiempo Libre CAPE-PAC (King et al., 2007) 
6.2.2.4. Cuestionario de Evaluación de Variables Personales y

Ambientales Relacionadas con el Desarrollo Positivo del Niño

\subsubsection{Procedimiento}

6.2.4. Análisis Estadísticos

\subsection{Resultados}

6.3.1. Análisis Descriptivos

6.3.1.1. Puntuaciones Generales en Resultados Personales de los Alumnos de Primaria

\subsubsection{Análisis Inferenciales}

6.3.2.1. Análisis de la Influencia de Variables Personales en los

Resultados Personales de Alumnos de Primaria

6.3.2.1.1. Diferencias en Función de la Presencia de NEAE

6.3.2.1.2. Diferencias en Función del Género

6.3.2.1.3. Diferencias en función de la Comunidad Autónoma

6.3.2.2. Análisis de la Influencia de Variables Educativas en los

Resultados Personales de Alumnos de Primaria Informadas por los Propios Alumnos

6.3.2.2.1. Diferencias en Función del Curso Escolar

6.3.2.2.2. Diferencia en Función de la Realización de Asambleas en el Aula

6.3.2.2.3. Diferencias en Función de la Seriedad con la que los

Docentes Toman en Cuenta la Opinión de los Alumnos

6.3.2.2.4. Diferencias en Función de Hablar de la Diversidad del Alumnado en Clase

6.3.2.2.5. Diferencias en Función de Hablar con el Tutor sobre la

Propia Forma de Aprender

6.3.2.3. Análisis de la Influencia de Variables Educativas en los

Resultados Personales de los Alumnos Informadas por los Docentes

6.3.2.3.1. Diferencias en Función de la Categoría de NEAE de los

6.3.2.3.2. Diferencias en Función de los Años de Actividad Docente 
6.3.2.3.4. Diferencias en Función de la Presencia de Aseos Adaptados

en el Centro Educativo

6.3.2.3.5. Diferencias en Función de la Presencia de Aulas Amplias

6.3.2.3.6. Diferencias en Función de Material Escolar Adaptado

6.3.2.3.7. Diferencias en Función de Patio Escolar Adaptado

6.3.2.4. Análisis de la Influencia de Variables Familiares en los

Resultados Personales de los Alumnos Informadas por los Progenitores

6.3.2.4.1. Diferencias en Función del Rango de Edad

6.3.2.4.2. Diferencias en Función del Nivel Educativo

6.3.2.4.3. Diferencias en Función del Estatus Laboral

6.3.2.4. Diferencias en Función de los Ingresos Económicos

6.3.2.4.5. Diferencias en Función de Miembro/s Dedicado/s a la

Crianza del Hijo

6.3.2.4.6. Diferencias en Función de ser Miembros de una Asociación

Proveedora de Servicios

\subsection{Discusión}

6.4.1. Resultados Personales Generales de los Alumnos de Primaria

6.4.1.1. Calidad de Vida Infantil

6.4.1.2. Recursos Personales y Sociales para la Resiliencia

6.4.1.3. Participación en Actividades de Ocio y Tiempo Libre por Alumnos de Primaria

6.4.2.1. Presencia de NEAE

6.4.2.2. Género

6.4.2.3. Localización Geográfica

6.4.3. Influencia deVariables Educativas en los Resultados Personales de los Alumnos de Primaria

6.4.3.3. Desarrollo de Actividades Inclusivas en Clase 255

6.4.3.4. Recursos Físicos y Materiales del Centro 256 
6.4.4. Influencia de Variables familiares en los Resultados Personales

de los Alumnos

6.4.4.1. Estatus Cultural y Socioeconómico de los Padres

6.4.4.2. Crianza y Cuidado del Hijo

6.4.4.3. Miembros de Asociaciones Proveedoras de Servicios

CAPITULO 7 - El Papel de la Resiliencia y la Participación en la Calidad de Vida Infantil

Introducción

7.1. Planteamiento Inicial

7.1.1. Objetivos de Estudio

7.1.1.1. Objetivo General

7.1.1.2. Objetivos Específicos

\subsection{Método}

7.2.1. Participantes

7.2.2. Procedimiento

7.2.3. Instrumentos

7.2.4. Análisis

7.2.4.1. Modelos de Regresión Lineal Múltiple

7.2.4.2. Análisis de Efectos de Moderación con Process

\subsection{Resultados}

7.3.1. Análisis Preliminares

7.3.2. Análisis Principales

7.3.2.1. Variables Predictivas de la Calidad de Vida Infantil 
7.3.2.2. Efectos de Moderación en Calidad de Vida Infantil

7.3.2.2.1. Efectos de Moderación sobre los Efectos Principales de la

Resiliencia en el Bienestar Infantil

7.3.2.2.2. Efectos de Moderación a Partir de los Niveles de Participación

\subsection{Discusión}

7.4.1. Limitaciones y Líneas de Investigación Futuras

CAPITULO 8 - Conclusiones Generales de la Investigación Análisis de Factores Determinantes de la Calidad de Vida de Alumnos con NEAE y Sin Ellas

\section{Introducción}

\subsection{Resultado Generales}

8.1.1. Parte Teórica

8.1.1.1. Capítulo 1

8.1.1.2. Capítulo 2

8.1.1.3. Capítulo 3

8.1.1.4. Capítulo 4

8.1.2. Parte Empírica

8.1.2.1. Capítulo 5

8.1.2.2. Capítulo 6

8.1.2.3. Capítulo 7

8.2. Implicaciones Prácticas 330

8.3. Limitaciones y Pasos Futuros $\quad 348$

$\begin{array}{ll}\text { 8.4. Conclusiones } & 350\end{array}$

REFERENCIAS BIBLIOGRÁFICAS 353

$\begin{array}{ll}\text { ANEXO } 1 & 431\end{array}$

$\begin{array}{ll}\text { ANEXO } 2 & 443\end{array}$

$\begin{array}{ll}\text { ANEXO } 3 & 453\end{array}$ 


\section{INDICE DE FIGURAS}

Figura 1. Teoría ecológica del desarrollo de Bronfrenbrenner $\quad 10$

Figura 2. Modelo de Funcionamiento Humano de la CIF (OMS, 2001) 16

Figura 3. Relación conceptual entre calidad de vida, participación en actividades diversas y resiliencia en el marco de desarrollo infantil positivo

Figura 4. Modelo ecológico de mejora de la calidad 64

Figura 5. Modelo hipotético del constructo de participación: dimensiones principales y conceptos relacionados

Figura 6. Modelo de la Funcionamiento Humano 91

Figura 7. Modelo teórico multidimensional de factores contextuales que afectan a la participación infantil en actividades de ocio y tiempo libre

Figura 8. Representación de los componentes de la definición de resiliencia de Michael Ungar

Figura 9. Modelo resultante del análisis factorial confirmatorio de la CYRM-28

Figura 10. Síntesis metodología seguida para la adaptación poblacional de la CYRM-28

Figura 11. Representación estadística del modelo de moderación. Efecto condicional en $\mathrm{Y}=\mathrm{o} 4+\mathrm{aX}+\mathrm{bZ}+\mathrm{cXZ}+\mathrm{e} 4$

Figura 12. Representación gráfica relación bienestar social, resiliencia social y participación en actividades de tipo informal, muestra total de alumnos de Primaria ( $=199)$

Figura 13. Representación gráfica relación bienestar escolar, resiliencia social y participación en actividades de tipo formal, grupo de alumnos de Primaria con NEAE ( $\mathrm{N}=99)$

Figura 14. Representación gráfica relación bienestar escolar, resiliencia social y participación en actividades de tipo informal, grupo de alumnos de Primaria sin NEAE $(\mathrm{N}=100)$ 


\section{INDICE DE TABLAS}

Tabla 1. Clasificación de las NEAE en la actual Ley Orgánica para la Mejora de la Calidad Educativa

Tabla 2. Principios de la Conceptualización, Medida y Aplicación de Calidad de Vida

Tabla 3. Dimensiones centrales, conceptualización e indicadores de CV en población infantil, actualizadas

Tabla 4. Definición de los distintos planos sistémicos que afectan a la 53 CV de la persona

Tabla 5. Variables moderadoras y mediadoras de la CV y variables específicas estudiadas

Tabla 6. Instrumentos nacionales e internacionales para la medida de CV infantil

Tabla 7. Factores asociados a la mejora de las dimensiones de la CV individual (Schalock et al., 2002, 2003)

Tabla 8. Instrumentos que valoran la participación infantil en actividades diversas

Tabla 9. Principales barreras y facilitadores personales y ambientales para la participación infantil en actividades de ocio y tiempo libre

Tabla 10. Definiciones de Resiliencia VV.AA.

Tabla 11. Instrumentos de evaluación de la resiliencia para poblaciones infantiles y adolescentes

Tabla 12. Modelo ecológico en resiliencia adaptado a población infantil

Tabla 13. Listado de tensiones y descripción de cada una de ellas

Tabla 14. Relación entre las tensiones para el desarrollo de la resiliencia y las dimensiones, indicadores de calidad de vida infantil y factores asociados a su mejora

Tabla 15. Número y contenido de los ítems añadidos a la versión española de la CYRM-28

Tabla 16. Características sociodemográficas y educativas de la muestra de alumnos $(\mathrm{N}=374)$ 
Tabla 17. Características de las muestras de docentes $(\mathrm{N}=49)$ y familiares $(\mathrm{N}=106)$ participantes

Tabla 18. Estadísticos descriptivos de los 28 ítems seleccionados para los análisis de validez interna

Tabla 19. Resultados de los índices de bondad de ajuste de los cuatro modelos factoriales probados

Tabla 20. Comunalidades y cargas factoriales de los ítems para el modelo bifactorial de segundo orden

Tabla 21. Valores de los índices de determinación, simplicidad y replicabilidad del modelo bifactorial y su modelo factorial de partida

Tabla 22. Comunalidades, cargas factoriales, varianza explicada y correlaciones entre factores del modelo factorial de 22 ítems de la versión adaptada de la CYRM

Tabla 23. Contenido ítems de la versión adaptada, versión original, escalas y subescalas de pertenencia

Tabla 24. Estadísticos descriptivos, fiabilidad, intervalos de confianza y correlaciones de los factores con variables externas y escalas del Kidscreen-27 $(\mathrm{N}=374)$

Tabla 25. Variables de estudio

Tabla 26. Información del alumnado sobre características sociodemográficas y educativas $(\mathrm{N}=199)$

Tabla 27. Información de los docentes características de los alumnos participantes y su contexto educativo $(\mathrm{N}=49)$

Tabla 28. Información de las familias sobre características del contexto familiar y de crianza de los alumnos participantes $(\mathrm{N}=106)$

Tabla 29. Estadísticos descriptivos de las puntuaciones en calidad de vida $(\mathrm{N}=194)$

Tabla 30. Estadísticos descriptivos de las puntuaciones en resiliencia $(\mathrm{N}=140)$

Tabla 31. Estadísticos descriptivos de las puntuaciones en participación $(\mathrm{N}=138)$

Tabla 32. Puntuaciones en resultados personales en función de la presencia de NEAE 
Tabla 33. Resultados personales de la muestra total, subgrupo de alumnos con NEAE y subgrupo sin ellas en función de la CC.AA.

Tabla 34. Resultados personales de la muestra total, subgrupo de alumnos con NEAE y subgrupo sin ellas en función de la realización de asambleas en el aula

Tabla 35. Resultados personales de la muestra total, subgrupo de alumnos con NEAE y subgrupo sin ellas, en función de la seriedad que los docentes dan a la opinión de los alumnos

Tabla 36. Barreras y facilitadores de la calidad de vida, resiliencia y participación de alumnos de Primaria con NEAE y sin ella

Tabla 37. Variables de estudio y estadísticos descriptivos media y des278 viación típica

Tabla 38. Correlaciones significativas halladas entre las variables objeto 282 de estudio $(\mathrm{N}=199)$

Tabla 39. Análisis de regresión para bienestar físico y bienestar emocio284 nal $(\mathrm{N}=199)$

Tabla 40. Análisis de regresión para bienestar familiar, bienestar social y 286 bienestar escolar $(\mathrm{N}=199)$

Tabla 41. Efectos de moderación de la participación (formal e informal) 290 en la relación entre resiliencia social y bienestar infantil en alumnos de Primaria con y sin NEAE

Tabla 42. Efectos condicionados por valores altos, medios y bajos de 293 participación en actividades de ocio 




\section{Capítulo 1}

Concepción del Desarrollo Infantil

Positivo de Niños en Condiciones Diversas de Vida 



\section{Concepción del Desarrollo Infantil Positivo de Niños en Condiciones Diversas de Vida}

\section{Introducción}

En este primer capítulo de tesis se realiza una aproximación teórica inicial al desarrollo de niños en condiciones diversas de vida desde una visión de desarrollo infantil positivo y fomento de entornos educativos inclusivos.

La finalidad de este capítulo es presentar el marco teórico de la investigación "Análisis determinantes de la calidad de vida de alumnos con necesidades específicas de apoyo educativo y sin ellas". Para ello, en los siguientes apartados se conceptualiza el desarrollo infantil desde un enfoque de crecimiento positivo, basado en el respeto y promoción de los derechos humanos de todos los niños, con independencia de las condiciones personales y ambientales en las que crece cada uno de ellos. Este planteamiento se centra en la interacción que el niño mantiene con sus entornos cercanos de desarrollo, tal como el contexto educativo, así como en las oportunidades y obstáculos presentes en ellos, que intervienen en los procesos de desarrollo infantil e influyen en la consecución de resultados de vida saludables y exitosos.

A lo largo de este capítulo se abordan los conceptos de calidad de vida, participación y resiliencia infantil como resultados personales significativos que proveen a los niños de activos y recursos para navegar con éxito y negociar con sus entornos próximos las vías que dan acceso a un desarrollo infantil positivo.

\subsection{Desarrollo Infantil}

La infancia es una etapa fundamental del desarrollo humano que surge de la interacción entre la herencia genética y las influencias del ambiente en el que el niño vive (Souza y Verissimo, 2015). A medida que el niño va creciendo, lo hacen también sus capacidades y competencias personales y sociales. Este crecimiento depende en gran medida de la estimulación que recibe de su entorno cercano, así como de la constante interacción con su 
medio, que propicia la adaptación a situaciones presentes y futuras de vida, permitiéndole integrar el conocimiento adquirido y desarrollar su potencial como persona (Camargo Ramos y Pinzón-Villate, 2012).

En estos primeros años de vida la persona pasa por diversos periodos de desarrollo, cada uno de ellos definido por características propias del proceso madurativo del ser humano y su relación con el ambiente. La adolescencia se concibe como el periodo que da paso de la infancia a la juventud. Según la Organización Mundial de la Salud (OMS y UNICEF, 2013) esta etapa transcurre entre los 10 y 19 años de edad, y en ella tienen lugar importantes procesos de maduración y aprendizaje destinados a la interacción, integración, desarrollo personal y social del niño.

La calidad del desarrollo durante la adolescencia se relaciona, por una parte, con la reducción de problemas derivados de condiciones personales, como la discapacidad u otros trastornos de desarrollo, y de condiciones sociales de riesgo como la pobreza, la violencia u otras desventajas socioambientales (Camargo Ramos et al., 2012; De Castro, Allen-Leigh, Katz, Salvador-Carrulla y Lazcano-Ponce, 2013). Por otra parte, el desarrollo integral de los menores también se corresponde con el aprovechamiento de activos y recursos presentes en sus entornos próximos, que respondan a sus necesidades y propicien el alcance del potencial de cada uno de ellos (PonceMeza, 2017).

En las sociedades contemporáneas los niños reciben influencias de diferentes ambientes tales como la familia, la escuela, los medios de comunicación, entre otros. La complejidad de estas influencias a medida que crecen no sólo dependen del propio desarrollo natural del niño (MuñozSilva, 2005), sino también de los cambios en los contextos sociales en los que tiene lugar dicho desarrollo, los cuales están marcados por transformaciones económicas, sociales y culturales que impactan en sus vidas, así como en las perspectivas mundiales existentes sobre el desarrollo infantil (Koller y Verma, 2017). 


\subsubsection{Concepción Mundial Contemporánea de Infancia}

Desde la segunda mitad del siglo pasado hasta la fecha, el movimiento a favor de la infancia y su desarrollo pleno, que ha involucrado a políticos, investigadores y otros agentes sociales, ha llevado a reconocer a los niños como sujetos de derecho (Jaramillo, 2007), dándoles un papel protagonista como personas y miembros de una sociedad.

La Declaración de los Derechos del Niño (ONU, 1959) reconoció la protección de los derechos humanos en la infancia e impulsó la atención hacia temas centrales del desarrollo como la salud, educación y la prevención de problemas del desarrollo infantil. La Convención sobre los Derechos del Niño (ONU, 1989) se dirigió a todos los niños del mundo con independencia de sus condiciones personales o ambientales particulares, estableciendo sus derechos humanos básicos, tales como, el derecho a la supervivencia, al desarrollo pleno, de protección sobre influencias perjudiciales, abuso o explotación, así como su participación plena en la vida familiar, social y cultural del contexto del que forman parte (OMS et al., 2013).

Con respecto a los niños y niñas con discapacidad, la Convención (ONU, 1989) también estableció las obligaciones de los Estados miembros de hacerse responsables de asegurar que estos niños gocen de los derechos y libertades fundamentales en igualdad de condiciones que sus iguales sin discapacidad (OMS et al., 2013). En tanto que, más recientemente, la Convención Internacional sobre los Derechos de las Personas con Discapacidad (UNESCO, 2006) ha proclamado el derecho a la educación de las personas con discapacidad desde la igualdad de oportunidades y la no discriminación.

Estas proclamas mundiales han sentado las bases para el cambio y la atención a la infancia desde una perspectiva de bienestar y calidad de vida dirigida al desarrollo pleno y exitoso de todos los niños, marcando el rumbo de las políticas públicas, la investigación y la práctica social en materia de desarrollo infantil y juvenil. 


\subsubsection{Desarrollo Infantil Positivo}

Con objeto de dar respuesta al reconocimiento mundial del papel del menor, en los últimos años la investigación sobre desarrollo infantil y juvenil se ha centrado en explorar las formas en que los diferentes entornos ecológicos son capaces de fomentar el desarrollo positivo de los más jóvenes, yendo más allá de un enfoque individual de déficits y riesgos. Un marco ecológico de desarrollo postula que la familia, la escuela, el vecindario y sus contextos socioculturales más amplios sirven como factores de promoción e inhibición del desarrollo infantil positivo (Smith, Witherspoon y Osgood 2017). Dentro de este contexto de desarrollo, una buena crianza familiar, los apoyos escolares, las relaciones de apego seguro con adultos y compañeros se consideran activos del crecimiento positivo del niño (Leffert et al., 1998).

El desarrollo positivo (DP) se conceptualiza como un proceso de desarrollo y un enfoque de programación juvenil, orientado a fomentar el crecimiento sano y positivo de los más jóvenes (Geldhof et al., 2014). Este paradigma se centra en mejorar las fortalezas de los menores, establecer contextos atractivos de apoyo y brindar oportunidades para la interacción bidireccional y constructiva entre la persona y el contexto en el que se desarrolla (Lerner, Phelps, Forman y Bowers, 2009; Snyder y Flay, 2012). En la práctica, los modelos en DP se esfuerzan en construir actitudes positivas, competencias personales, habilidades sociales, es decir, en desarrollar activos a través del aumento de relaciones positivas, apoyos sociales y oportunidades que fortalecen y ayudan a los menores a florecer en su entorno, así como a influir en él mejorándolo (Taylor, Oberle, Durlak y Weissberg, 2017).

\subsubsection{Desarrollo Positivo como Proceso}

Definir el DP como un proceso es aceptar la idea de plasticidad o cambio a lo largo de la vida (Lerner, 1984). Según Lerner (1984) es la flexibilidad de la persona al cambio lo que representa la fuerza fundamental del desarrollo humano. Sin embargo, las trayectorias de desarrollo de cualquier persona pueden estar definidas tanto por valencias positivas, como negativas. Desde 
el enfoque de DP, el objetivo es buscar las vías que conectan a las personas con sus contextos, de tal forma que mejore la probabilidad de cambio y se promuevan características positivas del desarrollo humano (Lener, 2002, 2004, Lerner et al., 2009).

A nivel teórico, el DP postula que el desarrollo humano está organizado por procesos innatos y adaptativos que predisponen a las personas a ser activas y experimentar integridad y bienestar (Thomaes, Sedikides, van den Bos, Hutteman y Reijntjes, 2017), asumiendo una tendencia natural del ser humano al crecimiento y ajuste psicológico. Mientras que, los conflictos en el desarrollo son conceptualizados en términos de interacciones entre factores contextuales -personales y ambientales- que nutren a la persona, más que como déficits o riesgos individuales determinantes para un desarrollo saludable (Smith et al., 2017). En esta línea, la investigación en curso ha demostrado cómo los entornos que proporcionan recursos positivos a sus jóvenes son contextos de desarrollo positivo donde los menores muestran tasas más bajas de resultados negativos, así como mayores evidencias de desarrollo saludable (Koller et al., 2017). Un ejemplo de ello se encuentra en los resultados de un estudio sobre positividad en la escuela llevado a cabo con adolescentes colombianos, en el que se evidenció la capacidad mediadora que tiene un clima escolar positivo sobre la positividad y el comportamiento pro-social de los jóvenes (Luengo-Kanacri et al., 2017).

Pero no sólo los entornos familiares, escolares y comunitarios favorecen condiciones de enriquecimiento personal, sino también los contextos socioeconómicos y culturales de los países determinados por sus gobiernos, organismos internacionales y sus propios ciudadanos (Camargo Ramos et al., 2012). Las características de unos y otros entornos crean los determinantes del desarrollo humano y las estructuras donde se encuentran los factores que influyen en el crecimiento infantil positivo (Bronfrenbrenner, 1979, 2002).

Bronfrenbrenner $(1979,2002)$ a través de su teoría de la ecología del desarrollo trató de integrar todos los posibles entornos en los que se produce el desarrollo humano, contribuyendo en gran medida a la actual visión del desarrollo infantil. Su teoría pone de relieve la importancia de los sistemas 
en los que tiene lugar la interacción del niño con su ambiente, donde se encuentran los factores que determinan el crecimiento del niño. En la Figura 1 se presentan los principales sistemas definidos por Bronfrenbrenner.

Figura 1. Teoría ecológica del desarrollo de Bronfrenbrenner

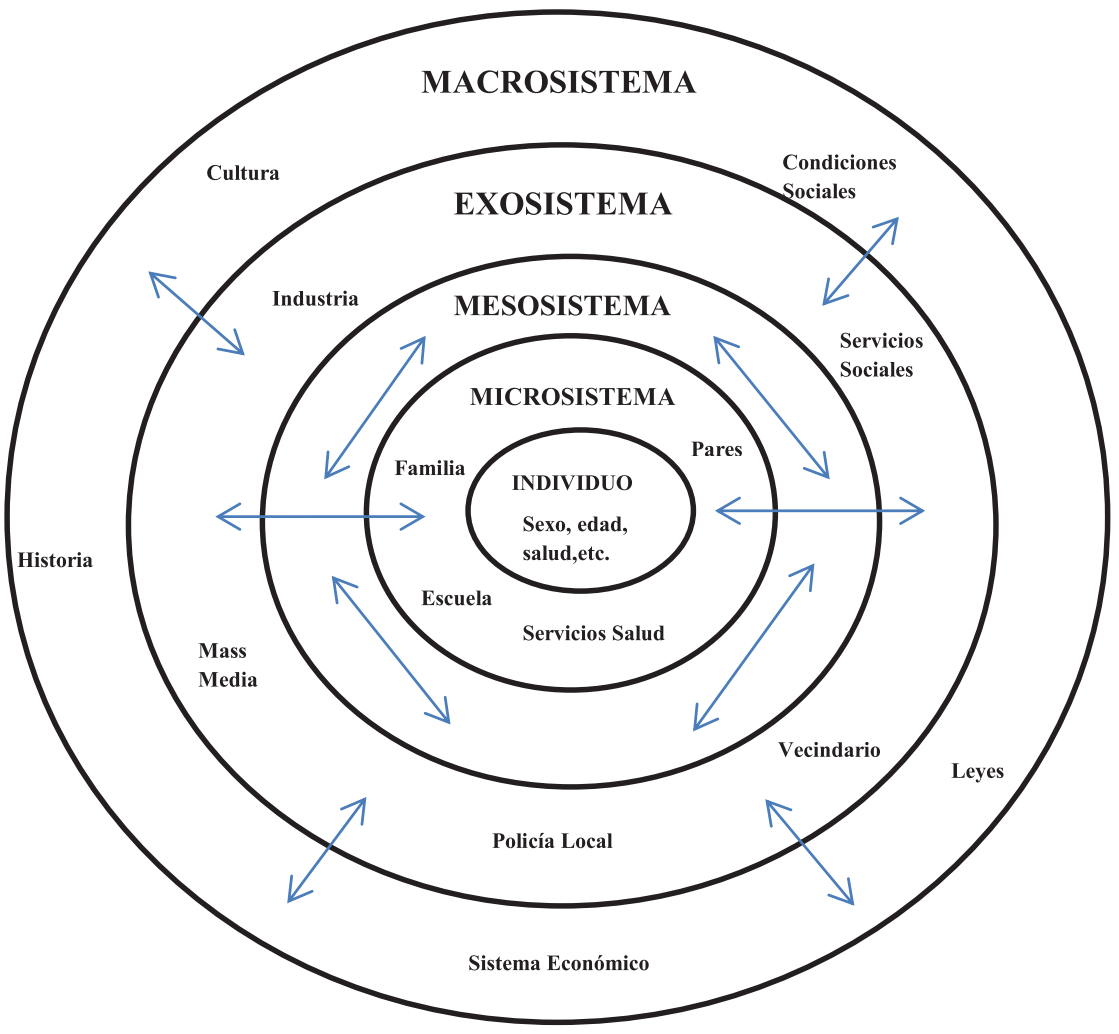

Nota. Adaptado de Abnormal child psychology (7 $7^{\mathrm{a}}$ ed.) (p. 49), por E. J. Mash y D. A. Wolfe, 2019, Cengage Learning.

Según la teoría de sistemas impulsada por Bronfrenbrenner todos los aspectos referentes al proceso de desarrollo infantil, el contexto en el que tiene lugar y las características del propio niño como persona pueden ser clasificados como factores protectores o de riesgo, según favorezcan o dificulten el desarrollo infantil (Souza et al., 2015). 
Para otros autores, el desarrollo positivo es el proceso de relaciones mutuamente adaptativas y beneficiosas entre los niños y los contextos en los que tiene lugar su crecimiento (Eichas, Montgomery, Meca y Kurtines, 2017). Esta premisa se basa en los trabajos de Lerner y colaboradores, quienes a través de un estudio longitudinal investigaron cuáles de las relaciones que se establecen entre los jóvenes y sus ecologías promueven la prosperidad en su desarrollo, así como cuáles tienen un carácter preventivo sobre conductas de riesgo o problemáticas (Lerner et al., 2009). Los resultados de Lerner y su equipo mostraron cómo la alineación de las fortalezas y habilidades juveniles con los recursos contextuales enfocados al crecimiento positivo fomentan la prosperidad de los más jóvenes (Lerner, Lerner, Bowers y Geldhof, 2015), así como el enriquecimiento del propio entorno, dando lugar a relaciones entre el individuo y su contexto que son beneficiosas para ambas partes.

Esta visión transaccional define el desarrollo infantil como el producto de las interacciones dinámicas que se establecen entre el niño y las experiencias que su contexto familiar, social y cultural le proporciona (Sameroff y Fiese, 1990), igualando el papel del niño y el ambiente, y estableciendo una interconexión entre ambos mutuamente determinante (Jaramillo, 2007). Es decir, la forma en que los niños interactúan con su ambiente lo altera y modifica, provocando nuevas y específicas respuestas del ambiente sobre el niño que afectan a su desarrollo. Así, un mismo ambiente, contexto o personas no influyen por igual en todos los niños (Sameroff et al., 1990), reconociendo la existencia de variabilidad interindividual en el desarrollo humano (Geldhof et al., 2014).

Como veremos en el apartado siguiente, la finalidad de los programas de DP es aumentar la contribución de los jóvenes a sus ecologías, al mismo tiempo que se potencian sus activos y disminuye la probabilidad de comportamientos problemáticos que afectan a su desarrollo positivo (Geldhof et al., 2014). 


\subsubsection{Desarrollo Positivo como Programación Infantil y Juvenil}

Genéricamente los programas centrados en el desarrollo positivo se basan en fomentar recursos contextuales que propician el desarrollo de las potencialidades de los menores. Para ello, estos programas se orientan hacia la prevención de riesgos, el fomento de la resiliencia, la creación de activos y habilidades para la vida (Koller et al., 2017). En este sentido se ha comprobado cómo intervenciones para la auto-transformación de los jóvenes ofrecen oportunidades para que éstos amplíen y mejoren aquellos aspectos de sus vidas que son significativos para ellos, dándoles la posibilidad de definir la dirección de su propio desarrollo positivo (Eichas et al., 2017).

Sin embargo, un programa particular no puede ofrecer todas las oportunidades de desarrollo y los apoyos que en general los jóvenes necesitan para crecer de forma positiva, aun cuando estos están expuestos a las mismas circunstancias de vida (Koller et al., 2017). Es decir, el crecimiento de los más jóvenes puede ir en muchas direcciones dependiendo de la interacción de los factores de riesgo y protección personales y ambientales presentes en cada contexto de desarrollo infantil (Geldhof et al., 2014). Por tanto, es a partir de las oportunidades de participación e inclusión que los programas orientados al DP Influyen de forma positiva en el crecimiento de cada participante, ofreciéndoles vivencias y estrategias que los prepare para una vida futura significativa y de bienestar (Leman, Smith y Petersen, SRCD Ethnic-Racial Issues and International Committees, 2017).

Los programas en DP, por una parte, deben propiciar vivencias para el desarrollo de habilidades para la vida, dada la relevancia que tiene su adquisición durante la niñez y adolescencia para que el crecimiento positivo se mantenga en etapas posteriores de vida (Cacioppo, 2002; Gresham, Cook, Crews y Kern, 2004). Mientras que, por otra, deben conectarse y colaborar con los entornos de desarrollo próximo en los que cada niño experimenta su proceso de desarrollo individual. Es decir, los servicios y apoyos sociales brindados a través de los programas de DP se tornan más efectivos y sostenibles a lo largo del tiempo, cuando responden a las necesidades de los jóvenes y de sus entornos (Oshri, Tropple y Carlson, 2017). Cuando es 
así, las intervenciones juveniles posibilitan a su vez la interacción dinámica y continua entre el menor y el ambiente en el que se desarrolla (Lerner et al., 2015).

Por otra parte, cabe señalar que con asiduidad los conceptos y programas de DP están orientados a grupos de jóvenes categorizados como vulnerables, debido a sus "menores" índices de habilidades, recursos u oportunidades disponibles para su desarrollo positivo (Banco Mundial, 2006). Sin embargo, para favorecer la riqueza tanto de las personas como de sus contextos, estos programas deben estar disponibles y accesibles para todos los jóvenes, haciendo participes a aquellos grupos desfavorecidos o minorías, como son los menores con discapacidad, los cuales, con asiduidad, requieren servicios y apoyos específicos a sus necesidades especiales (Wehmeyer, 2009), así como incluir a sus iguales sin ellas pertenecientes a grupos sociales con mayores activos y recursos ambientales para su desarrollo saludable y exitoso.

Actualmente, pese a los avances contemporáneos en desarrollo infantil y juvenil, aún existe la necesidad de mejorar los servicios públicos, programas e intervenciones dirigidos al DP de niños en condiciones de vida diversas, con la finalidad de garantizar recursos que contribuyan a una vida de calidad desde su crecimiento positivo y bienestar personal (De Castro et al., 2013).

\subsection{La Diversidad en la Infancia}

Los avances en el campo de la infancia han llevado a aceptar la existencia de distintos determinantes que afectan de manera negativa al desarrollo y bienestar infantil, entre los que se encuentran la pobreza, la ausencia de un contexto educativo de calidad, la falta de acceso o disponibilidad de servicios sociales o de salud, la presencia de discapacidad u otras condiciones personales y ambientales que influyen en el desarrollo potencial del niño (De Castro et al., 2013). Desde una perspectiva transaccional, es necesario articular los apoyos fundamentales sociales, políticos y culturales que todos los niños requieren con objeto de fomentar su desarrollo pleno e integral (Jaramillo, 2007). Para ello, es preciso conocer qué experiencias de vida son 
importantes y significativas para ellos, qué factores y procesos contribuyen a su adaptación y bienestar (Oshri et al., 2017), así como en qué medida estos son similares o diferentes a los de la población infantil general u otras poblaciones específicas de niños.

Con respecto a los niños con discapacidad, al igual que otras poblaciones infantiles en riesgo, éstos están expuesto en gran medida a factores como la pobreza, el estigma y la discriminación, la institucionalización, violencia, abuso, acceso limitado a programas y servicios sociales que afectan a la interacción con su entorno y al desarrollo pleno de sus capacidades y potencialidades como personas (UNICEF, 2013). La discapacidad es una de las diversas realidades sociales que viven los niños que hacen patente la carencia de políticas públicas capaces de garantizar el diagnóstico, la prevención y la canalización de acciones dirigidas a la estimulación temprana, a través de los servicios sociales, educativos y comunitarios que respondan a las necesidades específicas que tiene cada niño.

En los últimos años se ha dado un paso notable hacia el reconocimiento social de la diversidad humana (Oliver, 1998). Así por ejemplo, tanto la Convención sobre los Derechos del Niño (ONU, 1989), como la Convención sobre los Derechos de las Personas con Discapacidad (UNESCO, 2006) proclaman que los niños con discapacidad tienen los mismos derechos que los demás niños a la atención, educación y protección de su desarrollo integral adecuado (UNICEF, 2013). En concreto la Convención sobre los Derechos de las Personas con Discapacidad (CDPD) exige el disfrute de todos los derechos humanos y libertades fundamentales de los niños que experimentan discapacidad, señalando la importancia de la intervención temprana y la inclusión en el sistema educativo general, como respuestas sociales a las necesidades especiales y de desarrollo de este grupo específico de niños (UNESCO, 2006).

Sin embargo, aunque se ha avanzado en el reconocimiento social de las personas con discapacidad como sujetos de pleno derecho, los niños con necesidades especiales con frecuencia son excluidos de las actividades y programas generales elaborados para la estimulación del desarrollo infantil, 
perdiendo oportunidades para recibir apoyo y recursos especializados que satisfagan sus derechos y libertades humanas (UNICEF, 2012). Esta falta de inclusión tienen efecto negativo sobre el potencial desarrollo del niño, asociándose al deterioro y aparición de nuevos problemas y barreras que condicionan el éxito de sus trayectorias de vida (Gorter, Stewart y Woodbury-Smith, 2011).

En el esfuerzo mundial por crear y mantener sociedades sostenibles que garanticen el respeto de los derechos humanos, así como el crecimiento y progreso de todos sus miembros, ciertos organismos internacionales han elaborado modelos funcionales de desarrollo humano con el fin de conseguir un entendimiento más holístico de las condiciones que dan paso al desarrollo integral de las personas con limitaciones en su funcionamiento. Uno de los modelos más reconocidos es la Clasificación Internacional del Funcionamiento, de la Discapacidad y de la Salud (en adelante CIF) y su versión para niños y jóvenes (en adelante CIF-NJ) (OMS, 2001, 2007).

\subsubsection{La Clasificación Internacional del Funcionamiento, de la} Discapacidad y de la Salud, y su Versión para Niños y Jóvenes, (OMS, 2001, 2007)

La CIF y la CIF-NJ (OMS, 2001, 2007) representan un marco conceptual desarrollado desde el campo de la salud, mediante el cual el funcionamiento humano y la discapacidad pueden ser discutidas, descritas y medidas (TenHove y Rosenbaum, 2018). Sus elementos principales son las funciones y estructura del cuerpo, las actividades, la participación y los factores presentes en el contexto de desarrollo. Estos cuatro elementos se encuentran interconectados, de modo que al evaluar la salud general de una persona deben considerarse y usarse todos ellos de forma interactiva (Stucki, 2005).

La CIF define el funcionamiento humano desde tres dominios: 1) funciones del cuerpo y estructuras, que son las funciones fisiológicas de las diferentes partes del organismo, 2) actividades o realización de tareas o acciones por parte de la persona y, 3) participación, que se refiere al 
acto de involucrarse en las diferentes áreas vitales. Para comprender el funcionamiento de la persona en cada uno de los tres dominios, la CIF (OMS, 2001) utiliza el modelo socio-ecológico de interacción personaambiente de Bronfrebrenner (1979, 2002), a partir del cual el desarrollo potencial de una persona viene determinado por la relación dinámica entre sus estados de salud (enfermedades, trastornos, lesiones, etc.) y sus factores contextuales, que son las características personas y ambientales que definen su entorno próximo de desarrollo. En la CIF (OMS, 2001), los factores ambientales, que constituyen el entorno físico, social y actitudinal en el que las personas desarrollan sus vidas, adquieren gran relevancia dado su efecto facilitador o de obstáculo sobre todos los componentes del funcionamiento y la discapacidad. De este modo, la discapacidad se define como el resultado de la interacción entre las limitaciones de la persona y el entorno en la que ésta se desarrolla (Figura 2).

Figura 2. Modelo de Funcionamiento Humano de la CIF (OMS, 2001)

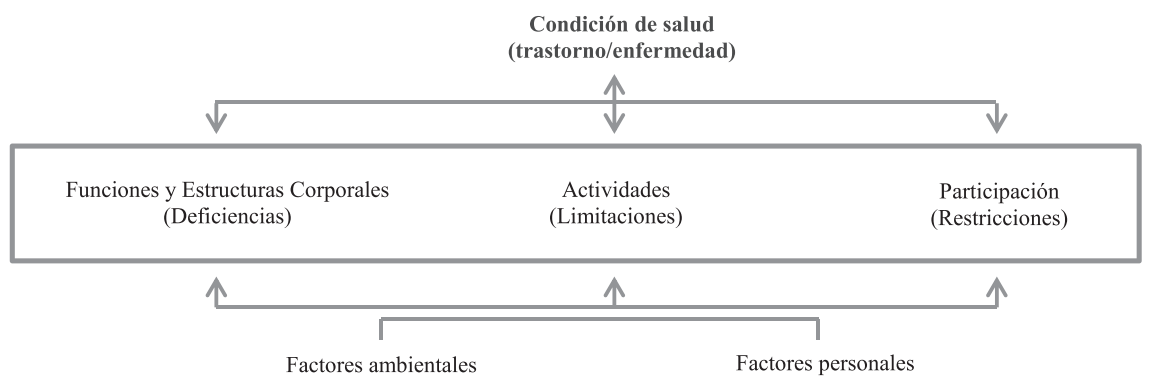

Nota. Recuperado de Clasificación Internacional del Funcionamiento, de la Discapacidad y de la Salud: CIF (p. 21), por Organización Mundial de la Salud, 2001, IMSERSO, OMS y OPS.

Desde el modelo de la CIF, la falta de coordinación entre las condiciones sociales y otros factores personales y ambientales pueden provocar tanto deficiencias en el funcionamiento del organismo (problemas de salud), como restricciones en la participación y limitaciones en la actividad cotidiana de la persona (Wehmeyer, 2009). Mientras que, la coherencia entre las intervenciones y los factores contextuales favorecerá la integridad del 
funcionamiento orgánico, así como la participación en actividades de la vida diaria, lo que en materia de desarrollo infantil se traduce en un crecimiento positivo y saludable del niño.

Al igual que en los modelos de desarrollo infantil positivo, en la CIF el foco de atención se dirige a la interacción de las condiciones personales del niño con los recursos y oportunidades que el entorno próximo genera para el fomento y desarrollo de sus capacidades y competencias como persona (Muntaner, 2010). Así, el aumento de la estimulación desde el entorno cercano del niño provoca mayores niveles de aprendizaje y desarrollo (OMS et al., 2013). Sin embargo, es importante tener en cuenta que aunque el medio ambiente desempeña un papel principal en la predicción de resultados personales, no es el único contribuyente, siendo la combinación de factores personales y ambientales los que determinan la dirección del desarrollo infantil (Ten-Hove et al., 2018).

La CIF responde a la exigencia social de adoptar un modelo de desarrollo humano biopsicosocial que guie la planificación e implementación de programas a edades tempranas (Ten-Hove et al., 2018). Dado su modelo ecológico, es también una herramienta útil para ayudar a definir el desarrollo positivo de menores en condiciones de vida de diversas, que permite incorporar otros conceptos relevantes, tales como el de bienestar y calidad de vida (Ravens-Sieberer el al., 2008: Ravens-Sieberer et al., 2014b; Edwards, Huebner, Connell y Patrick, 2002) o el de resiliencia (Ten-Hove et al., 2018; Ungar, 2015), a los componentes de participación y factores contextuales de su marco (Badia, Longo, Orgaz y Gómez-Vela, 2013; Smith y Schonert-Reichl, 2013), posibilitando de esta forma una definición del desarrollo infantil basada en los resultados personales de los propios niños y en su interacción con los factores que determinan su contexto próximo de desarrollo. En el capítulo tres de este trabajo se ahondará en las características de este modelo, así como su adaptación teórica a la participación infantil en actividades diversas como aquellas realizadas en contextos de ocio y tiempo libre. 


\subsection{Resultados Personales Significativos en la Infancia}

Debido al reconocimiento actual acerca de la importancia de que los menores desempeñen un papel activo en su desarrollo y se presenten como autores de sus propias vidas (Koller et al., 2017), para el desarrollo de este trabajo se ha decidido analizar los resultados personales obtenidos por los niños en tres de las variables hoy día más relevantes en investigación, política y práctica, en material de desarrollo infantil y juvenil. Estas variables son: la calidad de vida, la participación en actividades de ocio y tiempo libre y la resiliencia infantil (Badia et al., 2013; King et al., 2003, 2009; Schalock y Verdugo, 2002, 2003; Ungar, 2012, 2015; Wallander y Koot, 2016).

\subsubsection{Calidad de Vida Infantil}

El interés por el bienestar y la calidad de vida infantil nace del desarrollo de indicadores relacionados con la infancia derivados del movimiento de indicadores sociales de los años 60, las proclamas internacionales acerca del reconocimiento de los derechos y libertades del niño, y los informes de UNICEF sobre el estado mundial de la población infantil en condiciones diversas de vida, que han llevado a la creación de una agenda global para el desarrollo infantil basado en el bienestar desde los servicios sociales públicos (De Castro et al., 2013).

A partir de estos antecedentes, los investigadores del campo de desarrollo infantil han ido profundizando en los aspectos fundamentales de los indicadores de bienestar, dando lugar a avances teóricos y metodológicos orientados a sistematizar su medida alrededor de temas centrales como una visión infantil de bienestar en contraposición a la de supervivencia, tener en cuenta indicadores de valencia positiva como negativa, así como elementos objetivos y subjetivos del desarrollo infantil (Ravens-Sieberer et al., 2014b; Verdugo y Schalock, 2013b; Wallander et al., 2016). El resultado de estos trabajos ha sido una herramienta mediante la cual combatir la desigualdad social, incidiendo en las políticas públicas desde acciones gubernamentales enfocadas a favorecer el desarrollo de una infancia de calidad. 
Entre los modelos de bienestar infantil existentes, para el desarrollo de esta investigación nos hemos apoyo en el modelo de calidad de vida individual propuesto por Schalock y colaboradores (2002, 2003). Este modelo se centra en la conceptualización, evaluación y aplicación de indicadores dirigidos a operacionalizar resultados personales relevantes y valiosos para las personas con discapacidad y sin ella en diferentes áreas de vida (educación, salud, familia, etc.). Tras un extenso trabajo de revisión y construcción científica, los autores definen calidad de vida como un estado deseado de bienestar personal, que se conceptualizada a partir de ocho dimensiones (bienestar emocional, relaciones interpersonales, bienestar material, desarrollo personal, bienestar físico, autodeterminación, inclusión social y derechos), que han de completarse desde un punto de vista objetivo y subjetivo (Gómez, Verdugo, Arias y Arias, 2011; Schalock y Verdugo, 2013a; Schalock, Verdugo, Gómez, Reinders, 2016a). Estas dimensiones contienen propiedades tanto universales como relativas a la cultura, y son sensibles a las características personales y a factores ambientales del entorno en el que las personas se desarrollan.

Con respecto a la infancia, promover la calidad de vida de los niños a través de servicios y apoyos que satisfagan las necesidades que tienen en relación a la conexión con ellos mismos y otras personas, no sólo requiere la detección de indicadores de bienestar infantil, sino también de otros indicadores de crecimiento positivo. Algunos de estos indicadores a detectar son la disponibilidad y acceso a las actividades significativas que se desarrollan en su entorno de desarrollo próximo (OMS, 2007; King et al., 2003, 2009), la adquisición de activos y competencias personales para su desenvolvimiento, así como los recursos ambientales presentes para el fomento de su desarrollo saludable y exitoso, todo ello orientado a la consecución de resultados personales significativos (Oshri et al., 2017; Schalock et al., 2016a).

Atendiendo a los indicadores para una vida infantil de calidad, defendidos por la Convención sobre los Derechos de los Niños (ONU, 1989), a continuación se presenta otra de las variables de interés en el campo del desarrollo infantil, la participación en actividades diversas, la cual se relaciona 
con el bienestar y crecimiento positivo de todos los jóvenes (Badia et al., 2013; Shikako-Thomas et al., 2012; Schreuer, Sachs y Rosenblum, 2014).

\subsubsection{Participación Infantil}

Basándonos en la creciente evidencia científica sobre la relevancia de la participación infantil y juvenil en diferentes áreas de vida, en especial en aquellas destinadas al ocio y disfrute (Badia et al., 2013; King et al., 2007; Majnemer et al., 2010), y su relación con el bienestar y calidad de vida de niños y jóvenes en condiciones diversas de vida (Badia et al., 2013; Schreuer et al., 2014; Shikako-Thomas et al., 2012), la participación en actividades de ocio y tiempo libre aparece como otra variable determinante del desarrollo infantil positivo.

Como hemos visto con anterioridad, la CIF (OMS, 2001) define participación como el acto de involucrarse en situaciones de vida. Mientras que, en su versión para niños y jóvenes (OMS, 2007), actividades de ocio se conceptualiza como el tiempo destinado a actividades elegidas libremente, que los niños realizan cuando no están involucrados en áreas vitales de autocuidado o trabajo escolar. Según los expertos en participación infantil, la realización de actividades de ocio es imprescindible para el desarrollo de los niños, ya que es en este contexto donde desarrollan competencias personales y sociales, establecen relaciones de amistad, fomentan sus estados de salud física y emocional, y encuentran significados y propósitos para desarrollar sus vidas (King et al., 2003, 2009; Longo, Badia y Orgaz, 2012).

Hay diversos contextos en los que se puede experimentar el ocio durante el tiempo libre (King, 2003, Law et al., 2006; Majnemer et al., 2008; Rosenblum, Sachs y Schreuer, 2010), uno de ellos es la participación en actividades extraescolares (Koller et al., 2017; PNUD, 2009). El nexo común entre todos estos contextos son las oportunidades que proporcionan para el aprendizaje de habilidades socioemocionales que reducen la aparición de otros comportamientos problemáticos, sobre todo cuando la actividad de estos entornos se basa en la evidencia científica (Belgrave, Reed, Plybon y 
Corneille, 2004; Kremer, Maynard, Polanin, Vaughn, Sarteschi, 2015; Tebes et al., 2007).

En este sentido, la investigación ha demostrado que la estructura, el apoyo, el sentido de pertenencia y compromiso en entornos extraescolares se asocian positivamente con resultados de desarrollo positivo en jóvenes (Smith et al., 2017), resaltando la importancia que la calidad de un contexto como el extraescolar tiene en aspectos, tales como, la competencia, el cuidado, la conexión y la cultura de todos los niños durante su educación Primaria (Lerner et al., 2009; King, 2003, 2009).

Otros estudios también han evidenciado la existencia de diferencias significativas en la influencia que la participación en este tipo de actividades tiene sobre el desarrollo de sus participantes (Albrecht, 2007; Badia et al., 2013; Law et al., 2006). Sin embargo, más allá de los resultados diferenciales de unas y otras, todas estas investigaciones suponen un apoyo empírico sobre la influencia que el contexto extraescolar tiene como activo del desarrollo infantil (Cross, Gottfredson, Wilson, Rorie y Connell, 2010; Gottfredson, Cross, Wilson, Rorie y Connell, 2010). Así como el potencial que los programas de actividades después del horario escolar tienen en la promoción de competencias infantiles socioemocionales y habilidades personales para negociar con éxito sus trayectorias de vida (Pierce, Bolt y Vandell, 2010). Sin embargo, al igual que en los programas de desarrollo positivo, la calidad de estas actividades es clave para que actúen como potenciadoras del desarrollo infantil (Smith et al., 2017).

Actualmente se sabe que para que los programas extraescolares sean efectivos, la planificación de sus actividades tiene que estar basada en la impresión que los propios jóvenes tienen de ellas (Oshri et al., 2017). Así por ejemplo, la participación activa de los jóvenes en actividades creativas y grupales fomenta resultados personales más altos de atención y disfrute (Mahoney, Larson y Eccles, 2005). En tanto que, la participación en aquellas actividades valoradas como más satisfactorias y significativas les ayuda a desarrollar sentimientos de valía y autoeficacia a través de su participación significativa (Bandura, 1986). 
Por tanto, la participación en actividades positivas fuera de la escuela se destaca como un contexto clave para el acceso y disponibilidad de oportunidades de desarrollo presentes en el entorno durante la infancia y adolescencia (Simpkins, Vest y Becnel, 2010). Lo que se consigue, facilitando activos de desarrollo relacionados no sólo con la reducción de comportamientos juveniles de riesgo, sino también con resultados personales importantes de resiliencia y bienestar personal (Brooks, 2006; Exenberge y Juen, 2013; Scales et al., 2001). Así, los programas y actividades extraescolares ayudan a desarrollar competencias y a negociar con éxito las tareas de desarrollo más importantes de la infancia y la adolescencia (Mahoney et al., 2005; Smith et al., 2017).

Involucrar a los niños en actividades de ocio y tiempo libre fuera del horario escolar significativas para ellos, por una parte, promueve la adquisición de competencias para la vida como la creatividad, el optimismo o las habilidades emocionales y sociales (Shikako-Thomas et al., 2012), fomentando el bienestar personal y social a través de experiencias de control y confianza en sí mismo (Albertín et al., 2013; Adolfsson, 2011). Mientras que, por otra, sirve a los profesionales del campo del desarrollo infantil como indicador de salud y funcionamiento positivo (OMS, 2007).

Dado que para comprender las vías que dan acceso al desarrollo infantil positivo se requiere investigar los procesos a través de los cuales los factores de riesgo y protección interactúan en sus entornos de desarrollo próximo, en el siguiente apartado se presenta la tercera y última variable seleccionada para el análisis de resultados personales significativos en niños con condiciones diversas de vida, la resiliencia.

\subsubsection{Resiliencia Infantil}

Todos los niños nacen con un potencial de crecimiento y desarrollo que puede tomar cualquier dirección dependiendo de las influencias de su ambiente y de la interacción que el niño establece con su entorno cercano (UNESCO, 1985). Para potenciar el crecimiento positivo de los más jóvenes, 
el foco de atención se dirige hacia los factores, situaciones y las relaciones que crean a su alrededor: comunidades, familias, recursos disponibles y bienestar general (Ungar, 2015b), con objeto de comprender las vías que dan acceso al desarrollo exitoso en cada niño. Desde esta perspectiva, la vulnerabilidad infantil tiene más que ver con las transacciones que existen entre los factores de riesgo y protección que actúan sobre ellos que con las características de la propia persona (Brown, Jean-Marie y Beck, 2010).

La investigación ha analizado el papel que diferentes factores presentes en los contextos de desarrollo tiene sobre el crecimiento infantil. Los resultados han evidenciado cómo los factores de riesgo que ponen a prueba el desarrollo del niño tienen la capacidad de predecir tasas altas de resultados negativos, tales como, pobreza, discapacidad, violencia, etc., lo que comúnmente se ha denominado determinantes sociales de la salud (Friedli, 2009). Mientras que, cuando el entorno proporciona más activos y recursos se fomenta la adaptación positiva del niño a su contexto, disminuyendo la influencia de otros factores perjudiciales (Ten-Hove et al., 2018). Por su parte, los denominados factores de protección tiene el rol de modificar la respuesta que la persona puede tener frente a situaciones de vida difíciles, más que fomentar el desarrollo en entornos normales (Windle, 2011).

Entre los principales factores de protección identificados en la infancia se encuentra el apoyo social recibido de adultos e iguales del entorno próximo (Oshri et al., 2017). Según la evidencia científica, el apoyo social es el factor más común e importante presente en el desarrollo infantil positivo de todos los niños (Duggan y Dijkers, 1999; Shoshani y Slone, 2013). Con respecto a los niños con discapacidad, la investigación ha evidenciado que los factores que protegen contra resultados de desarrollo negativos son muy similares a los de otras poblaciones de niños en condiciones adversas de vida, destacando nuevamente el papel protector del apoyo social (Oshri et al., 2017).

Según Smith y Schinert-Reichl (2013) estudiar el funcionamiento humano desde la perspectiva de resiliencia puede ser de utilidad para 
comprender muchas de las interacciones positivas que tienen lugar durante el desarrollo y crecimiento infantil en situaciones adversas de vida, como la de los niños con condiciones asociadas de discapacidad.

Conceptualmente, resiliencia se define como un proceso dinámico de adaptación al entorno capaz de potenciar las fortalezas internas del niño y los factores externos que lo favorecen (Connor y Davidson, 2003; Rutter, 2012). Según los expertos, la resiliencia nace de la interacción entre la persona y su ambiente, y se dirige al crecimiento positivo y al bienestar significativo del niño en cada situación y etapa de vida (Rutter, 2012; Masten, 2007; Ungar, 2011).

Los resultados en resiliencia resaltan la importancia de proporcionar a los niños oportunidades para el establecimiento de relaciones positivas y significativas desde sus entornos de desarrollo próximo, tales como el contexto de actividades extraescolares analizado con anterioridad (King et al., 2003, 2009), o el contexto educativo ordinario (Hawkins et al., 2005; Ungar, 2015a), dada la relevancia de ambos para proporcionar activos y recursos que apoyen las trayectorias de vida de los más jóvenes hacia vías de desarrollo significativo y pleno.

Tanto el modelo de resiliencia (Ungar, 2011, 2012), como los modelos de calidad de vida (Schalock et al., 2002, 2003; Verdugo et al., 2013b) y participación en actividades diversas (OMS, 2001, 2007; King et al., 2003), están íntimamente relacionados con el desarrollo personal pleno y armónico. Orientados al campo del desarrollo infantil, la unión de estos tres constructos puede constituir un nuevo criterio para abordar las intervenciones educativas, sanitarias y sociales con menores, así como una herramienta para evaluar las estrategias de mejora que llevan a cabo los profesionales de la infancia. En la Figura 3 se presenta la relación entre estos tres constructos respaldada por la evidencia científica presentada en este capítulo. 
Figura 3. Relación conceptual entre calidad de vida, participación en actividades diversas y resiliencia en el marco de desarrollo infantil positivo

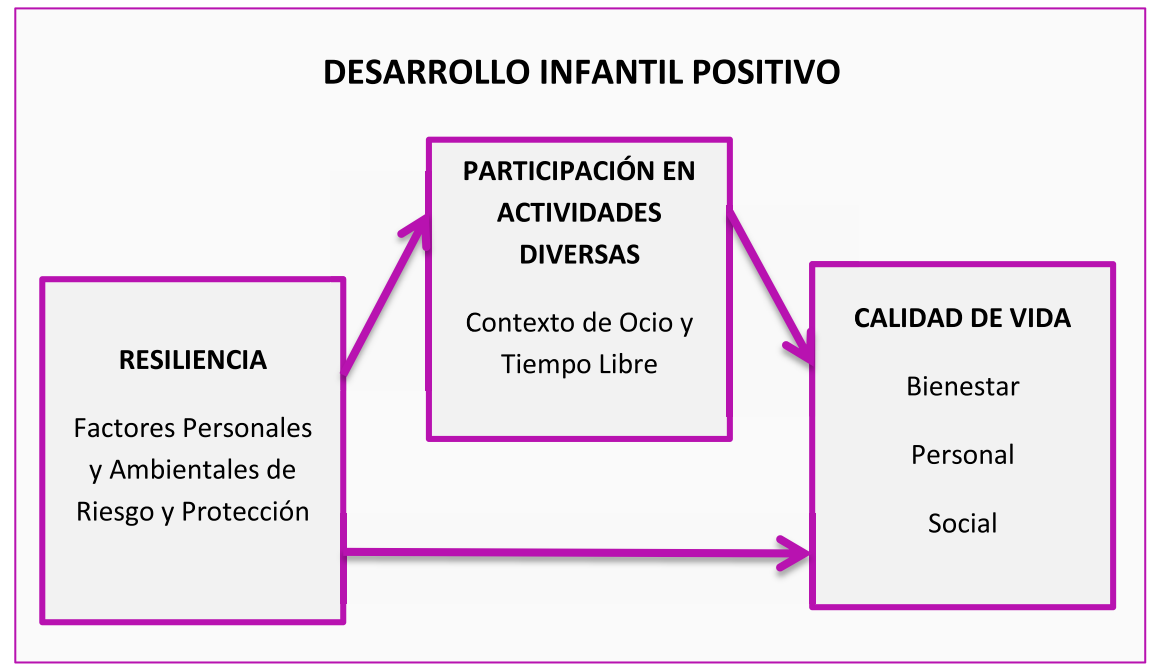

Nota. Elaborado a partir de Badia et al., 2013; OMS, 2001, 2007; Oshri et al., 2017; Ravens-Sieberer et al., 2014b; Smith et al., 2013; Ungar, 2015a; entre otros.

Estos tres modelos conceptuales, defendidos por parte de la comunidad científica especializada en desarrollo infantil, están cambiando los modos y formas de abordar las intervenciones con los más jóvenes. Por una parte, la percepción que los niños tienen de su calidad de vida y de aquellos aspectos que conforman su bienestar personal y social. Por otra parte, la disponibilidad y acceso a la participación en actividades diversas en contextos de ocio y tiempo libre. Por último, las características para la resiliencia propias y de su entorno que actúan como fuentes de protección o riesgo ante los desafíos del día a día e influyen en el desarrollo infantil exitoso.

El objetivo general de este trabajo es analizar los resultados personales en calidad de vida, participación en actividades diversas de ocio y resiliencia infantil, así como la relación que se establece entre estas tres variables y el peso de otras variables personales o familiares en dichos resultados, a fin de comprender el papel facilitador o limitador de todas ellas en el bienestar y desarrollo integral de niños en condiciones diversas de vida. 
Los resultados derivados de esta investigación permitirán formular nuevas propuestas prácticas, útiles para las escuelas y otros servicios educativos para reconocer y responder a las diversas necesidades de niños y jóvenes, atendiendo a su bienestar y capacitación para la vida adulta. Es decir, conocer y comprender la percepción que los niños tienen de sus contextos próximos de desarrollo, a través de su bienestar, participación y resiliencia, permitirá seguir avanzando en la planificación y desarrollo de intervenciones cada vez más exitosas, centradas en el desarrollo infantil positivo y significativo de cada niño.

En definitiva, y con respecto al ámbito profesional, centrarse en la consecución de resultados personales significativos de bienestar, participación y resiliencia se plantea como una técnica de intervención que enfatiza el potencial y bienestar humano de los más jóvenes (UNESCO, 2005). Con objeto de avanzar en esta línea de conocimiento, en los siguientes capítulos teóricos se realizará un análisis pormenorizado del papel, conexión e influencia que tienen diferentes factores del contexto implicados en el desarrollo infantil sobre estos resultados personales propuestos como determinantes para el crecimiento positivo y saludable de los más jóvenes.

\subsection{Desarrollo Infantil Positivo Aplicado al Contexto Educativo}

La atención mundial sobre el desarrollo infantil ha avanzado la visión que la sociedad tiene del niño desde la mera supervivencia hacia modelos inclusivos de desarrollo que permiten a todos los niños prosperar y crecer de forma saludable (CDN, 1989; CDPD, 2006; UNICEF, 2006). En materia de educación, el Marco de Acción Dakar (Foro Mundial sobre la Educación, 2000) y la Conferencia Mundial sobre Atención y Educación de la Primera Infancia (UNESCO, 2010) son las dos proclamas mundiales más relevantes que han impulsado el derecho a la educación de calidad de todos los niños, considerando la atención, protección, sanidad y educación como pilares para la supervivencia, crecimiento, desarrollo y aprendizaje infantil. 
Dado que durante esta etapa de vida todo momento constituye una situación potencial de aprendizaje, favorecer entornos adecuados, como por ejemplo, una escuela de calidad, es una de las claves para el desarrollo de activos y recursos en niños y jóvenes (Camargo Ramos et al., 2012; Eichas et al., 2017; Shoshani et al., 2013), tal como demuestra el estudio de LuengoKancri y colaboradores (2017) sobre clima escolar y conductas adolescentes pro-sociales en escuelas colombianas.

El clima socio-afectivo en el que tiene lugar el proceso de aprendizaje se encuentra determinado por las interacciones sociales de todos los miembros de la comunidad educativa, así como el grado de afectividad que se genera durante las actividades educativas (Jaramillo, 2007). No obstante, las barreras del sistema educativo ordinario para abordar las necesidades de aprendizaje de sus alumnos, así como las nociones subyacentes sobre déficits individuales, se reflejan en las actitudes discriminatorias hacia alumnos con condiciones diversas de vida y la falta de acción hacia la diversidad de habilidades, intereses y lenguajes de todos los alumnos del aula (Echeita, 2013; Wehmeyer, 2009).

\subsubsection{Un Modelo de Educación Basado en el Bienestar y Desarrollo Pleno} del Niño

En el campo educativo los modelos situados en el campo de la acción social otorgan especial importancia a la detección de barreras y facilitadores para la accesibilidad, la participación y el aprendizaje de todos los alumnos. En la actualidad el mayor exponente es el modelo de inclusión educativa de Booth y Ainscow (2002, 2015), defendido por la mayor parte de la comunidad científica, profesional y política en el ámbito educativo. Al igual que en el modelo funcional de la CIF (OMS, 2001), en el modelo de educación inclusiva las barreras y facilitadores aparecen en la interacción del alumno y su entorno educativo (Muntaner, 2013). De esta forma, los problemas ya no surgen de los déficits de los alumnos, sino de la falta de adecuación entre éstos y su ambiente (Muntaner, Forteza, Roselló, Verger y De la Iglesia, 2010), adquiriendo importancia la defensa de apoyos como 
medios para alcanzar resultados personales positivos para el funcionamiento óptimo del niño (AAIDD, 2001). En este sentido, Wehmeyer (2009) en su estudio sobre tercera generación de prácticas inclusivas, plantea la educación como: "un tipo de apoyo, que mejora el funcionamiento humano al aumentar la capacidad de una persona para desenvolverse en un amplio espectro de entornos" (p. 49).

\subsubsection{Educación Inclusiva}

El principio de inclusión se centra en la defensa de los derechos humanos y civiles a nivel mundial (UNICEF Comité Español, 2014), reconociendo la equidad, la cooperación y la solidaridad como principios de vida básicos, y la diversidad en las aulas como fuente de enriquecimiento y no como barrera para el aprendizaje del alumnado.

Para la educación inclusiva, la asistencia de todo el alumnado es la condición básica para el cambio en las prácticas educativas, mientras que la participación en todas las actividades ordinarias de la escuela es la condición necesaria que da término a la tercera y última condición, el aprendizaje significativo de los alumnos, que se refleja en sus resultados personales (Booth et al., 2002, 2015; Schalock y Verdugo, 2013b). Desde estos tres principios esenciales: asistencia, participación y aprendizaje la respuesta a las necesidades del alumnado se centra en el diseño de apoyos individualizados dentro del aula ordinaria y no en programas específicos para la compensación de déficits y normalización del alumnado (Navarro Barba, 2011).

Sin embargo, a través del diagnóstico de necesidades individuales los sistemas educativos ordinarios abordan una estrecha banda de necesidades de aprendizaje. Este modus operandi provoca la incapacidad de las escuelas de responder a la diversidad de su alumnado e impone barreras al aprendizaje de todos los alumnos en igualdad.

Desde el modelo inclusivo, la educación de los alumnos con necesidades educativas debe centrarse en la inclusión del alumno en todos los ámbitos comunes del sistema educativo. Para que esta inclusión sea efectiva se 
requiere de los apoyos y recursos adecuados que se consiguen, a través de la inversión en políticas nacionales y locales progresistas, cualificación profesional, instalaciones accesibles, puesta en marcha de programas y métodos de enseñanza flexibles y recursos educativos que benefician a todos los alumnos por igual, y no sólo aquellos con necesidades educativas específicas (UNICEF, 2013). De esta forma, atendiendo a la diversidad del alumnado, eliminando las barreras estructurales y facilitando apoyos individualizados, dándoles acceso a una educación inclusiva y de calidad, se fomenta el desarrollo integral de todos los niños y niñas sobre la base de una sociedad más diversa y justa (Booth et al., 2002, 2015; UNESCO, 2006; Foro Mundial sobre la Educación, 2000; UNESCO, 2010).

\subsubsection{Alumnos con Necesidades Específicas de Apoyo Educativo (NEAE)}

La actual Ley Orgánica para la Mejora de la Calidad Educativa (Ley Orgánica 8,2013) define al alumnado con NEAE como aquel que requiere atención educativa diferente a la ordinaria, por presentar necesidades educativas especiales (NEE), altas capacidades intelectuales (ACI), incorporación tardía al sistema educativo ordinario u otras NEAE, para que el alumno pueda alcanzar el máximo desarrollo posible de sus capacidades personales y en todo caso los objetivos establecidos con carácter general para todo el alumnado. (Tabla 1).

Tabla 1. Clasificación de las NEAE en la actual Ley Orgánica para la Mejora de la Calidad Educativa

\begin{tabular}{lll}
\hline Grupo & Definición & Tipología \\
\hline Alumna- & Alumnado valorado con NEE por los & Discapacidad física \\
do con & equipos o servicios de orientación edu- & Discapacidad intelectual \\
necesidades & cativa que requiere por un periodo de su & Discapacidad auditiva \\
educativas & escolarización o a lo largo de toda ella, & Discapacidad visual \\
especiales & determinados apoyos y atenciones educa- & Trastorno generalizados del \\
(NEE) & tivas específicas asociadas a discapacidad o & desarrollo \\
& trastornos de desarrollo graves. & Trastornos graves de conducta/ \\
& & personalidad Plurideficiencias
\end{tabular}




\begin{abstract}
Alumno Alumnado valorado con ACI por equiposo con Altas servicios de orientación educativa que recibe Capacidades atención educativa a través de medidas Intelectuales específicas: adaptaciones curriculares de pro(ACI) fundización o de ampliación del currículo, flexibilización del periodo de escolarización, y/o participación en programas extracurriculares de enriquecimiento.
\end{abstract}

Alumnado Alumnado procedente de otros países que en con integra- el curso escolar de referencia se ha incorpoción tardía rado a las enseñanzas obligatorias del sistema en el sistema educativo español

educativo

español

Otras Alumnado con retraso madurativo, neu-

NEAE $^{\mathrm{a}}$ dictaminado con precisión durante la etapa de educación infantil
Predominio intelectual

Talento simple, múltiple o complejo Superdotación intelectua

Escolarizado en 1 a 2 cursos inferiores al correspondiente por edad

Atención educativa especifica dirigida a facilitar su inclusión escolar, superar desfase curricular o dominio de la lengua vehicular del proceso de enseñanza

Trastorno del desarrollo del lenguaje y la comunicación Trastornos del aprendizaje Alumnos con desconocimiento grave de la lengua de instrucción

Alumnado en situación de desventaja socio-educativa

Nota. ${ }^{a}$ (NEAE) Necesidades Específicas de Apoyo Educativo. Elaborado a partir de Ley Orgánica 2, 2006; Ley orgánica 8, 2013.

Aunque la identificación de niños con discapacidad u otras condiciones de riesgo asociadas es de utilidad para la creación de políticas, prácticas y prestación de servicios específicos, se debe reconocer que los niños en origen no se consideran diferentes por sus condiciones personales o ambientales particulares, y que todos ellos aspiran a participar plenamente en su entorno cercano junto al resto de compañeros y adultos (OMS et al., 2013). Por ello, se debe evitar etiquetar a los niños solamente por sus necesidades educativas, con objeto de evitar actitudes discriminatorias y de rechazo social (Law y Kelly, 2005; Boer, Pijl y Minnaert, 2012; UNESCO, 2006).

Pese a este conocimiento, hoy día en el contexto escolar sigue existiendo una fuerte tendencia por parte de los alumnos sin NEAE y otros miembros de la comunidad educativa a estigmatizar y discriminar a sus compañeros 
con discapacidad. El informe emitido por UNICEF (2013) sobre el estado de los niños con necesidades especiales, informa que los menores con discapacidad física, sensorial o mental se encuentran entre los niños más estigmatizados y marginados del mundo. Mientras que, un estudio realizado sobre estigmatización y discriminación de alumnos con NEE ha puesto en evidencia que la mayoría de estos alumnos perciben una actitud negativa de sus compañeros en la escuela Primaria (Idrees e Ilyas, 2012)

Como se ha comentado con anterioridad un recurso esencial es el apoyo social, que en la comunidad educativa propicia interacciones positivas entre todos sus miembros. Este recurso se consigue a través de intervenciones dirigidas a la orientación de actitudes y respuestas positivas entre compañeros, maestros y resto de miembros de la comunidad educativa (UNICEF, 2013). En esta línea, se ha evidenciado que entornos escolares con adultos menos críticos, que involucran activamente a los alumnos junto a compañeros de apoyo, ayudan a los niños a reportar mayores índices de eficacia colectiva, haciéndoles sentir más capaces y dispuestos de influir positivamente en el comportamiento de sus compañeros (Smith et al., 2017).

A nivel teórico los marcos de referencia que nos permiten configurar un sistema educación de calidad son la defensa de los derechos humanos, la concepción social de la discapacidad, la perspectiva organizativa como base del desarrollo institucional, los modelos de recursos comunitarios y los enfoques de investigación aplicada dirigidos a la acción (Schalock et al., 2002, 2003, 2013b). Desde este prisma, las dificultades de aprendizaje de los alumnos están íntimamente relacionadas con la estructura y la organización de las escuelas, lo cual justifica la imperativa necesidad de iniciar un proceso de transformación profunda en las instituciones educativas, ofreciendo a las organizaciones escolares los recursos necesarios para fomentar el desarrollo óptimo de todos sus miembros (Ungar, 2015b).

El modo de hallar un consenso entre el sistema educativo y los planteamientos inclusivos planteados por Booth y colaboradores $(2002,2015)$ puede encontrarse en el análisis y aplicación de las aportaciones derivadas de conceptos como el de calidad de vida (Schalock et al., 2002, 2003), 
participación (King et al., 2003, 2009) o florecimiento de la resiliencia (Ungar, 2012) desde un enfoque del desarrollo infantil basado en la aplicación de los derechos humanos (ONU, 1989). Estos tres conceptos aluden al logro de estándares relacionados con las condiciones de vida de una persona y la satisfacción que estas condiciones le proporcionan. Sin embargo, implementar estas aportaciones teóricas a la realidad de niños con NEAE y sin ellas requiere un proceso de reflexión sobre las contribuciones de cada concepto a la mejora de la respuesta educativa ofrecida a todo el alumnado. Este trabajo de investigación tiene la finalidad de abordar este proceso de reflexión dirigido a la mejora de las prácticas educativas en los centros escolares.

\subsection{Conclusiones}

A lo largo de este capítulo se ha tratado teóricamente el desarrollo infantil, concebido como la primera etapa de vida de los seres humanos. Según la literatura consultada esta primera etapa se encuentra determinada por las relaciones que se establecen entre las características personales e influencias ambientales, las cuales dan lugar a experiencias personales que marcan el proceso de desarrollo de cada niño (Geldhof et al., 2014; Lerner et al., 2009; Snyder et al., 2012; Smith et al., 2017).

Actualmente el niño ocupa un papel central en el panorama mundial, mostrándose como sujeto de pleno derecho ante la sociedad de la que forma parte (Jaramillo, 2007). Esta visión, que se ha ido instaurando a lo largo del siglo XX, conlleva un cambio en la forma en la que los adultos se acercan y actúan con respecto a la infancia. Los nuevos métodos se enfocan principalmente en proporcionar un desarrollo pleno y positivo al niño, basado en fomentar una vida de calidad y bienestar infantil.

De esta forma, el desarrollo positivo se presenta como un enfoque de intervención juvenil centrado en promover las características personales de los más jóvenes y enriquecer los entornos de desarrollo próximo, proporcionando apoyos y oportunidades para la interacción constructiva entre los menores y los contextos en los que se lleva a cabo su crecimiento 
y desarrollo como personas (Lerner et al., 2009; Snyder et al., 2012). Este enfoque de desarrollo infantil se basa en la teoría ecológica de Bronfrenbrenner (1979, 2002), la cual define los distintos sistemas en los que tiene lugar la interacción entre el niño y su ambiente, estableciendo una división de niveles personales y sociales en los que incluir los factores que determinan el crecimiento del niño (Figura 1).

El paradigma de desarrollo infantil presentado ha sido adoptado por diferentes campos del saber dedicados a intervenir profesionalmente con la infancia, los cuales han desarrollo modelos dirigidos a defender y promocionar el potencial y bienestar de los niños desde la base de la diversidad humana. Dos de estos modelos son la versión para niños de la CIF (OMS, 2007) elaborada por profesionales bio-psico-sanitarios, y el modelo de inclusión educativa para el fomento de la calidad del sistema educativo (Booth y Ainscow, 2002, 2015). Para estos dos modelos los factores presentes en los contextos de desarrollo actúan como barreras y facilitadores para el crecimiento infantil positivo. Estos factores aparecen en la interacción del niño con su ambiente, y por tanto, los problemas en el desarrollo no son causados por déficits personales, sino por la inadecuación entre el menor y su ambiente (Muntaner et al., 2010; OMS et al., 2013; Ten-Hove et al., 2018; Wehmeyer, 2009).

En general, la visión ecológica del desarrollo infantil define el crecimiento como el resultado de las interacciones dinámicas que se dan entre el niño y las experiencias que su contexto familiar, social y cultural les proporciona (Sameroff y Fiese, 1990). Desde un punto de vista práctico, para que estos resultados sea positivos y significativos los expertos recomiendan centrarse en analizar los factores y procesos que contribuyen a la adaptación y bienestar infantil desde la perspectiva propia del menor, así como en estudiar en qué medida estos resultados varían entre poblaciones de niños en condiciones diversas de vida (Oshri et al., 2017). 
Tres de los resultados infantiles que más interés ha despertado en los últimos tiempos son el de calidad de vida, participación y resiliencia infantil (Badia et al., 2013; OMS, 2001, 2007; King et al., 2003, 2009; Schalock y Verdugo, 2002, 2003; Ungar, 2012, 2015; Wallander y Koot, 2016). Desde una perspectiva ecológica, calidad de vida hace referencia a aquellos aspectos del contexto de desarrollo que propician el bienestar personal y social del niño, en tanto que su participación se refiere a la disponibilidad y acceso que el niño tiene a la realización de actividades en contextos diversos, como en este capítulo ha sido el contexto de ocio y tiempo libre. Por último, las características para la resiliencia aluden a los activos personales y recursos del ambiente que actúan como factores de protección o riesgo en los procesos de desarrollo infantil.

En este capítulo se ha priorizado la importancia de centrarse en la consecución de resultados personales significativos de bienestar, participación y resiliencia para conocer las diversas necesidades del niño, a través de su propio punto de vista. También se ha fundamentado, cómo este enfoque permite desarrollar nuevas propuestas prácticas basadas en la respuesta a dichas necesidades, fomento del bienestar y capacitación para la vida adulta de cada niño. Desde este prisma, el objetivo general de este trabajo es analizar los resultados personales en calidad de vida, participación y resiliencia infantil, la relación que se establece entre estas tres variables y el peso de otras variables personales y ambientales en dichos resultados, a fin de comprender el papel facilitador o limitador de todas ellas en el bienestar y desarrollo integral de niños en condiciones diversas de vida.

En definitiva, a través de los resultados obtenidos con el presente trabajo de investigación, se espera conseguir información sobre experiencias personales que ayudan a los niños y adolescentes a desarrollarse de forma plena y saludable. Esta información será de utilidad práctica para educadores, proveedores de servicios educativos y administradores de políticas públicas. Así como, para la organización y puesta en marcha de estrategias dirigidas al logro de resultados personales significativos durante la infancia y la adolescencia. 
En los siguientes capítulos teóricos se realizará un análisis pormenorizado del papel, conexión e influencia que tiene los constructos de calidad de vida, participación en contextos de ocio y tiempo libre y resiliencia en el desarrollo infantil positivo y exitoso. 

Capítulo 2

Conceptualización de Calidad de Vida Infantil

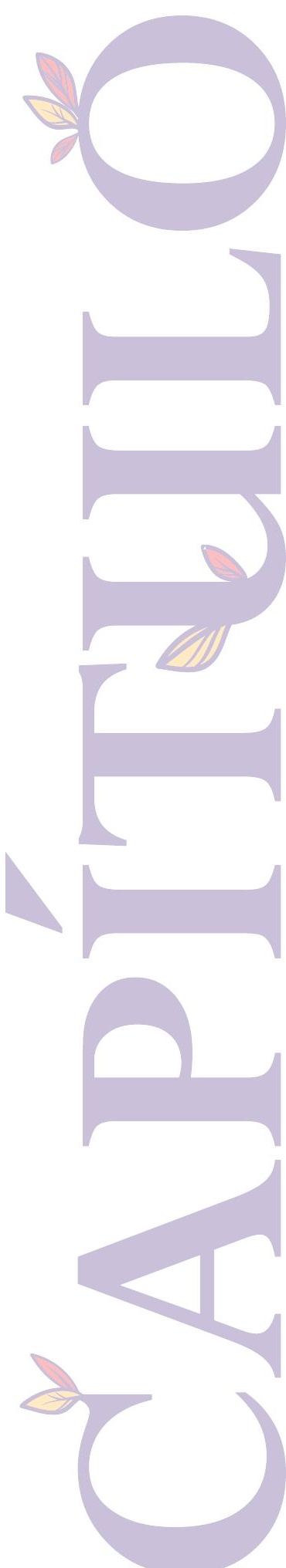





\section{Conceptualización de Calidad de Vida Infantil}

\section{Introducción}

Calidad de vida es un concepto sutil y versátil relacionado con componentes concernientes con la buena vida, el bienestar y la satisfacción del ser humano. Ha sido progresivamente adoptado por diversas disciplinas y campos del saber, cada uno de los cuales lo ha ido definiendo para sus propios fines. Su esencia conceptual forma parte del discurso del hombre desde los albores de nuestra historia. De este modo, Epicuro, padre de la filosofía de la felicidad, ya planteó las bases para una vida de placer y bienestar en la Antigua Grecia. Pero ha sido durante los cambios y movimientos sociales acaecidos durante el siglo pasado cuando ha crecido su influencia social, el interés científico por su conceptualización, su evaluación y su aplicación profesional (Gómez-Vela y Sabeh, 2000). El uso del término desde diferentes disciplinas y voces sociales, tales como, líderes políticos, economistas, profesionales de la salud, ciencias ambientales y sociología, así como otros colectivos sociales, lo ha generalizado a nivel mundial y ligado a otros conceptos como el de "desarrollo" o "discapacidad", dirigidos todos a la comprensión de la diversidad y la complejidad social contemporánea (Cantú-Martínez, 2015; Schalock et al., 2002, 2003; Van Loon, Bonham, Peterson, Schalock, Claes y Decramer, 2013; Wallander et al., 2016).

En el campo de la discapacidad, bajo las perspectivas biopsicosociales del funcionamiento humano propuestas por la Organización Mundial de la Salud (OMS, 2001) y la Asociación Americana de Discapacidades Intelectuales y del Desarrollo (AAIDD, 2011), el concepto de calidad de vida (en adelante, CV) está aportando un marco teórico y empírico con relevantes implicaciones prácticas para el desarrollo de las personas con discapacidad en las diferentes áreas de vida.

Existen diversos modelos teóricos sobre CV de personas con y sin discapacidad (Cummins, 2000, 2005; Edwards, Huebner, Connell y Partick, 2002; Schalock et al., 2002, 2003; Wallander et al., 2016), que lo describen como un concepto multidimensional, compuesto por factores objetivos y 
subjetivos influenciados por los valores personales y variables ambientales. El modelo propuesto por Schalock y colaboradores (2002, 2003), centrado en la conceptualización, medida y aplicación de CV a nivel sistémico es uno de los que mayor implicación ha tenido los últimos años, debido en gran medida al extenso y riguroso trabajo de revisión realizado para su construcción científica. Para estos autores el aspecto más revolucionario del constructo es su potencial para mejorar los resultados personales de las personas con discapacidad, así como los de otros colectivos sociales, en diversos ámbitos de vida (Schalock, Gadner y Bradley, 2007; Schalock, Verdugo, Bonham, Fantova y Vanloon, 2008; Verdugo, 2006; Schalock et al., 2016a). Pero para su consecución la aplicación del modelo debe ir acompañada del cambio y mejora de las prácticas profesionales, la redefinición y transformación de las organizaciones proveedoras de servicios y recursos para el desarrollo de una vida plena y significativa, así como la potenciación de las políticas públicas basadas en la CV de las personas (Schalock et al., 2013a; Schalock, Verdugo y Lee, 2016b; Schalock, Verdugo y van Loon, 2018).

En origen, el estudio y desarrollo conceptual de CV se ha centrado en población adulta, siendo relativamente reciente su enfoque a población infantil (Ben-Arieh, Casas, Frønes y Korbin, 2014). La investigación sobre CV infantil se ha desarrollado especialmente desde el campo de la salud, relacionando ambos conceptos (CV y Calidad de Vida relacionada con la Salud) con el funcionamiento de poblaciones concretas de niños y jóvenes con enfermedades, discapacidad u otras limitaciones en el desarrollo (Wallander et al., 2016). Este hecho ha provocado una comprensión restringida del significado potencial de CV en poblaciones generales de niños y jóvenes, el cual se torna importante por múltiples razones siendo una de ellas su valor añadido para abordar los derechos y el bienestar de todos los niños como ciudadanos del mundo (UNICEF, 2016).

Como veremos en este capítulo la investigación se dirige hacia una visión más global de la CV infantil, tratando de unificar la experiencia subjetiva de bienestar del niño con los dominios de vida que se presentan comúnmente relevantes durante esta etapa de vida y, dado que, el proceso de interacción 
entre el niño y el entorno es fundamental para su desarrollo (Bronfenbrenner, 1986), el ambiente se presenta como un concepto relacionado e importante para comprender la CV infantil.

Entre los distintos contextos en los que están integrados los niños (la familia, la escuela, el grupo de pares, la comunidad, entre otros) en este trabajo nos centramos en el educativo. En primer lugar, por su importancia para entender la CV infantil. En segundo, por la capacidad del propio constructo para constituirse como marco de referencia idóneo para favorecer la mejora de la planificación educativa, la respuesta a las necesidades del alumnado desde el desarrollo de apoyos individualizados, la participación de todos los miembros de la comunidad educativa en la labor del centro y, en definitiva, el avance hacia la educación integral de todo el alumnado (GómezVela, 2007; Muntaner, 2010; Sabeh, Verdugo y Prieto, 2006; Verdugo, 2011; Wehmeyer, 2009).

Para conocer el desarrollo del constructo y su devenir hasta la actualidad en los siguientes apartados realizaremos un recorrido histórico por el concepto de CV que nos llevará a su concepción actual en población infantil y su aplicación en el ámbito educativo.

\subsection{Antecedentes Teóricos del Concepto Calidad de Vida}

El concepto Calidad de Vida surge públicamente en los discursos económicos y políticos sobre el papel del Estado en el bienestar de los ciudadanos tras la Segunda Guerra Mundial como principio análogo al bienestar material. En la década de los 50, al demostrase que el ingreso per cápita de un país no era un indicador suficiente, Naciones Unidas (ONU) apuntó a la medida del bienestar personal desde diferentes áreas de vida: salud, educación, empleo, vivienda, nutrición, etc., lo que dio lugar a la medida del nivel de vida valorada a través de encuestas ciudadanas en diferentes países a partir de 1965. En ese momento, el nivel de vida se conceptualizó como la posesión de ciertos bienes y recursos materiales (dinero, posesiones materiales, conocimiento, energía mental y física, relaciones sociales, entre 
otros), mediante los cuales la persona puede dirigir conscientemente sus condiciones de vida (Cardona y Agudelo, 2005).

En EEUU la investigación generada en torno a las condiciones de vida de sus ciudadanos dio origen a una importante corriente conocida como Movimiento de los Indicadores Sociales (Bauer, 1966). La evidencia científica surgida a partir de este movimiento derivó en la propuesta de políticas públicas para el bienestar social (Rapley, 2003; Rodríguez-Jaume, 2000). El término indicador social se presentó desde una aproximación normativa que consideraba las condiciones reales de vida de los ciudadanos en seis dimensiones básicas: salud y enfermedad; movilidad social; ambiente físico; ingresos y pobreza; orden público y seguridad; y aprendizaje, ciencia y arte (Exenberger et al., 2013). Esta herramienta pronto se hizo evidente que no sólo era importante registrar las condiciones objetivas de vida, sino también como éstas eran percibidas por los diferentes grupos sociales.

Las nuevas aportaciones del valor subjetivo del bienestar de la década de los 70 (Andrews y Withey, 1976; Campbell, Converse y Rogers, 1976) hicieron que CV se constituyese como un concepto integrador del bienestar en las diferentes áreas de vida, formado por indicadores objetivos y subjetivos sobre la percepción de satisfacción y bienestar personal ante diferentes condiciones vitales (Gómez-Vela et al., 2000).

El reconocimiento de la relevancia científica del concepto condujo en la década de los 80 al despegue de su investigación, así como al énfasis de su utilidad política y a la adopción del término para la defensa de los derechos humanos y civiles de distintos colectivos sociales, como el de las personas con discapacidad, y el desarrollo de sus oportunidades. La revolución por la búsqueda de resultados de calidad comenzó a consolidar un marco conceptual desde el que evaluar resultados personales, guía para la planificación y desarrollo de servicios de calidad y criterio desde el que evaluar la eficacia de estos recursos y servicios sobre el desarrollo y bienestar de las personas (Schalock, Bonham y Verdugo, 2008; Schalock et al., 2018), que favoreció un cambio en la visión de colectivos diferentes a la mayoría dominante (Schalock et al., 2002, 2003). 
Todas estas acciones vieron su concreción en la década de los 90 con el esfuerzo científico común dirigido al desarrollo de un marco teórico y de acción en y para la CV. El discurso multidisciplinar a nivel mundial llevó a la especificación del constructo, a la precisión de su medida y la integración de su aplicación en la práctica profesional (Gómez, Verdugo y Arias, 2010), convirtiéndolo en agente de cambio que obligaba a políticos, técnicos y profesionales de distintos ámbitos a llevar a cabo reformas a todos los niveles del sistema para mejorar las condiciones sociales y personales que dan lugar a una vida de calidad (Schalock et al., 2008).

\subsection{Calidad de Vida, Concepto y Definición}

La definición y conceptualización de CV conlleva múltiples cuestiones técnicas y filosóficas (Schalock et al., 2002, 2003). A pesar de los esfuerzos realizados en los últimos años para definir y operativizar el concepto, precisar la CV ha sido una difícil labor aún hoy vigente. En la actualidad, no existe una definición consensuada sobre $\mathrm{CV}$, ni acuerdo sobre las dimensiones objetivas y subjetivas que deberían considerarse como indicadoras del concepto (Cantú-Martínez, 2015; Wallander et al., 2016). Según algunos autores, esto es debido al carácter multidisciplinar de su medida que da lugar a una gran diversidad de definiciones concernientes a las diferentes perspectivas y enfoques de los investigadores; a la selección de diversos dominios e indicadores para la aplicación de su medida en contextos determinados; así como a la propia finalidad de la evaluación (Borthwick-Duffy, 1996; Fernández-Mayoralas y Rojo, 2005; Urzúa y Caqueo-Urízar, 2012). Sin embargo, como veremos a continuación, han sido notorios los esfuerzos de algunos autores por establecer principios básicos que medien en el trabajo teórico y aplicado referente a CV (Bothwick-Duffy, 1992; Cummins, 1996, 1997; Felce y Perry, 1995; OMS, 1995; Schalock et al., 2002, 2003)

Históricamente una de las influencias más importantes sobre el concepto ha sido la del campo de la medicina, a raíz de la definición de salud adoptada por la Organización Mundial de la Salud (OMS, 1948) como estado completo 
de bienestar físico, mental y social, y no sólo como ausencia de enfermedad. El enfoque de Calidad de Vida Relacionada con la Salud (CVRS) ha dominado fuertemente la bibliografía científica al utilizarlo como medida estándar de resultados de salud, enfermedad y tratamiento. Sin embargo, el uso de CVRS ha estado más enfocado al desarrollo de indicadores dirigidos a la evaluación de la experiencia subjetiva de la persona en condiciones de enfermedad, discapacidad, deterioro e intervención clínica, que a la construcción teórica de su modelo (de Civita et al., 2005; Fernández-Mayoralas et al, 2005). Esta tendencia se representa en el amplio abanico de instrumentos disponibles para la medida de la CVRS, como se comprobará posteriormente en el apartado de evaluación de la CV infantil.

En relación con la infancia, una revisión realizada en 2008 detectó más de 90 instrumentos dirigidos a poblaciones infantiles con enfermedades específicas y sin ellas (Solans et al., 2008), de los cuales al menos 30 fueron construidos para su uso genérico con niños (Ravens-Sieberer et al., 2006). Entre estas herramientas destacan: Child Health Questionnaire (Landgraf, Abetz y Ware, 1996); Health related quality of life questionnaire for children and young (Ravens-Sieberer el al., 2008); Youth Quality of Life Instrument (Edwards et al., 2002). Estos instrumentos permiten la evaluación y comparación de diversos estados de salud y/o el equilibrio entre la cantidad y calidad de vida de niños con y sin limitaciones en sus condiciones de salud. El desarrollo de éstas y muchas otras herramientas bajo el enfoque biomédico ha destacado dos aspectos centrales inherentes a la mayoría de las definiciones de CVRS: la subjetividad y la multidimensionalidad de la medida de CVRS (Matza, Swensed, Flood, Secnik y Leidy, 2004; Payot y Barrington, 2011).

Pese a los esfuerzos de los investigadores por ampliar el rango de acción y aplicabilidad de la medida de CVRS, su limitación conceptual a una serie de dominios concretos y la confusión de los profesionales del campo para discernir los conceptos de salud y CV llevó en la década de los 90 a la necesidad de redefinir el concepto desde aproximaciones más holísticas y globales que las del discurso médico. 
Entre la gran proliferación de trabajos científicos de estos años cabe destacar los estudios de Cummins (1996, 1997), dada su influencia sobre trabajos posteriores para la medida del concepto. Para Cummins (1996), el eje objetivo lo representaba los valores culturales normativos del bienestar y las circunstancias de vida actuales de la persona. Mientras que, de acuerdo con Campbell y colaboradores (1976), el eje subjetivo lo establecía el juicio y evaluación individual que hace la persona sobre diversas condiciones de vida, como por ejemplo la satisfacción en la escuela.

Otra aportación destacable fue la realizada por Bothwick-Duffy (1992), quien propuso tres categorías en las cuales podían adecuarse las distintas definiciones dadas hasta la época: 1) la calidad de las condiciones de vida de una persona (los componentes objetivos); 2) la satisfacción con la vida (los componentes subjetivos); y 3) las condiciones de vida de una persona junto con la satisfacción experimentada. A la que Felce y colaboradores (1995) añadieron una cuarta categoría relacionada con: 4) la combinación de las condiciones de vida y la satisfacción personal relativa a dichas condiciones y determinada por el sistema de valores de la persona. Esta última propuesta ha sido la que más acogida ha tenido por la comunidad científica especializada en CV al permitir la construcción y validación de escalas y la aplicación de modelos explicativos, análisis factoriales y multinivel (Cardona et al., 2005).

Por su parte, la Organización Mundial de la Salud (en adelante OMS) también ofreció su propia definición de CV, describiéndola como la percepción individual de la propia posición en la vida dentro de un contexto cultural y sistema de valores en que la persona vive, relacionada con sus objetivos, expectativas, estándares e intereses (OMS, 1995).

Para la OMS el concepto de CV es equiparable al de bienestar, el cual enmarca la salud y los estados relacionados con ella (OMS, 1948). Desde la perspectiva de la organización, los dominios de salud pertenecen al espectro de factores intrínsecos a la persona (experiencias subjetivas), mientras que los dominios relacionados con la salud son los factores extrínsecos a ella que la determinan (experiencias globales de salud o con un tratamiento determinado), dando lugar a los estados de bienestar relacionados con la salud 
o a la CVRS. Más recientemente, la OMS ha añadido un tercer componente para referirse al nexo de unión entre ambos dominios: el funcionamiento, que engloba las estructuras y funciones corporales, las actividades y la participación de la persona (OMS, 2001). Mediante el concepto de funcionamiento, la OMS amplifica el constructo de salud agregando a la experiencia de bienestar los factores contextuales (personales y ambientales), los cuales forman un tercer grupo de dominios no relacionados directamente con la salud. El sistema elaborado por la OMS a través de la Clasificación Internacional del Funcionamiento, de la Discapacidad y de la Salud (OMS, 2001), al cubrir aspectos no relacionados con la salud, aumenta el concepto de CVRS añadiéndole un componente objetivo a la experiencia de bienestar y dirige sus esfuerzos hacia la universalidad del modelo a la población en general (Ravens-Sieberer el al., 2008; Edwards et al., 2002).

La definición de CV ofrecida por la OMS (1995), coherente con los componentes de la categoría combinada de Felce y su equipo (1995), supone el intento por parte de un organismo internacional de unificar los criterios del concepto desde la ética del bienestar humano, el desarrollo internacional y el diálogo interdisciplinar e intercultural (Nava-Galán, 2012). Esta definición enfatiza el componente subjetivo de la $\mathrm{CV}$ al ser la propia persona la que a partir de su relación con el medio da valor a sus circunstancias vitales, pero también a los aspectos históricos y culturales de la sociedad en la que tiene lugar dicha interacción. Al otorgar significado al contexto en el que viven las personas, esta aproximación da lugar al componente cultural de $\mathrm{CV}$, es decir, lo que hace que la vida tenga sentido y calidad son los significados culturales y representaciones sociales que la persona construye en interacción con el entorno en el que vive y se desarrolla (Cardona et al., 2005; Iwasaki, 2007; Sacks y Kern, 2008; Schalock et al., 2002, 2003).

Según Cantú-Martínez (2015), actualmente las referencias al concepto CV están íntimamente relacionadas con las aspiraciones sociales dirigidas a la mejora de las condiciones sociales y personales de las distintas poblaciones, comunidades y colectivos del mundo. Desde la perspectiva de desarrollo humano se crítica la definición del bienestar a través de simples indicadores 
económicos de crecimiento. Una de estas críticas viene recogida en las ideas defendidas por Amartya Sen (1993, 2002) sobre la determinación del bienestar a partir de las libertades y capacidades para el desarrollo de la persona inserta en una sociedad dada. Para este autor, las personas difieren en sus necesidades básicas, siendo más importante para ellas la realización que la posesión o el acceso a determinados bienes, por tanto, lo que tiene realmente valor son las actividades y funciones que la persona es capaz de realizar a nivel personal y social (Urquijo, 2014). Esta concepción implica una aproximación al crecimiento y desarrollo humano más allá de la obtención de bienes y recursos económicos, ligada a la evaluación en términos de capacidades para el funcionamiento que tienen las personas para realizar aquello que valoran en la vida (OMS, 1995; OMS, 2001), lo que según Sen (1993, 2002) sería la libertad y capacidad del ciudadano en una sociedad para hacer y ser. Esta libertad es el fin último del desarrollo humano, así como el medio para acceder a las oportunidades sociales (educación, salud, ocio y tiempo libre), políticas, económicas y de mercado para la toma de decisiones y participación ciudadana (Cardona et al., 2005), que definen la calidad de las vivencias de una determinada persona.

Llegados a este punto podemos decir que, pese a los problemas referentes al consenso conceptual y operativo del constructo de $\mathrm{CV}$, hoy en día la mayoría de los teóricos participes en la construcción del concepto aceptan que $\mathrm{CV}$ pertenece a un universo ideológico que adquiere sentido en relación con un sistema de valores construido, a través de las experiencias de vida de cada persona en un contexto y época determinada (Tonon, 2009). La evaluación que la persona hace de sus situaciones vitales responde a los sentimientos experimentados en ellas, siendo la $\mathrm{CV}$ el valor que otorga la persona a cada vivencia.

El esfuerzo científico, profesional y social dirigido a la conceptualización, medida y aplicación de la CV en este último siglo queda reflejado en doce principios básicos expuestos por un grupo de investigadores de referencia en el área (Schalock et al., 2002, 2003; Schalock, 2005). Estos doce principios (Tabla 2) engloban la naturaleza del concepto desde su auge en los años 80 
ligado a los discursos de igualdad, inclusión, capacitación y desarrollo de oportunidades; el posterior movimiento de reforma de la década de los 90 , centrado en la evaluación de la eficacia de programas desarrollados por los servicios sociales para proporcionar resultados de calidad (Schalock et al., 2006); hasta la actualidad, con la aplicación del constructo en el desarrollo y optimización de servicios y organizaciones dirigidas a favorecer el logro de resultados personales significativos, que a su vez se retroalimenta mediante la búsqueda de pruebas científicas que apoyen el desarrollo de buenas prácticas basadas en la evidencia (Schalock et al, 2016a, Schalock et al., 2018).

Tabla 2. Principios de la Conceptualización, Medida y Aplicación de Calidad deVida

\section{Conceptualización}

1. La CV es multidimensional y está influida por factores personales y ambientales, $\mathrm{y}$ su interacción.

2. La CV tiene los mismos componentes para todas las personas.

3. La CV tiene componentes subjetivos y objetivos.

4. La CV se mejora con la autodeterminación, los recursos, el propósito de vida, y un sentido de pertenencia.

\section{Medida}

1. La medida en CV implica el grado en el que las personas tienen experiencias de vida que valoran.

2. La medida en $\mathrm{CV}$ refleja las dimensiones que contribuyen a una vida completa e interconectada.

3. La medida en CV considera los contextos de los ambientes físico, social y cultural que son importantes para las personas.

4. La medida en $\mathrm{CV}$ incluye medidas de experiencias tanto comunes a todos los seres humanos como aquellas únicas a las personas.

\section{Aplicación}

1. La aplicación del concepto CV mejora el bienestar dentro de cada contexto cultural.

2. Los principios de CV deben ser la base de las intervenciones y los apoyos.

3. Las aplicaciones de $\mathrm{CV}$ han de es estar basadas en evidencias.

4. Los principios de CV deben tener un sitio destacado en la educación y formación profesional.

Nota. Recuperado de Calidad deVida. Manual para profesionales de la educación, salud y servicios sociales (p. 379), por R. L. Schalock et al., 2003, Alianza. 
Los doce principios presentados han sentado los esfuerzos del nuevo siglo sobre una base conceptual y empírica rigurosa que guía la medida y aplicación del constructo, y está dando lugar al consenso en relación a cuatro directrices para las prácticas en CV. Estas cuatro directrices son: 1) el reconocimiento de su multidimensionalidad; 2) el desarrollo de indicadores concretos a cada una de las dimensiones concernientes; 3) que tengan en cuenta aspectos subjetivos y objetivos de una vida de calidad, y; 4) se centren en predictores de resultados personales que mejoran la CV de la persona (Schalock et al., 2006).

En definitiva, el resultado de todos estos movimientos y trabajos desarrollados en torno a CV han originado la noción mundial del término como un concepto sensibilizador, que proporciona referencia y guía para la construcción social de un modelo sistémico para la evaluación de las áreas centrales de una vida de calidad desde un enfoque individual, y cuyos resultados se dirigen a la aplicación de políticas y prácticas orientadas al fomento del bienestar y satisfacción con la vida de las personas en general (Gómez et al., 2010).

Realizado este recorrido histórico, a continuación nos centraremos en la concreción teórica de uno de los modelos en calidad de vida más aceptados a nivel internacional, debido a su carácter integral. El rigor científico seguido para su construcción, el impacto en la innovación y mejora de las prácticas profesionales (investigación aplicada, formación profesional especializada, entre otros) orientadas a ámbitos diversos, tales como el educativo, así como su aplicabilidad en relación con las personas con discapacidad y otros colectivos sociales como el de población infantil con necesidades específicas, justifica que nos detengamos en su análisis. Este es, el modelo de calidad de vida individual de Schalock y su equipo (2002, 2003).

\subsection{El Modelo de Calidad de Vida de Schalock et al. (2002, 2003)}

El modelo de CV de Schalock y colaboradores (2002, 2003) parte de la defensa de los derechos a una vida de calidad y bienestar de las personas con discapacidad, y se implementa a partir de la innovación y mejora de 
los resultados personales y organizacionales relacionados con la CV. Los autores conceptualizan CV como un estado deseado de bienestar personal: a) compuesto por múltiples dominios de vida; b) subjetivos y objetivos; c) con propiedades ligadas a la cultura y otras de carácter universal; d) e influenciado por características personales y variables ambientales.

El potencial del modelo en el ámbito de la discapacidad lo ha convertido en uno de los más utilizados en el campo de los servicios sociales y lo ha impulsado como principio básico para la prestación de servicios (Gómez et al. , 2010). Para potenciar su enfoque aplicado, el modelo pretende conectar las evidencias obtenidas desde la investigación con prácticas y políticas en materia de discapacidad y otros colectivos minoritarios, con un fin común: la mejora de la CV de las personas.

2.3.1. El Modelo de Calidad de Vida Individual de Schalock et al. (2002, 2003) Aplicado a Población Infantil

Dada la evolución del concepto CV, el modelo de Schalock y colaboradores (2002, 2003) estaba orientado originalmente al campo de la salud y los servicios sociales enfocados al fomento de los principios de calidad de vida de las personas adultas con discapacidad, siendo más reciente su aplicación a población infantil (Wallander et al., 2016).

Enfocar el crecimiento positivo y el bienestar personal de los niños desde los principios de CV como: 1) marco de referencia para la prestación de servicios, 2) fundamento para prácticas basadas en la evidencia y 3) guía para la elaboración de estrategias que mejoran su calidad de vida, requiere primeramente ahondar en sus raíces conceptuales para posteriormente definir sus principios de medida y aplicación (Gómez et al., 2010; Schalock et al., 2002, 2003). 


\subsubsection{Conceptualización}

Los autores conceptualizan la calidad de vida como:

Un estado deseado de bienestar personal compuesto por varias dimensiones centrales, que están influenciadas por factores personales y ambientales. Estas dimensiones centrales son iguales para todas las personas, pero pueden variar individualmente en la importancia y valor que se les atribuye. La evaluación de las dimensiones está basada en indicadores que son sensibles a la cultura y al contexto en que se aplica (Verdugo, Schalock, Arias, Gómez y Jordán de Urríes, 2013c, p. 445).

El constructo de CV individual (Schalock et al., 2002, 2003) está representado por ochos dimensiones centrales: bienestar emocional, relaciones interpersonales, desarrollo personal, bienestar físico, autodeterminación, bienestar material, inclusión social y derechos. Esta estructura multidimensional ha sido validada transculturalmente en las dos últimas décadas (Gómez, Verdugo, Arias y Arias, 2011; Schalock et al., 2005; Wang, Schalock, Verdugo y Jenaro, 2010), durante las cuales se ha ratificado la validez del modelo.

En relación con la investigación sobre CV infantil, Schalock y su equipo (2002, 2003) revisaron la investigación internacional existente hasta principios de los años 2000 e identificaron las dimensiones más citadas. En primer lugar, estaban las referidas a bienestar emocional y desarrollo personal de los menores, seguido de las referentes a relaciones interpersonales e inclusión social. En tercera posición se situaban las dimensiones bienestar físico, autodeterminación y bienestar material, siendo la de derechos la menos analizada por la comunidad científica. Estas dimensiones de CV se operacionalizan a través de indicadores que representan las percepciones, comportamientos o condiciones específicas de cada dimensión.

En la Tabla 3 se presenta las dimensiones centrales e indicadores de CV en educación y educación especial identificados por Schalock y colaboradores (2002, 2003) y su revisión actualizada en el área de investigación sobre CV infantil (Wallander et al., 2016). 
Tabla 3. Dimensiones centrales, conceptualización e indicadores de $\mathrm{CV}$ en población infantil, actualizadas

\begin{tabular}{|c|c|c|c|}
\hline $\begin{array}{l}\text { Dimensiones } \\
\text { centrales }\end{array}$ & Conceptualización & $\begin{array}{l}\text { Indicadores } \\
\text { originales }\end{array}$ & $\begin{array}{l}\text { Indicadores } \\
\text { actualizados }\end{array}$ \\
\hline Bienestar emocional & $\begin{array}{l}\text { Sentirse tranquilo, seguro, sin } \\
\text { agobios, no estar nervioso }\end{array}$ & $\begin{array}{l}\text { Satisfacción, } \\
\text { Auto-concepto }\end{array}$ & $\begin{array}{l}\text { Satisfacción } \\
\text { Afectos positivos } \\
\text { Espiritualidad } \\
\text { Seguridad per- } \\
\text { sonal }\end{array}$ \\
\hline Desarrollo personal & $\begin{array}{l}\text { Posibilidad de aprender distintas } \\
\text { cosas, tener conocimientos y reali- } \\
\text { zarse personalmente }\end{array}$ & Educación & $\begin{array}{l}\text { Educación } \\
\text { Logros educativos } \\
\text { Significado y } \\
\text { propósito }\end{array}$ \\
\hline $\begin{array}{l}\text { Relaciones } \\
\text { interpersonales }\end{array}$ & $\begin{array}{l}\text { Relacionarse con distintas perso- } \\
\text { nas, tener amigos y llevarse bien } \\
\text { con la gente }\end{array}$ & $\begin{array}{l}\text { Relaciones } \\
\text { Familiares, } \\
\text { Amigos e } \\
\text { Iguales }\end{array}$ & $\begin{array}{l}\text { Apoyos social } \\
\text { Relaciones con } \\
\text { iguales } \\
\text { Amigos }\end{array}$ \\
\hline Inclusión social & $\begin{array}{l}\text { Ir a lugares de la ciudad o barrio } \\
\text { donde van otras personas y par- } \\
\text { ticipar en sus actividades como } \\
\text { uno más. Sentirse miembro de la } \\
\text { sociedad, sentirse integrado, contar } \\
\text { con el apoyo de otras personas }\end{array}$ & $\begin{array}{l}\text { Integración y } \\
\text { Participación } \\
\text { en la comu- } \\
\text { nidad }\end{array}$ & $\begin{array}{l}\text { Vida familiar } \\
\text { Experiencias } \\
\text { escolares } \\
\text { Participación en la } \\
\text { comunidad } \\
\text { Condiciones } \\
\text { ambientales }\end{array}$ \\
\hline Bienestar físico & $\begin{array}{l}\text { Tener buena salud, sentirse en } \\
\text { buena forma física, tener hábitos } \\
\text { de alimentación saludable }\end{array}$ & $\begin{array}{l}\text { Salud y } \\
\text { Forma física }\end{array}$ & $\begin{array}{l}\text { Salud personal } \\
\text { Comportamien- } \\
\text { tos de riesgo y } \\
\text { seguros }\end{array}$ \\
\hline Autodeterminación & $\begin{array}{l}\text { Decidir por sí mismo y tener } \\
\text { oportunidad de elegir las cosas } \\
\text { que quiere, cómo quiere que sea su } \\
\text { vida, su trabajo, su tiempo libre, el } \\
\text { lugar donde vive, las personas con } \\
\text { las que está }\end{array}$ & Autonomía & $\begin{array}{l}\text { Autonomía } \\
\text { Logros en la vida }\end{array}$ \\
\hline Bienestar material & $\begin{array}{l}\text { Tener suficiente dinero para } \\
\text { comprar lo que se necesita y desea } \\
\text { tener, tener vivienda y lugar de } \\
\text { trabajo adecuados }\end{array}$ & $\begin{array}{l}\text { Estado } \\
\text { económico }\end{array}$ & Economía familiar \\
\hline Derechos & $\begin{array}{l}\text { Ser considerado igual que el resto } \\
\text { de la gente, que le traten igual, que } \\
\text { respeten su forma de ser, opinio- } \\
\text { nes, deseos intimidad, derechos. }\end{array}$ & $\begin{array}{l}\text { Dignidad } \\
\text { Respeto e } \\
\text { Igualdad }\end{array}$ & $\begin{array}{l}\text { Estándares de vida } \\
\text { Formar parte de la } \\
\text { comunidad } \\
\text { Seguridad futura }\end{array}$ \\
\hline
\end{tabular}

Nota. Adaptado de Schalock et al. (2003), Schalock et al. (2013a) y Wallander et al. (2016). 
La evaluación de la situación o aspiraciones de la persona a través de estos indicadores se refleja en resultados personales que el modelo define como las aspiraciones definidas y valoradas personalmente (Schalock et al., 2007) y los beneficios resultantes derivados de las actividades, servicios y apoyos que recibe la persona de su entorno (Schalock y Verdugo, 2013b). Para la valoración de los resultados personales en CV el modelo utiliza un enfoque ecológico (Bronfenbrenner, 1979, 2002), que integra las dimensiones e indicadores centrales de CV con los distintos niveles de interacción entre la persona y su ambiente. Este enfoque se dirige a la aplicación del concepto en los diferentes ámbitos (educación, salud, familia, organización, políticas) que científicamente se han demostrado relevantes para una vida de calidad (Schalock et al., 2002; 2003; Verdugo et al., 2013b).

Según el enfoque ecológico adoptado por Schalock y su equipo (2002, 2003), los distintos niveles del sistema social que afectan a la CV de la persona son: microsistema, mesosistema y macrosistema. La definición de cada uno de ellos se presenta en la Tabla 4.

Tabla 4. Definición de los distintos planos sistémicos que afectan a la CV de la persona

\begin{tabular}{ll}
\hline Planos sistémicos & Definición \\
\hline Microsistema & Contexto social inmediato, como la familia, hogar, grupo de iguales \\
& y lugar de trabajo, que afecta directamente a la vida de la persona
\end{tabular}

Mesosistema Vecindario, comunidad, agencias de servicios y organizaciones, que afecta directamente al funcionamiento del microsistema

Macrosistema Patrones culturales más amplios, tendencias socio-políticas, sistemas económicos y otros factores relacionados con la sociedad, que afectan directamente a nuestros valores, creencias y al significado de palabras y conceptos

Nota. Recuperado de Discapacidad e Inclusión: Manual para la Docencia (p. 448), por M. A. Verdugo y R. L. Schalock (Coord.) (2013b), Amarú Ediciones.

Además del planteamiento sistémico, el modelo ecológico escogido para la conceptualización de CV individual tiene en cuenta las variables personales y los factores ambientales relacionados con los resultados de calidad en 
la adecuación entre el individuo y su entorno. Los estudios más recientes sobre la conceptualización del término citan las características personales y factores ambientales como variables que moderan o median en la relación entre la competencia personal, las demandas u oportunidades ambientales y los resultados personales obtenidos en dicha interacción (Schalock et al., 2016a). En la Tabla 5 se presentan variables moderadoras, mediadoras y asociadas a la CV identificadas en la investigación.

Tabla 5. Variables moderadoras y mediadoras de la $C V$ y variables específicas estudiadas

\begin{tabular}{|c|c|}
\hline Variables moderadoras & Variables específicas estudiadas \\
\hline $\begin{array}{l}\text { Características } \\
\text { demográficas personales }\end{array}$ & $\begin{array}{l}\text { Género, raza, funcionamiento intelectual, conducta adap- } \\
\text { tativa, estatus socioeconómico }\end{array}$ \\
\hline Cultura de la organización & $\begin{array}{l}\text { Nivel de participación personal del cliente, nivel de opor- } \\
\text { tunidades de crecimiento personal }\end{array}$ \\
\hline Factores unida familiar & $\begin{array}{l}\text { Ingresos familiares, tamaño familiar, localización geográ- } \\
\text { fica, preferencias religiosas, estructura familiar }\end{array}$ \\
\hline Variables mediadoras & Variables específicas estudiadas \\
\hline Estatus personal & $\begin{array}{l}\text { Plataforma residencial, estatus laboral, estatus de salud, } \\
\text { nivel de autodeterminación, bienestar subjetivo (emocio- } \\
\text { nal) }\end{array}$ \\
\hline Sistema provisión & Servicios y apoyos individualizados \\
\hline Factores comunitarios & $\begin{array}{l}\text { Expectativas normativas, actitudes, impacto medios de } \\
\text { comunicación }\end{array}$ \\
\hline
\end{tabular}

Nota. Recuperado de "Moving us toward a theory of individual quality of life" por R. L. Schalock et al. (2016a). American Journal of Intellectual and Developmental Disabilities, 121, p.4.

Para mayor información sobre el modelo teórico de Schalock et al. (2002, 2003) remitimos a uno de los últimos estudios publicado por el equipo, en él se analiza desde estándares científicos actualizados la conceptualización de $\mathrm{CV}$, la integración de sus componentes, su evaluación, así como la aplicación y el uso de sus términos (Schalock et al., 2016a). 


\subsection{Evaluación de la Calidad de Vida Infantil}

Pese al escaso interés durante las primeras etapas de estudio científico, la publicación de trabajos sobre la CV infantil y juvenil ha crecido en gran medida en los últimos años. Aunque la proliferación de estudios comenzó a surgir desde el ámbito médico, dado el enfoque limitado del concepto CVRS ya argumentado, la comunidad científica se enfocó al desarrollo de modelos más amplios capaces de dar cuenta de los niveles de satisfacción y bienestar percibido por los propios niños. Estos modelos se especializan en las condiciones personales y ambientales a las que están expuestos en sus contextos de desarrollo cotidianos, tales como su entorno educativo (Muntaner et al., 2010; Sabeh, 2003; Wallander et al., 2016).

Como vimos anteriormente, las medidas subjetivas de CV surgen como complemento a la información ofrecida por los indicadores sociales objetivos (Fernandes, Mendes y Teixeira, 2012; Lamb y Land, 2014), dando mayor valor a las personas, sus experiencias, opiniones y evaluaciones subjetivas ante diversas condiciones de vida. Esta tendencia social, y en investigación, ha establecido el bienestar subjetivo (BS) como un constructo multidimensional, de orientación positiva, que circunscribe aquellos aspectos que informan acerca del valor que tiene la vida para una persona (Ravens-Sieberer, Karow, Barthel y Klasen, 2014c). Aunque, la investigación en BS infantil es aún escasa para establecer los principios acerca de la naturaleza, determinantes y función del BS de niños, las primeras investigaciones han hallado relaciones positivas entre los niveles de satisfacción vital y resultados personales a nivel comportamental, social o escolar (Wallander et al., 2016), que apoyan la importancia de ahondar en la medida de BS de población infantil con objeto de ampliar el marco de acción del constructo de CV en esta etapa de vida.

En este sentido, avanzar hacia una comprensión integral de la CV infantil, requiere el desarrollo de herramientas globales que integren componentes objetivos y subjetivos de bienestar en dominios específicos de vida, como el educativo, familiar, tiempo dedicado al ocio, entre otros, capaces de captar el impacto que las diferentes intervenciones (indicadores 
sociales) tienen sobre la experiencia de vida de los niños (BS), en los diversos contextos de interacción en los que se desenvuelven y crean sus vidas a lo largo de su crecimiento.

En la Tabla 6 se presentan algunos de los instrumentos para la medida de la calidad de vida infantil con más respaldo científico a nivel nacional e internacional. Las características descritas servirán de criterio para la elección del cuestionario mediante el cual se evaluará la calidad de vida infantil en este trabajo. 


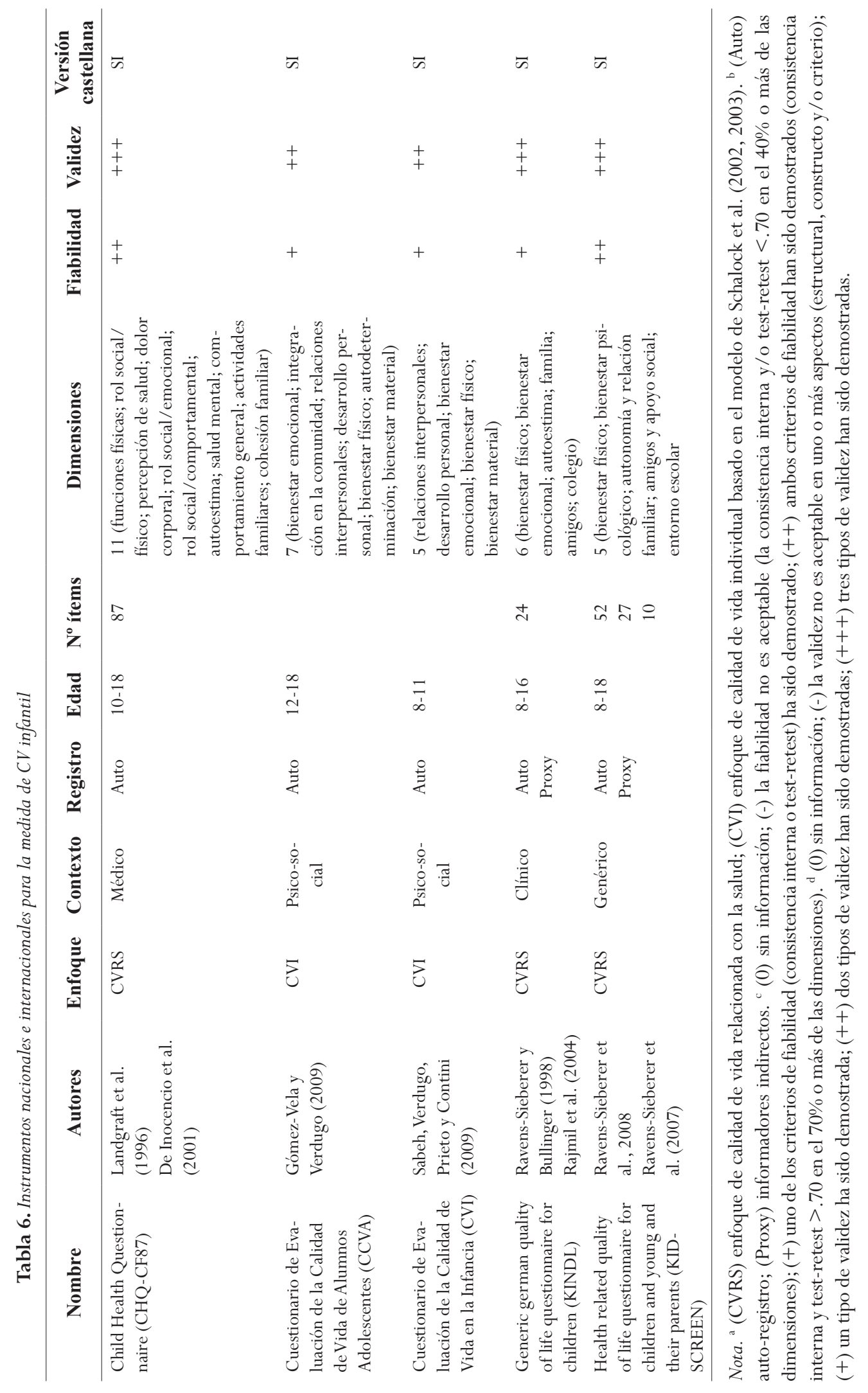




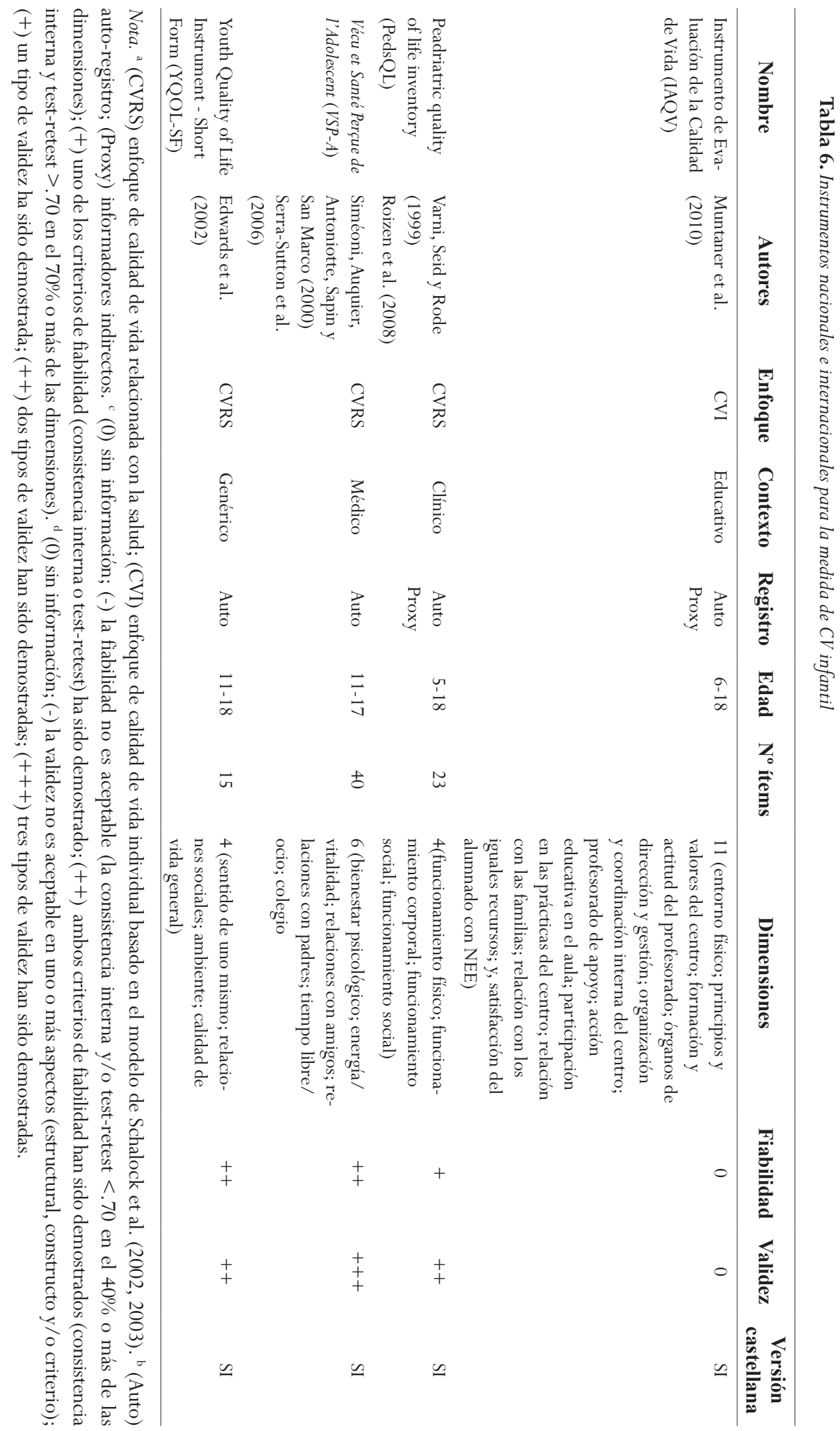


A nivel internacional se han desarrollado muchos instrumentos para medir la CV infantil, la mayoría desarrollados desde el enfoque de CVRS para poblaciones específicas y genéricas de niños con enfermedad y sin ella (Huebner y Hills, 2013; Ravens-Sieberer et al., 2014c; Solans et al., 2008). Algunos de ellos cuentan con gran respaldo científico como el Kidscreen (Ravens-Sieberer et al., 2008), el PedsQL (Varni et al., 1999), o el KINDL (Ravens-Sieberer et al., 1998), así como con propiedades psicométricas probadas y aceptadas (Rajmil et al., 2004; Solans et al., 2008), tales como VSP-A (Siméoni et al., 2000), o el CHQ-CF87 (Landgraft et al., 1996).

En concreto, el Kidscreen (Ravens-Sieberer et al., 2008) es una herramienta desarrollada para la medida transcultural de la CVRS de poblaciones genéricas y clínicas entre 8 y 18 años de edad, siendo el primer instrumento construido simultáneamente en 14 países diferentes (Alemania, Austria, España, Francia, Grecia, Países Bajos, Hungría, Irlanda, República Checa, Polonia, Reino Unido, Suecia y Suiza). Para la valoración de la CV el Kidscreen reconoce la contribución del contexto a la experiencia personal, combinando elementos que abordan directamente el bienestar de los niños con elementos que valoran la calidad de los contextos en los que viven. Para dicha evaluación el instrumento cuenta con tres versiones: el Kidscreen-27 (Ravens-Sieberer et al., 2007) con cinco dimensiones de medida, el Kidscreen-52 (Ravens-Sieberer et al., 2008) con 8 dimensiones y el Kidscreen-10 con una dimensión de calidad de vida global (Ravens-Sieberer et al., 2010). Otras singularidades del Kidscreen respecto a otros instrumentos es la valencia positiva o negativa de sus ítems que permite captar un rango mayor de aspectos relacionados con el BS, así como la posibilidad de extraer la información del propio niño o de un proxy, facilitando la comparación y complementación de sus medidas (versiones auto-informe e informantes indirectos). Estas tres características: inclusión de distintos dominios de vida para la medida de bienestar, valencia positiva y negativa de sus ítems y versiones para diferentes informantes, aportan una medida más amplia de CV a la realizada desde el enfoque de CVRS. Como complemento a estas características, los resultados de fiabilidad, validez y sensibilidad de la escala 
(Ravens-Sieberer et al., 2008; Ravens-Sieberer et al., 2014b) han hecho que sea uno de los instrumentos más utilizados y con mayor relevancia a nivel internacional para la medida de CV de poblaciones infantiles genéricas y/o con condiciones clínicas asociadas.

A nivel nacional se enfatiza las aportaciones realizadas por investigadores españoles en el diseño de modelos de CV en edad infantil, la construcción de instrumentos para su evaluación y la demostración de la utilidad práctica de su medida en el ámbito educativo (Gómez-Vela, 2007; Sabeh et al., 2006; Muntaner, 2013). El resultado de estos trabajos ha sido la elaboración de herramientas válidas para el estudio de la CV, el desarrollo y bienestar personal de alumnos con y sin necesidades educativas, de los que destacan por su importancia: 1) el Cuestionario de Evaluación de la Calidad de Vida en la Infancia: CVI (Sabeh et al., 2009), 2) el Cuestionario de Evaluación de la Calidad de Vida de Alumnos Adolescentes: CCVA (Gómez-Vela et al., 2009), y 3) el Instrumento de Evaluación de la Calidad de Vida: IAQV (Muntaner et al., 2010), todos ellos construidos bajo los principios del modelo de Schalock y colaboradores $(2002,2003)$ aplicado al contexto educativo.

Los estándares, dimensiones e indicadores de los modelos a partir de los cuales se elaboraron estos tres instrumentos hacen referencia al conjunto de factores que componen el bienestar personal en los diversos ámbitos de vida en los que los niños y jóvenes interactúan y se desarrollan a nivel de sistemas (Verdugo, 2006). Estas herramientas de evaluación son recursos útiles para el diseño de sistemas de evaluación dirigidos a la reflexión del profesorado acerca de la influencia que las prácticas educativas de sus escuelas ejercen sobre las dimensiones de CV de sus alumnos. Sus resultados permiten la aplicación de los principios de CV a la mejora y eficiencia de la respuesta educativa de las instituciones escolares, a partir de la evidencia empírica proporcionada. Tanto el CVI (Sabeh et al., 2009), el CCVA (Gómez-Vela et al., 2009), como el $I A Q V$ (Muntaner et al., 2010) se orientan al desarrollo de estrategias de cambio centradas en los resultados personales, mediante la mejora de servicios y entorno, donde el foco de atención es la CV, el bienestar y desarrollo personal del propio alumno (Muntaner, 2013). Para 
más información acerca de las utilidades prácticas de estas herramientas remitimos a los trabajos originales de sus autores citados en el texto (Sabeh, 2003; Sabeh et al., 2006; Gómez-Vela et al., 2004; Gómez-Vela et al., 2006; Muntaner et al., 2010).

Sin embargo, pese al exhaustivo trabajo realizado para el desarrollo de estas herramientas, dado que todavía son escasos los estudios sobre la utilidad teórica y práctica de sus medidas en diferentes contextos de desarrollo y bienestar infantil, la discusión acerca de sus componentes está aún en sus fases iniciales, así como el planteamiento de sus indicadores para la evaluación y aplicación de sus resultados (Gómez-Vela, 2007; Verdugo, 2009). Por otra parte, la existencia de otros instrumentos para la evaluación de la CV infantil en población general y con necesidades específicas con mayor cobertura científica (ver Tabla 6), ha llevado a la elección del Kidscreen en su versión 27 ítems (Ravens-Sieberer el al., 2007; Urzúa et al., 2009) para evaluación de la calidad de vida infantil en este trabajo.

Esta elección se sustenta en varios criterios. Primero, se trata del primer instrumento transcultural desarrollado para la medida de la CV infantil y juvenil en Europa (Quiceno y Vinaccia, 2013), entre la que se encuentra la versión española con propiedades psicométricas demostradas (Aymerich et al., 2005). Segundo, ha sido ampliamente utilizado con poblaciones infantiles y juveniles diversas (Badia et al., 2013; Davis et al., 2010; Michel, Bisegger, Fuhr, Abel y Kidscreen-Group 2009; Ravens-Sieberer el al., 2007; Ravens-Sieberer el al., 2008). Tercero, aunque parte del ámbito de la salud, su constructo pretende superar las limitaciones del enfoque de CVRS y constituirse como una medida de CV más amplía a las del campo puramente sanitario (Ravens-Sieberer et al., 2013a; Ravens-Sieberer et al., 2014b), debido a ello, los procedimientos científicos seguidos para su elaboración y validación lo hace un instrumento aceptable, fiable y válido para su aplicación en población general infantil (a partir de los 8 años) y adolescente (hasta los 18 años) (Aymerich et al., 2005). Por último, para su elección también se han tenido en cuenta dos de los objetivos operativos de esta investigación. 
El primero de ellos, la adaptación y validación a población infantil española de un instrumento transcultural para la medida de la resiliencia de alumnos de Primaria con necesidades específicas de apoyo educativo (NEAE) y sin ellas, la Child and Youth Resilience Measure: CYRM (Ungar y Liebenberg, 2011), cuyo modelo teórico asocia los recursos personales y sociales para el desarrollo de la resiliencia infantil con resultados de bienestar personal y experiencias de vida satisfactorias, en la interacción entre el niño en condiciones adversas de vida y su ambiente (Ungar, 2004, 2008, 2011). En una investigación previa llevada a cabo con adolescentes españoles se ha demostrado la sinergia entre el constructo de CV medido por el Kidscreen y el de resiliencia (Simón-Saiz, Fuentes-Chacón, Garrido-Abejar, Serrano-Parra, Larrañaga-Rubio, Yubero-Jiménez, 2018). En esta investigación se propone examinar la validez convergente entre las medidas del Kidscreen y la versión adaptada de la $C Y R M$, así como la existencia de relaciones subyacentes entre ellas en población infantil española.

El segundo objetivo es explorar la relación entre los constructos de CV y participación infantil en actividades diversas de ocio y tiempo libre, medida a través de la adaptación a población infantil y juvenil española del Children's Assessment of Participation and Enjoyment: CAPE (King et al., 2004; Longo, Badia y Orgaz, 2012). Para el desarrollo de este trabajo se ha consideradora conveniente el uso del Kidscreen y el CAPE como instrumentos de medida de calidad de vida y participación infantil, dada la asociación significativa mostrada por sus medidas en investigaciones previas con población juvenil española con necesidades educativas y sin ellas (Badia et al., 2013; Longo et al., 2012).

A lo largo de los siguientes capítulos se aportaran más argumentos teóricos y pruebas empíricas que avalan la decisión de seleccionar el Kidscreen (Ravens-Sieberer et al., 2007), frente a otros instrumentos presentados, para el estudio de los factores determinantes de la CV de alumnos de Primaria españoles con NEAE y sin ellas. 


\subsection{Aplicación del Concepto Calidad de Vida a Población Infantil con NEAE y Sin Ellas}

A pesar de la escasez de resultados empíricos, CV infantil se ha propuesto en los últimos años como marco de referencia para definir los objetivos en el ámbito de la educación de alumnos con NEAE y sin ellas (Schalock et al., 2002, 2003; Turnbull, Turnbull, Wehmeyer y Park, 2006), lo que está originado, como hemos visto en el apartado anterior, el desarrollo de su investigación y medida (Gómez-Vela et al., 2009; Sabeh et al., 2009; Muntaner et al., 2010; Ravens-Sieberer et al., 2008).

Aplicado a la escuela, el concepto de CV se fundamenta en tres premisas clave: 1) ha evolucionado desde un principio sensibilizador a un agente de cambio que guía la dirección de la mejora educativa a través de resultados personales de calidad; 2) ha vinculado los movimientos de cambio educativo con el paradigma de apoyos centrado en la persona, adecuando la interacción entre los alumnos y su entorno; y 3) está actuando como marco de referencia en el proceso de mejora y búsqueda de nuevos modelos educativos (Muntaner, 2013).

Como agente de cambio, CV emerge con fuerza en el campo educativo porque incide con particularidad en el papel de los apoyos y entornos en los que la persona se desenvuelve (AAIDD, 2011; OMS, 2001; Whemeyer, 2009). Más allá de la visión de enriquecimiento individual, CV ofrece un nuevo marco para comprender y actuar sobre el efecto que determinados factores contextuales tienen en la satisfacción y condiciones de vida de los niños, lo que en el ámbito educativo se traduce en la identificación, desarrollo y evaluación de apoyos, servicios y políticas para los alumnos en general y para los que tienen NEAE en particular (Schalock et al., 2002, 2003).

Abordar la aplicación del concepto de CV desde el modelo ecológico propuesto por Schalock y colaboradores (2002, 2003), permite guiar los procesos de aplicación del concepto y las técnicas de mejora de la calidad. Las ocho dimensiones clave se combinan con los tres niveles de sistemas, dando lugar a un modelo ecológico guía para la aplicación del concepto de 
$\mathrm{CV}$ en las distintas áreas de vida en las que los menores se desenvuelven (Figura 4).

Figura 4. Modelo ecológico de mejora de la calidad

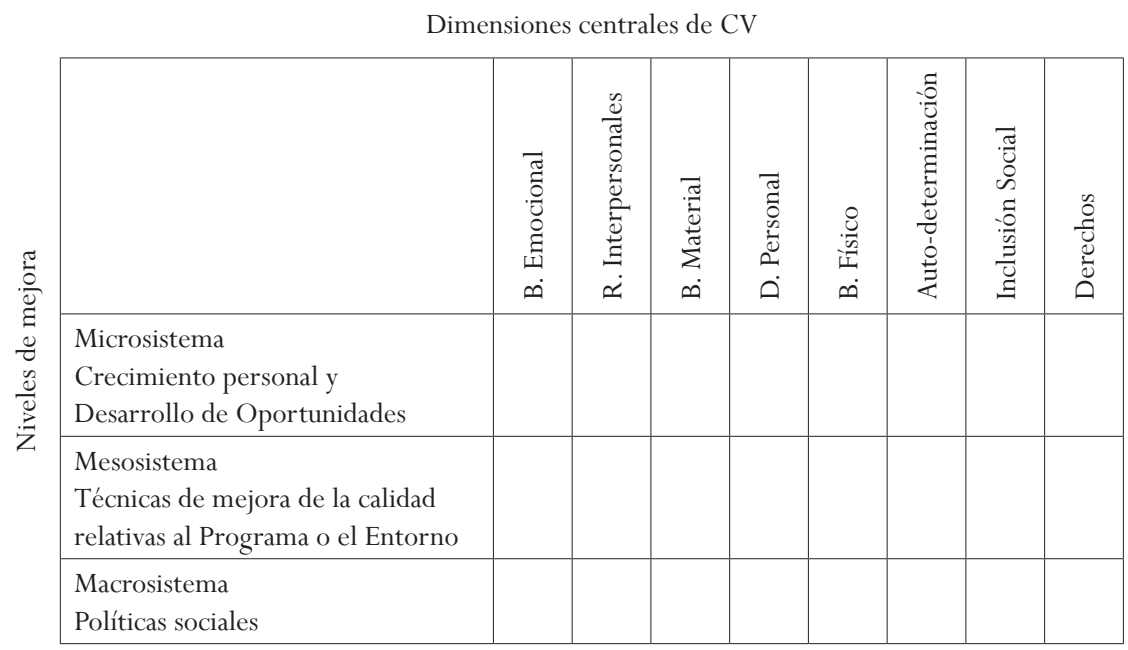

Nota. Recuperado de Calidad deVida. Manual para profesionales de la educación, salud y servicios sociales (p. 283), por R. L. Schalock et al., 2003, Alianza.

\subsubsection{Aplicación del Concepto CV Infantil a Nivel del Microsistema}

A nivel aplicado, la mejora de la CV individual es consecuencia de una buena correspondencia entre lo que la persona desea o necesita y su consecución, lo que se traduce en técnicas de ajuste persona-entorno como las necesarias para que un alumno con necesidades educativas específicas acceda, participe y obtenga resultados personales de calidad (OMS, 2001; AAIDD; 2011; Booth et al., 2002, 2015).

A este respecto, la investigación sobre $\mathrm{CV}$ infantil ha evidenciado que en edades inferiores (de 8 a 11 años) no se hallan diferencias debidas a características personales, como la presencia de Necesidades Educativas Especiales (NEE), en la satisfacción que muestran unos y otros niños en las distintas dimensiones de vida (Verdugo y Sabeh, 2002). Estos resultados concuerdan con la idea defendida por expertos en CV y discapacidad acerca 
de que el bienestar y la satisfacción con las condiciones de vida son universales para todas las personas, con independencia de otras condiciones personales o ambientales (Schalock et al., 2002, 2003; De la Iglesia, Forteza, Rossellço, Verger y Muntaner, 2012). Mientras que, a edades mayores (a partir de los 12 años) se ponen de manifiesto diferencias en las dimensiones de desarrollo personal, bienestar físico y autodeterminación entre alumnos con y sin necesidades educativas, en las que el grupo de adolescentes con NEE expresa menos niveles de satisfacción (Gómez-Vela, 2007).

Por otra parte, mientras que a edades inferiores los niños otorgan mayor importancia a las dimensiones de bienestar físico, social y psicológico, a partir de los 12 años la dimensión de relaciones interpersonales comienza a adquirir mayor peso en la satisfacción de los adolescentes. A partir de esta edad, las actividades que más bienestar producen dejan de ser aquellas relacionadas con el juego, para convertirse en actividades de tipo deportivo, cultural y social (viajes, ocio o salidas) (Verdugo et al., 2002). Estos mismos autores también encontraron diferencias en los niveles de CV entre adolescentes argentinos y españoles (Verdugo et al., 2002), que apoyan la relevancia del componente cultural sobre la percepción de satisfacción y bienestar con la vida defendida en investigación (Ravens-Sieberer et al., 2014c).

En los resultados expuestos se aprecian algunos de los temas centrales relativos a la medida de la $\mathrm{CV}$ individual citados en la literatura, tales como, la variabilidad intra e interpersonal, los cambios en la percepción del bienestar relacionados con el ciclo vital, la influencia de los sistema de valores personales y el control personal o del contexto personal sobre las dimensiones de CV (Diener, Inglehart y Tay, 2013; Schalock et al., 2002, 2003; Wallander et al., 2016). Estos resultados personales obtenidos por niños y adolescentes suponen un punto de partida para la elaboración de técnicas centradas en el ajuste persona-entorno, dirigidas al fomento y mejora de la CV percibida por alumnos con y sin NEAE. En la Tabla 7 se presenta un listado de factores asociados a cada dimensión útiles para el desarrollo de técnicas dirigidas al incremento de la CV personal (Schalock et al., 2002, 2003). 
Tabla 7. Factores asociados a la mejora de las dimensiones de la CV individual (Schalock et al., 2002, 2003)

\begin{tabular}{|c|c|}
\hline Dimensiones & Factores asociados \\
\hline Bienestar emocional & $\begin{array}{l}\text { Incremento de entornos seguros, estables, predecibles, } \\
\text { feedback positivo. }\end{array}$ \\
\hline Relaciones interpersonal & Amistad, intimidad, familias \\
\hline Bienestar material & Propiedades, posesiones, empleo. \\
\hline Desarrollo personal & $\begin{array}{l}\text { Rehabilitación funcional, educación orientada a lo aplicado, } \\
\text { tecnología aumentativa. }\end{array}$ \\
\hline Bienestar físico & Atención sanitaria, movilidad, hábitos saludables, nutrición. \\
\hline Autodeterminación & Elecciones, control personal, decisiones, metas personales. \\
\hline Inclusión social & Roles comunitarios, integración comunitaria, voluntariado. \\
\hline Derechos & $\begin{array}{l}\text { Privacidad, acceso al voto, procesos legales, responsabilida- } \\
\text { des cívicas }\end{array}$ \\
\hline
\end{tabular}

Nota. Adaptado de Schalock et al. (2003), Schalock et al. (2013a)

Dado que lo que los niños perciben y sienten viene determinado en buena medida por los ambientes en los que se desarrollan y viven, a continuación trataremos el siguiente nivel de aplicación de CV, el mesosistema. En concreto, nos centraremos en el contexto educativo y su capacidad como ambiente para desarrollar técnicas, estrategias y prácticas dirigidas al fomento de las diferentes dimensiones que componen una vida de calidad, desde los modelos de desarrollo y bienestar planteados en este trabajo.

\subsubsection{Aplicación del Concepto CV Infantil a Nivel Mesosistémico}

Actualmente la sociedad se encuentra inmersa en un maremágnum de transformaciones sociales y culturales que afectan a muchos ámbitos de vida en lo que las personas se organizan y desenvuelven. Estas condiciones hacen que las organizaciones no pueden quedarse ancladas en modelos conceptuales y prácticos arcaicos, sino que tengan que avanzar a medida que cambian las exigencias y necesidades de sus ambientes, buscando estrategias que fomenten su transformación a partir de soluciones creativas 
e innovadoras (Schalock et al., 2013b; Schalock et al., 2016b; Schalock et al., 2018, Verdugo y Schalock, 2013a).

La escuela, como organización, requiere revisar sus formas de actuar de acuerdo a las necesidades cambiantes de su entorno (Gairín y Rodríguez, 2011). Al analizar la realidad educativa y sus prácticas, se hallan multitud de cambios dirigidos a la incorporación de respuestas más aceptables a los valores y prioridades prestablecidos, en relación con: la atención a la diversidad, progreso de las comunidades de aprendizaje, desarrollo de aprendizajes significativos, participación activa, o fomento de la calidad y riqueza de las áreas que conforman la experiencia y bienestar de los alumnos como individuos miembros activos de una sociedad (Wallander et al., 2016). Sin embargo, los propósitos y métodos utilizados se presentan con frecuencia aislados y descoordinados lo que favorece gran parte de los fracasos educativos conocidos, tales como, la desmotivación y el bajo rendimiento del alumnado en edades mayores, la aparición de conductas disruptivas y de riesgo, o el desajuste entre alumnos con determinadas necesidades y su entorno cercano (Echeita, 2013; Echeita y Jiménez, 2007; Urbina, Simón y Echeita, 2011; Wehmeyer, 2009).

La mejora educativa se presenta en los centros escolares como un reto permanente, pero dado que los cambios en el sistema educativo se producen con lentitud, incrementar la eficacia de la respuesta educativa hacia todos los alumnos requiere el desarrollo de estrategias y procesos que planifiquen las respuestas de cambio y mejora educativa de la escuela como organización (Ainscow, 1999; Arnaiz, Moresa, Abellán, 2008; Gairín et al., 2011; Jurado, 2009; Schalock et al., 2002, 2003).

En una investigación realizada con objeto de analizar la situación de la inclusión educativa en España desde la perspectiva de alumnos con discapacidad, familias y profesionales de la educación, se evidencia que aunque se ha avanzado en la sensibilización del profesorado hacia la diversidad del alumnado, así como en la normalización y fomento del compañerismo entre alumnos, aún hay muchas carencias referentes a infraestructuras, servicios y recursos para la atención a la diversidad (Verdugo et al., 2009), 
así como carencias formativas e informativas del profesorado para atender a la diversidad del alumnado y promover su inclusión (González-Gil MartínPastor, Poy y Jenaro, 2016). Según los informantes, aún hoy las escuelas se encuentran ancladas en un modelo educativo de integración y respuestas a las necesidades basadas en la compensación de déficits, más que direccionadas al cambio global de estructuras y funciones escolares a nivel organizativo (Verdugo et al., 2013b). Los agentes implicados denuncian mayor participación de las administraciones educativas, así como la aplicación de innovaciones y modernización de las metodologías escolares como bases del cambio y mejora educativa.

Estos resultados nos invitan a cuestionar las modalidades de trabajo existentes y dominantes en el ámbito educativo, en las que los profesionales tienen un papel relevante y decisivo para su mantenimiento o cambio (Muntaner, 2013). A este respecto, Ainscow (1999) tras su experiencia en trabajos de campo basados en la observación y análisis de las prácticas escolares de profesores en Inglaterra, enumeró un listado de temas claves para el proceso de cambio y mejora de la calidad de la educación de los colegios, referentes a: 1) la planificación escolar participativa; 2) la diversidad como oportunidad de aprendizajes; 3) análisis de procesos de exclusión; 4) uso de recursos disponibles para el apoyo al aprendizaje; 5) desarrollo de un lenguaje común; 6) prevención de riesgo mediante condiciones de apoyo; 7) liderazgo eficaz compartido; 8) políticas democráticas escolares; 9) planificación cooperativa; 10) estrategia de coordinación y tiempos; 11) análisis reflexivo del entorno; 12) políticas para el desarrollo de personal y prácticas en el aula. Este listado dio origen a una herramienta desarrollada para el análisis y progreso de las prácticas escolares dirigida a las propias comunidades escolares: el Índice para la Inclusión (Booth et al., 2002, 2015). El instrumento se basa en un marco teórico de educación inclusiva desarrollado a partir de evidencia empírica y su finalidad es analizar las barreras y facilitadores ambientales que afectan al acceso, participación y progreso significativo de alumnos en riesgo de exclusión o marginalización, a tres niveles de análisis: culturas, políticas y prácticas escolares (Ainscow, 1999; Booth et al., 2002, 2015). 
El Índice para la Inclusión (Booth et al., 2002, 2015) supone una herramienta con validez empírica y transcultural para el cambio organizativo de las escuelas. Datos sobre su utilidad y aplicación a nivel nacional los encontramos en los trabajos desarrollados por el equipo de Muntaner en la Islas Baleares (De la Iglesia et al., 2012; Muntaner, 2013; Muntaner et al., 2010) sobre estándares e indicadores dirigidos a analizar la CV de alumnos con discapacidad en su proceso educativo. Estos trabajos son la base científica del instrumento $I A Q V$ (Muntaner et al., 2010) presentado en el apartado de evaluación de la CV infantil. Su administración en contextos escolares ha puesto en evidencia resultados como: 1) la limitada capacidad de decisión y modificación por parte de la comunidad del centro para la mejora y adaptación de infraestructuras escolares, 2) la escasa colaboración entre familias y escuela, y limitado conocimiento de éstas respecto a la inclusión y atención a la diversidad, 3) diferencias en la respuestas a las necesidades educativas del alumnado con discapacidad entre centros y niveles educativos, con escasa valoración de las necesidades personales para la planificación de actividades educativas individuales, así como dirigidas a la sensibilización del alumnado, y 4) la escasa formación del profesorado en inclusión y atención a la diversidad, adaptaciones curriculares o flexibilización de las prácticas de enseñanza-aprendizaje, entre otros temas referentes al progreso inclusivo (González-Gil et al., 2016; De la Iglesia et al., 2012).

La aplicación del IAQV (Muntaner et al., 2010) en los centros educativos también ha puesto de manifiesto la falta de motivación intrínseca por parte de los profesores de aula para reflexionar sobre las prácticas diarias de sus escuelas o proponer mejoras, fundamentada desde la opinión de los profesionales en la carga de tareas cotidianas que tienen dentro del aula y en el centro en su conjunto (Muntaner et al., 2010). Pese a todo, el instrumento se ha demostrado válido como guía para la puesta en marcha de procesos de reflexión y cambio hacia prácticas educativas inclusivas, enfocadas a la mejora de la CV del alumnado con y sin NEAE, desde un paradigma de innovación y mejora organizacional de la escuela. 
Como la investigación pone de manifiesto, los centros educativos son un contexto privilegiado para potenciar procesos de mejora cuando se fomenta la capacidad institucional de auto-revisión, planificación y acción estratégica dirigida al progreso de la organización como sistema (Gairín et al., 2011). Si consideramos el cambio educativo desde su marco histórico y cultural, su mejora no es sencilla. La práctica dirigida a la transformación de los procesos educativos desde el marco de CV implica poner en marcha modelos de funcionamiento escolar basados en la colaboración y cooperación entre los distintos agentes del contexto educativo y socio-comunitario, evitando la fragmentación de los distintos servicios, unidades, departamentos y, en definitiva, sistemas que lo componen (Acosta y Terigi, 2015; Jurado, 2009).

Desde la perspectiva ecológica el cambio debe ir orientado a la interacción de las actuaciones realizadas desde los distintos niveles del sistema educativo, esto es, a nivel individual o del microsistema (desarrollo de prácticas educativas basadas en los resultados personales de calidad para el alumno y el desarrollo de apoyos individualizados, por ejemplo), a nivel de la estructura y función escolar o del mesosistema (mejora de los espacios físicos del centro o cambios organizativos en los equipos docentes y en su modelos de funcionamiento y colaboración), así como a nivel del macrosistema, referente a la implicación de las políticas públicas y administraciones educativas para la aplicación de acciones estratégicas orientadas al fomento del desarrollo y CV del alumnado, y la eficiencia de la escuela como organización educativa (Gairín et al., 2011; Jurado, 2009; Schalock et al., 2002; 2003). Este último nivel se desarrolla a continuación.

\subsubsection{Aplicación del Concepto CV Infantil a Nivel del Macrosistema}

La aplicación de CV a personas con necesidades especiales requiere políticas públicas y acciones sociales congruentes con el concepto. Como se ha expuesto con anterioridad, a lo largo de sigo XX los profundos cambios y movimientos sociales acaecidos han hecho avanzar la nociones sociales acerca de realidades, tales como, el desarrollo infantil, la discapacidad, la educación, 
el bienestar o la calidad de vida de las personas. En la nueva sociedad del conocimiento el mundo está dirigiendo su atención a modelos ecológicos de acción, fundamentados en un paradigma de derechos humanos y civiles, capaces de minimizar los riesgos y mejorar las condiciones de vida personales y colectivas de las sociedades del mundo. Desde este nuevo paradigma el bienestar de una población se consigue a través de políticas públicas relacionadas con la $\mathrm{CV}$, la puesta en marcha de estrategias comunitarias para la mejora de la calidad, la implicación de todos los miembros de la sociedad para el cambio, y la aportación de evidencia científica para la mejora y eficacia de los procesos de cambio (AAIDD, 2011; Booth et al., 2002, 2015; OMS, 2001, 2007; Schalock et al., 2002, 2003; UNICEF, 2016; Verdugo et al., 2013b)

Con respecto al contexto educativo, el término calidad ocupa un puesto central en el debate de las políticas educativas nacionales e internacionales de nuestro siglo (Abellán, De Haro y Escarbajal, 2010). En España, la apuesta por una educación de calidad nos remite a la Ley Orgánica 1/1990 de Ordenación General del Sistema Educativo (LOGSE), y nos acompaña hasta nuestros días con la actual Ley Orgánica 8/2013 para la Mejora de la Calidad Educativa (LOMCE). En sus preámbulos la calidad de la enseñanza es un objetivo prioritario del proceso de reforma educativa, la cual se concreta en propuestas estratégicas de ordenación educativa, currículum, organización escolar, formación del profesorado, evaluación de alumnado y sistemas de participación (MECD, 2015).

Más allá de los pormenores y divergencias ideológicas, juicios, beneficios y prejuicios de las diferentes reformas educativas acometidas en nuestro país desde finales del siglo pasado, a lo largo de toda esta corriente legislativa se puede apreciar cómo el sistema educativo avanza hacia un concepto de la calidad en educación que promueve el cambio hacia aproximaciones más globales de enseñanza, aprendizaje y desarrollo humano, centrándose, no sólo en la evaluación de estándares educativos tradicionales (OCDE, 2006, 2007), sino también en la inclusión de nuevos indicadores sociales y personales que orienten el desarrollo de estrategias de enseñanza y aprendizaje que respondan 
a las realidades y necesidades de la escuela de hoy como reflejo de la sociedad actual, tales como, el fomento de la comunicación, convivencia, respeto a la diversidad, relaciones interpersonales o participación democrática (Ossa, Quintana y Mendoza, 2015), acordes a los principios de calidad, bienestar y desarrollo infantil defendidos en este trabajo.

Actualmente, la inclusión es uno de los grandes retos de la educación mundial que conlleva transformaciones cualitativas en el modo de concebir, organizar, planificar, impartir y evaluar la enseñanza y el aprendizaje de las personas en todos los ámbitos socioeducativos (Muntaner et al., 2010). Algunos de los marcos de referencia que permiten configurar la inclusión en el contexto educativo son: la defensa de los derechos humanos del niño (ONU, 1989), la concepción social de discapacidad (AAIDD, 2011; OMS, 2001; UNECOS, 2006), así como la perspectiva organizativa como base del desarrollo institucional, los modelos de recursos comunitarios y los enfoques de investigación aplicada dirigidos a la acción (Schalock et al., 2002, 2003; Schalock et al., 2016b; Schalock et al., 2018). Desde este prisma, la inclusión educativa se constituye como un indicador de calidad que supone garantizar los principios de igualdad, no discriminación, accesibilidad y diseño universal, guiados por el derecho a la educación de todos los alumnos (Booth et al., 2002, 2011; Calderón, 2014; Wehmeyer, 2009).

Estrechamente relacionados con los principios inclusivos emergen tres modelos conceptuales defendidos por parte de la comunidad científica especializada en crecimiento infantil positivo, que están cambiando los modos y formas de abordar las intervenciones educativas, sanitarias y sociales con población infantil. Por una parte, el modelo de calidad de vida infantil expuesto en a lo largo de este capítulo, centrado en el desarrollo, evaluación y aplicación de indicadores dirigidos a operacionalizar resultados personales relevantes y valiosos para los niños con y sin NEAE en sus diferentes áreas de vida (Schalock et al., 2002, 2003; Schalock et al., 2016a). Por otra, su participación en actividades diversas (OMS, 2001, 2007; King, et al., 2003) y los recursos personales y ambientales para el desarrollo de su resiliencia presentes en los entornos de desarrollo próximo (Ungar 2004, 2008, 2011), 
que actúan como fuentes de protección o riesgo ante los desafíos del día a día e influyendo en los resultados de crecimiento infantil.

El valor conceptual y operativo de estas dos últimas variables, así como su conexión con la CV infantil y aporte al crecimiento infantil positivo será desarrollado en los próximos dos capítulos teóricos. Para posteriormente, en la parte empírica de este trabajo, desentrañar las vías que dan acceso al desarrollo infantil integral y mediante las cuales niños en condiciones diversas de vida celebran su crecimiento a partir de resultados personales significativos de bienestar personal, participación en actividades diversas y recursos para el desarrollo de su resiliencia.

\subsection{Conclusiones}

El desarrollo teórico ofrecido en este capítulo sobre la evolución teórica, operativa y práctica del concepto de CV infantil, nos lleva en esta investigación a:

- Adoptar una concepción multidimensional del concepto de CV infantil que englobe componentes objetivos y subjetivos de la satisfacción y bienestar de los niños ante las diferentes condiciones de vida en las que se desarrollan (Wallander et al., 2016).

- Tener en cuenta tanto los indicadores que representan las percepciones, comportamientos o condiciones específicas de cada dimensión del bienestar personal de los niños (Schalock et al., 2002, 2003), como los factores contextuales presentes en sus diferentes ámbitos de vida capaces de determinar resultados personales de salud, educación, desarrollo y bienestar en niños en condiciones diversas de vida (OMS, 2001; 2007; Ravens-Sieberer et al., 2014b).

- Considerar el enfoque ecológico de interacción persona-ambiente (Bronfenbrenner, 1979, 2002), que nos obliga a reflexionar no sólo sobre las características personales de los niños tales como su género, edad, condición clínica, educativa, etc., sino también sobre los factores 
ambientales (tipo de escolaridad, barreras físicas o arquitectónicas, apoyos sociales disponibles, etc.) que median, moderan y/o predicen los resultados personales en CV infantil (AAIDD, 2011; OMS, 2001; 2007; Schalock et al., 2016a).

- Evaluar los indicadores de calidad de vida y bienestar infantil a través de una herramienta con suficientes garantías científicas, como el Kidscreen (Ravens-Sieberer et al., 2008) en su versión de 27 ítems (Ravens-Sieberer et al., 2007; Urzúa et al., 2009), dada la dificultad de su medida en población infantil y el desarrollo aún inicial de su modelo teórico. La versión castellana de este instrumento ha demostrado su validez en la evaluación del bienestar de niños y jóvenes con NEE y sin ellas (Badia et al., 2013), por lo que se ha considerado una herramienta apta para evaluar la CV de alumnos con NEAE y sin ellas, así como para la aplicación de sus resultados a la orientación y diseño de la mejora educativa en nuestro país.

Por tanto, adoptamos los principios del concepto CV infantil expuestos en este capítulo como guía para el desarrollo del actual trabajo de investigación, el cual está orientado a la comprensión de la naturaleza del crecimiento positivo y desarrollo integral de alumnos con NEAE y sin ellas, y a la valoración de la influencia de su entorno cercano en él. Para ello, a lo largo de este trabajo se analizaran las dimensiones asociadas a una vida de calidad y factores determinantes personales y ambientales que influyen en el ajuste biopsicosocial del alumno con su entorno y la expresión de su bienestar personal.

Como se ha expresado anteriormente uno de los factores candidatos como determinantes de CV infantil es una variable íntimamente relacionada con ella, la participación en actividades de ocio y tiempo. Investigaciones nacionales e internacionales recientes ha evidenciado su impacto sobre diferentes dimensiones del bienestar de los niños (Badia et al., 2013; Dahan-Oliel, Shikako-Thomas y Majnemer, 2012; Shikako-Thomas et al., 2012; Schreuer et al., 2014). Los resultados hallados por éstas y otras investigaciones sobre la influencia de la participación en el desarrollo positivo e integral de la 
infancia tienen importantes implicaciones prácticas para la promoción de una vida de calidad y bienestar de niños en condiciones diversas de vida, a través del diseño de estrategias, prácticas y programas orientados a la mejora y calidad de la intervención psicoeducativa.

A lo largo del siguiente capítulo se desarrollará el constructo de participación infantil en actividades de ocio y tiempo libre, el modelo teórico y operativo seleccionado para su estudio en este trabajo y las evidencias científicas más destacadas acerca de su relación con el constructo de CV y los recursos personales y ambientales para el desarrollo de la resiliencia y crecimiento infantil positivo. 



\section{Capítulo 3}

Conceptualización de Participación

Infantil en Actividades de Ocio y Tiempo Libre
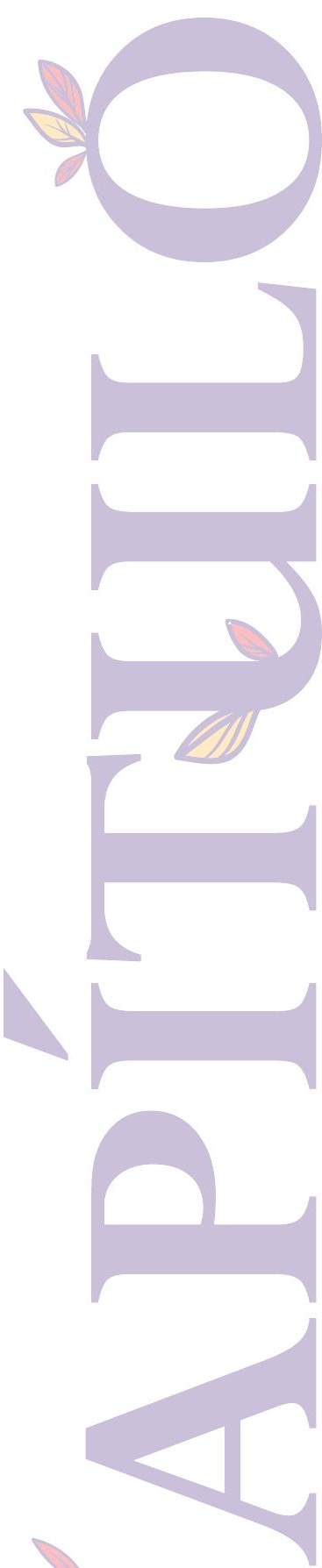



\section{Conceptualización de Participación Infantil en Actividades de Ocio y Tiempo Libre}

\section{Introducción}

El concepto de participación es usado con frecuencia en discursos políticos, debates educativos y comunitarios, así como informes sociales y sanitarios, relacionándolo con otras nociones como la de desarrollo, igualdad de oportunidades o calidad de vida (Almqvist y Granlund, 2005). La importancia adquirida en el discurso público ha llevado a la participación a ser considerada un elemento clave para la mejora y eficacia de políticas sociales, prácticas, programas e intervenciones dirigidas al desarrollo y bienestar personal de los niños en nuestras sociedades (Imms et al., 2016a; King et al., 2003). Esta importancia deriva en gran medida de los movimientos y cambios sociales acontecidos durante el siglo pasado descritos en los capítulos anteriores, los cuales han impulsado transformaciones en los modos de entender y actuar sobre los problemas de nuestras sociedades y sus ciudadanos.

Para entender el desarrollo del concepto de participación infantil partimos de la Declaración de los Derechos del Niño (ONU, 1959) y la Convención de la Asamblea General de Naciones Unidas (ONU, 1989), las cuales han permitido avances normativos significativos en materia de desarrollo, participación y bienestar infantil a nivel mundial, a través de políticas enfocadas a la promoción de los derechos de niños y jóvenes.

A pesar del reconocimiento por parte de las naciones del mundo de la Declaración de los Derechos del Niño, aun hoy existe un desconocimiento general por parte de la población adulta de todos los derechos promulgados (UNICEF Comité Español, 2014). Con respecto al derecho de participación, éste es definido por la convención como el proceso continuo de expresión e intervención infantil en la toma de decisiones concernientes a su desenvolvimiento en las diferentes áreas de vida en las que el niño se desarrolla (ONU, 1989). En particular, el desconocimiento de este artículo se asocia a diversas causas. Por una parte, la visión cultural tradicional acerca del 
desarrollo del niño, que lo conceptualiza como una trayectoria de diferentes etapas de edad asociadas cada una de ellas a una serie de competencias y necesidades predefinidas, que son respondidas por los adultos responsables en ámbitos como la familia, la escuela, el tiempo libre, etc. (Fleer y Hedegaard, 2010; Hedegaard, 2009). Esta visión social del niño fomenta una imagen de vulnerabilidad, actitudes de sobreprotección y la desconfianza hacia el valor de las opiniones infantiles (Hogansen, Powers, Geenen, GilKashiwabara, y Powers, 2008; Smith, 2006). Por otra parte, la insuficiente difusión y divulgación social de los derechos de la infancia mantiene su ignorancia, la falta de estructuras sociales para su promoción práctica, así como la escasa implementación de programas para la participación infantil basados en la evidencia científica, que son un medio eficaz para el desarrollo de la autoestima, las habilidades comunicativas, sociales y personales cuando tiene lugar en los diferentes contextos sociales cercanos al niño (Kirby y Bryson, 2002).

\subsection{Participación en Actividades de Ocio y Tiempo Libre}

Son muchos los ámbitos en los que se puede ejercer el derecho a la participación: familia, escuela, comunidad, política, entre otros. Dentro de todos ellos nos centramos en la realización de actividades de ocio y tiempo libre dado su papel como medio de expresión y comunicación de pensamientos, sentimientos y experiencias, así como capacidad para mejorar el bienestar y calidad de vida infantil (Adolfsson, Malmqvist, Pless, y Granuld, 2011; Longo, Badia, Orgaz y Verdugo, 2012; Shikako-Thomas et al., 2012) y contribuir al desarrollo significativo, saludable y armónico de niños y adolescentes (Imms et al., 2017).

Desde el modelo de participación infantil presentado en este capítulo, el ocio se define como una experiencia personal, o social, caracterizada por la libertad de elección y la experimentación de sentimientos de bienestar, satisfacción, relaciones de amistad y sentido de pertenencia (Hawkins, 1993; Adolfsson et al., 2011; Imm, Froude, Adair y Shields, 2016b). De 
esta forma, la esencia de la participación en actividades de ocio y tiempo libre se relaciona íntimamente con la motivación intrínseca de la persona, reflejando la variedad de intereses, preferencias y elecciones personales hacia la realización de actividades placenteras. Estas actividades pueden realizarse solo o en compañía, en ambientes próximos o distales, pero siempre enfocados al disfrute y enriquecimiento de la persona que las realiza (AAIDD, 2011; King et al., 2003; Imms et al., 2016b; Longo, Badia y Orgaz, 2012).

Con respecto a la participación de niños diversos en actividades de ocio y tiempo libre, ni las proclamas mundiales, ni la evidencia científica acerca de los efectos positivos de la participación, son capaces de garantizar por ellas mismas que niños con diferentes características personales y ambientales tengan las mismas oportunidades sociales de participación en sus entornos educativos, ni comunitarios (DfEs, 2004; Law et al., 2006). Como tampoco, que las diferentes entidades y organizaciones enfocadas a la promoción social del ocio se esfuercen por hacer sus servicios cada vez más inclusivos, encargarse de que sus profesionales reciban formación para comprender la riqueza de la diversidad, y la implementen en sus prácticas profesionales para facilitar el desarrollo, aprendizaje y satisfacción de niños y jóvenes de diferentes colectivos a partir de sus experiencias de ocio (FYME, 2009).

En parte este hecho es debido a que el ocio infantil es considerado a nivel social por sus cualidades instrumentales, tales como, una oportunidad para la conciliación de la vida laboral de los padres y el tiempo libre de sus hijos (MEPSYD, 2008), más que por su valor educativo para el enriquecimiento personal y social de los niños participantes. Asimismo, con frecuencia las propuestas recreativas ofrecidas para niños son un reflejo de aquellas preestablecidas para los adultos, sin tener en cuenta las preferencias y necesidades de los menores para la ofer ta y planificación de su tiempo libre. Por otra parte, las desigualdades sociales también son otra fuente que condiciona la participación de los niños en este ámbito de vida, determinando el acceso al ocio de unos y no otros. Como consecuencia de lo expuesto, la mayoría de los estudios realizados con poblaciones infantiles y juveniles con necesidades 
especiales revelan niveles moderados o bajos de participación en actividades diversas de ocio y tiempo libre (Bult, Verschuren, Lindeman, Jongmans y Ketelaar, 2014; Engel-Yeger, Jarus, Anaby, y Law, 2009; Fauconnier et al., 2009; Schreuer, Sachs y Rosenblum, 2014).

En España, con objeto de fomentar acciones y programas enfocados a la participación de todos los niños en actividades de ocio y tiempo libre se ha publicado en I y II Plan Estratégico Nacional de Infancia y Adolescencia (MTAS, 2006; MSSSI, 2013). Entre sus objetivos se encuentra el favorecer un entorno físico, medioambiental, social, cultural y político capaz de promover el desarrollo adecuado de las capacidades de niños y adolescentes a través del juego, el ocio y el tiempo libre, mediante la creación de espacios accesibles y seguros, tanto en zonas urbanas, como rurales. Sin embargo, a pesar de esta iniciativa política el III y IV Informe de Aplicación de la Convención sobre los Derechos del Niño en España pone en evidencia la escasa participación de niños y jóvenes en actividades diversas a las preestablecidas por los currículums formales, tales como, actividades deportivas, aprendizaje de idiomas o informática, típicas de los currículums o programas extraescolares (MEPSYD, 2008). Según Vidal y Mota (2008), uno de cada tres niños no realiza ninguna actividad extraescolar deportiva, mientras que dos de cada tres no desempeña ninguna otra basada en el aprendizaje de habilidades o enriquecimiento personal. En esta línea, también cabe resaltar el excesivo énfasis en la competición entre iguales que se establece en aquellas actividades de ocio de tipo deportivo implementadas para menores (Síndic de Greuges, 2014).

Más allá de la escasa comprensión acerca de sus efectos positivos y aplicabilidad socioeducativa, la participación en actividades de ocio y tiempo libre sigue siendo defendida como indicador de salud y funcionamiento positivo, relevante para el desarrollo de competencias personales y sociales en niños y adolescentes en general (Kirby et al., 2002; Wilkes, Cordier, Bundy, Docking y Munro, 2011). Así como, para la adquisición de habilidades adaptativas e inclusión en la comunidad de niños y jóvenes con diversas condiciones personales y sociales (AAIDD, 2011; Shikako-Thomas et al., 2012). Los 
resultados de éstas y otras investigaciones citadas apoyan la utilidad práctica de la participación en actividades de ocio para profesionales, investigadores y políticos, quienes tienen el deber de facilitar su realización en diversos ámbitos sociales y crear oportunidades que engloben a todos los niños de nuestras sociedades (OMS, 2007).

Gracias a los cambios acontecidos en torno a la respuesta a la diversidad que direcciona la práctica infantil hacia un marco inclusivo, poco a poco se va dejando atrás el tradicional marco asistencial para la atención a las necesidades individuales de los menores. Las nuevas líneas de acción se orientan hacia el uso de recursos naturales y sociales para el fomento del desarrollo óptimo y bienestar personal de los niños, así como a la promoción de su interacción social a partir de la participación en actividades diversas de su comunidad (OMS, 2001, 2007). Este nuevo enfoque de actuación está siendo reconocido y asumido a nivel internacional por diferentes agentes educativos, tales como, familias, escuelas y administraciones educativas, favoreciendo un proceso de transformación en la forma de comprender y operar que tienen los distintos sistemas con responsabilidad en materia de infancia (UNESCO, 1994; 2000; 2006). Algunos de los primeros pasos se reflejan en el incremento de servicios y recursos educativos y lúdicos, el aumento del número de instalaciones, la mejora de la formación profesional, o la mayor atención a la participación activa de niños en su proceso de desarrollo, entre otros, lo que en definitiva promueve el desempeño y aprendizaje de calidad de los niños (Echeita et al., 2009; Göransson, Nilholm y Karlsson, 2011; Tisdall y Riddell, 2006).

\subsection{Desarrollo Conceptual del Constructo Participación en Actividades Diversas de Ocio y Tiempo Libre}

Desde la publicación de la Clasificación Internacional del Funcionamiento, la Discapacidad y la Salud de la Organización Mundial de la Salud: CIF (OMS, 2001), y su versión para niños y jóvenes: CIF-NJ (OMS, 2007), el interés por la participación como resultado personal de funcionamiento $\mathrm{y}$ salud ha aumentado en gran medida. 
En la CIF la discapacidad es definida como un concepto que comprende el deterioro, las limitaciones en la actividad y las restricciones de la participación (OMS, 2007), la participación es definida como el acto de involucrarse en situaciones de vida (OMS, 2001), la actividad como la realización de tareas o acciones por parte de la persona (OMS, 2001), mientras que las restricciones de la participación como los problemas que una persona puede experimentar para la participación en situaciones de vida definidas como normales por una cultura o sociedad determinada (OMS, 2001). Dichas definiciones vinculan la participación con el ambiente utilizando para su explicación un enfoque ecológico de interacción persona-entorno (Bronfenbrenner, 1979, 2002; 1992), en el que las características personales y las variables ambientales juegan un papel relevante en el efecto de dicha interacción sobre los resultados de participación y funcionamiento personal del niño (OMS, 2001, 2007), determinando lo qué éste hace, con quién, dónde, cómo lo hace y cuál es el beneficio de tal actuación (Cornwall, 2008; Longo, et al., 2012).

Desde el marco de funcionamiento humano propuesto por la OMS, la investigación sobre participación se ha centrada más en el desarrollo de su medida y, en menor grado, en el avance del aspecto conceptual del constructo. La falta de un modelo conceptual robusto ha provocado dificultades y críticas en la interpretación y aplicabilidad de los resultados de participación obtenidos en las investigación realizadas (Granlund, 2013; Imms et al., 2016a; Maxwell, Alves y Granlund, 2012). Según algunos expertos, el problema de la cuestión conceptual del fenómeno es, en parte, producido por la falta de claridad y precisión de las definiciones dadas en la clasificación de la OMS, donde actividad y participación se presentan como dos términos separados, pero componentes de un mismo dominio de funcionamiento humano (Badley, 2008; Schuntermann, 2005). Dicha imprecisión ha otorgado la oportunidad a los investigadores de enfocar la medida de participación desde los contextos específicos en los que ésta se evalúa (Eriksson, Welander y Granlund, 2007), lo que por una parte está evidenciado la multidimensionalidad del fenómeno de participación 
(Granlund et al., 2012), mientras por otra da lugar a la crítica de la validez y la aplicabilidad de su medida (Coster, et al., 2012; Perenboom y Chorus, 2003). En unos de sus últimos trabajos Imms y colaboradores (2016a) comparan el desarrollo científico del constructo de participación con el de calidad de vida, el cual ha requerido un trabajo extenso y sistemático por parte de expertos que aclare la confusión y el desacuerdo sobre los resultados de investigación surgidos tras el reconocimiento de su importancia y la proliferación de estudios en el tema. Como hemos visto en el capítulo anterior, el trabajo de recopilación y síntesis en calidad de vida ha dado lugar a una serie de acuerdos sobre las características del constructo que permite el desarrollo de modelos de calidad de vida consistentes y aplicables como el de Schalock y Verdugo (2002, 2003), que según Imms y colaboradores (2016a) es el proceso requerido para la clarificación y validez del modelo de participación.

Con objeto de aportar luz a cerca del concepto de participación, diversos autores han llevado a cabo revisiones sistemáticas de la literatura tratando de aislar los componentes principales y asociados al fenómeno de participación hallados en la investigación. Los análisis lingüísticos llevados a cabo en estos trabajos detectan dos dimensiones principales de participación: la asistencia y la participación como realización (Granlund, 2013; King, 2013; Maxwell, 2012) y una serie de conceptos relacionados como la preferencia, la competencia en la actividades y el sentido de sí mismo, incluidos con frecuencia en la literatura de participación por su relación con ella, pero no esenciales para la experiencia de participación en sí misma (Imms et al., 2016b). A continuación se precisan estas cuestiones.

\subsubsection{Asistencia y Participación}

Asistencia y participación se reconocen actualmente como los dos temas vinculados directamente. La asistencia es definida como el hecho de estar presente en la actividad que se realiza. Mientras que la participación, entendida como realización de una actividad, se refiere a la experiencia en sí 
misma y se relaciona con temas como la implicación, el ajuste, la motivación, la conexión social y los afectos percibidos durante su ejecución (Maxwell et al., 2012)

La asistencia es reconocida desde el modelo de la CIF como la frecuencia con la que la persona participa en actividades cotidianas. Está determinada por la disponibilidad y el acceso a las mismas situaciones de vida que otras personas (OMS, 2001). Desde su perspectiva social, la CIF-NJ (OMS, 2007) enfoca la participación como la provisión o restricción de oportunidades para la participación activa del niño en los mismos contextos y actividades que otras personas (UNCRC, 1989; UNESCO, 1994; 2006), y no tanto desde la experiencia subjetiva de participación. Dado el carácter objetivo y observable, así como la facilidad de su medida, la asistencia ha sido ampliamente utilizada en investigación como indicador de participación, siendo operativizada como la frecuencia de participación o rango de actividades realizadas (Granlund, 2013).

Por su parte la participación, entendida como realización de actividades, incluye o contempla el carácter subjetivo de la experiencia de participación. Ésta envuelve actividades que los niños hacen por sí mismos, en soledad o compañía, que no son necesariamente una expresión de su inclusión social, lo cual hace que esté menos sometida a estándares sociales y culturales que la dimensión de asistencia (Maxwell et al., 2012). De esta forma, la realización hace referencia al carácter voluntario, la implicación individual y el afecto asociado a la experiencia de participación. La investigación ha evaluado la participación a través de indicadores como el disfrute (King et al., 2007) o la persistencia (Axelsson, Granlund y Wilder, 2013; Fuhs, Farran y Nesbitt, 2013; McWilliam y Casey, 2008). Sin embargo, el afecto positivo, operativizado a través del goce o disfrute experimentado durante la realización de una actividad, no está necesariamente asociado a la implicación o persistencia con la que ésta se realiza. Así por ejemplo, los niños pueden estar intensamente involucrados en el desarrollo de una actividad de tipo formal o académica y no por ello experimentar disfrute o felicidad durante su realización (Jarus Anaby, Bart, Engel-Yeger y Law, 2010; Rosenberg y 
Bart, 2016), y viceversa, un niño con limitaciones en su funcionamiento puede asistir a una actividad recreativa desempeñando menor grado de actividad, pero percibir un grado de felicidad o disfrute igual o mayor a otros compañeros participantes (Shikako-Thomas et al., 2008). Estos resultados suponen un dilema en la interpretación y medida de esta dimensión en investigación, que conlleva el reto de aislar los componentes que predicen distintos patrones de participación en contextos diversos.

Según los resultados de la revisión realizado por Imms y colaboradores (2016a), mientras que la asistencia es entendida como el requisito previo a la experiencia de participación, la participación como realización de una actividad parece ser el motor relacionado con una serie de factores intrínsecos a ella, entre los cuales la investigación ha destacado la preferencia, la competencia en la actividad y el sentido que la persona desarrolla de sí misma (Almqvist et al., 2005; Bult et al., 2014; Clarke et al., 2011; King, Law, Petrenchik y Hurley, 2013).

La investigación sobre participación ha relacionado la preferencia con la voluntad, la elección y la motivación intrínseca (Majnemer et al., 2010), determinada en parte por la historia personal del niño, así como las creencias y valores de las personas de su entorno social (Eriksson y Lindstrom, 2006), a través de las cuales se ha demostrado la posibilidad de predecir el futuro funcionamiento cotidiano de adolescentes con necesidades especiales (Edbom, Malmberg, Lichtenstein, Granlund y Larsson, 2010). Los expertos también relacionan la preferencia con el éxito en experiencias anteriores de participación, así como con el nivel de disfrute experimentado (Bult et al., 2014; Simpkins, Ripke, Huston y Eccles, 2005; Watkinson, Dwyer y Nielsen, 2005). Las bajas correlaciones entre la preferencia y la participación real en actividades diversas halladas en niños con limitaciones en el funcionamiento en contraste con sus iguales sin ellas (Majnemer et al., 2010; Yalon-Chamovitz, Mano, Jarus y Weinblatt, 2006), se ha tratado de explicar como una discrepancia entre el deseo de participar en dichas actividades y no hacerlo, debido a factores ambientales presentes en su entorno (Bult et al., 2014). Aunque, aún no se ha estudiado en profundidad 
dicha discrepancia, sí se ha encontrado que bajas tasas de preferencia en actividades físicas a los 8 años de edad reducen los niveles de participación en este tipo de actividades a los 16 años (Kantomaa et al., 2011); así como, que menor autoeficacia percibida se asocia a niveles más bajos de preferencia por actividades cotidianas en niños con necesidades especiales (Engel-Yeger y Hanna-Kasis, 2010).

La investigación también ha encontrado relaciones moderadas entre la autoeficacia percibida y la frecuencia de asistencias a ellas (Almqvist et al., 2005). La autoeficacia, entendida como la competencia mostrada en la realización de una actividad, es consistente con la definición dada por la CIF (OMS, $2001)$ sobre limitaciones, en términos de calidad o cantidad en la ejecución de una actividad y valoradas en relación a lo que cabría esperar en niños con desarrollo típico. A este respecto, otras investigaciones han evidenciado que el aumento de la autoeficacia se asocia al desarrollo de habilidades adquiridas a partir de la participación en actividades diversas (Engel-Yeger et al., 2010; Law et al., 2006; Rosenberg et al., 2016), lo que a su vez tiene que ver con la cantidad y calidad de la ejecución de la actividad (OMS, 2001). Así como, con el aumento del sentido de sí mismo, a través de temas como la confianza, la autoestima y los sentimientos de satisfacción desarrollados a partir de la participación en actividades cotidianas, que nuevamente se vincula con la autoeficacia percibida (Clarke et al., 2011).

Un modelo de relación entre los conceptos presentados es el propuesto por Imms y colaboradores (2016a), quienes conjeturan que una vez asegurada la asistencia, la experiencia de participación puede incluir la competencia en la actividad, el sentido de autoeficacia, confianza y autoestima, así como la influencia en las preferencias de participación en actividades diversas. Este modelo se presenta en la Figura 5 que es, a su vez, una adaptación del modelo propuesto por Maxwell et al. (2012) referente a la participación de niños y jóvenes en el contexto educativo. 
Figura 5. Modelo hipotético del constructo de participación: dimensiones principales y conceptos relacionados

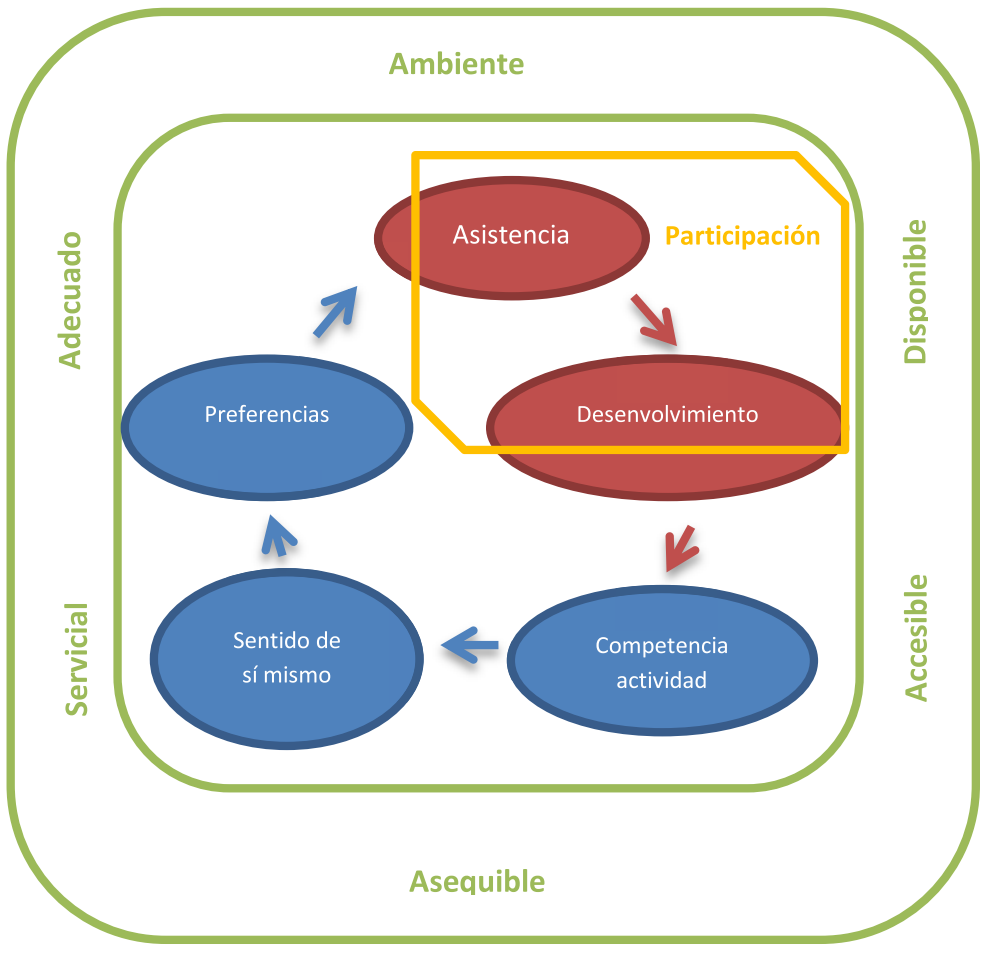

Nota. Adaptado de "Participation: a systematic review of language, definitions, and constructs used in intervention research with children with disabilities”, por C. Imms et al., 2016, Development Medicine \& Child Neurology, 58(1), p. 36.

Según este modelo los factores intrínsecos como la preferencia, la competencia y el sentido del yo se presentan como conceptos importantes, pero no esenciales para la participación. Son conceptos asociados a las dimensiones principales de la experiencia de participación: asistencia y desenvolvimiento (realización). Estos factores intrínsecos vinculados a otros factores ambientales de tipo físico, actitudinal y social, influyen en los resultados personales de participación de niños con y sin necesidades especiales, y muestran capacidad para predecir niveles y patrones futuros de participación (King, 2013). 


\subsubsection{Raíces Conceptuales de la Participación: Perspectiva Social e}

\section{Individual}

Los componentes asistencia y participación, y los conceptos relacionados (preferencia, competencia y sentido del yo) aluden a dos perspectivas sobre la participación en una actividad: la social y la individual (Granlund et al., 2012; Hollenweger y Moretti, 2012). La perspectiva social, defendida por la CIF y la CIF-NJ (OMS, 2001, 2007), describe la función de la participación como la promoción de oportunidades que igualen la frecuencia de asistencia de distintos niños a las mismas actividades. Mientras que, la perspectiva individual se centra en la intensidad de participación con la que el niño está envuelto en actividades diversas, y si el ambiente está acomodado y resulta accesible para facilitar resultados personales significativos de participación (Maxwell, 2012). Ambas perspectivas conceptuales formarían un continuo de participación que está fuertemente determinado por factores personales y ambientales (Coster et al., 2012; Eriksson, 2005), que dan lugar a patrones de participación dependientes al contexto específico en el que tiene lugar el fenómeno de participación (Eriksson et al., 2007).

Por tanto, para comprender la naturaleza de la participación, la investigación debe de centrarse en el contexto donde la persona desarrolla las actividades cotidianas de su vida. Dicho contexto tiene el potencial de favorecer u obstaculizar el impacto de las características del entorno personal, físico, social y actitudinal, a través de factores que actúan como facilitadores o barreras para la participación en actividades diversas (OMS, 2001, 2007). Pero también, potencial para actuar como escenario en el que los factores personales y ambientales establecen cuáles son los aspectos significativos de cada entorno en particular, el valor de lo que se hace y las opciones de comportamiento que tiene las personas a su disposición, todo ello determinado por un largo rango de actividades y roles sociales que son independientes del estado personal del individuo (Badley, 2008). A través de estas dos cualidades el contexto se vincula directamente con la experiencia subjetiva de participación del niño, determinando la frecuencia de la asistencia (OMS, 2001, 2007) y la intensidad con la que el niño percibe 
subjetivamente su participación mediante la realización de actos, tareas y desempeño de roles sociales en diversas situaciones de vida (Badley, 2008; Granlund, 2009; Maxwell et al., 2012; Simeonsson, Carlson, Huntington, McMillen y Brent, 2001) (Figura 6).

Figura 6. Modelo de la Funcionamiento Humano

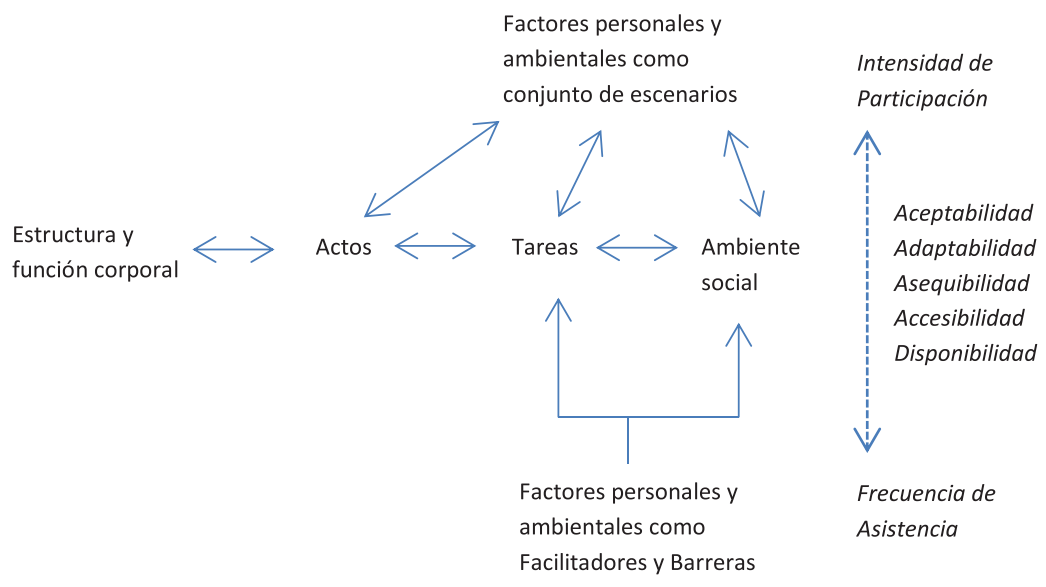

Nota. Adaptado de Bringing more to participation (Tesis Doctoral, Jönköping University) (p. 22), por G. Maxwell, 2012.

Con objeto de identificar patrones de participación en contextos particulares los expertos han analizado las características personales y variables ambientales separadamente, tratando de hallar factores con capacidad de mediar o predecir resultados personales válidos para la intervención y mejora de la participación a edades tempranas. Estas investigaciones, centradas en el marco de funcionamiento humano (OMS, 2001, 2007), han identificado distintos factores asociados directa o indirectamente al fenómeno de la participación de niños con y sin discapacidad. Los hallazgos y resultados de estas investigaciones están posibilitando la elaboración de modelos dinámicos de interacción persona-ambiente (Bronfenbrenner, 1979, 2002; 1992), que explican la participación infantil en entornos diversos. Ejemplos de estos modelos son los propuestos por Maxwell y colaboradores (2012), 
enfocado en la participación en el entorno educativo, o el de King y otros (2003), orientado a la participación en actividades de ocio y tiempo libre de niños con discapacidad. En el siguiente apartado nos centraremos en este último, dada su relevancia para conceptualizar la participación de niños con necesidades especiales en actividades de ocio y tiempo libre, y los factores que se relacionan con ella.

\subsection{Factores del Contexto que Afectan a la Participación de los Niños en Actividades de Ocio y Recreo (King et al., 2003)}

Tras la creciente evidencia científica acerca del potencial del contexto sobre los resultados personales del niño, los actuales modelos conceptuales sobre la participación infantil se orientan al análisis de múltiples factores y niveles de participación del niño en su entorno. King et al. (2003) han elaborado un modelo multidimensional que trata de explicar la participación infantil en actividades de ocio, a partir de la definición de tres tipos de factores y las relaciones establecidas entre ellos. El modelo pretende servir de herramienta guía en el diseño de investigaciones, políticas sociales e intervenciones prácticas dirigidas a la mejora de la participación de niños y jóvenes con necesidades especiales y sus familias (Longo y Badia, 2009).

Para el desarrollo de su modelo conceptual King y colaboradores (2003) se centran en la definición de la naturaleza y funcionamiento de factores que afectan a la ocurrencia de la participación en actividades de ocio y tiempo libre. El análisis parte de un enfoque socio-ecológico, donde los resultados de participación son el efecto de interacciones dinámicas establecidas a nivel sistémico entre el niño y su ambiente (Bronfenbrenner, 1979, 2002; 1992). Dado que la finalidad del modelo es aumentar la calidad y la cantidad de la participación, los autores utilizan un lenguaje positivo y proactivo (Mancini, Coster, Trombly, Heeren, 2000), basado en las fortalezas personales y las oportunidades del ambiente para generar resultados personales significativos en la participación del niño en actividades de ocio y tiempo libre. Consecuentemente los factores descritos en el modelo se presenta desde 
el polo positivo de su continuo, es decir, como facilitadores o apoyos y no como limitaciones o restricciones para la participación infantil (OMS, 2001, 2007).

Para definir los factores potencialmente importantes los autores realizaron una revisión de la literatura en cuatro campos de investigación: 1) participación de la población con discapacidad desde la perspectiva de la rehabilitación (Mactavish, Schleien y Tabourne, 1997; Sloper, Knussen, Turner, y Cunningham, 1991); 2) factores de riesgo y protección para la resiliencia de niños en contextos adversos (Garmezy, 1985; Rutter, 1987); 3) factores determinantes de las actividades de ocio y tiempo libre (Crawford y Goodbey, 1987; Jackson y Searle, 1985); 4) factores generales que influyen en las actividades físicas y el ejercicio (Allison, 1996; DiLorenzo, Stucky-Ropp, Vander Wal y Gotham, 1998). Esta revisión reveló la existencia de factores comunes a la participación y específicos a su realización en entornos de ocio y tiempo libre, y demostró la relevancia de un modelo multidimensional para determinar la participación de niños con necesidades especiales.

Basándose en los resultados de dicha revisión los autores han desarrollado un modelo teórico de los factores contextuales determinantes de la participación de los niños, que la conceptualiza como el resultado de la interacción de una serie de factores pertenecientes a los entornos comunitario (factores estructurales), familiar (factores interpersonales) y personal (factores intrapersonales) en los que el niño está inmerso (King, et al., 2009). Los factores descritos en el modelo tienen la capacidad de ayudar u obstaculizar la participación infantil actuando como facilitadores o barreras de ésta (OMS, 2001, 2007), así como de predecir efectos directos o indirectos de su ocurrencia al comprender cómo cada uno de ellos se relaciona con el resto de factores presentes en diversas situaciones de participación de ocio y tiempo libre (Figura 7). 
Figura 7. Modelo teórico multidimensional de factores contextuales que afectan a la participación infantil en actividades de ocio y tiempo libre

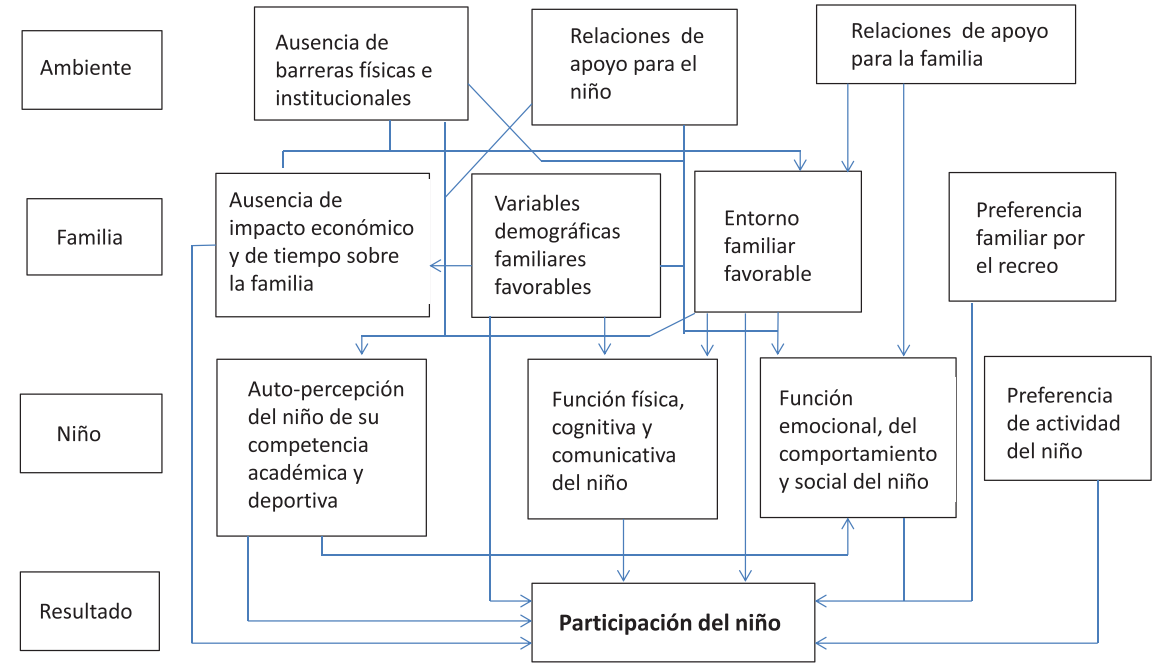

Nota. Recuperado de "Un modelo conceptual de los factores que afectan a la participación en las actividades de ocio y recreo de los niños con discapacidades”, por King et al., 2009, Siglo Cero, 40(2), (p. 12).

Como se ve en la Figura 7, el modelo esboza las relaciones hipotéticas establecidas entre los factores de los tres niveles analizados (ambiente, familia y niño) tratando de describir posibles causas de los resultados personales de participación del niño. Debido a que su relación puede ser directa (variables predictoras) o indirecta (variables mediadores o moderadoras), el modelo destaca la importancia de explorar el papel de las diversas variables intervinientes y su interacción, a fin de conocer los mecanismos que mejoran o limitan los niveles de participación. Con respecto a la aplicabilidad del modelo, este análisis es de suma importancia, ya que la intervención sobre un factor (función emocional, comportamental y social del niño), sin tener en cuenta la influencia mediadora de otro factor sobre él (barreras físicas e institucionales a nivel ambiental), puede no conllevar la mejora 
de los resultados personales de participación del niño, debido a fallos en la interpretación de las relaciones dinámicas entre las variables intervinientes en participación y funcionamiento infantil (King et al., 2003, 2009).

\subsubsection{Factores que Influyen en la Participación en Actividades de Ocio y}

\section{Tiempo Libre}

A continuación se presenta los tres niveles de factores relacionados con los resultados de participación infantil propuestos por King y colaboradores (2003 , 2009), bajo la base de la actual evidencia científica sobre participación infantil, desarrollo y discapacidad. La mayoría de los resultados presentados provienen de investigaciones trasversales, por lo que los patrones de participación presentados por sus autores proceden en buena parte de la lógica teórica y en menor grado de resultados empíricos basados en estudios longitudinales, los cuales tienen el potencial de describir las trayectorias de desarrollo desde visiones más globales (Imms et al., 2016a), al apoyarse en los cambios acontecidos a lo largo del tiempo (King, 2013).

\subsubsection{Factores Relacionados con el Niño}

\subsection{Asistencia: Diversidad y Frecuencia de Participación}

La investigación pone de manifiesto la influencia de características personales como la edad o el género en los niveles de participación en actividades de ocio y tiempo libre de niños con discapacidad (Adolfsson et al., 2011; Bult et al., 2014; Engel et al., 2009; Shikako-Tomas et al., 2008) y sin ella (Allison, et al., 2005; King, et al., 2007; Síndic de Greuges, 2014; Schreuer et al., 2014).

A este respecto, los estudios han hallado una disminución en los dominios de asistencia a actividades recreativas y físicas con el trascurso de la edad que se refleja en menor diversidad y frecuencia de participación en actividades de ocio, especialmente en el caso de niños con necesidades especiales (Imms et al., 2016b; Bult, Verschiren, Jongmas, Lindeman, y Ketelaar, 2011). Por 
otra parte, mientras que los varones suelen participar más en actividades físicas y deportivas, las niñas suelen hacerlo en aquellas de tipo no deportivo como las sociales o artísticas (Longo et al., 2009; Rosenblum et al., 2010; Síndic de Greuges, 2014). Estos resultados se repiten en niños y niñas con discapacidad (Law, et al., 2006). También se ha encontrado un efecto de interacción entre el género y la discapacidad, que indica menores niveles de participación en actividades recreativas en niñas con discapacidad con respecto a sus pares con y sin ellas (Schreuer et al., 2014), resultado que informa de la existencia de un doble factor de riesgo para la participación de las niñas en actividades de ocio.

Con respecto a la presencia de necesidades especiales, la investigación pone de manifiesto diferencias significativas entre menores con y sin discapacidad en relación con la diversidad y frecuencia de participación en actividades de ocio y tiempo libre (Engel-Yeger et al., 2009; King et al., 2007). Con frecuencia, los resultados de estas investigaciones indican que los niños con desarrollo típico asisten a un mayor rango de actividades diversas que sus iguales con limitaciones en su funcionamiento, siendo las diferencias más llamativas en actividades de ocio de tipo formal, como las ofrecidas por los currículos educativos (actividades de tipo físico), e informales que requieren participación en compañía (actividades sociales) (Coster, et al., 2012; Law, Petrenchik, King y Hurley, 2007; Majnemer et al., 2010; Palisano et al., 2011; Shimoni, Engel-Yeger, y Tirosh, 2010).

El tipo de discapacidad y las necesidades de apoyo también han sido identificados como variables influyentes en el acceso al ocio, asociando el funcionamiento cognitivo, físico y comportamental de niños con necesidades especiales a la variedad y cantidad de actividades de ocio en las que estos participan (Bult et al., 2011; Imms, Reilly, Carlin y Dodd, 2008). Los resultados ponen de manifiesto un efecto menos determinante que otros factores intervinientes como el género, el nivel socioeconómico familiar o las infraestructuras físicas para la participación en actividades diversas (Bult et al., 2014; Coates y Vickerman, 2008; Eriksson y Granlund, 2004; Shikako-Tomas et al., 2008). 


\subsection{Intensidad: Disfrute y Preferencia de Participación}

Con independencia de la diversidad y frecuencia de asistencia a actividades de ocio y tiempo libre de niños con y sin necesidades especiales, la investigación encuentra niveles similares de disfrute entre ambos grupos en aquellas actividades en las que participan (Majnemer et al., 2008). La presencia de discapacidad o necesidades especiales tampoco da lugar a diferencias significativas en la preferencia que muestran niños o jóvenes por participar en actividades de ocio y tiempo libre (Bult et al., 2014; Schreuer et al., 2014; Shimoni et al., 2010). Estos resultados apoyan la hipótesis de que la discapacidad es independiente a la experiencia subjetiva de participación en actividades diversas.

La investigación ha encontrado relaciones positivas entre las preferencias de participación y el grado de autoeficacia percibida, así como con la participación real en actividades de ocio y tiempo libre (Bult et al., 2014; Engel-Yeger et al., 2010; Kantomaa et al., 2011). La autoeficacia percibida, así como los sentimientos de inseguridad y vergüenza fueron definidos por Bandura (1977) como factores intrínsecos capaces de limitar la motivación del niño para participar en actividades diversas, como las de ocio y tiempo libre (Wikes et al., 2011). A este respecto, investigaciones recientes defienden que la autopercepción sobre las competencias personales para la realización de actividades físicas, sociales o recreativas actúan como fortalezas o barreras personales que facilitan o restringen la asistencia y participación de niños con necesidades especiales (Clarke et al., 2011; Coates et al., 2008; Healy, Msetfi, y Gallagher, 2013; Shields, Synnot, y Kearns, 2015).

Las relaciones estadísticas encontradas entre los niveles de participación, las experiencias subjetivas y la construcción del autoconcepto parecen apoyar la perspectiva individual de la participación (Almqvist et al., 2005). Dado que este proceso comienza a edades tempranas y se desarrolla durante el trascurso del tiempo, la discapacidad como factor de riesgo necesita ser analizado en relación a cómo ésta afecta a la participación social del niño, y a sus posibilidades de desarrollo y adquisición de habilidades adaptativas en contextos específicos (Bøttcher y Dammeyer, 2013; King, 2013). 


\subsubsection{Factores Relacionados con el Ambiente}

Tanto la CIF/CIF-NJ (OMS, 2001, 2007), como la actual literatura científica sobre participación destacan el papel de los factores ambientales sobre los resultados de participación de niños y jóvenes con y sin discapacidad. Como ya se ha mencionado anteriormente, la CIF (OMS, 2001) define las restricciones en la participación en actividades cotidianas como fenómenos socialmente construidos, en las que los factores ambientales pueden actuar como facilitadores o barreras para la asistencia e intensidad de la participación del niño (OMS, 2007; Maxwell, 2012). Estos factores incluyen aspectos del mundo externo que forman los contextos de vida de la persona, así como el modo en que dichos contextos afecta a su funcionamiento. Según la CIF/ CIF-NJ (OMS, 2001, 2007), el efecto del ambiente sobre los resultados de participación se presenta a través de factores físicos, sociales y actitudinales de los entornos en los que los niños típicamente desarrollan sus actividades cotidianas.

En relación con la participación infantil en actividades de ocio y tiempo libre, la literatura científica reciente resalta el efecto facilitador o de obstáculo de las variables físicas, sociales y actitudinales de contextos específicos como el entorno familiar, escolar o comunitario, en los resultados de participación de niños con y sin discapacidad (Dunn, Coster, Cohn, y Orsmond 2009; Haegele, y Sutherland, 2015; Longo et al., 2013; Rosenberg et al., 2012). En este trabajo, analizaremos los efectos de los factores ambientes más destacados en los resultados de participación a nivel familiar y comunitario.

\subsection{Variables del Ambiente Familiar}

La investigación sobre participación ha asociado variables familiares, tales como, el nivel socioeconómico y educativo de los padres, la cohesión familiar o las actitudes, expectativas y preferencias de los padres, con los resultados de participación de sus hijos con y sin discapacidad en actividades de ocio y tiempo libre (Dunn et al., 2009; Heah, Case, McGuire, y Law, 2007; King et al., 2006; Law, et al, 2006). 
Con respecto a niños con necesidades especiales, la evidencia científica sugiere que niveles educativos e ingresos económicos más altos actúan como factores familiares facilitadores de la asistencia del hijo a actividades de ocio diversas (Shikako-Tomas et al., 2008), mientras que las preferencias familiares particulares y la falta de conciencia sobre la importancia de la participación del hijo para su desarrollo, se asocian a restricciones en la participación en actividades de ocio y tiempo libre (Rosenberg et al., 2012). En cuanto al género de los hijos con discapacidad, nuevamente la información disponible indica diferencias en los resultados de participación. Según la investigación, los padres ponen significativamente más limites, barreras y precauciones al deseo de participación de las hijas, lo que identifica la sobreprotección como una barrera para el acceso y la participación de las niñas con necesidades especiales (Hogansen et al., 2008). Por último, las creencias de autoeficacia de los padres están asociadas a buenas prácticas parentales que favorecen los resultados de participación de hijos con y sin discapacidad, al promover factores de crecimiento intrínsecos del niño, tales como, sus competencias de afrontamiento y ajuste positivo al entorno (Missiuna et al., 2006; Summer, Larkin, y Dewey, 2008).

\subsection{Variables del Ambiente Comunitario}

Tras el entorno familiar otras áreas de vida importantes para el desarrollo y participación de los menores en actividades lúdicas son su entorno escolar y comunitario. A continuación se describen factores físicos, sociales y actitudinales que según la literatura influyen en la participación infantil y juvenil en actividades de ocio y tiempo libre en estas áreas de vida.

\subsection{Factores Físicos}

La investigación sobre participación infantil resalta el papel facilitador de factores físicos como la disposición de transporte, adaptación de actividades mediante la modificación de materiales, cambios de secuencias en las tareas, uso de dispositivos adaptados, sistemas alternativos de comunicación, etc., 
en los niveles de participación de niños y jóvenes con discapacidad en actividades diversas de ocio y tiempo libre (Longo et al., 2009; King et al., 2009). Sin embargo, estos y otros estudios destacan que los alumnos con necesidades especiales con frecuencia experimentan barreras materiales que afectan su inclusión, acceso y participación en las actividades escolares y extraescolares ofrecidas por sus centros educativos (Coates et al., 2008; Connors y Stalker, 2007) y a las realizadas fuera del contexto escolar, de tipo físico y deportivo (Fitzgerald, Taylor, y LaValle, 2003). Estos resultados se relacionan con los de otros autores quienes denuncian la alta frecuencia con la que estos alumnos realizan actividades pasivas y sedentarias durante su tiempo libre (Law et al., 2007).

La investigación también ha encontrado relación entre el tipo de centro escolar (ordinario vs específico) al que asisten los niños con necesidades especiales y sus resultados en participación en actividades de ocio y tiempo libre. Así, aunque la escolarización en escuelas ordinarias es defendida por teóricos y prácticos como un facilitador de la participación social de niños y adolescentes con discapacidad (Badia, Orgaz, Verdugo, Ullan y Martínez, 2011), la evidencia indica que los alumnos con necesidades educativas que asisten a escuelas ordinarias perciben un alto grado de dependencia de los apoyos ofrecidos por los adultos y más barreras ambientales para la interacción con sus iguales (Nordström, 2011; Law et al., 2007). Por su parte, los alumnos que asisten a centros específicos muestran altas tasas de frecuencia de participación en actividades extraescolares, pero una menor diversidad de participación en actividades inclusivas fuera de sus centros educativos (Kleinert, Miracle, y Sheppard-Jones, 2007).

De esta forma, con independencia del tipo de centro educativo, las barreras físicas y limitaciones en el carácter inclusivo de las actividades complementarias y extraescolares ofrecidas por las escuelas u otras entidades comunitarias, provoca la falta de oportunidades para el acceso y participación equitativa de alumnos con discapacidad y otros alumnos con necesidades específicas o pertenecientes a colectivos sociales desfavorecidos (Síndic de Greuges, 2014). 


\subsection{Factores Sociales}

La literatura científica asocia el apoyo social a una mayor participación en actividades de ocio y tiempo libre (Abraham Gregory, Wolf, y Pemberton, 2002; Longo et al., 2013). Desde los modelos sociales de la discapacidad, el apoyo en sí mismo se percibe como un facilitador o una barrera para la participación en actividades de ocio que puede ser provisto desde distintos ámbitos de vida (individual, social, emocional o físico) (AAIDD, 2011; OMS, 2001, 2007).

En el entorno escolar, así como en otros ámbitos orientados al ocio fuera de la escuela, las interacciones sociales positivas de alumnos con necesidades educativas con adultos e iguales contribuyen a su participación en actividades diversas (Almqvist et al., 2005). Sin embargo, como ya hemos explicitado a lo largo de este trabajo, muchos de estos alumnos encuentran multitud de barreras no sólo materiales, sino también sociales, para participar de forma inclusiva con sus iguales (Coster et al., 2012; Tamm y Skär, 2000). Estas barreras les lleva a pasar la mayor parte de su tiempo en la escuela y fuera de ella realizando actividades en soledad (Law et al., 2006; Law et al., 2007). Además del rechazo social de sus compañeros (Longo et al., 2009), los mensajes del entorno sobre la incapacidad para participar en diversas situaciones de vida, tales como el ocio, influyen negativamente sobre la autoeficacia y la motivación personal de los niños con limitaciones en su funcionamiento, que como hemos visto anteriormente son factores intrínsecos con capacidad de facilitar u obstaculizar la asistencia y participación del niño en actividades recreativas, sociales y físicas (Coates et al., 2008; Wikes et al., 2011).

En cuanto a la percepción de los adultos del apoyo social dirigido a la participación de menores con necesidades especiales, la investigación pone de manifiesto que los profesores del área de educación física perciben menos recursos de apoyo por parte de las administraciones con respecto a otras áreas de enseñanza, como las clases de inglés o matemáticas (Morley Bailey, Tan, y Cooke, 2005; Haegele et al., 2015). Este hecho, unido a la alta tasa de profesores de educación física que no programan sus actividades con el objetivo de facilitar la disponibilidad y acceso de todos sus alumnos 
a ellas (Blinde y McCallister, 1998; Spencer-Cavaliere, y Watkinson, 2010), provoca barreras sociales que afectan a la experiencia subjetiva de participación de los niños con necesidades educativas especiales, que además fomentan comportamientos de discriminación y exclusión por parte de sus compañeros sin ellas (Coates et al., 2008).

\subsection{Factores Actitudinales}

Con referencia a las actitudes del entorno hacia la participación de niños y jóvenes con limitaciones en su funcionamiento en actividades de ocio y tiempo libre, la investigación ha puesto de relieve que las actitudes negativas hacia las personas con discapacidad tienen la capacidad de actuar como barreras para su participación e inclusión social (Flórez, Aguado y Alcedo, 2009).

En la escuela, las actitudes de los profesores hacia la atención a la diversidad se ha relacionado con la capacidad de éstos para afrontar la enseñanza de su alumnado con necesidades especiales (Croll y Moses, 2000; Haegele et al., 2015). Como ya se ha resaltado, la falta de formación docente no sólo restringe la participación de alumnos diversos en actividades cotidianas de la escuela, sino también en actividades de ocio realizadas en su tiempo libre (Tamm et al., 2000; Law et al., 2006).

Los estudios inciden en el poder de padres y profesores para actuar como barreras para la asistencia y participación de niños y jóvenes con y sin discapacidad, al ejercer control sobre las preferencias y elecciones de las actividades que éstos realizan (Badia et al., 2009; Buttimer y Tierney, 2005; Palisano et al., 2011). Por otro lado, las actitudes de los iguales sin discapacidad durante la realización de actividades inclusivas condiciona la experiencia subjetiva de la participación de niños y jóvenes con discapacidad (Garrote, 2017). Las actitudes negativas de los compañeros influyen en la construcción intrapersonal e historia personal del niño, lo cual no sólo afecta a la experiencia presente de participación, sino también a las actitudes futuras hacia la asistencia a esas u otras actividades de ocio realizadas por menores 
que experimentan restricciones en su participación (Imms et al., 2016b).

Por último, las actitudes culturales de la comunidad y la sociedad también se ven reflejadas en los resultados de participación infantil, especialmente en casos con discapacidad (Adolfsson et al., 2011; Schreuer et al., 2014). Dado que la realización de actividades de ocio en entornos comunitarios es tan importante para la experiencia de participación, como las desarrollas en contextos más personales como en familia o soledad, resulta determinante que las comunidades, administraciones y políticas públicas reconozcan la naturaleza y papel de la participación infantil, así como su responsabilidad en el fomento de oportunidades para la disponibilidad y acceso a actividades lúdicas a nivel comunitario y social (FYME, 2009; MEPSYD, 2008; Síndic de Greuges, 2014). El propósito de este reconocimiento es mejorar los resultados de participación en menores que por discapacidad u otras condiciones personales o ambientales, ven limitadas sus oportunidades de participación en actividades de ocio y tiempo libre inclusivas (OMS, 2001, 2007; King et al., 2003, 2009; Kramer, Olsen, Mermelstein, Balcells, y Liljenquist, 2012).

A pesar del esfuerzo científico por comprender de forma holística el fenómeno de la participación y sus determinantes contextuales, la investigación aún no proporciona claridad acerca de si los efectos de los factores ambientales sobre los niveles de participación en actividades de ocio son más fuertes que los asociados a los factores personales (Kowalchuk y Crompton, 2009; Arim, Findlay, y Kohen, 2012). Tampoco, sobre cómo determinados factores ambientales influyen en patrones específicos de participación en contextos particulares, estableciendo con precisión la interacción, el papel y el peso de cada uno de ellos (King, 2013; Shields et al., 2015).

Con la finalidad de aunar todas estas evidencias aisladas, y a veces dispares, los expertos están orientando sus esfuerzos en investigación en diferentes sentidos. Por una parte, hacia el diseño de estudios longitudinales que den la oportunidad de estudiar las trayectorias y cambios en las variables implicadas en los procesos de interacción entre el niño y su ambiente (Imms 
et al., 2017). Se ha demostrado que, los estudios longitudinales facilitan la detección de factores mediadores y predictores de los resultados personales de participación de niños con y sin necesidades especiales en contextos concretos (Eriksson et al., 2004; Noreau y Boschen, 2010). Por otra, hacia la realización de revisiones sistemáticas que valoran la participación desde diferentes ámbitos (persona, familia, escuela, comunidad) y permiten mejorar nuestro conocimiento sobre el impacto del ambiente en el grado (diversidad/intensidad), experiencia subjetiva (diversión y disfrute) y contexto (localización y compañía) en el que tiene lugar la participación de menores con y sin discapacidad (Shields et al., 2015). Por último, hacia el desarrollo de marcos teóricos consistentes basados en evidencias empíricas y la lógica teórica, como el de King y colaboradores (2003), que ayudan a operacionalizar la participación desde enfoques cada vez más integrales, que tratan de registrar las dinámicas de los factores, procesos y beneficios de la participación (King, 2013). En definitiva, todos estos esfuerzos se dirigen a la aplicación del paradigma de participación a políticas y prácticas que optimicen la experiencia de participación infantil y juvenil y beneficios para el desarrollo de sus vidas, desde una base conceptual y empírica solida (Kramer et al., 2012).

\subsection{Evaluación de la Participación de Niños Con y Sin Discapacidad en Actividades de Ocio y Tiempo Libre}

Desde la publicación de la CIF (OMS, 2001) se han elaborado multitud de instrumentos que evalúan la participación infantil con y sin discapacidad en diferentes situaciones de vida. Dada la multidimensionalidad del fenómeno, así como su relación dinámica con otros conceptos como el de actividad o ambiente, la elaboración de medidas de participación conlleva diversos desafíos que los investigadores han de tener en cuenta durante la construcción de los instrumentos (Coster et al., 2012) o el diseño de evaluaciones (King, 2013). Algunos de estos desafíos son por ejemplo, la capacidad de la herramienta para valorar las dimensiones objetivas y subjetivas de participación; captar procesos tanto singulares como generales 
del fenómeno; diferenciar los conceptos de "participación" y "actividad"; medir la participación en diversos entornos o concretar la medida en uno particular, como la participación en el hogar, la escuela, el ocio y tiempo libre, entre otros (Phillips, Olds, Boshoff y Lane, 2013).

Dada la complejidad del fenómeno, los expertos recomiendan la necesidad combinar distintas metodologías para la recogida de información, tales como la observación sistemática, entrevistas, e incluso el uso de métodos alternativos como los registros fisiológicos (King, et al., 2013). La metodología cuantitativa complementa la información recopilada mediante métodos cuantitativos como los cuestionarios auto-administrados o las encuestas aplicadas a proxys (familia, profesionales, iguales). El uso de metodologías mixtas permite englobar el registro de la participación de más niños en condiciones diversas de vida, así como obtener una panorámica más amplía y dinámica de la experiencia de la participación de todos ellos, con miras a fomentar su comprensión teórica y aplicación práctica.

Tras lo expuesto y teniendo en cuenta los objetivos de esta investigación, que se desarrollarán en la parte empírica de esta tesis, en este apartado nos centraremos en la medida cuantitativa de la participación infantil. Para ello, describiremos una serie de instrumentos de evaluación de la participación en actividades lúdicas. Analizaremos las semejanzas y diferencias de cada instrumento, así como las potencialidades y limitaciones de cada uno de ellos. Por último, identificaremos el instrumento seleccionado para esta investigación y justificaremos las razones de su elección.

Para una mejor comprensión de las bondades y limitaciones de los instrumentos revisados en la Tabla 8 se presenta las principales características de alguno de los más importantes. Dichas características serán utilizadas como criterio para valorar la elección de uno de ellos en este trabajo. 


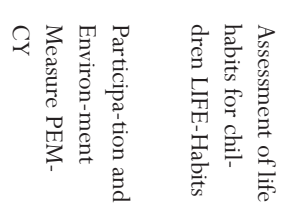

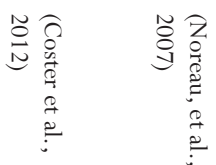

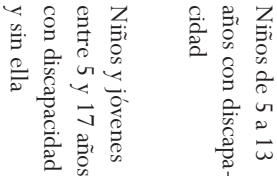

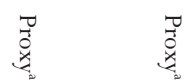

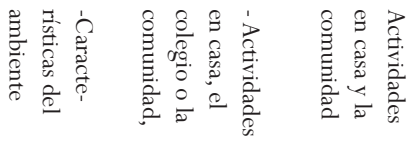

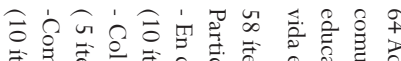

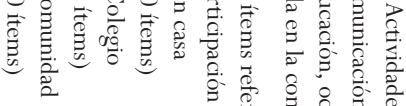

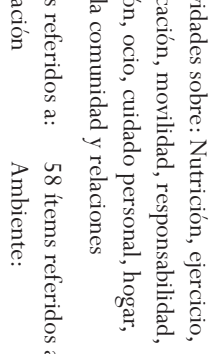

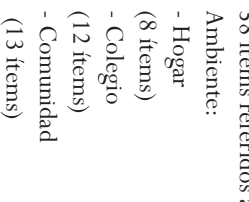

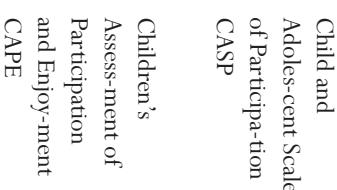

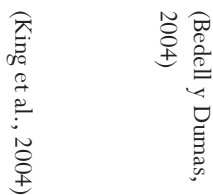

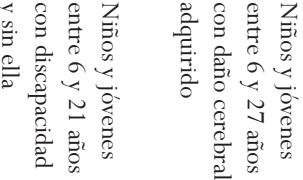

范范

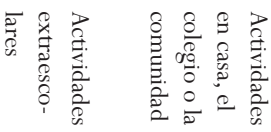

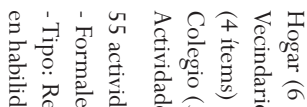

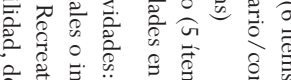

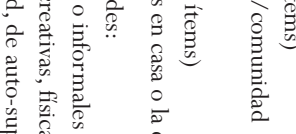

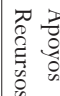

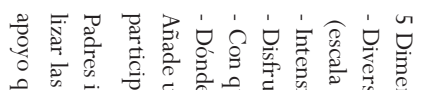

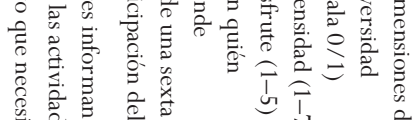

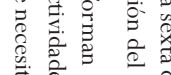

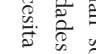

焉.

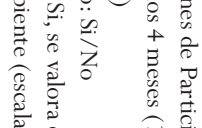

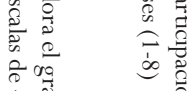

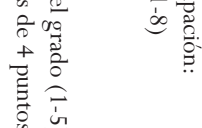

总总

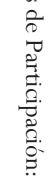

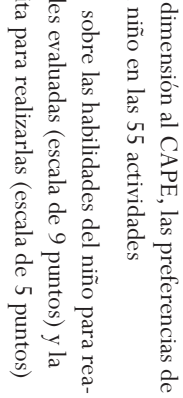

z

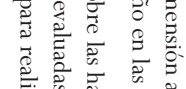

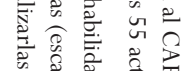

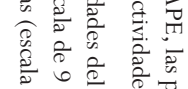

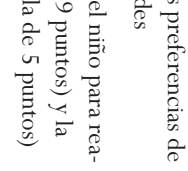

z $\simeq$

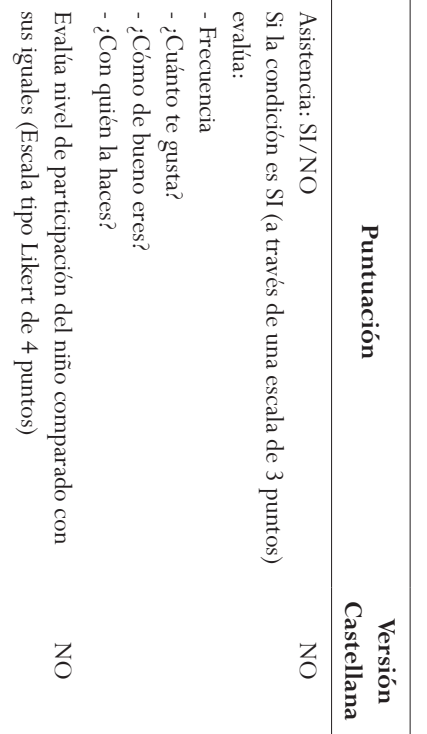


Como se aprecia en la Tabla 8, los distintos instrumentos presentados valoran la experiencia de participación en diversos contextos sociales: hogar, escuela y/o comunidad, desde diferentes componentes del fenómeno. Algunos de ellos tienen en cuenta sólo los componentes objetivos de la participación (la asistencia a actividades diversas, por ejemplo), como el Frequency of Participation Questionnaire: FPQ- Grupo SPARCLE (Fauconnier et al., 2009) que registra la frecuencia de asistencia de los niños a actividades en entornos sociales. Mientras otros tienen en cuenta tanto indicadores objetivos (la frecuencia y la diversidad de participación), como componentes psicológicos asociados a la realización de las actividades presentadas, como el Preteen Paly Profile (Henry, 2000) que valora la satisfacción o autoeficacia percibida, o el Children's Assessment of Participation and Enjoyment: CAPE (King et al., 2004) que estima el disfrute y la preferencia de participación. Otros instrumentos, además de evaluar los resultados de participación del niño, añaden a su medida factores ambientales para registrar los apoyos, barreras y recursos del entorno percibidos para la participación infantil, como el Participation and Environment Measure: PEM-CY (Coster et al., 2012).

Todos ellos enfocan su medida a la participación en niños con discapacidad y sin ellas. Pero solo dos están construidos para que sean los propios niños quienes informen de su participación en actividades diversas: el Preteen Paly Profile (Henry, 2000) y el CAPE (King et al., 2004). Mientras que, sólo el CAPE (King et al., 2004) ha sido traducido y validado a población española con y sin discapacidad, mostrando propiedades psicométricas adecuadas y su relación con el constructo de calidad de vida (Longo et al., 2012).

Tras la revisión y análisis de los diferentes instrumentos disponibles para la evaluación de la participación infantil en actividades de ocio y tiempo libre diversas, para el desarrollo de esta investigación se ha seleccionado el CAPE (King et al., 2004), por los siguientes motivos:

- Es un instrumento que valora tanto componentes objetivos (diversidad, frecuencia, localización y socialización) como subjetivos 
(disfrute y preferencia) de la experiencia de participación en actividades extraescolares.

- Evalúa la participación en contextos diversos: hogar, escuela y comunidad.

- La información la proporciona el propio protagonista que realiza la acción: niños y jóvenes con y sin necesidades especiales.

- Es una medida de carácter transcultural, con suficientes evidencias empíricas sobre la fiabilidad y validez de su medida (Bult et al., 2010; Longo et al., 2012).

- La versión española presenta cualidades psicométricas adecuadas (Longo et al., 2012).

- La investigación ha demostrado correlaciones positivas entre su medida y el constructo de calidad de vida (Badia, et al., 2013; DahanOliel et al., 2012; Shikako-Thomas et al., 2012).

\subsection{Participación Infantil en Actividades de Ocio y Calidad de Vida}

La investigación sobre participación infantil está analizando la asociación que se estable entre la participación en actividades de ocio y tiempo libre y los niveles de calidad de vida percibidos por distintas poblaciones infantiles y juveniles (Badia et al., 2013; Dahan-Oliel et al., 2012; Shikako-Thomas et al., 2012; Schreuer et al, 2014). Los resultados de estas investigaciones ponen de manifiesto que la asistencia a actividades de ocio favorece el bienestar subjetivo del menor y contribuye a la satisfacción en diferentes áreas de vida, tales como el bienestar físico y emocional (Badia et al., 2013; DahanOliel et al., 2012; Schreuer et al, 2014), el desarrollo de competencias personales y sociales (Shikako-Thomas et al., 2012; Wilkes et al., 2011) y la autodeterminación cuando se dan oportunidades a los menores para el control y elección de las actividades realizadas (Adolfsson et al., 2011; Bult et al., 2014). 
Con respecto a la influencia de factores contextuales, tanto personales como ambientales, Badia y colaboradores (2013) han encontrado que la participación en actividades extraescolares de niños y jóvenes con y sin necesidades especiales en general mejora el bienestar físico, la autonomía, el apoyo social y las relaciones familiares, con independencia del tipo de discapacidad. Por el contrario las restricciones ambientales para la participación infantil dan lugar a un entramado de factores (Tabla 9), que amenazan el desarrollo óptimo y calidad de vida de aquellos niños con menores oportunidades para interactuar con su entorno (Van Naarden Braun, Yeargin-Allsopp y Lollar, 2006). A este respecto, la investigación también ha hallado relaciones positivas entre la participación y la dimensión de inclusión social del constructo de calidad de vida. La evidencia sugiere que la participación en actividades lúdicas favorece la inclusión social en diferentes contextos en los que los niños típicamente se desenvuelven e interaccionan con su entorno (familia, escuela y comunidad, por ejemplo), cuando se les facilita el acceso y la disponibilidad para realizar diversas actividades en su tiempo libre (Almqvist, Hellnas, Stefansson y Granlund, 2006; Orlin et al., 2010). Mientras que, las limitaciones o barreras ambientales (físicas, sociales o actitudinales) para la asistencia y participación se relacionan con menores resultados en calidad de vida de niños con necesidades especiales (ShikakoThomas et al., 2012). 
Tabla 9. Principales barreras y facilitadores personales y ambientales para la participación infantil en actividades de ocio y tiempo libre

\begin{tabular}{|c|c|c|c|c|c|}
\hline \multirow{2}{*}{$\begin{array}{l}\text { Dimensiones } \\
\text { Participación }\end{array}$} & & \multicolumn{2}{|c|}{ Objetiva } & \multicolumn{2}{|c|}{ Subjetiva } \\
\hline & & Diversidad & Frecuencia & Disfrute & Preferencia \\
\hline \multicolumn{6}{|l|}{ Factores } \\
\hline \multicolumn{6}{|l|}{ Personales } \\
\hline & Edad & $\begin{array}{l}\text { disminución a } \\
\text { mayor edad, } \\
\text { Barrera }\end{array}$ & $\begin{array}{l}\text { disminución a } \\
\text { mayor edad, } \\
\text { Barrera }\end{array}$ & & \\
\hline & Género & $\begin{array}{l}\text { diferencias de } \\
\text { género, Barrera }\end{array}$ & $\begin{array}{l}\text { niveles más } \\
\text { bajos en niñas, } \\
\text { Barrera }\end{array}$ & & \\
\hline & $\begin{array}{l}\text { Grado } \\
\text { necesidades } \\
\text { especiales }\end{array}$ & $\begin{array}{l}\text { niveles más } \\
\text { bajos en niños } \\
\text { con necesidades } \\
\text { más severas, } \\
\text { Barrera }\end{array}$ & $\begin{array}{l}\text { niveles más } \\
\text { bajos en niños } \\
\text { con necesidades } \\
\text { más severas, } \\
\text { Barrera }\end{array}$ & $\begin{array}{l}\text { no diferen- } \\
\text { cias signifi- } \\
\text { cativas entre } \\
\text { grupos, } \\
\text { Facilitador }\end{array}$ & $\begin{array}{l}\text { no diferencias } \\
\text { significativas } \\
\text { entre grupos, } \\
\text { Facilitador }\end{array}$ \\
\hline \multicolumn{6}{|l|}{ Factores } \\
\hline Físicos & Ingresos & $\begin{array}{l}\text { niveles más } \\
\text { altos a mayor } \\
\text { nivel de ingre- } \\
\text { sos, Facilitador }\end{array}$ & $\begin{array}{l}\text { niveles más } \\
\text { altos a mayor } \\
\text { nivel de ingre- } \\
\text { sos, Facilitador }\end{array}$ & & \\
\hline Sociales & $\begin{array}{l}\text { Nivel } \\
\text { educativo }\end{array}$ & $\begin{array}{l}\text { niveles más } \\
\text { altos a mayor } \\
\text { nivel educativo, } \\
\text { Facilitador }\end{array}$ & $\begin{array}{l}\text { niveles más } \\
\text { altos mayor } \\
\text { nivel educativo, } \\
\text { Facilitador }\end{array}$ & & \\
\hline \multirow[t]{3}{*}{ Actitudinales } & $\begin{array}{l}\text { Control } \\
\text { familiar }\end{array}$ & & & & $\begin{array}{l}\text { control } \\
\text { expresión de } \\
\text { preferencias } \\
\text { infantiles, } \\
\text { Barrera }\end{array}$ \\
\hline & $\begin{array}{l}\text { Creencias de } \\
\text { la eficacia } \\
\text { del hijo }\end{array}$ & $\begin{array}{l}\text { niveles más } \\
\text { bajos a menor } \\
\text { confianza en las } \\
\text { competencias } \\
\text { del hijo, Barrera }\end{array}$ & & & \\
\hline & $\begin{array}{l}\text { Importancia } \\
\text { familiar } \\
\text { hacia la } \\
\text { participa- } \\
\text { ción }\end{array}$ & $\begin{array}{l}\text { niveles más ba- } \\
\text { jos con incons- } \\
\text { ciencia familiar, } \\
\text { Barrera }\end{array}$ & $\begin{array}{l}\text { niveles más ba- } \\
\text { jos con incons- } \\
\text { ciencia familiar, } \\
\text { Barrera }\end{array}$ & & \\
\hline
\end{tabular}




\begin{tabular}{|c|c|c|c|c|c|}
\hline \multirow{2}{*}{$\begin{array}{l}\text { Dimensiones } \\
\text { Participación }\end{array}$} & & \multicolumn{2}{|c|}{ Objetiva } & \multicolumn{2}{|c|}{ Subjetiva } \\
\hline & & Diversidad & Frecuencia & Disfrute & Preferencia \\
\hline \multicolumn{6}{|l|}{ Factores } \\
\hline \multicolumn{6}{|l|}{ Comunitarios } \\
\hline \multirow[t]{5}{*}{ Físicos } & Medios y & niveles más altos & niveles más altos & & \\
\hline & Servicios & a más poyos y & a más poyos y & & \\
\hline & materiales & $\begin{array}{l}\text { recursos, Facili- } \\
\text { tador }\end{array}$ & $\begin{array}{l}\text { recursos, Facili- } \\
\text { tador }\end{array}$ & & \\
\hline & Tipo de cen- & niveles más altos & niveles más altos & & \\
\hline & tro educativo & $\begin{array}{l}\text { en centro edu- } \\
\text { cativo ordinario, } \\
\text { Facilitador }\end{array}$ & $\begin{array}{l}\text { en centro educa- } \\
\text { tivo específico, } \\
\text { Facilitador }\end{array}$ & & \\
\hline \multirow[t]{10}{*}{ Sociales } & Interacción & niveles más altos & niveles más altos & niveles más & niveles más \\
\hline & Social & $\begin{array}{l}\text { a más interac- } \\
\text { ción, Facilitador }\end{array}$ & $\begin{array}{l}\text { a más interac- } \\
\text { ción, Facilitador }\end{array}$ & $\begin{array}{l}\text { altos a más } \\
\text { interacción, } \\
\text { Facilitador }\end{array}$ & $\begin{array}{l}\text { altos a más } \\
\text { interacción, } \\
\text { Facilitador }\end{array}$ \\
\hline & $\begin{array}{l}\text { Mensajes } \\
\text { sociales }\end{array}$ & $\begin{array}{l}\text { niveles más bajos } \\
\text { con mensajes ne- } \\
\text { gativos, Barrera }\end{array}$ & & & $\begin{array}{l}\text { mensajes ne- } \\
\text { gativos afectan } \\
\text { a las preferen- } \\
\text { cias, Barrera }\end{array}$ \\
\hline & Falta de & disminución & disminución & & \\
\hline & oportunida- & a mayores & a mayores & & \\
\hline & des sociales & limitaciones & limitaciones & & \\
\hline & & para el acceso y & para el acceso y & & \\
\hline & & disponibilidad & disponibilidad & & \\
\hline & & de recursos, & de recursos & & \\
\hline & & Barrera & Barrera & & \\
\hline \multirow[t]{13}{*}{ Actitudinales } & Actitudes & Barrera & & Barrera & Barrera \\
\hline & sociales & & & & \\
\hline & negativas & & & & \\
\hline & Menor & menor partici- & menor partici- & más actitudes & \\
\hline & formación & pación escolar, & pación escolar, & negativas de & \\
\hline & docente para & Barrera & Barrera & los iguales, & \\
\hline & la atención a & & & Barrera & \\
\hline & la diversidad & & & & \\
\hline & Actitudes & menores niveles & menores niveles & & \\
\hline & culturales & con actitudes & con actitudes & & \\
\hline & hacia la & conservadoras y & conservadoras y & & \\
\hline & diversidad & discriminantes, & discriminantes, & & \\
\hline & & Barreras & Barreras & & \\
\hline
\end{tabular}

Nota. Elaborada a partir de Almqvist et al., 2006; Badia et al., 2013; Bult et al., 2011; Bult et al., 2014; Engel-Yeger et al., 2009; Orlin et al., 2010; Shikako-Thomas et al., 2012; Van Naarden Braun et al., 2006. 
Los resultados personales significativos en calidad de vida y participación están íntimamente relacionados a las oportunidades para que los niños en general, y aquellos con necesidades especiales en particular, expresen su percepción acerca del disfrute y preferencia hacia la realización de actividades diversas en su tiempo libre (Bult et al., 2011; Bult et al., 2014). Según los hallazgos, dar oportunidades para la participación en actividades significativas y adaptadas a las habilidades y preferencias de cada niño fomenta su crecimiento saludable y calidad de vida (Almqvist et al., 2006; ShikakoThomas et al., 2012).

A este respecto, no sólo las familias, sino también los poderes públicos y administraciones encargadas de implementar las políticas infantiles a nivel local, tienen un papel central en la prevención de riesgos y fomento de oportunidades para el desarrollo saludable y satisfactorio de la infancia, especialmente en aquellos casos o colectivos que por las características de su ambiente ven coartadas sus oportunidades para exponerse a situaciones de ocio diversas junto a sus iguales con entornos de desarrollo más favorables. Sin embargo, mientras que a nivel político y estatal siga sin garantizarse el acceso y disponibilidad al tiempo libre, la participación en grupos de iguales permanecerá limitada al ámbito de la educación formal y la realización de actividades de ocio seguirá estando restringido por criterios desiguales de admisión, franjas etarias, precios de las actividades, etc. Estos factores ambientales seguirán condicionando la participación inclusiva en actividades realizadas durante el tiempo libre, la realización de actividades diversas en grupo heterogéneos y el aprendizaje significativo y satisfactorio de los menores. Además, la ausencia de recursos enfocados al ocio educativo hace también que niños y adolescentes con mayores barreras para la participación pasen parte de su tiempo libre en soledad realizando actividades pasivas, tales como, ver la televisión, jugando a videojuegos o alguna otra actividad con aparatos tecnológicos, ocasionando contextos de ocio cada vez más individualizados.

Las diferencias significativas halladas en investigación en participación de niños y jóvenes con necesidades especiales y sin ellas destacadas en 
este capítulo (Badia et al., 2013; Engel-Yeger et al., 2009; Fauconnier et al., 2009; Noreau et al., 2007), acentúan aún más si cabe, la necesidad imperante de incluir a aquellos alumnos con necesidades específicas en los diferentes ámbitos sociales donde se dan las oportunidades a niños y jóvenes de experimentar y tener éxito en la participación de actividades diversas. De esta forma, dada la naturaleza del fenómeno, la participación en actividades de ocio se presenta como una estrategia de calidad para el sistema educativo. La participación de ocio en el ámbito educativo es capaz de ofrecer respuestas adecuadas a niños y jóvenes con y sin necesidades específicas, posibilitando situaciones para el aprendizaje y logro de resultados personales significativos (Bult et al., 2014; Ditterline y Oakland, 2009; Engel-Yeger et al., 2010; Kantomaa, 2011; Wikes et al., 2011). Mientras que, junto al modelo de calidad de vida (Schalock et al., 2002, 2003), la participación tiene el potencial de favorecer el crecimiento integral, positivo y saludable de todos los niños, siendo especialmente relevante su aplicación en aquellos con necesidades especiales.

La manera de implementar la participación en actividades de ocio diversas de niños con y sin necesidades especiales, es mediante la provisión de apoyos individualizados que favorezcan el acceso y disponibilidad de todos los recursos y oportunidades existentes en el entorno próximo. Así, la movilización de recursos y apoyos sociales promueve la asistencia y desempeño óptimo de todos los niños con independencia de las capacidades, características personales y variables ambientales presentes en el entorno de cada niño (Booth y Ainscow, 2002, 2015; Bøttcher et al., 2013; DfEs, 2004; Wehmeyer, 2009).

\subsection{Conclusiones}

El recorrido teórico realizado a lo largo de este capítulo sobre el desarrollo conceptual y operativo del constructo de participación en actividades de ocio y tiempo libre nos ofrece una visión de la participación infantil multidimensional, formada por elementos de carácter objetivo tales 
como la frecuencia y diversidad de la asistencia a actividades diversas, y de carácter subjetivo referidos a la intensidad de la participación, que define la experiencia misma de participación mediante una serie de factores personales intrínsecos (Almqvist et al., 2005; Bult et al., 2014; Clarke et al., 2011; Imms et al., 2016a; King et al., 2013; Maxwell, 2012).

Según la literatura analizada, tanto la asistencia, como la intensidad de la participación, están fuertemente determinadas por factores personales y ambientales presentes en el contexto específico donde tienen lugar la experiencia de participación (Coster et al., 2012; Eriksson, 2005; Eriksson et al., 2007). Esta influencia se produce a través de las características del entorno personal, físico, social y actitudinal en el que tiene lugar la participación, otorgando al contexto un papel facilitador u obstaculizador para la participación infantil en actividades diversas. La influencia y peso de las diferentes características personales y variables ambientales detectadas por la investigación han sido presentadas en el apartado 3.1 y Tabla 9 de este capítulo. El análisis de estos factores se ha llevado a cabo a partir de diferentes instrumentos de medida (Tabla 8) que valoran la participación infantil desde los enfoques multidimensional (OMS, 2001, 2007) y socioecológico de interacción persona-ambiente (Bronfenbrenner, 1979, 2002; 1992) defendidos a lo largo de este trabajo.

Entre todas las herramientas analizadas destaca el Children's Assessment of Participation and Enjoyment: CAPE (King et al., 2004) por su cobertura teórica y empírica para la medida de la participación infantil en actividades de ocio y tiempo libre. El CAPE evalúa la experiencia objetiva y subjetiva de la participación de ocio en contextos diversos, a través de la información proporcionada por los propios niños y jóvenes con y sin necesidades especiales. Su extenso uso en contextos diverso a nivel mundial la ha convertido en una medida transcultural de reconocido impacto científico. La versión española presenta propiedades psicométricas adecuadas (Longo et al., 2012), además de su asociación significativa con el constructo de calidad de vida (Badia et al., 2013) presentado en el capítulo anterior. Por ello, para el desarrollo de esta investigación hemos seleccionado el CAPE para la evaluación de la 
participación en actividades de ocio y tiempo libre de alumnos de Primaria con necesidades específicas de apoyo educativo y sin ellas en el análisis de los factores determinantes de su calidad de vida infantil, con la finalidad de detectar patrones específicos de participación en contextos particulares (King, 2013; Shields et al., 2015), que permitan establecer con precisión la interacción, el papel y el peso que las diferentes variables estudiadas en esta investigación juega en el desarrollo infantil positivo.

El modelo de participación infantil presentado en este trabajo defiende la participación en contextos lúdicos y de ocio como un posible factor protector capaz de mitigar los riesgos comportamentales y psicopatológicos, que nacen de la incongruencia entre el desarrollo personal del niño con necesidades educativas y las demandas y expectativas de los entornos en los que el participa (Bøttcher et al., 2013). El modelo se enfoca a la promoción de los factores personales y ambientales con capacidad de apoyar y facilitar resultados personales significativos de participación (King et al., 2003), satisfacción y bienestar en las diferentes áreas de vida en las que el niño se desarrolla (Adolfsson et al., 2011; Badia et al., 2013; Dahan-Oliel et al., 2012; Schreuer et al, 2014). Sin embargo, no hay que perder de vista que fomentar un crecimiento sano no sólo implica promover características saludables, sino también disminuir aquellos factores que impiden al niño alcanzar el máximo potencial dentro de cada fase de su desarrollo (Rodríguez, Pérez, Gázquez y Rodríguez, 2013). En esta línea emerge el paradigma de resiliencia, el cual permite analizar los factores de riesgo y protección que intervienen en la interacción del niño con su entorno y dan lugar a diferencias en los resultados personales de participación (King et al., 2003) y calidad de vida (Ungar, 2012).

En el siguiente capítulo se acomete el desarrollo conceptual y empírico del constructo de resiliencia, en el que analizaremos su relación con la percepción que tienen los niños de su calidad de vida y participación en actividades diversas, así como su aplicabilidad e implicación para la práctica con niños con y sin NEAE. 

Capítulo 4

Conceptualización de Resiliencia Infantil 



\section{Conceptualización de Resiliencia Infantil}

\section{Introducción}

El creciente énfasis en la compresión sistémica de las influencias sociales sobre el bienestar del niño (Boothby, Strang y Wessells, 2006; Reed, Fazel, Jones, Panter-Brick y Stein, 2012) y en el potencial impacto de las políticas y las prácticas sobre su salud, bienestar y calidad de vida (Ager, 2013; UNICEF, 2011), ha generado en el campo de la investigación el desafío de desarrollar teorías cada vez más complejas capaces de clarificar y dar respuesta al desarrollo positivo de niños inmersos en sociedades diversas desde el punto de vista étnico, racial, social y personal (Luthar y Cicchetti, 2000a; Ungar, 2008, Windle, 2011). Este reto ha dirigido a una parte de los profesionales comprometidos con la salud pública y la política social a impulsar el crecimiento positivo de niños en circunstancias de vida adversas, lo que teóricamente se ha nombrado como resiliencia, desde el ámbito del misterio a un enfoque de salud y acción ciudadana basado en la evidencia científica (Khanlou y Wray, 2014).

Los orígenes del concepto de resiliencia se remontan a estudios realizados en los años 60 y 70 del siglo pasado realizados desde el campo de la psicopatología del desarrollo con jóvenes expuestos a circunstancias de adversidad significativa (Werner, 1971). En estos trabajos longitudinales los investigadores observaron cómo un porcentaje alto e inesperado de niños pertenecientes a poblaciones típicamente definidas de riesgo, mostraban resultados positivos de salud física y mental pese a la presencia de múltiples variables de tipo estructural, familiar e individual de valencia negativa (Werner; 1992; Werner y Smith, 1982, 2004). En aras de descifrar la naturaleza y funcionalidad de tales resultados y predecir su ocurrencia en la edad adulta, la investigación se centró en el estudio de poblaciones de niños y jóvenes en condiciones de riesgo. Se exploró el funcionamiento infantil en múltiples circunstancias adversas, tales como, niños institucionalizados, expuestos a entornos de guerra o económicamente en desventaja (Garmezy, 1983; Garmezy, Maten y Tellegen, 1984), problemas crónicos de salud (Well 
y Schwebel, 1987), enfermedad mental de los padres (Masten y Coatsworth, 1998), maltrato (Beeghly y Cicchetti, 1994), eventos catastróficos (O’Dougherty-Wright, Masten, Northwood y Hubbard, 1997) y pobreza urbana y violencia (Luthar, 1999). Más recientemente la investigación se ha centrado en la adaptación positiva de niños afectados por situaciones de guerra, niños emancipados y niños víctimas de violencia (Barber, 2008, Holt, Buckley, Whelan, 2008; Liebel, 2004; Panter-Brick, 2002, Taylor, 2005).

En el transcurso de este tiempo, las definiciones del término han sido numerosas, también la investigación realizada desde múltiples disciplinas y niveles de análisis (Luthar, Cicchetti, y Becker 2000b, Prince-Embury y Saklofske, 2013). Mientras que algunos investigadores han asumido que la resiliencia está localizada dentro de la persona (Block y Block, 1980; Davidson et al., 2005), otros han propuesto múltiples fuentes y vías para su ocurrencia incluyendo diferentes niveles del contexto social en los que el niño se desarrolla (Luthar, et al., 2000b; Luthar et al., 1991; Masten 2001, Masten Best y Garmezy, 1991; Ungar, 2004; Werner et al., 1992). El debate científico acerca de si representa un rasgo, un proceso o un resultado, si es una variable global o específica a una situación dada, si es necesaria la adversidad para su representación y, en tal caso, qué tipo de adversidad se requiere para su demostración, ha generado una divergencia de enfoques respecto a la definición, criterios y estándares de resiliencia, que han dificultado su conceptualización, medida y aplicación hasta la actualidad (Ungar, 2015a).

En las últimas décadas, la investigación sobre resiliencia ha crecido exponencialmente. Una sencilla revisión de la literatura científica realizada por Fergus y Zimmerman (2005) en PubMed utilizando las palabras claves "adolescencia", "adolescente", "resiliencia", "resiliente" y "factores protectores" encontró: cuarenta y nueve citas de 1975 a 1984, doscientas seis de 1985 a 1994, y setecientas cincuenta y seis de 1995 a 2004. Esta plétora de estudios ha llevado en los últimos años a la exigencia científica de aclarar cómo definimos la resiliencia, cuáles son sus determinantes más importantes, cómo contribuyen a su comprensión diferentes metodologías y, cuáles son las maneras más efectivas de tratarla (Phelps et al., 2007; 
Skinner, Matthews, y Burton, 2005; Southwick, Bonanno, Masten, PanterBrick, y Yehuda, 2014; Zolkoski y Bullock, 2012). Los resultados de estos trabajos están contribuyendo sustancialmente al estudio de la resiliencia. Desde exhaustivas revisiones sistemáticas para dilucidar los antecedentes, consecuencias y atributos esenciales del concepto (Khanlou et al., 2014; Luthar et al., 2000b; Windle, 2011), a la construcción de herramientas de evaluación (Connor y Davidson, 2003; Hurtes y Allen, 2001; Ungar et al., 2011) y la aplicabilidad del constructo en población infantil y juvenil en contextos específicos (Fergus et al., 2005; Grotberg, 1995), como los niños con necesidades especiales en sus entornos cotidianos (familia, escuela, comunidad, por ejemplo) (Ungar, 2015a). Pese a todos estos esfuerzos, sigue abierto el debate acerca de si la resiliencia es un concepto útil o tautológico (Friedman, 2005; Ungar, 2011).

\subsection{Desarrollo Conceptual del Constructo de Resiliencia}

Desde la definición de resiliencia psicológica propuesta por Rutter (1987) como el papel positivo de las diferencias individuales en la respuesta de las personas a circunstancias de vida de estrés y adversidad, gran parte de la investigación posterior se ha centrado en el análisis de la interacción de factores protectores y de riesgo en poblaciones juveniles en situaciones potenciales de adversidad (Prince-Embury, 2014). La mayoría de las definiciones aceptan la resiliencia como la capacidad de sobrellevar la adversidad o recuperarse ante experiencias negativas, centrándose en las fortalezas en vez de los déficits para la descripción de perfiles de desarrollo saludable (Fergus et al., 2005; Southwick et al., 2014). Sin embargo, a pesar del desarrollo vertiginoso de la investigación de las últimas décadas y la creciente frecuencia del uso del término resiliencia, aún hoy hay una sorprendente falta de consenso y claridad en el significado e implicaciones de la palabra (Ager, 2013).

Como se aprecia en la Tabla 10, la mayoría de las definiciones propuestas tienen el reconocimiento subyacente a un elemento común, la presencia de adaptación, riesgo, adversidad o desafío (Khanlou et al., 2014). Más 
concretamente, Wald, Taylor, Asmundson, Jang y Stapleton (2006) en una revisión sobre el concepto destacaron que en la mayoría de los casos estas definiciones comparten una serie de características relacionadas con las fortalezas humanas, algún tipo de perturbación y crecimiento tras la exposición a la adversidad. Así como, una serie de distinciones en el intento de definir su construcción (Ungar, 2015a), como la aportada de Luthar y colaboradores (2000b) al distinguir la resiliencia como un proceso dinámico de desarrollo que implica la interacción de atributos personales con circunstancias ambientales, frente a la concepción de resiliencia como un mero rasgo característico de ciertas persona (Block et al., 1980).

Tabla 10. Definiciones de ResilienciaVV.AA.

\begin{tabular}{|c|c|}
\hline Autor/es y año & Definición \\
\hline $\begin{array}{l}\text { American Psycho- } \\
\text { logical Association } \\
(2014)\end{array}$ & $\begin{array}{l}\text { El proceso de adaptarse positivamente a la adversidad, trauma, tragedia, } \\
\text { amenazas o incluso fuentes importantes de estrés, tales como, problemas fa- } \\
\text { miliares o relacionales, serios problemas de salud, estrés laboral o financiero. }\end{array}$ \\
\hline $\begin{array}{l}\text { Connor et al. } \\
(2003)\end{array}$ & $\begin{array}{l}\text { La resiliencia encarna las cualidades personales que permiten prosperar fren- } \\
\text { te a la adversidad }[\ldots] \text {. La resiliencia es una característica multidimensional } \\
\text { que varía con el contexto, el tiempo, la edad, el género y el origen cultural, } \\
\text { así como dentro de un individuo sometido a diferentes circunstancias de } \\
\text { vida. }\end{array}$ \\
\hline Windle (2011) & $\begin{array}{l}\text { Resiliencia es el proceso de negociación efectiva, adaptación o manejo } \\
\text { fuentes significativas de estrés o trauma. Los recursos internos del individuo, } \\
\text { su vida y su ambiente facilitan esta capacidad de adaptación y "recuperación” } \\
\text { frente a la adversidad. A través del curso de la vida, la experiencia de la } \\
\text { resiliencia variará. }\end{array}$ \\
\hline $\begin{array}{l}\text { Luthar et al. } \\
\text { (2000b) }\end{array}$ & $\begin{array}{l}\text { La resiliencia es un proceso dinámico en el que los individuos muestran una } \\
\text { adaptación positiva a pesar de experiencias significativas de adversidad y } \\
\text { trauma. Este término no representa un rasgo de personalidad o un atributo } \\
\text { del individuo [...]. Más bien, es un constructo bidimensional que implica } \\
\text { exposición a la adversidad y la manifestación de resultados de ajuste positivo. }\end{array}$ \\
\hline Masten (2001) & $\begin{array}{l}\text { La resiliencia se refiere a una clase de fenómenos caracterizados por buenos } \\
\text { resultados a pesar de serias amenazas para la adaptación o el desarrollo. }\end{array}$ \\
\hline $\begin{array}{l}\text { OMS (Friedli, } \\
\text { 2009) }\end{array}$ & $\begin{array}{l}\text { La resiliencia es un fenómeno que concierne a la adaptación positiva del indi- } \\
\text { viduo mediante factores de protección y activos moderadores de los factores } \\
\text { de riesgo, que reducen el impacto de resultados de riesgo en las vidas de las } \\
\text { personas. }\end{array}$ \\
\hline $\begin{array}{l}\text { Richardson } \\
(2002)\end{array}$ & $\begin{array}{l}\text { El proceso de hacer frente a factores de estrés, adversidad, cambio u opor- } \\
\text { tunidad de una manera que resulta en la identificación, fortalecimiento y } \\
\text { enriquecimiento de cualidades "resilientes" o procesos protectores. }\end{array}$ \\
\hline
\end{tabular}




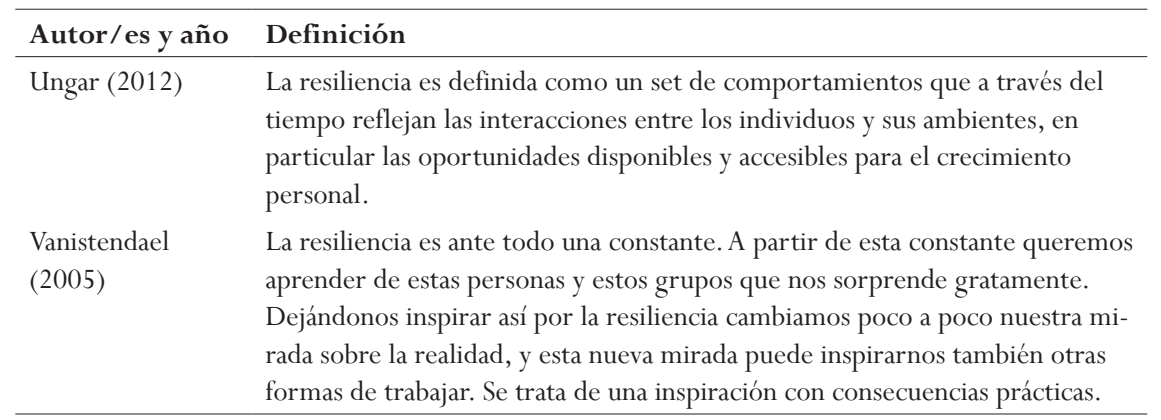

Con el fin de aclarar la esencia conceptual de la resiliencia, en los últimos años, la comunidad científica especializada ha realizado una serie de revisiones sistemáticas del constructo tratando de determinar sus antecedentes, consecuencias y atributos esenciales (Fletcher y Sarkar, 2013; Lee, Cheung y Kwong, 2012; Luthar y Zelazo, 2003; Ungar, 2011; Windle, 2011).

\subsubsection{Antecedentes y Consecuentes de la Resiliencia}

El principal antecedente considerado por la literatura es la adversidad, mientras que su consecuencia más destacada la adaptación positiva. A continuación se desarrollan ambos conceptos.

\subsubsection{La Adversidad}

En la investigación sobre resiliencia, adversidad hace referencia al riesgo. Para Panter-Brick, Eggerman y Tomlinson (2014), el riesgo es tanto una noción estadística como una categorización social. La noción estadística del riesgo conduce a buscar factores asociados y asignar individuos a grupos sociales de bajo y alto riesgo, haciendo alusión por tanto a poblaciones y no a individuos particulares (Panter-Brick y Fuentes, 2010). Cabe destacar que, en teoría de la resiliencia, los factores de riesgo se conciben como variables contingentes cuyos valores están sometidos al tiempo y lugar en el que acontecen (Polk, 1997). 
En relación a la adversidad, Luthar y colaboradores (2000a) defendieron que ésta abarca típicamente circunstancias negativas de la vida que estadísticamente se asocian con dificultades de ajuste. En la mayoría de los casos las adversidades que se van presentando no constituyen mayores desastres, sino riesgos o desafíos comunes a los que van respondiendo las personas en sus vidas cotidianas (Davis, Luecken y Lemery-Chalfant, 2009). Pero, en ocasiones, la suma de un número considerado de riesgos ocasiona situaciones de adversidad fuertes que requieren la puesta en marcha de procesos dinámicos en respuesta al estrés intenso ocasionado (Davydov, Stewart, Ritchie y Chaudieu, 2010). De esta forma, cuando la adversidad se define como un evento que predice desajuste en el funcionamiento humano, presumiblemente se ponen en marcha procesos de resiliencia para la adaptación positiva de la persona a tales circunstancias vitales.

Por otra parte, dado que la percepción de riesgo para una persona en un contexto adverso puede amplificar o atenuar la angustia subjetiva, Khanlou y colaboradores (2014) han acuñado el término vulnerabilidad diferencial para referirse a diferentes grados de afección experimentados por distintas personas expuestas a determinadas circunstancias de vida potencialmente adversas. Por tanto, para valorar la potencialidad del riesgo es importante tener en cuenta tanto su medida objetiva (limitaciones en el funcionamiento, por ejemplo), como subjetiva (percepción de discapacidad, por ejemplo). Según Windle (2011), la naturaleza de la relación riesgo-adversidad puede ser usada en investigación aplicada para guiar la fuerza de la resiliencia.

\subsubsection{La Adaptación Positiva}

La adaptación positiva ha sido definida como la competencia social manifestada comportamentalmente, o el éxito en el cumplimiento de las tareas típicas de desarrollo humano (Luthar et al., 2000a). A este respecto, Ungar y colaboradores (2011) han declarado que muy comúnmente la investigación sobre resiliencia ha definido la adaptación positiva desde un discurso psicológico occidental con énfasis en las capacidades individuales 
y relacionales, como el éxito académico o relaciones saludables, careciendo de sensibilidad a la variabilidad cultural y los factores que contextualizan cómo la resiliencia es definida por distintas poblaciones y se manifiesta en diferentes prácticas de sus vidas diarias.

Algunos de los índices utilizados por la investigación en resiliencia para valorar la adaptación positiva han sido las competencias mostradas por los niños ante ciertas situaciones, o la ausencia de desajustes emocionales o comportamentales (Luthar et al., 2000a; Rutter, 1999). Esto conlleva que a menudo las explicaciones teóricas de la resiliencia encapsulan otras construcciones psicosociales que se superponen con la noción de resiliencia, tales como, la vulnerabilidad, el ajuste positivo, la competencia o la autoeficacia. Para más información sobre el nexo y diferencia entre estos constructos y el de resiliencia puede consultarse el trabajo de Prince-Embury (2014), entre otros trabajos citados en este texto.

\subsubsection{Atributos}

Con respecto a sus atributos, a lo largo de su evolución conceptual la resiliencia ha ido cambiando progresivamente las propiedades que definen su constructo, siendo concebida en un principio como un rasgo de personalidad, posteriormente como un conjunto de características personales, un proceso dinámico entre características personales y variables ambientales, hasta su versión actual más amplia que la conceptualiza desde un enfoque sistémico (Tempski et al., 2015). La complejidad de la teoría de la resiliencia ha sido explicada por Luthar y Brown (2007) por la presencia de dos atributos principales: 1) se aplica para comprender e intervenir en poblaciones en riesgo en pos de su bienestar; 2) utiliza los conocimientos y métodos de diversas disciplinas.

Para una mayor comprensión de esta evolución teórica haremos un repaso por las diferentes etapas de estudio a través de las cuales ha evolucionado el concepto de resiliencia. Masten y Wright (2009) describen cuatro etapas en la investigación, realizadas principalmente por investigadores del desarrollo 
que han abordado el estudio del constructo desde diferentes perspectivas a través del tiempo.

\subsubsection{Primera Etapa de Investigación}

En un primer momento la investigación fue de exploración y descripción del concepto. Desde una aproximación psicológica los investigadores trataban de capturar las medidas de resiliencia en diferentes situaciones adversas e identificar las características personales que daban lugar a resultados de éxito (Gramezy, 1983; Rutter, 1987; Werner et al., 1982). A raíz de los hallazgos con poblaciones de jóvenes en riesgo, Rutter (1987) y otros investigadores (Baldwin et al., 1993; Brooks, 1994; Luthar y Zigler., 1991, 1992) definieron la resiliencia desde un enfoque psicológico e individual, sin atender en un principio a influencias ambientales. Los hallazgos de éstas y otras investigaciones dieron lugar a un listado de factores personales que hipotéticamente actuaban como protectores del riesgo y promocionaban el desarrollo de la resiliencia psicológica. Entre las cualidades personales más destacadas por la literatura de aquel tiempo se encuentran: las habilidades intelectuales (Baldwin et al., 1993; Brooks, 1994; Jacelon, 1997; Luthar et al., 1991, 1992; Masten et al., 1998; Rutter, 1987; Wolff, 1995; Wright et al., 1997); el buen temperamento (Jacelon, 1997; Luthar et al., 1991; Werner et al., 1982; Wright et al., 1997; Wyman et al., 1992); la autonomía (Werner et al., 1982); la independencia (Polk, 1997); la sociabilidad (Brooks, 1994); las estrategias de afrontamiento efectivas (Brooks, 1994; Jacelon, 1997; Luthar et al., 1991); y las habilidades de comunicación (Werner et al., 1982).

Las evidencias de esta primera etapa de estudio parecía implicar que los individuos resilientes eran extraordinarios y que la resiliencia se presentaba como una característica personal que no era accesible a todas las personas (Price-Embury, 2014), siendo fácil suponer que la habilidades cognitivas serían una fortaleza interna de la persona, mientras la discapacidad intelectual un rasgo de vulnerabilidad ante situaciones de adversidad (Ungar, 2012). 


\subsubsection{Segunda Etapa de Investigación}

A medida que la investigación avanzaba se hacía más evidente la influencia del ambiente social en los resultados personales en resiliencia. Los investigadores comenzaron a identificar variables del entorno cercano con capacidad para actuar como factores protectores del desarrollo positivo ante adversidad. Estos factores incluían en mayor medida variables del entorno familiar como el afecto, la cohesión o la estructura familiar, el apoyo emocional, los estilos positivos de apego y la existencia de al menos una figura segura o cuidador cercano (Baldwin et al., 1993; Brooks, 1994; Garmezy, 1991; Luthar et al., 1991; Masten et al., 1998; Rutter, 1987; Werner et al., 1982; Wolff, 1995; Wright et al., 1997, Wyman et al., 1992). Así como, variables ambientales del contexto próximo a la familia como experiencias escolares positivas (Brooks, 2006; Rutter, 1987; Werner et al., 1982; Wright et al., 1997), relaciones positivas con iguales (Cowen y Work, 1988; Werner et al., 1982; Wright et al., 1997) y con otros adultos (Brooks, 1994; Garmezy, 1991; Werner et al., 2004; Wright et al., 1997).

El número creciente de factores identificados llevó a su agrupación en tres grandes áreas de estudio: 1) atributos personales, 2) factores familiares, y 3) características de los entornos sociales cercanos (Luthar et al., 2000b). Los factores protectores también fueron denominados como activos o recursos (Prince-Embury, 2014). Los activos hacían referencia a factores positivos que residían en el individuo (la autoeficacia, por ejemplo), mientras que los recursos incluían factores ambientales, como el apoyo familiar, que promovían el desarrollo positivo de los jóvenes (Fergus et al., 2005). En contraste a los factores protectores que influenciaban resultados de desarrollo positivos se encontraban las variables ligadas a la adversidad, los factores de riesgo (Polk, 1997).

El hallazgo de diferencias en los resultados asociados a unos y otros factores dependiendo de las características de los contextos adversos en los que se evaluaban, llevó en la década de los 90 a un cambio en el foco de estudio sobre resiliencia. En estos años, se pasó de identificar factores aislados con capacidad de incidir en los resultados de desarrollo y funcionamiento 
humano, a explorar los procesos subyacentes mediante los cuales los niños superaban la adversidad que experimentaban en sus vidas (Flecher et al., 2013; Luthar, et al., 2000a). Los investigadores se orientaron entonces a la búsqueda y descripción de mecanismos de protección que explicaran los patrones divergentes de crecimiento infantil frente a diferentes contextos de adversidad.

Al examinar las relaciones multivariadas entre factores de riesgo, factores de protección y resultados en desarrollo, los investigadores encontraron tres mecanismos que explicaban los patrones divergentes de crecimiento: el modelo compensatorio, el modelo de protección y el modelo de exposición. Se explican a continuación.

\subsection{Modelo Compensatorio}

Este modelo analiza la contribución independiente de los factores de riesgos y los factores protectores (activos y recursos) a los resultados de desarrollo. A partir de análisis estadísticos como la regresión múltiple y los modelos de ecuaciones estructurales, los investigadores examinaron los efectos principales de estas variables y observaron cómo los recursos que tienen efectos directos pueden ser beneficiosos en condiciones de alto y bajo riesgo (Windle, 2011). Una personalidad extrovertida puede ser considerada como un activo interno útil independientemente de la exposición o no a situaciones de riesgo, por ejemplo. Los factores de este modelo fueron denominados factores promotores.

\subsection{Modelo de Protección}

El modelo de protección describe cómo la presencia de uno o varios factores protectores (activos o recursos) influyen en la dirección y fuerza del riesgo. Estos factores son representados como reguladores o reductores de los efectos de riesgo en los resultados de desarrollo (Windle, 2011). Los factores protectores son comúnmente probados a través de modelos de regresión múltiple y son importantes para explicar la resiliencia en estudios longitudinales que analizan 
las trayectorias de desarrollo saludable ante circunstancias de adversidad crónica (discapacidad, minorías raciales, desventajas socioeconómicas, etc.).

\subsection{Modelo de Exposición}

Este modelo describe la relación curvilínea entre los factores de riesgo y los resultados, es decir, como la exposición a niveles bajos y altos de riesgo se asocia a resultados negativos, mientras que los niveles de exposición moderados conllevan a ganancias en los resultados de desarrollo (Ungar, 2011). En este modelo, los procesos de resiliencia depende del nivel de exposición al riesgo y los factores que intervienen en él son denominados factores moderadores (Fletcher et al., 2013). Un ejemplo de mecanismo moderador de la exposición al riesgo dependiente del estilo educativo familiar es el aumento de la calidad de la enseñanza en preescolar (Hall et al., 2009; Sylva, 2000). De esta forma, la calidad de la enseñanza actúa como predictor positivo de las variaciones en el progreso de la capacidad de los niños durante la primera etapa escolar (Hall et al., 2009). Sin embargo, esta misma variable (la calidad de la enseñanza en preescolar), no tiene el mismo efecto moderador cuando hay otros factores de riesgo con mayor influencia, como son las desventajas socioeconómicas, cuando se analiza el funcionamiento de los niños en etapas escolares posteriores (Schoon, 2006). Lo que sugiere que, a pesar de los beneficios de la atención temprana, estas intervenciones no son capaces por si solas de proteger contra los efectos negativos de otras variables con mayor influencia en etapas posteriores del desarrollo (Windle, 2011).

El enfoque ecológico (Bronfenbrenner, 1979, 2002) comienza a surgir en este periodo como una perspectiva útil para la consideración de la resiliencia, tornándose en poco tiempo fundamental para la elaboración de su constructo. Desde este nuevo prisma, la resiliencia se define como un producto de la interacción de distintos factores de riesgo y protección a nivel individual, familiar y social (Masten, 2001), y su modelo teórico incorpora una compresión más compleja de cómo los factores individuales y los factores sociales interactúan para dar forma a la agencia personal y a las oportunidades 
estructurales presentes en los ambientes donde se produce la interacción dinámica entre la persona y su entorno (Lynam, De Jong, Sheil, Kusumanto, y Evans, 2007; Panter-Brick, 2014). Desde la perspectiva de la complejidad los investigadores observan, por ejemplo, que lo contrario de la influencia positiva de tener un amigo para la resiliencia del niño no es necesariamente no tenerlo, ni que la participación en actividades extraescolares o en la comunidad se relaciona directamente con resultados positivos en desarrollo, mientras que no participar conlleva un riesgo para la salud o funcionamiento del niño (Fergus et al., 2005). Evidencias como éstas llevan a los expertos a plantearse qué es un resultado positivo en resiliencia (Khanlou et al., 2014; Ungar, 2004).

En definitiva, esta segunda etapa refleja un incremento de la sofisticación del concepto y su medida, enfatizando su conceptualización como proceso dinámico en lugar de rasgos o eventos dados en un momento concreto del tiempo. La ampliación y profundización de esta perspectiva fue creciendo cada vez más y haciendo más evidente la necesidad de pasar a la acción a través de intervenciones dirigidas desde las evidencias científicas disponibles (Khanlou et al., 2014).

\subsubsection{Tercera Etapa de Investigación}

Consolidada dentro de un marco ecológico (Bronfenbrenner, 1979, 2002) la resiliencia evoluciona desde el enfoque psicológico clásico de las primeras etapas a perspectivas más sociales, tales como, las aproximaciones interaccionista, construccionista o transaccional. A partir de las aportaciones de estos nuevos enfoques sociológicos, actualmente la resiliencia se entiende como el resultado de las negociaciones entre los individuos y sus ambientes (Ungar, 2004) que determinan trayectorias de vida que son significativas para las personas (Ungar, 2011). Para los investigadores de esta nueva fase el alcance de la teoría de la resiliencia deriva de la comprensión de aquellas interacciones recíprocas entre el individuo y su ambiente, que tienen la cualidad de dar como resultado el ajuste entre la persona y su entorno (Ungar, 2012). 
Bajo las nuevas aproximaciones de corte sociológico los investigadores observan las variadas influencias que se establecen entre los factores de riesgo y los factores protectores en las vidas de los jóvenes (Gutman, Sameroff y Eccles, 2002; Luthar et al., 2000b; Olsson, Bond, Burns, VellaBrodrick y Sawyer, 2003; Sameroff, Gutman y Peck, 2003; Serbin y Karp, 2004). Estos procesos de interacción dan lugar a efectos cascada de riesgos y factores de protección en los que factores determinantes asociados a la resiliencia pueden ser resultados o predictores, dependiendo de la situación y el momento en el que se evalúa la resiliencia de la persona (Masten y Powell, 2003). Estas evidencias hacen que el estudio teórico de la resiliencia se torne un laberinto de relaciones multivariadas, que desafía el ingenio y la agudeza de los investigadores en la elaboración de modelos heurísticos que respondan a la complejidad de su constructo. Según Fergus et al., (2005), para la comprensión de los mecanismos subyacentes de resiliencia las investigaciones requieren incluir factores acumulativos de riesgo, activos y recursos que deben ser estudiados a través de estudios longitudinales y metodologías innovadoras que capten la naturaleza y funcionalidad de los distintos elementos intervinientes en los procesos de la resiliencia.

Un avance significativo en la conceptualización de la resiliencia es la crecienteadopción de escenarios teóricosque reflejan lainteracción de sistemas adaptativos múltiples (Masten et al., 2003; Panter-Brick et al., 2012). Este nuevo enfoque se deriva del creciente interés en la investigación por la teoría de la complejidad, es decir, el estudio multidisciplinario del funcionamiento de los sistemas biológicos, ecológicos, organizativos, sociales, económicos y la interacción entre ellos, dando lugar a sistemas adaptativos complejos (Forés y Grané; 2012). Desde la teoría de la complejidad, la resiliencia no es sólo el resultado acumulativo de una serie de factores protectores, sino la integración de estos factores en uno o varios sistemas auto-reguladores que influyen en la capacidad para responder al riesgo o adversidad (Ager, 2013). En su estudio sobre comunidades afganas, Eggerman y Panter-Brick (2010) exponen que "no hay salud sin salud mental, salud mental sin unidad familiar, unidad familiar sin trabajo, dignidad y una economía en funcionamiento, ni 
economía sin una buena gobernanza" (p.83), esta idea refleja claramente la implicación de la interacción de sistemas para el desarrollo de la resiliencia.

Aplicada al desarrollo infantil, la idea básica del modelo ecológico de sistemas es que los niños desarrollan sus actividades diarias dentro de ecologías que son habitadas y co-construidas junto otros grupos culturales y sociales (Skinner et al., 2005). Desde esta perspectiva, las características del funcionamiento humano identificadas en los sistemas de desarrollo cotidianos tienen gran importancia adaptativa a través de diversos factores de estrés y situaciones amenazantes (Masten, 2001). Los sistemas protectores presentes durante las distintas etapas y trayectorias de vida incluyen las relaciones de apego y apoyo, habilidades personales para resolver los problemas, destrezas de autorregulación involucradas en dirigir o inhibir la atención, la emoción y la acción, la motivación y la auto-eficacia, la construcción de significados y sentido de coherencia en la vida, así como la influencia activa de las tradiciones históricas y culturales (Masten et al., 2009). El modelo ecosistémico tiene en cuenta tanto los riesgos como las oportunidades ofrecidas al niño durante su desarrollo como resultado de la interacción de factores biológicos, psicológicos, fuerzas sociales y culturales (Skinner et al., 2005). Las oportunidades de desarrollo se encuentran en las relaciones que el niño establece con su entorno, que se definen a través de la estimulación emocional, social y material que es compatible con sus necesidades y capacidades en momentos específicos de sus trayectorias de vida (Garbarino y Ganzel, 2000). De esta forma, Masten et al. (2009) definen la resiliencia como la capacidad de un sistema dinámico para adaptarse con éxito a las situaciones cotidianas y cambiantes de la vida, a través de trayectorias que establecen el funcionamiento saludable de las personas (Southwick et al., 2014).

Todas estas evidencias e innovaciones en el estudio de la resiliencia posibilitan la modificación de la trayectorias de desarrollo saludable, a través de intervenciones con las personas y las circunstancias de vida en la que éstas se encuentran (Ungar, 2015a). Según Ungar (2012), es en las estructuras cercanas a un individuo donde se encuentras las oportunidades de desarrollo 
y, por tanto, donde se forma la capacidad del niño para experimentar la resiliencia ante la adversidad. Los recursos que apoyan los resultados del desarrollo se pueden extraer de todos los dominios: personal, familiar, comunitario, institucional y social. Estos dominios representan sistemas adaptativos discretos, pero conectados. Debido a que están conectados, las intervenciones en un dominio pueden tener influencia en otro, y dado que son adaptativos se auto-regulan desplegando los recursos disponibles para compensar los recursos perdidos (Ager, 2013).

Con respecto a la generalización de la resiliencia, existe una fuerte evidencia de la eficacia de una serie de programas para la mejora de la salud y bienestar social de niños y jóvenes expuestos a circunstancias sociales de alto riesgo (Ungar, 2015a; Fergus et al., 2005). Un ejemplo es el Proyecto de Desarrollo Seattle (Hawkins Kosterman, Catalano, Hill y Abbott, 2005) dirigido a la mejora del funcionamiento en la escuela y la transición al ámbito laboral, así como la promoción de la salud mental, emocional y la reducción de comportamientos de riesgo como el consumo de sustancias. El programa ha demostrado que intervenciones globales realizadas durante los grados escolares elementales para fortalecer: 1) las prácticas de enseñanza en las escuelas públicas, 2) las prácticas parentales en las familias urbanas multiétnicas, y, 3) asegurar que los niños tengan las habilidades emocionales y sociales para participar en la vida social de la escuela primaria, tiene efectos positivos significativos sobre el funcionamiento y la salud mental de los niños participantes cuando tienen 21 años (Hawkins et al., 2005). Otros ejemplos de intervenciones para la promoción de la resiliencia son el programa de jóvenes ingeniosos (Shochet et al., 2001), o el programa de ritos de transición para adolescentes y familias (Harvey y Hill, 2004), entre otros.

En suma, la tercera etapa de investigación en resiliencia adopta la teoría de la complejidad para su conceptualización y tiene como foco el desarrollo de programas que buscan promover o aumentar los procesos protectores, a través intervenciones preventivas, así como la evaluación de su eficacia mediante estudios de control aleatorio o métodos cuasi-experimentales (Khanlou et al., 2014). Actualmente, el reto está en encontrar métodos 
eficaces que mejoren la construcción de la resiliencia, basados en la compleja combinación de factores de riesgo y protección que con frecuencia están moderados por factores culturales (Rashid et al., 2014). Estos métodos deben fundamentarse en la actual plataforma de interacción de sistemas y los resultados derivados dirigirse al modelamiento de las políticas públicas para el desarrollo saludable de niños en diversas circunstancias desafiantes de vida (Ager, 2013; Windle, Bennett y Noyes, 2011).

\subsubsection{Cuarta Etapa de Investigación}

Masten (2007) propone una última etapa en investigación sobre resiliencia que muestra el creciente interés por el funcionamiento de los niveles neuronales y psicobiológicos dentro del enfoque eco-sistémico. Frecuentemente estos estudios se centran en analizar la resiliencia a nivel más molecular, es decir, qué procesos interactúan a nivel biológico. Aunque aún es pronto para esta asunción, los hallazgos de esta nueva línea de investigación podrían influenciar el conocimiento de la resiliencia y los comportamientos adaptativos desde áreas tales como la plasticidad neuronal.

Según Ungar (2011), la comprensión de la resiliencia ha pasado de una perspectiva de desarrollo positivo como un milagro cotidiano del niño vulnerable (Master, 2001), a un enfoque más amplio sobre los procesos complejos entre sistemas ambientales que interactúan para fomentar buenos resultados de desarrollo (biológico, psicológico y social, por ejemplo), que son relevantes para la comprensión de los procesos de resiliencia en comunidades culturalmente diversas (Ungar, 2012). El actual paradigma considera a los niños como agentes activos en sus trayectorias de desarrollo, con capacidad de influenciar, afectar y cambiar sustancialmente sus condiciones de vida (Luthar et al., 2000a). El reto actual de la investigación en resiliencia infantil está en dar cuenta simultáneamente del peso que tiene la persona y el ambiente en el mismo modelo explicativo. 
En resumen, actualmente la resiliencia se considera como:

1. Un proceso que depende de las interacciones entre distintos sistemas en los que la persona se desarrolla a lo largo del tiempo,

2. constante, ya que la misma persona pueda estar en diferentes partes del continuo de resiliencia dependiendo de los sistemas de apoyo disponibles y los desafíos enfrentados a lo largo del tiempo,

3. global o específico dependiendo del nivel de análisis, así la resiliencia ante los desafíos puede ser experimentada como un proceso global, aunque en su estudio se presuponen dominios específicos de resiliencia (personal, social, comunitaria, por ejemplo).

En definitiva, más allá de la complejidad que entraña la definición y conceptualización de su constructo (Fergus et al., 2005; Kaplan, 2002, 2005; Luthar et al., 2000b; Prince-Embury, 2014) existe una creciente evidencia sobre la eficacia de las intervenciones centradas en la resiliencia (Adi, Kiloran, Janmohamed y Stewart-Brown, 2007; Prince-Embury et al., 2013; Ungar, 2015b), por lo que adquiere capital importancia llegar a acuerdos sobre qué medir, cómo y cuándo medirlo (Khanlou et al., 2014).

\subsection{Instrumentos para Medir la Resiliencia Infantil}

A pesar de que la adolescencia es el ámbito conceptual de la investigación sobre resiliencia, el desarrollo de su medida se ha orientado más al diseño de instrumentos para población adulta, dirigido desde el ámbito clínico y centrándose con asiduidad en la medida de su componente individual y psicológico (Bartone, 2007; Block y Kremen, 1996; Connor et al., 2003; Friborg Hjemdal, Rosenvinge, y Martinussen 2003; Wagnild y Young, 1993). El desarrollo de instrumentos para operativizar la resiliencia en poblaciones juveniles y contextos sociales más amplios es más reciente y aún requiere mayor validación y evidencia de su utilidad práctica (Constantine y Benard; 2001; Hjemdal, Friborg, Stiles, Martinussen y Rosenvinge, 2006; Hurtes et al., 2001; Prince-Embury, 2006, 2008; Ungar, et al., 2008). 
Por otra parte, son pocos los trabajos científicos llevados a cabo para la revisión de escalas y evaluación de su rigor psicométrico (Ahern, Kiehl, Sole y Byers, 2006; Békaert, Masclet, y Caron 2011; Windle et al., 2011). Entre estos trabajos destaca el realizado por Windle y colaboradores (2011), en el que a partir de una revisión por pares se evalúa la calidad psicométrica de quince instrumentos de resiliencia, de los cuales cuatro han sido desarrollados para su administración en poblaciones de niños o adolescentes: 1) Youth Resiliency Assessing Developmental Strength: ADS-YR (Donnon y Hammond, 2007); 2) The Resiliency Attitudes and Skills Profil: RASP (Hurtes et al., 2001); 3) California healthy Kids Survey- Resilience andYouth Development Module: RYDM (Constantine et al., 2001); y 4) Child y Youth Resilience Measure: CYRM (Ungar et al., 2008). Mientras que, un quinto instrumento se trata de una adaptación a población de jóvenes (a partir de 18 años de edad) de la escala para adultos Connor-Davidson Resilience Scale: CD-RISC (Campbell-Sills y Stein, 2007). Los autores evaluaron las calidad de la medida de las escalas, a través de siete estándares: validez de contenido, consistencia interna, validez de criterio, validez de constructo, fiabilidad test-retest, generalización, reproductividad, sensibilidad, efectos de suelotecho, e interpretabilidad de la medida (Windle et al., 2011). Aunque ninguna de las escalas examinadas cumplía todos los criterios examinados, los autores resaltan la calidad general y potencialidad de la medida de dos de ellas la RISC /CD (Campbell-Sills et al., 2007; Connor et al., 2003) y la CYRM (Ungar et al., 2008). La RISC/CD destaca por la consistencia interna de su medida y validez de su constructo, sin embargo no ha sido elaborado para la evaluación de la resiliencia en niños ni adolescentes, además se centra sólo en el plano individual del constructo. Por su parte, la $C Y R M$ muestra una buena adecuación conceptual y alta validez de contenido, que radica en el esfuerzo de sus autores por elaborar una medida estándar de resiliencia transcultural (Ungar et al., 2011), pero su estructura está aún en fase de comprobación (Daigenault, Dion, Hébert, McDuff y Collin-Vézina, 2013; Windle et al., 2011). 
En la Tabla 11 se presentan los ochos instrumentos más destacados por la literatura científica para la medida de la resiliencia en población infantil y juvenil. Estos instrumentos ha sido elaborados o adaptados (Campbell-Sills et al., 2007) para valorar la resiliencia en poblaciones de jóvenes adolescentes. Solamente la mitad de las escalas evalúan la resiliencia en población infantil: Resilience and Youth Development Module: RYDM (Sun y Stewart, 2007), Assessing Developmental Strengths questionnaires: $A D S-C R$ (Donnon et al., 2007) y, Devereux Student Strengths Assessment: DESSA (LeBuffe, Shapiro y Naglieri, 2005), Resiliency Scales for Children y Adolescents: RSCA (PrinceEmbury, 2006, 2008). Sin embargo, estas medidas en comparación con sus versiones para poblaciones de mayor edad son las que menos garantías psicométricas muestran. Así, por ejemplo, mientras la versión de la RYDM para estudiantes de Secundaria ha demostrado la validez de su constructo y la consistencia interna de su media, la versión para estudiantes de Primaria no ha reproducido psicométricamente la multidimensionalidad de su modelo teórico (Windle et al., 2011). 


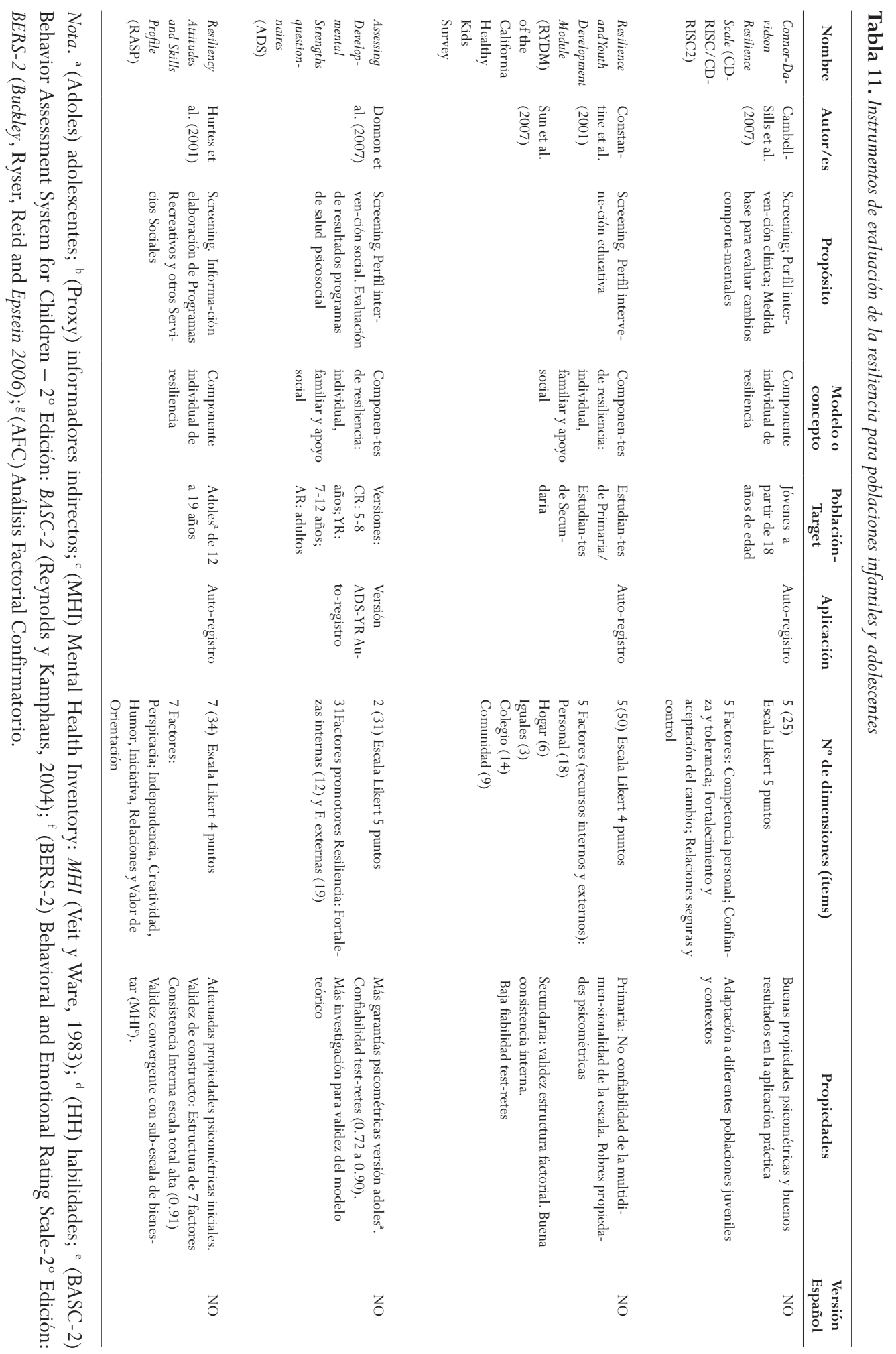




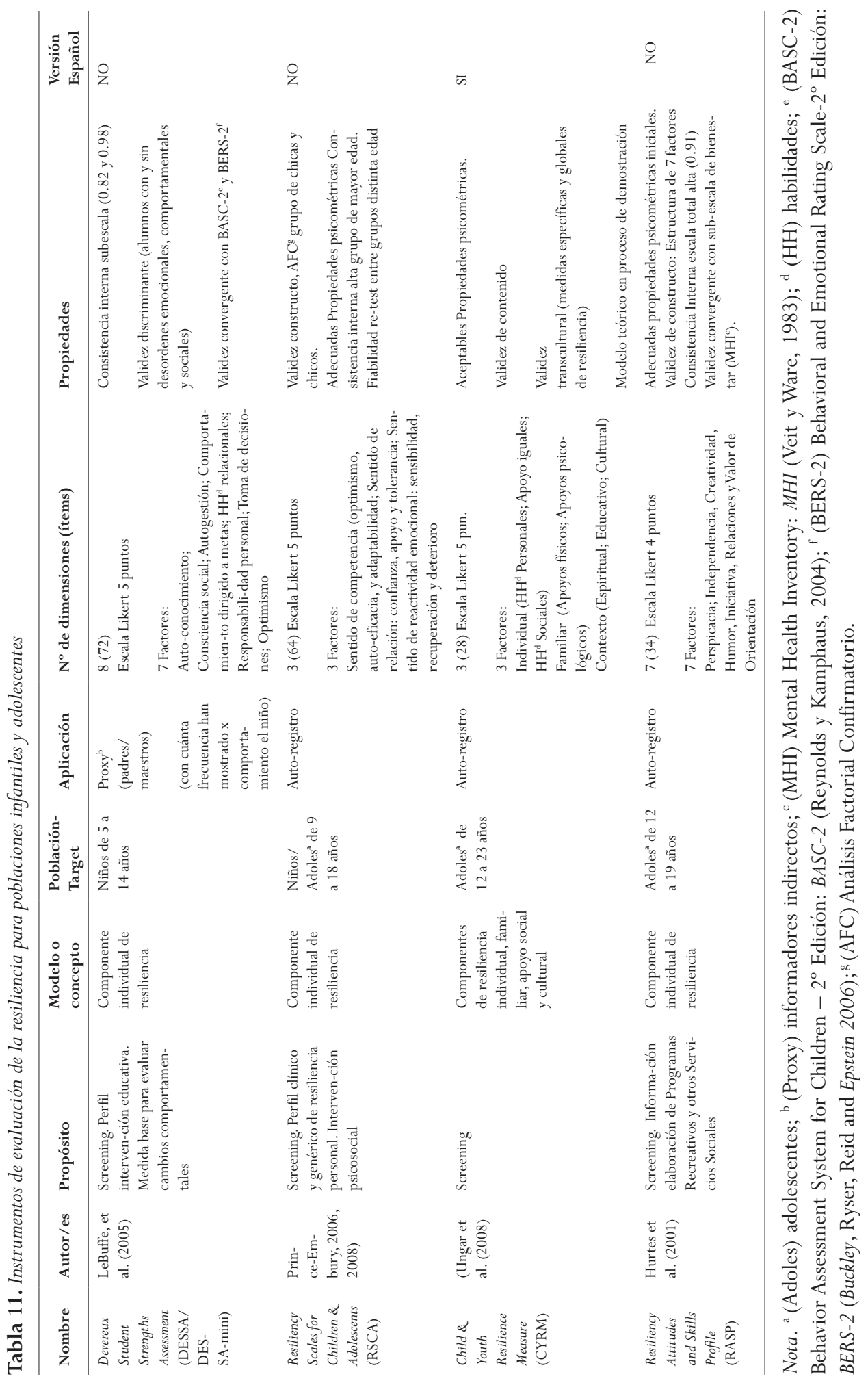


En relación a los modelos teóricos en los que se basan estos instrumentos, la amplia mayoría se centran en la medida del componente individual y psicológico de la resiliencia, obviando las influencias ambientales y las interacciones dinámicas entre la persona y su entorno, las cuales ha sido fuertemente fundamentadas por la literatura científica en resiliencia (Luthar et al., 2003; Masten, 2001; Panter-Brick, 2014; Rutter, 2012; Ungar, 2012; Zolkoski et al., 2012). De esta forma, sólo dos de las escalas presentadas amplían su evaluación a factores ambientales y tienen en cuenta tanto factores internos, como factores externos fortalecedores, como la RYM (Constantine et al., 2001) y la $A D S$ (Donnon et al., 2007). Mientras que, únicamente la CYRM (Ungar et al., 2008) agrega a su medida el componente contextual y cultural de resiliencia.

Por último, con respecto a las poblaciones objeto de estudio, las escalas presentadas han sido construidas para medir los factores determinantes y asociados a la resiliencia en poblaciones genéricas o clínicas, pero ninguna de ellas contempla o se dirige expresamente a la valoración de resultados en resiliencia de niños o jóvenes con discapacidad o necesidades educativas especiales y, en los que respecta al alcance de este trabajo, tampoco han sido adaptadas o probadas en este tipo de poblaciones.

En resumen, algunos de los problemas más destacados de los instrumentos de resiliencia presentados son:

- Adaptación de instrumentos para población adulta a poblaciones infantiles y/o juveniles, en vez de construcción de instrumentos específicos a las características de las poblaciones objeto de estudio.

- Foco en la medida del componente individual de resiliencia y en contrapartida poca operativización de los componentes sociales, contextuales y culturales de su constructo.

- Dificultad de la replicabilidad de los modelos teóricos en poblaciones de niños y / o jóvenes, que conlleva la no disponibilidad de instrumentos dirigidos a población infantil. 
- Falta de evidencia de su validez y aplicabilidad práctica, dado a su escasa administración y replicabilidad en poblaciones infantiles y juveniles diversas.

- Moderadas, bajas o incompletas garantías psicométricas de las escalas disponibles dada su insuficiente uso en estudios de desarrollo infantil saludable.

Ausencia de información sobre la medida de resiliencia infantil y juvenil en poblaciones bajo adversidad de colectivos concretos como los niños o jóvenes con discapacidad o estudiantes con necesidades específicas de apoyo educativo (NEAE).

Basándonos en la revisión conceptual y operativa realizada del constructo, para el desarrollo de este trabajo optamos por un enfoque en resiliencia híbrido que reconozca el valor de combinar múltiples perspectivas teóricas y empíricas en el estudio de la resiliencia infantil, tal como representa el modelo socio-ecológico de resiliencia de Ungar (2011) que se describe a continuación.

\subsection{Modelo Socio-Ecológico en Resiliencia (Ungar, 2004, 2008, 2011)}

\subsubsection{Conceptualización Socio-Ecológica de la Resiliencia Infantil}

La resiliencia, conceptualizada como sistema, se define como el resultado de la interacción recíproca entre influencias ambientales e individuales que permite a la persona adaptarse al medio a pesar de la adversidad, incluyendo en estas relaciones sus valores subjetivos, culturales, sociales e influencias éticas (Rutter, 2012; Tempski et al., 2015). Este enfoque ha sido descrito por Ungar (2004) como un enfoque transaccional o "ecológico" de resiliencia. Apoyado en la visión transaccional, el constructo de resiliencia se define a través de cuatro áreas principales o sistemas a partir de los cuales la resiliencia puede emerger durante el desarrollo infantil (Tabla 12). 
Tabla 12. Modelo ecológico en resiliencia adaptado a población infantil

\begin{tabular}{|c|c|c|}
\hline Niveles Sistémicos & Sistemas & Definición \\
\hline Microsistema & $\begin{array}{l}\text { Persona; Familia; } \\
\text { Grupo de iguales, etc. }\end{array}$ & $\begin{array}{l}\text { Interacciones familiares, con iguales y adultos } \\
\text { cercanos que condicionan las características } \\
\text { individuales }\end{array}$ \\
\hline Mesosistema & $\begin{array}{l}\text { Escuela; Organizacio- } \\
\text { nes de la comunidad; } \\
\text { etc. }\end{array}$ & $\begin{array}{l}\text { Interacciones entre microsistemas que deter- } \\
\text { minan la naturaleza de los recursos disponibles } \\
\text { para el desarrollo de las personas e influyen en la } \\
\text { capacidad para prosperar }\end{array}$ \\
\hline Exosistema & $\begin{array}{l}\text { Estructuras institu- } \\
\text { ciones y políticas; } \\
\text { servicios públicos y } \\
\text { privados; etc. }\end{array}$ & $\begin{array}{l}\text { Entornos institucionales, servicios y políticas en } \\
\text { los que interactúan los cuidadores de los niños }\end{array}$ \\
\hline Macrosistema & $\begin{array}{l}\text { Contexto histórico; } \\
\text { contexto cultural, } \\
\text { etc. }\end{array}$ & $\begin{array}{l}\text { Leyes, costumbres y prácticas culturales que } \\
\text { proporcionan oportunidades para el desarrollo } \\
\text { positivo de los niños bajo estés/en riesgo }\end{array}$ \\
\hline
\end{tabular}

Nota. Elaborado a partir de Brodersen (2013) y Ungar (2011).

La adopción de una perspectiva ecológica no sólo presupone la existencia de ciertas circunstancias de tipo adverso, factores de riesgo y factores protectores que se combinan entre los diversos niveles de interacción persona-ambiente, sino también un juicio normativo de lo que constituyen resultados indicativos de resiliencia (Lee, Kwong, Cheung, Ungar. y Cheung, 2010). Este juicio normativo ha llevado a parte de la comunidad científica asumir la neutralidad u objetividad en el uso de los indicadores de resiliencia a través de contextos diversos (perspectiva ética) (Fletcher et al., 2013). Según Ungar (2008) con frecuencia los resultados en resiliencia infantil han sido definidos por la investigación desde una noción eurocéntrica de desarrollo saludable, tales como, buen funcionamiento escolar, presencia de un cuidador, formas seguras de apego, relaciones de amistad, formas de adaptación no delincuentes, etc. (Rashid et al., 2014). Sin embargo, la evidencia pone de manifiesto que para una comprensión precisa del fenómeno son necesarias aproximaciones sensibles a los factores comunitarios y culturales que ayudan a la contextualización de cómo la resiliencia es definida por diversas poblaciones y manifestada en su vida cotidiana (perspectiva émica) (Arrington y Wilson, 2000; Shek, 2005; Ungar, 2004, 2008; Walsh, 2006). 
Desde la interpretación ecológica, la resiliencia es a la vez el resultado de la interacción del individuo con su ambiente, como el proceso mediante el cual tiene lugar este resultado (Ungar et al., 2007). Proceso y resultado son al mismo tiempo influenciados por el contexto y cultura donde se desarrolla el niño (Lerner 2006; Luthar et al., 2003, Rutter, 2012).

Para tener en cuenta la especificidad cultural y contextual acerca de cómo la resiliencia se expresa, Ungar (2008), desde una visión construccionista, incorpora dos nuevos componentes a la comprensión de la resiliencia: la navegación y negociación de los individuos en sus ambientes para sustentar su estado de salud y bienestar ante condiciones de vida adversas.

La navegación reenfoca nuevamente la resiliencia hacia el individuo, no en términos de atributos personales como los defendidos en las primeras etapas de estudio del constructo, sino desde un enfoque de agencia personal y estructuras de oportunidades impregnadas de significados culturales y contextuales (Lynam et al., 2007; Panter-Brick, 2014). El concepto de navegación implica el movimiento de los individuos hacia los recursos que están accesibles y disponibles en el entorno (Ungar, 2011). En este sentido Skinner y colaboradores (2005) han demostrado que no sólo las habilidades latentes de niños con discapacidad contribuyen al éxito en su desarrollo, sino también la capacidad del entorno para crear las condiciones sociales y físicas que contribuyen a su expresión.

La negociación por su parte se refiere a la capacidad de los individuos y colectivos sociales para atribuir significado a los recursos accesibles y disponibles en su medio (Ungar, 2011). Desde esta perspectiva, la percepción del niño sobre qué aspectos del entorno experimenta como más protectores estará influenciada por el sistema de creencias transmitido generacionalmente. Es decir, tener éxito en la escuela puede ser percibido por el niño como un recurso psicosocial útil si la familia y la sociedad valoran la educación como tal, así como si el niño percibe el éxito de su futuro como dependiente de sus resultados en la escuela (Cross, 1998). 
La adopción de estos dos componentes implica que el éxito de la resiliencia reside en la interacción recíproca entre los individuos, las construcciones que éstos tengan de su estado de bienestar y la construcción social de bienestar que tiene el colectivo del que forman parte (Ungar, 2004). El sentido de lo que somos, nuestra identidad de salud o vulnerabilidad, depende de estos procesos de co-construcción y negociación con nuestro entorno (Ungar, 2012). Reconociendo así la existencia de una cultura integrada y un juicio perteneciente a un contexto normativo específico que puede alinearse con el punto de vista subjetivo de la persona (Ungar, 2004). De esta forma, los resultados asociados con la resiliencia y los procesos que mitigan el riesgo y contribuyen al desarrollo y bienestar de las personas, dependen en buena medida de cómo los individuos resuelven las tensiones de su vida diaria para alcanzar un funcionamiento saludable (Sameroff et al., 2003; Wyman, 2003).

A partir de un análisis exhaustivo de la literatura sobre desarrollo, Ungar (2011) ha puesto de manifiesto que la noción de resiliencia centrada en las cualidades individuales del niño tergiversa la comprensión de los antecedentes del desarrollo positivo. Los resultados de un número amplio de investigaciones indican que las cualidades del niño y su motivación para acceder a los recursos disponibles y navegar entre las barreras y obstáculos existentes, tales como la discapacidad o desventajas socioeconómicas familiares, no parece ser tan determinantes como el grado de adecuación del entorno al nivel de riesgo al que está expuesto el niño (Beckett et al., 2006; Solis, 2003; Taylor, 2005; Tiet et al., 1998). Estas investigaciones evidencian que a media que la adversidad crece y hay presentes más factores que atentan contra el desarrollo saludable del niño, los resultados de resiliencia parecen depender más de la sostenibilidad de recursos culturalmente significativos que de los factores individuales del niño, es decir, de la accesibilidad y disponibilidad de recursos ambientales a lo largo del tiempo (Ungar, 2011). Por ejemplo, Beckett y colaboradores (2006) en un estudio longitudinal sobre el desarrollo de niños rumanos adoptados, demostraron que aquellos niños con deterioro cognitivo más alto y estancias más prolongadas en orfanatos eran los que mostraban mayor grado de recuperación entre los 
6 y 11 años de edad. A pesar de que seguían mostrando discapacidad, los niños más desfavorecidos eran los que tenían más probabilidad de exhibir ganancias como resultado de un ambiente facilitador (Beckett et al., 2006). De esta forma, el foco parece estar tanto en cómo el ambiente responde a las necesidades del niño, como qué hace el niño para aprovechar los recursos existentes.

Sin embargo, es importante notar que en contextos de mayor adversidad, cuando los niños se encuentran bajo cantidades significativas de estrés, la atención debe dirigirse primero al ambiente, analizando el papel que juegan las ecologías sociales y físicas en los resultados de desarrollo positivo de los más pequeños (Seccombe, 2002; Ungar, 2012; Wyman, 2003). Como clave de cambio Ungar (2011) propone cultivar el entorno creando las condiciones óptimas para aumentar la resiliencia infantil, como por ejemplo proporcionando una guardería pública de calidad subvencionada (Peters, 2005). Desde este prisma el foco de investigación tendría que estar en la calidad de la guardería como resultado de desarrollo, suponiendo que cuanto más accesible y disponible sea una guardería de calidad más se desarrollará una población de niños en riesgo con el paso del tiempo. En este tipo de estudios la cuestión central no es si un niño específico se beneficia individualmente de un recurso sino el hecho de que la guardería esté presente, así como las oportunidades de cambio que ésta posibilita a aquellos padres en situación social más desfavorecida (Seccombe, 2002; Ungar, 2012).

Ampliando los modelos de resiliencia basados en el desarrollo individual a la sostenibilidad de los recursos ambientales como facilitadores del desarrollo y bienestar del niño, esta perspectiva socio-ecológica sitúa la resiliencia como una teoría que enfatiza primero la naturaleza de la ecología social y física del niño, segundo los procesos de interacción entre el ambiente y el niño, y tercero las tendencias específicas del niño hacia el desarrollo positivo (Bottrell, 2009; Hudziak y Bartels, 2008; Lerner y Overton, 2008). A partir de estos supuestos Ungar (2004, 2008, 2011, 2012) incorpora la visión de resiliencia como un fenómeno cultural sensible al contexto, definiendo contexto como la capacidad de las instituciones (escuelas, políticas sociales, 
por ejemplo) para fomentar al bienestar de las comunidades y respuesta de las necesidades de los niños, mientras que la cultura sería los valores, creencias y prácticas asociadas con el afrontamiento de desafíos cotidianos (Ungar et al., 2007). Es desde este sentido donde las vías que determinan las trayectorias de desarrollo dependen de la disponibilidad y accesibilidad de los recursos que sustentan la salud y el significado dado a cada uno de ellos dentro de la cultura y contexto del niño. De este modo, utilizando la expresión del comportamiento de Lewin (1951), Ungar (2008) define la resiliencia como:

La capacidad de los individuos para navegar por sus trayectorias de vida a través de los recursos psicológicos, sociales, culturales y físicos que mantienen su bienestar, así como su capacidad individual y colectiva para negociar que estos recursos sean facilitados y experimentados de forma culturalmente significativa (p. 225) (Figura 8).

Figura 8. Representación de los componentes de la definición de resiliencia de Michael Ungar

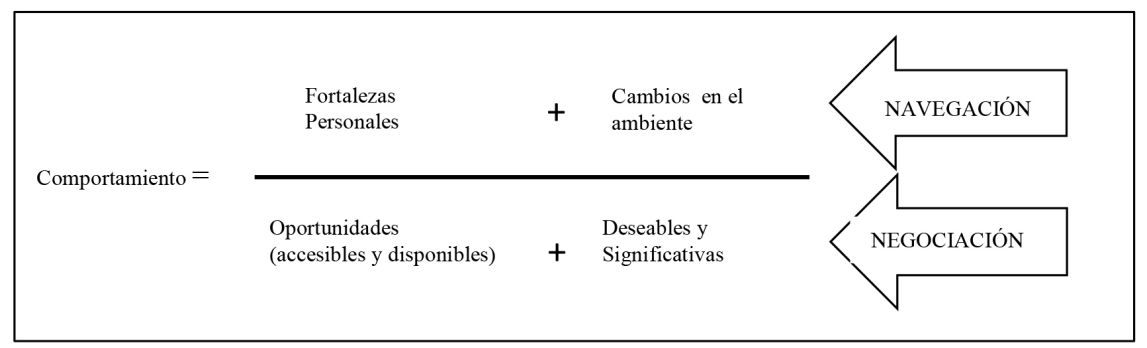

Nota. Adaptado de "Resilience across cultures", por M. Ungar, 2008, British Journal of Social Work, 38, 225.

Cambiar el enfoque del niño a la ecología social y física de éste, sitúa el discurso de la resiliencia en la capacidad del entorno para proveer las necesidades individuales (Vygotsky, 1978). Desde esta perspectiva, la resiliencia se localiza dentro de una red de recursos que incluye: recursos materiales, relacionales, identidad cuerpo y mente, poder y control, participación comunitaria, cohesión comunitaria y justicia social (Ungar et al., 2007). Cuando hay menos barreras estructurales para que el niño navegue por los recursos accesibles y disponibles 
durante su trayectoria de desarrollo, el modelo socio-ecológico presupone que los factores de riesgo ecológicos son menos importantes que las características individuales. Pero a medida que los factores de riesgo crecen se espera que las influencias de los factores ecológicos sobre los resultados personales de desarrollo también aumenten. En este sentido, los resultados personales del niño variarán en la medida en que el ambiente proporcione los recursos que el niño necesita durante su trayectoria de desarrollo. Mientras que, el éxito de las intervenciones en resiliencia dependerá de que los recursos ofrecidos por los servicios clínicos, educativos, sanitarios o sociales sean suficientemente intensos, culturalmente apropiados y personalmente significativos para favorecer el crecimiento del mayor número de niños (Ungar, 2011, 2012, 2015a).

\subsubsection{Evaluación Socio-Ecológica de la Resiliencia Infantil y Juvenil}

Para identificar los recursos facilitadores de la resiliencia infantil con capacidad de incidir en el desarrollo positivo y la calidad de vida de niños y niñas con necesidades diversas en diferentes contextos (Adi et al., 2007; Ager, 2013; Cowen et al., 1988; Exenberger et al., 2013; Lee et al. , 2010; Rashid et al., 2014; Shek, 2005; Ungar, 2008), Ungar y colaboradores proponen una medida amplía de resiliencia que incorpore aspectos del constructo de múltiples dominios, tales como, funcionamiento familiar, apoyo social, habilidades individuales de afrontamiento, así como componentes del contexto cultural y espiritual (Ungar et al., 2008; Liebenberg, Ungar y Van de Vijver, 2012; Ungar et al., 2011). Dichos dominios protegen contra resultados de desarrollo adversos durante las trayectorias de vida niños y jóvenes (Brodersen, 2013).

Una de las medidas desarrolladas bajo los principios expuestos es la Child and Youth Resilience Measure: CYRM, creada por el Resilience Research Centre (RRC) como parte del Proyecto de Resiliencia Internacional que involucró a catorce comunidades de once países de todo el mundo (Ungar et al., 2011). 
Dado que el modelo ecológico de resiliencia desarrollado por Ungar (2008) concibe el constructo como susceptible a las variaciones del contexto, los autores de la CYRM (Ungar et al., 2011) entienden que al examinar la resiliencia en diferentes culturas sus indicadores potenciales deben ser negociados con las poblaciones objeto de estudio. Para ello, Ungar y colaboradores (2008) utilizaron métodos de investigación ideográficos y nomotéticos con objeto de capturar la diversidad de los puntos de vista de las personas con respecto a sus ubicaciones sociales en la comunidad, así como los aspectos globales de la resiliencia. A través de grupos focales y entrevistas con jóvenes y adultos de contextos mundiales minoritarios y mayoritarios, se trató de captar las experiencias personales de resiliencia desde múltiples vías (Ungar et al., 2007). Los resultados mostraron que los jóvenes que se consideran a sí mismos "resilientes", y por sus comunidades, son aquellos que navegan exitosamente sus vidas a través de una serie de tensiones (Tabla 13). Estos chicos encuentran un camino para resolver estas tensiones de forma simultánea, de acuerdo a las fortalezas y recursos disponibles propios, así como a los existentes dentro de sus familias, comunidades y culturas (Ungar et al., 2007). De esta forma, la experiencia de resiliencia de los jóvenes depende tanto de las soluciones dadas, como de lo buenas que sean éstas para dirigir los desafíos que plantea cada tensión, dentro de las limitaciones sociales y políticas de la comunidad en la que se desarrolla la acción.

Tabla 13. Listado de tensiones y descripción de cada una de ellas

\begin{tabular}{ll}
\hline Tensiones & Descripción \\
\hline $\begin{array}{l}\text { Acceso a relaciones de } \\
\text { apoyo }\end{array}$ & $\begin{array}{l}\text { Relaciones significativas con miembros familiares, iguales y otras } \\
\text { personas de la comunidad. }\end{array}$ \\
$\begin{array}{l}\text { Desarrollo de una identi- } \\
\text { dad personal deseable }\end{array}$ & $\begin{array}{l}\text { Tener un sentido de sí mismo deseable, un propósito personal y } \\
\text { colectivo, y capacidad de auto-evaluación de las propias fortalezas, } \\
\text { debilidades, aspiraciones, creencias y valores, que incluye la identifi- } \\
\text { cación espiritual y religiosa. }\end{array}$ \\
Experiencias de poder y & $\begin{array}{l}\text { Experiencias de autocuidado y cuidado del otro, capacidad para } \\
\text { influir en los cambios del entorno físico y social para acceder a los } \\
\text { control }\end{array}$ \\
& recursos de salud. \\
\hline
\end{tabular}




\begin{tabular}{|c|c|}
\hline Tensiones & Descripción \\
\hline $\begin{array}{l}\text { Experiencias de justicia } \\
\text { social }\end{array}$ & $\begin{array}{l}\text { Experiencias relacionadas con la búsqueda de un papel significativo } \\
\text { en la comunidad que conlleva la aceptación e igualdad social. }\end{array}$ \\
\hline $\begin{array}{l}\text { Acceso a los recursos } \\
\text { materiales }\end{array}$ & $\begin{array}{l}\text { Oportunidades financieras, educativas, médicas y laborales o/y } \\
\text { disponibilidad de asistencia social, así como acceso a alimentos, } \\
\text { ropa, vivienda. }\end{array}$ \\
\hline $\begin{array}{l}\text { Experiencias de un sentido } \\
\text { de cohesión con otras } \\
\text { personas }\end{array}$ & $\begin{array}{l}\text { Equilibrio de los intereses personales con el sentido de responsabili- } \\
\text { dad hacia el bien común. Sentirse parte de algo más grande que uno } \\
\text { mismo. }\end{array}$ \\
\hline $\begin{array}{l}\text { Adherencia a la tradiciones } \\
\text { culturales }\end{array}$ & $\begin{array}{l}\text { Adherencia o conocimiento de las prácticas culturales, valores y } \\
\text { creencias locales o globales. }\end{array}$ \\
\hline
\end{tabular}

Nota. Adaptado de "Unique pathways to resilience across cultures", por M. Ungar et al., 2007, Adolescence, 42(166), 295.

Las siete tensiones identificadas son temas principales que se repiten en todos los grupos culturales participantes. El hallazgo de estos siete temas permitió el desarrollo de una medida cuantitativa de resiliencia que explica los resultados de éxito en el desarrollo de los niños desde múltiples vías (Chen, DeSouza, Chen, Wang, 2006; Shernoff y Schmidt, 2008), la medida de resiliencia infantil y juvenil: CYRM (Ungar et al., 2011). La CYRM fue elaborada inicialmente para jóvenes entre 9 y 23 años, aunque posteriormente se han construido otras versiones de la escala para su aplicación en niños de menor edad (CYRM-26); adultos a partir de 24 años; y, proxies (PMK) (Ungar et al., 2011).

La finalidad de la CYRM es medir los recursos (individuales, relacionales, comunitarios y culturales) accesibles y disponibles a partir de los cuales las personas pueden desarrollar su resiliencia. Los resultados de los análisis de los datos cualitativos y cuantitativos recogidos han dado lugar a la estructura de la CYRM-28 (Liebenberg et al., 2012). Dadas las características del proceso de construcción de la $C Y R M-28$, la escala está diseña para mostrar buena validez de contenido en referencia al contexto específico en el que se administra, y al mismo tiempo comparte suficiente homogeneidad para la comparación entre poblaciones de diferentes culturas (Windle et al., 2011). Por tanto, además de incorporar los factores individuales, familiares y sociales evaluados por 
otros instrumentos análogos (Constantine et al., 2001; Donnon et al., 2007; Hjemdal et al., 2007), la CYRM-28 añade el componente cultural que crea la originalidad de su medida. Sin embargo, pese a su alta validez de contenido, la $C Y R M-28$ no tiene actualmente ninguna validez predictiva (Windle et al., 2011), en comparación con otras escalas de resiliencia (Connor et al., 2003; Friborg, Hjemdal, Rosenvinge y Martinussen 2003; Hurtes et al., 2001), lo que genera la necesidad de su aplicación en múltiples contextos con objeto validar su modelo operativo y explorar las aplicaciones potenciales de esta herramienta (Daigneault et al., 2013).

Todos los trabajos desarrollados desde el RRC fundamentan cada vez más la resiliencia como constructo socio-ecológico, y están dando lugar a importantes implicaciones prácticas para el crecimiento positivo de niños y jóvenes expuestos a contextos desafiantes, tales como los derivados a la presencia de necesidades especiales o discapacidad (Alvord, Rich y Berghorst, 2016; Gilmore, Campbell, Shochet y Roberts, 2013; Hall et al., 2009).

\subsection{Resiliencia Infantil y Discapacidad}

La investigación en resiliencia infantil en el campo de la discapacidad es uno de los ejemplos que desafía la perspectiva normativa del desarrollo exitoso de niños y jóvenes expuestos a situaciones de riesgo (Ungar, 2004). Desde un enfoque de resiliencia clásico, la presencia de deterioro en el funcionamiento podría conducir erróneamente a criterios de exclusión en investigación y prácticas a poblaciones de niños y jóvenes con discapacidad o presencia de necesidades especiales (Runswick-Cole y Goodley, 2013), al suponer que carecen de las características personales necesarias para el florecimiento de su resiliencia (Masten, 2001). Al obviar otros factores personales y ambientales presentes en los diferentes sistemas en los que el niño con discapacidad interactúa y se desarrolla, se limita la posibilidad de crear contextos desafiantes para personas con necesidades especiales, más allá de las propias condiciones de discapacidad (Young Green y Rogers, 2008). 
Con objeto de conocer y potenciar las vías mediante las que niños y jóvenes con discapacidad celebran sus identidades y afirman su estatus como personas con necesidades especiales, es importante estudiar la construcción de la resiliencia (Ungar, 2004, 2008) desde una visión social de discapacidad (Oliver, 2004), que conlleve la crítica y redefinición de los supuestos de desarrollo normal y de los comportamientos indicativos de resiliencia en niños y jóvenes con condiciones diversas (Runswick et al., 2013).

Como hemos visto anteriormente, existe un acuerdo generalizado por parte de la literatura en resiliencia acerca de la necesidad de la exposición a adversidad o riesgo para su expresión (Luthar et al., 2001; Masten, 2001; Ungar, 2015b). Con respecto al ámbito de la discapacidad, es evidente que una sociedad dis/capacitante amenaza con poner a los niños con necesidades especiales en situación de riesgo y vulnerabilidad, por tanto, es importante definimos el riesgo en el ámbito de la discapacidad para entender las vías que dan acceso a la red de recursos que favorecen la presencia de la resiliencia en niños con necesidades especiales (Ungar, et al., 2007). Según Runswick y su equipo (2013), el riesgo puede ser percibido como vulnerabilidad ante una situación adversa (Ungar, 2015b), pero también como una oportunidad de crecimiento a través de la exposición a situaciones desafiantes y la búsqueda de emoción. De esta forma, una característica definitoria de las personas que tienen poder y control en sus vidas es la capacidad de asumir riesgos, pero también de tener oportunidades estructurales para asumirlos (Wehmeyer, 1992, 1997; Verdugo et al., 2015).

La exposición al riesgo o la falta de él, es una cuestión clave a lo largo de todo el ciclo vital de las personas con discapacidad. Como vimos en el capítulo de participación, cuando los niños con discapacidad son excluidos de las actividades cotidianas de sus comunidades están expuestos a cantidades de riesgo mayores, tales como aislamiento social (Imms, Reilly, Carlin y Dodd, 2009; Law, Petrenchik, King y Hurley, 2007; Palisano et al., 2011; Schreuer, Sachs y Rosenblum, 2014), merma en el desarrollo potencial de sus competencias sociales y personales (Coastsworth et al., 2005; Passmore y French, 2003; Shikako-Thomas et al., 2012; Wilkes, Cordier, Bundy, 
Docking y Munro, 2011), así como a una mayor probabilidad de desajustes biopsicosociales (Adolfsson, 2011; Badia et al., 2013; Dahan-Oliel et al., 2012; Schreuer et al, 2014). Los riesgos sociales provenientes de la falta de oportunidades estructurales se suman a los riesgos derivados de las limitaciones propias que conllevan ciertas condiciones de discapacidad, por ejemplo, bajar un tobogán para un niño con discapacidad física, jugar en un equipo de futbol para una niña con trastorno del espectro autista, o cantar en un coro niño con discapacidad auditiva (Runswick-Cole et al., 2013). Además, las tendencias de sobreprotección y discriminación positiva suponen otro riesgo en sí mismo, al crear contextos sociales extremadamente seguros en los que todo está bajo control de los adultos y las necesidades de los niños son respondidas antes de que éstas surjan, anulando la capacidad del niño para asumir riesgos, exponerse a situaciones desafiantes, buscar las fuentes de resiliencia y crecer ante la adversidad (Schreuer et al., 2014; Ungar, 2012).

Para los niños en situación de discapacidad, las oportunidades que dan acceso a los recursos de resiliencia, así como los factores de riesgos asociados a un desarrollo poco éxito, se encuentran en el hogar, pero también en las escuelas, hospitales, servicios de atención temprana, organizaciones proveedoras de servicios, así como en las instituciones de la comunidad que ofrecen servicios y ayudas financieras. De esta forma, la promoción de oportunidades de desarrollo para los niños con discapacidad se expande más allá de la familia, hacia las interacciones con una serie de organismos sociales y políticos que crean oportunidades o barreras para su desarrollo infantil potencial y saludable (Ager, 2013; Panter-Brick, 2014; Friedli, 2009). La capacidad de las familias para reunir recursos, navegar a través de burocracias, servicios sociales y sistemas jurídicos para acceder a las fuentes de apoyo, puede afectar significativamente a las trayectorias del desarrollo de los niños con discapacidad (Skinner et al., 2005). En este sentido, Skinner y colaboradores (2005) han evidenciado que las familias con hijos con necesidades especiales perciben los sistemas proveedores de servicios como agentes facilitadores de oportunidades para el desarrollo de sus hijos, a través 
de apoyos que les ayudan a mantener las rutinas diarias y las necesidades básicas que promueven el bienestar familiar. Pero también, estos sistemas y actividades desarrolladas dan forma a las nociones que las familias tienen de la discapacidad y de lo que sus hijos necesitan (Ungar, 2011).

Desde la visión del niño, la investigación sobre discapacidad y resiliencia está demostrando que la movilidad de los menores, así como la accesibilidad y disponibilidad de los recursos para su desarrollo, influyen en la formación de la identidad de los jóvenes con discapacidad (Ungar, 2012). De esta forma, la capacidad de los menores para navegar hacia los recursos que sostiene su resiliencia está estrechamente relacionada a las condiciones familiares, comunitarias y culturales que facilitan u obstaculizan la sostenibilidad de los recursos de salud, así como a las facilidades ofrecidas por estos contextos para acceder a dichos recursos y experimentarlos de forma culturalmente significativa, que a su vez dan lugar a las experiencias de bienestar en diferentes áreas de vida (Lee et al., 2010; Skinner et al., 2005; Ungar, 2012).

\subsection{Resiliencia Infantil y Calidad de Vida}

Según Khanlou y colaboradores (2014) la construcción de la resiliencia y de los factores protectores asociados con ella es una de las vías para mejorar la salud y el bienestar de las personas. Bajo el paraguas del enfoque socio-ecológico (Ungar, 2004, 2007, 2011), los hallazgos de los estudios en desarrollo infantil positivo respaldan firmemente la contribución de la resiliencia a la calidad de vida (CV) de niños y jóvenes diversos (Park y Peterson, 2006; Peterson y Park, 2011; Tempski et al., 2015), como se ha fundamentado a lo largo de este capítulo.

Para una mejor comprensión de la relación entre resiliencia y calidad de vida infantil en la Tabla 14 se presenta la relación conceptual establecida entre las tensiones para el desarrollo de la resiliencia juvenil identificadas por Ungar y su equipo (2007) y las dimensiones e indicadores de calidad de vida infantil (Schalock et al., 2002, 2003; Wallander et al.,, 2016). La tabla también incluye factores asociados a la mejora de la CV detectados por la 
investigación (Schalock et al., 2003; Schalock et al., 2016), que muestran las vías que favorecen el bienestar y la satisfacción personal, a través de la accesibilidad y disponibilidad de recursos en los entornos de desarrollo próximo (Ungar, 2011; 2015a).

Tabla 14. Relación entre las tensiones para el desarrollo de la resiliencia y las dimensiones, indicadores de calidad de vida infantil y factores asociados a su mejora

\begin{tabular}{|c|c|c|c|}
\hline $\begin{array}{l}\text { Tensiones } \\
\text { Resiliencia }\end{array}$ & $\begin{array}{l}\text { Dimensiones } \\
\text { centrales } \mathrm{CV}^{\mathrm{a}}\end{array}$ & $\begin{array}{l}\text { Indicadores } \\
\mathrm{CV}^{\mathrm{a}} \text { infantil }\end{array}$ & Factores Asociados a $\mathrm{CV}^{\mathrm{a}}$ \\
\hline $\begin{array}{l}\text { Acceso a relacio- } \\
\text { nes de apoyo }\end{array}$ & $\begin{array}{l}\text { Bienestar emo- } \\
\text { cional }\end{array}$ & $\begin{array}{l}\text { Satisfacción } \\
\text { Afectos positivos } \\
\text { Espiritualidad } \\
\text { Seguridad personal }\end{array}$ & $\begin{array}{l}\text { Incremento de entornos } \\
\text { seguros, estables, predecibles, } \\
\text { feedback positivo }\end{array}$ \\
\hline $\begin{array}{l}\text { Desarrollo de una } \\
\text { identidad personal } \\
\text { deseable }\end{array}$ & $\begin{array}{l}\text { Desarrollo } \\
\text { personal }\end{array}$ & $\begin{array}{l}\text { Educación } \\
\text { Logros educativos } \\
\text { Significado y propósito }\end{array}$ & Amistad, intimidad, familias \\
\hline $\begin{array}{l}\text { Experiencias de } \\
\text { un sentido de } \\
\text { cohesión con otras } \\
\text { personas }\end{array}$ & $\begin{array}{l}\text { Relaciones in- } \\
\text { terpersonales }\end{array}$ & $\begin{array}{l}\text { Apoyos social } \\
\text { Relaciones con iguales } \\
\text { Amigos }\end{array}$ & $\begin{array}{l}\text { Propiedades, posesiones, } \\
\text { empleo }\end{array}$ \\
\hline \multirow[t]{2}{*}{$\begin{array}{l}\text { Adherencia a } \\
\text { la tradiciones } \\
\text { culturales }\end{array}$} & Inclusión social & $\begin{array}{l}\text { Vida familiar } \\
\text { Experiencias escolares } \\
\text { Participación en la } \\
\text { comunidad } \\
\text { Condiciones ambien- } \\
\text { tales }\end{array}$ & $\begin{array}{l}\text { Rehabilitación funcional, edu- } \\
\text { cación orientada a lo aplicado, } \\
\text { tecnología aumentativa. }\end{array}$ \\
\hline & Bienestar físico & $\begin{array}{l}\text { Salud personal } \\
\text { Comportamientos de } \\
\text { riesgo y seguros }\end{array}$ & $\begin{array}{l}\text { Atención sanitaria, movilidad, } \\
\text { hábitos saludables, nutrición. }\end{array}$ \\
\hline $\begin{array}{l}\text { Experiencias de } \\
\text { poder y control }\end{array}$ & $\begin{array}{l}\text { Autodetermi- } \\
\text { nación }\end{array}$ & $\begin{array}{l}\text { Autonomía } \\
\text { Logros en la vida }\end{array}$ & $\begin{array}{l}\text { Elecciones, control personal, } \\
\text { decisiones, metas personales. }\end{array}$ \\
\hline $\begin{array}{l}\text { Acceso a los re- } \\
\text { cursos materiales }\end{array}$ & $\begin{array}{l}\text { Bienestar ma- } \\
\text { terial }\end{array}$ & Economía familiar & $\begin{array}{l}\text { Roles comunitarios, integración } \\
\text { comunitaria, voluntariado. }\end{array}$ \\
\hline $\begin{array}{l}\text { Experiencias de } \\
\text { justicia social }\end{array}$ & Derechos & $\begin{array}{l}\text { Estándares de vida } \\
\text { Formar parte de la } \\
\text { comunidad } \\
\text { Seguridad futura }\end{array}$ & $\begin{array}{l}\text { Privacidad, acceso al voto, pro- } \\
\text { cesos legales, responsabilidades } \\
\text { cívicas }\end{array}$ \\
\hline
\end{tabular}

Nota. ${ }^{\text {a }}$ (CV) Calidad de Vida. Elaborado a partir de Schalock et al. (2002, 2003), Schalock et al. (2016) y Ungar et al. (2007). 
Los resultados de otras investigaciones también sugieren que el valor de las creencias personales de los niños respecto a su resiliencia son un recurso cognitivo que contribuye al mantenimiento de su calidad de vida frente a la adversidad (Lee et al., 2012; Lee et al., 2010). Sin embargo, a pesar del efecto positivo de estas creencias, la exposición a otros factores de riesgo de origen social son determinantes para el cultivo del bienestar (Hall et al., 2009; Ungar, Theron y Didkowsky, 2011). Desde esta perspectiva, una compresión sistémica de la resiliencia infantil es enriquecida por el conocimiento existente sobre los determinantes sociales de la salud (Friedli, 2009; WHO, 2004a; WHO, 2004b), la comprensión de las diferentes dimensiones de la adversidad y riesgo en la infancia (Masten, 2001; Ungar, 2015b) y otros factores que contribuyen a la salud y bienestar atribuibles a la política social, el funcionamiento familiar y la capacidad de la comunidad para responder a las necesidades de los niños (Ager, 2013; Panter-Brick, 2014).

La Organización Mundial de la Salud (Friedli, 2009) define los determinantes sociales de la salud como las circunstancias en las que las personas nacen, crecen, viven, trabajan y envejecen. Estas circunstancias son el resultado de la distribución del capital natural, social y financiero a nivel mundial, nacional y local, que depende a su vez de las políticas sociales adoptadas (Ungar, 2015b). Los determinantes sociales de la salud explican la mayor parte de las inequidades sociales y sanitarias del mundo (WHO, 2004a; WHO, 2004b) e influyen en la salud física y mental de las personas (Friedli, 2009; Heymann Hertzman, Barer y Evans 2006). En esta línea, la investigación socio-ecológica en resiliencia sugiere que aumentar la capacidad de aislar los factores de riesgo, construir relaciones entre las personas y fomentar los recursos personales y ambientales ayuda a reducir la vulnerabilidad diferencial asociada a resultados biopsicosociales negativos (Khanlou et al., 2014), incidiendo sobre las condiciones vida de las personas y, en consecuencia, sobre las percepciones que éstas tienen de su bienestar y satisfacción personal y social (Schalock et al., 2002, 2003; Ungar, 2012). 


\subsection{Conclusiones}

En definitiva, para el estudio de los factores asociados a la resiliencia de niños con NEAE y sin ellas con capacidad de influir en su calidad de vida, partimos del modelo socio-ecológico de resiliencia propuesto por Ungar (2004, 2007, 2011, 2012). Como hemos visto, el modelo define la resiliencia como el conjunto de competencias o comportamientos que a lo largo del tiempo reflejan las interacciones de los individuos con una variedad de ambientes y, en particular, las oportunidades de crecimiento personal que están disponibles y accesibles en los diferentes niveles de su contexto social y cultural. Ungar y colaboradores (2008) proponen un modelo operativo compuesto por tres dimensiones que permite analizar los factores que promueven el bienestar bajo condiciones de vida adversas. Estas tres dimensiones (individual, familiar y contextual) hacen referencia a la propia persona, pero también a los contextos en los que se encuentran las fuentes que posibilitan la manifestación de fortalezas y oportunidades para su adaptación y crecimiento personal (Ungar y Liebenberg, 2009).

Este enfoque teórico de resiliencia distingue entre las fortalezas generales de la población y el rol específico que juegan cuando individuos, familias o comunidades están bajo situaciones de estrés concretas o continuas, como la presencia de discapacidad o necesidades especiales (Runswick-Cole et al., 2013; Ungar, 2012). Se centra en buscar indicadores de resiliencia en las variaciones ambientales que se producen como respuesta positiva a la adversidad desde el nivel individual, familiar y contextual, que propician resultados positivos de cambio (Ungar et al., 2011).

Actualmente, en España no disponemos de instrumentos de evaluación de resiliencia para población infantil con discapacidad y sin ella. Por este motivo, se ha llevado a cabo un proceso de búsqueda y análisis de escalas internacionales, presentado en el apartado de instrumentos de este capítulo. En esta revisión tampoco se encontró ninguna escala internacional que valorará la resiliencia en población infantil con discapacidad (o necesidades educativas especiales) y sin ella. Por tanto, existía la necesidad de elaborar o adaptar uno de los instrumentos existentes. Para el desarrollo de esta investigación se ha optado 
por la segunda opción. El instrumento seleccionado para el estudio de la resiliencia en alumnos con NEAE y sin ellas ha sido la Child andYouth Resilience Measure: CYRM-28 (Liebenberg et al., 2012). Las razones que justifican la elección de esta escala han sido las siguientes:

- Se basa en un modelo socio-ecológico de resiliencia que tiene en cuenta tanto las competencias potenciales del individuo, como los apoyos y barreras existentes en los diferentes ambientes en los que se desenvuelve, y las variaciones en la medida específicas al contexto cultural (Ungar, 2011).

- Su marco teórico coincide con los planteamientos teóricos de la Clasificación Internacional del Funcionamiento, la Discapacidad y la Salud de la Organización Mundial de la Salud (OMS, 2001) y su versión infantil (OMS, 2007), el modelo de CV de Schalock y colaboradores (2002, 2003) y el modelo de participación infantil en actividades diversas de King y colaboradores (2003, 2009), seleccionados para el análisis de los determinantes de la CV de población infantil con y sin necesidades específicas.

- Es una medida de carácter transcultural (Ungar et al., 2008).

- Sus propiedades psicométricas son aceptables. Los resultados preliminares obtenidos por el RRC tras la aplicación de la CYRM en 11 países muestran una consistencia interna adecuada $(\alpha .88)$. También ha sido valorada su alta validez de contenido (Windle et al., 2011). Sin embargo, su estructura teórica aún no ha sido demostrada. Los resultados previos apunta a una estructura dependiente al contexto de aplicación, debido a que las fuentes y factores relacionados con la resiliencia son percibidos, valorados y empleados de manera diferente en función de variables culturales, contextuales e individuales como el género (Ungar et al., 2011).

- Aunque la edad de la población a la que va dirigida la escala original no coincide con la población objeto de estudio de esta investigación, la edad inferior de los destinatarios de la escala original coincide con 
la edad techo de nuestra población objeto de estudio. Además, a nivel internacional se están realizando adaptaciones de la herramienta para niños de 5 a 9 años y para adultos jóvenes de más de 23 (RRC, 2018).

En la segunda parte de este trabajo se acomete la traducción, adaptación y validación de la CYRM-28 (Liebenberg et al., 2012) a población infantil española con NEAE y sin ellas. También se comprobaran los perfiles de resiliencia en función de diversas variables personales y ambientales. Posteriormente, analizaremos las relaciones hipotetizadas entre la resiliencia y los resultados personales en calidad de vida y participación en actividades de ocio de una muestra amplia de alumnos de Primaria con NEAE y sin ellas. Por último, discutiremos los hallazgos realizados y concluiremos con una síntesis sobre la potencialidad de las tres variables seleccionadas, calidad de vida, participación en actividades de ocio y resiliencia para la promoción del desarrollo positivo de los niños y niñas españoles con y sin necesidades específicas de apoyo educativo. 





\section{Introducción Parte Empírica}

A lo largo de los capítulos de la parte teórica de esta tesis se ha resaltado la importancia de enfocar el desarrollo infantil desde un prisma de crecimiento positivo. Para comprender el desarrollo de los niños desde un punto de vista saludable y exitoso, el planteamiento teórico de este trabajo se centra en la interacción del niño con su ambiente, más concretamente, en la interrelación que se establece entre los factores personales y ambientales, presentes en los contextos infantiles, con capacidad de determinar las vías del desarrollo infantil.

Tal como se justifica en la parte teórica de este trabajo, en las últimas décadas tres de los resultados personales más predominantes en el campo delainvestigación y práctica infantil han sido el de calidad de vida, participación y resiliencia en niños en condiciones diversas de vida (Badia et al., 2013; CIF, 2001, 2007; King et al., 2003, 2009; Schalock et al., 2002, 2003; Ungar, 2012, 2015; Wallander et al., 2016). En los capítulos 2, 3 y 4 se ha detallado cómo la investigación en cada uno de estos tres constructos está aportando luz a la comprensión de la naturaleza del crecimiento positivo, así como a la influencia que el entorno próximo tiene en él. Aunar estos tres constructos en un mismo modelo explicativo tiene el potencial de ampliar la actual perspectiva ecológica sobre desarrollo humano, basado en resultados personales significativos de bienestar y éxito infantil, ofreciendo un mapa conceptual más completo de las relaciones que se establecen entre los diferentes factores intervinientes en los procesos de crecimiento de niños que se desarrollan en contextos de vida diversos.

Para analizar las relaciones entre calidad de vida, participación en actividades diversas y resiliencia infantil, así como el peso de otros factores personales y ambientes en estas tres variables, son necesarios instrumentos fiables y válidos, capaces de avalar los resultados de las inferencias realizadas por los expertos en desarrollo infantil.

A nivel internacional, la investigación está dejando constancia de la fortaleza de algunas de estas herramientas, tales como, las analizadas en la parte teórica de este trabajo. Tres de ellas han sido las seleccionadas para esta investigación, el instrumento kidscreen-27 (Ravens-Sieberer et al., 2007) que mide la calidad 
de vida infantil relacionada con la salud, el CAPE (King et al., 2007) construido para registrar aspectos objetivos y subjetivos de la participación en actividades de ocio y tiempo libre, y la medida de resiliencia $C Y R M-28$ (Ungar et al., 2011) elaborada para evaluar los recursos personales y ambientales que actúan como fuentes de resiliencia en menores en situaciones adversas de vida. Estas herramientas proporcionan información, ofrecida por los propios niños, acerca de las experiencias personales vividas en los entornos próximos de desarrollo. En sus procesos cotidianos de desarrollo, estas experiencias se traducen como barreras o facilitadores que ayudan u obstaculizan su crecimiento positivo, dando lugar a resultados personales más o menos significativos para ellos.

A nivel nacional, contar con herramientas que aporten tal profundidad de información resulta de capital importancia para la realización de intervenciones infantiles de calidad en España, destinadas a la gran diversidad de niños que se desarrollan dentro de sus fronteras, tales como, los de la población objeto de estudio de esta tesis: niños que por sus condiciones personales y/o ambientales presentan necesidades específicas de apoyo educativo en su contexto escolar, y sus compañeros sin ellas. Investigaciones previas se han ocupado de garantizar la viabilidad de algunos de estos instrumentos dirigidos a población infantil y juvenil en condiciones diversas de vidas, como las versiones españolas del kidscreen (Ravens-Sieberer et al., 2007; Ravens-Sieberer et al., 2008) y el CAPE (Longo et al., 2012). En tanto que en el presente trabajo nos ocuparemos de garantizar la disponibilidad de la CYRM-28 (Ungar et al., 2011), y el uso conjunto de estas tres herramientas para alumnos españoles de Primaria con NEAE y sin ellas.

En definitiva, con la finalidad de ofrecerles entornos de desarrollo que favorezcan su bienestar e integridad personal y social, así como respuestas a las necesidades individuales de cada uno de ellos, la investigación española requiere seguir profundizando en el desarrollo teórico y operativo de los constructos de calidad de vida, participación y resiliencia infantil, por lo que esta investigación propone:

1. Adaptar y validar la medida de resiliencia CYRM-28 (Ungar et al., 2011) población infantil española de alumnos de Primaria con NEAE y sin ellas. 
2. Identificar variables personales y ambientales asociadas a los resultados personales en calidad de vida, resiliencia y participación en actividades de ocio y tiempo libre de alumnos de Primaria con NEAE y sin ellas.

3. Analizar la relación que se establece entre los resultados en calidad de vida, resiliencia y participación en actividades diversas de alumnos de Primaria con NEAE y sin ellas.

Los objetivos planteados pretenden proporcionar información válida para la planificación, elaboración y puesta en marcha de intervenciones que favorezcan la consecución de resultados de vida positivos en población infantil y juvenil. Esta información será de utilidad práctica para los profesionales del campo del desarrollo infantil, tales como, educadores, proveedores de servicios educativos y administradores de políticas públicas, quienes podrán elaborar nuevas propuestas prácticas, centradas en el bienestar y capacitación para la vida adulta de los más jóvenes, desde el fomento de las ecologías escolares e innovación del sistema educativo en las que se sustentas las escuelas de enseñanza ordinaria de nuestro país.

La investigación desarrollada para la consecución de estos objetivos se detalla en los siguientes tres capítulos. En el capítulo 5 se describe de forma pormenorizada el proceso de adaptación y validación de la medida de resiliencia CYRM-28(Ungar et al., 2011) para población infantil española, en el capítulo 6 se presentan los resultados de los análisis inferenciales sobre los resultados personales en calidad de vida, participación en actividades extraescolares y resiliencia infantil de alumnos de Primaria con NEAE y sin ellas, así como la influencia de otras variables personales y ambientales en dichos resultados, mientras que en el capítulo 7 se acomete el estudio de las relaciones causales y condicionales existentes entre las tres variables de interés. Para concluir este trabajo, en el capítulo 8 se presenta los resultados generales obtenidos, las aportaciones científicas realizadas e implicaciones para la práctica infantil, así como las limitaciones y pasos futuros de esta línea de investigación. 



\section{Capítulo 5}

Adaptación de la CYRM-28 a Población Infantil Española de Alumnos con Necesidades Específicas de Apoyo Educativo y Sin Ellas

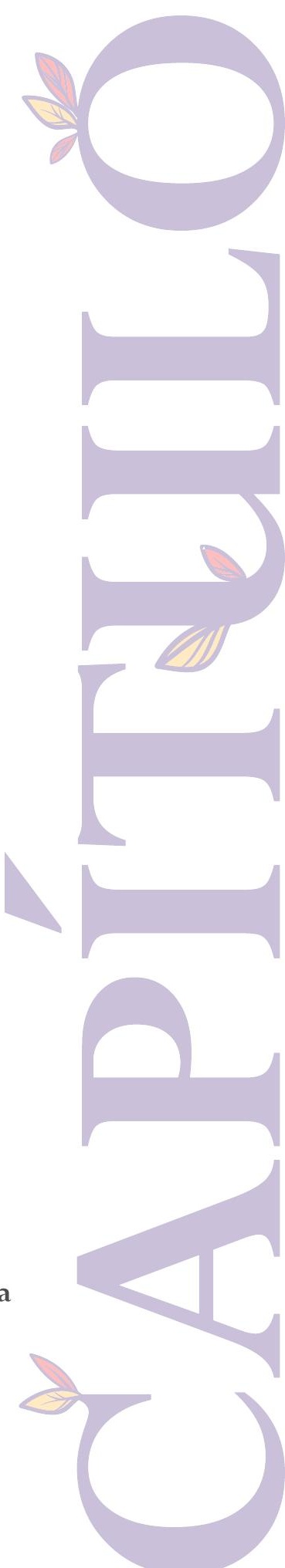





\section{Adaptación de la CYRM-28 a Población Infantil Española de Alumnos con Necesidades Específicas de Apoyo Educativo y Sin Ellas}

\section{Introducción}

En este primer capítulo de la parte empírica de la presente investigación se aborda el proceso de adaptación de la escala de resiliencia transcultural CYRM-28 (Ungar el at., 2011) a población infantil española. Concretamente, la versión infantil española de la $C Y R M$ ha sido adaptada para analizar y describir la resiliencia en alumnos de Primaria con necesidades NEAE y sin ellas. Para su elaboración se ha seguido los criterios guía de Comisión Internacional de Tests para el desarrollo de escalas adaptadas a contextos culturales e idiomáticos distintos a los de las escalas originales (ITC, 2017; Muñiz, Elosua y Hambleton, 2013). La versión adaptada de la escala consta de 22 ítems agrupados en 3 subescalas de resiliencia: familiar, individual y social. La CYRM-22 nos permite evaluar la percepción que niños españoles entre 10 y 12 años tienen de sus recursos personales y ambientales para el desarrollo de su resiliencia. A continuación se detalla el procedimiento seguido para el desarrollo de la CYRM-22.

\subsection{Planteamiento Inicial}

Como vimos en el capítulo anterior la resiliencia se presenta como un constructo dirigido a la evaluación e intervención del riesgo presente en la vida de los niños durante sus etapas de desarrollo (Brodersen, 2013). Más concretamente, el Resilience Research Centre (RRC, 2017) de Canadá define la resiliencia como:

1. La capacidad de las propias personas para dirigirse (navegar) hacia los recursos que sustentan su bienestar,

2. la capacidad de los entornos físicos y sociales en los que se desarrolla la propia persona para proveer de tales recursos, y 
3. la capacidad de las personas, sus familias y sus comunidades para negociar las formas culturalmente significativas para compartir los recursos.

Desde este enfoque socio-ecológico, resiliencia es sinónimo de cumplir con las expectativas preestablecidas culturalmente sobre lo que significa un adecuado funcionamiento personal y social en un determinado contexto (Brodersen 2013). De esta forma, la resiliencia se vuelve especialmente susceptible a las variaciones del contexto, a la sostenibilidad de los recursos existentes para apoyar el desarrollo positivo de personas pertenecientes a distintos colectivos sociales, así como a las diferencias de estatus y poder entre las personas como individuos y dentro de un grupo para definir su propio bienestar (Bottrell, 2009; Ungar, 2012).

El avance teórico del constructo de resiliencia ha llevado a la construcción de diversas escalas para su medida en población infantil, juvenil y adulta. Sin embargo, como se ha visto con anterioridad en este trabajo, el desarrollo de la medida de resiliencia aún está en sus etapas iniciales. Actualmente existen pocos instrumentos consistentes que valoren la resiliencia en las primeros años de vida. De estos, la mayoría se centran en poblaciones adolescentes y juveniles, y en menor grado en población infantil. Aquellos desarrollados para evaluar la resiliencia infantil muestran escasas propiedades psicométricas y poca capacidad de validar la estructura factorial del modelo teórico de partida (Windle et al., 2011). Además, en lo que concierne a la presente investigación, ninguna de ellas ha sido adaptada a población infantil o juvenil con discapacidad o necesidades especiales.

Por otra parte, dada la evolución teórica del constructo, así como la complejidad de su medida, la mayoría de las escalas de resiliencia se centran en su plano individual y en menor grado en una visión ecológica más amplía que tenga en cuenta variables de distintos niveles de interacción personaambiente (individuo, familia, comunidad). De todos ellos la $C Y R M$ es la única medida desarrollada hasta el momento que valora el componente cultural para la evolución positiva de la persona ante situaciones de estrés, riesgo o adversidad (Windle et al., 2011; Ungar et al., 2011). 


\subsubsection{La Medida de Resiliencia Infantil y Juvenil (CYRM)}

La medida de resiliencia de niños y jóvenes (CYRM) es un instrumento que valora los recursos individuales, relacionales, comunitarios y culturales que están accesibles y disponibles para las personas, y que tienen potencial para reforzar su resiliencia (Ungar et al., 2011). El instrumento ha sido desarrollado por el RRC a través del proyecto internacional de resiliencia llevado a cabo en 14 comunidades juveniles de 11 regiones del mundo (Canadá, África, China, Rusia, Colombia, Estados Unidos, etc.). La finalidad de este proyecto fue investigar las tensiones entre la homogeneidad y heterogeneidad en los resultados de resiliencia de jóvenes de distintas comunidades del mundo, con objeto de elaborar una medida transcultural de resiliencia (Ungar y Liebenberg, 2009).

El proyecto de construcción de la CYRM siguió cuatro fases: 1) contextualización; 2) desarrollo de la medida; 3) aplicación piloto; 4) análisis estadísticos. La descripción del procedimiento detallado puede consultarse en los trabajos publicados por Ungar y su equipo (Ungar et al., 2005; Ungar et al., 2007). Los resultados de dicho trabajo dieron lugar a una escala de 58 ítems (Ungar et al., 2007). Posteriormente, con objeto de reducir la escala a aquellos ítems que mejor representaban el constructo de resiliencia en las 14 comunidades participantes, se realizó un análisis que redujo la escala a 28 ítems (Liebenberg et al., 2012). La validez de esta última versión, la CYRM-28, fue probada con dos grupos de jóvenes canadienses (Liebenberg et al., 2012). Con la información del primer grupo de jóvenes se realizó un análisis factorial exploratorio que dio lugar a una estructura de tres factores capaz de explicar el 59\% de la variabilidad de los datos. Con respecto al análisis de su consistencia interna, el alfa de Cronbanch fue aceptable en las tres agrupaciones, oscilando en un rango de 0.65 a 0.91 . Mientras que, la correlación entre factores (de .583 a .773) mostró una relación positiva y significativa entre ellos. El contenido teórico de los factores hacía alusión a: 1) características individuales; 2) relación con los cuidadores primarios; y 3) componentes contextuales que facilitan el sentido de pertenencia. Estas categorías se correspondían con indicadores del constructo de resiliencia, 
tales como, la autoeficacia, la sociabilidad y la conexión cultural (Garmezy, 1991; Luthar et al., 2000a; Masten, 2001; Rutter 1999; Werner et al., 2004). En una segunda fase de estudio, a través de análisis multigrupo, se confirmó la estructura de tres factores de la escala y se hallaron sub-dimensiones dentro de cada uno de los tres componentes (Figura 9). Como evidencias de validez se realizaron pruebas de validez discriminante utilizando como variable de comparación la pertenencia al grupo de la minoría o la mayoría sociocultural de la población objeto de estudio (Liebenberg et al., 2012).

Figura 9. Modelo resultante del análisis factorial confirmatorio de la CYRM-28

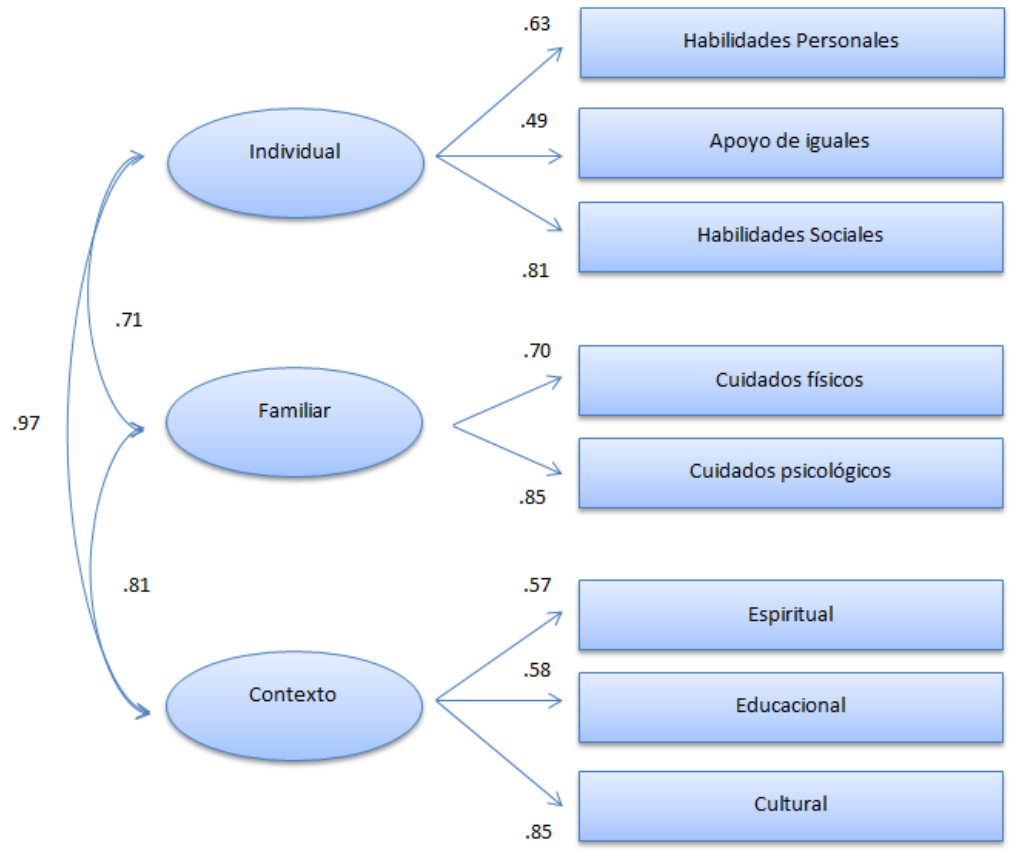

Nota. Adaptado de The Child and Youth Resilience Measure-28: User Manual (p. 17), por Resilience Research Centre, 2009, Dalhousie University.

Investigaciones posteriores han demostrado la consistencia interna de su medida, alta validez aparente, así como fuertes cargas factoriales en las subescalas de la CYRM-28 (Daigneault, Dion, Hébert, McDuff y Collin- 
Vézina, 2013; Panter-Brick, Hadfield, Dajani, Eggerman, Ager y Ungar, 2017; Sanders, Munford, Thimasarn-Anwar y Liebenberg, 2015). Estos resultados han sido obtenidos con datos provenientes de grupos de adolescentes con necesidades complejas que acuden a servicios comunitarios, tales como, intervenciones en salud mental u otros servicios sociales.

Una de las principales aportaciones de la medida de la CYRM es su marco transcultural. Dada la tendencia actual de un mundo cada vez más globalizado, con una alta tasa de movimientos migratorios y gran diversidad cultural, una herramienta de evaluación que genera resultados consistentes independientemente del contexto cultural del participante es actualmente de gran valor (Muñiz et al., 2013; Van de Vijver y Poortinga, 2005). Por otra parte, el modelo socio-ecológico de su medida (Bronfenbrenner, 1979, 2002) permite evaluar la resiliencia en una amplia variedad de ámbitos concernientes a la vida de las personas, además de los efectos positivos que está mostrando su aplicación en intervenciones socio-comunitarias (Ungar, 2015b). Dadas estas dos cualidades de la $C Y R M$, amplitud contextual y transculturalidad de su medida, desde esta investigación se prevé que los resultados de una herramienta basada en un marco socio-ecológico de resiliencia puedan tener un impacto positivo sobre la forma en que son conceptualizados por los agentes educativos los alumnos con NEAE y sin ellas, así como en la mejora, cambio y eficacia de las intervenciones educativas en atención a la diversidad.

\subsubsection{La Medida de Resiliencia para Población Infantil con NEAE y Sin Ellas}

Aunque la $C Y R M$ no está diseñada específicamente para ser utilizada con alumnos con NEAE se ha seleccionado esta escala y no otra, debido al modelo teórico que sustenta su medida y al procedimiento llevado a cabo para su aceptabilidad, validez y utilidad sociocomunitaria (Ungar, 2016). En otras investigaciones sobre desarrollo de poblaciones de adolescentes en riesgo, la CYRM ha demostrado su potencial para discernir entre diferentes niveles y patrones de resiliencia en jóvenes expuestos a diversas circunstancias adversas 
(Brodersen, 2013; Collin-Vézina, Coleman, Milne, Vender y Daigneault, 2011; Montoya et al., 2011). La mayor parte de estas investigaciones se han realizado desde el ámbito social, sanitario o clínico con poblaciones de menores expuestos a violencia, pobreza o marginalización racial. Sin embargo, no se ha encontrado ningún trabajo orientado desde el campo de la educación que contemple directamente la resiliencia en población infantil con discapacidad o NEAE. Por ello, los objetivos de esta parte de nuestro estudio han sido:

1. Adaptar la $C Y R M$-28 (Ungar et al., 2011) a la población infantil española.

2. Validar la versión adaptada de la $C Y R M-28$ para su uso con alumnos de Primaria con NEAE y sin ellas.

Los objetivos específicos para el alcance de los dos objetivos generales expuestos han sido los siguientes:

1. Adaptar la CYRM-28 (Ungar et al., 2011) a población infantil española:

1. Elaborar una primera versión de la escala siguiendo los criterios establecidos por los autores para la adaptación de la escala original a otros contextos (Ungar, 2016) y los criterios de la Comisión Internacional de Test (ITC, 2017; Muñiz et al., 2013).

2. Realizar una aplicación piloto de la escala en una muestra de estudiantes de tercer ciclo de Primeria con NEAE y sin ellas.

2. Validar la versión adaptada de la $C Y R M-28$ para su uso con alumnos de Primaria con NEAE y sin ellas:

2.1. Analizar la calidad psicométrica de los ítems para determinar la consistencia de su medida y descartar aquellos ítems que no aportan valor a la escala.

2.2. Estudiar la estructura interna de la escala tratando de probar el modelo multidimensional de la escala original.

2.3. Comprobar la validez externa de la estructura resultante mediante correlatos externos y pruebas de validez convergente con la medida de calidad de vida Kidscreen-27 (Ravens-Sieberer et al., 2007). 
2.4. Alcanzar una versión definitiva de la escala ajustándonos a los resultados psicométricos obtenidos tras la aplicación inicial del instrumento.

3. Utilizar la versión definitiva de la escala como medida de crecimiento positivo de alumnos de Primaria con NEAE y sin ellas, y como herramienta de análisis de factores determinantes de su calidad de vida.

\subsection{Método}

La escala que presentamos se ha desarrollado siguiendo los criterios guía de la Comisión Internacional de Tests (ITC, 2017; Muñiz et al., 2013) y los criterios expuestos por los autores de la CYRM-28 (Ungar, 2016) para la adaptación de la escala a contextos locales.

\subsubsection{Procedimiento}

El proceso de adaptación de la escala de resiliencia a población infantil española consta de una serie de etapas, a través de las cuales se fue dando consecución a los objetivos expuestos en el apartado anterior (Figura 10).

Figura 10. Síntesis metodología seguida para la adaptación poblacional de la CYRM-28

\section{ADAPTACIÓN LINGÜIISTICA Y CULTURAL DE LA CYRM - 28}

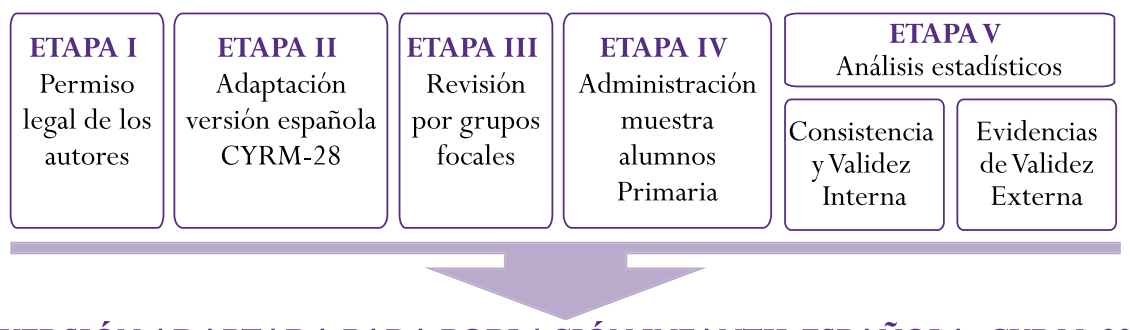

VERSIÓN ADAPTADA PARA POBLACIÓN INFANTIL ESPAÑOLA: CYRM-22

Nota. Adaptado de "Construcción y validación de escalas de medición en salud: revisión de propiedades psicométricas”, por Luján-Tangarife y Cardona-Arias, 2015, Archivos de medicina, 11,3:1, 3 . 
Previamente a la fase de construcción de la versión adaptada de la escala de resiliencia se llevó a cabo un exhaustivo trabajo de revisión bibliográfica a nivel nacional e internacional, mediante el cual se realizó la evaluación teórica y operativa de las actuales escalas de resiliencia más destacadas en el campo de la investigación y la práctica profesional. Este trabajo de revisión ha sido descrito en el capítulo 4 de la parte teórica de esta investigación. A partir de esta primera fase de cribado, se seleccionó la escala de resiliencia CYRM28 debido a las características previamente descritas. Para más información sobre esta primera fase remitimos a los apartados 2 y 6 del capítulo 4 de este trabajo.

A continuación detallaremos cada una de las etapas concernientes a la adaptación de la $C Y R M-28$ a contexto a población infantil española de alumnos con NEAE y sin ellas.

\subsubsection{Etapa I: Permiso Legal de los Autores}

Atendiendo a las condiciones legales para adaptación de escalas (ITC, 2017) contactamos con el Dr. Ungar y la Dra. Liebenberg, coautores de la escala original, para obtener el permiso legal que nos permitiera llevar a cabo el trabajo de adaptación de la $C Y R M-28$ a población infantil española. A partir de este contacto la autora autorizó la adaptación de la escala, nos facilitó la versión colombiana de la $C Y R M-28$ y recomendó seguir el manual elaborado para el uso de la CYRM-28 en diferentes contextos mundiales (Ungar, 2016).

\subsubsection{Etapa II: Adaptación de la CYRM-28 a Contexto Infantil Español}

Se revisó el contenido lingüístico de los 28 ítems y se realizaron modificaciones léxicas para facilitar la comprensión de los niños españoles a las preguntas. Tomando en consideración las recomendaciones realizadas por el manual de la CYRM-28 (Ungar, 2016), se seleccionaron 10 ítems contextualizados a la población diana como complemento a la medida global de resiliencia. Para ello se tuvo en cuenta las características de la población 
objeto de estudio, el contexto en el que se iba a realizar la evaluación y el modelo teórico de partida. Se añadieron 10 preguntas referidas a fortalezas internas (ítem 27: sé encontrar solución a mis dificultades), habilidades sociales (ítem 30: doy abrazos a la gente que quiero) y oportunidades familiares (ítem 32: mi familia confía en mi), que aludían a la percepción que los niños tienen de sus recursos personales, relacionales y familiares para el desarrollo de la resiliencia (Tabla 15).

Tabla 15. Número y contenido de los ítems añadidos a la versión española de la CYRM-28

\begin{tabular}{cl}
\hline $\mathbf{N}^{0}$ ítems & Contenido \\
\hline 16 & En casa tengo la oportunidad de demostrar que soy responsable \\
22 & Sé que es lo que no sé me da bien \\
27 & Sé encontrar solución a mis dificultades \\
28 & Mis maestros piensan que soy listo/inteligente \\
29 & Doy abrazo a la gente que quiero \\
30 & Me da vergüenza que los demás sepan cómo me siento \\
31 & Pienso en lo que me gustaría ser de mayor \\
32 & Mi familia confía en mi \\
33 & Soy capaz de conseguir lo que me propongo \\
36 & Me gusta cómo soy con los demás \\
\hline
\end{tabular}

La inclusión de estos 10 ítems dio lugar a una escala de 38 ítems con preguntas referidas a las dimensiones individual, familiar y contextual de la resiliencia del niño.

\subsubsection{Etapa III: Revisión por Grupos Focales}

Con objeto de analizar la sencillez, utilidad y aceptación de su contenido, la escala fue sometida a la evaluación de dos grupos focales, uno formado por alumnos de tercer ciclo de Primaria con NEAE y sin ellas, y otro con docentes. Ambos grupos examinaron paralelamente el contenido de las instrucciones de los 38 ítems y el formato de respuesta de la escala. Con ánimo de facilitar su comprensión se propusieron modos alternativos de expresión lingüística y se seleccionaron ejemplos de la vida diaria de los 
niños como complemento al contenido de cada ítem. Por último, se valoró la idoneidad del formato de respuesta de 5 puntos tipo Likert para responder a las 38 preguntas planteadas. El resultado de esta tercera etapa fue una escala de 38 ítems adaptada a la población infantil española preparada para su administración a una muestra amplía de alumnos con NEAE y sin ellas.

\subsubsection{Etapa IV: Administración a una Muestra de Alumnos de Primaria}

Dado que la adaptación de un cuestionario a una población diferente para la que fue confeccionado puede alterar la consistencia y validez de su medida, la versión adaptada de la escala de resiliencia: $C Y R M$ - 38, fue administrada a una muestra de 374 alumnos de tercer ciclo de Primaria con NEAE y sin ellas. El tamaño de la muestra era suficientemente amplio para los análisis posteriores (Martínez-Arias, Hernández-Lloreda y Hernández-Lloreda, 2014; Muñiz et al., 2013). Sus características y el procedimiento de acceso a ella se describen en el apartado siguiente.

\subsection{Solicitud Autorización y Consentimiento Informado}

El procedimiento de aplicación de la $C Y R M-38$ se realizaba en sesiones de cuarenta y cinco minutos de duración que correspondían a una sesión lectiva escolar. El cuestionario se administraba colectivamente a alumnos en general y aquellos con NEAE que no necesitaban apoyos adicionales para la realización de la tarea. Primeramente, se exponía brevemente el objetivo de la tarea, se recalcaba su carácter anónimo y confidencial, y la importancia de contestar a todas las preguntas, además se ofrecía un turno de preguntas para la aclaración de dudas. Tras esta primera fase daba comienzo la tarea de respuesta al cuestionario. La evaluadora principal estaba en todo momento presente ofreciendo ayuda ante posibles dudas o dificultades. Cada alumno completaba su cuestionario. Al final, se abría un turno de palabra en el cual se pedía a los alumnos su apreciación sobre el contenido, la dificultad y la utilidad de la tarea realizada. 
En el caso de aquellos alumnos que requerían apoyo personalizado para la respuesta personal y autónoma a la $C Y R M-38$ se proporcionaba la ayuda y soportes necesarios para la realización de la tarea. Estos apoyos iban desde la aplicación individual de las escalas, lectura en voz alta de las preguntas, soportes visuales a los ítems y formatos de respuesta, ejemplos adicionales para la comprensión del contenido de algunas preguntas, hasta la dedicación de varias sesiones para la realización completa de la evaluación.

Adicionalmente, los alumnos respondían a la escala de calidad de vida para población infantil Kidscreen-27 (Ravens-Sieberer et al., 2007), descrita en el capítulo 2 de la parte teórica de este trabajo, y a un cuestionario sobre variables sociodemográficas y educativas. La aplicación de ambos instrumentos se realizaba en una segunda sesión de evaluación, siguiendo el mismo procedimiento de administración detallado para la $C Y R M-38$. Por otra parte, durante el tiempo que duraba las sesiones de evaluación de los alumnos, los equipos directivos se encargaban de facilitar a docentes y familiares voluntarios un cuestionario sociodemográfico para el registro de la información escolar y familiar de los niños. Los instrumentos dirigidos a familias se enviaban a los domicilios y posteriormente eran entregados por las familias en los centros escolares. Tanto las respuestas de la escala Kidscreen-27 (Ravens-Sieberer et al., 2007), como la de los cuestionarios sociodemográficos para alumnos, docentes y familiares, fueron utilizadas en la etapa de análisis estadísticos para examinar la validez externa de la escala adaptada de resiliencia.

\subsubsection{Participantes}

El procedimiento de muestreo fue incidental. Sin embargo, pese a no ser una muestra probabilística, ésta reprodujo bastante fielmente las características de la población objeto de estudio.

La información se recogió a lo largo de cuatro cursos escolares, desde 2013 hasta 2016. Durante los dos primeros años la investigación se realizó en la Comunidad de Catilla y León (Salamanca y Ávila), y los dos últimos 
en Andalucía (Granada). El procedimiento de recogida de información comenzaba con el contacto directo, o vía telefónica, con la jefatura de estudios o dirección de los centros escolares. Posteriormente, se les facilitaba la carta de invitación a la participación donde se presentaba al equipo investigador, los objetivos de la investigación, el procedimiento de recogida de información y los beneficios de la participación en el estudio para los centros educativos colaboradores.

Como requisitos para la participación de los estudiantes, éstos tenían que estar matriculados en educación ordinaria y cursar tercer ciclo de Primaria. Como requerimiento adicional, se valoraba positivamente la presencia de NEAE para la participación del alumno en la investigación.

Tras el acuerdo de participación de las escuelas, se enviaba la carta de consentimiento informado a las familias trámite centro educativo. Una vez obtenido el consentimiento paterno se establecían las fechas para la administración de la escala. Todas las evaluaciones se llevaron a cabo personalmente para gestionar la evaluación y atender las necesidades y dudas de los alumnos participantes. El anonimato y confidencialidad de la información se aseguró a través de un código alfanumérico que remplazaba el nombre personal de los estudiantes participantes.

Finalmente, participaron en el estudio 374 alumnos y alumnas de tercer ciclo de Primaria con NEAE y sin ellas de las Comunidades Autónomas de Catilla y León y Andalucía. El total de alumnos participantes fue agrupado en función de diversas variables sociodemográficas y educativas (Tabla 16). Esta información sociodemográfica se obtuvo a partir de la información proporcionada por el alumnado y los profesionales de la educación participantes. 
Tabla 16. Características sociodemográficas y educativas de la muestra de alumnos $(N=374)$

\begin{tabular}{|c|c|c|c|}
\hline Variable & Categoría & $\mathbf{N}$ & $\%$ \\
\hline \multirow{2}{*}{ Sexo } & Niños & 199 & 53.4 \\
\hline & Niñas & 174 & 46.6 \\
\hline \multirow{4}{*}{ Edad } & 10 años & 124 & 33.2 \\
\hline & 11 años & 164 & 43.9 \\
\hline & 12 años & 76 & 20.3 \\
\hline & 13 años & 9 & 2.4 \\
\hline \multirow{2}{*}{$\mathrm{NEAE}^{\mathrm{a}}$} & $\mathrm{Si}$ & 80 & 21.4 \\
\hline & No & 294 & 78.6 \\
\hline \multirow{4}{*}{ Grupo NEAE ${ }^{a}$} & $\mathrm{NEE}^{\mathrm{b}}$ & 43 & 53.7 \\
\hline & $\mathrm{ACI}^{\mathrm{c}}$ & 10 & 12.5 \\
\hline & Integración tardía & 5 & 6.3 \\
\hline & Otras NEAE & 22 & 27.5 \\
\hline \multirow{2}{*}{ Curso } & $5^{\circ}$ & 202 & 54 \\
\hline & $6^{\circ}$ & 171 & 45.7 \\
\hline \multirow{3}{*}{ Titularidad del centro } & Público & 197 & 52.7 \\
\hline & Concertado & 172 & 46 \\
\hline & Privado & 4 & 1.1 \\
\hline \multirow{3}{*}{ CC.AA ${ }^{d}$} & Andalucía & 327 & 87.4 \\
\hline & $\mathrm{CyL}^{\mathrm{e}}$ & 46 & 12.3 \\
\hline & Otra & 1 & 0.3 \\
\hline
\end{tabular}

Nota. ${ }^{a}$ (NEAE) Necesidades Específicas de Apoyo Educativo. ${ }^{\text {b }}$ (NEE) Necesidades Educativas Especiales. ${ }^{\mathrm{c}}$ (ACI) Altas Capacidades Intelectuales. ${ }^{\mathrm{d}}$ (CC.AA) Comunidades Autónomas; ${ }^{\mathrm{e}}$ $(\mathrm{CyL})$ Castilla y León.

La distribución del género fue bastante homogénea $\left(\chi_{1}^{2}=1.68, \mathrm{p}>0.05\right)$. La edad media de los participantes fue de 10.9 años con una desviación típica de 0.79 , dentro de un rango de 10 a 13 años de edad. La distribución de esta variable evidenció cuatro grupos no homogéneos $\left(\chi_{3}^{2}=143.13, \mathrm{p}<0.05\right)$. El mayor número de casos se concentró en el grupo de 11 años (43.9\%), seguido del grupo de 10 años (33.2\%). 
De los 374 alumnos participantes en el estudio, 80 presentaban NEAE según los criterios de la actual ley educativa (Ley Orgánica 8, 2013). Actualmente, el sistema educativo español reconoce cuatro categorías de NEAE en las que se incluyen alumnos que por diversas circunstancias personales o sociales requieren durante su etapa educativa o en algún momento de ella apoyos educativos adicionales a la enseñanza ordinaria. Estas cuatro categorías son: 1) necesidades educativas especiales (NEE) por discapacidad o alteraciones en el desarrollo; 2) altas capacidades intelectuales (ACI); 3) incorporación tardía al sistema educativo, y 4) otras categorías de NEAE. Esta última categoría engloba el alumnado con retraso madurativo, trastornos del desarrollo del lenguaje y la comunicación, trastornos del aprendizaje, desconocimiento grave de la lengua de instrucción y situación de desventaja socioeducativa (MECD, 2017a). En nuestra muestra la categoría de NEAE más representada fue la de alumnos con NEE (53.7\%), seguida de la categoría de alumnos con otras NEAE (27.5\%), estudiantes con ACI (12.5) y, por último, integración tardía en el sistema educativo español (6.3\%). En términos generales, el porcentaje muestral de alumnos con NEAE de la muestra (21.4\%) superaba en representación al del sistema educativo ordinario (MECD, 2017b). La justificación de este desfase se debe a los objetivos del segundo y tercer estudio presentados en la parte empírica de este trabajo, en los cuales examinaremos los resultados personales de alumnos con NEAE y sin ellas en busca de factores del contexto moduladores de dichos resultados, así como relaciones subyacentes entre ellos que favorecen u obstaculizan el desarrollo infantil positivo.

Todos los alumnos participantes pertenecían a tercer ciclo de Primaria con una distribución del alumnado bastante homogénea con respecto a la variable curso $\left(\chi_{1}^{2}=2.58, \mathrm{p}>0.05\right)$, quedando ambos niveles bien representados. Con respecto a la titularidad de los centros educativos en los que se administró la escala, 52.7\% de los participantes asistían a centros de educación pública, mientras que el 46\% lo hacían a centros de educación concertada. La información de cuatro participantes, aunque cumplían el 
criterio de ser alumnos de enseñanza ordinaria, fue recogida a través de asociaciones privadas proveedoras de apoyo y servicios para el crecimiento positivo de los niños. Por último, la información sobre la Comunidad Autónoma en la que fue recogida la información pone de relieve una clara sobre-representación de los alumnos pertenecientes Andalucía (87.4\%), con respecto a los procedentes de Castilla y León (12.3\%).

Paralelamente, se recogió información de su entorno escolar y familiar para el estudio de la validez externa de la escala adaptada. En la Tabla 17 se presentan las variables escolares y familiares utilizadas para el análisis de los correlatos externos. Esta información fue proporcionada por padres y docentes de un subgrupo de alumnos participantes, y será utilizada posteriormente para el cumplimiento de otros objetivos de este trabajo.

Tabla 17. Características de las muestras de docentes $(N=49)$ y familiares $(N=106)$ participantes

\begin{tabular}{|c|c|c|c|c|}
\hline Informante & Variable & Categoría & $\mathbf{N}$ & $\%$ \\
\hline \multicolumn{5}{|l|}{ Doncente } \\
\hline & \multirow[t]{3}{*}{ Años de actividad docente } & Menos de 15 años & 18 & 36.7 \\
\hline & & De 16 a 30 años & 13 & 26.5 \\
\hline & & Más de 30 años & 5 & 10.2 \\
\hline \multicolumn{5}{|l|}{ Familia } \\
\hline \multirow[t]{6}{*}{ Madre } & \multirow[t]{3}{*}{ Nivel educativo } & Sin estudios formales & 1 & 100 \\
\hline & & Educación Obligatoria & 28 & 27.2 \\
\hline & & Educación Superior & 74 & 71.8 \\
\hline & \multirow[t]{3}{*}{ Estatus laboral } & Autónoma & 11 & 10.5 \\
\hline & & Empleada & 59 & 56.2 \\
\hline & & Desempleada & 35 & 33.3 \\
\hline \multirow[t]{10}{*}{ Padre } & \multirow[t]{3}{*}{ Nivel educativo } & Sin estudios formales & 5 & 5.1 \\
\hline & & Educación Obligatoria & 30 & 30.3 \\
\hline & & Educación Superior & 64 & 64.6 \\
\hline & \multirow[t]{3}{*}{ Estatus laboral } & Autónomo & 26 & 26.5 \\
\hline & & Empleado & 53 & 54.1 \\
\hline & & Desempleado & 19 & 19.4 \\
\hline & \multirow[t]{4}{*}{ Ingresos económicos } & Menos de $9000 €$ /anuales & 23 & 24.2 \\
\hline & & De 9000 a $17000 € /$ anuales & 27 & 28.4 \\
\hline & & De 17000 a $30000 €$ /anuales & 25 & 26.3 \\
\hline & & Más de $30000 € /$ anuales & 20 & 21.1 \\
\hline
\end{tabular}




\begin{tabular}{lllrr}
\hline Informante & Variable & Categoría & N & \% \\
\hline $\begin{array}{l}\text { Miembros dedicado } \\
\text { a la crianza del hijo }\end{array}$ & Ambos progenitores & 47 & 52.8 \\
& & Madre & 37 & 41.6 \\
& Padre & 4 & 4.5 \\
& Otros & 1 & 1.1 \\
& \multirow{2}{*}{ Miembros de una asociación } & Si & 56 & 75.7 \\
& & No & 18 & 24.3
\end{tabular}

Cuarenta y nueve docentes dieron información acerca de ciertas características del entorno educativo de un subgrupo de alumnos participantes. Entre la información escolar recogida, se solicitó el número de años de actividad docente. La distribución de esta variable no fue homogénea $\left(\chi_{2}^{2}=24.04, p<0.05\right)$. La mayor parte de los profesionales participantes llevaban menos de 15 años trabajando como docentes (56.7\%) y en menor medida entre 16 y 30 años (27.8\%), siendo el grupo de docentes con más de 30 años de experiencia laboral el menos representado en la muestra (15.6\%).

Ciento seis familias ofrecieron información sobre características del entorno familiar del hijo de un subgrupo de alumnos participantes. La edad media de las madres fue de 43.1 años, mientras que la de los padres de 44.7 años, ambos grupos con una desviación típica de 5.6. La mayoría de las madres $(71.8 \%)$ y padres $(64.6 \%)$ participantes tenían un nivel educativo superior y se encontraban laboralmente activos en el momento de la evaluación (Tabla 3). La distribución de los ingresos familiares anuales fue homogénea $\left(\chi_{3}^{2}=1.13, \mathrm{p}>0.05\right)$, quedando las cuatro categorías de ingresos similarmente representadas. La crianza y cuidado del hijo era en su mayor parte compartida por ambos progenitores (52.8\%) o responsabilidad única de la madre (41.6). Por último, las familias informaron sobre su pertenencia a asociaciones proveedoras de apoyos y servicios para el crecimiento positivo de los niños. La mayor parte de las familias que respondieron a esta variable informaron ser miembros de una asociación de estas características (75.7\%). 


\subsubsection{Análisis Estadísticos}

\subsubsection{Etapa V: Análisis Estadísticos}

Una vez recogida la información de los participantes se realizaron los análisis estadísticos correspondientes para comprobar la idoneidad psicométrica, potencial explicativo y utilidad de la medida de la versión adaptada de la CYRM-28.

Para el desarrollo de todos estos análisis se utilizaron los programas estadísticos SPSS v.21 y FACTOR 10.5.03. (Lorenzo-Seva y Ferrando, 2006; 2013). SPSS v.21 se utilizó para los análisis exploratorios iniciales de los ítems y el estudio de su consistencia interna, así como para los análisis posteriores realizados para el estudio de la validez externa de la escala, mediante correlaciones bivariadas entre escalas y variables externas. El estudio de la estructura interna, mediante matrices de correlaciones policóricas se realizó con las opciones avanzadas de FACTOR 10.5.03. FACTOR es un programa para el desarrollo de análisis factoriales semi-confirmatorios enmarcado tanto en los modelos de ecuaciones estructurales (SEM), como en las teorías de respuesta al ítem (TRI) (Ferrando y Lorenzo-Seva, 2017ª). Los análisis realizados con FACTOR a través de estudios de simulación están demostrando un alto grado de desarrollo técnico, el cual es comparable, e incluso superior en algunos de sus análisis, al de otros programas estadísticos comerciales (Lloret, Ferreres, Hernández y Tomás, 2017).

\subsection{Consistencia y Validez de la Medida de Resiliencia}

En primer lugar se realizó un análisis exploratorio de los 38 ítems y se examinó la frecuencia, distribución central y variabilidad de sus respuestas. Posteriormente se exploró la consistencia interna de su medida. Se comprobó su índice de homogeneidad, eliminándose aquellos ítems con coeficientes elemento-total por debajo de 0.300 (Martínez-Arias et al., 2014). Se volvió a calcular los índices de confiabilidad de los ítems restantes, tales como, la correlación múltiple al cuadrado y el coeficiente de fiabilidad Alfa de Cronbach (Cortada de Kohan, 1999). 
Para estudiar la estructura interna de la escala y analizar su coincidencia con la estructura de la escala original, se realizó un análisis factorial semiconfirmatorio (Ferrando y Lorenzo-Seva, 2013; Ferrando et al., 2017a). El análisis de los coeficientes de correlación entre ítems se desarrolló a partir de la matriz de correlaciones policóricas de los datos, más idónea para el análisis de variables ordinales creadas mediante el uso de escalas de cuantificación tipo Likert que las correlaciones lineales de Pearson (Bandalos y Finney, 2010; Bryant y Satorra, 2012; Ferrando y Lorenzo-Seva, 2014; Muthén y Kaplan, 1992).

Para la estimación de los parámetros del modelo se seleccionó el método de extracción mínimos cuadrados no ponderados: ULS (Joreskög, 1977) y su variante robusta RULS (Yang-Wallentin, Jöreskog y Luo, 2010), con estadísticos de ajuste basados en la corrección de medias, tal como implementa el programa FACTOR (Lorenzo-Seva et al., 2006; 2013). ULS es el método de estimación paramétrico basado en la matriz de correlaciones policóricas $\mathrm{y}$, por tanto, recomendado para variables categóricas y distribuciones asimétricas (Morata-Ramírez, Holgado-Tello, Barbero-García y Méndez, 2015; Schmitt, 2011), que está demostrando el mismo grado de satisfacción técnica en el ajuste de modelos factoriales exploratorios y semiconfirmatorios que los procedimientos confirmatorios clásicos (Ferrando et al., 2017a). Por su parte, para lograr la simplicidad máxima de los factores se utilizó el método de rotación oblicua Promin (Lorenzo-Seva, 1999), que funciona comparativamente a Oblimin superándolo ligeramente al producir soluciones más simples (Ficapal-Cusí Torrent-Sellens, Boada-Grau y Hontangas-Beltrán, 2014; Lorenzo-Seva et al., 2006, 2013). Promin se basa en un análisis de Procrustes Generalizado para la comparación de conjunto de datos (Lorenzo-Seva, Kiers y Ten Berge, 2002; Ten Berge, 1977), que optimiza la solución factorial resultante. Con respectos a las saturaciones de los ítems, fueron considerados significativos pesos factoriales superiores a 0.300 (Álvarez, Castro, González-González, Álvarez y Campo, 2016).

Con objeto de contrastar el ajuste global del análisis factorial (AF) se probaron 4 modelos plausibles de factores: 3 modelos multidimensionales 
de $1^{\circ}$ orden; y 1 modelo bifactorial de $2^{\circ}$ orden. La idoneidad de los modelos se valoró a partir de los siguientes índices: la raíz cuadrada media del error de aproximación (RMSEA) y el índice de bondad de ajuste (GFI), como medidas de ajuste absoluto que determinan el grado de exactitud en que el modelo global predice satisfactoriamente la matriz de correlaciones observada (Lévy-Mangin y Varela-Mallou, 2006); el índice de ajuste no normalizado (NNFI) y el índice de ajuste comparativo (CFI) como medidas de ajuste incremental con respecto al modelo de independencia nula (Lloret-Segura et al., 2014; Ferrando et al., 2017b); y la raíz media cuadrática residual estandarizada (RMSR), como medida de las diferencias entre los valores predichos y los realmente observados. Los índices GFI, NNFI y CFI se valoraron como aceptables a partir de 0.90 (Bentler y Bonett, 1980), y RMSEA y RMSR por debajo de .08 (Hu y Bentler, 1999). Aunque para una mayor idoneidad del modelo global seleccionado se tuvieron en cuenta valores superiores a 0.95 para GFI, NNFI y CFI, e inferiores a 0.05 para RMSEA (Lévy-Mangin et al., 2006; Marhs, Hau y Wen, 2004).

Otro índice calculado fue la variación mejorada del Análisis Paralelo: AP (Horn, 1965) sobre la base del análisis de factor de rango mínimo (MRFA), que ofrece el programa FACTOR (Timmerman y Lorenzo-Seva, 2011). El AP-MRFA se realizó como alternativa a los métodos clásicos de estimación de factores (Lloret-Segura et al., 2014). Para la retención de factores el AP-MPFA utiliza 2 criterios: la media de la varianza aleatoria extraída y el percentil 95 del porcentaje aleatorio de varianza, reteniendo aquellos factores en los que los datos reales superen a los estimados aleatoriamente (Ferrando Lorenzo-Seva, 2017b; Timmerman et al., 2011). Adicionalmente, se valoró el criterio de información bayesiano de Schwarz: BIC (Schwarz, 1978) y se tuvo en cuenta el modelo operativo de la escala original para decidir el número más apropiado de factores.

Alternativamente, para la elección del modelo más óptimo se exploró: 1) la determinación y precisión de las puntaciones de los factores propuestos; 2) la simplicidad de la solución factorial; 3) la replicabilidad 
del constructo; y 4) la cercanía de los datos a la unidimensionalidad de las soluciones factoriales obtenidas (Ferrando et al., 2017b).

Para determinar la precisión de la puntuación de los factores se obtuvo, por un lado, el índice de determinación de los factores: FDI (Brown y Croudace, 2015). Valores a partir de 0.90 indican que las estimaciones correspondientes a las puntuaciones de los factores salientes son buenas representaciones de las puntuaciones de los factores latentes (Grice, 2001). Por otro lado se calculó el ORION o fiabilidad total de las puntuaciones de N-EAP oblicuas anteriores totalmente informativas. En donde las EAP son las estimaciones esperadas a posteriori de las puntuaciones de rasgos latentes en los modelos de respuesta al ítems (Ferrando y Lorenzo-Seva, 2016). Los valores de referencia del ORION se sitúan por encima de 0.80 .

La simplicidad de las estructuras de los factores se estimó mediante el índice de Simpleza (S) de Bentler (Bentler, 1977) y el índice simpleza de carga (LS) (Lorenzo-Seva, 2003). Estos índices evalúan la tendencia de los ítems a cargar sobre una sola dimensión, cuanto más altos son los valores más simple es la solución (Ferrando et al., 2017b). Puntuaciones a partir de 0.90 apoyan la simplicidad de la solución factorial dada (Lorezo-Seva, 2003).

Para evaluar la replicabilidad del constructo se calculó el coeficiente $\mathrm{H}$ (Hancock, 2001) que evalúa cuán bien un conjunto de ítems representa un factor latente (Dominguez-Lara, 2016). Coeficientes a partir de 0.70 indican que hay una variable latente bien definida $y$, por tanto, con mayor probabilidad que se mantenga a través de los estudios (Hacock y Muller, 2000). El programa FACTOR ofrece dos medidas de $\mathrm{H}$ : H-latente, que indica cuán bien puede ser identificado un factor a través de las variables de respuesta latente que subyacen a las puntuaciones observadas, y H-observada, que muestra cuán bien el factor puede ser identificado a partir de las puntuaciones (Ferrando y Lorenzo-Seva, en prensa).

En tanto que, para el estudio de la cercanía de los datos a la unidimensionalidad se calculó el ECV o la varianza común explicada correspondiente al primer factor saliente, que mide esencialmente la dominancia del primer factor 
MRFA sobre los siguientes factores obtenidos (Ferrando et al., 2017b). Es importante notar que una clara dominancia de éste puede ser compatible con una polarización multidimensional de los datos (Reise, Cook y Moore, 2015).

\subsection{Evidencias de validez externa}

Para probar la validez externa de la versión adaptada de la CYRM-28 a población infantil española se realizaron pruebas de correlación bivariada entre las puntuaciones de los factores y diecisiete variables independientes de tipo personal y ambiental (escolar y familiar). También se obtuvieron las correlaciones entre estas puntuaciones y cinco escalas de contraste correspondientes al cuestionario de calidad de vida infantil Kidscreen-27. Los resultados de estos análisis dieron evidencias de validez de contraste y relación con otras variables personales y del entorno cercano del niño. La validez discriminante de la escala adaptada de resiliencia será probada en el capítulo 6 al analizar los resultados personales de alumnos con NEAE y sin ellas en función de variables personales y ambientales de su entorno cercano.

\subsection{Resultados}

\subsubsection{Análisis Descriptivos}

En primer lugar se realizó un análisis exploratorio de los 38 ítems incluidos en la escala. Los análisis de su consistencia interna desvelaron 10 artículos con correlaciones elemento-total por debajo de 0.300. Siguiendo las indicaciones de Nunnally y Bernstein (1994) estos 10 ítems fueron eliminados. A continuación, se realizó un segundo análisis estadístico de los ítems y se volvió a comprobar los índices de confiabilidad de los ítems restantes. El resultado de esta primera criba fue una escala compuesta de 28 ítems con un alfa de Cronbach de 0.88 . De estos 28 ítems, 7 pertenecían al apartado de ítems del contexto local de la escala adaptada y 21 a la escala original: 9 pertenecientes a la escala de resiliencia individual, 6 a la de resiliencia familiar, y 6 a la de resiliencia del contexto (Ungar, 2016). 
La Tabla 18 presenta los índices de distribución central (media) y dispersión (desviación típica, asimetría y curtosis) de los ítems. Los análisis descriptivos de los 28 ítems mostraron que sus distribuciones eran por lo general asimétricas, con coeficientes de asimetría y curtosis superiores a 1. La prueba de Mardia (1970) constató el incumplimiento del supuesto de normalidad multivariante (Coeficiente de Mardia $=1278.116 ; \mathrm{p}=$ $0.0000 *)$. Teniendo en cuenta que el rango de opción de respuesta oscilaba entre 1 y 5 puntos, las medias de los ítems fueron altas. La puntuación media más alta fue de 4.82 (ítem 20: creo que es importante ayudar a los demás) y la más baja de 3.99 (ítem 24: cuando tengo un problema normalmente puedo solucionarlo sin hacerme daño y sin hacérselo a otros).

Tabla 18. Estadísticos descriptivos de los 28 items seleccionados para los análisis de validez interna

\begin{tabular}{ccccc}
\hline Ítem & Medía & DT $^{\mathbf{a}}$ & Asimetría & Curtosis \\
\hline 2 & 4.04 & .834 & -0.597 & 0.021 \\
3 & 4.58 & .812 & -2.313 & 5.72 \\
4 & 4.33 & .945 & -1.428 & 1.512 \\
6 & 4.41 & .780 & -1.534 & 2.951 \\
8 & 4.83 & .504 & -3.852 & 17.762 \\
10 & 4.45 & .857 & -1.735 & 3.031 \\
11 & 4.47 & .855 & -1.988 & 4.233 \\
12 & 4.01 & 1.070 & -0.96 & 0.279 \\
13 & 4.17 & 1.050 & -1.212 & 0.79 \\
14 & 4.57 & .743 & -1.956 & 4.113 \\
15 & 4.23 & .929 & -1.343 & 1.875 \\
16 & 4.37 & .883 & -1.379 & 1.565 \\
17 & 4.75 & .661 & -3.096 & 10.732 \\
19 & 4.08 & .848 & -0.838 & 0.815 \\
20 & 4.82 & .502 & -3.619 & 16.672 \\
21 & 4.53 & .769 & -1.828 & 3.459 \\
24 & 3.99 & 1.020 & -0.97 & 0.555 \\
25 & 4.77 & .641 & -3.766 & 17.669 \\
26 & 4.72 & .643 & -2.659 & 7.58 \\
27 & 4.09 & .858 & -1.064 & 1.791 \\
28 & 4.21 & .915 & -1.313 & 2.536 \\
31 & 4.36 & 1.100 & -1.825 & \\
\hline & & & & \\
\hline
\end{tabular}




\begin{tabular}{ccccc}
\hline Ítem & Medía & DT $^{\mathrm{a}}$ & Asimetría & Curtosis \\
\hline 32 & 4.50 & .816 & -1.959 & 4.073 \\
33 & 4.24 & .777 & -0.758 & 0.054 \\
34 & 4.70 & .728 & -2.814 & 7.878 \\
35 & 4.63 & .643 & -2.212 & 7.088 \\
36 & 4.33 & .735 & -0.972 & 0.956 \\
38 & 4.75 & .596 & -3.299 & 14.029 \\
\hline
\end{tabular}

Nota. Ítem $=$ rango de puntuación de los ítems de 1 (nunca) a 5 (siempre) puntos. ${ }^{a}(\mathrm{DT})$ Desviación típica.

Tras la inspección del poder discriminativo de los ítems (índice de homogeneidad) y la distribución de sus puntuaciones, y teniendo en cuenta el número de opciones de respuesta y el tamaño de la muestra $(\mathrm{N}=374)$, se seleccionó un modelado policórico para el análisis de la estructura interna de la escala (Lloret et al., 2014).

\subsubsection{Análisis Validez Interna}

Debido a que en el presente estudio se ha realizado la adaptación de la CYRM-28 a una población objeto de estudio con características diversas a la de la escala original, en la que se han añadido y eliminado ítems de la versión original de la escala. Para el estudio de la estructura interna de la versión adaptada de la $C Y R M$ se optó por realizar un análisis semi-confirmatorio con el programa estadístico FACTOR (Ferrando et al., 2006; 2013). Por otra parte, teniendo en cuenta el tamaño muestral, tipo de respuesta categórica y la distribución de las puntuaciones de los ítems, se realizó un análisis factorial no lineal basado en la matriz de correlaciones policóricas (Ferrando et al., 2014). El ajuste del análisis factorial a la matriz policórica de los ítems es equivalente a la versión de Samejima (1969) del modelo de respuesta graduada en teoría de respuesta al ítem (TRI) (Ferrando et al., 2013; Reckase, 2009).

Los resultados de la media de adecuación muestral Kaiser-Mayer-Olkin $(\mathrm{KMO}=0.83) \mathrm{y}$ el test de esfericidad de Bartlett's $\left(\chi_{(171)}^{2}=17000.3\right.$, 
$\mathrm{p}<.001$ ), así como de la matriz de determinación (0.0004), sugirieron que la correlaciones entre los ítems eran suficientemente consistentes para ajustarse a un modelo factorial.

En referencia al número de factores los resultados de la implementación óptima del AP (Timmerman et al., 2011) indicaron que el número más apropiado de factores a extraer eran 2. Por su parte, el índice de bondad de ajuste BIC también alcanzó su mínimo en el modelo de 2 factores (Tabla 19).

Seguidamente a los análisis univariantes de los ítems y tras comprobar la adecuación de los datos, se puso a prueba la estructura factorial de los ítems a través de 4 modelos factoriales hipotéticos: 3 modelos factoriales de primer orden y un $4^{\circ}$ modelo bifactorial de segundo orden. Para la elección del número hipotético de factores a examinar se tuvo en cuenta, tanto consideraciones de tipo teórico (modelo factorial de la escala original), como empírico (recomendaciones estadísticas de los índices AP-MRFA y BIC en el análisis de los datos).

La Tabla 19 muestra los índices de bondad de ajuste obtenidos para los 4 modelos factoriales probados: a) un modelo de 2 factores; b) un modelo de 3 factores; c) un modelo de 3 factores reducido, a partir del cual se exploró; d) un modelo bifactorial formado de un factor general y 3 factores específicos. A nivel global, los 4 modelos obtuvieron valores óptimos en los diferentes índices de ajuste valorados. Comprobamos como en todos los casos se cumple el criterio de $\chi^{2} /$ gl $<2$ de Hoelter (1983). Del mismo modo el RMSEA da lugar a valores de ajuste superiores a los recomendables $(<.05)$, al igual que RMSR $(<.08)$. Con respecto a los índices incrementales (GFI, CFI y NNFI) todos se sitúan por encima de 0.95 . Sin embargo, dado el método de estimación utilizado (ULS), la elección del modelo más adecuado se realizó mediante la evaluación del ajuste de aquellos índices que no dependen directamente de la ji-cuadrado: el índice GFI y RMSR (Ferrando et al., 2014; McDonald, 1999). 
Tabla 19. Resultados de los índices de bondad de ajuste de los cuatro modelos factoriales probados

\begin{tabular}{cccccccccc}
\hline Modelos & N & $\begin{array}{c}\text { \% varianza } \\
\text { explicada }\end{array}$ & $\chi^{2}$ & RMSEA & GFI & RMSR & NNFI & CFI & BIC \\
\hline A & 378 & 40.0 & $479.68(323)$ & .038 & .96 & .07 & .98 & .99 & 966.544 \\
B & 378 & 45.6 & $403.35(297)$ & .033 & .97 & .06 & .99 & .99 & 1052.507 \\
C & 231 & 49.6 & $207.35(168)$ & .027 & .98 & .06 & .99 & .99 & 717.399 \\
D & 231 & 55.3 & $162.23(149)$ & .016 & .99 & .05 & .99 & .99 & 799.797 \\
\hline
\end{tabular}

Nota. RMSEA $=$ error cuadrático medio de aproximación; GFI $=$ bondad del índice de ajuste; RMSR = residuo cuadrático medio; CFI = índice de ajuste comparativo; BIC $=$ criterio de información bayesiano; $\mathrm{a}=$ Modelo bidimensional de primer orden $(28$ ítems); $\mathrm{b}=$ Modelo multidimensional de primer orden (28 ítems); $\mathrm{c}=$ Modelo reducido multidimensional de primer orden (22 ítems); $\mathrm{d}=$ Modelo bifactorial de segundo orden: 1 factor general y 3 factores agrupados (22 ítems).

El primer modelo examinado fue una estructura de 2 factores de primer orden. Los valores obtenidos en los índices GFI (GFI $=.96)$ y RMSR (RMSR $=.07)$, mostraron el buen ajuste del modelo. El valor de BIC fue menor que en el segundo modelo probado de 3 factores, tal como indicó el AP-MRFA. En cuanto a las cargas factoriales, la saturación de los ítems fue variada (promedio entre .305 y 1.001), obteniendo un ítem con carga superior a la unidad, el cual saturaba en ambos factores (ítems 26). A continuación, se examinó un modelo de 3 factores que mostró un ajuste sensiblemente mejor que el modelo anterior $(\mathrm{GFI}=.97 \mathrm{y}$ RMSR $=.06)$. Las cargas factoriales de este modelo fluctuaban entre -.302 y 0.919 , y un elemento que no llegaba al peso mínimo estimado (ítem 28). Al comprobar el contenido de los ítems de cada factor (Kahana, Youngstrom y Glutting, 2002), se apreció que los ítems con pesos mayores se referían a: fortalezas internas (Factor 1); resiliencia familiar (Factor 2); apoyo de iguales (Factor 3), coincidiendo a groso modo con el contenido de las escalas de la versión original de la CYRM-28. Las correlaciones entre factores fueron altas y significativas oscilando de $\mathrm{r}=$ .562 a $r=.751(\mathrm{p}<.001)$.

Con objeto de simplificar la segunda solución factorial obtenida se eliminaron de la matriz factorial rotada aquellos ítems con cargas inferiores a 0.40 (Martínez-Arias et al., 2014). Los ítems seleccionados fueron el 
3, 20, 26, 28, 31 y 32. Estos 6 ítems eran además los más conflictivos de las agrupaciones factoriales formadas en el segundo modelo, debido a: su contenido ambiguo con respecto al factor en el que saturaban (ítems 3: para mi es importante ir a la escuela - Factor 2: resiliencia familiar); cargas cruzadas similares (ítems 20: creo que es importante ayudar a los demás, saturaba en los Factores 1 y 2); o ausencia de carga en ningún factor (ítems 28: mis maestros piensan que soy inteligente). Los 22 ítems restantes se volvieron a rotar, dando lugar a una tercera estructura factorial. Este modelo formado por 3 factores de primer orden superó a los dos modelos anteriores, mostrando un excelente ajuste a los datos de partida $(\mathrm{GFI}=.98 ; \mathrm{RMSR}=.06)$. Además, aumentó el porcentaje de varianza explicada y disminuyó el valor del BIC con respecto al modelo base de 3 factores. Todos los ítems presentaron cargas factoriales altas y significativas $(\lambda$ entre .382 y $.883 ; \mathrm{p}<.001)$, y sus factores estaban altamente correlacionados entre sí (de .523 a .689). La solución factorial de este modelo fue más parsimoniosa que las dos estructuras anteriores.

Las altas correlaciones factoriales observadas en la tercera estructura examinada llevó al análisis de un modelo jerárquico de segundo orden, con un factor general y 3 factores agrupados. Este cuarto modelo fue el que mejores índices de ajuste reflejó con respecto a los cuatro modelos examinados (GFI = $.99 ;$ RMSR $=.05)$, siendo capaz de explicar un 55.3\% de la variabilidad de los datos. La Tabla 20 muestra las comunalidades y patrón de cargas salientes en la solución bifactorial. En ella se puede observar: 1) pesos factoriales entre .350 y. 645 ( $\mathrm{p}<.001)$ para un factor general de resiliencia, con ausencia de carga en el ítem 34 (tengo un grupo de amigos en la escuela), el cual comparte su carga entre los factores agrupados 1 y 2; 2) cargas factoriales principales entre .422 y $.333(\mathrm{p}<.001)$ para el Factor 1 relativo a recursos internos del niño para la resiliencia; 3) cargas factoriales principales entre .616 y .353 ( $<$ <.001) para el Factor 2 concerniente a recursos familiares para la resiliencia, con una carga cruzada superior a .300 en el ítem 34 que satura significativamente más alto en el tercer factor; y 4) cargas factoriales principales entre .677 y .316 ( $\mathrm{p}<$ .001) para el Factor 3 referido al apoyo social para la resiliencia, con un peso de valencia negativa en el ítem 12 (habló con mi familia sobre cómo me siento), 
cuyo contenido teórico daba cuenta de la falta de adecuación con el resto de ítems de la agrupación.

Tabla 20. Comunalidades y cargas factoriales de los items para el modelo bifactorial de segundo orden

\begin{tabular}{|c|c|c|c|c|c|}
\hline Ítems $^{\mathrm{a}}$ & $\mathrm{C}^{\mathrm{b}}$ & $F^{a}{ }^{a}$ & $F 1^{b}$ & $F 2^{\mathrm{b}}$ & $\mathrm{F}^{\mathrm{b}}$ \\
\hline 24 & .450 & .509 & .442 & & \\
\hline 2 & .311 & .350 & .394 & & \\
\hline 6 & .402 & .511 & .376 & & \\
\hline 16 & .400 & .440 & .338 & & \\
\hline 27 & .376 & .455 & .333 & & \\
\hline 8 & .512 & .364 & & .616 & \\
\hline 10 & .377 & .400 & & .467 & \\
\hline 38 & .482 & .503 & & .443 & \\
\hline 17 & .546 & .600 & & .391 & \\
\hline 34 & .668 & & & .353 & .677 \\
\hline 15 & .560 & .451 & & & .584 \\
\hline 19 & .480 & .521 & & & .453 \\
\hline 21 & .549 & .532 & & & .450 \\
\hline 11 & .535 & .536 & & & .385 \\
\hline 12 & .529 & .614 & & & -.366 \\
\hline 36 & .361 & .510 & & & .316 \\
\hline 4 & .517 & .675 & & & \\
\hline 13 & .425 & .542 & & & \\
\hline 14 & .445 & .634 & & & \\
\hline 25 & .493 & .645 & & & \\
\hline 35 & .375 & .577 & & & \\
\hline
\end{tabular}

Nota. Ítem $=$ rango de puntuación de los ítems de 1 (nunca) a 5 (siempre) puntos; $\mathrm{C}=$ Comunalidades. ${ }^{\mathrm{a}}$ (FG) Factor general; ${ }^{\mathrm{b}}$ (F1, F2 y F3) Factores agrupados.

El modelo bifactorial presentaba una estructura simple según los principios propuestos por Thurstone (1935): cada factor tenía su propia distribución de cargas, con pocos pesos altos y el resto próximos a cero y cada variable saturaba significativamente en un único factor (Gaskin, 2016). Sin embargo, al calcular las confiabilidades marginales (ORION) correspondientes a cada 
factor agrupado [Factor 1 (.67); Factor 2 (.60); Factor $3(.72)$ ] y para el Factor General (.88), se obtuvieron índices de fiabilidad por debajo de los valores de referencia (Ferrando et al., 2016). Llegados a este punto, se decidió comparar los índices de determinación, precisión, simplicidad y replicabilidad del modelo bifactorial, con los de su modelo de partida: el modelo reducido de 3 factores de primer orden.

Tabla 21. Valores de los índices de determinación, simplicidad y replicabilidad del modelo bifactorial y su modelo factorial de partida

\begin{tabular}{|c|c|c|c|c|c|c|c|}
\hline & & \multicolumn{2}{|c|}{$\begin{array}{c}\text { Determinación y } \\
\text { Precisión de los factores }\end{array}$} & \multicolumn{2}{|c|}{$\begin{array}{c}\text { Simplicidad de la solu- } \\
\text { ción factorial }\end{array}$} & \multicolumn{2}{|c|}{$\begin{array}{l}\text { Replicabilidad } \\
\text { del constructo }\end{array}$} \\
\hline & & ORION & FDI & $S$ & SL & H-l & H-o \\
\hline \multirow[t]{3}{*}{$\mathrm{C}^{\mathrm{a}}$} & $\mathrm{F} 1$ & .84 & .92 & .98 & .40 & .88 & .72 \\
\hline & F2 & .90 & .95 & & & .85 & .77 \\
\hline & F3 & .85 & .92 & & & .87 & .71 \\
\hline \multirow[t]{4}{*}{$\mathrm{d}^{\mathrm{b}}$} & $\mathrm{F} 1$ & .66 & .81 & .90 & .33 & .62 & .48 \\
\hline & F2 & .60 & .77 & & & .64 & .38 \\
\hline & F3 & .72 & .85 & & & .79 & .57 \\
\hline & FG & .88 & .94 & & & .87 & .77 \\
\hline
\end{tabular}

Nota . ORION $=$ Confiabilidad marginal; FDI $=$ Índice de determinación de factores; $\mathrm{S}$ $=$ Índice de simpleza de Bentler; SL = Índice de sencillez de carga; $\mathrm{H}-\mathrm{l}=$ Coeficiente H-latente; H-o $=$ Coeficiente H-observado. ${ }^{a}$ (c) Modelo reducido multidimensional de primer orden. ${ }^{\mathrm{b}}$ (d) Modelo bifactorial de segundo orden: 1 factor general y 3 factores agrupados.

Los resultados de estos análisis (Tabla 21) muestran que la solución más precisa, simple y replicable es el tercer modelo factorial explorado. Todos los índices calculados para este tercer modelo fueron aceptables, encontrándose dentro de los márgenes de confianza descriptos con anterioridad. Por tanto, aunque un análisis factorial de segundo orden ajustó bien la matriz de datos $(\mathrm{GFI}=.99 ; \mathrm{RMSR}=.05)$, sugiriendo que las puntuaciones totales de la versión adaptada de CYRM podrían ser tratadas como medidas de un factor general de resiliencia, los datos relativos a esta investigación parecen ser escasos para demostrar tal aseveración. Sin embargo, para no dejar pendiente el tema de la unidimensionalidad de la escala adaptada se obtuvo el índice de varianza común esperada: ECV unidimensionales (Rodríguez, Resise, 
Haviland, 2016) para la solución reducida de 3 factores de primer orden. El valor de ECV fue de .79 indicando que de toda la varianza común explicada por este tercer modelo (Tabla 8), el 79\% ya era explicada por el primer factor calculado, lo que apoya un modelo jerárquico de resiliencia como el probado en este estudio.

Con respecto a los resultados de la estructura interna de la escala, los análisis factoriales realizados con las puntuaciones de la versión de la CYRM adaptada permitieron obtener un modelo de 3 factores de primer orden ajustado. La Tabla 22 muestra las comunalidades iniciales de los ítems, las saturaciones de la estructura factorial rotada, su varianza explicada y la matriz de correlación entre factores del modelo factorial seleccionado. El peso factorial más bajo fue de -.314 y el de la comunalidad de .280. El número de ítems agrupado en cada factor $(\mathrm{F} 1=8 ; \mathrm{F} 2=8 ; \mathrm{F} 3=6)$ fue adecuado al criterio mínimo de 3 ítems de Costello y Osborne (2005). El alto valor de simplicidad factorial indicado por los índices de simplicidad de Bentler (.98) y el de sencillez de carga (.40), fue ratificado por la inspección visual de la matriz de cargas rotada. Sólo hubo un elemento con estructura compleja, el ítems 12 que se relacionaba con el primer y tercer factor, pero con un peso significativamente mayor en el primero de ellos. La varianza total explicada de este modelo fue de $49.6 \%$.

Tabla 22. Comunalidades, cargas factoriales, varianza explicada y correlaciones entre factores del modelo factorial de 22 items de la versión adaptada de la CYRM

\begin{tabular}{|c|c|c|c|c|}
\hline Ítems & $\mathrm{C}$ & $F 1^{a}$ & $\mathrm{~F}^{\mathrm{b}}$ & $\mathrm{F}^{\mathrm{c}}$ \\
\hline 17. Mi familia está conmigo en los momentos difíciles & .559 & .848 & & \\
\hline 12. Hablo con mi familia sobre cómo me siento & .520 & .741 & & -.314 \\
\hline $\begin{array}{l}\text { 25. Cuando estoy con mi familia no tengo miedo, me } \\
\text { siento seguro }\end{array}$ & .477 & .650 & & \\
\hline 4. Mis padres saben que pienso y cómo me siento & .506 & .639 & & \\
\hline 14. Sé a quién pedir ayuda cuando lo necesito & .376 & .565 & & \\
\hline 8. Mi familia se preocupa por mi & .318 & .506 & & \\
\hline 10. Disfruto de las costumbre de mi cultura & .322 & .473 & & \\
\hline 38. Estoy orgulloso de la cultura de mi familia & .410 & .435 & & \\
\hline $\begin{array}{l}\text { 24. Cuando tengo un problema normalmente puedo solu- } \\
\text { cionarlo sin hacerme daño y sin hacérselo a otros }\end{array}$ & .462 & & .779 & \\
\hline
\end{tabular}




\begin{tabular}{|c|c|c|c|c|}
\hline Ítems & $\mathbf{C}$ & $F 1^{a}$ & $\mathbf{F} 2^{\mathrm{b}}$ & $\mathrm{F}^{\mathrm{c}}$ \\
\hline 6. Respeto las normas de casa y del cole & .409 & & .678 & \\
\hline 27. Se encontrar solución a mis dificultades & .380 & & .597 & \\
\hline 2. Ayudo a la gente con la que vivo & .280 & & .570 & \\
\hline $\begin{array}{l}\text { 13. En el cole tengo la oportunidad de demostrar que soy } \\
\text { responsable }\end{array}$ & .423 & & .533 & \\
\hline $\begin{array}{l}\text { 16. En casa tengo la oportunidad de demostrar que soy } \\
\text { responsable }\end{array}$ & .344 & & .483 & \\
\hline 33. Soy capaz de conseguir lo que me propongo & .250 & & .434 & \\
\hline 35. En general sé cuáles son las cosas que mejor hago & .258 & & .382 & \\
\hline 34. Tengo un grupo de amigos en la escuela & .593 & & & .883 \\
\hline $\begin{array}{l}\text { 15. Mis compañeros piensan que es divertido estar } \\
\text { conmigo }\end{array}$ & .557 & & & .766 \\
\hline $\begin{array}{l}\text { 21. Tengo amigos que me apoyan y ayudan cuando lo } \\
\text { necesito }\end{array}$ & .556 & & & .653 \\
\hline $\begin{array}{l}\text { 11. Tengo amigos que están a mi lado en los momentos } \\
\text { difíciles }\end{array}$ & .540 & & & .594 \\
\hline 19. Me gustan cómo me tratar las demás personas & .393 & & & .582 \\
\hline 36. Me gusta cómo soy con los demás & .329 & & & .419 \\
\hline Varianza total explicada (\%) & & 33.4 & 9.2 & 6.9 \\
\hline \multicolumn{5}{|l|}{ Matriz de correlaciones entre factores } \\
\hline $\mathrm{F} 1^{\mathrm{a}}$ & & 1 & & \\
\hline $\mathrm{F} 2^{\mathrm{b}}$ & & $.689 * * *$ & 1 & \\
\hline $\mathrm{F}^{\mathrm{c}}$ & & $.553 * * *$ & $.523 * * *$ & 1 \\
\hline
\end{tabular}

Nota. Comunalidades. ${ }^{a}$ (F1) factor 1 , recursos familiares para la resiliencia. ${ }^{\mathrm{b}}$ (F2) factor 2 , recursos personales para la resiliencia. ${ }^{\mathrm{c}}$ (F3) Factor 3, recursos sociales para la resiliencia. $* * *=\mathrm{p}<.001$.

El contenido teórico de estos tres factores se correspondía en gran medida con el modelo de 3 dimensiones de la CYRM-28 probado por Liebenberg y su equipo (2012) (ver Figura 8), a la vez que mostraba una estructura propia correspondiente a las características singulares de la población infantil española. De esta forma, el primer factor que hace referencia a los recursos familiares para la resiliencia infantil, fue el que más correspondencia mostró con su factor de origen "relación del niño con sus cuidadores primarios", segundo componente de la $C Y R M-28$. Con respecto al segundo factor, "recursos personales para la resiliencia”, 5 de sus 8 ítems pertenecían al 
componente individual de la $C Y R M-28$, y los 3 restantes fueron ítems añadidos seleccionados en el proceso de adaptación de la escala. Por último, el tercer factor de nuestro modelo al que hemos nombrado "recursos sociales para la resiliencia”, fue el que más difería en contenido del tercer componente de la CYRM-28 referente al contexto, ya que sólo 2 de sus 6 ítems correspondían a esta dimensión. Este tercer factor se relacionaba en gran medida con la dimensión individual con 3 ítems pertenecientes a ella, en concreto con su sub-dimensión de “apoyo de iguales". El último ítem del tercer factor pertenecía al grupo de indicadores añadidos para la adaptación de la escala a población infantil española. En la Tabla 23 se específica la correspondencia entre los ítems de la versión adaptada y los ítems de la escala original, así como las escalas y subescalas de pertenencia. 


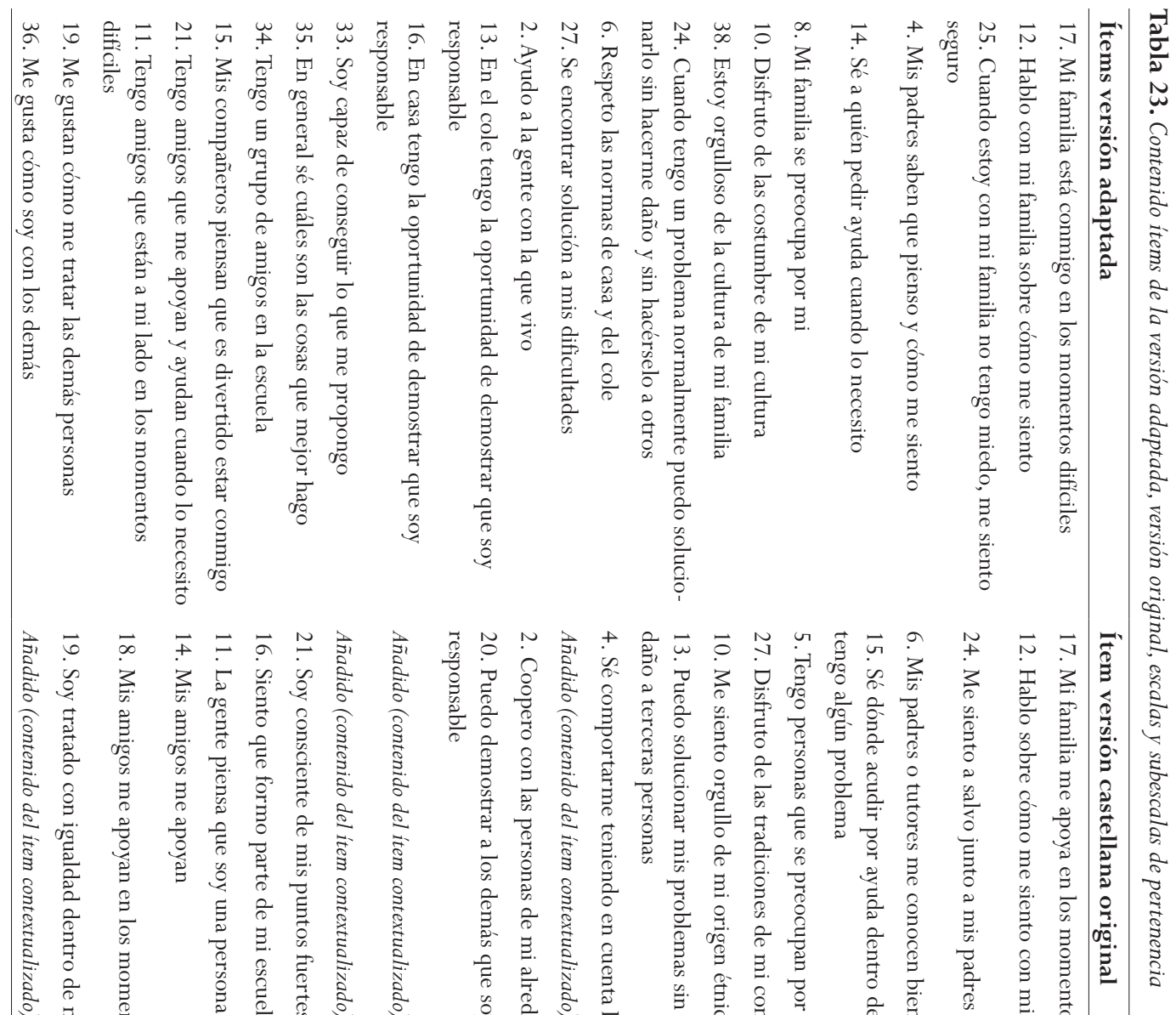

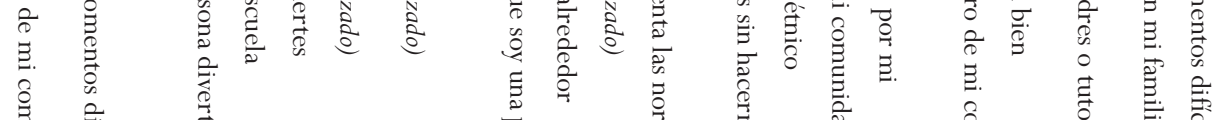

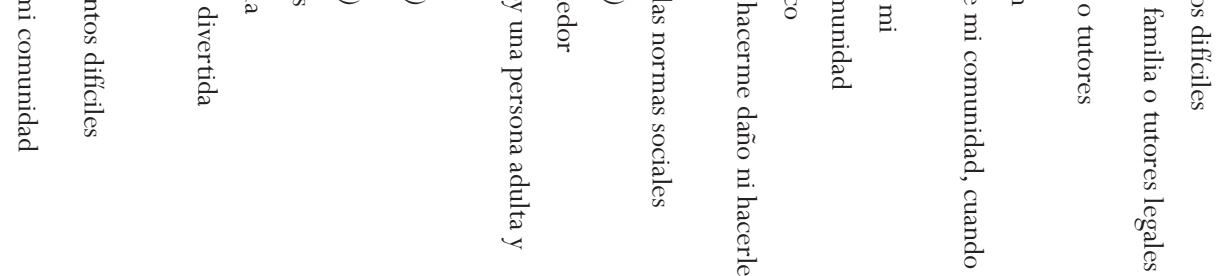

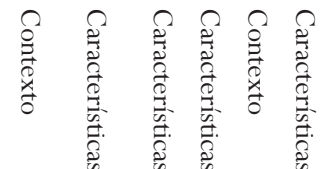

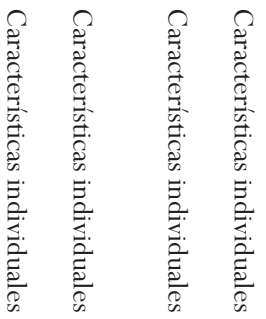

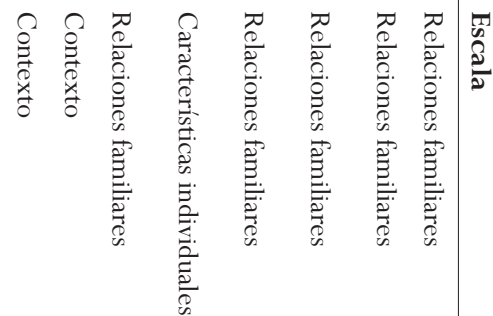

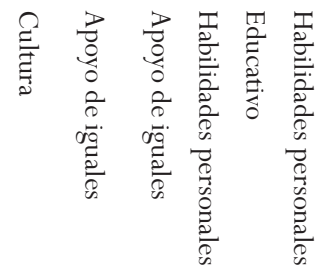

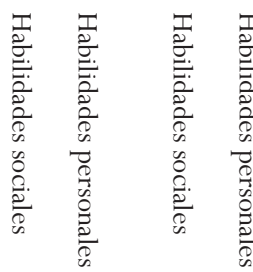

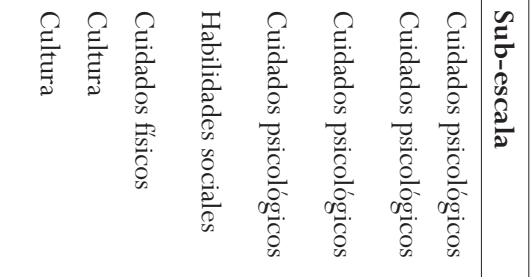


Finalmente, tras los análisis factoriales realizados, se obtuvo una escala de resiliencia de 22 ítems adaptada a población infantil española de alumnos con NEAE y sin ellas. A continuación, se comprobó los correlatos de su estructura multidimensional con diversas variables externas y las cinco escalas de bienestar del cuestionario de calidad de vida para población infantil Kidscreen-27 (Ravens-Sieberer et al., 2007), con objeto de probar su validez externa y convergente.

\subsubsection{Análisis Validez Externa}

En este apartado se presentan los estadísticos descriptivos de las escalas de la versión adaptada de la $C Y R M-22$, su consistencia interna, así como las primeras evidencias de su validez externa.

La Tabla 24 muestra la media, desviación estándar y confiabilidad de los tres factores. Todos los factores mostraron una fiabilidad alfa de Cronbach por encima de .70 (Nunnally et al., 1978): $\alpha_{\mathrm{F} 1}=0.73 \alpha_{\mathrm{F} 2}=0.73 ; \alpha_{\mathrm{F} 3}$ $=0.78$. Mientras que, el alfa de Cronbach estandarizado de la escala total aumento a .90 , valor muy similar al estimado mediante el índice de fiabilidad Omega (Mc Donald, 1999) que fue de 0.90.

En la Tabla 10 también se presentan las correlaciones de los factores con diecisiete variables externas de tipo personal y ambiental recogidas para probar la validez externa de la escala. Así como, las correlaciones con las cinco escalas de bienestar del cuestionario de calidad de vida infantil Kidscreen-27 (Ravens-Sieberer et al., 2007), con objeto de confirmar la validez convergente de la versión adaptada de la CYRM-28. 
Tabla 24. Estadísticos descriptivos, fiabilidad, intervalos de confianza y correlaciones de los factores con variables externas y escalas del Kidscreen-27 $(N=374)$

\begin{tabular}{|c|c|c|c|c|c|}
\hline \multicolumn{2}{|c|}{$\begin{array}{c}\text { Estadísticos descriptivos } \\
\text { y Fiabilidad }\end{array}$} & & $F 1^{a}$ & $\mathbf{F} 2^{\mathrm{b}}$ & $\mathrm{F}^{\mathrm{c}}$ \\
\hline$M^{d}$ & & & 36.24 & 33.71 & 26.17 \\
\hline $\mathrm{DT}^{\mathrm{e}}$ & & & 3.73 & 4.16 & 3.57 \\
\hline $\begin{array}{l}\text { Consistencia in } \\
\text { (95\% intervalo }\end{array}$ & e confianza) & & $\begin{array}{c}0.72 \\
(0.62-0.72)\end{array}$ & $\begin{array}{c}0.73 \\
(0.66-0.75)\end{array}$ & $\begin{array}{c}0.80 \\
(0.74-0.81)\end{array}$ \\
\hline \multirow{9}{*}{\multicolumn{2}{|c|}{$\begin{array}{l}\text { Características } \\
\text { Individuales }\end{array}$}} & Variables & $\mathbf{F} 1^{a}$ & $\mathbf{F} 2^{\mathrm{b}}$ & $\mathrm{F}^{\mathrm{c}}$ \\
\hline & & Género & $.128 *$ & $.128 *$ & .090 \\
\hline & & $\begin{array}{l}\text { Presencia de } \\
\text { NEAE }\end{array}$ & $.201 *$ & $.280 * *$ & .146 \\
\hline & & $\begin{array}{l}\text { Comunidad } \\
\text { autónoma }\end{array}$ & .059 & $.111 *$ & .075 \\
\hline & & $\begin{array}{l}\text { Tipo de } \\
\text { centro }\end{array}$ & .042 & $.204 * *$ & .078 \\
\hline & & Curso & .055 & .102 & .007 \\
\hline & & $\begin{array}{l}\text { Años activi- } \\
\text { dad docente } \\
\text { tutor }\end{array}$ & .058 & $.234 *$ & .190 \\
\hline & & $\begin{array}{l}\text { Seriedad de } \\
\text { la opinión del } \\
\text { alumno para } \\
\text { el tutor }\end{array}$ & $.135 *$ & $.153 * *$ & $.118 *$ \\
\hline & & $\begin{array}{l}\text { Asambleas en } \\
\text { clase }\end{array}$ & $.154 * *$ & .100 & $.129 *$ \\
\hline & $\begin{array}{l}\text { Características } \\
\text { familiares }\end{array}$ & $\begin{array}{l}\text { Rango de } \\
\text { edad }\end{array}$ & .055 & .076 & .062 \\
\hline & & & .003 & .048 & .066 \\
\hline & & $\begin{array}{l}\text { Nivel educa- } \\
\text { tivo }\end{array}$ & .055 & .004 & .062 \\
\hline & & & .028 & .009 & .163 \\
\hline & & Estado laboral & $.223 *$ & .065 & .122 \\
\hline & & & .088 & .040 & .051 \\
\hline & & $\begin{array}{l}\text { Ingresos } \\
\text { familiares }\end{array}$ & .005 & .085 & .122 \\
\hline & & $\begin{array}{l}\text { Miembro/s } \\
\text { dedicado a la } \\
\text { crianza }\end{array}$ & .140 & $.222 *$ & .184 \\
\hline
\end{tabular}




\begin{tabular}{|c|c|c|c|c|c|}
\hline $\begin{array}{c}\text { Correlatos } \\
\text { externos }\end{array}$ & Categorías & Variables & $F 1^{a}$ & $\mathbf{F} 2^{\mathrm{b}}$ & $\mathrm{F}^{\mathrm{c}}$ \\
\hline & & $\begin{array}{l}\text { Miembro de } \\
\text { una asocia- } \\
\text { ción }\end{array}$ & .063 & $.332 * *$ & .148 \\
\hline \multirow[t]{6}{*}{$\begin{array}{c}\text { Validez } \\
\text { convergente }\end{array}$} & Instrumento & Escalas & $F 1^{a}$ & $\mathbf{F} 2^{b}$ & $\mathbf{F} 3^{\mathrm{c}}$ \\
\hline & $\begin{array}{l}\text { Kindscreen-27 } \\
\text { (Ravens-Sieber- } \\
\text { er et al., 2007) }\end{array}$ & $\begin{array}{l}\text { Bienestar } \\
\text { físico }\end{array}$ & $.302 * *$ & $.334 * *$ & $.302 * *$ \\
\hline & & $\begin{array}{l}\text { Bienestar } \\
\text { emocional }\end{array}$ & $.294 * *$ & $.390 * *$ & $.473 * *$ \\
\hline & & $\begin{array}{l}\text { Vida familiar } \\
\text { y autonomía }\end{array}$ & $.332 * *$ & $.244 * *$ & $.319 * *$ \\
\hline & & $\begin{array}{l}\text { Apoyo social } \\
\text { y amigos }\end{array}$ & $.350 * *$ & $.313 * *$ & $.558 * *$ \\
\hline & & $\begin{array}{l}\text { Bienestar } \\
\text { escolar }\end{array}$ & $.411 * *$ & $.490 * *$ & $.482 * *$ \\
\hline
\end{tabular}

Nota. ${ }^{\text {a }}$ (F1) Resiliencia familiar. ${ }^{\mathrm{b}}$ (F2) Resiliencia individual. ${ }^{\mathrm{c}}(\mathrm{F} 3)$ Resiliencia social. ${ }^{\mathrm{d}}(\mathrm{M})$ Media. ${ }^{\mathrm{e}}$ (DT) Desviación típica. ${ }^{*} \mathrm{p}<.05 ; * \mathrm{*}<.01 ; * * \mathrm{p}<.001$.

Los alumnos participantes en nuestro estudio mostraron puntuaciones altas en las tres escalas de resiliencia. Las puntuaciones medias más altas se obtuvieron en la escala de resiliencia familiar, seguida de la escala de resiliencia individual y, por último, resiliencia social.

Los análisis de correlación mostraron relaciones positivas entre los factores y variables externas de tipo personal, escolar y familiar. En concreto la escala de resiliencia familiar correlación positiva y significativamente con variables escolares sobre metodología inclusiva en el aula (realizar asambleas en clase y seriedad de la opinión de los alumnos para los profesores), el género y la presencia de NEAE. La dimensión de resiliencia individual fue la escala que más correlaciones significativas estableció con las diferentes tipologías de variables registradas (Tabla 10). Mientras que la tercera escala, resiliencia social, lo hizo únicamente con dos, nuevamente con las variables escolares sobre metodología inclusiva citadas anteriormente. 
Por último, los análisis de correlación entre las escalas de resiliencia y las dimensiones de calidad de vida, también mostraron relaciones positivas entre todos los pares de escalas analizadas. Todos los valores de las correlaciones fueron medios-altos señalando la gran interconexión entre ambos conceptos, pero también su independencia para considerarlos dos constructos diferentes.

\subsection{Discusión}

La finalidad de este capítulo ha sido describir el proceso seguido para la adaptación y validación de la versión española de $C Y R M-28$ a población infantil española, debido a la inexistencia de un instrumento psicológico de sus características en contexto español. Este capítulo responde por tanto, aún objetivo instrumental del proyecto "análisis de determinantes de la calidad de vida de alumnos con NEAE y sin ellas" defendido en este trabajo.

Tras el proceso de adaptación descrito en este capítulo se ha obtenido una escala adaptada de resiliencia de 22 ítems. Las evidencias de validez interna centradas en la dimensionalidad del instrumento nos permiten concluir que la versión infantil española, CYRM-22 está compuesta de tres subescalas: resiliencia familiar, resiliencia individual y resiliencia social. Estas tres dimensiones hacen referencia a los recursos personales y ambientales de tipo familiar, individual y social para el desarrollo de la resiliencia infantil en nuestro país.

la primera dimensión de la versión española de la $C Y R M$ está formada por ocho indicadores de resiliencia familiar para el crecimiento positivo de los niños. Esta dimensión representan 33.4\% de la varianza explicada. Contiene aspectos tales como la comunicación, seguridad o desarrollo de actividades familiares. Esta dimensión contiene 5 de los 7 ítems de la subescala original, mientras que de los tres ítems restantes, uno corresponde a la subescala individual (14. Sé a quién pedir ayuda cuando lo necesito) y dos a la de contexto (10. Disfruto de las costumbres de mi cultura; 38. Estoy orgullo de la cultura de mi familia). Sin embargo, es interesante destacar que el 
contenido de estos dos últimos ítems hace referencia a los recursos culturales de tipo familiar para el desarrollo de la resiliencia del niño.

La segunda dimensión es la de resiliencia individual y está relacionada con los recursos personales y oportunidades de su ambiente cercano para la representación de las propias fortalezas del niño, que le permiten hacer frente a los desafíos y problemáticas de su día a día. Representa el 9.2\% de la variabilidad total y también está compuesta de ocho ítems. Está dimensión contiene 5 indicadores de la subescala original y 3 ítems añadidos en el proceso de adaptación de la escala adaptada. Estos tres ítems hacen alusión a las oportunidades ambientales (16. En casa tengo la oportunidad de demostrar que soy responsable) y fortalezas internas (33. Soy capaz de conseguir lo que me propongo; 35. En general sé cuáles son las cosas que mejor hago) para la representación de la resiliencia individual.

La última dimensión, resiliencia social, está relacionada fuertemente con el apoyo de los iguales como recursos sociales para el desarrollo de la resiliencia infantil. Representa el 6.9\% de la varianza total y está formado por seis ítems, de los cuales cuatro aluden a las relaciones de apego y confianza con los iguales. Esta dimensión es la que más difiere de su homónima en escala original. Contiene tres indicadores de la subdimensión apoyo de iguales de la subescala de resiliencia individual original, dos ítems de la subescala de resiliencia contextual, y un ítem añadido relativo a la percepción social que tienen los niños de sí mismos (36. Me gusta como soy con los demás).

En conjunto, las tres dimensiones representa el 49.6\% de la variabilidad total de la escala, superando la capacidad explicativa de la escala original CYRM-28 (40.4\%) (Lieberbeng et al., 2012) y de la adaptación francesa CYRM-27 (39\%) (Daigneault et al., 2013). Las correlaciones entre los tres factores en nuestro estudio son medias-altas: .689 (F1 y F2), .553 (F1 y F3) y .523 (F2 y F3), indicando la fuerte relación existente entre las tres dimensiones de resiliencia que miden y, al mismo tiempo, su capacidad para evaluar diferentes aspectos de ésta. 
Pese a la estructura multidimensional probada, la $C Y R M-22$ muestra en su totalidad una fuerte carga unidimensional, tal como sucede con otras escalas de resiliencia que a pesar de tratar de probar una estructura jerárquica de resiliencia han mostrado un grado de unidimensionalidad elevado, donde las facetas específicas de resiliencia apenas aportan información más allá del primer factor general obtenido (Ponce-Cisternas, 2015). Este hecho conlleva la necesidad de trabajar la estructura interna de la versión infantil española CYRM-22 con muestras de mayor tamaño, con objeto de realizar estudios de validez cruzada y análisis factoriales confirmatorios, o su alternativa ESEM (Asparouhov y Muthén, 2009). Pese a la defensa teórica de un constructo de resiliencia multidimensional, a nivel empírico parece difícil separar las características personales de resiliencia de las provenientes del ambiente, de hecho, en nuestro estudio el primer factor concerniente a recursos familiares para el desarrollo de la resiliencia infantil, es capaz de explicar el 67.34\% del total de varianza explicada por los tres factores del modelo resultante. Cabe destacar también, que mientras que en las adaptaciones juveniles y adultas los indicadores de resiliencia individual son los primeros en saturar (Daigneault et al., 2013; Lieberbeng et al., 2012; Ponce-Cisternas, 2015), en nuestro estudio con población infantil el primer factor ha estado compuesto principalmente por indicadores referentes a la familia. Este hecho, nos lleva a reflexionar acerca de la importancia que los recursos del entorno inmediato al niño juegan en el desarrollo de su resiliencia (Ungar, 2012; 2015; Walsh, 2006).

El diseño de la CYRM-22 aúna las potencialidades de los instrumentos de resiliencia individual y resiliencia contextual, incluyendo un amplio y representativo rango de circunstancias donde los niños españoles pueden percibir recursos para el desarrollo de su resiliencia familiar, personal y social. Ha mostrado fuertes evidencias de la consistencia y validez interna de su medida. El valor de la fiabilidad total de la escala (.90) es similar al de otras adaptaciones de la $C Y R M-28$, mientras la de sus subescalas de encuentran por debajo de éstas (Ungar y Lieberbeng, 2013). Sin embargo, todas ellas se encuentran dentro de los valores de referencia (Nunnally et al., 
1978). Respecto a la validez de su modelo, los altos valores obtenidos en los índices de ajuste a los datos (GFI $=.98 ;$ RMSR $=.06)$, apoyan con fuerza el modelo de resiliencia infantil de tres factores, así como la simplicidad ( $\mathrm{S}=$ .98) y replicabilidad de su estructura (H latente de .85 a .88). Por último, las correlaciones positivas y significativas obtenidas entre sus dimensiones, variables externas de tipo personal y ambiental, y las escalas de bienestar del instrumentos Kidscreen-27 (Ravens-Sieberer et al., 2007), han mostrado los primeros indicios de la validez externa de la CYRM-22. Las correlaciones positivas y significativas obtenidas entre las dimensiones de la $C Y R M-22$ y el Kidscreen-27, reflejan el estrecho vínculo que mantiene la resiliencia con el bienestar físico, emocional y social de la persona, ya defendido en este trabajo y examinado por otros investigadores (Lee et al., 2010).

Prestando atención a las cinco fuentes de validez enunciadas por los estándares para el desarrollo de pruebas psicológicas y educativas (AERA, APA, NCME, 2014). La validez del contenido de la CYRM-22 se ha asegurado mediante el trabajo realizado por los autores originales de la de la escala en el proyecto internacional para el desarrollo de la medida de resiliencia transcultural (Ungar, 2016). La validez de los procesos de respuesta se apoya en el procedimiento seguido para la recogida de la información, en que se trató en todo momento de garantizar la respuesta autónoma, libre y significativa de los alumnos encuestados. La validez interna se ha trabajo mediante un proceso de análisis estadísticos minucioso, utilizando tecnologías de vanguardia en análisis factoriales y adaptando los métodos utilizados a los datos de partida, buscando reproducir el modelo de la escala original sin perder de vista las características propias de la población objeto de estudio de este trabajo y, por ende, las posibles diferencias en la formación de la estructura interna de la escala adaptada. La validez externa ha sido estudiada mediante la correlación de las puntuaciones obtenidas en las escalas con otras variables dependientes (Kidscreens-27) e independientes (características personales y variables ambientales). Por último, las consecuencias de la evaluación de la resiliencia infantil, que serán estudiadas en capítulos sucesivos, al someter los resultados a análisis de tipo inferencial. 
Más allá de la potencialidad de la escala, el presente estudio tiene determinadas limitaciones. Las principales limitaciones están en el reducido rango de edad de los participantes (de 10 a 12 años), el limitado tamaño muestral $(\mathrm{N}=374)$ y la restringida representatividad española de la muestra (2 Comunidades Autónomas), lo cual limita el estudio de su validez y la generalización de los resultados al resto de la población infantil española. Otra limitación importante a destacar, está en la participación voluntaria de centros y familias, lo cual dio lugar a una muestra no probabilística. Sin embargo, aunque el muestro incidental es utilizado con frecuencia en investigación en psicología aplicada (Muñiz et al., 2013), según algunos autores no representa una amenaza importante para la validez del estudio (Highhouse y Gillespie, 2008).

Estas limitaciones, así como el carácter semi-confirmatorio de los análisis factoriales realizados, conllevan la necesidad de seguir profundizando en el estudio de la medida de resiliencia en población infantil española. Será necesaria una muestra más heterogénea de niños capaz de abarcar el conjunto completo de opciones de respuesta, cumpliendo los supuestos de normalidad y homocedasticidad de la varianza, que permitan el desarrollo de análisis paramétricos basados en la comparación de medias y otras técnicas robustas de análisis de datos (Martínez-Arias, 2014). Por otra parte, los autores de esta adaptación proponemos el estudio de la validez de la escala con muestras cruzadas, así como el análisis de su estructura interna mediante ESEM (Asparouhov y Muthén, 2009), como alternativa a los análisis confirmatorios clásicos. También, sería de interés administrar la escala en las primeras etapas de la adolescencia (de 12 a 14 años), para estudiar los cambios en la percepción de los niños acerca de la disponibilidad de recursos para su crecimiento positivo. Además de, probar su validez utilizando otras medidas de resiliencia que permitan estudiar la convergencia o discriminación entre diferentes instrumentos de un mismo constructo.

En definitiva, pese a sus limitaciones, en este capítulo se han aportado suficientes evidencias empíricas que apoyan la fiabilidad y validez de la medida de la $C Y R M-22$ para su uso con población infantil española de alumnos 
de Primaria de alumnos con NEAE y sin ellas. Quedando por explorar la utilidad de la escala en la evaluación e intervención para el desarrollo de la resiliencia infantil, tema que excede a los objetivos de este capítulo.

\subsection{Conclusiones}

Sobre la base de los hallazgos de este estudio podemos afirmar que la primera versión española de la escala de resiliencia infantil presenta garantías psicométricas apropiadas y puede ser útil para evaluar las percepciones que los niños tienen sus recursos personales y ambientales para el desarrollo de la resiliencia (Garmezy, 1991; Luthar et al., 2000a; Masten, 2001; Rutter 1999; Werner et al., 2004; Ungar, 2012; 2015). La escala está compuesta de 22 ítems y 3 factores, muestra una fiabilidad adecuada y evidencias de validez interna y externa. Es un instrumento simplificado y adaptado al contexto infantil español, de fácil aplicación a niños con NEAE y sin ellas. En este sentido, el presente estudio contribuye a aumentar el conocimiento sobre desarrollo infantil positivo y deja abierto el camino sobre resiliencia infantil a investigaciones futuras, tal como veremos en capítulos sucesivos.

A nivel específico, los resultados obtenidos con el primer sondeo de la escala tienen importantes implicaciones prácticas tanto en el ámbito educativo, como socio-comunitario. La CYRM-22 puede resultar de interés a agentes educativos y gubernamentales interesados en implementar programas y políticas para desarrollo integral de los menores. El instrumento podría utilizarse en evaluación psico-pedagógica, aportando un conocimiento más profundo sobre la visión que tiene el propio niño acerca de sus recursos personales y los recursos ambientales ofrecidos por su entorno próximo para su crecimiento positivo, facilitando el desarrollo de intervenciones significativas para sus protagonistas principales, los niños. 



\section{Capítulo 6}

Variables Personales y Ambientales Asociadas a los

Resultados Personales en Calidad de Vida, Participación y Resiliencia de Alumnos de Primaria con NEAE y Sin Ellas

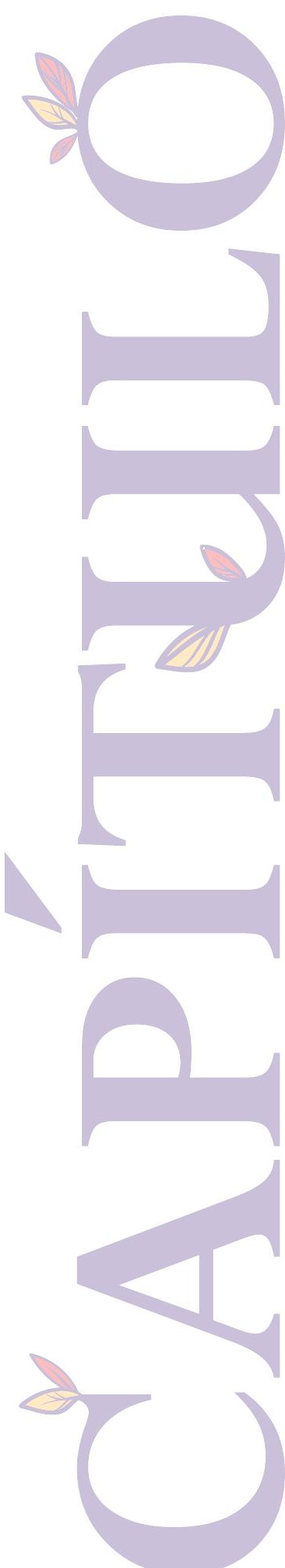





\section{Variables Personales y Ambientales Asociadas a los Resultados Personales en Calidad de Vida, Participación y Resiliencia de Alumnos de Primaria con NEAE y Sin Ellas}

\section{Introducción}

Tras el proceso de adaptación y validación de la medida de resiliencia CYRM-22 (Ruiz et al., en prensa) acometido en el capítulo anterior en el que se han ofrecido pruebas sobre la calidad psicométrica de las puntuaciones de resiliencia aportadas por la escala desarrollada, junto a los instrumentos seleccionados para la medida de la calidad de vida infantil y su participación en actividades de ocio y tiempo libre, en este capítulo se aborda el análisis de variables personales y ambientales asociadas a los resultados personales de alumnos de Primaria con NEAE y sin ellas.

Concretamente, este capítulo se centra en analizar el papel que juegan diversas variables personales y ambientales en el desarrollo positivo y bienestar infantil, así como en explorar la existencia de diferencias significativas en los resultados personales de los niños en función de los valores obtenidos en dichas variables. Los resultados de estos análisis resultan de extrema importancia para la elaboración de estrategias de mejora y eficacia en el diseño de programas socio y psicoeducativos dirigidos al fortalecimiento del desarrollo integral de todos los niños.

A nivel aplicado, desde el enfoque sistémico adoptado como marco teórico de esta investigación, la importancia estriba en focalizar la intervención en el nivel de desarrollo (personal, familiar, educativo, social, etc.) en el que se detecten las mayores incongruencias entre el funcionamiento del niño y su entorno, con la finalidad de facilitar trayectorias de desarrollo en las que los niños puedan negociar con sus ambientes los recursos necesarios y significativos para experimentar una vida de calidad.

En los siguientes apartados se presenta el diseño de estudio y resultados obtenidos acerca de cómo los valores de ciertas variables personales, familiares y educativas determinan de forma diferencial los resultados en 
bienestar, resiliencia y participación en actividades diversas de alumnos de Primaria con NEAE y sin ellas.

\subsection{Planteamiento Inicial}

A lo largo de los capítulos de la parte teórica de este trabajo se ha presentado una revisión exhaustiva de la literatura científica más relevante y actual en el campo del desarrollo infantil de niños con diferentes condiciones personales y/o ambientes, que ha definido el crecimiento positivo infantil desde las nociones de calidad de vida individual, participación en actividades de ocio y tiempo libre y recursos para el desarrollo de la resiliencia infantil.

Desde un enfoque de desarrollo infantil sistémico los modelos teóricos de estas tres variables defendidos asumen la asociación de resultados particulares con variables personales y ambientales del contexto en el que los niños se desarrollan. Según éstos, el impacto de ciertas variables sobre el bienestar, la participación y resiliencia infantil determina la valencia y dirección de los resultados personales obtenidos por niños en condiciones de vida diversas (King et al., 2003, 2009; Schalock et al., 2002, 2003; Ungar, 2011).

En investigación, las variables personales con capacidad de producir cambios en los resultados personales infantiles son denominadas factores personales. Los factores personales representan características biológicas, psicológicas o sociales, tales como la edad, el género, determinadas condiciones genéticas y/o cognitivas, u otras características comportamentales, que definen y predisponen el desarrollo del niño de forma interna. Frente a las variables de tipo personal se encuentran las variables ambientales, que son las características del entorno en el que los niños viven, funcionan y crecen. Las variables ambientales con capacidad de influir en las trayectorias de vida de las personas son conocidas como factores ambientales. Estos factores pueden ser de tipo ambiental, social, cultural, etc., como por ejemplo, la zona geográfica de residencia, los recursos económicos familiares, los apoyos materiales y sociales presentes, o las tradiciones culturales y/o religiosas de una sociedad. Por tanto, desde un enfoque de desarrollo infantil socio-ecológico que presupone la interacción 
mutua entre persona y ambiente, la forma que cada factor tiene de interactuar con el resto de factores presentes en un determinado contexto da lugar a los condicionantes biopsicosociales del desarrollo infantil (Bronfenbrenner, 1979, 2002; CIF, 2001; 2007; Ungar, 2011).

Una importante cantidad de estudios sobre desarrollo infantil positivo se han centrado en analizar la relación que se establece entre factores del contexto y cada una de las tres variables estudiadas, tratando de desvelar cómo esta asociación influye en los resultados personales y crecimiento infantil positivo. Algunos de los resultados más relevantes hallados pueden ser consultados en los Capítulos 2, 3 y 4 de la parte teórica de este trabajo. En general, la investigación ha evidenciado ampliamente la influencia que ciertas características personales y variables ambientales tienen en la adecuación entre el niño y su entorno, a través de su asociación con resultados personales significativos (Schalock et al., 2013b). La presencia de estos factores del contexto se ha detectado en todos los niveles sistémicos, desde los más personales y cercanos al niño (personal o familiar, por ejemplo), hasta niveles de interacción de más alto rango como el social, político o cultural (Schalock et al. 2016; Ungar, 2012).

Más específicamente, la investigación en calidad de vida infantil ha demostrado cómo los factores contextuales presentes en los diferentes ámbitos de desarrollo son capaces de determinar resultados personales de salud, educación, crecimiento positivo y bienestar personal en niños en condiciones de vida diversas (OMS, 2001; 2007; Ravens-Sieberer et al., 2014b; Wallander et al., 2016). Esta línea de investigación ha otorgado importancia no sólo al papel que las características personales (p.e., género, edad, condiciones clínicas o educativas) tiene sobre estos resultados, sino también a la reflexión acerca del impacto directo o indirecto que otras variables del contexto próximo como el tipo de escolaridad, las barreras físicas, sociales u actitudinales, los apoyos materiales o sociales disponibles, las condiciones políticas o históricas de una determinada época y lugar, etc., pueden ejercer en las condiciones de vida y el bienestar subjetivo de los niños (AAIDD, 2011; OMS, 2001; 2007; Schalock et al., 2016a). 
En referencia a la participación infantil de ocio y tiempo libre, la investigación está tratando de explicar las discrepancias que niños con y sin necesidades especiales muestran en sus valores de participación, a partir de la influencia de ciertos factores del contexto presentes en sus entornos próximos de desarrollo (Bult et al., 2014; Kantomaa et al., 2011; EngelYeger et al., 2010). Según estos trabajos, los factores ambientales de tipo físico, actitudinal y social al vincularse a las características personales de unos y otros niños influyen en sus resultados personales de participación de forma diferencial, dando lugar a patrones de participación dependientes al contexto específico de cada niño (Coster et al., 2012; Eriksson, 2005; Ericksson et al., 2007). Estos patrones vienen determinados por la valencia que adquieren dichos factores, pudiendo ejercer un efecto facilitador u obtaculizador sobre la participación en actividades diversas de ocio y tiempo libre (OMS, 2001, 2007). De esta forma, los factores personales y ambientales presentes en un entorno de desarrollo particular establecen cuáles son los aspectos que dan lugar a resultados personales significativos de participación infantil (Badley, 2008; Granlund, 2009; Maxwell et al., 2012), siendo capaces a su vez de predecir resultados futuros de desarrollo infantil (King, 2013). En el apartado 3 del Capítulo 3 se presentan los hallazgos más relevantes en investigación sobre los factores del contexto asociados a la participación infantil de ocio y tiempo libre. Mientras que en la Tabla 9 de ese mismo capítulo se listan los principales factores personales y ambientales que actúan como barreras y facilitadores para la participación infantil en el contexto de desarrollo de ocio y tiempo libre (Almqvist et al., 2006; Badia et al., 2013; Bult et al., 2011; Bult et al., 2014; Engel-Yeger et al., 2009; Orlin et al., 2010; Shikako-Thomas et al., 2012; Van Naarden Braun et al., 2006).

Por último, desde su inicios la investigación en resiliencia se ha basado en gran medida en hallar factores protectores que actúen sobre condiciones de riesgo asociadas al desarrollo infantil en circunstancias adversas de vida (Fergus et al., 2005). Así, los trabajos realizados desde el ámbito de la resiliencia infantil se han centrado en el análisis de la interacción entre factores protectores y de riesgo que condicionan los procesos de desarrollo 
de niños y jóvenes en condiciones diversas de vida (Prince-Embury, 2014). Los hallazgos de estas investigaciones han dado lugar a un amplio listado de factores del contexto infantil personal y ambiental que, teóricamente, actúan como protectores del riesgo al promocionar recursos personales y sociales que favorecen el surgimiento de la resiliencia infantil. El listado y descripción de estos factores puede verse desde el subarpatado 1.3.1., hasta el 1.3.4., del Capítulo 4 de esta tesis. Actualmente, desde un enfoque de resiliencia socio-ecológico, los resultados personales en resiliencia han sido fuertemente asociados a las características sociales, políticas y culturales de los entornos próximos de desarrollo, que determinan las barreras estructurales para que los niños naveguen y negocien los recursos accesibles y disponibles durante sus trayectorias de vida (Ungar et al., 2007; Ungar, 2011). Desde el enfoque socio-ecológico, la interacción entre los activos personales y los recursos socio-ambientales establece las vías que dan acceso a condiciones de bienestar personal y desarrollo infantil positivo (Ager, 2013; Friedli, 2009; Hall et al., 2009; Panter-Brick, 2014; Schalock et al., 2016; Ungar 2011, 2015a).

En el campo aplicado, el conocimiento sobre aquellas características personales y variables ambientales con capacidad de influir en las trayectorias de desarrollo infantil, tiene un importante peso a la hora del diseño e implementación de intervenciones sociales y psicoeducativas centradas en la promoción de resultados personales significativos. Debido a que la intervención profesional sobre un factor personal, como puede ser la función emocional, comportamental o social infantil, sin tener en cuenta la influencia de otras variables del contexto sobre dicho funcionamiento, puede ocasionar una merma en el impacto de la intervención a causa de la falta de consideración acerca de las relaciones dinámicas que se establecen entre lo que es significativo para el niño (bienestar social, participación en actividades extraescolares de tipo informal, recursos familiares para el desarrollo de su resiliencia, por ejemplo) y otros factores presentes en el contexto (p.e., presencia de NEAE, disponibilidad y/o acceso a determinados recursos materiales o humanos, estatus socioeconómico familiar, entre otros) que condicionan la valencia de sus resultados personales (King et al., 2003, 2009; Windle, 2011). 
Focalizar la investigación en este entramado de relaciones entre factores personales y ambientales amplía el rango de acción profesional, al otorgar los recursos científicos adecuados para el desarrollo de prácticas centradas en la mejora de los resultados infantiles, desde un prisma de acción global que tiene en cuenta el conjunto completo de la escena donde el niño representa los diferentes papeles sociales asignados. Desde la perspectiva presentada, el primer objetivo práctico es que el niño llegue a ser actor principal de su propia vida. De esta manera, si consideramos que es en las estructuras cercanas al niño donde se encuentran las oportunidades reales para su desarrollo (Ungar, 2012), el foco de la intervención seguirá centrado en el niño, pero desde el aprovechamiento y cambio de aquellos recursos que potencian o limitan su satisfacción vital y desarrollo pleno. En este sentido, como ya se expuso con anterioridad, los resultados personales de los niños variarán en la medida en que los profesionales, a través de sus intervenciones, faciliten el acceso y disponibilidad de los recursos que necesitan durante sus trayectorias de desarrollo, teniendo en cuenta que estos recursos deben de ser suficientemente intensos, culturalmente apropiados y personalmente significativos para favorecer el crecimiento del mayor número de niños (Ungar, 2011, 2012, 2015).

A partir de este planteamiento inicial, en el presente capítulo nos disponemos a analizar el peso que ciertas variables personales y ambientales (Tabla 25) tienen sobre los resultados personales de alumnos de Primaria con NEAE y sin ellas, con la finalidad de desvelar las relaciones dinámicas que se establecen entre estas variables y ampliar el conocimiento existente sobre la influencia de factores personales y ambientales en la calidad de vida, participación en actividades diversas de ocio y tiempo libre, y los recursos personales y ambientales para el desarrollo de la resiliencia infantil. Este estudio es la antesala al análisis de los procesos subyacentes que determinan las vías que dan acceso al bienestar y calidad de vida infantil que acometeremos en el Capítulo 7 de este trabajo, en el cual se explorará cómo las tres variables de interés interactúan entre ellas para formar vías de desarrollo infantil positivo. Conocer qué variables actúan como factores 
determinantes de la calidad de vida infantil, así como la interacción que se establece entre diferentes factores presentes en sus contextos de desarrollo, permite ahondar en los procesos subyacentes que dan origen y direccionan el crecimiento infantil positivo de niños en condiciones de vida diversas.

A continuación, se presentan los objetivos planteados en este estudio.

\subsubsection{Objetivos de Estudio}

\subsubsection{Objetivo General}

Identificar variables personales y ambientales (educativas y familiares) asociadas a las puntuaciones en calidad de vida, resiliencia y participación en actividades de ocio y tiempo libre de alumnos de Primaria con NEAE y sin ellas.

\subsubsection{Objetivos Específicos}

1. Examinar la existencia de diferencias significativas en las puntuaciones calidad de vida, resiliencia y participación de alumnos de Primaria con NEAE y sin ellas, en función de las variables personales: presencia de NEAE, género y comunidad autónoma de residencia.

2. Analizar la existencia de diferencias significativas en las puntuaciones calidad de vida, resiliencia y participación de alumnos de Primaria con NEAE y sin ellas, en función de las variables educativas: curso escolar, realización de actividades de tipo inclusivo, categoría NEAE, años de actividad docente del tutor y recursos escolares para la inclusión educativa.

3. Examinar la existencia de diferencias significativas en las puntuaciones calidad de vida, resiliencia y participación de alumnos de Primaria con NEAE y sin ellas, en función de las variables familiares: rango de edad, nivel educativo y estado laboral de la madre y padre, nivel de ingresos económicos familiares, miembro /s dedicado / s a la crianza del hijo y pertenencia a asociaciones proveedoras de servicios. 
Estos objetivos se sustentan en una serie de hipótesis fundamentadas en estudios previos revisados y presentados en la primera parte de este trabajo.

- Hipótesis 1. Se esperan diferencias significativas en los resultados personales de los alumnos de Primaria evaluados en función de variables personales.

- Hipótesis 2. Se esperan diferencias significativas en los resultados personales de los alumnos de Primaria con NEAE y sin ellas evaluados en función de variables educativas.

- Hipótesis 3. Se esperan diferencias significativas en los resultados personales de los alumnos de Primaria con NEAE y sin ellas evaluados en función de variables familiares.

Seguidamente se presenta el proceso metodológico realizado para su comprobación.

\subsection{Método}

El diseño de esta investigación es de carácter trasversal, con una muestra de conveniencia de 199 alumnos de Primaria con NEAE y sin ellas. En la Tabla 25 se presentan las variables independientes y dependientes utilizadas para el desarrollo del estudio. 
Tabla 25. Variables de estudio

\begin{tabular}{|c|c|c|c|}
\hline Tipo & Contexto & Variable & Dimensiones \\
\hline \multirow[t]{21}{*}{$\begin{array}{l}\text { Variables } \\
\text { Independientes }\end{array}$} & Personal & Presencia de $\mathrm{NEAE}^{\mathrm{a}}$ & \\
\hline & & Género & \\
\hline & & $\begin{array}{l}\text { Comunidad Autónoma de } \\
\text { resiliencia }\end{array}$ & \\
\hline & Escolar & Curso escolar & \\
\hline & & $\begin{array}{l}\text { Realización de actividades de } \\
\text { tipo inclusivo en clase }\end{array}$ & Realización de Asambleas \\
\hline & & & $\begin{array}{l}\text { Seriedad dada a la opinión } \\
\text { de los alumnos }\end{array}$ \\
\hline & & & $\begin{array}{l}\text { Hablar de la diversidad } \\
\text { del alumnado }\end{array}$ \\
\hline & & & $\begin{array}{l}\text { Hablar sobre el propio } \\
\text { estilo de aprendizaje }\end{array}$ \\
\hline & & Categoría NEAE ${ }^{a}$ & \\
\hline & & $\begin{array}{l}\text { Años de actividad docente } \\
\text { tutor }\end{array}$ & \\
\hline & & $\begin{array}{l}\text { Recursos escolares para la } \\
\text { inclusión educativa }\end{array}$ & Rampas \\
\hline & & & Aseos adaptados \\
\hline & & & Aulas amplias \\
\hline & & & Patio escolar adaptado \\
\hline & Familiar & Rango de edad & \\
\hline & & Nivel educativo & Padre/Madre \\
\hline & & Estatus laboral & Padre/Madre \\
\hline & & Ingresos económicos & Padre/Madre \\
\hline & & Miembro/s dedicado/s crianza & \\
\hline & & hijo & \\
\hline & & $\begin{array}{l}\text { Miembro de asociación provee- } \\
\text { dora de servicios }\end{array}$ & \\
\hline \multirow[t]{10}{*}{$\begin{array}{l}\text { Variables } \\
\text { dependientes }\end{array}$} & Calidad de vida & Bienestar & Físico \\
\hline & & & Emocional \\
\hline & & & Familiar \\
\hline & & & Social \\
\hline & & & Escolar \\
\hline & Resiliencia infantil & Resiliencia & Familiar \\
\hline & & & Individual \\
\hline & & & Social \\
\hline & $\begin{array}{l}\text { Participación en } \\
\text { actividades de ocio } \\
\text { y tiempo libre }\end{array}$ & Participación & Diversidad \\
\hline & & & Preferencias \\
\hline
\end{tabular}

Nota. ${ }^{a}$ (NEAE) Necesidades Específicas de Apoyo Educativo. 


\subsubsection{Participantes}

En el estudio participaron 99 alumnos de tercer ciclo de Primaria con NEAE y un grupo equivalente en género, edad y curso de 100 alumnos sin ellas, pertenecientes a 2 Comunidades Autónomas de España. La edad media de los estudiantes participantes fue de 11.25 años $(\mathrm{SD}=.85)$. Los alumnos proporcionaron información acerca de sus características sociodemográficas y educativas (Tabla 26).

Tabla 26. Información del alumnado sobre características sociodemográficas y educativas ( $N=199)$

\begin{tabular}{lccc}
\hline Variable & Categoría & $\mathbf{N}^{\mathbf{o}}$ & $\boldsymbol{\%}$ \\
\hline Sexo & Niños & 119 & 59.8 \\
& Niñas & 80 & 40.2 \\
Edad & 10 años & 38 & 19.1 \\
& 11 años & 88 & 44.2 \\
& 12 años & 58 & 29.1 \\
& 13 años & 15 & 7.5 \\
CC.AA & Andalucía & 108 & 54.3 \\
& CyL & 90 & 45.2 \\
Curso & $5^{\circ}$ & 90 & 45.2 \\
& $6^{\circ}$ & 109 & 54.8 \\
Realización de asambleas en el aula & Si & 111 & 55.8 \\
& No & 85 & 42.7 \\
Seriedad de la opinión de los alumnos para el profesor tutor & Si & 164 & 82.4 \\
& No & 32 & 16.1 \\
Hablar de la diversidad del alumnado en el aula & Si & 102 & 51.3 \\
& No & 94 & 47.2 \\
Hablar sobre la propia forma de aprender del alumno con el tutor & Si & 100 & 50.3 \\
& No & 96 & 48.2 \\
\hline
\end{tabular}

Notas. ${ }^{\text {a }}$ (CC.AA.) Comunidades Autónomas. ${ }^{\text {b }}$ (CyL) Castilla y León.

Paralelamente, se recogió información de su entorno escolar y familiar para la realización de los contrastes de hipótesis planteados en esta parte del estudio. Esta información fue proporcionada por 49 docentes y 106 familiares de los alumnos participantes. En las Tablas 27 y 28 se presentan información descriptiva sobre las variables escolares y familiares utilizadas para los análisis 
e inferencias estadísticas presentadas en los siguientes apartados.

Tabla 27. Información de los docentes características de los alumnos participantes y su contexto educativo $(N=49)$

\begin{tabular}{|c|c|c|c|}
\hline Variable & Categoría & $\mathbf{N}^{\mathbf{o}}$ & $\%$ \\
\hline \multirow[t]{2}{*}{ Presencia de $\mathrm{NEAE}^{\mathrm{a}}$} & $\mathrm{Si}$ & 99 & 49.7 \\
\hline & No & 100 & 50.3 \\
\hline \multirow[t]{4}{*}{ Grupo de NEAE } & $\mathrm{NEE}^{\mathrm{b}}$ & 55 & 55.6 \\
\hline & $\mathrm{ACI}^{\mathrm{c}}$ & 10 & 10.1 \\
\hline & Integración tardía & 9 & 9.1 \\
\hline & Otras NEAE ${ }^{\mathrm{a}}$ & 25 & 25.3 \\
\hline \multirow[t]{2}{*}{ Titularidad del centro educativo } & Público & 96 & 48.2 \\
\hline & Concertado & 99 & 49.7 \\
\hline \multirow[t]{3}{*}{ Años de actividad docente profesional informante } & Menos de 15 años & 18 & 36.7 \\
\hline & De 16 a 30 años & 13 & 26.5 \\
\hline & Más de 30 años & 5 & 10.2 \\
\hline \multicolumn{4}{|l|}{ Disponibilidad en el centro escolar de: } \\
\hline \multirow[t]{2}{*}{ Rampas } & $\mathrm{Si}$ & 52 & 26.1 \\
\hline & No & 75 & 37.7 \\
\hline \multirow[t]{2}{*}{ Aseos adaptados } & $\mathrm{Si}$ & 60 & 30.2 \\
\hline & No & 67 & 33.7 \\
\hline \multirow[t]{2}{*}{ Aulas amplias } & $\mathrm{Si}$ & 75 & 37.7 \\
\hline & No & 52 & 26.1 \\
\hline \multirow[t]{2}{*}{ Material escolar adaptado } & $\mathrm{Si}$ & 48 & 24.1 \\
\hline & No & 79 & 39.7 \\
\hline \multirow[t]{2}{*}{ Patio adaptado } & $\mathrm{Si}$ & 52 & 26.1 \\
\hline & No & 21 & 10.6 \\
\hline
\end{tabular}

Nota. ${ }^{a}$ (NEAE) Necesidades Específicas de Apoyo Educativo; ${ }^{\mathrm{b}}$ (NEE) Necesidades Educativas Especiales; ${ }^{\mathrm{C}}$ (ACI) Altas Capacidades Intelectuales. 
Tabla 28. Información de las familias sobre características del contexto familiar y de crianza de los alumnos participantes $(N=106)$

\begin{tabular}{|c|c|c|c|c|}
\hline Informante & Variable & Categoría & $\mathrm{N}^{\mathrm{o}}$ & $\%$ \\
\hline \multirow[t]{8}{*}{ Madre } & Rango de edad & De 29 a 43 años & 40 & 20.1 \\
\hline & & De 44 a 53 años & 44 & 22.1 \\
\hline & Nivel educativo & Sin estudios formales & 1 & 1.0 \\
\hline & & Educación Obligatoria & 28 & 27.2 \\
\hline & & Educación Superior & 74 & 71.8 \\
\hline & Estatus laboral & Autónoma & 11 & 10.5 \\
\hline & & Empleada & 59 & 56.2 \\
\hline & & Desempleada & 35 & 33.3 \\
\hline \multirow[t]{18}{*}{ Padre } & Rango de edad & De 30 a 44 años & 40 & 20.1 \\
\hline & & De 45 a 57 años & 41 & 20.6 \\
\hline & Nivel educativo & Sin estudios formales & 5 & 5.1 \\
\hline & & Educación Obligatoria & 30 & 30.3 \\
\hline & & Educación Superior & 64 & 64.6 \\
\hline & Estatus laboral & Autónomo & 26 & 26.5 \\
\hline & & Empleado & 53 & 54.1 \\
\hline & & Desempleado & 19 & 19.4 \\
\hline & Ingresos económicos & Menos de $9000 € /$ anuales & 23 & 24.2 \\
\hline & & De 9000 a $17000 € /$ anuales & 27 & 28.4 \\
\hline & & De 17000 a $30000 € /$ anuales & 25 & 26.3 \\
\hline & & Más de $30000 € /$ anuales & 20 & 21.1 \\
\hline & $\begin{array}{l}\text { Miembro/s dedicado/s a la } \\
\text { crianza del hijo }\end{array}$ & Ambos progenitores & 47 & 52.8 \\
\hline & & Madre & 37 & 41.6 \\
\hline & & Padre & 4 & 4.5 \\
\hline & & Otros & 1 & 1.1 \\
\hline & Miembros de una asociación & $\mathrm{Si}$ & 56 & 75.7 \\
\hline & & No & 18 & 24.3 \\
\hline
\end{tabular}




\subsubsection{Instrumentos}

6.2.2.1. El Cuestionario de Calidad de Vida Kidscreen-27 (Ravens-Sieberer et al., 2007)

El Kidscreen-27 (Ravens-Sieberer et al., 2007) es un instrumento transcultural desarrollado por el Grupo Europeo Kidscreen para evaluar la calidad de vida relacionada con la salud de población infantil y juvenil general y con condiciones de salud crónicas. La versión del Kidscreen utilizada para este estudio consta de 27 ítems que permiten valorar el bienestar físico, psicológico y social de niños y jóvenes entre 8 y 18 años, a través de 5 dimensiones: 1) bienestar físico, definida en términos de salud general, funcionamiento físico (p.e., ¿te has sentido bien y en forma?) y energía vital percibida (5 ítems); 2) bienestar emocional, definida como estado de ánimo (p.e., ¿has estado de buen humor?), sentimientos (p.e., ¿te has sentido triste?) y satisfacción con la vida (9 ítems); 3) bienestar familiar, definida en términos de vida familiar (p.e., ¿tus padres han tenido tiempo para ti?) y autonomía (p.e., ¿has tenido suficiente tiempo para ti?) (9 ítems); 4) bienestar social, definida desde la relación con iguales y amigos (p.e., ¿te has divertido con tus amigos?) (4 ítems); y 5) bienestar escolar, definido como energía y satisfacción con la actividad escolar (p.e., ¿te has sentido bien en el colegio?) (4 ítems). Los participantes valoran la frecuencia de bienestar percibido en el transcurso de una semana en una escala de 1 (nunca) a 5 (siempre) puntos. La versión española presenta propiedades psicométricamente adecuadas y ha sido valida a población juvenil con discapacidad y sin ella (Longo et al., 2012; Guijarro 2013). En el presente estudio, la consistencia interna de las subescalas fluctúa en un intervalo de .58 (escala de bienestar familiar) a .78 (escala de bienestar social) y su medida ha mostrado correlaciones positivas y significativas con las puntuaciones de las dimensiones de resiliencia de la CYRM-22 (Ruiz et al., en prensa), cuyo proceso de adaptación y validación a población infantil española ha sido presentado en el Capítulo 5 de este trabajo. Siguiendo las recomendaciones del Grupo Kidscreen (Ravens-Sieberer et al., 2005) las puntuaciones se convierten en puntuaciones $\mathrm{T}(\mathrm{M}=50, \mathrm{SD}=+/-10)$, donde los valores más altos indican niveles mayores de bienestar subjetivo. 
La escala es válida para evaluar la calidad de vida relacionada con la salud (CVRS) y de utilidad para detectar poblaciones infantiles en riesgo, realizar encuestas epidemiológicas y estudios diferenciales en niños y adolescentes con condiciones de salud crónicas y sin ellas, evaluar los resultados de intervenciones socio-sanitarias, así como para obtener perfiles de calidad de vida de población infantil y juvenil (Guijarro, 2013), entre otras utilidades.

\subsubsection{La Medida de Resiliencia CYRM-22 (Ruiz et al., en prensa)}

La CYRM-22 (Ruiz et al., en prensa) es un instrumento que mide los recursos personales y ambientales para el desarrollo de la resiliencia de niños con NEAE y sin ellas, de entre 10 y 12 años. La CYRM-22 es una escala de resiliencia adaptada de la Child andYouth Resilience Measure: CYRM-28 (Ungar et al., 2011), que ha dado garantías psicométricas de fiabilidad (rangos de consistencia interna de .72 a .80), validez interna (estructura factorial de 3 dimensiones) y validez externa (correlaciones positivas y significativas con las medidas de bienestar del cuestionario Kidscreen-27), como resultado de un proceso exhaustivo de adaptación y validación a población infantil española presentado en el Capítulo 5 de este trabajo. La escala está formada por 22 ítems divididos en tres subescalas: 1) resiliencia familiar, valorada a través de recursos familiares físicos y psicológicos (p.e., mi familia está conmigo en los momentos difíciles) facilitados por la familia para el desarrollo positivo del niño (8 ítems); 2) resiliencia personal, definido por las competencias internas (p.e., se encontrar solución a mis dificultades) y oportunidades externas (p.e., en el cole tengo la oportunidad de demostrar que soy responsable) que fortalecen al niño en su día a día (8 ítems); y 3) resiliencia social, que hace referencia a los recursos sociales (p.e., tengo un grupo de amigos en la escuela) y apoyos recibidos por parte de iguales (p.e., tengo amigos que me apoyan y ayudan cuando lo necesito) para el afrontamiento de desafíos y dificultades infantiles (6 ítems). Las puntuaciones de las subescalas tienen un rango de 1 a 5 puntos, donde 1 indica bajos y 5 altos niveles de resiliencia percibida. La escala original CYRM-28 (Ungar et al., 2011) ha dado pruebas de validez discriminante mediante la comparación de las puntuaciones 
de grupos de jóvenes de minorías y mayorías socioculturales del mundo (Liebenberg et al., 2012). En el actual estudio se pone a prueba la utilidad de la escala para obtener información diferencial entre grupos de alumnos con NEAE y sin ellas, a partir de los resultados obtenidos en resiliencia en función de sus valores en variables del contexto personal y ambiental.

6.2.2.3. Cuestionario de Participación en Actividades de Ocio y Tiempo Libre CAPE-PAC (King et al., 2007)

El CAPE-PAC (King et al., 2007) es un instrumento que valora componentes tanto objetivos como subjetivos de la participación en actividades de ocio y tiempo libre por parte de niños y jóvenes con discapacidad y sin ella. Incluye 6 dimensiones: diversidad, intensidad, socialización, ubicación, disfrute y preferencias de participación en actividades de ocio y tiempo libre. Contempla 55 actividades de ocio dividas por 1) tipo de actividad: recreativa, física, social, basada en habilidad y auto-enriquecimiento; y 2) nivel de estructuración: actividades formales (p.e., clase de natación) e informales (p.e., ir a una fiesta). Para este estudio se utilizan las puntaciones totales obtenidas por los alumnos en las dimensiones de diversidad y preferencias de participación. El CAPE$P A C$ es una herramienta de carácter transcultural que cuenta con evidencia empírica suficiente sobre la fiabilidad y validez de su medida (Badia et al., 2013; Bult et al., 2014; Imms et al., 2017; Majnemer et al., 2010). La versión española del CAPE presenta propiedades psicométricas adecuadas, con índices de fiabilidad superiores a 0.70 en todas sus dimensiones y validez comprobada a partir de las correlaciones positivas y significativas entre el instrumento y la versión española del cuestionario de calidad de vida Kidscreen-52 (Longo et al., 2012). Con respecto al PAC, debido a la inexistencia de estudios empíricos previos que muestren las propiedades psicométricas del instrumento en contexto infantil español, su uso se fundamenta en las pruebas de validez y fiabilidad demostradas por estudios internacionales en los cuales se ha evidenciado la adecuación y utilidad de su medida (Bult, et al., 2014; Imms, et al., 2017; King et al., 2007). En referencia a su utilidad práctica, la administración del CAPE-PAC con diferentes poblaciones infanto- 
juveniles está permitiendo identificar factores del contexto que actúan como barreras o facilitadores para la participación de niños y jóvenes con discapacidad y sin ella en su entorno familiar, social y comunitario. Estos resultados posibilitan la puesta en marcha de intervenciones psicoeducativas y programas de ocio y tiempo libre para el fomento de la participación infantil activa y significativa en diversos contextos sociales y personales.

6.2.2.4. Cuestionario de Evaluación de Variables Personales y Ambientales Relacionadas con el Desarrollo Positivo del Niño

Es un listado de variables del contexto personal (p.e., género, edad, presencia de discapacidad o necesidades específicas de apoyo educativo, categoría y tipología de estas condiciones si las hubiera, etc.), y ambiental de tipo físico, social y actitudinal (p.e., factores familiares como tipo de estructura familiar y recursos para la crianza del hijo, escolares como experiencia docente y desarrollo de metodologías inclusivas en el aula y comunitarios como recursos materiales y físicos, para la participación y aprendizaje del niño, etc.), con potencial para influir en el desarrollo positivo infantil. A través de sus ítems esta herramienta ayuda a definir los entornos cotidianos en los que el niño se desenvuelve. Este listado contempla variables que en la literatura científica se han relacionado con los resultados personales para el crecimiento positivo infantil (Booth y Ainscow, 2002, 2015; Muntaner, 2013; Wehmeyer, 2009; King et al., 2003; Ungar 2011). La información es proporcionada por el propio niño, así como adultos pertenecientes al entorno cercano de éste, tales como, familiares y profesionales de la educación. El listado se ha construido con la finalidad de aislar y analizar variables del contexto próximo de alumnos de Primaria con NEAE y sin ellas con capacidad de actuar como barreras y/o facilitadores de la calidad de vida y crecimiento infantil positivo. 


\subsubsection{Procedimiento}

A nivel general, el procedimiento para la recogida de la información de niños y adultos para el análisis de la influencia de variables contextuales en los resultados personales de alumnos de Primaria con NEAE y sin ellas, sigue una secuencia similar a la descrita en el Capítulo 5: 1) contacto con los centros educativos y solicitud de consentimiento informado por parte de las familias de los alumnos participantes; 2) programación de sesiones grupales o individuales para la administración de los instrumentos de evaluación a alumnos con NEAE y sin ellas; 3) adaptación de estas sesiones a las características del alumnado participante, así como la puesta en marcha de los recursos y apoyos necesarios para la respuesta individual y autónoma de todos los alumnos a los ítems de los cuestionarios; y 4) administración de cuestionarios con preguntas sociodemográficas y educativas a docentes y familiares cercanos al entorno del niño.

Debido al interés de esta parte del trabajo por conocer los resultados personales de alumnos con NEAE, así como su determinación según ciertas variables personales y del ambiente, la presencia de NEAE fue uno de los criterios principales para la participación de los alumnos en el estudio. Por otra parte, con objeto de conocer las diferencias entre alumnos con NEAE y sin ellas, otro criterio fue la formación de un grupo equivalente en edad, género y curso de alumnos sin NEAE que permitiera posteriormente la realización de análisis para la consecución de objetivos y contrastes de hipótesis planteados.

Para la recogida de la información se elaboró un cuadernillo de evaluación compuesto de tres partes. (Anexo 1,2 y 3) La primera de ellas iba dirigida al niño y estaba formada por un listado de preguntas sociodemográficas y educativas, seguido del cuestionario de resiliencia CYRM-22 (Ruiz et al., en prensa), el cuestionario de calidad de vida Kidscreen-27 (Ravens-Sieberer et al., 2007) y el cuestionario de participación en actividades de ocio y tiempo libre CAPE-PAC (King et al., 2007) (Anexo 1). La segunda parte era el cuestionario de evaluación de variables personales y ambientales relacionadas con el desarrollo positivo del niño orientado a docentes, (Anexo 2) la tercera 
el mismo cuestionario orientado a familias (Anexo 3). De esta forma, al finalizar la evaluación cada alumno participante contaría potencialmente con un cuadernillo completo con información de tipo personal y ambiental referente a las características propias de su desarrollo infantil.

Lainformación por parte de adultos del entorno cercanoalniño era recogida paralelamente a la realización de la evaluación infantil. Esta información era solicitada a docentes y familiares de los alumnos participantes, quienes colaboraron en el estudio de forma voluntaria y anónima. Los cuestionarios para adultos eran entregados al comienzo de la fase de evaluación infantil y recogidos antes de su finalización. Debido a que la participación era voluntaria y que los cuestionarios eran auto-administrados por los propios participantes adultos se produjo mayor pérdida de información que en el caso de los niños, quedando un amplio número de casos de alumnos sin la información complementaria de su entorno cercano.

En definitiva, al finalizar el periodo de evaluación se contó con una amplia matriz de información compuesta por datos del propio niño, así como de su entorno educativo y familiar, a partir de la cual se realizaron los análisis que se presentan a continuación.

\subsubsection{Análisis Estadísticos}

La codificación de la información y su posterior tratamiento estadístico se llevó a cabo mediante el empleo de paquetes estadísticos SPSS-21.

Para la ejecución de los contrastes de hipótesis planteados en esta parte del estudio se realizaron procedimientos de estadística descriptiva e inferencial. Inicialmente se llevó a cabo un análisis descriptivo de las variables (frecuencia y porcentajes) con objeto de caracterizar a los participantes encuestados. Así como, análisis exploratorios (media, desviación típica y pruebas de normalidad) mediante los que se examinó la distribución de la muestra y de sus puntuaciones. 
Para comprobar la normalidad de los datos se realizó e interpretó la prueba de Kolmogorov-Smirnov para muestras grandes (Pallant, 2001). De acuerdo con los valores calculados se identificó el incumplimiento de la normalidad en la distribución de las puntuaciones en resultados personales, lo que llevó al análisis de diferencias entre grupos mediante estadística no paramétrica (Curado et al., 2013).

Por último, para determinar la influencia de las variables del contexto en los resultados personales de los alumnos se realizaron las pruebas no paramétricas correspondientes a cada caso (“U” de Mann-Whitney o Análisis de Varianza de Kruskal-Wallis), considerando significativas todas aquellas diferencias con una probabilidad asociada $\mathrm{p}<.05$. El análisis de diferencias se llevó a cabo con la muestra total de alumnos con NEAE y sin ellas, así como con ambos subgrupos de alumnos por separado.

\subsection{Resultados}

\subsubsection{Análisis Descriptivos}

6.3.1.1. Puntuaciones Generales en Resultados Personales de los Alumnos de Primaria

Primeramente, con objeto conocer sus puntuaciones generales en calidad de vida, resiliencia y participación de ocio infantil, se calculó la media y desviación típica de las puntuaciones en resultados personales de los alumnos de Primaria. Los participantes obtuvieron puntuaciones medias altas en las dimensiones de calidad de vida (Tabla 29), resiliencia (Tabla 30) y en la dimensión de preferencias de participación (Tabla 31). Mientas que, las puntuaciones medias de la dimensión de diversidad de participación fueron moderadas (Tabla 31). 
Tabla 29. Estadísticos descriptivos de las puntuaciones en calidad de vida $(N=194)$

\begin{tabular}{lccc}
\hline Dimensión & Rango & Media $\left(\mathbf{D T}^{\mathrm{a}}\right)$ & Kormogorov-Smirnov \\
\hline Bienestar físico & $0-100$ & $48.54(11.06)$ & $.121 * * *$ \\
Bienestar psicológico & $0-100$ & $49.66(9.94)$ & $.123 * * *$ \\
Autonomía y Vida familiar & $0-100$ & $50.28(8.17)$ & $.146 * * *$ \\
Apoyo social y Amigos & $0-100$ & $49.52(10.94)$ & $.221 * * *$ \\
Entorno escolar & $0-100$ & $50.32(10.10)$ & $.196 * * *$ \\
\hline
\end{tabular}

Nota. ${ }^{a}$ (DT) Desviación típica. *** $\mathrm{p}<.001$.

Tabla 30. Estadísticos descriptivos de las puntuaciones en resiliencia $(N=140)$

\begin{tabular}{lccc}
\hline Dimensión & Rango & Media $\left(\right.$ DT $\left.^{\mathbf{a}}\right)$ & Kormogorov-Smirnov \\
\hline Resiliencia familiar & $0-40$ & $36.14(3.75)$ & $.162 * * *$ \\
Resiliencia individual & $0-40$ & $33.54(4.44)$ & $.101 * * *$ \\
Resiliencia social & $0-30$ & $26.44(3.36)$ & $.145 * * *$ \\
\hline
\end{tabular}

Nota. $^{\text {a }}$ (DT) Desviación típica. ***valores altamente significativos $\mathrm{p}<.001$.

Tabla 31. Estadísticos descriptivos de las puntuaciones en participación $(N=138)$

\begin{tabular}{lcccc}
\hline Dimensión & Dominio de Actividad & Rango & Media (DT $\left.{ }^{a}\right)$ & Kormogorov-Smirnov \\
\hline Diversidad & Total & $0-55$ & $30.23(8.22)$ & .047 \\
Preferencias & Total & $55-165$ & $130.43(17.12)$ & $.070 *$ \\
\hline
\end{tabular}

Nota. ${ }^{a}$ (DT) Desviación típica. *valores significativos $\mathrm{p}<.05$.

Previamente a los contraste de hipótesis se analizó el cumplimiento de los supuestos de normalidad de las puntuaciones examinadas (última columna Tablas 5, 6 y 7). Los estadísticos de Kormogorov-Smirnov informaron del incumplimiento del supuesto de normalidad en la distribución de las puntuaciones de todas las dimensiones de calidad de vida y resiliencia. Con respecto a las puntuaciones de participación, mientras que las puntuaciones de la dimensión de diversidad se distribuían normalmente, las de preferencias no cumplieron el supuesto. Por tanto, dado que a excepción de participación el resto de escalas mostraba distribuciones no normales, se utilizó de forma genérica pruebas no paramétricas para la realización de los análisis de diferencias entre grupos (Curado et al., 2013). 
Para responder a los objetivos de estudio planteados, en los siguientes apartados se presenta: 1) las diferencias significativas halladas en los resultados personales de los alumnos en función de las variables personales presencia de NEAE, género y comunidad autónoma de residencia; 2) los resultados más significativos hallados en el análisis de diferencias entre grupos en función de las variables educativas informadas por alumnos y docentes, y; 3) la influencia de las variables familiares más significativas en los resultados personales de los alumnos de Primaria con NEAE y sin ellas.

\subsubsection{Análisis Inferenciales}

6.3.2.1. Análisis de la Influencia de Variables Personales en los Resultados Personales de Alumnos de Primaria

\subsection{Diferencias en Función de la Presencia de NEAE}

La primera variable utilizada para contrastar los resultados personales alcanzados por los alumnos de Primaria fue la presencia de NEAE, dada su importancia teórica y empírica en este estudio. Los resultados indicaron diferencias significativas entre alumnos con NEAE y sus compañeros sin ellas en las puntuaciones obtenidas en bienestar psicológico $(\mathrm{z}=-2.555 ; \mathrm{p}<.05)$ y resiliencia individual $(\mathrm{z}=-2.928 ; \mathrm{p}<.01)$. En ambas subescalas de calidad de vida y resiliencia los alumnos con NEAE puntuaron significativamente por debajo que sus compañeros sin ellas (Tabla 32).

Tabla 32. Puntuaciones en resultados personales en función de la presencia de NEAE

\begin{tabular}{lcccc}
\hline Dimensión/Dominio & Presencia NEAE $^{\mathbf{a}}$ & $\mathbf{N}$ & Rango $^{\mathbf{b}}$ & $\mathbf{Z}$ \\
\hline Bienestar físico & $\mathrm{Si}$ & 95 & 96.10 & -.342 \\
Bienestar psicológico & $\mathrm{No}$ & 99 & 98.84 & \\
& $\mathrm{Si}$ & 96 & 87.56 & $-2.555 *$ \\
Autonomía y Vida familiar & $\mathrm{No}$ & 99 & 108.12 & \\
& $\mathrm{Si}$ & 96 & 96.40 & -.392 \\
Apoyo social y Amigos & $\mathrm{No}$ & 99 & 99.56 & \\
& $\mathrm{Si}$ & 96 & 100.53 & -.632
\end{tabular}




\begin{tabular}{lcccc}
\hline Dimensión/Dominio & Presencia NEAE $^{\mathbf{a}}$ & $\mathbf{N}$ & Rango $^{\mathbf{b}}$ & $\mathbf{Z}$ \\
\hline Entorno escolar & $\mathrm{Si}$ & 96 & 98.70 & -.174 \\
Resiliencia familiar & $\mathrm{No}$ & 99 & 97.32 & \\
& $\mathrm{Si}$ & 74 & 66.77 & -1.839 \\
Resiliencia individual & $\mathrm{No}$ & 71 & 79.49 & \\
& $\mathrm{Si}$ & 75 & 63.95 & $-2.928 * *$ \\
Resiliencia social & $\mathrm{No}$ & 72 & 84.47 & \\
& $\mathrm{Si}$ & 74 & 67.07 & -1.621 \\
Diversidad de Participación & $\mathrm{No}$ & 70 & 78.24 & \\
& $\mathrm{Si}$ & 86 & 83.70 & -1.454 \\
Preferencias de Participación & $\mathrm{No}$ & 92 & 94.92 & \\
& $\mathrm{Si}$ & 68 & 72.77 & -.497 \\
\hline
\end{tabular}

Nota. Rango $=$ rango promedio, prueba U de Mann Whitney. a (NEAE) Necesidades Específicas de Apoyo Educativo. * $\mathrm{p}<.05 ; * * \mathrm{p}<.01$.

A partir de este primer análisis de diferencias el resto de contrastes se realizaron con las puntuaciones del grupo total de alumnos de Primaria participantes, y se repitieron con las del subgrupo de alumnos con NEAE y el subgrupo de alumnos sin ellas. En los siguientes apartados se presentaran los resultados más relevantes obtenidos en estos análisis.

\subsection{Diferencias en Función del Género}

Tanto la muestra general de alumnos de Primaria, como los subgrupos de alumnos con NEAE y alumnos sin ellas analizados mostraron diferencias significativas en las puntuaciones de diversidad de participación en función del género. Concretamente, las alumnas con NEAE obtuvieron puntuaciones promedio significativamente más altas que sus compañeros con NEAE $($ Promedio $=51.35$ vs. Promedio $=38.37)$. Esta misma tendencia se halló entre chicas y chicos en el subgrupo de alumnos sin NEAE (Promedio = 53.64 vs. Promedio $=41.47)$. 


\subsection{Diferencias en función de la Comunidad Autónoma}

Al analizar las puntuaciones en resultados personales en función de la comunidad autónoma en la que vivían los alumnos en el momento de la evaluación, se observaron diferencias significativas en diversas dimensiones de calidad de vida, resiliencia y participación. En general, los alumnos de Andalucía evaluados puntuaban por encima que sus compañeros de Castilla y León en la mayoría de las dimensiones (Tabla 33). Por su parte, los alumnos con NEAE que habitaban en Andalucía puntuaban significativamente más alto en resiliencia individual y social que sus compañeros con NEAE de Castilla y León (Tabla 33). Mientras que, el subgrupo de alumnos sin NEAE de Andalucía lo hacía en bienestar físico, apoyo social y amigos, y preferencias de participación (Tabla 33). 


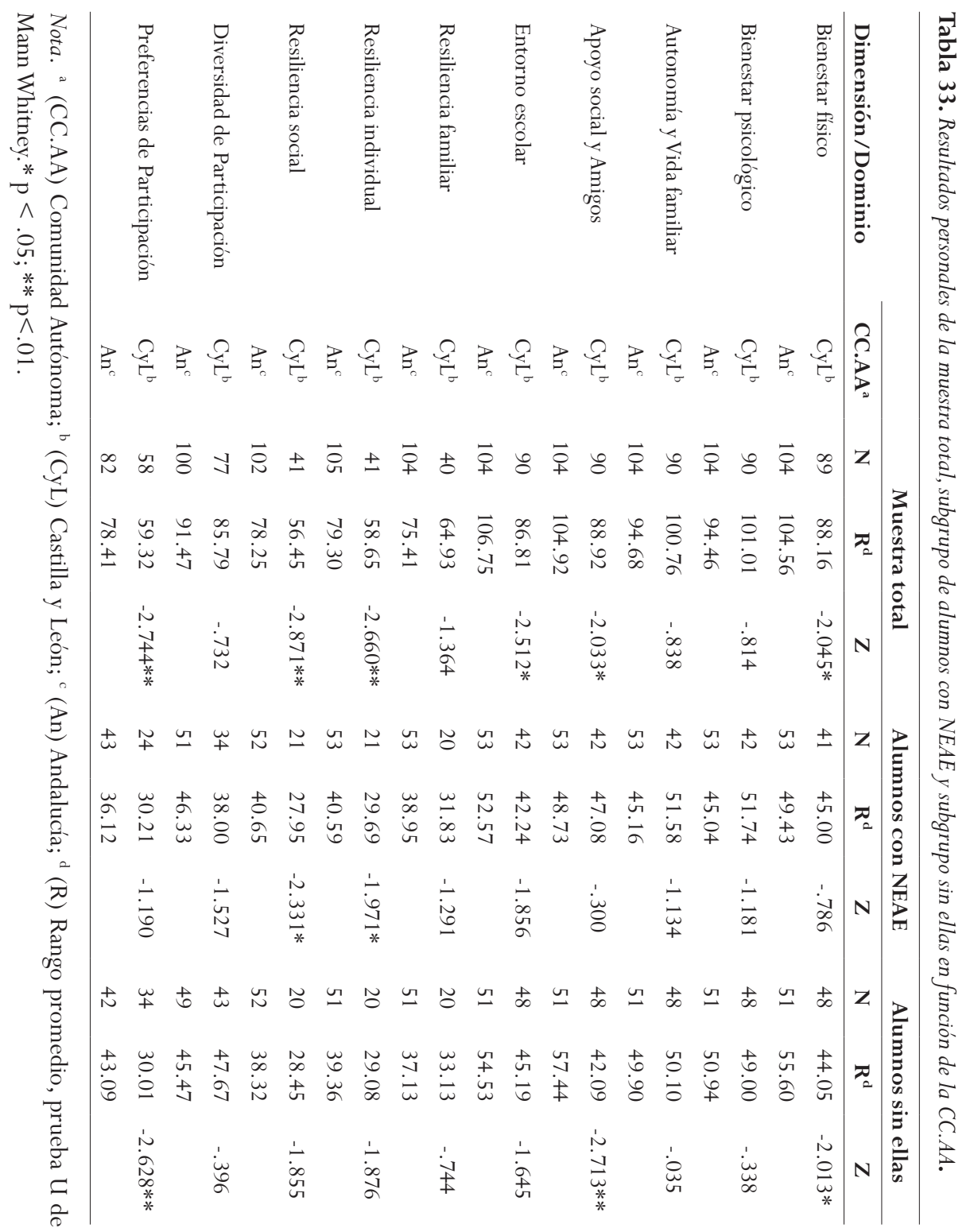


6.3.2.2. Análisis de la Influencia de Variables Educativas en los Resultados Personales de Alumnos de Primaria Informadas por los Propios Alumnos

6.3.2.2.1. Diferencias en Función del Curso Escolar

El conjunto de alumnos participantes mostraron diferencias significativas en bienestar familiar en función del curso escolar que realizaban $(z=-2.224$, $\mathrm{p}<.05)$. Las pruebas U de Mann-Whitney informaron que los alumnos de $6^{\circ}$ curso presentaban promedios de puntuación más altos en bienestar familiar que sus compañeros de $5^{\circ}$ (Promedio $=106.04$ vs. Promedio $\left.=88.02\right)$. Con respecto a los subgrupos analizados, la única diferencia hallada fue en las puntuaciones de bienestar físico de los alumnos $\sin \operatorname{NEAE}(\mathrm{z}=-1.975, \mathrm{p}<.05)$. En esta ocasión, los alumnos de menor curso obtenían puntuaciones más altas que sus compañeros mayores (Promedio $=56.33$ vs. Promedio $=44.94$ ) .

6.3.2.2.2. Diferencia en Función de la Realización de Asambleas en el Aula

La primera variable educativa informada por los alumnos sobre las metodologías inclusivas desarrolladas en sus escuelas fue la realización de asambleas, grupos de discusión y debates en el aula. Al analizar los resultados personales obtenidos por los alumnos participantes en función de la realización o no de asambleas, se hallaron diferencias significativas en diversas dimensiones de calidad de vida, resiliencia y participación, tanto en la muestra total, como los subgrupos de alumnos analizados. Estas diferencias pueden verse con más detalle en la Tabla 34. 


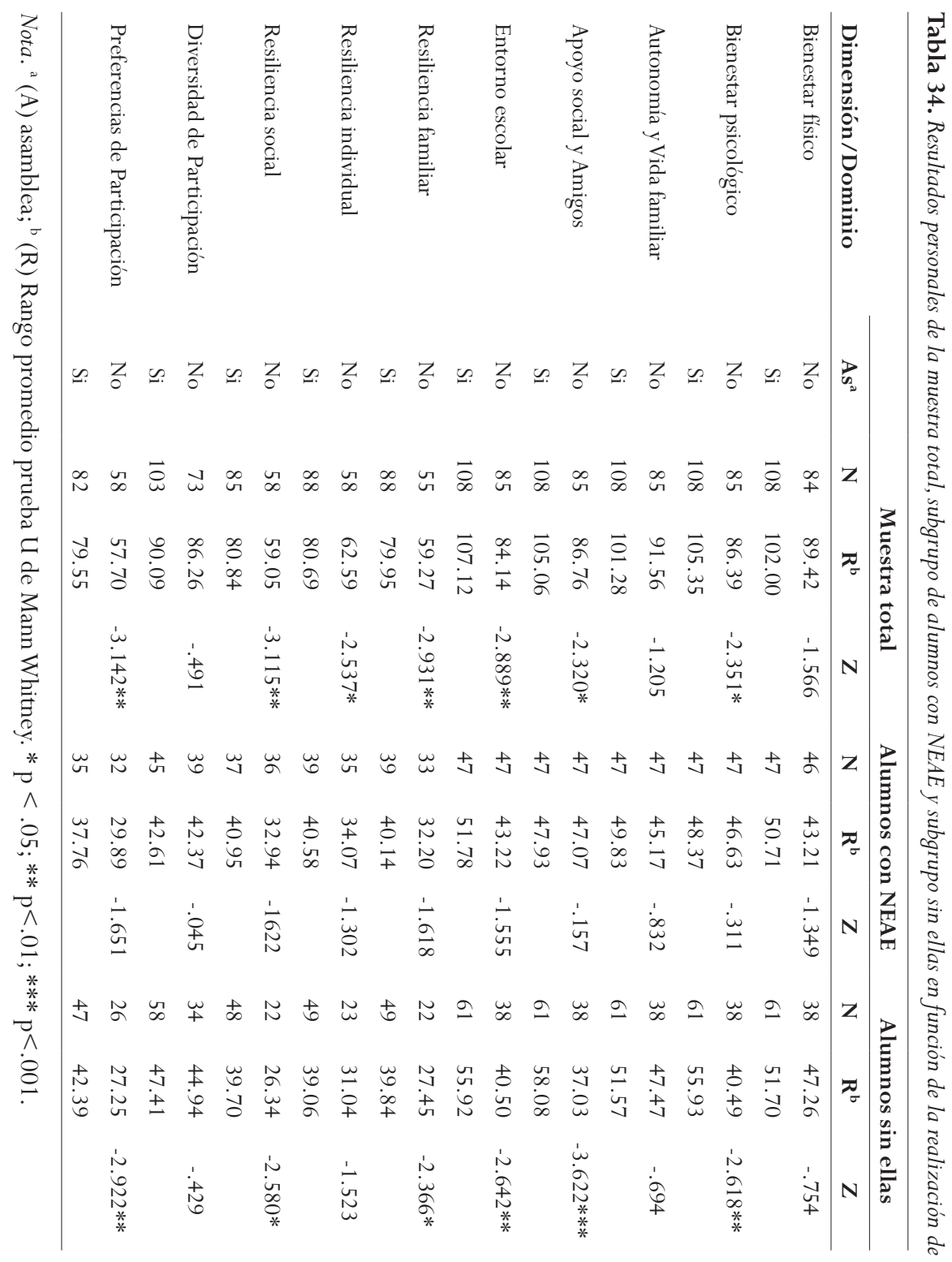

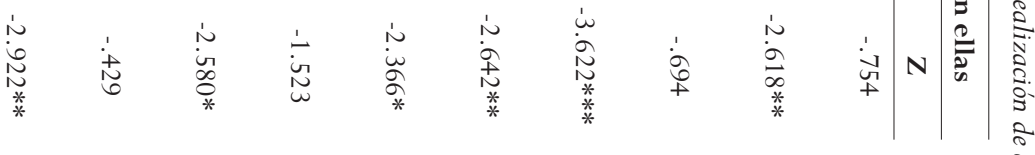


6.3.2.2.3. Diferencias en Función de la Seriedad con la que los Docentes Toman en Cuenta la Opinión de los Alumnos

Las pruebas U de Mann-Whitney mostraron diferencias significativas en diferentes puntuaciones de calidad de vida, resiliencia y participación, tanto de la muestra total, como de los subgrupos de alumnos con NEAE y sin ellas, en función de que los docentes mostrasen o no seriedad hacía las opiniones de los alumnos (Tabla 35).

Tabla 35. Resultados personales de la muestra total, subgrupo de alumnos con NEAE y subgrupo sin ellas, en función de la seriedad que los docentes dan a la opinión de los alumnos

\begin{tabular}{|c|c|c|c|c|c|c|c|c|c|c|}
\hline \multirow[b]{2}{*}{$\begin{array}{l}\text { Dimensión/ } \\
\text { Dominio }\end{array}$} & \multicolumn{4}{|c|}{ Muestra total } & \multicolumn{3}{|c|}{ Alumnos con NEAE ${ }^{a}$} & \multicolumn{3}{|c|}{ Alumnos sin ellas } \\
\hline & S.D.O ${ }^{b}$ & $\mathbf{N}$ & $\mathbf{R}^{\mathrm{b}}$ & $\mathbf{Z}$ & $\mathbf{N}$ & $\mathbf{R}^{\mathrm{c}}$ & $\mathbf{Z}$ & $\mathbf{N}$ & $\mathbf{R}^{\mathrm{b}}$ & $\mathbf{Z}$ \\
\hline \multirow[t]{2}{*}{$\begin{array}{l}\text { Bienestar } \\
\text { físico }\end{array}$} & No & 32 & 87.14 & -1.050 & 17 & 42.62 & -.745 & 15 & 45.60 & -.649 \\
\hline & $\mathrm{Si}$ & 160 & 98.37 & & 76 & 47.98 & & 84 & 50.79 & \\
\hline \multirow[t]{2}{*}{$\begin{array}{l}\text { Bienestar } \\
\text { psicológico }\end{array}$} & No & 32 & 84.72 & -1.368 & 17 & 46.85 & -.109 & 15 & 37.97 & -1.773 \\
\hline & $\mathrm{Si}$ & 161 & 99.44 & & 77 & 47.64 & & 84 & 52.15 & \\
\hline \multirow[t]{2}{*}{$\begin{array}{l}\text { Autonomía y } \\
\text { Vida familiar }\end{array}$} & No & 32 & 79.69 & -1.927 & 17 & 43.88 & -.607 & 15 & 34.63 & $-2.262 *$ \\
\hline & $\mathrm{Si}$ & 161 & 100.44 & & 77 & 48.30 & & 84 & 52.74 & \\
\hline \multirow[t]{2}{*}{$\begin{array}{l}\text { Apoyo social y } \\
\text { Amigos }\end{array}$} & No & 32 & 83.11 & -1.582 & 17 & 41.15 & -1.104 & 15 & 42.30 & -1.151 \\
\hline & $\mathrm{Si}$ & 161 & 99.76 & & 77 & 48.90 & & 84 & 51.38 & \\
\hline \multirow[t]{2}{*}{$\begin{array}{l}\text { Entorno } \\
\text { escolar }\end{array}$} & No & 32 & 68.95 & $-3.167 * *$ & 17 & 35.71 & $-2.015 *$ & 15 & 33.03 & $-2.527 *$ \\
\hline & $\mathrm{Si}$ & 161 & 102.57 & & 77 & 50.10 & & 84 & 53.03 & \\
\hline \multirow[t]{2}{*}{$\begin{array}{l}\text { Resiliencia } \\
\text { familiar }\end{array}$} & No & 22 & 49.41 & $-2.806 * *$ & 13 & 26.69 & -1.882 & 9 & 23.94 & -1.898 \\
\hline & $\mathrm{Si}$ & 121 & 76.11 & & 59 & 38.66 & & 62 & 37.75 & \\
\hline \multirow[t]{2}{*}{$\begin{array}{l}\text { Resiliencia } \\
\text { individual }\end{array}$} & No & 22 & 50.16 & $-2.817 * *$ & 13 & 26.69 & $-2.121 *$ & 9 & 26.56 & -1.531 \\
\hline & $\mathrm{Si}$ & 124 & 77.64 & & 61 & 38.66 & & 63 & 37.92 & \\
\hline \multirow[t]{2}{*}{$\begin{array}{l}\text { Resiliencia } \\
\text { social }\end{array}$} & No & 20 & 54.98 & $-1.999 *$ & 12 & 26.04 & -.525 & 8 & 18.94 & $-2.476 *$ \\
\hline & $\mathrm{Si}$ & 123 & 74.77 & & 61 & 39.94 & & 62 & 37.64 & \\
\hline \multirow[t]{2}{*}{$\begin{array}{l}\text { Diversidad de } \\
\text { Participación }\end{array}$} & No & 28 & 64.61 & $-2.708 * *$ & 16 & 34.84 & -1.397 & 12 & 29.50 & $-2.368 *$ \\
\hline & $\mathrm{Si}$ & 148 & 93.02 & & 68 & 44.30 & & 80 & 49.05 & \\
\hline
\end{tabular}




\begin{tabular}{lccccccccccc}
\hline & \multicolumn{3}{c}{ Muestra total } & \multicolumn{7}{c}{ Alumnos con NEAE } & \multicolumn{2}{c}{ Alumnos sin ellas } \\
\cline { 2 - 10 } $\begin{array}{l}\text { Dimensión/ } \\
\text { Dominio }\end{array}$ & S.D.O $^{\mathbf{b}}$ & $\mathbf{N}$ & $\mathbf{R}^{\mathrm{b}}$ & $\mathbf{Z}$ & $\mathbf{N}$ & $\mathbf{R}^{\mathrm{c}}$ & $\mathbf{Z}$ & $\mathbf{N}$ & $\mathbf{R}^{\mathrm{b}}$ & $\mathbf{Z}$ \\
\hline $\begin{array}{l}\text { Preferencias } \\
\text { de Participa- } \\
\text { ción }\end{array}$ & No & 25 & 56.68 & -1.880 & 16 & 23.75 & $-2.413 *$ & 9 & 36.78 & -.034 \\
& $\mathrm{Si}$ & 115 & 73.50 & & 51 & 37.22 & & 64 & 37.03 &
\end{tabular}

Nota. ${ }^{\text {a }}$ (NEAE) Necesidades Específicas de Apoyo Educativa; ${ }^{\text {b }}$ (S.D.O.) Seriedad docentes opinión alumnos; ${ }^{\mathrm{c}}(\mathrm{R})$ Rango promedio, prueba U de Mann Whitney. * $\mathrm{p}<.05 ; * * \mathrm{p}<.01$.

\subsection{Diferencias en Función de Hablar de la Diversidad del Alumnado en Clase}

Los resultados de la prueba U Mann-Whitney no revelan ninguna diferencia significativa en las puntuaciones de la muestra total de alumnos en función de hablar o no de la diversidad del alumnado en clase. A nivel descriptivo, a excepción de las dimensiones de bienestar físico y bienestar emocional, las puntuaciones en resultados personales fueron ligeramente más altas en aquellos casos en los que los alumnos informaron realizar esta actividad inclusiva en el aula, mostrando nuevamente dicha disposición al crecimiento positivo cuando el factor inclusivo está presente.

Los análisis con el subgrupo de alumnos con NEAE mostraron diferencias significativas en las puntuaciones de resiliencia familiar $(\mathrm{z}=-2.371, \mathrm{p}<.05)$, en función de la variable hablar de la diversidad en el aula. Los alumnos con NEAE que informaban realizar este tipo de actividad en el aula obtenían puntuaciones promedio mayores que sus compañeros con NEAE que no la realizaban (Promedio $=41.69$ vs. Promedio $=30.02$ ). Con respecto al grupo de alumnos sin NEAE, los análisis no paramétricos no destacaron ninguna diferencia significativa en función de esta variable educativa.

6.3.2.2.5. Diferencias en Función de Hablar con el Tutor sobre la Propia Forma de Aprender

Los alumnos de la muestra total mostraron diferencias significativas en las puntuaciones de preferencias de participación $(\mathrm{z}=-3.372, \mathrm{p}<.001)$, 
en función de hablar con el tutor sobre la propia forma de aprender del alumno. Aquellos estudiantes que informaban realizar dicha actividad con sus docentes obtuvieron promedios de puntuación en preferencias más altos que los que informaron no hacerlo.

Al examinar los resultados del grupo de alumnos con NEAE, se observó que los alumnos que afirmaban realizar esta actividad con sus docentes puntuaban significativamente por debajo que los que no en autonomía y vida familiar $(\mathrm{z}=-2.038, \mathrm{p}<.05)$. Mientras que, puntuaban significativamente más alto en preferencias de participación $(\mathrm{z}=-2.019, \mathrm{p}<.05)$. Por su parte, el grupo de alumnos sin NEAE obtuvo puntuaciones significativas mayores en bienestar emocional $(\mathrm{z}=-2.227, \mathrm{p}<.05)$ y preferencias de participación $(\mathrm{z}=$ $-2.711, \mathrm{p}<.01)$, cuando informaban realizarla.

6.3.2.3. Análisis de la Influencia de Variables Educativas en los Resultados Personales de los Alumnos Informadas por los Docentes

\subsection{Diferencias en Función de la Categoría de NEAE de los Alumnos}

Las pruebas no paramétricas de Kruskal-Wallis no evidenciaron diferencias significativas en las puntuaciones de calidad de vida, resiliencia, ni participación, en función del grupo de necesidades educativas al que pertenecían los alumnos con NEAE participantes.

\subsection{Diferencias en Función de los Años de Actividad Docente}

La variable años de actividad docente produjo diferencias significativas en los resultados de la muestra total de alumnos en bienestar físico $\left(\chi^{2}=6,095\right.$, $\mathrm{p}<.05)$, resiliencia individual $\left(\chi^{2}=6,360, \mathrm{p}<.05\right)$, preferencias de participación $\left(\chi^{2}=7,635, \mathrm{p}<.05\right)$. En todos los casos los alumnos de profesores que informaron tener entre 16 y 30 años de experiencia docente puntuaron más alto que el resto de sus compañeros. Por el contrario, los alumnos de docentes que informaron llevar entre 1 y 15 años fueron aquellos que puntuaron más bajo en dichas dimensiones, a excepción de en bienestar físico 
donde los alumnos del grupo de docentes con más de 30 años de experiencia profesional fueron quienes menor puntuación mostraron.

En el grupo de alumnos con NEAE los análisis chi-cuadrado no destacaron ninguna diferencia significativa en función de los años de actividad docente. Por su parte, los análisis con el grupo de alumnos sin NEAE desvelaron diferencias significativas en las puntuaciones de resiliencia individual $\left(\chi^{2}=6,624, \mathrm{p}=.036\right)$, donde nuevamente los alumnos de profesores con una experiencia laboral de entre 16 y 30 años obtenían las mayores puntuaciones.

\subsection{Diferencia en Función de la Presencia de Rampas en el Centro Escolar}

Las pruebas U de Mann-Whitney revelaron diferencias significativa en función de la presencia o no de rampas en las escuelas en las puntuaciones de diversidad de participación $(\mathrm{z}=-3.914, \mathrm{p}<.001)$, apoyo social y amigos $(\mathrm{z}=$ $2,487, \mathrm{p}<.05)$ y bienestar emocional $(\mathrm{z}=-2.120, \mathrm{p}<.05)$. De forma sistemática la presencia de rampas en el centro educativo provocaba puntuaciones mayores en las diferentes dimensiones de calidad de vida, resiliencia y participación valoradas.

En el grupo de alumnos con NEAE los análisis mostraron diferencias significativas en diversidad de participación $(\mathrm{z}=-2.770, \mathrm{p}<.01)$. Mientras que, en el grupo de alumnos sin ellas la presencia o no de rampas provocaba diferencias significativas en las puntuaciones de diversidad de participación $(\mathrm{z}=-2.520$, $\mathrm{p}<.05)$, apoyo social y amigos $(\mathrm{z}=-2.320, \mathrm{p}<.05)$ y resiliencia familiar $(\mathrm{z}=$ $2.089, \mathrm{p}<.05)$. En todas ellas la presencia de rampas provocaba un aumento significativo de los resultados personales obtenidos por ambos grupos de alumnos.

\subsection{Diferencias en Función de la Presencia de Aseos Adaptados en el Centro Educativo}

Las pruebas U de Mann Whitney no mostraron diferencias significativas en las puntuaciones de la muestra total de alumnos en función de la presencia de aseos adaptados en las escuelas. 
En el grupo de alumnos con NEAE los análisis revelaron diferencias significativas en las puntuaciones de resiliencia social $(\mathrm{z}=-2.253, \mathrm{p}<.05)$ $\mathrm{y}$ diversidad de participación $(\mathrm{z}=-2.261, \mathrm{p}<.05)$ en función de la variable educativa analizada. Sin en cambio, en el grupo de alumnos sin NEAE no se detectó ninguna diferencia significativa destacable.

\subsection{Diferencias en Función de la Presencia de Aulas Amplias}

No se hallaron diferencias significativas en las puntuaciones en resultados personales de la muestra total de alumnos, ni en los subgrupos de alumnos con NEAE y sin ellas en función de la presencia de aulas amplias en sus centros escolares.

\subsection{Diferencias en Función de Material Escolar Adaptado}

Con respecto a la presencia de material escolar adaptado los alumnos de la muestra total mostraron diferencias significativas en las puntuaciones de resiliencia individual $(\mathrm{z}=-2.593, \mathrm{p}<.05)$. Los alumnos que no disponían de material escolar adaptado en sus centros puntuaban por encima en resiliencia individual que sus compañeros que sí.

Los análisis con el grupo de alumnos con NEAE también desvelaron diferencias significativas en resiliencia individual $(\mathrm{z}=-2.791, \mathrm{p}<.01)$. Nuevamente, los alumnos con NEAE que no contaban con material escolar adaptado puntuaban por encima que sus compañeros con NEAE en centros que sí. Mientras que, en el grupo de alumnos sin NEAE los análisis no mostraron diferencias significativas en resultados personales.

\subsection{Diferencias en Función de Patio Escolar Adaptado}

Los alumnos de la muestra total no mostraron diferencias significativas en resultados personales en función de la presencia de patios escolares adaptados en sus centros educativos. 
En el grupo de alumnos con NEAE, aquellos que disponían de patios adaptados en sus escuelas obtuvieron puntuaciones significativamente mayores en apoyo social y amigos que sus compañeros que no disponían $(\mathrm{z}=$ -2044, $\mathrm{p}<.05)$. Mientras que en el grupo de alumnos sin NEAE no se detectaron diferencias entre uno y otro grupo.

6.3.2.4. Análisis de la Influencia de Variables Familiares en los Resultados Personales de los Alumnos Informadas por los Progenitores

\subsection{Diferencias en Función del Rango de Edad}

Las pruebas U Mann Whitney no mostraron diferencias significativas en calidad de vida, resiliencia o participación en función del rango de edad del padre, ni de la madre.

Con respecto a los subgrupos de alumnos con NEAE y sin ellas, los contrastes tampoco destacaron diferencias significativas en función del rango de edad del padre, pero si con respecto al rango de edad de la madre. En el grupo de alumnos con NEAE, el grupo de alumnos con madres de mayor edad obtuvo puntuaciones significativamente más altas en autonomía y vida familiar $(z=-2.069, \mathrm{p}=<.05)$. Mientras que el grupo de alumnos sin NEAE mostró diferencias significativas en bienestar físico $(\mathrm{z}=-2.171, \mathrm{p}<.05)$. Los alumnos sin NEAE y madres más jóvenes puntuaron por encima que los alumnos con madres mayores.

\subsection{Diferencias en Función del Nivel Educativo}

No se encontraron diferencias significativas en los resultados personales de la muestra total de alumnos en función del nivel educativo de los padres.

Los contrastes tampoco desvelaron diferencias significativas en el subgrupo de alumnos con NEAE, pero si en el subgrupo de alumnos sin ellas. Concretamente, se hallaron diferencias significativas en las puntuaciones de bienestar escolar $(\mathrm{z}=-2.275, \mathrm{p}<.05)$ y resiliencia individual $(\mathrm{z}=-2.144, \mathrm{p}<.05)$ en función del nivel educativo del padre. Los alumnos sin NEAE con padres 
con un nivel educativo superior puntuaban por encima que sus compañeros con padres de nivel educativo medio.

\subsection{Diferencias en Función del Estatus Laboral}

Las pruebas H de Kruskal-Wallis no revelaron diferencias significativas en las puntuaciones de la muestra total de los alumnos en función estado laboral del padre ni de la madre.

Los análisis con los subgrupos de alumnos con NEAE y sin ellas tampoco revelaron diferencias significativas en los resultados de calidad de vida, resiliencia o participación en función de esta variable.

\subsection{Diferencias en Función de los Ingresos Económicos}

Los alumnos de la muestra total mostraron diferencias significativas en las puntuaciones de bienestar emocional $\left(\chi^{2}=9.148 ; \mathrm{p}<.05\right)$ en función del nivel de ingresos económicos familiares. Los alumnos de familias con ingresos medios puntuaron por encima que sus compañeros de familias con ingresos menores y mayores.

Con respecto al grupo de alumnos con NEAE las pruebas de KruskalWallis manifestaron diferencias significativas en las puntuaciones de bienestar escolar $\left(\chi^{2}=9.124 ; \mathrm{p}<.05\right)$, donde los alumnos con NEAE de familias con ingresos bajos puntuaron por encima que el resto de grupos. Mientras que, en el grupo de alumnos sin NEAE las puntuaciones mostraron diferencias significativas en bienestar emocional $\left(\chi^{2}=8.999 ; \mathrm{p}<.05\right)$, autonomía y vida familiar $\left(\chi^{2}=12,958 ; \mathrm{p}<.01\right)$ y resiliencia familiar $\left(\chi^{2}=7.873 ; \mathrm{p}<.05\right)$. Los alumnos sin NEAE de familias con ingresos medios obtuvieron puntuaciones significativamente más altas que los otros grupos en bienestar emocional, familiar y resiliencia familiar. 


\subsection{Diferencias en Función de Miembro/s Dedicado/s a la Crianza del Hijo}

Las pruebas U de Mann-Whitney detectaron diferencias significativas en las puntuaciones de autonomía y vida familiar $(\mathrm{z}=-1.966 ; \mathrm{p}<.05)$ y resiliencia familiar $(\mathrm{z}=-2.123 ; \mathrm{p}<.05)$, en función del miembro o miembros dedicados a la crianza del hijo. En ambos casos los alumnos de la muestra total en cuyas familias ambos progenitores compartían la responsabilidad de su crianza y cuidado puntuaban más alto que aquellos compañeros donde la responsabilidad recaía únicamente sobre las madres.

En el grupo de alumnos con NEAE se detectaron diferencias significativas en las puntuaciones de autonomía y vida familiar $(\mathrm{z}=-2.254 ; \mathrm{p}<.05)$, resiliencia familiar $(\mathrm{z}=-1.972 ; \mathrm{p}<.05)$, resiliencia individual $(\mathrm{z}=-2.492 ; \mathrm{p}<.05)$ y resiliencia social $(\mathrm{z}=-1.998 ; \mathrm{p}<.05)$. En todos $\operatorname{los}$ casos los alumnos en cuyas familias la crianza era compartida obtenían puntuaciones más altas. Mientras que, en el grupo de alumnos sin NEAE no se detectaron diferencias significativas en resultados personales.

6.3.2.4.6. Diferencias en Función de ser Miembros de una Asociación Proveedora de Servicios

Las pruebas U de Mann-Whitney revelaron diferencias significativas en las puntuaciones en resiliencia individual $(\mathrm{z}=-2.922 ; \mathrm{p}<.01)$, en función de la pertenencia o no a una asociación proveedora de servicios. En este caso, los alumnos de la muestra total que informaron ser miembros de una asociación puntuaron significativamente más bajo que aquellos que no.

Cuando se realizaron estos mismos análisis con el grupo de alumnos con NEAE, los datos volvieron a informar de diferencias significativas en resiliencia individual $(\mathrm{z}=-2.092 ; \mathrm{p}<.01)$. Nuevamente los alumnos con NEAE que asistían a este tipo de organizaciones puntuaban por debajo que sus compañeros con NEAE que no lo hacían. Con respecto al grupo de alumnos sin NEAE, no se pudieron realizar los contrastes, debido a la falta de casos en una de las categorías respuesta de la variable analizada, concretamente en la categoría "pertenencia a una asociación proveedora de servicios". 
A continuación se discuten estos resultados a la luz de la actual investigación científica sobre calidad de vida y desarrollo infantil positivo.

\subsection{Discusión}

El objetivo general de este capítulo ha sido analizar la influencia que variables del contexto personal, educativo y familiar tienen en los resultados personales de alumnos de Primaria con NEAE y sin ellas. La información aportada por los niños y adultos de su entorno cercano ha permitido analizar el papel de dichas variables en la existencia de diferencias significativas en la percepción que los niños tienen de su calidad de vida, resiliencia y participación en actividades de ocio. En los siguientes apartados se discuten los resultados obtenidos de forma pormenorizada.

\subsubsection{Resultados Personales Generales de los Alumnos de Primaria}

Previamente al análisis de las diferencias entre grupos de alumnos de Primaria en función de sus valores en las distintas variables personales y ambientales estudiadas se examinaron los resultados personales obtenidos en calidad de vida, resiliencia y participación por el conjunto de alumnos de Primaria.

\subsubsection{Calidad de Vida Infantil}

Los resultados en calidad de vida evidencian que, en general, los alumnos de Primaria tienen una percepción positiva de su calidad de vida mostrándose satisfechos con las posibilidades para el crecimiento y desarrollo que les brinda su entorno familiar, escolar y de amistad. Estos resultados coinciden con los obtenidos en una investigación transcultural sobre salud mental y bienestar en población infantil europea (Erhart, Ottova, Gaspar, Nickel, RavensSieberer y HBSC Positive Health Focus Group, 2009). Las puntuaciones más positivas se refieren a los ámbitos vida familiar y escolar, lo que pone de manifiesto la importancia del entorno cercano del niño en la percepción que 
tiene de su bienestar subjetivo, tal y como defiende el modelo de calidad de vida individual de Schalock y colaboradores (2002, 2003, 2013).

\subsubsection{Recursos Personales y Sociales para la Resiliencia}

Con respecto a las medidas de resiliencia, en general, los resultados muestran que los alumnos de Primaria participantes tienen una percepción positiva de sus recursos personales y sociales para el desarrollo de su resiliencia. Estos resultados personales nos informan acerca de cómo los niños perciben su capacidad de navegar y negociar con sus ecologías sociales y físicas las vías que dan acceso a un desarrollo exitoso (Ungar, 2011). Sin embargo, dado que desde la visión del modelo socio-ecológico de resiliencia las trayectorias de desarrollo infantil depende del grado de facilitación ambiental, con cambios en los resultados personales dependientes del nivel de recursos necesarios proporcionados o limitados por el ambiente, se hace necesario analizar hasta qué punto estos resultados en resiliencia son sensibles a factores del contexto infantil español.

Por tanto, aunque una lectura superficial de los datos podría sugerir que los resultados personales en resiliencia de alumnos de Primaria con NEAE y sin ellas son positivos, en los siguientes apartados exploraremos cómo fluctúan los valores de estos resultados en función de la intervención de variables contextuales, tales como, ciertas características personales de los niños y otras variables ambientales presentes en los entornos cercanos en los que éstos desarrollan sus vidas. La finalidad de estos análisis es desvelar las vías que favorecen el funcionamiento infantil saludable, a través de la disponibilidad y accesibilidad de recursos positivos y significativos presentes en el contexto que facilitan la interacción positiva entre el niño y sus entornos de desarrollo próximos (Lewin, 1951; Rutter, 1987, 2012; Sameroff y Rosenblum, 2006). 
6.4.1.3. Participación en Actividades de Ocio y Tiempo Libre

En relación con la participación, la investigación a nivel internacional ha puesto de manifiesto los beneficios en el funcionamiento y bienestar del niño asociados a la realización de actividades de ocio y tiempo libre (OMS, 2001, 2007; King et al., 2003; Badia et al. 2013). En nuestro estudio los alumnos informan participar en un número moderado de actividades fuera del horario escolar y al mismo tiempo un alto grado de preferencia por participar en ellas. Estas actividades se refieren a jugar con las mascotas, ir a pasear, hacer deporte de equipo, jugar a juegos o ir en bicicleta, visitar a otras personas, escuchar música, así como recibir clases de arte, de música y danza, participar en asociaciones de tiempo libre, en definitiva, realizar actividades variadas de tipo extraescolar. Los resultados obtenidos concuerdan con el informe emitido por el Comité español de UNICEF sobre la infancia en España (2014), según el cual la inexistencia de documentos, estadísticas o políticas sobre la educación no formal provoca una invisibilidad de ésta en el currículo formativo infantil, limitando la participación de los menores al ámbito de la educación formal, descuidando otros contextos de participación con potencial educativo como es el del ocio y tiempo libre.

En los siguientes apartados analizaremos los resultados personales obtenidos en función de distintas variables del contexto personal y ambiental de los niños, en busca de factores con capacidad de actuar como barreras o facilitadores del desarrollo positivo y bienestar infantil. A partir de los valores de los alumnos en variables, tales como, presentar o no NEAE, realizar o no asambleas en clase, tener un tutor con más o menos años de experiencia docente o pertenecer a una familia con ingresos socioeconómicos bajos, medios o altos, entre otras, examinaremos los niveles de calidad de vida, resiliencia y participación en actividades de ocio de alumnos con NEAE y sin ella, tomando en consideración para su interpretación la evidencia científica previa. Este estudio nos permitirá comprobar cuáles de estas variables tiene potencial para actuar como factores que determinan resultados personales positivos y significativos en población infantil de alumnos con NEAE y sin ellas. 
6.4.2. Influencia de Variables Personales en los Resultados Obtenidos por Alumnos de Primaria

\subsubsection{Presencia de NEAE}

La presencia de NEAE ha sido la primera variable de tipo personal analizada. Los datos han puesto en evidencia que cuando los alumnos presentan NEAE muestran una percepción de su bienestar emocional y de los recursos presentes en su contexto para el desarrollo de su resiliencia personal significativamente inferior a sus compañeros sin ellas. Estos resultados son de suma relevancia para las trayectorias de desarrollo de unos y otros niños si tenemos en cuenta los indicadores que definen ambas medidas. Por un lado, la satisfacción vital, el auto-concepto, los afectos positivos, la espiritualidad y la seguridad personal en la dimensión bienestar emocional (Verdugo et al., 2013; Wallander et al., 2016) y, por otro, la percepción que tienen de sus habilidades personales y sociales, así como las oportunidades ofrecidas por su entorno para su expresión en la dimensión de resiliencia personal (Brondersen, 2013; Liebenberg et al., 2012; Ungar, 2011).

Sin embargo, el hecho que las diferentes tipologías de NEAE no ocasionen diferencias significas en los resultados personales de alumnos de Primaria con diversas condiciones biopsicosociales, desvela que, más allá de las necesidades educativas particulares que presentan unos u otros alumnos, es la etiqueta general de la presencia de ellas la que determina las oportunidades y barreras que impone su ambiente normativo para que los diferentes alumnos pongan a prueba sus competencias personales y sociales en el manejo de desafíos y conflictos presentes en su día a día (Ungar, 2004, 2008; Acle, Roque, Zacatelco, Lozada y Martínez, 2007), que a la vez se relaciona con la vivencia de experiencias subjetivas que determinan el valor del bienestar personal percibido (Khanlou et al., 2014; Lee et al., 2010; Skinner et al., 2005; Ungar, 2012). Resultados análogos fueron hallados por Sabeh y colaboradores (2002) quienes evaluaron la percepción de la calidad de vida de niños y niñas con necesidades educativas y sin ellas en España y Argentina. 
Los resultados de este estudio aportan pruebas a la veracidad del modelo socio-ecológico de resiliencia, según el cual, cuando los procesos de navegación y negociación infantil son limitados o coartados por restricciones del entorno, los niños ante condiciones de vida adversas ven impactado su bienestar y funcionamiento saludable (Samerroff et al., 2003; Wyman, 2003; Ungar, 2004, 2008). En este caso, es la presencia de NEAE en un sistema social que prima la normalidad antes que la diversidad humana lo que genera el conflicto en la interacción entre el niño y su entorno (Oliver, 1998; Runswick-Cole et al., 2013; Ungar, 2012; Wolfensberger, 1972).

A continuación analizaremos las diferencias más significativas halladas en resultados personales en función de las variables personales y ambientales seleccionadas, centrándonos en los resultados diferenciales obtenidos por el grupo de alumnos con NEAE y el grupo sin ellas en aquellos casos en los que se considere su relevancia teórica y práctica.

\subsubsection{Género}

Los resultados ponen de manifiesto una participación mayor en actividades diversas de ocio y tiempo libre del grupo femenino frente al masculino, con indiferencia de la presencia de NEAE. Estos resultados no concuerdan con los de investigaciones previas, en los que se ha evidenciado diferencias de género a favor de la participación masculina en actividades extraescolares diversas (Law, et al., 2006; Longo et al., 2009; Síndic de Greuges, 2014), siendo aún más comprometida la participación en el grupo de niñas con necesidades especiales que en el grupo sin ellas (Schreuer et al., 2014).

Resulta llamativo que al analizar las diferencias en función del género, la única variable capaz de producir diferencias significas en los resultados personales de niñas y niños haya sido su diversidad de participación en el ámbito del ocio y tiempo libre. La importancia de esta variable radica en su potencial para generar oportunidades de igualdad de género y equiparación en derechos y deberes (Sanchez-Herrero, 2008). Dada la repercusión que la participación en actividades diversas tiene en la configuración de la identidad 
personal, roles sociales y hábitos de vida, diversos estudios nacionales se han centrado en explorar estos resultados diferenciales entre niños y niñas (Caballo, Caride y Gradaílle, 2012; IUNDIA, 2016). Estos y otros estudios ya citados han puesto de manifiesto el predominio de la participación masculina en tipologías de actividad centradas en el ocio recreativo y deportivo, mientras que las niñas dedican su tiempo libre a actividades más pasivas de tipo social y cultural (Longo et al., 2009; Síndic de Greuges, 2014).

Según Sánchez-Herrero (2008), la perspectiva de género en el estudio del ocio se convierte en una herramienta esencial para comprender los estilos de vida de hombres y mujeres, debido a su relación con los estereotipos sociales que condiciona el reparto desigual de actividades diversa, así como el impacto que estas diferencias tienen en la calidad de vida y bienestar subjetivo de las personas. Dado el valor del ocio y tiempo libre en el desarrollo infantil, unir al estudio de la diversidad de participación de niños y niñas sus preferencias hacia la participación en tipologías distintas de actividad, así como la discrepancia entre ambas variables, permitiría conocer los estereotipos sociales de participación tradicionales, la flexibilidad de los roles de género en el ámbito del ocio y tiempo libre y, por último, la creación de oportunidades de participación adaptadas a los intereses reales de los menores, a través de las cuales puedan desarrollar sus capacidades y sentimientos más allá de otras consideraciones personales o sociales. Desde esta perspectiva, el estudio de las discrepancias entre la diversidad de participación y preferencias individuales surge como estrategia educativa en el ámbito del ocio y tiempo libre de interés para investigaciones futuras.

\subsubsection{Localización Geográfica}

La localización geográfica ha sido otro importante indicador utilizado para analizar las inequidades sociales en poblaciones infantiles de diferente índole, dado las posibilidades o barreras que vivir en un determinado emplazamiento frente a otro (rural vs. urbano, norte vs. sur, alto vs bajo nivel socioeconómico, por ejemplo) ocasiona en los resultados de salud y 
crecimiento positivo de los niños (OMS, 2004; UNICEF, 2015). En general, la investigación ha fundamentado estas diferencias en la relación existente entre las peculiaridades ambientales, estructurales o culturales de cada lugar y la evaluación que hacen los niños a cerca de sus experiencias cotidianas de bienestar (Urzúa, Caqueo-Urízar, Albornoz y Jara, 2013).

Con respecto a los resultados personales obtenidos en esta investigación en función de la Comunidad Autónoma de residencia, los alumnos con NEAE y sin ellas de Castilla y León (CyL) informan tener una percepción de su bienestar físico, social y escolar significativamente menor que sus iguales andaluces. Estos resultados coinciden con los presentados en el informe de Unicef sobre bienestar infantil desde el punto de vista de los niños (2012), donde CyL aparece como una de las comunidades autónomas españolas con las medias de bienestar más bajas. Concretamente, los índices de bienestar en el contexto escolar fueron los menores de toda España. Este informe también pone en evidencia que mayores tasas de participación se asociación a niveles de bienestar personal más altos (UNICEF, 2012), tal como se aprecia en los grupos de alumnos analizados en este estudio. Estos resultados coinciden con la tesis defendida por Aguirre (2012), en su trabajo sobre factores contextuales y calidad de vida en las actividades de ocio de jóvenes y adultos con discapacidades en el desarrollo, en la que dos de sus resultados más destacados fueron el predominio de las variables ambientales sobre las características personales en los resultados personales de los participantes, así como la asociación de los niveles de bienestar personal percibido con la participación de los jóvenes en actividades de ocio y tiempo libre.

Las diferencias en la percepción que los alumnos tienen de sus recursos individuales y sociales para el desarrollo de su resiliencia, también hace alusión a estos aspectos socio-ambientales específicos a cada lugar geográfico, e informa de la existencia de factores del contexto local particulares que favorecen la respuesta sana y adaptativa frente a circunstancias adversas, como pueden ser la presencia de NEAE durante el desarrollo infantil (Amar, Kotliarenko y Abello, 2014). Los resultados en resiliencia concuerdan a su vez con las evidencias empíricas sobre las diferencias transculturales en la 
expresión de la resiliencia infantil (Liebenberg et al., 2012), según las cuales la percepción que los niños tienen sobre aquellos aspectos de su vida que experimenta como más o menos significativos, está íntimamente ligada al sistema de valores transmitido generacionalmente (Ungar, 2011).

Dado que, según la teoría socio-ecológica defendida en este trabajo, el desarrollo positivo del niño depende de la construcción que éste tenga de su estado de bienestar y la construcción social de bienestar que tiene el colectivo del que forma parte (Ungar, 2004), para conocer los factores del contexto local que actúan en estos procesos de co-construcción y comprender cómo influyen en la identidad que el niño elabora de su estado de salud y vulnerabilidad (Ungar, 2012), sería interesante el estudio diferencial de las relaciones entre los aspectos ambientales idiosincráticos de cada región y las características personales de los niños residentes en ellas. Los resultados de estos análisis otorgarían claridad acerca de los procesos causales que dan lugar a las diferencias en resultados personales de niños con circunstancias similares de desarrollo, pero pertenecientes a zonas geográficas distintas.

\subsubsection{Influencia de Variables Educativas en los Resultados Personales de} los Alumnos de Primaria

\subsubsection{Curso}

Las únicas diferencias referentes al curso escolar de los alumnos han sido en los resultados de bienestar familiar. Teniendo en cuenta que los indicadores de esta dimensión se definen en torno a las relaciones familiares, el tiempo pasado en familia, así como a la autonomía personal y económica de los hijos, el hecho de que los alumnos de cursos más altos perciban mayores niveles de bienestar familiar puede hallarse en que el grupo de alumnos de mayor edad perciba más oportunidades para la expresión de su independencia familiar, reportándoles sentimientos más positivos sobre la cantidad y calidad del tiempo pasado en familia. Estas diferencias obtenidas no concuerdan con las hipótesis establecidas y demostradas por los autores originales de la versión española del Kidscreen (Aymerich et al., 2005), los cuales evidenciaron 
niveles de calidad de vida mayores en el grupo de participantes de menor edad. Dada la escasa diferencia etaria entre los participantes de ambos cursos en nuestro estudio, sería interesante su replicabilidad en una franja de edad mayor que permitiese una comparación entre grupos más pormenorizada.

\subsubsection{Experiencia Docente}

Los resultados de la experiencia docente medida como los años de actividad profesional de los maestros indican que, aquellos con un recorrido profesional medio (de 16 a 30 años) son los que originan en sus alumnos con y sin NEAE niveles más altos de bienestar personal y preferencias hacia la participación en actividades diversas de tipo extraescolar, así como mayores oportunidades para el desarrollo de su resiliencia individual (Knight, Balatti, Haase, y Henderson, 2010). Estos resultados apoyan el papel de los docentes como facilitadores del desarrollo positivo de sus alumnos, así como la importancia de la experiencia profesional como clave para la transformación educativa y cambio de los modelos de enseñanza-aprendizaje preestablecidos (Jurado, 2009; Schalock et al., 2013; Vezub, 2007).

\subsubsection{Desarrollo de Actividades Inclusivas en Clase}

Con respecto al desarrollo de actividades inclusivas en el aula, el hecho realizar asambleas, considerar seriamente la opinión de los alumnos, hablar de la diversidad y de la propia forma de aprender de cada alumno, genera resultados significativamente superiores en las medidas de bienestar, resiliencia y participación de alumnos con NEAE y sin ellas. Estos resultados informan acerca de los medios profesionales que los docentes tienen a su alcance para facilitar el cambio en su comunidad educativa, a través de prácticas inclusivas que dan lugar a resultados personales de bienestar y desarrollo positivo en el conjunto de alumnos (Booth et al., 2002, 2015; Muntaner et al., 2010; Schalock et al., 2013). 


\subsubsection{Recursos Físicos y Materiales del Centro}

Nuevamente como las influencias halladas en los resultados personales de los alumnos a partir la realización de actividades inclusivas en el aula, la disponibilidad y acceso a rampas, aseos, patios y materiales escolares adaptados, provoca aumentos significativos en los niveles generales de bienestar, resiliencia y participación de alumnos de Primaria con y sin NEAE.

Centrándonos en los resultados de alumnos con NEAE, los datos informan que contar con recursos físicos y materiales para la respuesta a sus necesidades educativas facilita al mismo tiempo su participación en actividades diversas, así como la motivación por participar en ellas (Longo et al., 2009; King et al., 2009). La presencia de estos recursos también aumenta las oportunidades que tienen los alumnos con NEAE de interactuar con su entorno escolar, favoreciendo tanto el desarrollo de su resiliencia individual y social, como el bienestar percibido a partir de la relación con sus iguales y apoyo social recibido (Uriarte, 2006; Henderson y Milstein, 2003). Estos resultados apuntan una vez más hacia el establecimiento de apoyos y puesta en marcha de prácticas inclusivas que permitan a todos los niños acceder, participar y aprender en interacción con su medio escolar (Booth et al., 2002, 2015).

\subsubsection{Influencia de Variables familiares en los Resultados Personales de los} Alumnos

\subsubsection{Estatus Cultural y Socioeconómico de los Padres}

Los análisis no desvelan diferencias destacables en los resultados personales de alumnos de Primaria en función de la edad, el nivel educativo o el estatus laboral de los padres, más allá de diferencias puntuales en relación a la edad de la madre y nivel educativo del padre en los grupos de alumnos con NEAE y sin ellas. Sin embargo, cuando analizamos las diferencias entre grupos de alumnos en función del nivel socio-económico de las familias hallamos que, en general los alumnos de familias con ingresos medios perciben un bienestar emocional mayor que sus compañeros de familias con ingresos menores o mayores. 
Los ingresos económicos, al igual que el lugar de residencia, ha sido una variable socidemográfica ampliamente utilizada como indicador social de bienestar en investigación aplicada, mostrando su implicación en las desigualdades estructurales entre distintos grupos sociales y en la calidad de los entornos familiares y comunitarios en los que tiene lugar el desarrollo infantil (Bauer, 1966; Exenberger et al., 2013; Schalock et al., 2016a). Los resultados de este estudio vuelven a corroborar una vez más la importancia del nivel económico familiar para la promoción de oportunidades personales y sociales para el crecimiento infantil positivo. Sin embargo, pese a lo demostrado en otros estudios del género (Paz y Serra, 2008), en nuestro estudio no son los niveles económicos familiares más altos los que mayor satisfacción y significado tienen para el niño, sino niveles intermedios que posibilitan el acceso y disponibilidad de recursos materiales y sociales donde los niños pueda desarrollar con libertad sus funciones cotidianas (Sen, 1993, 2002).

Con respecto a los grupos específicos de alumnos con NEAE y sin ellas. Mientras que, en el grupo de alumnos con NEAE niveles socioeconómicos más bajos se asocian de manera significativa a una percepción mayor de bienestar escolar, en el grupo de alumnos sin NEAE un estatus socioeconómico familiar más alto se relaciona con niveles significativamente menores de bienestar emocional y bienestar familiar, siendo nuevamente los niveles socioeconómicos medios los que mayor bienestar emocional y familiar reportan. Estos resultados vuelven a resaltar la importancia del carácter subjetivo del bienestar desde edades tempranas, en contra a aquellas posturas reduccionistas que defienden una vida de calidad desde el acceso y posesión de recursos materiales (WHO, 2004a; WHO, 2004b; Ungar, 2015b).

Cuando los niños perciben carencias (físicas, materiales, emocionales, afectivas, entre otras) en sus ambientes cercanos, buscan la respuesta a sus necesidades en otras parcelas de vida. A edades tempranas, como la de los alumnos participantes, las fallas afectivas o socioeconómicas familiares son cubiertas por la institución escolar, donde los niños encuentran personas 
significativas (iguales, profesionales y otros adultos) que responden y apoyan su crecimiento, así como una estructura organizada que idealmente cubre sus necesidades primarias, amortigua sus dificultades e inseguridades y modela su desarrollo personal y social. Por tanto, la escuela como organización tiene la capacidad de generar en los niños sentimientos de seguridad y bienestar, siendo especialmente significativa para niños en situación de mayor riesgo asociado a su desarrollo, como en este estudio son los alumnos con NEAE de familias con niveles socio-económicos más bajos (Ungar, 2011).

En suma, los resultados de esta investigación resaltan que para los niños por delante de la posesión de bienes y recursos económicos se encuentran la cohesión familiar, el desarrollo de relaciones de intimidad y afecto con sus seres queridos, la seguridad de las figuras de apego y la vivencia compartida de experiencias familiares. De esta forma, son los niveles económicos intermedios los que permiten responder tanto a las necesidades materiales básicas para la subsistencia infantil, como a sus necesidades personales y sociales primarias, alentando el desarrollo personal y la libertad de los niños para construir su propias trayectorias de desarrollo (Sen, 1993, 2002; Ungar, 2011; Urquijo, 2014).

\subsubsection{Crianza y Cuidado del Hijo}

Los análisis de este estudio han mostrado diferencias destacables en los resultados personales de bienestar y resiliencia en contexto familiar obtenidos por alumnos con NEAE y sin ellas, en función de si la responsabilidad de la crianza y cuidado del hijo es compartida por ambos progenitores o recae únicamente sobre uno de ellos, la madre. Estos resultados vuelven a subrayar la importancia de la calidad del entorno familiar sobre los resultados personales de los menores. En general, los alumnos con NEAE y sin ellas perciben mayores niveles de bienestar y resiliencia familiar cuando ambos progenitores comparten las labores de su crianza, cuidado y educación, tal como defiende Windle (2011) en su modelo sistémico de resiliencia en el que acentúa la estabilidad, el apoyo y la cohesión familiar como tres de 
los componentes principales del sistema familiar para el desarrollo de la resiliencia y bienestar infantil.

Con respecto al grupo de alumnos con NEAE, los resultados son congruentes con los obtenidos por Ancle (2005) quien demostró que la falta de apoyo de la pareja hacia la madre es otro de los indicadores que incide negativamente sobre el desarrollo positivo de niños con necesidades especiales. En esta línea, Armstrong, Birnie-Lefcovitch y Ungar (2005) también manifestaron que el apoyo social de las familias, su bienestar y la capacidad de los padres para fortalecer la resiliencia del hijo son factores familiares que median en el desarrollo y fortalecimiento de las capacidades de niños con dificultades en su funcionamiento mental, emocional y físico.

En un marco de desarrollo infantil que destaca la capacidad de los individuos y sus entornos para negociar formas culturalmente significativas que den acceso y disponibilidad a recursos promotores de salud y bienestar, conocer y comprender cómo las diferentes formas de estructura familiar contemporáneas (biparental, monoparental, padres separados, compuestas de dos familias nucleares distintas, etc.) determinan el funcionamiento familiar (cohesión, apoyo, estabilidad, finanzas, vivienda, entre otros) y afectan al desarrollo personal del niño resulta de extrema importancia en una sociedad en la que las formas tradicionales de familia están evolucionando a sistemas familiares cada vez más complejos. El avance en esta línea de investigación es además relevante para la adaptación de intervenciones y programas dirigidos a la mejora del funcionamiento familiar (Khanlou et al., 2010) desde los actuales esquemas familiares que se están gestando en la sociedad actual, dados los resultados hallados acerca del efecto que el ajuste conyugal tiene sobre el funcionamiento y bienestar de niños con condiciones de discapacidad y desarrollo típico (Lickenbrock, Ekas y Whitman, 2011; Risdal y Singer, 2004).

En suma, estos resultados permiten identificar otro factor facilitador del desarrollo integral de los niños, como es la cohesión familiar, más allá de otros factores obstaculizadores como son la presencia de NEAE como etiqueta, niveles socioeconómicos familiares extremos, la carencia de 
recursos físicos, materiales y/o profesionales en el entorno escolar para el acceso, participación y aprendizaje de alumnos con NEAE y sin ellas, entre otros.

\subsubsection{Miembros de Asociaciones Proveedoras de Servicios}

La importancia de los resultados obtenidos en esta última variable ambiental examinada radica en los niveles significativamente inferiores en resiliencia individual hallados en alumnos con NEAE cuando éstos asisten a asociaciones proveedoras de servicios. Teniendo en cuenta los indicadores que conforman dicha dimensión (habilidades personales y sociales, y oportunidades o limitaciones ambientales para su desarrollo), cabe preguntarse si los niños usuarios de estos servicios obtienen niveles inferiores de resiliencia individual como consecuencia de sus déficits personales en habilidades y competencias personales y/o sociales, o si este contexto profesional y de intervención psicológica, socioeducativa y comunitaria, está limitando las oportunidades y fortalezas del niño para la adquisición, desarrollo y expresión de su resiliencia individual.

En base a estos resultados, investigaciones en la línea del modelo de resiliencia socio-ecológico de Ungar (2011) están desafiando la perspectiva normativa del desarrollo exitoso de niños con condiciones personales de discapacidad o dificultades en su funcionamiento cotidiano (Runswick et al., 2013), y haciendo un llamamiento al estudio de los factores ambientales que limitan la posibilidad de crear entornos desafiantes en los que niños con necesidades especiales puedan encontrar oportunidades estructurales adaptas para el florecimiento de su resiliencia, así como situaciones en las que experimentar bienestar a través de la interacción con su entorno (Schreuer et al., 2014; Ungar, 2012). En este sentido, las organizaciones proveedoras de servicios dirigidas a la atención temprana y desarrollo infantil positivo, requieren revisar sus formas de teorizar e implementar las intervenciones profesionales dirigidas a niños con condiciones de desarrollo diversas y a sus familias, las cuales se encaminan a ellas en busca de información y 
soporte para la calidad de vida, autodeterminación y crecimiento positivo de sus hijos con necesidades especiales (Skinner et al., 2005). Referencias de estos cambios se pueden encontrar en los últimos trabajos desarrollados por Schalock et al. 2013b; 2016b; 2018) sobre la transformación de las organizaciones proveedoras de servicios a través de soluciones creativas e innovadoras basadas en la evidencia científica.

Llegados a este punto, con objeto de sintetizar los resultados obtenidos y hacerlos operativos para investigaciones futuras, en la Tabla 36 se presenta los resultados más destacados sobre los factores del contexto personal y ambiental que actúan como barreras o facilitadores de la calidad de vida, resiliencia y participación infantil en actividades de ocio y tiempo libre, identificados en este estudio. 


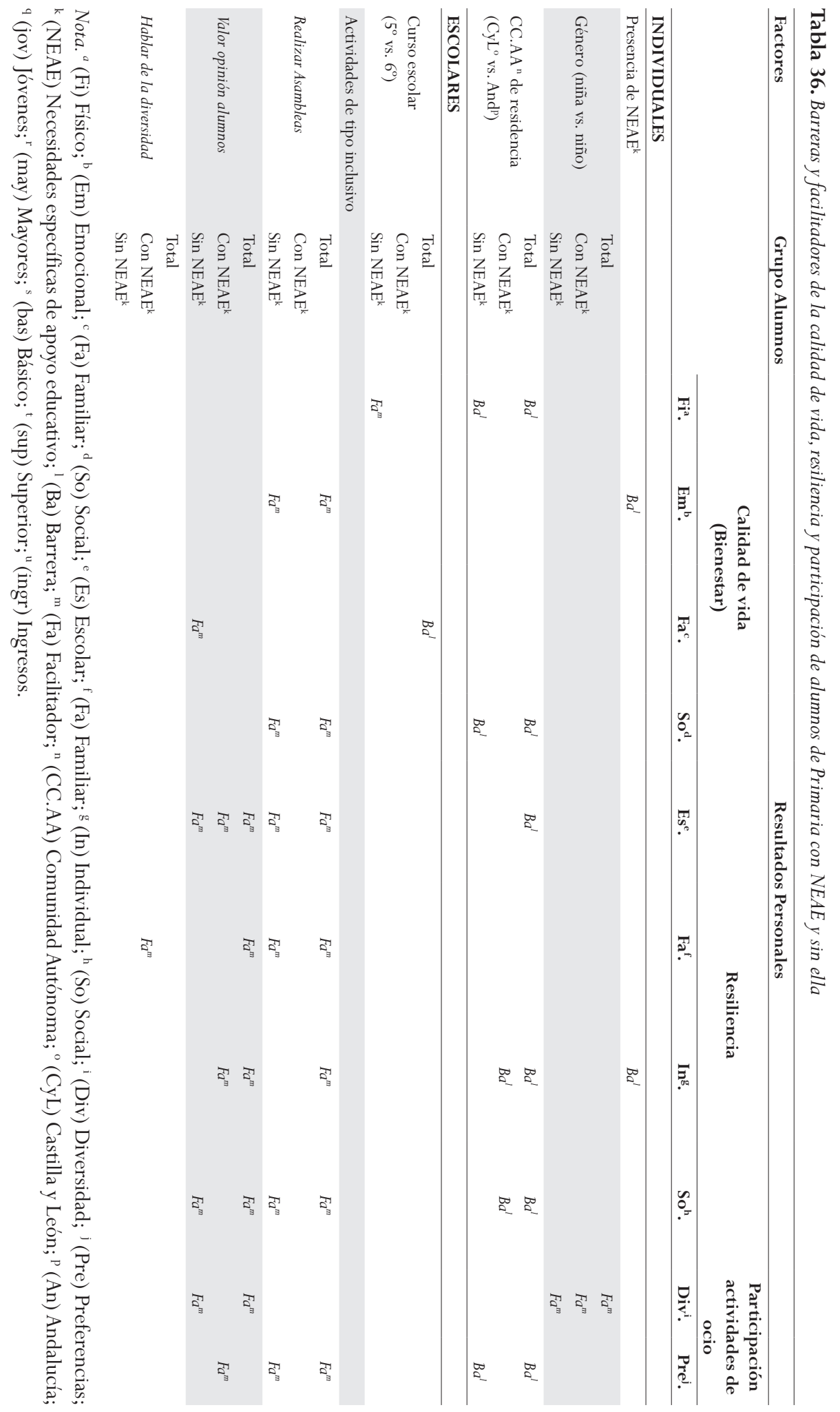




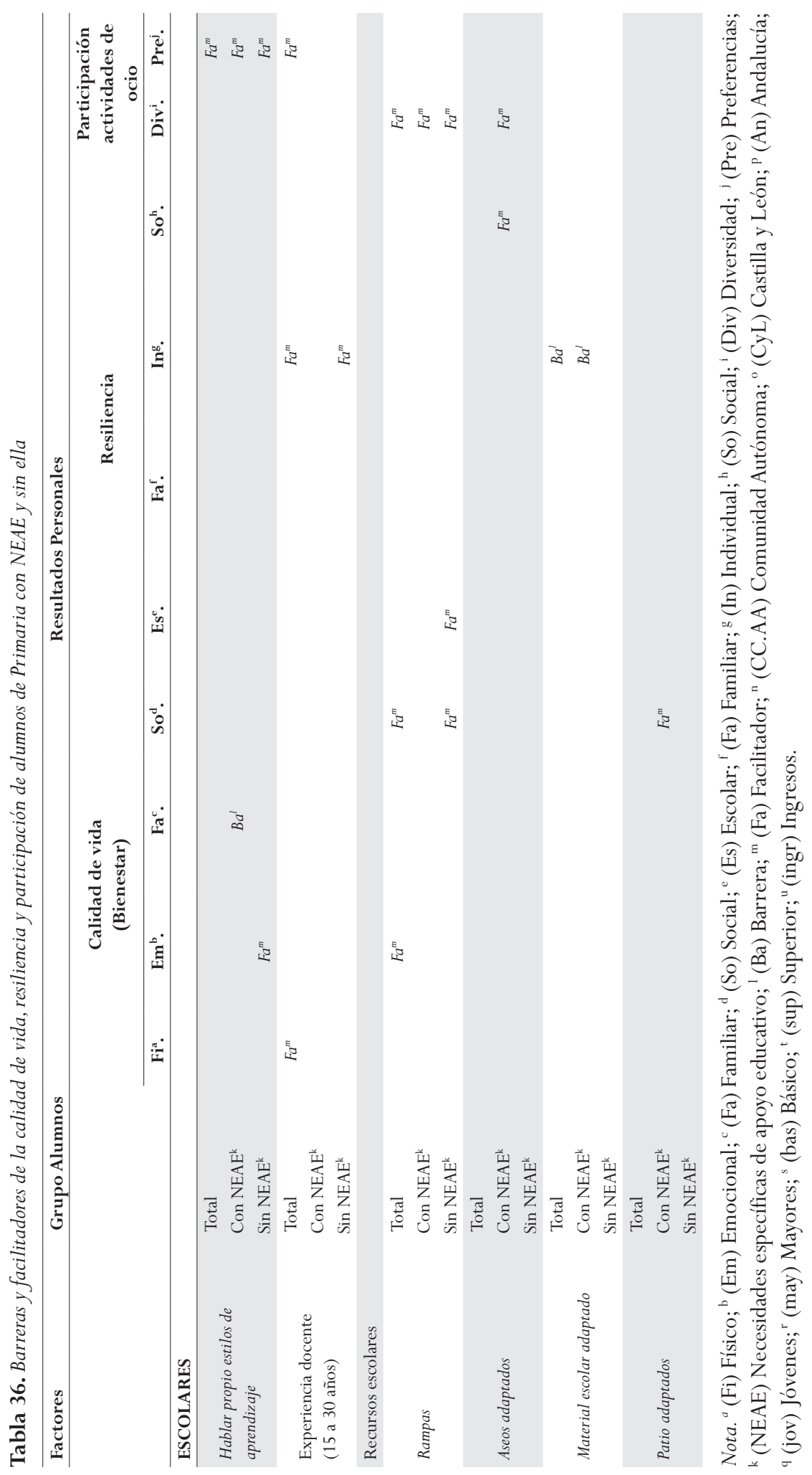




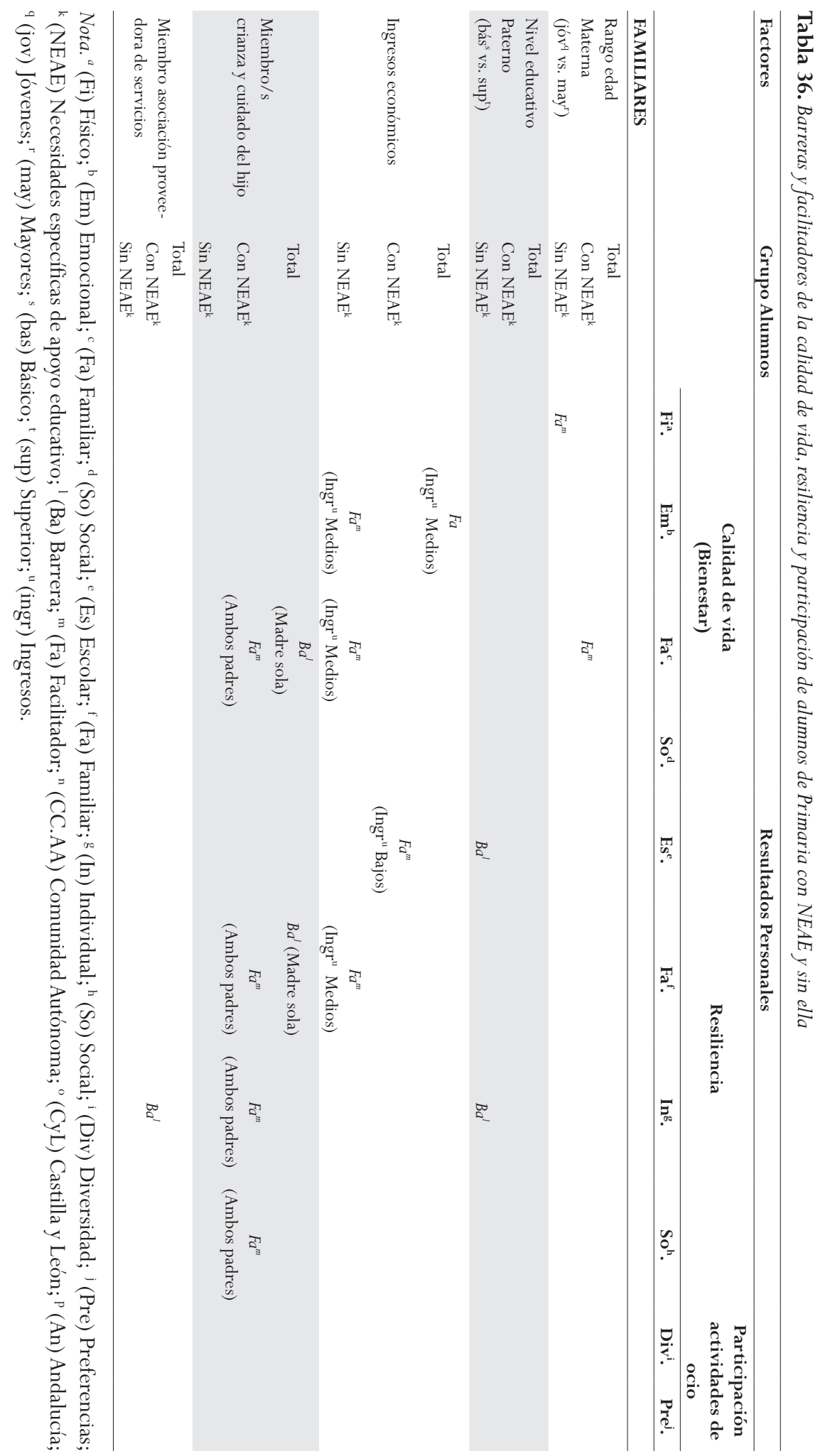




\subsection{Conclusiones}

La finalidad de este capítulo ha sido aportar nuevas evidencias acerca de los factores del contexto asociados a los resultados personales en calidad de vida, resiliencia y participación en actividades diversas de ocio y tiempo libre de alumnos de Primaria con NEAE y sin ellas. Esta finalidad responde a la importancia que tiene para el avance del conocimiento teórico en desarrollo y bienestar infantil, así como en la comprensión acerca de las vías que facilitan el crecimiento infantil positivo de todos los niños sin excepción, explorar la influencia que determinadas variables personales y ambientales tienes en los resultados de bienestar, resiliencia y participación en actividades de ocio de niños con diversas condiciones educativas asociadas y sin ellas.

En conjunto los resultados de este estudio muestran el efecto que los factores del contexto cercano al niño tienen sobre sus resultados de bienestar personal y desarrollo infantil positivo, destacando el peso positivo que las variables educativas de tipo inclusivo y las variables familiares, que demarcan cohesión y estabilidad, tienen sobre dichos resultados.

Cabe también destacar los resultados diferencias hallados entre el grupo de alumnos con NEAE y sin ellas bajo específicas condiciones ambientales, como por ejemplo el efecto diferencial que ejerce contar con patio adaptado sobre los resultados personales de uno y otro grupo de alumnos, o el beneficio personal que obtienen de su entorno escolar los alumnos con NEAE de familias con bajos niveles socioeconómicos, así como el efecto que la estructura familiar para la crianza y educación del hijo muestra sobre este mismo grupo de alumnos, no destacando ningún efecto significativo sobre el grupo de alumnos sin ellas. Estos resultados diferenciales son importantes para la implementación de intervenciones adaptadas a las características personales y ambientales de cada niño, dirigidas a la promoción de su calidad de vida y crecimiento positivo, a través de estrategias y prácticas enfocadas a la consecución de resultados personales significativos.

El carácter voluntario de la participación de niños y adultos en el estudio ha sido su principal limitación, la cual ha conllevado la perdida de información 
personal, educativa y familiar. Esta limitación, unida al hecho que el estudio sólo ha podido ser administrado a alumnos de Primaria con NEAE y sin ellas de dos comunidades autónomas españolas, ha conllevado que la muestra sea de conveniencia, dificultando por tanto la generalidad de los resultados al resto de población de alumnos de Primaria con NEAE y sin ellas de España.

Otro factor que ha supuesto una perdida información importante ha sido el carácter auto-administrado y sin supervisión de los cuestionarios dirigidos a adultos, a lo que se une la deseabilidad social de los participantes que se representó en un exceso de respuestas positivas en ciertos ítems, la escasa variabilidad de respuesta en algunos de ellos y, por tanto, la reducción del número de ítems pertenecientes a los cuestionarios de docentes y familiares.

Para investigaciones futuras sobre esta línea de investigación se recomienda la obligatoriedad de la participación del sistema educativo en el estudio, el seguimiento de un evaluador especializado durante el proceso de recogida de la información proporcionada por niños y adultos, así como la redacción de los ítems dirigidos a adultos en valencia positiva y negativa para controlar el efecto de deseabilidad social en las respuestas dadas.

Pese a las limitaciones citadas los resultados del estudio son de importante aplicación para el cambio del sistema educativo ordinario, así como para la innovación en las intervenciones socio y psicoeducativas implementadas por las organizaciones proveedoras de servicios de atención temprana y desarrollo infantil positivo, dirigidas a alumnos con condiciones de desarrollo específicas y a sus familias. Estos aspectos serán tratados con mayor profundidad en el capítulo de conclusiones de esta tesis.

En definitiva, a partir de este estudio se han aportado suficiente evidencia empírica que apoya la influencia de los factores del contexto personal y ambiental en la percepción que los alumnos de Primaria con NEAE y sin ellas tienen de su calidad de vida, recursos personales y sociales para el desarrollo de su resiliencia y participación en actividades diversas de ocio y tiempo libre. Sobre la base de los hallazgos descritos podemos afirmar que el desarrollo infantil está influenciado significativamente por las 
características personales y ambientales de los entornos próximos en los niños experimentan sus vidas de forma cotidiana, y que es a partir de estas influencias que los niños con condiciones diversas de vida encuentran las vías o los límites para la construcción de sus propias trayectorias de vida, en concordación e interacción directa con su ambiente.

Con el objeto de seguir ahondando en el conocimiento acerca de las vías que favorecen el desarrollo de dichas trayectorias infantiles, en el siguiente y último capítulo empírico abordaremos el estudio sobre las posibles relaciones que se establecen entre los valores de bienestar, resiliencia y participación infantil en actividades de ocio y tiempo libre. En concreto exploraremos si la resiliencia y participación infantil son capaces de determinar y de qué forma los resultados de calidad de vida de alumnos con NEAE y sin ellas bajo el foco y la evidencia de la literatura científica previa. 



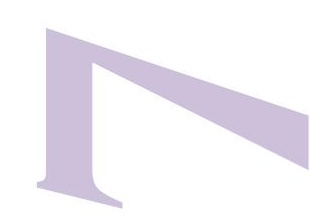

Capítulo 7

El Papel de la Resiliencia y la Participación en la Calidad de Vida Infantil

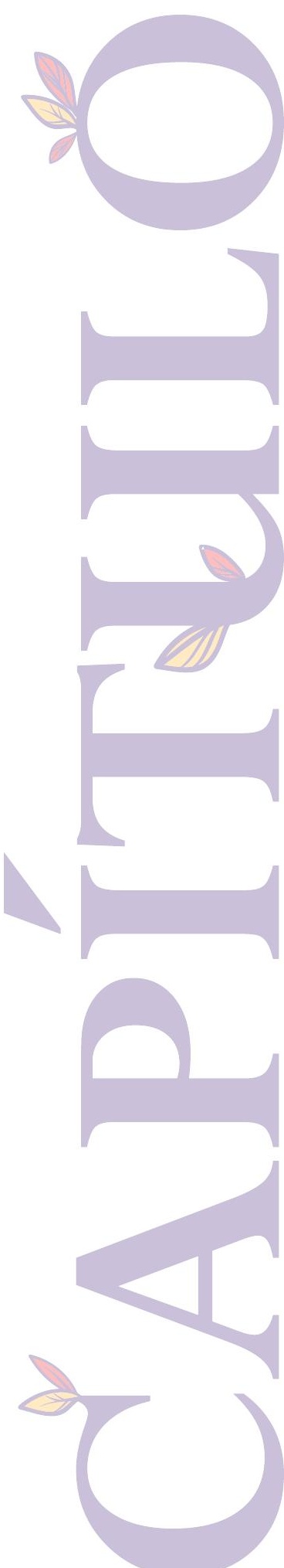





\section{El Papel de la Resiliencia y la Participación en la Calidad deVida Infantil}

\section{Introducción}

Tal como se ha expuesto a lo largo de esta tesis doctoral, a nivel mundial existe un creciente interés en definir el desarrollo infantil desde resultados personales de calidad y bienestar subjetivo. La construcción social de un modelo sistémico para evaluar las áreas centrales de una vida infantil de calidad, no sólo se interesa en aislar factores del contexto asociados a resultados personales significativos en la adecuación entre el niño y su entorno, sino también en cómo estos factores establecen relaciones entre ellos que dan lugar a procesos que direccionan las trayectorias del desarrollo infantil.

Tras analizar la influencia que variables de tipo personal y ambiental tienen en los resultados personales de bienestar, resiliencia y participación de alumnos de Primaria con NEAE y sin ellas, en el presente capítulo exploraremos la existencia de interacciones entre las tres variables (calidad de vida, participación en actividades de ocio y resiliencia infantil), con la finalidad de ahondar en la comprensión de las vías mediante las cuales niños en condiciones de vida diversas ven potenciado su bienestar y desarrollo integral, a través de la relación positiva con su ambiente.

\subsection{Planteamiento Inicial}

La investigación sobre los factores asociados a la calidad de vida de niños en condiciones diversas de vida ha puesto en evidencia la existencia de relaciones entre el bienestar infantil y la participación en actividades de ocio y tiempo libre (Badia et al., 2013; Dahan-Oliel et al., 2012; ShikakoThomas et al., 2012; Schreuer et al, 2014), así como entre el bienestar y los recursos para el desarrollo de la resiliencia infantil (Park y Peterson, 2006; Peterson y Park, 2011; Tempski et al., 2015). Sin embargo, dentro de los límites abarcables de este estudio no se han hallado investigaciones que 
analicen y proporcionen información sobre la interacción entre estas tres variables y su contribución al funcionamiento positivo y calidad de vida de menores con NEAE y sin ellas.

Más concretamente, la investigación sobre el desarrollo de niños con discapacidad y sin ella ha demostrado ampliamente que la asistencia a actividades de ocio y tiempo libre favorece el bienestar subjetivo y contribuye a la satisfacción en diferentes áreas de vida en las que los niños se desarrollan (Almqvist et al., 2006; Orlin et al., 2010). Mientras que, las barreras ambientales para la asistencia y participación en actividades diversas da lugar a una serie de condiciones (ver Tabla 2 Capítulo 3) que amenazan el desarrollo óptimo y la calidad de vida de niños con menores oportunidades para interactuar con su entorno (Van Naarden Brain et al., 2006; ShikakoThomas et al., 2012). Pese a estos y otros resultados ya presentados, la investigación en curso aún no ha proporcionado claridad acerca de la relación que se establece entre las distintas dimensiones de participación y calidad de vida infantil, ni la dirección y fuerza de esta relación bajo diferentes condiciones personales y/o ambientales, las cuales den lugar a patrones específicos de resultados personales en contextos particulares, como el de alumnos de Primaria con NEAE y sin ellas. Por tanto, aunque existen hallazgos parciales que apoyan los efectos de la participación en la calidad de vida infantil, aún faltan estudios que prueben modelos más complejos en los que se explore con precisión la interacción que se establece entre ambas variables (King, 2013).

Por otro lado, desde el enfoque ecológico, los hallazgos de la investigación sobre resiliencia infantil también respaldan la contribución de ésta a la calidad de vida de los menores (Ungar, 2011). Resultados recientes sugieren que el valor de las creencias personales acerca de los activos individuales y recursos ambientales disponibles y accesibles para hacer frente a los desafíos del día a día, supone en sí mismo un recurso cognitivo que favorece el bienestar infantil ante situaciones adversas de vida (Lee et al., 2012; Lee et al., 2010). No obstante, como ya se ha expuesto con anterioridad, la investigación en resiliencia también pone de manifiesto que la exposición a otros factores 
de riesgo condiciona el efecto potencial que los factores protectores tienen sobre el funcionamiento adaptativo y el bienestar infantil (Hall et al., 2009), haciendo necesario el estudio combinado de unos y otros factores para comprender el efecto final que tiene su interacción en los resultados de calidad de vida de los menores (Fergus et al., 2005). Para mayor información remitimos al apartado 5 del Capítulo 4.

Debido a que el modelo conceptual escogido para el estudio de la calidad de vida infantil presupone una visión contextual del desarrollo del niño, en el que el bienestar se define como resultados personales positivos derivados de la interacción entre factores individuales y ambientales presentes en los diferentes sistemas en los que la persona se desenvuelve (Schalock et al., 2016), para la comprensión de estas interacciones, los factores intervinientes deben establecerse analíticamente como variables con capacidad de explicar, predecir, mediar y/o moderar el bienestar que los niños perciben en las diferentes áreas de vida en las que se desarrollan.

Según Leticia Guriano (2013), incluir en el análisis de los procesos causales de un determinado fenómeno variables con capacidad de provocar efectos condicionales en las relaciones directas halladas, supone un claro signo de madurez y sofisticación alcanzada en investigación, ya que la identificación de terceras variables intervinientes (denominadas mediadores o moderadores), así como el esclarecimiento del papel que juegan en los efectos directos establecidos entre otras variables (dependientes e independientes), permite explicar efectos alternativos sobre los mecanismos subyacentes que dan lugar a los procesos causales del fenómeno estudiado (Ato y Vallejo, 2011), como en este caso es la calidad de vida infantil. Desde esta perspectiva, y con la finalidad de hacer avanzar el conocimiento actual sobre desarrollo infantil positivo, en este estudio nos proponemos explorar la existencia de relaciones multivariantes entre las variables propuestas y, más concretamente, identificar el papel que cada una de ellas juega en la calidad de vida infantil, centrándonos en el potencial efecto directo que la participación y/o resiliencia tiene sobre los niveles de bienestar, así como en el posible papel moderador de unas sobre otras. 
De acuerdo con Baron y Kenny (1986), un factor moderador específica las condiciones bajo las cuales se produce un efecto dado, determinando su fuerza y dirección (reduciéndolo, incrementándolo, anulándolo o invirtiéndolo). Es decir, una variable moderadora es aquella que afecta de forma previa a la interacción entre dos variables, de modo que la naturaleza del impacto de la variable independiente (predictor) sobre la variable dependiente (criterio) varía según los valores del moderador (Etchebarne, O’Connell y Roussos, 2008; Holmbeck, 1997). De esta forma, el estudio de la moderación se refiere al análisis acerca de cuándo o en qué circunstancias se produce el efecto directo encontrado entre dos variables, posibilitando identificar subgrupos de la población objeto de estudio con mecanismos causales diferenciales, como por ejemplo qué alumnos responden mejor a una determinada intervención psicoeducativa o para cuáles podría ser más recomendable otro tipo de prácticas (Kraemer, Wilson, Fairburn y Agras, 2002).

La investigación en calidad de vida ha detectado variables personales (autodeterminación, existencia de objetivos personales, auto-refuerzo, entre otras), sociales (soportes naturales, profesionales, educativos, ambientales que forman el sistema de apoyos de la persona) y para el crecimiento personal (oportunidades individuales, familiares, organizaciones, políticas y sociales) con capacidad de explicar y/o predecir los resultados de calidad de vida de personas con discapacidad, actuando como factores determinantes de los niveles de bienestar y satisfacción personal (Schalock et al., 2016). Así como, variables del entorno personal (género, comportamiento adaptativo, por ejemplo), familiar (estructura familiar, localización geográfica) y organizacional (oportunidades para el crecimiento personal) con capacidad de moderar los efectos que las variables predictoras de tipo personal y ambiental tienen sobre los resultados de calidad de vida de adultos con discapacidad y sin ella (Gómez et al., 2010).

Al ampliar el modelo de calidad de vida infantil hacia el estudio de factores personales y ambientales con capacidad de predecir y moderar la relación entre el niño y su entorno, la investigación se direcciona hacia 
una perspectiva socio-ecológica centrada en el estudio de la naturaleza del entorno infantil social y físico, los procesos de interacción entre el ambiente y el niño, y las tendencias específicas del niño hacia el desarrollo positivo. Este nuevo enfoque coincide con los marcos de investigación sobre resiliencia (Ungar, 2004, 2008, 2011) y participación (CIF/CIF-NJ, 2001, 2007; King et al., 2003) propuestos en este trabajo, lo que permite aunar sus conceptos y aumentar el marco de acción de sus constructos y, en definitiva, el conocimiento actual sobre desarrollo infantil positivo.

En resumen, tras la evidencia científica previa acerca de la existencia de asociaciones entre participación y resiliencia con la calidad de vida infantil, en este capítulo nos proponemos ir un paso más allá al examinar la capacidad explicativa que los recursos para el desarrollo de la resiliencia y la participación en actividades diversas de ocio y tiempo libre tienen sobre la calidad de vida infantil. Además analizaremos si los niveles de participación moderan, y de qué forma, los efectos que la resiliencia tiene sobre los niveles de bienestar infantil. Teniendo en cuenta investigaciones previas ya citadas (Gómez et al., 2010; King, 2003; Schalock et al., 2016), se espera que la participación actúe como un mecanismo para el desarrollo positivo al aumentar los efectos que los recursos para la resiliencia tienen sobre el bienestar de los niños en diferentes áreas de vida. De esta forma, al proporcionar un contexto amistoso, receptivo y situacional para la vivencia de experiencias positivas, la participación en este tipo de actividades funcionará como una estrategia reguladora del crecimiento positivo que protege contra el riesgo de desajuste psicosocial a niños con altos niveles de bienestar, con independencia de otras características personales como son la edad, el género o la presencia de NEAE. 


\subsubsection{Objetivos de Estudio}

Los objetivos que guían el presente estudio son los siguientes:

\subsubsection{Objetivo General}

Analizar la relación que se establece entre las variables calidad de vida, resiliencia y participación en actividades diversas en población española de alumnos de Primaria con NEAE y sin ellas.

\subsubsection{Objetivos Específicos}

» Determinar qué parte de la variabilidad de la calidad de vida infantil puede explicarse a partir de los niveles de resiliencia familiar, social e individual, y la diversidad de participación en actividades de tipo formal e informal, controlando el efecto del género, el curso y la presencia de NEAE sobre el bienestar infantil.

»Explorar si los efectos directos de la resiliencia en la calidad de vida de alumnos de Primaria con y sin NEAE son moderados por sus niveles de participación en actividades diversas de ocio y tiempo libre. Es decir, analizar los efectos condicionales de la participación sobre el bienestar infantil a través del efecto de la resiliencia.

\subsection{Método}

\subsubsection{Participantes}

Para el desarrollo de esta parte de la investigación se cuenta con una muestra de estudiantes de $3^{\circ}$ curso de Primaria compuesta por 199 alumnos, 99 de los alumnos presentaban NEAE y 100 alumnos sin ellas equivalentes en género, edad y curso. Esta muestra de alumnos es la misma que la utilizada para el estudio presentado en el Capítulo 6. Para ver las características generales y el procedimiento para su selección remitimos al apartado 2.1. de dicho capítulo. 


\subsubsection{Procedimiento}

El procedimiento de recogida de información también coincide con el desarrollado en el estudio del Capítulo 6. Los pasos seguidos corresponde a tres fases fundamentales: 1) contacto con los centros de educación de Primaria y consentimiento informado de las familias para la participación de los menores, 2) programación y realización de varias sesiones grupales o individuales para la administración de cuestionarios a alumnos de Primaria con NEAE y sin ellas, 3) realización de análisis estadísticos correspondientes a los objetivos planteados en esta parte de estudio. Para más información acerca del procedimiento seguido remitimos al apartado 2.3. del Capítulo 6.

\subsubsection{Instrumentos}

Nuevamente los instrumentos seleccionados coinciden con los tres cuestionarios utilizados en el estudio de variables personales y ambientales asociadas a los resultados personales en calidad de vida, participación y resiliencia de alumnos de Primaria con NEAE y sin ellas. Recordemos:

- El Cuestionario de Calidad deVida Kidscreen-27 (Ravens-Sieberer et al., 2007).

- La medida de Resiliencia CYRM-22 (Ruiz et al., en prensa)

- Cuestionario de participación en actividades de ocio y tiempo libre CAPE-PAC (King et al., 2007)

Para más información acerca de su medida, propiedades psicométricas y aplicabilidad remitimos al apartado 2.2. del Capítulo 6.

\subsubsection{Análisis}

En laTabla 37 se presentan las 13 variables sometidas a análisis, su tratamiento estadístico, media y desviación típica. Las variables personales (género, curso y NEAE) fueron transformadas en variables dummy $(0,1)$. En tanto que, las medidas de calidad de vida, resiliencia y participación se establecieron en puntuaciones $\mathrm{T}(\mathrm{M}=50, \mathrm{SD}=10)$. 
Tabla 37. Variables de estudio y estadísticos descriptivos media y desviación típica

\begin{tabular}{lcc}
\hline Variables & Media & DT $^{\mathbf{a}}$ \\
\hline Independientes & .60 & .49 \\
Género & .55 & .50 \\
Curso & .50 & .50 \\
NEAEb & 49.54 & 9.99 \\
Resiliencia Familiar & 48.82 & 11.24 \\
Resiliencia Personal & 50.30 & 10.05 \\
Resiliencia Social & 49.92 & 10.15 \\
Participación formal & 49.14 & 10.36 \\
Participación informal & & \\
Dependientes & 48.54 & 11.06 \\
Bienestar físico & 49.72 & 9.95 \\
Bienestar emocional & 50.28 & 8.15 \\
Bienestar familiar & 49.57 & 10.74 \\
Bienestar social & 50.29 & 10.09 \\
Bienestar escolar & & \\
\hline
\end{tabular}

Nota. ${ }^{\text {a }}$ (DT) desviación típica; ${ }^{\text {b }}$ (NEAE) Necesidades Específicas de Apoyo Educativo.

Tras el estudio descriptivo de las variables se analizan las correlaciones que se establecen entre ellas. Posteriormente se lleva a cabo análisis de regresión lineal multivariante para investigar el poder explicativo de la resiliencia y la participación sobre la calidad de vida infantil. Por último, se explora si la participación modera la relación entre resiliencia y bienestar y, si es así, si la participación junto a la resiliencia apoya un modelo promotor de la calidad de vida infantil.

Para conocer la asociación entre las variables se utiliza la correlación producto-momento de Pearson. Mientras que, para determinar si las variables de resiliencia y participación seleccionadas funcionan como predictoras y/o moderadoras de los cambios en los resultados de las dimensiones de calidad de vida, se aplican procedimientos de regresión lineal múltiple usando SPSS v.21 y la macro de Process para SPSS (Hayes, 2013). 


\subsubsection{Modelos de Regresión Lineal Múltiple}

Para comprender cuánta variabilidad de los niveles de bienestar puede ser explicada por los predictores explorados se realiza una serie de modelos de regresión lineal múltiple para cada dimensión de calidad de vida (bienestar físico, bienestar familiar, bienestar social y bienestar escolar). En cada serie se llevan a cabo 4 análisis de regresión. Primero, un análisis para controlar el efecto de las variables personales género, curso y NEAE. Segundo, un análisis de regresión para valorar el peso individual de la resiliencia (familiar, individual y social). Tercero, otro para valorar el peso que la diversidad de participación en actividades de ocio (de tipo formal e informal) tiene en la variabilidad total de cada una de las dimensiones de calidad de vida. Por último, un cuarto análisis de regresión que incluye las dimensiones de resiliencia y participación conjuntamente, para evaluar el valor compensatorio de unas variables sobre otras en los resultados de calidad de vida infantil. Por tanto, las cinco dimensiones de bienestar actúan como variables dependientes en todos los modelos probados. En tanto que la resiliencia familiar, la resiliencia social, la resiliencia individual, la diversidad de participación en actividades formales y la diversidad de participación en actividades informales son tratadas como posibles predictores.

El desarrollo de los análisis individuales de regresión lineal múltiple tiene como objetivo explorar los cambios en las contribuciones estimadas de los predictores en los modelos de bienestar (usando los coeficientes y $\mathrm{R}^{2}$ ) de manera independiente, es decir, sin cruzar o sumar las cargas de las variables sometidas análisis en el mismo modelo como sucede en el análisis de regresión jerárquica. Para garantizar la no violación de los supuestos de regresión multivariante se realizan los diagnósticos correspondientes. Se inspecciona la matriz de correlación, el gráfico de probabilidad de los residuos normalizados (P-P) y el diagrama de dispersión de cada uno de los modelos probados. Tanto los valores de tolerancia, como los valores de FIV se encuentran dentro de los umbrales de aceptación. Las pruebas de significación se llevan a cabo al nivel de $p<.05$. Las puntuaciones de las 
dimensiones de resiliencia y participación se centran en torno a su gran media para reducir problemas de escala y multicolinealidad entre variables.

\subsubsection{Análisis de Efectos de Moderación con Process}

Según Ato et al. (2011), una vez establecida una relación asumida como causal entre una variable independiente $(\mathrm{X})$ y otra dependiente $(\mathrm{Y})$, una cuestión de interés en investigación aplicada es considerar el efecto de terceras variables $(Z)$ en dicha relación. De esta forma, en el presente trabajo la curiosidad por la existencia de efectos de interacción entre las variables de estudio lleva a analizar los efectos condicionales de la participación en el bienestar infantil, a través de la resiliencia. Estos análisis se realizan mediante modelos de regresión lineal múltiple llevados a cabo con el procedimiento Process de Hayes (2013). En concreto se analiza si la participación en actividades formales e informales moderaba el efecto principal que la resiliencia social muestra en la calidad de vida infantil. En la Figura 11 se presenta una representación visual del modelo de moderación general probado en los distintos análisis que veremos en el apartado 3.2.2. de este capítulo.

Figura 11. Representación estadística del modelo de moderación. Efecto condicional en $Y=o_{4}+a X$ $+b Z+c X Z+e_{4}$

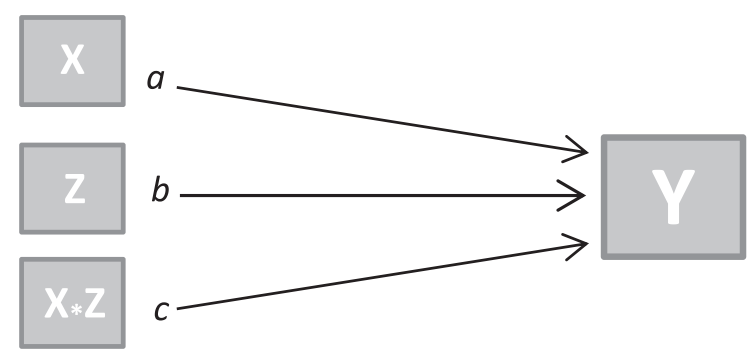

Nota. Adaptado de "PROCESS: A versatile computational tool for observed variable mediation, moderation, and conditional process modeling”, por A. F. Hayes, 2012, Recuperado de http: / /www.afhayes.com/public/process2012.pdf. 
En este enfoque los coeficientes de las variables de resiliencia (a), participación (b) y el producto cruzado de ambos coeficientes (c) se calculan mediante muestreo bootstrap basado en 5000 muestras (Field, 2013). El efecto de la interacción entre resiliencia y participación (c), que es el componente esencial del modelo de moderación, se prueba usando intervalos de confianza (IC) del 95\%. El efecto de $X Z$ se considera significativo cuando el intervalo de confianza no incluye el valor 0 (Hayes, 2013).

Se prueban 3 series de modelos de moderación, una con las puntuaciones de la muestra total de alumnos de Primaria, otra con el subgrupo de alumnos con NEAE y una última serie con el subgrupo de alumnos sin ellas. Cada una de estas series consiste en 10 modelos de moderación, 2 por cada una de las 5 dimensiones de bienestar infantil. En concreto, uno para valorar el efecto de interacción de la participación en actividades formales y la resiliencia social sobre los resultados de calidad de vida, y otro para el efecto de interacción de la participación en actividades informales y la resiliencia social. La presencia de significación en el efecto de interacción es interpretada como cambio en el efecto principal de la resiliencia social sobre el bienestar infantil debido a los niveles del moderador (participación en actividades diversas de tipo formal o informal).

En el caso de efectos de moderación significativos sobre la variable resultado (bienestar), la variable moderadora (participación) es dividida estadísticamente en tres categorías de puntuación (percentiles altos, medios y bajos), para el estudio detallado de los efectos directos condicionados (resiliencia). Para una mejor interpretación de los efectos de participación como moderador en el apartado de resultados se incluye la representación visual de los modelos más destacados. La representación visual permite explorar el impacto que la interacción entre los niveles de las variables resiliencia y participación tiene sobre los resultados de bienestar infantil, a través de las siguientes categorías creadas: 1) grupo de baja participación y baja resiliencia, 2) grupo de baja participación y alta resiliencia, 3) grupo de alta participación y baja resiliencia, y 4) grupo de alta participación y alta resiliencia. 


\subsection{Resultados}

\subsubsection{Análisis Preliminares}

Los resultados de las correlaciones ponen en evidencia relaciones positivas y significativas entre todos los niveles de resiliencia y bienestar infantil, y relaciones positivas moderadas entre la participación en actividades informales y los niveles de bienestar familiar, social y escolar (Tabla 38). Los datos no muestran ninguna relación entre las puntuaciones en actividades formales y las cincos dimensiones de calidad de vida.

Con respecto a la relación entre variables personales y los resultados en bienestar, se halla una asociación significativa entre la variable NEAE y bienestar emocional, y entre el curso y las dimensiones de bienestar familiar y escolar. No se evidencia ninguna correlación entre género y calidad de vida (Tabla 38).

Tabla 38. Correlaciones significativas halladas entre las variables objeto de estudio $(N=199)$

\begin{tabular}{|c|c|c|c|c|c|c|c|}
\hline Variables & 1 & 2 & 3 & 4 & 5 & 6 & 7 \\
\hline 1 Género & - & & & & & & \\
\hline 2 Curso & $.21 * *$ & - & & & & & \\
\hline $3 \mathrm{NEAE}^{\mathrm{a}}$ & & & - & & & & \\
\hline $4 \mathrm{BF}^{\mathrm{b}}$ & & & & - & & & \\
\hline $5 \mathrm{BE}^{\mathrm{c}}$ & & & $-.21 * *$ & $44 * *$ & - & & \\
\hline $6 \mathrm{BFa}^{\mathrm{d}}$ & & $.18 * *$ & & $.33 * *$ & $.46 * *$ & - & \\
\hline $7 \mathrm{BS}^{\mathrm{e}}$ & & & & $.32 * *$ & $.46 * *$ & $.54 * *$ & - \\
\hline $8 \mathrm{BEs}^{\mathrm{f}}$ & & & & $.24 * *$ & $.39 * *$ & $.44 * *$ & $.46 * *$ \\
\hline $9 \mathrm{RF}^{\mathrm{g}}$ & & & $-.20 *$ & $.27 * *$ & $.26 * *$ & & $.26 * *$ \\
\hline $10 \mathrm{RI}^{\mathrm{h}}$ & & & $-.27 * *$ & $.30 * *$ & $.36 * *$ & $.28 * *$ & $.27 * *$ \\
\hline $11 \mathrm{RS}^{\mathrm{i}}$ & & & $-.17 *$ & $.34 * *$ & $.48 * *$ & $.43 * *$ & $.48 * *$ \\
\hline \multicolumn{8}{|l|}{$12 \mathrm{PF}^{\mathrm{j}}$} \\
\hline $13 \mathrm{PI}^{\mathrm{k}}$ & $.23 * *$ & & & & & & $.17 *$ \\
\hline Variables & 8 & 9 & 10 & 11 & 12 & 13 & \\
\hline \multicolumn{8}{|l|}{1 Género } \\
\hline \multicolumn{8}{|l|}{2 Curso } \\
\hline \multicolumn{8}{|l|}{$3 \mathrm{NEAE}^{\mathrm{a}}$} \\
\hline \multicolumn{8}{|l|}{$4 \mathrm{BF}^{\mathrm{b}}$} \\
\hline $5 \mathrm{BE}^{\mathrm{c}}$ & & & & & & & \\
\hline
\end{tabular}




\begin{tabular}{|c|c|c|c|c|c|c|}
\hline Variables & 8 & 9 & 10 & 11 & 12 & 13 \\
\hline \multicolumn{7}{|l|}{$6 \mathrm{BFa}^{\mathrm{d}}$} \\
\hline \multicolumn{7}{|l|}{$7 \mathrm{BS}^{\mathrm{e}}$} \\
\hline $8 \mathrm{BEs}^{\mathrm{f}}$ & - & & & & & \\
\hline $9 \mathrm{RF}^{\mathrm{g}}$ & $.33 * *$ & - & & & & \\
\hline $10 \mathrm{RI}^{\mathrm{h}}$ & $.45 * *$ & $.54 * *$ & - & & & \\
\hline $11 \mathrm{RS}^{\mathrm{i}}$ & $.53 * *$ & $.37 * *$ & $.53 * *$ & - & & \\
\hline $12 \mathrm{PF}^{j}$ & & & & & - & \\
\hline $13 \mathrm{PI}^{\mathrm{k}}$ & $.16 *$ & $.23 * *$ & $.29 * *$ & $.29 * *$ & $.632 * *$ & - \\
\hline
\end{tabular}

Nota. ${ }^{\mathrm{a}}$ (NEAE) Necesidades Específicas de Apoyo Educativo, ${ }^{\mathrm{b}}$ (BF) bienestar físico, ${ }^{\mathrm{c}}$ (BE) bienestar emocional, ${ }^{\mathrm{d}}$ ( BFa) bienestar familiar, ${ }^{\mathrm{e}}$ (BS) bienestar social, ${ }^{\mathrm{f}}$ (BEs) bienestar escolar, ${ }^{\mathrm{g}}$ (RF) Resiliencia familiar, ${ }^{\mathrm{h}}$ (RI) resiliencia individual, ${ }^{\mathrm{i}}$ (RS) resiliencia social, ${ }^{\mathrm{j}}$ (PF) participación en actividades formarles, ${ }^{\mathrm{k}}$ ( PI) participación en actividades informales. La tabla incluye las correlaciones significativas entre variables, * $\mathrm{p}<.05 * * ; \mathrm{p}<.01 * * *$; $\mathrm{p}<.001$.

\subsubsection{Análisis Principales}

7.3.2.1. Variables Predictivas de la Calidad de Vida Infantil

Tras comprobar que las variables correlacionan entre ellas, se explora el posible efecto directo de las variables de resiliencia y participación en actividades de ocio sobre los resultados de calidad de vida infantil, con independencia del género, el curso y la presencia o no de NEAE de los participantes. Para ello, se llevan a cabo cinco series de análisis de regresión lineal múltiple, una serie por cada dimensión de calidad de vida. En cada una de las series se prueban 4 modelos de regresión. En el Modelo 1 se analiza el efecto principal de las variables personales sobre el bienestar. En el Modelo 2 el efecto principal de las dimensiones de resiliencia. En el Modelo 3 el efecto de las dimensiones de participación. Por último, en el Modelo 4 se realiza un análisis del efecto combinado de la resiliencia y la participación sobre el bienestar. El objetivo de estos análisis es estudiar de forma independiente el efecto predictor que la resiliencia, la participación y/o las variables personales tiene sobre los resultados de bienestar infantil, así como el efecto de la combinación de resiliencia y participación. 
Los resultados de regresión para cada una de las cinco dimensiones de bienestar han sido unificados en dos tablas, con objeto de simplificar su presentación. Los resultados de regresión para las dimensiones de corte individual, bienestar físico y bienestar emocional, se presentan en la Tabla 39. Mientras que en la Tabla 40 se exponen los resultados de regresión para las dimensiones de corte social, bienestar familiar, bienestar social y bienestar escolar.

La Tabla 39 presenta los resultados de los modelos de regresión para bienestar físico y bienestar emocional como variables dependientes. La columna de la izquierda muestra los resultados de los 4 análisis de regresión para bienestar físico y la columna de la derecha para bienestar emocional.

Tabla 39. Análisis de regresión para bienestar físico y bienestar emocional $(N=199)$

\begin{tabular}{|c|c|c|c|c|c|c|c|c|}
\hline & \multicolumn{4}{|c|}{ Bienestar físico } & \multicolumn{4}{|c|}{ Bienestar emocional } \\
\hline & B & $T$ & $\mathbf{R}^{2}$ & $\mathbf{F}$ & B & $T$ & $\mathbf{R}^{2}$ & $\mathbf{F}$ \\
\hline Modelo 1 & & & .01 & .34 & & & .05 & $3.39 *$ \\
\hline Género & .04 & .49 & & & -.02 & -.30 & & \\
\hline Curso & -.05 & -.72 & & & .08 & 1.12 & & \\
\hline NEAE $^{a}$ & .03 & .35 & & & -.21 & $-2.93 * *$ & & \\
\hline Modelo 2 & & & .13 & $6.75 * * *$ & & & .21 & $12.00 * * *$ \\
\hline $\mathrm{RF}^{\mathrm{b}}$ & .15 & 1.56 & & & .06 & .65 & & \\
\hline $\mathrm{RI}^{\mathrm{c}}$ & .09 & .90 & & & .13 & 1.29 & & \\
\hline $\mathrm{RS}^{\mathrm{d}}$ & .21 & $.21 *$ & & & .35 & $3.94 * * *$ & & \\
\hline Modelo 3 & .02 & 1.58 & & & & & .02 & 1.72 \\
\hline $\mathrm{PF}^{\mathrm{e}}$ & .11 & 1.07 & & & -.10 & -1.00 & & \\
\hline $\mathrm{PI}^{\mathrm{f}}$ & .04 & .42 & & & .18 & 1.84 & & \\
\hline Modelo 4 & & & .19 & $5.52 * * *$ & & & .29 & $10.15 * * *$ \\
\hline $\mathrm{RF}^{\mathrm{b}}$ & .15 & 1.52 & & & .08 & .86 & & \\
\hline $\mathrm{RI}^{\mathrm{c}}$ & .11 & 1.04 & & & .16 & 1.63 & & \\
\hline $\mathrm{RS}^{\mathrm{d}}$ & .27 & $2.87 * *$ & & & .43 & $4.86 * * *$ & & \\
\hline $\mathrm{PF}^{\mathrm{e}}$ & .24 & $2.27 *$ & & & .02 & .19 & & \\
\hline $\mathrm{PI}^{\mathrm{f}}$ & -.21 & -1.88 & & & -.13 & -1.22 & & \\
\hline
\end{tabular}

$\overline{\text { Nota } . \mathrm{B}=\text { coeficiente estandarizado Beta } ;} T=$ valor de $\mathrm{t} ; \mathrm{R}^{2}=$ coeficiente de determinación del modelo; $\mathrm{F}=$ índice de significación $\mathrm{F}$. El efecto de las variables personales (género, curso, NEAE) se controla en el Modelo 1. El efecto principal de los factores de resiliencia y participación se analiza separadamente en los Modelos 2 y 3 . El efecto compensatorio de ambas variables se explora en el Modelo 4. ${ }^{a}$ (NEAE) necesidades específicas de apoyo educativo, ${ }^{\mathrm{b}}(\mathrm{RF})$ resiliencia familiar, ${ }^{\mathrm{c}}(\mathrm{RI})$ resiliencia individual, ${ }^{\mathrm{d}}(\mathrm{RS})$ resiliencia social, 
(PF) participación en actividades formarles, ${ }^{\mathrm{f}}(\mathrm{PI})$ participación en actividades informales. * $\mathrm{p}<.05 ; * * \mathrm{p}<.01 ; * * * \mathrm{p}<.001$.

\subsection{Bienestar Físico}

Con respecto a las variables personales (Modelo 1) los resultados muestran que el género se asociaba positivamente con el bienestar físico, lo que significa que los chicos informan de mayores niveles de bienestar que las chicas. Mientras que el curso se asocia negativamente, es decir, los alumnos de $5^{\circ}$ curso perciben menores niveles de bienestar físico que sus compañeros de $6^{\circ}$ curso. Por último, la presencia de NEAE se asociaba positivamente, siendo los alumnos con NEAE los que mayores niveles de bienestar físico informan. Sin embargo, ninguna de estas variables predice significativamente la variabilidad del bienestar físico en alumnos de $3^{\circ}$ ciclo de Primaria con y sin NEAE.

En referencia a las medidas de resiliencia y participación, los resultados evidencian que la resiliencia predice individual y de forma combinada el bienestar físico infantil (Modelos 2 y 4), mientras que la participación solo lo hace de manera conjunta (Modelo 4). Concretamente, la resiliencia social es la variable que mayor poder predictivo presenta en los distintos modelos probados para bienestar físico, aumentando su capacidad cuando la participación en actividades formales se une a ella (Modelo 4). En todos los análisis los niveles de resiliencia se asocian de manera positiva al bienestar físico, en tanto que los niveles de participación lo hacen positiva o negativamente dependiendo de la función (Tabla 39).

\subsection{Bienestar Emocional}

Los resultados de los análisis de regresión para el bienestar emocional muestran en el Modelo 1 que la presencia NEAE es capaz de predecir de manera individual un porcentaje de la variabilidad del bienestar emocional (Tabla 3). En el Modelo 2, la resiliencia vuelve a presentarse como el 
mejor predictor explicando un 21\% de la variabilidad total del bienestar emocional. Mientras que, la participación de manera individual no muestra un poder predictivo destacable. En el modelo final (Modelo 4) el porcentaje de varianza explicada aumentaba al 29\%, siendo nuevamente la resiliencia social la beta más alta $\left(B=.43, t_{(127)=} 4.86, p<.001\right)$.

Los resultados de los modelos de regresión para bienestar familiar, bienestar social y bienestar escolar como variables dependientes se presentan en la Tabla 40. La columna de la izquierda muestra los resultados de los 4 análisis de regresión para bienestar familiar, la columna del medio para bienestar social y la columna de la derecha para bienestar escolar.

Tabla 40. Análisis de regresión para bienestar familiar, bienestar social y bienestar escolar $(N=199)$

\begin{tabular}{|c|c|c|c|c|c|c|c|c|}
\hline & \multicolumn{4}{|c|}{ Bienestar familiar } & \multicolumn{4}{|c|}{ Bienestar social } \\
\hline & B & $T$ & $\mathbf{R}^{2}$ & $\mathbf{F}$ & B & $T$ & $\mathbf{R}^{2}$ & $\mathbf{F}$ \\
\hline Modelo 1 & & & .04 & 2.46 & & & .01 & .57 \\
\hline Género & -.02 & -.21 & & & -.09 & -1.16 & & \\
\hline Curso & .18 & 2.51 & & & .01 & .10 & & \\
\hline NEAE $^{a}$ & -.05 & -.77 & & & -.04 & -.50 & & \\
\hline Modelo 2 & & & .25 & $15.06 * * *$ & & & .24 & $14.26 * * *$ \\
\hline $\mathrm{RF}^{\mathrm{b}}$ & .34 & $3.76 * * *$ & & & .10 & 1.10 & & \\
\hline $\mathrm{RI}^{\mathrm{c}}$ & -.10 & -1.03 & & & -.02 & -.02 & & \\
\hline $\mathrm{RS}^{\mathrm{d}}$ & .34 & $3.89 * * *$ & & & .45 & $5.13 * * *$ & & \\
\hline Modelo 3 & & & .03 & 2.38 & & & .04 & $3.13 *$ \\
\hline $\mathrm{PF}^{\mathrm{e}}$ & -.05 & -.47 & & & .02 & .16 & & \\
\hline $\mathrm{PI}^{\mathrm{f}}$ & .19 & 1.95 & & & .18 & 1.83 & & \\
\hline Modelo 4 & & & .28 & $9.43 * * *$ & & & .30 & $10.29 * * *$ \\
\hline $\mathrm{RF}^{\mathrm{b}}$ & .33 & $3.55 * *$ & & & .09 & .92 & & \\
\hline $\mathrm{RI}^{\mathrm{c}}$ & -.07 & -.65 & & & .06 & .57 & & \\
\hline $\mathrm{RS}^{\mathrm{d}}$ & .37 & $4.13 * * *$ & & & .48 & $5.42 * * *$ & & \\
\hline $\mathrm{PF}^{\mathrm{e}}$ & .02 & .19 & & & .08 & .77 & & \\
\hline $\mathrm{PI}^{\mathrm{f}}$ & -.05 & -.50 & & & -.05 & -.46 & & \\
\hline
\end{tabular}




\begin{tabular}{|c|c|c|c|c|}
\hline \multirow[b]{3}{*}{ Modelo 1} & \multicolumn{4}{|c|}{ Bienestar escolar } \\
\hline & $\mathbf{B}$ & $T$ & $\mathbf{R}^{2}$ & $\mathbf{F}$ \\
\hline & & & .01 & .61 \\
\hline Género & -.09 & -1.21 & & \\
\hline Curso & -.05 & -.73 & & \\
\hline $\mathrm{NEAE}^{\mathrm{a}}$ & -.03 & -.35 & & \\
\hline Modelo 2 & & & .32 & $20.47 * * *$ \\
\hline $\mathrm{RF}^{\mathrm{b}}$ & .07 & .79 & & \\
\hline $\mathrm{RI}^{\mathrm{c}}$ & .23 & $2.50 *$ & & \\
\hline $\mathrm{RS}^{\mathrm{d}}$ & .37 & $4.42 * * *$ & & \\
\hline Modelo 3 & & & .03 & 2.45 \\
\hline $\mathrm{PF}^{\mathrm{e}}$ & .00 & .03 & & \\
\hline $\mathrm{PI}^{\mathrm{f}}$ & .17 & 1.7 & & \\
\hline Modelo 4 & & & .41 & $16.75 * * *$ \\
\hline $\mathrm{RF}^{\mathrm{b}}$ & .07 & .77 & & \\
\hline $\mathrm{RI}^{\mathrm{c}}$ & .36 & $3.87 * * *$ & & \\
\hline $\mathrm{RS}^{\mathrm{d}}$ & .38 & $4.67 * * *$ & & \\
\hline $\mathrm{PF}^{\mathrm{e}}$ & .22 & $2.44 *$ & & \\
\hline $\mathrm{PI}^{\mathrm{f}}$ & -.22 & $-.22 *$ & & \\
\hline
\end{tabular}

Nota. $\mathrm{B}=$ coeficiente estandarizado Beta; $T=$ valor de $\mathrm{t} ; \mathrm{R}^{2}=$ coeficiente de determinación del modelo; $\mathrm{F}=$ índice de significación $\mathrm{F}$. El efecto de las variables personales (género, curso, NEAE) se controla en el Modelo 1. El efecto principal de los factores de resiliencia y participación se analiza separadamente en los Modelos 2 y 3 . El efecto compensatorio de ambas variables se explora conjuntamente en el Modelo 4. ${ }^{a}$ (NEAE) necesidades específicas de apoyo educativo, ${ }^{\mathrm{b}}(\mathrm{RF})$ resiliencia familiar, ${ }^{\mathrm{c}}(\mathrm{RI})$ resiliencia individual, ${ }^{\mathrm{d}}(\mathrm{RS})$ resiliencia social, ${ }^{\text {e }}(\mathrm{PF})$ participación en actividades formarles, ${ }^{\mathrm{f}}$ (PI) participación en actividades informales. $* \mathrm{p}<.05 ; * * \mathrm{p}<.01 ; * * \mathrm{p}<.001$.

\subsection{Bienestar Familiar}

El primer modelo probado evidencia que ninguna de las variables personales incluidas contribuye significativamente a la variabilidad del bienestar familiar (Tabla 40). Mientras que, en el Modelo 2 la resiliencia es capaz de explicar el 25\% de la varianza del bienestar familiar, siendo los valores de resiliencia social $\left(B=.34, t_{(136)}=3.89, p<.001\right)$ y de resiliencia familiar $\left(B=.34, t_{(136)=} 3.76, p<.001\right)$ los más predictivos. Con respecto al peso individual de la participación en el bienestar familiar, los análisis no 
destacan ningún poder predictivo significativo (Modelo 3). Por último, los resultados del modelo aditivo vuelven a presentar la resiliencia social $(B=$ $\left..37, t_{(127)}=4.13, p<.001\right)$ y la resiliencia familiar $\left(B=.33, t_{(127)}=3.55, p<.01\right)$ como las variables predictoras del bienestar familiar en población infantil (Modelo 4).

\subsection{Bienestar Social}

Los resultados del Modelo 1 informan que las variables personales (género, curso, NEAE) no contribuyen significativamente al cambio en el bienestar social, como tampoco lo hace la participación en actividades de ocio de tipo formal e informal (Modelos 2 y 4). En tanto que la resiliencia, en su dimensión social, vuelve a presentarse como la variable con mayor poder predictivo individual y colectivamente (Modelo 2 y 4). El modelo combinado es capaz de explicar hasta el 30\% de la variabilidad total del bienestar social infantil, destacando otra vez la resiliencia social como el efecto principal $\left(B=.48, t_{(127)=} 5.42, p<.001\right)$.

\subsection{Bienestar Escolar}

Nuevamente, el primer modelo probado con variables personales no ofrece poder predictivo significativo sobre la variabilidad del bienestar escolar infantil (Tabla 40). Mientras que, en el Modelo 2 las dimensiones de resiliencia es capaces de predecir el 32\% de la varianza de bienestar escolar, concretamente la resiliencia social $\left(B=.37, t_{(136)}=4.42, p<.001\right)$ y la resiliencia individual $\left(B=.23, t_{(136)=} 2.50, p<.05\right)$. El peso de las dimensiones de participación no es significativo de forma individual (Modelo 3), pero si cuando se incluye junto a la resiliencia en el último modelo probado. El modelo aditivo (Modelo 4) es capaz de explicar el 41\% de la variabilidad total de las puntuaciones de bienestar escolar infantil. 
En general, los resultados de los modelos de regresión informan del dominio de la resiliencia sobre el resto de variables analizadas, enmarcándola como variable predictora de la calidad de vida infantil. Los efectos principales hallados de resiliencia sobre las dimensiones de bienestar apoyan un modelo de resiliencia promotor de la calidad de vida infantil. Además, dado que los resultados de los modelos de regresión presentan de forma reiterada la resiliencia social como la variable con el efecto directo más alto, la resiliencia social surge como la dimensión de resiliencia con mayor capacidad predictiva de los niveles de bienestar infantil.

Por su parte, los resultados de regresión no muestran que la participación en actividades diversas de ocio tenga, por sí misma, un poder predictivo destacable sobre la calidad de vida de alumnos españoles de Primaria con NEAE y sin ellas. Aunque sí se evidencian cierta significación cuando el peso de la participación sobre el bienestar se analiza de forma conjunta a la resiliencia. Estos resultados hacen sospechar a cerca de un posible efecto indirecto de participación en el bienestar infantil, a través del efecto principal de la resiliencia.

\subsubsection{Efectos de Moderación en Calidad de Vida Infantil}

Para comprobar si el efecto principal de la resiliencia social en el bienestar infantil es moderado por los niveles de participación en actividades diversas de ocio y tiempo libre, se explora el impacto que la participación (variable moderadora, $M_{o}$ ) tiene sobre la calidad de vida infantil (variable dependiente, $Y$ ), a través de la interacción entre resiliencia social (variable independiente, $X$ ) y diversidad de participación en actividades de tipo formal e informal (producto de $X M_{0}$ ) (véase Figura 10). En aquellos casos en los que se prueba la existencia de moderación, se analiza en qué dirección condicionan los niveles de participación los resultados de calidad de vida infantil, a través del efecto principal de resiliencia social. Todos estos análisis se efectúan mediante modelos de interacción entre variables realizados con la macro de Process para SPSS (Hayes, 2013). 
7.3.2.2.1. Efectos de Moderación sobre los Efectos Principales de la Resiliencia en el Bienestar Infantil

Los resultados de los análisis de moderación se presentan en la Tabla 41. La columna de la izquierda muestra los resultados de los efectos condicionales para la muestra total de alumnos de Primaria, la columna central los resultados para el subgrupo de alumnos con NEAE y la columna de la derecha para el subgrupo de alumnos sin NEAE.

Tabla 41. Efectos de moderación de la participación (formal e informal) en la relación entre resiliencia social y bienestar infantil en alumnos de Primaria con y sin NEAE

\begin{tabular}{|c|c|c|c|c|c|c|c|c|}
\hline \multirow{2}{*}{\multicolumn{3}{|c|}{ Modelo }} & \multicolumn{3}{|c|}{ Total de alumnos $(\mathrm{N}=199)$} & \multicolumn{3}{|c|}{ Alumnos con $\operatorname{NEAE}^{a}(\mathrm{~N}=99)$} \\
\hline & & & & & $\mathbf{R}^{2}$ & & & $\mathbf{R}^{2}$ \\
\hline \multirow[t]{2}{*}{$\mathrm{VR}^{\mathrm{b}}$} & $\mathbf{E P}^{\mathrm{c}}$ & $\mathrm{EC}(\mathrm{m})^{\mathrm{d}}$ & $c$ & & & $c$ & & \\
\hline & & & $\mathrm{B}(\mathrm{SE})$ & CI $95 \%$ & & $\mathrm{~B}(\mathrm{SE})$ & CI 95\% & \\
\hline \multirow[t]{2}{*}{$\mathrm{BF}^{\mathrm{e}}$} & $\mathrm{RS}^{\mathrm{f}}$ & $\mathrm{PF}^{g}$ & $-.07(-.64)$ & {$[-.30, .15]$} & $.12 *$ & $-.09(.16)$ & {$[-.41, .23]$} & .08 \\
\hline & & $\mathrm{PI}^{\mathrm{h}}$ & $.01(.05)$ & {$[-.10, .08]$} & $.15 *$ & $-.01(.06)$ & {$[-.14, .11]$} & .12 \\
\hline \multirow[t]{2}{*}{$\mathrm{BE}^{\mathrm{i}}$} & $\mathrm{RS}^{\mathrm{f}}$ & $\mathrm{PF}^{\mathrm{g}}$ & $.02(.09)$ & {$[-.16, .21]$} & $.30 * * *$ & $.16(.14)$ & {$[-.13, .45]$} & $.27 * *$ \\
\hline & & $\mathrm{PI}^{\mathrm{h}}$ & $.01(.04)$ & {$[-.07, .08]$} & $.33 * * *$ & $-.00(.06)$ & {$[-.11, .11]$} & $.27 *$ \\
\hline \multirow[t]{2}{*}{$\mathrm{BFa}^{\mathrm{j}}$} & $\mathrm{RS}^{\mathrm{f}}$ & $\mathrm{PF}^{\mathrm{g}}$ & $.02(.08)$ & {$[-.15,3.64]$} & $.25 * * *$ & $.13(.12)$ & {$[-.12, .37]$} & $.23 *$ \\
\hline & & $\mathrm{PI}^{\mathrm{h}}$ & $-.00(.03)$ & {$[-.06, .06]$} & $.27 * * *$ & $-.01(.05)$ & {$[-.10, .08]$} & $.27 *$ \\
\hline \multirow[t]{2}{*}{$\mathrm{BS}^{\mathrm{k}}$} & $\mathrm{RS}^{\mathrm{f}}$ & $\mathrm{PF}^{\mathrm{g}}$ & $-.05(.11)$ & {$[-.27, .17]$} & $.25 * * *$ & $-.07(.18)$ & {$[-.43, .29]$} & $.21 *$ \\
\hline & & $\mathrm{PI}^{\mathrm{h}}$ & $-.08(.04)^{*}$ & {$[-.16,-.01]$} & $.34 * * *$ & $-.09(.06)$ & {$[-.21, .03]$} & $.33 * * *$ \\
\hline \multirow[t]{2}{*}{$\mathrm{BEs}^{1}$} & $\mathrm{RS}^{\mathrm{f}}$ & $\mathrm{PF}^{\mathrm{g}}$ & $.18(.10)$ & {$[-.01, .38]$} & $.32 * * *$ & $.34(.15) *$ & {$[.04, .64]$} & $.34 * * *$ \\
\hline & & $\mathrm{PI}^{\mathrm{h}}$ & $.04(.04)$ & {$[-.04, .12]$} & $.32 * * *$ & $.04(.06)$ & {$[-.08, .16]$} & $.33 * * *$ \\
\hline \multicolumn{3}{|c|}{ Modelo } & \multicolumn{3}{|c|}{ Alumnos sin $\mathrm{NEAE}^{\mathrm{a}}(\mathrm{N}=100)$} & & & \\
\hline \multirow[t]{2}{*}{$\mathbf{V R}^{\mathrm{b}}$} & $\mathbf{E P}^{\mathrm{c}}$ & $\operatorname{EC}(m)^{d}$ & & & $\mathbf{R}^{2}$ & & & \\
\hline & & & $c$ & & & & & \\
\hline \multirow[t]{2}{*}{$\mathrm{BF}^{\mathrm{e}}$} & $\mathrm{RS}^{\mathrm{f}}$ & $\mathrm{PF}^{\mathrm{g}}$ & $\mathrm{B}(\mathrm{SE})$ & CI 95\% & & & & \\
\hline & & $\mathrm{PI}^{\mathrm{h}}$ & $-.02(.17)$ & {$[-.36, .31]$} & $.26 * *$ & & & \\
\hline \multirow[t]{2}{*}{$\mathrm{BE}^{\mathrm{i}}$} & $\mathrm{RS}^{\mathrm{f}}$ & $\mathrm{PF}^{\mathrm{g}}$ & $-.05(.08)$ & {$[-.22, .11]$} & $.26 * *$ & & & \\
\hline & & $\mathrm{PI}^{\mathrm{h}}$ & $-.11(.12)$ & {$[-.34, .12]$} & $.42 * * *$ & & & \\
\hline \multirow[t]{2}{*}{$\mathrm{BFa}^{\mathrm{j}}$} & $\mathrm{RS}^{\mathrm{f}}$ & $\mathrm{PF}^{\mathrm{g}}$ & $-.02(.05)$ & {$[-.13, .09]$} & $.45 * * *$ & & & \\
\hline & & $\mathrm{PI}^{\mathrm{h}}$ & $-.12(.11)$ & {$[-.34, .11]$} & $.34 * * *$ & & & \\
\hline \multirow[t]{2}{*}{$\mathrm{BS}^{\mathrm{k}}$} & $\mathrm{RS}^{\mathrm{f}}$ & $\mathrm{PF}^{g}$ & $.02(.05)$ & {$[-.09, .13]$} & $.29 * * *$ & & & \\
\hline & & $\mathrm{PI}^{\mathrm{h}}$ & $.01(.14)$ & {$[-.26, .28]$} & $.39 * * *$ & & & \\
\hline \multirow[t]{3}{*}{$\mathrm{BEs}^{1}$} & $\mathrm{RS}^{\mathrm{f}}$ & $\mathrm{PF}^{g}$ & $-.11(.06)$ & {$[-.24, .01]$} & $.46 * * *$ & & & \\
\hline & & $\mathrm{PI}^{\mathrm{h}}$ & $.06(.13)$ & {$[-.19, .31]$} & $.36 * * *$ & & & \\
\hline & & & $.11(.06)$ & {$[-.01, .22]$} & $.37 * * *$ & & & \\
\hline
\end{tabular}

Nota. $\mathrm{R}^{2}=$ coeficiente de determinación del modelo; $c$ = efecto de interacción entre el efecto principal y el moderador; $\mathrm{B}(\mathrm{SE})=$ coeficiente (error estándar del efecto de interacción); CI 95\% = intervalo de confianza bootstrap al 95\%. a (NEAE) Necesidades Específicas de Apoyo Educativo, ${ }^{b}(\mathrm{VR})$ variable resultado, ${ }^{\mathrm{c}}(\mathrm{EP})$ efecto principal, ${ }^{\mathrm{d}}(\mathrm{EC}(\mathrm{m})$ ) efecto 
condicional (moderador), ${ }^{\mathrm{e}}(\mathrm{BF})$ bienestar físico, ${ }^{\mathrm{f}}(\mathrm{RS})$ resiliencia social, ${ }^{\mathrm{g}}(\mathrm{PF})$ participación en actividades formarles, ${ }^{\mathrm{h}}$ (PI) participación en actividades informales, ${ }^{\mathrm{i}}$ (BE) bienestar emocional, ${ }^{\mathrm{j}}$ (BFa) bienestar familiar, ${ }^{\mathrm{k}}$ (BS) bienestar social, ${ }^{\mathrm{l}}$ (BEs) bienestar escolar. ${ }^{*} \mathrm{p}<$ $.05 ; * * \mathrm{p}<.01 ; * * * \mathrm{p}<.001$.

En términos generales los resultados solo muestran efectos de moderación (Etchebarne et al., 2008) en bienestar social y bienestar escolar específicos a los distintos grupos de alumnos analizados, no hallándose un impacto completo, ni general, de participación sobre la calidad de vida infantil. No obstante, en casi todos los modelos de interacción probados se obtuvieron grandes magnitudes en las medidas del efecto total sobre los resultados de bienestar infantil. Los coeficientes de determinación $R^{2}$ de los modelos con valores significativos van desde .12 a .45 , es decir, mientras que en el modelo con el $R^{2}$ significativo más bajo el efecto combinado de resiliencia social y participación en actividades formales es capaz de predecir el 12\% de las variaciones en el bienestar físico de la muestra total, en el modelo con el $R^{2}$ significativo más alto la resiliencia social y la participación en actividades informales es capaz de predecir el $45 \%$ de la varianza total del bienestar emocional de alumnos sin NEAE (ver columnas $R^{2}$, Tabla 41).

Por otra parte, los resultados también ponen en evidencia que dependiendo de cada modelo la participación interfiere en el bienestar infantil de forma positiva o negativa (ver signo columna B(SE), Tabla 41), no existiendo una constante en la relación establecida entre las variables de participación, resiliencia social y bienestar infantil. La forma en que estas variables interaccionan indica el papel de la participación sobre la relación entre resiliencia social y bienestar infantil, dando lugar a un empeoramiento cuando $M_{0}$ disminuye la asociación entre $X$ e $Y$ (p.e., efecto de participación en actividades de tipo informal sobre la relación entre resiliencia social y bienestar social de alumnos de Primaria), o a una mejora cuando dicha asociación aumenta (p.e., efecto de participación en actividades de tipo formal sobre la relación entre resiliencia social y bienestar escolar de alumnos con NEAE) (Ato et al., 2011). 
En referencia a los efectos de moderación significativos obtenidos en cada uno de los grupos de alumnos analizados, los resultados revelan: 1) un efecto de interacción entre los niveles de participación en actividades informales y de resiliencia social que condiciona el bienestar social de la muestra total de alumnos $[\mathrm{B}(\mathrm{SE})=-.05(.04), p=.04], 2)$ un efecto de moderación, mediante el cual la participación en actividades de tipo formal condiciona los resultados en bienestar escolar de los alumnos con NEAE, a través de la interacción con la resiliencia social percibida $[\mathrm{B}(\mathrm{SE})=.34(.15)$, $p=.03$ ] y, 3) aunque en el grupo de alumnos sin NEAE los resultados no muestran ninguna interacción significativa entre participación y resiliencia social, una inspección más detallada desvela una significación marginal en bienestar escolar $[\mathrm{B}(\mathrm{SE})=.11(.06), p=.08]$, que informa sobre un efecto potencial de moderación causado por los niveles participación, de este grupo de alumnos, en actividades de ocio y tiempo libre de tipo informal.

En resumen, la diversidad de participación en actividades de ocio y tiempo libre de tipo formal e informal se presenta en este estudio como un moderador parcial de la relación entre la resiliencia social y las dimensiones de bienestar social y escolar en alumnos de Primaria con NEAE y sin ellas.

\subsection{Efectos de Moderación a Partir de los Niveles de Participación}

Para una comprensión más precisa de los efectos condicionales hallados en el bienestar infantil, a través de la interacción entre participación en actividades diversas y resiliencia social, se analiza la dirección y fuerza de cada uno de estos efectos bajos condiciones de alta, media y baja participación. La Tabla 42 muestra la significación obtenida en los efectos directos de resiliencia social sobre bienestar social y bienestar escolar condicionados por niveles altos, medios y bajos de participación en actividades de ocio y tiempo libre de tipo formal o informal. 
Tabla 42. Efectos condicionados por valores altos, medios y bajos de participación en actividades de ocio

\begin{tabular}{ccclrr}
\hline \multicolumn{2}{l}{ Total de alumnos } \\
\multicolumn{1}{c}{$\begin{array}{c}\text { Participación en } \\
{ }^{a}\end{array}$} & actividades informales & valores & $\boldsymbol{a}_{1} \theta$ (participación » bienestar social) & SE & CI 95\% \\
\hline$-.08 *$ & Baja & 16.96 & $2.19 * * *$ & .32 & {$[1.57,2.81]$} \\
$-.08 *$ & Media & 25.00 & $1.52 * * *$ & .28 & {$[.96,2.08]$} \\
$-.08 *$ & Alta & 30.04 & $1.10 * *$ & .42 & {$[.27,1.93]$} \\
\hline
\end{tabular}

\begin{tabular}{ccclrr}
\hline $\begin{array}{c}\text { Alumnos con NEAE } \\
\boldsymbol{a}_{2}{ }^{b}\end{array}$ & $\begin{array}{c}\text { Participación en } \\
\text { actividades formales }\end{array}$ & valores & $\boldsymbol{a}_{2} \theta$ (participación » bienestar escolar) & SE & CI 95\% \\
\hline $.34 *$ & Baja & 3.00 & $1.07 * *$ & .39 & {$[.30,1.85]$} \\
$.34 *$ & Media & 5.00 & $1.75 * * *$ & .32 & {$[1.11,2.40]$} \\
$.34 *$ & Alta & 7.48 & $2.60 * * *$ & .55 & {$[1.50,3.69]$} \\
\hline
\end{tabular}

\begin{tabular}{lllllr}
\hline \multicolumn{2}{c}{ Alumnos sin NEAE } & & & \\
$\boldsymbol{a}_{3}{ }^{\mathrm{c}}$ & $\begin{array}{c}\text { Participación en } \\
\text { actividades informales }\end{array}$ & valores & $\boldsymbol{a}_{3} \theta$ (participación » bienestar escolar) & SE & CI 95\% \\
\hline .11 & Baja & 19.72 & $1.22 * *$ & .40 & {$[.42,2.03]$} \\
.11 & Media & 25.50 & $1.84 * * *$ & .34 & {$[1.16,2.51]$} \\
.11 & Alta & 30.28 & $2.35 * * *$ & .50 & {$[1.35,3.34]$} \\
\hline
\end{tabular}

Nota. $\left(a_{1} \theta\right.$ (participación » bienestar social $)=$ efecto directo de resiliencia social sobre bienestar social condicionado por los valores de participación; SE = error estándar del efecto condicionado; CI 95\% = intervalo de confianza del efecto directo condicionado; $\left(a_{2} \theta\right.$ (participación » bienestar escolar $)=$ efecto directo de resiliencia social sobre bienestar escolar condicionado por los valores de participación; ( $a_{3} \theta$ (participación » bienestar escolar) $=$ efecto directo de resiliencia social sobre bienestar escolar condicionado por los valores de participación. ${ }^{a}\left(a_{1}\right)$ efecto de resiliencia social sobre bienestar social (condicionado); ${ }^{\mathrm{b}}\left(a_{2}\right)$ efecto de resiliencia social sobre bienestar escolar (condicionado); ${ }^{\mathrm{c}}\left(a_{3}\right)$ efecto de resiliencia social sobre bienestar escolar (condicionado).*p<.05;**p $<.01 ; * * \mathrm{p}<.001$.

Las columnas 1, 2 y 3 de la Tabla 42 informan que en el grupo de alumnos de la muestra total el efecto condicionado en bienestar social es negativo y estadísticamente significativo para bajos, medios y altos niveles de participación (recordemos, los niveles de $M_{o}$ disminuyen el efecto entre $X$ e $Y)$. En tanto que, en el subgrupo de alumnos con NEAE el efecto condicional hallado en su bienestar escolar es positivo y estadísticamente significativo (los niveles de $M_{o}$ aumentan el efecto entre $X$ e $Y$ ). Por último, en el subgrupo de alumnos sin ellas el efecto condicionado de la resiliencia social sobre el bienestar escolar es positivo pero no significativo. 
En general, estos resultados muestran que participar en más o menos actividades de ocio y tiempo libre de tipo formal o informal tiene un impacto en el bienestar social y escolar de los alumnos de Primaria con NEAE y sin ellas. Para comprender el valor y determinación que este impacto tiene sobre el bienestar infantil se analiza los efectos condicionados en cada grupo de alumnos, a través de su representación visual.

La Figura 12 muestra la relación entre la resiliencia social y el bienestar social de la muestra total de alumnos condicionada por niveles altos y bajos de participación en actividades de ocio de tipo informal. Como puede observarse, en el grupo de baja participación el efecto condicionado que la resiliencia social tiene en el bienestar social es mayor $\left[a_{1} \theta(\mathrm{SE})=2.19(.32)\right.$, $\mathrm{p}$ $=.00]$, que en el grupo de alta participación $\left[a_{1} \theta(\mathrm{SE})=1.10(.42), \mathrm{p}=.00\right]$. Este resultado implica que, aunque niveles altos de participación aumentan el valor del bienestar social, el impacto que la percepción de la resiliencia social tiene sobre el bienestar social es significativamente mayor en alumnos que no participaban en actividades de tipo informal que en aquellos que si participaban en ellas, con indiferencia de que estos presentaran o no NEAE.

Figura 12. Representación gráfica relación bienestar social, resiliencia social y participación en actividades de tipo informal, muestra total de alumnos de Primaria $(N=199)$

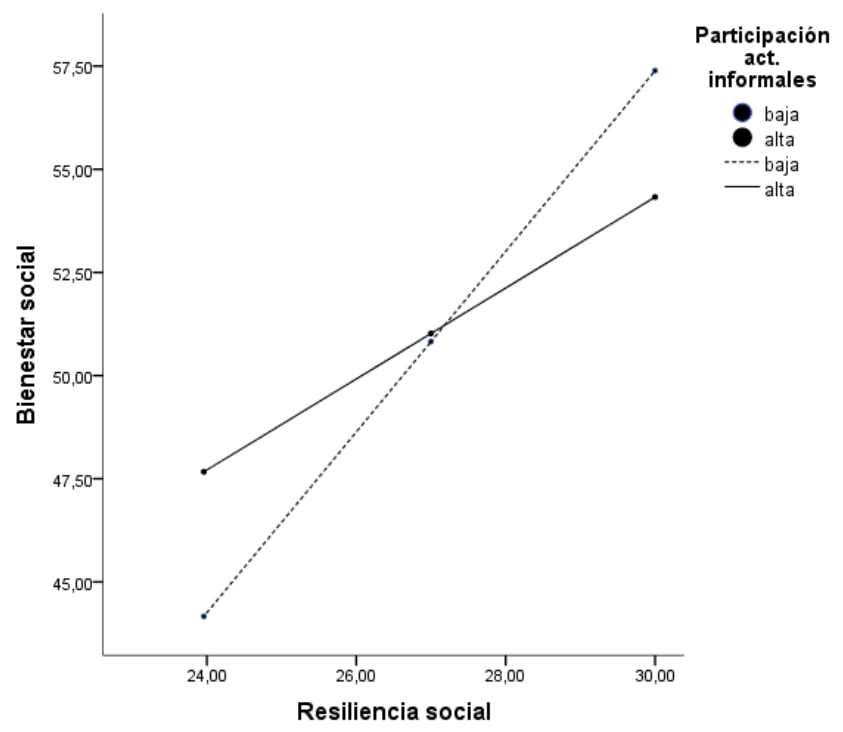


Por su parte, la Figura 13 muestra las pendientes simples de la relación entre resiliencia social y bienestar escolar condicionada por niveles bajos y altos de participación en actividades de tipo formal de alumnos con NEAE. Según los resultados, el efecto positivo que la resiliencia social tiene en el bienestar escolar es más fuerte cuando los alumnos con NEAE informan de altos niveles de participación $\left[a_{2} \theta(\mathrm{SE})=2.60(.55), p=.00\right]$, que bajos $\left[a_{2} \theta(\mathrm{SE})=1.07(.39), p=.00\right]$. Es decir, a medida que aumenta la participación el efecto directo que la resiliencia social muestra sobre el bienestar escolar también lo hacía. La Figura 13 también muestra que en condiciones de baja resiliencia social los alumnos con NEAE que participaban más perciben un bienestar escolar menor, en comparación a aquellos alumnos que participaban menos bajo las mismas condiciones de resiliencia social. Estos resultados presentan un mecanismo de compensación entre la participación en actividades formales y la resiliencia social que beneficia el bienestar infantil en el contexto escolar cuando los alumnos perciben mayores recursos sociales para el desarrollo de su resiliencia.

Figura 13. Representación gráfica relación bienestar escolar, resiliencia social y participación en actividades de tipo formal, grupo de alumnos de Primaria con NEAE (N=99)

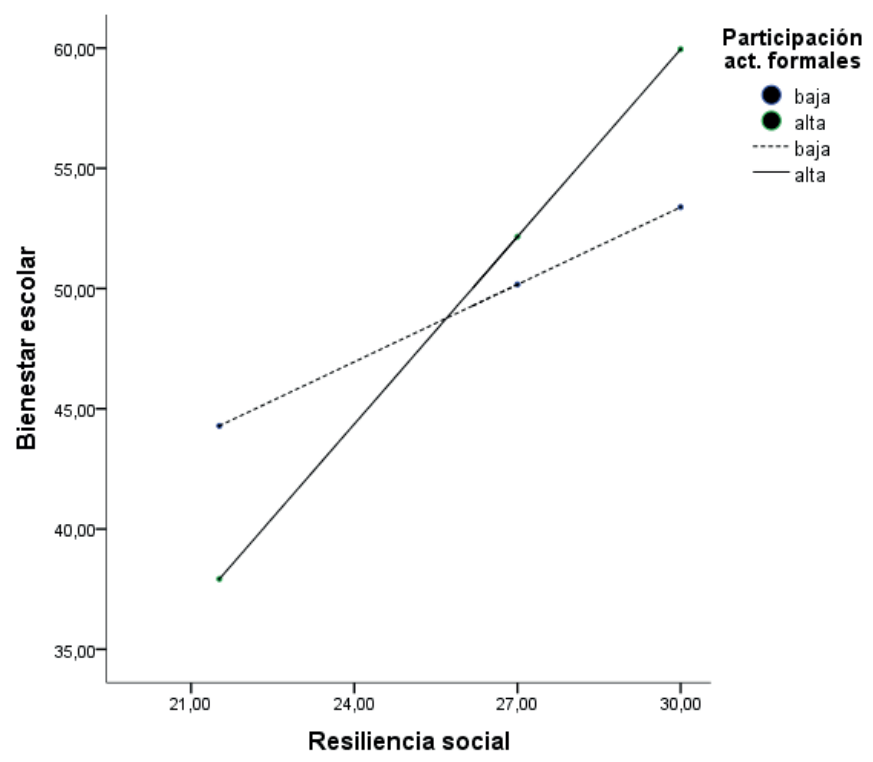


Por último, los resultados de la interacción entre participación en actividades informales y resiliencia social sobre el efecto del bienestar escolar de alumnos sin NEAE (Figura 14) muestra una tendencia similar a la descrita en el grupo de alumnos con NEAE. Nuevamente, niveles altos de participación provocan un impacto mayor en la relación entre resiliencia social y bienestar escolar $\left[a_{3} \theta(\mathrm{SE})=2.35(.50), p=.00\right]$. Mientras que, en condiciones de baja resiliencia social son los valores bajos de participación los que ocasionaban niveles más altos de bienestar escolar, en condiciones de alta resiliencia social son los niveles más altos de participación los que mayor bienestar escolar reportan en alumnos sin NEAE. Estos resultados vuelven a mostrar un efecto promotor del bienestar escolar a medida que crece la participación en actividades de tipo informal y los recursos sociales para el desarrollo de la resiliencia infantil.

Figura 14. Representación gráfica relación bienestar escolar, resiliencia social y participación en actividades de tipo informal, grupo de alumnos de Primaria sin NEAE $(N=100)$

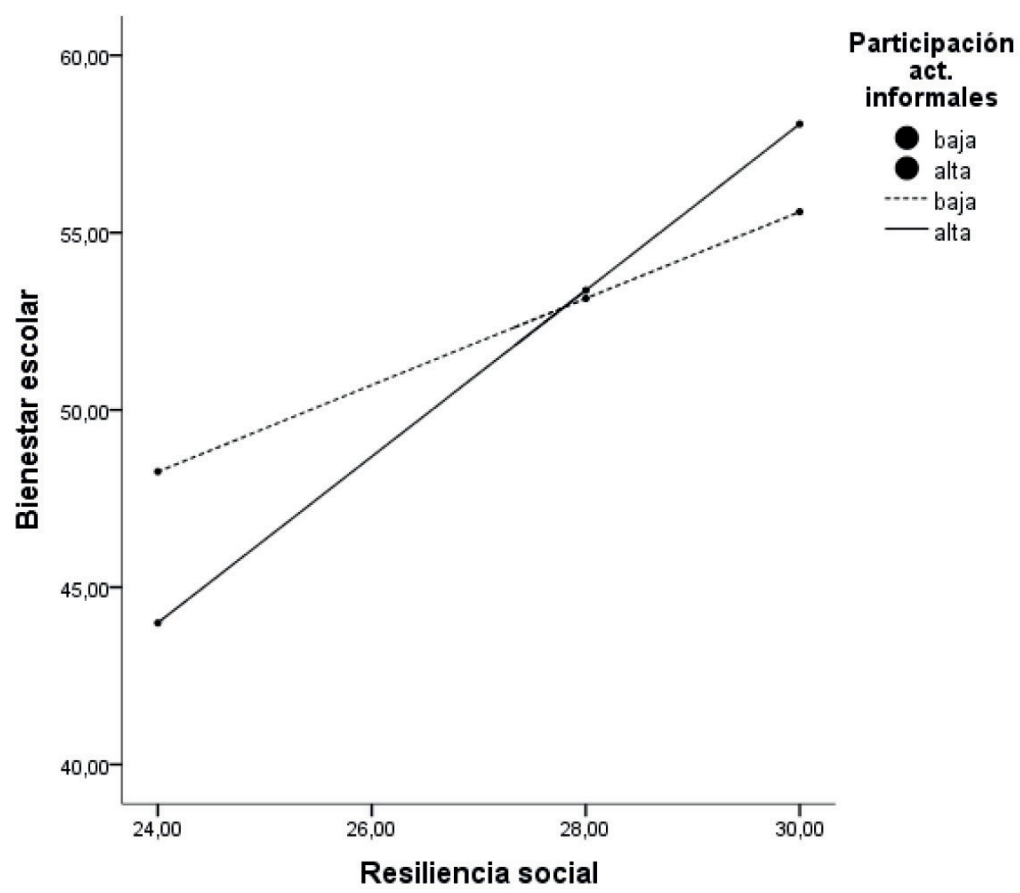


A modo de síntesis, los resultados de los modelos de moderación analizados muestran un efecto parcial de participación en actividades diversas sobre la relación que se establece entre resiliencia social y bienestar infantil, concretamente sobre los niveles de bienestar social y bienestar escolar de alumnos Primaria con NEAE y sin ellas. Este efecto condicional en el bienestar infantil se origina mediante la interacción entre la participación y la resiliencia social de estos alumnos. En el siguiente apartado ahondaremos sobre estos resultados bajo el foco de los hallazgos de investigaciones previas.

\subsection{Discusión}

En este capítulo se ha explorado la existencia de relaciones causales entre la calidad de vida infantil, la percepción que los niños tienen de sus recursos personales, familiares y sociales para el desarrollo de su resiliencia y la diversidad de su participación en actividades de ocio y tiempo libre de tipo formal e informal. Este estudio se ha realizado a través de modelos analíticos predictivos y condicionales. Sus objetivos generales han sido conocer hasta qué punto los niveles de participación y resiliencia contribuyen a la variación de los indicadores de calidad de vida infantil, y abordar los procesos subyacentes de estas asociaciones, tratando de explicar cómo y bajo qué condiciones de vida operan estas interacciones en el bienestar de niños con NEAE y sin ellas. La finalidad de este análisis es aportar nuevas evidencias científicas acerca del desarrollo de niños en condiciones de vida diversas, que permitan la elaboración de estrategias socioeducativas centradas en resultados personales de calidad (Schalock et al., 2016), las cuales serán presentadas en el siguiente y último capítulo de tesis doctoral.

A través de análisis de regresión, la información obtenida pone en evidencia que los recursos sociales, familiares e individuales para el desarrollo de la resiliencia infantil tienen la capacidad de predecir una gran proporción de las variaciones del bienestar infantil percibido, concerniente a las diferentes áreas de vida en la que los niños se desenvuelven e interactúan con su ambiente cotidiano. El efecto directo hallado de la resiliencia en la calidad 
de vida infantil, se da más allá de otras características personales como son el género, el curso y la presencia o no de NEAE, aportando nuevas evidencias acerca de la primacía de los factores ambientales, sobre los personales, en los resultados infantiles (Bottrell, 2009; Lerner et al., 2008). Al mismo tiempo los resultados de estos análisis destacan el efecto específico de la resiliencia social, sobre el efecto del resto de dimensiones de resiliencia analizadas. De este modo, del conjunto de variables analizadas, la resiliencia social surge como el mejor predictor de la calidad de vida infantil, indicando que los recursos sociales actúan como factores protectores frente a otros factores de riesgo (Luthar et al., 2000), con capacidad suficiente para producir por si mismos resultados personales de bienestar, positivos y significativos (Anyan, Worsley y Hjemdal, 2017; Earnshaw, Lang, Lippitt, Jin y Chaudoir, 2015; Orosová, Benka y Bavol'ár, 2017; Trompetter, Bohlmeijer, Lamers y Schreurs, 2016).

Con respecto al papel de la participación en actividades diversas de ocio y tiempo libre en la calidad de vida infantil, los resultados de esta investigación manifiestan que la diversidad de participación infantil en actividades de tipo formal e informal es capaz de predecir el bienestar infantil, cuando se combina con el efecto principal que la resiliencia tienen sobre el bienestar en las diferentes áreas de vida en las que los niños se desarrollan (bienestar físico, emocional, familiar, social y escolar). Más concretamente, los análisis de regresión lineal, realizados para evaluar la interacción entre variables, desvelan la existencia de un efecto moderador por parte de la participación en las relaciones establecidas entre la resiliencia social y el bienestar social y escolar de alumnos con NEAE y sin ellas. La fuerza y dirección de este efecto condicionado viene determinada por los valores altos y bajos de participación en actividades de tipo formal e informal, que se dan en distintos contextos de interacción entre el niño y su ambiente. De esta forma, mientras que en contextos sociales y de relación entre iguales son los alumnos de Primaria con menores niveles de participación en actividades de tipo informal los que más se benefician del efecto que la resiliencia social tiene sobre su bienestar social, con independencia de la presencia o no de NEAE, en el 
contexto escolar, son los alumnos que más participan los que mayor efecto perciben en su bienestar. Estos resultados de interacción entre resiliencia social y participación son congruentes con los de investigaciones previas, en las que se ha asociado el apoyo y las interacciones sociales positivas a una mayor participación en actividades de ocio y tiempo libre de jóvenes con discapacidad y sin ella (Longo et al., 2012), y de alumnos con necesidades educativas especiales en su entorno escolar (Almquist et al., 2005).

Este estudio proporciona evidencias científicas acerca de hechos, tales como, que en contextos de interacción social los niños bajo condiciones de baja participación, pero alta resiliencia social, son el grupo que mayor bienestar percibe. Este resultado informa de la existencia de un mecanismo de protección, mediante el cual los recursos o apoyos sociales son capaces de compensar las posibles carencias originadas por una baja participación en actividades de ocio y tiempo libre (Fergus et al., 2005), e incluso proporcionar más satisfacción y bienestar social de lo que lo hace la participación en un mayor número de actividades (Rosenberg et al., 2016). En tanto que en contextos escolares, a medida que aumentan la participación el efecto de la resiliencia social sobre el bienestar infantil también crece, determinando en mayor medida el bienestar escolar de los niños bajo condiciones de alta participación, frente a condiciones de baja participación. Esta interacción positiva entre dos tipos de factores ambientales, como son la resiliencia social y la participación en actividades diversas, define la existencia de un mecanismo promotor de bienestar infantil en un contexto específico de desarrollo (Fergus et al., 2005), el entorno escolar.

Resulta interesante destacar que en los análisis de regresión realizados, la resiliencia es la única variable que muestra capacidad explicativa directa sobre los niveles de bienestar infantil, en tanto que la participación manifiesta este potencial cuando se combina con los niveles de resiliencia social. En su artículo "Moving us toward a theory of individual quality of life" Schalock y colaboradores (2016) citan, entre los componentes predictivos de la calidad de vida, las oportunidades para el crecimiento personal como variables que facilitan la interacción entre el potencial personal y los distintos sistemas 
en los que la persona se desenvuelve. Esta definición de oportunidades para el crecimiento personal es congruente con el modelo de resiliencia socioecológica de Ungar (2011) en el que se basada la medida de resiliencia CYRM-22 (Ruiz et al., en prensa), utilizada para el desarrollo de esta investigación. En tanto que, en este mismo artículo (Schalock et al., 2016), la participación aparece como una estrategia para la mejora de la calidad de vida que representa su efecto, a través de las oportunidades que crea el ambiente para el desarrollo de la persona. Ambas premisas de la teoría de calidad de vida individual han sido probadas y demostradas parcialmente en este trabajo orientado al análisis de la calidad de vida infantil.

En general, los resultados descritos confirman las sospechas teóricas acerca de la existencia de relaciones subyacentes entre los factores que determinan los resultados personales de alumnos de Primaria con NEAE y sin ellas. Las relaciones específicas halladas en esta investigación favorecen o dificultan el desarrollo de esta población, a través de la interacción generada entre sus diferentes niveles de participación en actividades de ocio y tiempo libre, los recursos personales y sociales para el desarrollo de su resiliencia y la calidad de vida autopercibida.

A lo largo de este capítulo hemos aportado pruebas científicas nuevas acerca de las variables que predicen los resultados de una vida infantil de calidad, desde la visión de los propios niños. También se ha demostrado que, con respecto al peso que las variables de tipo personal y ambiental tienen sobre los resultados personales de los niños, los factores ambientales son los que mayor influencia muestran sobre las variaciones en los niveles de calidad de vida infantil, cuando se analizan unas y otras variables. Pese a ello, al analizar la interacción entre los factores seleccionados para este trabajo (resiliencia y participación) en diferentes grupos de niños, se han detectado diferencias entre alumnos con NEAE y sin ellas que evidencian procesos subyacentes específicos a los resultados de bienestar de cada grupo, tal y como destacan otras investigaciones previas (Almqvist et al., 2006; Skinner et al., 2005; Ungar, 2012; Lee et al., 2010; Shikako-Thomas et al., 2012). 
Concretamente, en este trabajo se ha demostrado que, aunque los niveles de participación en actividades diversas condicionan el efecto positivo que los recursos sociales para la resiliencia tienen sobre el bienestar escolar de todos los alumnos de Primaria participantes, este efecto viene determinado en alumnos con NEAE y sin ellas por su participación en diferentes tipologías de actividad. Es decir, mientras que en alumnos sin NEAE el aumento del efecto del bienestar escolar, a partir de la resiliencia social, se produce cuando participan en actividades de tipo informal, tales como, jugar al futbol o al baloncesto, jugar en los columpios, ir de excursión o al cine, entre otras actividades, en alumnos con NEAE este efecto está condicionado a la participación en actividades de tipo formal como recibir clases de arte, danza o música, hacer deportes de equipo, atletismo u otras actividades de tipo extraescolar realizadas en el cole o en otras asociaciones de ocio y tiempo libre. Estos resultados diferenciales acentúa la importancia de efectuar análisis de procesos condicionales en diferentes grupos sociodemográficos, ya que este tipo de análisis permite aislar las vías específicas, a través de las cuales la interacción entre distintas variables da lugar a resultados personales significativos en distintos subgrupos de participantes (Adi et al., 2007; Ungar, 2008).

A nivel práctico los resultados de este estudio tienen importantes implicaciones psicoeducativas, con respecto al fortalecimiento de los recursos personales y sociales para el desarrollo de la resiliencia infantil y, más concretamente, del apoyo social entre iguales, dada su determinación sobre el bienestar de los niños. Este recurso social pueden ser promovido, a través de una amplia diversidad de actividades, entre otros medios y estrategias, mediante las cuales crear ambientes nutricios en los que los niños tengan oportunidades para comunicarse, colaborar y desarrollar habilidades como la empatía o la asertividad. En la actualidad existen una gran cantidad de programas psicoeducativos basados en la evidencia que sirven de guía para la puesta en marcha de intervenciones dirigidas al fomento del desarrollo infantil positivo desde enfoques de trabajo sistémicos e inclusivos (Monjas, 2004, 2007; Monjas y González, 2000; Seligman, Ernst, Gillham, Reivich y 
Linkins, 2009; Ungar, 2015). Estas y otras herramientas educativas suponen en sí mismas recursos que favorecen el acceso y disponibilidad de oportunidades para el florecimiento de la resiliencia infantil que, como se ha evidenciado en este trabajo, es capaz de predecir la satisfacción y el bienestar que los niños perciben en diferentes contextos de su vida diaria. De esta forma, centrar las intervenciones dirigidas al fomento de la calidad de vida infantil en el crecimiento de su resiliencia podría ser un avance práctico importante para el desarrollo positivo e integral de todos niños.

En esta línea y en referencia a los hallazgos de la segunda parte de este estudio, la participación en actividades de ocio y tiempo libre se presenta como una estrategia concreta para el fortalecimiento del desarrollo positivo de niños en condiciones diversas de vida, tales como la presencia de NEAE. Mediante el fomento de la participación activa de los menores en diversas tipologías de actividad de tipo lúdico, sus entornos de desarrollo próximo pueden alimentar tanto el desarrollo de su resiliencia, como el bienestar personal percibido. Pero, para que el efecto de la participación sea lo más significativo posible en sus resultados personales, se requiere de una serie de cambios en la forma de pensar e implementar este tipo de actividades. Algunos de estos cambios se refieren al análisis del abanico de actividades de ocio disponibles en la escuela y otras organizaciones educativas, a la valoración de las preferencias de participación de los alumnos, al examen de las actividades disponibles para comprobar hasta qué punto son accesibles y responden a los intereses de todos y cada uno de los niños, así como al impulso de apoyos elaborados desde el enfoque de diseño universal y dirigidos a la promoción de la asistencia, participación y aprendizaje significativo de todos los niños (Booth et al., 2002, 2015), en sus entornos próximos de desarrollo. La implementación de estas tareas en las prácticas de los profesionales de la educación, ayuda a responder a las diferencias halladas en este investigación sobre los procesos subyacentes que dan lugar al bienestar escolar de alumnos con NEAE y sin ellas, las cuales acentúan la necesidad de incluir a todos los alumnos en las diferentes actividades que se desarrollan en sus entornos escolar y social, con indiferencia de sus condiciones personales y/o ambientales. 


\subsubsection{Limitaciones y Líneas de Investigación Futuras}

Aunque los hallazgos de este estudio proporcionan un punto de partida para examinar las condiciones específicas bajo las cuales alumnos de Primaria con NEAE y sin ellas perciben una vida de calidad y bienestar, el presente trabajo presenta una serie de limitaciones que nos insta a tener precaución a la hora de interpretar dichos resultados. Queda en manos de la investigación futura su mejora.

En primer lugar, pese al haber trato de representar fielmente las características de la población objeto de estudio, el tamaño de la muestra, así como el procedimiento incidental seguido para la recopilación de la información, no garantizan la generalidad de los datos al conjunto de alumnos españoles de Primaria con NEAE y sin ellas. Por tanto, estos resultados deben ser considerados preliminares, en tanto que, la investigación futura debería de tratar de replicar los hallazgos obtenidos en muestras formadas por alumnos de las distintas comunidades autónomas españolas y con un mayor número de alumnos de las diferentes categorías de NEAE, de tal forma que se asegure la representatividad muestral y se posibilite la realización de análisis diferenciales.

Por otra parte, la metodología de corte transversal también limita las conclusiones acerca de las relaciones causales entre los constructos analizados. Esta limitación es particularmente conflictiva en el caso de los resultados de moderación hallados y los efectos condicionales que la participación muestra en la asociación entre resiliencia social y bienestar infantil. En este punto, la investigación futura debería orientarse al desarrollo de estudios longitudinales que permitan explorar los posibles cambios en las asociaciones entre el bienestar, la resiliencia y participación infantil a lo largo del tiempo y el espacio (entornos de desarrollo próximos diversos), a través de un diseño longitudinal de modelos que integren factores personales y ambientales que protegen y/o amenazan la calidad de vida infantil, a través de interacciones complejas entre ellos (Hayes, 2013; Imms et al., 2016a; King, 2013; Orosová et al., 2017). 
Por último, también cabe mencionar el hecho de que en los efectos de moderación hallados la participación solamente impacte sobre las dimensiones de bienestar social y escolar, sin afectar al bienestar infantil en entornos más personales como el bienestar físico, emocional o, incluso, familiar. En este sentido, es licito pensar que al analizar el efecto que tiene la participación en el bienestar, a través de la resiliencia social, este efecto tenga lugar en aquellas condiciones de bienestar que se producen en entornos sociales más amplios, tales como, la relación con iguales o amigos, como viene definida en la medida de bienestar social del Kidscreen-27 utilizada, o las relaciones que se establecen en la escuela, a través del apoyo recibido y la participación realizada en diferentes tipologías de actividad. Por tanto, el efecto de moderación evidenciado es un efecto arbitrario ligado a contextos muy definidos, como son la relación con los iguales o en el centro educativo. Es posible que al realizar estos mismos análisis, a través de otras dimensiones de estos mismos constructos, así como con otras variables personales y ambientales que muestren sus significación en los procesos causales del bienestar infantil, se obtengan nuevas relaciones e interacciones entre ellos que permitan precisar, determinar y ampliar el conocimiento existente sobre la calidad de vida de alumnos de Primaria con NEAE y sin ellas.

Pese a las limitaciones descritas, las aportaciones de este trabajo son novedosas y válidas para el aumento del conocimiento sobre bienestar y desarrollo infantil positivo. El conocimiento generado a partir de este estudio es de utilidad para la puesta en marcha de prácticas educativas basadas en la evidencia, en las cuales la participación en actividades diversas de ocio sea la herramienta educativa que lleve como objetivo la satisfacción y bienestar personal de los alumnos, al que se llega creando oportunidades de crecimiento personal y social durante la realización de las actividades, que dan lugar a la adquisición de recursos y activos para el florecimiento de la resiliencia. 


\subsection{Conclusiones}

Con la finalidad de mejorar el conocimiento actual sobre la calidad de vida infantil, este estudio es el primero que proporciona evidencias sobre cómo la resiliencia infantil interactúa con la participación en actividades diversas de ocio y tiempo libre, para proporcionar resultados significativos de bienestar personal en alumnos con NEAE y sin ellas. Este estudio ha permitido obtener información acerca de cómo y cuándo la calidad de vida infantil se ve afectada por la interacción de los niveles de estos dos factores. A partir de los análisis desarrollados llegamos a las siguientes conclusiones:

» La investigación previa ha dado indicios de la asociación entre resiliencia infantil y calidad de vida, y de ésta con la participación en actividades diversas de población infantil en condiciones de vida diversas. Sin embargo, hasta el momento ningún estudio ha explorado la relación entre las tres variables, así como posibles procesos causales subyacentes entre ellas.

»A través de métodos correlacionales, el presente trabajo ha evidencia que los niveles de resiliencia infantil se asocian positiva y significativamente con el bienestar personal percibido por los niños en diferentes áreas de vida. En tanto que, la relación entre su diversidad de participación en actividades de ocio y tiempo libre y niveles de bienestar subjetivo es más débil y confusa.

>A través de análisis de regresión para el análisis de los procesos causales entre variables se ha hallado:

- Un nulo o bajo efecto causal de los factores personales analizados (género, edad, presencia de NEAE) sobre los niveles de calidad de vida infantil.

- Un efecto predictivo general de la resiliencia infantil sobre la calidad de vida de alumnos de Primaria con NEAE y sin ellas.

- Un predominio de la dimensión de resiliencia social, con respecto al resto de dimensiones de resiliencia, en la capacidad predictiva que muestra sobre los distintos dominios de calidad de vida valorados.

- Un efecto directo bajo de la dimensión de diversidad de participación 
sobre la calidad de vida infantil, que aumenta cuando se combina con el poder predictivo de la resiliencia infantil.

» Mientras que los análisis de moderación para la evaluación de terceras variables en los efectos directos de la resiliencia social en los niveles de bienestar infantil han desvelado:

- La existencia de un mecanismo de resiliencia promotor de la calidad de vida infantil, mediante el cual la participación en actividades de tipo formal e informal actúa sobre el bienestar percibido de los niños, a través de su interacción con los recursos sociales para el desarrollo de la resiliencia en entornos sociales, tales como, las relaciones establecidas entre iguales y en el colegio.

- En estos procesos causales, la resiliencia social actúa como predictor de la calidad de vida infantil. Mientras que, la participación actúa como una estrategia que modera el impacto de este factor predictor sobre el bienestar social y escolar del niño. Este efecto de moderación se produce a partir de la combinación de los niveles de diversidad de participación en actividades de ocio de tipo formal e informal y de resiliencia social percibida.

- En condiciones sociales, los niños con niveles menores de participación son los que más se benefician del impacto que la resiliencia social tiene sobre el bienestar percibido. En tanto que, en el entorno escolar son los que más participan los que se favorecen del efecto que los recursos sociales para el desarrollo de la resiliencia tiene sobre su bienestar.

- En el contexto escolar se produce además efectos diferenciales entre grupos de alumnos. En alumnos con NEAE el efecto de moderación sobre el bienestar se da al participar en actividades de ocio de tipo formal, en tanto que en alumnos sin ellas aparece cuando lo hacen en actividades de tipo informal.

»Los resultados obtenidos, nos ofrecen información sobre:

- La primacía de los factores ambientales sobre los factores personales en los resultados de calidad de vida y desarrollo infantil positivo. 
- Las vías a través de las cuales la resiliencia, la diversidad de participación y el bienestar percibido interactúan para definir una vida de calidad en alumnos de Primaria con NEAE y sin ellas.

Recursos para la puesta en marcha de adaptaciones y apoyos sociales, de tipo formal e informal, que creen oportunidades para participar, experimentar, aprender y tener éxito durante el desarrollo de una amplia diversidad de actividades desarrolladas en entornos sociales y escolares. Dadas los hallazgos de este estudio, se espera que estas prácticas basadas en la evidencia tengan un impacto directo sobre la calidad de vida infantil, a través del logro de resultados personales significativos (Booth et al., 2002, 2015; Bult, 2014; Schalock et al., 2013; Ungar, 2012).

Los hallazgos de este estudio, debido a su novedad, tienen que ser interpretados con cautela. Pese a aportar información adicional sobre el rol que la resiliencia y la participación juegan en los resultados de bienestar infantil, se requieren estudios futuros en esta línea de investigación para seguir desgranando las vías que dan acceso a una vida de calidad, a través de la interacción de otros factores personales y ambientales presentes en los contextos en los que tiene lugar el desarrollo infantil. Además de estudios transversales son necesarias investigaciones longitudinales que exploren, no solo el papel que variables como la resiliencia y la participación tienen en la calidad de vida infantil, sino también cómo actúan estos factores sobre el bienestar infantil a lo largo del tiempo, ampliando la población objeto de estudio a la siguiente etapa de vida, la adolescencia. Asimismo, mediante procedimientos de regresión lineal e interacción entre variables se debería analizar el rol que otros factores del contexto asociados a ciertos resultados personales tienen sobre la calidad de vida infantil, como aquellos evidenciados en el Capítulo 6. El desarrollo de esta línea de investigación ayudará a precisar más los procesos subyacentes que dan origen al bienestar y desarrollo infantil positivo en contextos diversos, aportando información válida para la creación de un modelo de la calidad de vida individual aplicado a población infantil.

Llegados a este punto del trabajo, en el siguiente y último capítulo presentaremos las conclusiones generales que ponen punto y final a esta investigación defendida como tesis doctoral. 



\section{Capítulo 8}

Conclusiones Generales de la Investigación Análisis de Factores Determinantes de la Calidad deVida de Alumnos con NEAE y Sin Ellas

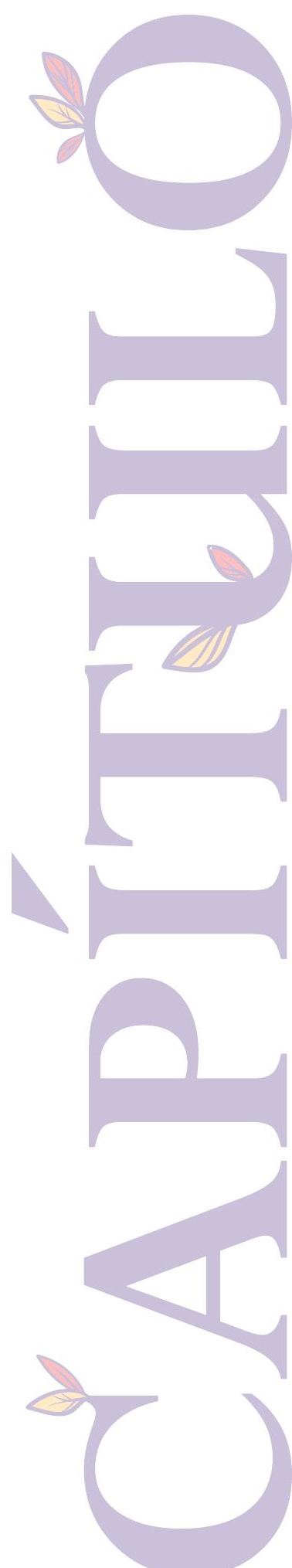





\section{Conclusiones Generales de la Investigación Análisis de Factores Determinantes de la Calidad de Vida de Alumnos con NEAE y Sin Ellas}

\section{Introducción}

La presente tesis doctoral ha tenido como finalidad definir el desarrollo infantil positivo desde resultados personales significativos de bienestar y crecimiento positivo. Para ello, su investigación se ha centrado en el análisis de la calidad de vida infantil desde el estudio de factores personales y ambientales presentes en el contexto de desarrollo infantil, y su interacción con resultados personales de bienestar, resiliencia y participación de los niños en actividades diversas.

Con objeto de resaltar las aportaciones más relevantes realizadas por este trabajo de investigación, en este último capítulo se presentan las conclusiones generales a las que han dado lugar los resultados obtenidos. Estas conclusiones se realizan desde un enfoque socio-ecológico de crecimiento infantil positivo centrado en el bienestar y desarrollo integral de niños en condiciones de vida diversas.

De esta forma, en este último capítulo se aborda de manera sintética las principales conclusiones derivadas de esta tesis doctoral en relación a: los resultados generales obtenidos, las aportaciones científicas realizadas, sus implicaciones prácticas más importantes, las limitaciones halladas a lo largo de la investigación y los pasos futuros que deben guiar esta línea de trabajo.

\subsection{Resultado Generales}

A la luz de la literatura actual sobre desarrollo infantil, el objetivo general de esta investigación ha sido obtener información sobre experiencias personales que ayudan a los niños a desarrollarse de forma plena y exitosa. Para la consecución de este objetivo el estudio se ha dividido en dos partes. 
Una primera parte teórica en la que, sobre la base de un modelo socioecológico de desarrollo infantil, se justifica la importancia de analizar los resultados personales de los niños a partir de tres variables de relevancia actual en investigación, política y práctica: la calidad de vida, la participación en actividades de ocio y tiempo libro y la resiliencia infantil. El valor de estas tres variables radica, no solo en su gran desarrollo teórico, sino también en su utilidad práctica como herramientas para definir e intervenir en el desarrollo positivo de niños en condiciones de vida diversas. En esta primera parte, también se destaca la influencia que tiene sobre el desarrollo infantil la interacción del niño con variables presentes en su entornos próximos (familiar, escolar o social), y de cómo la naturaleza de estas interrelaciones determina el valor de los resultados personales infantiles. Esta justificación teórica se lleva a cabo a través de cuatro capítulos.

Una segunda parte empírica en la que se analiza los resultados personales en $\mathrm{CV}$, participación en actividades diversas de ocio y tiempo libre y recursos para el desarrollo de la resiliencia de alumnos de Primaria con NEAE y sin ellas. Así como, la relación que se establece entre estas tres variables y el peso que otros factores del contexto personal y ambiental de los niños tienen sobre dichos resultados personales, con objeto de comprender el papel facilitador o de obstáculo de todas estas variables en el bienestar y desarrollo infantil pleno. Este trabajo de investigación se realiza través de tres capítulos empíricos.

Para sintetizar los hallazgos más relevantes realizados en cada una de estas dos partes de la investigación, a continuación se expone de manera pormenorizada los resultados e implicaciones evidenciadas en sus capítulos correspondientes. 


\subsubsection{Parte Teórica}

\subsubsection{Capítulo 1}

Con la finalidad de enmarcar el contexto de investigación de esta tesis doctoral, el desarrollo de niños en condiciones de vida diversas en contextos educativos inclusivos, el Capítulo 1 está dedicado a establecer las bases conceptuales del crecimiento infantil positivo desde un paradigma ecológico, sistémico y transaccional de desarrollo humano (Bronfrenbrenner, 1979, 2002; Sameroff et al., 1990). Concretamente el primer capítulo trata de hacer una aproximación inicial a la calidad de vida, la participación y la resiliencia infantil como variables clave para la consecución de resultados personales de éxito y bienestar, a los que el niño llega, a través de la interacción positiva de los factores presentes en el contexto en el que tiene lugar su desarrollo. Estas son las principales evidencias halladas en la literatura consultada.

» Según la teoría ecológica de Bronfrenbrenner (1979, 2002), todos los aspectos referentes al proceso de desarrollo infantil pueden ser clasificados como factores protectores o de riesgo, según favorezcan o dificulten la trayectoria de crecimiento del niño (Souza et al., 2015).

»Para el enfoque transaccional el desarrollo infantil es el resultado de las interacciones dinámicas que tienen lugar entre el niño y su contexto familiar, social y cultural, estableciéndose una interconexión entre ellos mutuamente determinante (Jaramillo, 2007; Sameroff et al., 1990).

» Desde esta perspectiva, las evidencias empíricas halladas permiten definir el desarrollo infantil positivo como un proceso de relaciones mutuamente adaptativas y beneficiosas entre los niños y los contextos en los que tiene lugar su crecimiento (Eichas et al., 2017; Lerner et al., 2015).

»En la práctica, la intervenciones infantiles basadas en el Desarrollo Positivo han demostrado ser efectivas en el crecimiento de sus participantes (Leman et al., 2017). Sin embargo, para favorecer la riqueza, tanto individual, como de sus contextos, estos programas 
requieren estar disponibles y accesibles para todos los menores (Wehmeyer, 2009).

»Para mejorar la calidad de estas intervenciones se requiere conocer qué experiencias personales son significativas, qué factores contribuyen a su bienestar general y qué semejanzas o diferencias se establecen entre poblaciones infantiles específicas (Jaramillo, 2007; Oshri et al., 2017).

» Para definir el desarrollo positivo de menores en condiciones diversas de vida una herramienta útil es la Clasificación Internacional del Funcionamiento, de la Discapacidad y de la Salud (OMS, 2001, 2007), al permitir incorporar otros conceptos clave, tales como, calidad de vida (Ravens-Sieberer et al., 2014b) y resiliencia infantil (Ungar, 2015), a los componentes de participación y factores contextuales de su modelo.

»En este paradigma biopsicosocial de desarrollo infantil positivo, la calidad de vida, la participación en actividades de ocio y tiempo libre y la resiliencia infantil se establecen como indicadores de salud y funcionamiento positivo, que reconocen el papel activo de los niños en la construcción de sus propias vidas. Concretamente:

- La calidad de vida infantil se presenta como un instrumento mediante el cual combatir la desigualdad social, a través del impulso de acciones gubernamentales dirigidas a la puesta en marcha de servicios y apoyos que satisfacen las necesidades personales y en relación con los demás, fomentan el bienestar y promueven el desarrollo infantil de calidad (De Castro el al., 2013; Oshri et al., 2017; Schalock et al., 2016b).

- La participación infantil en actividades de ocio y tiempo libre se destaca como un contexto clave para el acceso y disponibilidad de oportunidades de desarrollo, que facilita la adquisición de competencias para la vida (Shikako-Thomas et al., 2012), reduce los comportamientos juveniles de riesgo (Exenberge et al., 2013) y fomenta el bienestar personal y social de los niños (Albertín et al., 2013). 
- La resiliencia infantil se comprende como un proceso en el que los factores de protección son fortalecidos, frente a los factores de riesgo presentes en situaciones adversas de vida (Windle, 2011). Este proceso de crecimiento tiene lugar al brindar oportunidades para el establecimiento de relaciones positivas y significativas con el entorno (King et al., 2003, 2009; Ungar, 2015a).

» La unión de estos tres constructos constituye una herramienta para la planificación y evaluación profesional de intervenciones educativas, sanitarias y sociales, basadas en los resultados personales de los propios niños y en su interacción con los factores que determinan su contexto de desarrollo (UNESCO, 2005).

» Con respecto al ámbito educativo, las intervenciones clásicas del sistema educativo para responder a las necesidades de aprendizaje de los niños, se han centrado en la identificación y diagnóstico de alumnos con necesidades específicas de apoyo educativo (Wehmeyer, 2009).

»Esta metodología de trabajo ha ocasionado la etiqueta, discriminación y rechazo de la diversidad del alumnado (UNESCO, 2006), y ha obviado la multiplicidad de habilidades, intereses y lenguajes presentes en el conjunto de alumnos (Echeita, 2013).

» Dada la importancia del contexto educativo durante la infancia, el objetivo actual radica en confeccionar sistemas educativos de calidad basados en la defensa de los derechos y diversidad humana, inclusión educativa, cambio de los modelos organizativos, fomento de los recursos comunitarios y puesta en marcha de buenas prácticas basadas en la evidencia (Booth et al., 2015; Schalock et al., 2013b; Ungar, 2015b).

»El análisis y aplicación de las aportaciones derivadas de los conceptos de calidad de vida, participación y resiliencia infantil desde un enfoque de desarrollo infantil positivo, puede responder a las necesidades de innovación y cambio del sistema educativo ordinario (King et al., 2003, 2009; Schalock et al., 2002, 2003, Ungar, 2012). 
»Implementar estas aportaciones teóricas a la realidad de alumnos con NEAE y sin ellas, requiere un proceso de reflexión sobre las contribuciones de cada concepto a la mejora de la respuesta educativa ofrecida a la diversidad del alumnado.

» La finalidad de este trabajo de tesis doctoral ha sido abordar este proceso de reflexión dirigido a la mejora de las prácticas educativas en los centros escolares.

\subsubsection{Capítulo 2}

El Capítulo 2 está dedicado al análisis teórico del constructo de Calidad de Vida Infantil a fin de justificar teóricamente su estudio en la presente investigación. En él se realiza un recorrido histórico por el concepto, su desarrollo metodológico, su conceptualización para población infantil en condiciones diversas de vida y su aplicación al contexto educativo. A continuación se presenta una síntesis de los resultados obtenidos en el trabajo de revisión teórica realizado sobre CV infantil.

»E El concepto CV se relaciona con componentes referentes a la buena vida, el bienestar y la satisfacción del ser humano. Su investigación y aplicación tomó valor con el inicio de las políticas y movimientos sociales en pos de los derechos humanos. Actualmente su uso está ligado a otros conceptos claves, tales como, desarrollo, discapacidad, diversidad, entre otros (Cummins, 2000, 2005; Edwards et al., 2002; Schalock et al., 2002, 2003; Wallander et al., 2016).

» El modelo de CV de Schalock et al. (2002, 2003), de gran relevancia mundial por sus implicaciones científicas y prácticas, define la $\mathrm{CV}$ como un estado deseado de bienestar personal, compuesto por múltiples dominios de vida subjetivos y objetivos, con propiedades ligadas a la cultura y otras de carácter universal, e influenciado por características personales y variables ambientales. 
»Este modelo adopta un enfoque socio-ecológico para la conceptualización, medida y aplicación de la CV. Sus autores defienden el potencial del constructo para mejorar los resultados personales de poblaciones específicas, tales como, las personas con discapacidad (Schalock et al., 2016a).

» Inicialmente el constructo se centró en la $\mathrm{CV}$ de población adulta. Más recientemente, las primeras aproximaciones a la CV infantil se han realizado desde el ámbito de la salud - CVRS (Ravens-Sieberer et al., 2014c). Actualmente su estudio se extiende a otros contextos cotidianos de desarrollo infantil, tal como, el educativo (Gómez-Vela et al., 2009; Muntaner et al., 2010).

» A nivel operativo existen múltiples instrumentos de medida enfocados a la comprensión integral de la CV infantil. Éstos evalúan el impacto que diferentes experiencias de vida tiene en el bienestar subjetivo de los menores, desde modelos sistémicos y multidimensionales (Tabla $6)$.

»El Kidscreen (Ravens-Sieberer et al., 2008) es una medida transcultural de la CVRS de poblaciones genéricas y clínicas de entre 8 y 18 años de edad. Combina elementos de bienestar subjetivo con elementos que valoran la calidad de los contextos en los que tiene lugar el desarrollo de los menores.

» Sus resultados de fiabilidad, validez y sensibilidad (Ravens-Sieberer et al., 2008; Ravens-Sieberer et al., 2014b) lo hacen un instrumento de relevancia a nivel internacional para la medida de la CV de poblaciones infantiles en condiciones diversas de vida.

»Aplicado al contexto educativo, el concepto de CV se fundamenta en tres premisas (Muntaner, 2013):

- Es un agente de cambio que guía el proceso de mejora educativa mediante resultados personales de calidad. 
- Ha vinculado este proceso con el paradigma de apoyos centrado en la persona y el ajuste del individuo con su entorno.

- Actúa como marco de referencia en la búsqueda de nuevos modelos educativos.

»Con respecto a la diversidad del alumnado, la mejora de la respuesta educativa requiere un cambio de paradigma en el modelo educativo dirigido a las estructuras y funciones escolares, más que a la respuesta de necesidades basada en la compensación de déficits individuales (Ainscow, 1999; Verdugo et al., 2013b).

» La aplicación de instrumentos sistémicos centrados en la promoción de la inclusión educativa (Booth et al., 2002, 2015) y fomento de la CV infantil en el ámbito educativo (Muntaner et al., 2010), evidencian su validez como herramientas de innovación y mejora organizacional del sistema educativo.

» Dado que el presente trabajo de investigación se centra en la comprensión de la naturaleza del crecimiento positivo y desarrollo integral de alumnos con NEAE y sin ellas, se adoptan los fundamentos científicos expuestos sobre CV infantil, como constructo determinante en el estudio de las dimensiones de una vida de calidad y factores del contexto asociados.

\subsubsection{Capítulo 3}

El Capítulo 3 se orienta al análisis teórico del constructo de Participación Infantil en Actividades de Ocio y Tiempo Libre con el objeto de justificar teóricamente su estudio en esta investigación. El capítulo presenta el desarrollo conceptual y metodológico del constructo, su interacción con factores del contexto presentes en el entorno desarrollo infantil, y su asociación con el constructo de CV infantil. En los siguientes puntos se exponen los resultados más significativos obtenidos en el trabajo de revisión teórica realizado sobre participación infantil en actividades diversas. 
» La participación infantil en actividades de ocio y tiempo libre se define como un indicador de salud y funcionamiento positivo, asociado al desarrollo de competencias personales y sociales en general (Kirby et al., 2002; Wilkes et al., 2011), y a la promoción de la inclusión social de menores con diversas condiciones de vida personales y sociales (AAIDD, 2011; Shikako-Thomas et al., 2012).

» A nivel conceptual y desde una perspectiva individual la investigación diferencia dos ejes principales en la participación:

- Asistencia, referida al hecho de estar presente en la actividad realizada. Es el componente objetivo del constructo y se representa como el requisito previo a la experiencia de participación (Maxwell et al., 2012).

- Participación, como experiencia en sí misma. Es el componente subjetivo que refleja la relación de la participación con una serie de factores intrínsecos a ella, como la preferencia, la competencia y el sentido personal que la experiencia de la realización de la actividad da a la persona (Almqvist et al., 2005; Bult et al., 2014; King et al., 2013).

» La CIF-NJ (OMS, 2007) introduce la perspectiva social al estudio de la participación infantil. Ésta se refiere a la frecuencia de asistencia del niño a las mismas actividades. En tanto que la perspectiva individual hace alusión a la intensidad de participación con la que el niño está envuelto en ellas (Maxwell, 2012).

»Desde la perspectiva socio-ecológica de la CIF-NJ (OMS, 2007), el contexto tiene el potencial de favorecer u obstaculizar el impacto de la participación infantil, a través de factores que actúan como barreras o facilitadores de sus componentes.

» Para identificar patrones de participación en contextos particulares, la investigación ha analizado características personales y variables ambientales en busca de factores asociados a los resultados personales de participación infantil. Los hallazgos han dado lugar a diferentes modelos de participación infantil en actividades diversas que 
representan la interacción dinámica del niño con su ambiente (Imms et al., 2016a; King et al., 2003, 2009; Maxwell et al., 2012).

» Uno de estos modelos el del King et al. (2003, 2009), orientado a la participación en actividades de ocio y tiempo libre de niños con discapacidad y sin ella (Figura, 7). El modelo destaca la necesidad de explorar el papel de las variables intervinientes y su interacción, a fin de conocer los mecanismos que facilitan u obstaculizan los niveles de participación infantil.

» Los desarrollos teóricas entorno al concepto de participación infantil han dado lugar a múltiples herramientas de medida que valoran las dimensiones objetivas y subjetivas del constructo en diferentes entornos de participación (Tabla 8).

» El CAPE (King et al., 2004) es el instrumento asociado al modelo de King et al. (2003, 2009). Éste evalúa la experiencia objetiva y subjetiva de la participación de ocio en contextos diversos, a través de la información proporcionada por niños y jóvenes con y sin necesidades especiales. Se trata de una medida transcultural de impacto reconocido (Bult et al., 2010; Longo et al., 2012).

» El CAPE (King et al., 2004) ha ayudado a su vez a demostrar la asociación empírica ente participación y CV infantil (Badia et al., 2013).

» Los resultados de ésta y otras investigaciones evidencian que la asistencia a actividades de ocio favorece el bienestar personal del niño y contribuye a la satisfacción en diferentes áreas de vida (Badia et al., 2013; Dahan-Oliel et al., 2012; Schreuer et al, 2014), así como al desarrollo de competencias personales y sociales (Shikako-Thomas et al., 2012; Wilkes et al., 2011).

»En tanto que, las restricciones ambientales para la participación infantil dan lugar a un entramado de factores (Tabla 9), que amenazan el desarrollo óptimo y $\mathrm{CV}$ de aquellos niños con menores oportunidades para interactuar con su entorno (Van Naarden Braun, Yeargin-Allsopp 
et al., 2006), como son los niños con necesidades especiales (ShikakoThomas et al., 2012).

» Por tanto, junto al constructo de CV infantil, la participación en actividades diversas tiene el potencial de favorecer el crecimiento integral, positivo y saludable de todos los niños, siendo especialmente relevante su aplicación en aquellos con necesidades especiales.

» Tras lo expuesto en el Capítulo 3, se adopta el constructo de Participación Infantil en Actividades de Ocio y Tiempo Libre para el estudio de la CV infantil y factores asociados.

\subsubsection{Capítulo 4}

El Capítulo 4 está dedicado a la revisión teórica del constructo de Resiliencia Infantil como tercera variable con capacidad de intervenir en el bienestar y desarrollo positivo de niños en condiciones de vida diversas. En este capítulo se trata el desarrollo histórico, conceptual y metodológico del concepto, su enfoque socio-ecológico aplicado a poblaciones infantiles generales y específicas, y su relación con el concepto de CV infantil. A continuación se exponen los resultados más significativos hallados en el análisis teórico realizado.

»El estudio de la resiliencia nace con el interés de comprender los parámetros que determinan el crecimiento positivo de niños en circunstancias de vida adversas (Khanlou et al., 2014).

»El desarrollo de su estudio diferencia 4 etapas de investigación:

- $1^{\circ}$ Etapa: la resiliencia se presenta como un rasgo interno de la persona que da lugar a resultados personales de éxito (Gramezy, 1983; Rutter, 1987; Werner et al., 1982).

- $2^{\circ}$ Etapa: se identifica la influencia del ambiente en la resiliencia. Se analizan variables del entorno con capacidad de actuar como factores protectores o de riesgo del desarrollo infantil en condiciones adversas de vida (Garmezy, 1991; Luthar et al., 1991; Masten et al., 1998; Polk, 1997). Los factores se agrupan en tres grandes áreas: personal, 
familiar y social (Luthar et al., 2000b). La interacción entre factores da lugar a tres modelos que explican los patrones divergentes de crecimiento infantil: compensación, protección y exposición (Windle, 2011).

- $3^{\circ}$ Etapa: El concepto de resiliencia se enmarca dentro de los enfoques socio-ecológicos de desarrollo humano, a partir de los cuales la resiliencia se comprende como un proceso que tiene lugar, a través de las interacciones entre la persona y su ambiente (Ungar, 2012). Se desarrollan programas para promover la construcción de la resiliencia infantil y juvenil (Khanlou et al., 2014).

- $4^{\circ}$ Etapa: dentro de un enfoque eco-sistémico, comienza a investigarse los correlatos entre los resultados en resiliencia y el funcionamiento neuronal y psicobiológico de las personas (Masten, 2007).

» Todo este avance teórico conlleva el desarrollo de la medida de resiliencia, centrada en su mayor parte en la evaluación cuantitativa del componente individual y psicológico del constructo, enfocada a población adulta (Block et al., 1996; Connor et al., 2003; Wagnild et al., 1993)

» La operativización del constructo a población infantil y juvenil ha sido menor y más actual. Los instrumentos revisados (Tabla 11) muestran falta de validez y aplicabilidad, dada su escasa replicabilidad en poblaciones diversas, tales como, niños con necesidades especiales (Windle et al., 2011).

»De todos ellos, la CYRM (Ungar et al., 2008) es la única herramienta que añade el componente contextual y cultural a la medida de resiliencia infantil y juvenil. Los resultados preliminares de la versión CYRM28 (Ungar et al., 2011) muestran la consistencia interna y validez de contenido de la escala (Ungar et al., 2011; Windle et al., 2011).

»El modelo socio-ecológico de resiliencia adaptado a población infantil (Ungar, 2004, 2011), en el que se fundamenta la CYRM (Ungar et al., 2008), define la resiliencia como: 
- la capacidad de las personas para navegar por sus trayectorias de vida, a través de los recursos psicológicos, sociales, culturales y físicos que mantienen su bienestar, así como su capacidad individual y colectiva para negociar que estos recursos sean facilitados y experimentados de forma culturalmente significativa (Ungar, 2008, p. 225).

»Desde este modelo, el éxito de las intervenciones para la resiliencia infantil depende de que los recursos ofrecidos por los servicios públicos sean suficientemente intensos, culturalmente apropiados y personalmente significativos, con objeto de favorecer el crecimiento del mayor número de niños (Ungar, 2015a).

»A Aplicado al ámbito de las necesidades especiales, el reto está en cómo se define el riesgo para entender las vías que dan acceso a la red de recursos que favorecen la presencia de la resiliencia en niños de poblaciones específicas (Ungar, et al., 2007).

» Por su parte, la investigación en desarrollo infantil positivo, bajo un enfoque socio-ecológico, respalda firmemente la contribución de la resiliencia a la CV de niños y jóvenes en condiciones diversas de vida (Tabla 14) (Park et al., 2006; Tempski et al., 2015).

»El enfoque teórico de resiliencia presentado en este capítulo, se centra en buscar indicadores de resiliencia en las variaciones ambientales que se producen a nivel sistémico como respuesta positiva a la adversidad, dando lugar a resultados personales significativos (Ungar et al., 2011).

»Tras los argumentos científicos ofrecidos en el Capítulo 4, se selecciona la Resiliencia Infantil, junto a los constructos de CV y Participación Infantil en Actividades de Ocio y Tiempo Libre, para el análisis de factores determinantes de la CV de alumnos con NEAE y sin ellas que se lleva a cabo en la parte empírica de esta tesis doctoral. 


\subsubsection{Parte Empírica}

\subsubsection{Capítulo 5}

»Dentro de la parte empírica de esta investigación, el Capítulo 5, dada la inexistencia de una herramienta para la medida de la resiliencia infantil en contexto español, se centra en describir el proceso de adaptación y validación de la versión española de la medida de resiliencia para niños y jóvenes CYRM-28 (Ungar et al., 2011), a población infantil española de alumnos con NEAE y sin ellas. En los siguientes puntos se presentan los resultados más destacables de este trabajo.

» La CYRM-28 (Ungar et al., 2011) es un instrumento transcultural que valora la recursos individuales, relacionales, comunitarios y culturales accesibles y disponibles para el desarrollo de la resiliencia en niños y jóvenes.

» Su marco teórico coincide con los planteamientos teóricos del modelo de CV de Schalock y colaboradores $(2002,2003)$ y el modelo de participación infantil en actividades diversas de King y colaboradores (2003, 2009), seleccionados para el análisis de los determinantes de la $\mathrm{CV}$ de población infantil con y sin necesidades específicas.

» Investigaciones previas han demostrado la adecuación de la medida de la CYRM-28 (Daigneault et al., 2013; Panter-Brick et al., 2017; Sanders et al., 2015). Así como su alta validez de contenido (Windle et al., 2011). En tanto que su estructura interna se encuentra aún en fase de estudio.

»El proceso de adaptación y validación desarrollado en esta investigación ha dado lugar a la $C Y R M$-22, una escala de resiliencia adapta a población infantil española.

» La validez interna de la $C Y R M-22$ ha sido probada mediante el programa estadístico FACTOR 10.5.03 (Lorenzo-Seva et al., 2006; 2013). Los resultados de los análisis semi-confirmatorios realizados muestran una escala compuesta por tres dimensiones de resiliencia: familiar, personal 
y social, que hacen referencia a los recursos personales y ambientales para el desarrollo de la resiliencia infantil en nuestro país.

»El valor de la fiabilidad total de la CYRM-22 (.90) es similar al de otras adaptaciones de la CYRM-28, mientras que la de sus subescalas de encuentran por debajo de éstas (Ungar et al., 2013), aunque dentro de los valores de referencia (Nunnally et al., 1978).

» Para la validez externa se ha considerado la relación teórica existente entre los constructos de resiliencia y CV (Park et al., 2006; Peterson et al., 2011; Tempski et al., 2015). Los resultados de la correlación producto-momento de Pearson obtenidos entre las dimensiones de la CYRM-22 y las del Kisdscreen-27 (Ravens-Sieberer et al., 2007) demuestran que la CYRM-22 es válida para valorar la resiliencia infantil. Además, las correlaciones positivas y significativas obtenidas entre sus dimensiones y otras variables externas de tipo personal y ambiental evaluadas, también apoyan la validez del instrumento.

»En general, estos resultados evidencia que la CYRM-22 es un instrumento válido y fiable para evaluar los recursos familiares, personales y sociales que favorecen la resiliencia infantil en alumnos españoles con NEAE y sin ellas.

\subsubsection{Capítulo 6}

Con la disponibilidad de la medida de resiliencia adaptada a población infantil, en el Capítulo 6 se realiza el trabajo de análisis de variables personales y ambientales asociadas a los resultados personales de bienestar, resiliencia y participación en actividades diversas de alumnos de Primaria con NEAE y sin ellas. El propositito de este capítulo empírico ha sido explorar en qué medida ciertos factores del contexto infantil actúan como barreras o facilitadores del desarrollo positivo y bienestar de los niños en condiciones diversas de vida. A continuación se exponen los resultados principales de este estudio. 
»A nivel genérico los niños muestran una percepción positiva de su bienestar personal (físico y emocional) y del bienestar experimentado en sus entornos cotidianos de desarrollo (familiar, social y escolar), así como sobre los recursos personales y sociales disponibles para el desarrollo de su resiliencia.

»Con respecto a su participación en actividades diversas de ocio y tiempo libre, la intensidad de participación del conjunto de alumnos no se corresponde al número de actividades en las que personalmente les gustaría participar, dándose una discrepancia potencial entre la diversidad de participación y las preferencias hacia la realización de actividades extraescolares.

» $\mathrm{Al}$ analizar los resultados de $\mathrm{CV}$, resiliencia y participación infantil en función de los valores obtenidos en las variables de tipo personal y ambiental evaluadas, se halla que:

- Tanto la presencia de NEAE, el género, como el lugar de residencia son variables individuales que afectan a los resultados personales de los alumnos, en función de los valores que éstos adoptan en ellas.

- Especial mención merece el efecto que la presencia de NEAE ocasiona sobre los niveles de bienestar emocional y resiliencia individual percibidos por los alumnos con NEAE, los cuales se encuentran significativamente por debajo a los de sus compañeros sin ellas. Mientras que, las distintas categorías de NEAE no muestran dicha influencia sobre los resultados personales de los diferentes subgrupos de alumnos explorados (alumnos con necesidades educativas especiales, altas capacidades intelectuales, integración tardía en el sistema educativo y el grupo de otras NEAE).

- Los resultados significativos obtenidos en función de la presencia de NEAE muestra a su vez la capacidad de la escala CYRM-22 (Ruiz et al., en prensa) para obtener información diferencial de niños con diversas características personales, tal como han demostrado otras versiones de la escala administradas a distintas poblaciones 
juveniles (Brodersen, 2010; Liebenberg et al., 2012; Montoya et al., 2011).

- Con respecto a las variables de tipo educativo destacan el efecto positivo que la realización de actividades de tipo inclusivo en el aula, así como el acceso y disponibilidad de recursos físicos y materiales adaptados tienen sobre el bienestar, la resiliencia y participación extraescolar del conjunto de alumnos participantes. La influencia de este tipo de factores educativos es más relevante si cabe en el grupo de alumnos con NEAE.

- En el contexto educativo también destaca la influencia que los años de experiencia docente tienen sobre los resultados de resiliencia y participación de los alumnos, presentando a aquellos maestros con una experiencia laboral media como los profesionales con más potencial facilitador para sus alumnos.

- En el contexto familiar, tanto los niveles medios de ingresos económicos, como el hecho de compartir ambos progenitores la crianza y educación del hijo, han sido las dos variables del sistema familiar que más influencia positiva han mostrado sobre los resultados personales de unos y otros niños.

- Los resultados diferenciales obtenidos en resiliencia en función de las distintas variables educativas y familiares analizadas también demuestran la utilidad y validez de la escala CYRM-22 (Ruiz et al., en prensa) para obtener información específica de niños con características ambientales diversas.

\subsubsection{Capítulo 7}

Por último, con la finalidad de seguir avanzando en el conocimiento acerca de las vías que permiten a los niños acceder a trayectorias de vida positivas y significativas, en el Capítulo 7 de esta tesis se lleva a cabo el análisis de las relaciones causales y condicionales que se establecen entre los resultados 
personales de $\mathrm{CV}$, resiliencia y participación infantil en actividades de ocio y tiempo libre. Los resultados más relevantes de este estudio son los siguientes.

» La correlación producto-momento de Pearson demuestra la asociación positiva y significativa de los recursos para la resiliencia infantil y el bienestar infantil percibido en diferentes áreas de vida. En tanto que, en estos análisis no se obtiene significación en la relación entre la diversidad de participación infantil en actividades de ocio y tiempo libre y los dominios de CV.

»Los análisis de regresión realizados para el estudio de procesos causales entre bienestar, resiliencia y diversidad de participación infantil, evidencian:

- Un efecto bajo de los factores personales (género, edad y presencia de NEAE) en la variabilidad de la CV infantil.

- Un efecto predictivo general de los recursos para el desarrollo de la resiliencia (familiar, personal y social) sobre los dominios de CV infantil.

- Un efecto predictivo específico de los recursos para el desarrollo de la resiliencia social sobre los dominios de CV infantil.

- Un efecto predictivo bajo de la dimensión de diversidad de participación sobre la CV infantil, que aumenta al combinarse con las dimensiones de resiliencia infantil.

» Por su parte, los análisis de moderación para el estudio de la influencia de terceras variables en los efectos directos hallados de la resiliencia social sobre la CV infantil, resaltan:

- La existencia de un mecanismo de resiliencia promotor de la CV infantil. En este mecanismo la diversidad de participación en actividades extraescolares de tipo formal e informal actúa sobre el bienestar infantil percibido, a través de su interacción con los recursos sociales para el desarrollo de la resiliencia. 
- Concretamente, en este mecanismo la resiliencia social funciona como predictor de la CV infantil, mientras que la diversidad de participación en actividades de ocio y tiempo libre actúa como estrategia que modera el impacto de este factor sobre la CV infantil.

- Los efectos de moderación tiene lugar a partir de la combinación de los diferentes niveles de diversidad de participación en actividades de tipo formal e informal y el grado de resiliencia social percibida por los niños.

- La influencia de esta interacción sobre el bienestar infantil aparece específicamente en los entornos social y escolar de los niños.

- En el entorno social, los niños con una diversidad de participación más baja son aquellos que más se benefician del impacto que los recursos sociales para el desarrollo de la resiliencia tienen sobre el bienestar social percibido.

- En el entorno escolar, los niños con una diversidad de participación mayor son los que más se benefician del efecto que los recursos sociales para la resiliencia tienen sobre el bienestar escolar percibido.

- En el contexto escolar se observa además un efecto diferencial entre alumnos con NEAE y sin ellas.

- Mientras que, en el grupo de alumnos con NEAE el efecto de moderación sobre el bienestar escolar se da cuando participan en actividades de ocio de tipo formal, en el grupo de alumnos sin ellas aparece cuando lo hacen en actividades de tipo informal.

El trabajo de investigación de la parte empírica de esta tesis doctoral aporta información relevante al estudio del bienestar y desarrollo infantil positivo. En concreto, los resultados obtenidos suponen un avance científico en el estudio de la CV y crecimiento positivo de alumnos de Primaria con NEAE y sin ellas, dentro del contexto educativo español. En síntesis, esta tesis doctoral permite disponer en España de una herramienta con suficientes garantías psicométricas para evaluar la resiliencia en población infantil con 
condiciones diversas de vida, la CYRM-22 (Ruiz et al., en presa). Ofrece información sobre qué variables del entorno personal, familiar y escolar actúan como barreras o facilitadores para el desarrollo positivo de alumnos con NEAE y sin ellas, a través de sus resultados personales en $\mathrm{CV}$, recursos para el desarrollo de su resiliencia y participación en actividades diversas de ocio y tiempo libre. Así como, qué interacciones se establecen entre sus resultados personales en estas tres variables y cuáles de ellas dan lugar a vías que fomentan trayectorias de desarrollo basadas en el bienestar y crecimiento infantil positivo. El conocimiento generado en esta investigación resulta de gran utilidad para el ámbito de la intervención infantil y tratamiento de buenas prácticas basadas en la evidencia científica.

\subsection{Implicaciones Prácticas}

Los resultados de esta tesis doctoral representan una guía significativa para la orientación de profesionales implicados en el desarrollo infantil desde diversos ámbitos de acción, tales como, el educativo, el sanitario, el comunitario y/o el social.

Tanto a nivel teórico, como empírico, este trabajo proporciona conocimiento nuevo al campo de la CV y desarrollo infantil positivo, dejando la puerta abierta a la investigación futura para su profundización y análisis. En este sentido, entre las principales implicaciones científicas de este trabajo destacan las siguientes.

»La aportación realizada al estudio de la resiliencia infantil en España. Primero, a través de un exhaustivo trabajo de revisión teórica de la literatura internacional especializada en el tema. Segundo, mediante el trabajo empírico realizado para la adaptación y validación de la CYRM28 (Ungar et al., 2011) a contexto infantil español, que ha dado como resultado la medida de resiliencia infantil CYRM-22 (Ruiz et al., en prensa), adaptada a población española de alumnos de Primaria con NEAE y sin ellas. 
» La contribución al aumento del conocimiento sobre variables personales y ambientales que influyen en los resultados personales de niños en condiciones diversas de vida, tales como los alumnos de Primaria con NEAE y sin ellas. El análisis de estas variables ha posibilitado la elaboración de un listado de factores que actúan como barreras y/o facilitadores de la $\mathrm{CV}$, recursos para la resiliencia y participación en actividades de ocio y tiempo libre en población infantil española (Tabla 36).

»El inicio de una línea de investigación basada en el análisis de los procesos subyacentes que dan lugar a trayectorias infantiles de desarrollo positivo, a través del estudio de las relaciones e interacciones existentes entre los resultados de bienestar, resiliencia y participación de niños en condiciones de vida diversas.

A nivel empírico, los resultados alcanzados son de utilidad para la ejecución de cambios en la planificación de estrategias, recursos y programas educativos capaces de generar mejoras en contextos, tales como, el sistema educativo español y los centros escolares de enseñanza ordinaria asociados a él. En esencia, esta tesis doctoral ha puesto en evidencia que para la consecución de resultados positivos en desarrollo infantil, las intervenciones tienen que pasar de un enfoque basado en el tratamiento individual de problemáticas comportamentales y compensación de déficits individuales, a una visión más amplia orientada al cambio e innovación de las ecologías sociales en las que tienen lugar los procesos de desarrollo infantil más relevantes (Geldhof et al., 2014).

Como se ha argumentado a lo largo de este trabajo, un marco ecológico de desarrollo sostiene que la familia, la escuela, el vecindario y sus contextos socioculturales más amplios, actúan como factores de promoción e inhibición del desarrollo infantil positivo (Smith et al., 2017). Aplicar este paradigma al sistema educativo, precisa extender las intervenciones psicológicas escolares, desde el tratamiento de casos individuales hacía las ecología de las escuelas, atendiendo a los esfuerzos sistémicos que influyen en los factores contextuales que posibilitan el éxito en el desarrollo integral de todos los alumnos (Doll y Cumming, 2008). 
Para concretar el alcance práctico de las evidencias obtenidas en la presente investigación, a continuación se expone una serie de implicaciones prácticas aplicadas al cambio de paradigma educativo, desde el impulso de intervenciones escolares biopsicosociales orientadas a la calidad de vida y desarrollo infantil pleno.

»Intervención temprana basada en la promoción del desarrollo infantil positivo. Gran parte de los problemas sociales y de salud más graves que enfrentan las sociedades actuales, derivan de los patrones comportamentales establecidos durante la juventud (Kolbe, Kann, Everett y Hannan, 1997; Pearrow y Jones, 2020; Ten-Hove et al., 2018). Estos patrones tienen su origen en la exposición prolongada a experiencias infantiles adversas, las cuales conllevan un riesgo en el incremento de problemas conductuales, así como una amplia variedad de resultados negativos relacionados con desajustes en la salud física, psicológica y social de los menores, la disminución de su satisfacción vital, así como la reducción de los resultados positivos en el ámbito escolar (Anda, Chapman, Felitti, Edwards, Williamson, Croft y Giles 2002; Orosová, 2017; Samerroff et al., 2003; Wyman, 2003). Dentro del sistema educativo convencional, estos menores son identificados en la mayoría de los casos como alumnos con necesidades específicas de apoyo educativo, siendo derivados de manera desproporcionada a instalaciones profesionales para el tratamiento clínico e individual de sus necesidades. Una gestión eficiente de esta problemática social requiere la puesta en marcha de intervenciones tempranas basadas, no lo solo en la prevención de comportamientos problemáticos, sino también en la promoción de las fortalezas infantiles (Ten-Hove et al., 2018).

»Optimización de recursos educativos y coordinación con organizaciones proveedoras de servicios, para ampliar la red de acción escolar dirigida a la promoción del desarrollo infantil íntegro y saludable. Como institución gubernamental, el sistema de educación público es el que mayor inversión local, 
comunitaria y nacional realiza (MECD, 2019). Bien organizados y estructurados estos recursos económicos permiten optimizar el funcionamiento positivo desde intervenciones tempranas y acciones de prevención, así como abordar problemas personales y ambientales que interfieren en el desarrollo infantil íntegro y saludable. Para aquellas áreas del desarrollo infantil que típicamente quedan fuera del alcance del sistema educativo formal, la escuela como estructura educativa tienen el potencial de ampliar sus redes de acción hacia servicios alternativos a ella que proporcionen a sus alumnos los recursos de salud, educación y bienestar necesarios para su desarrollo vital. Esto se consigue, a través de la colaboración con instituciones sociales y comunitarias cuyas líneas de trabajo y herramientas dan forma a los servicios requeridos para responder a aquellas áreas del desarrollo infantil a las que el sistema educativo ordinario no puede proporcionar, de manera efectiva y permanente, los servicios de apoyo correspondientes (Pearrow et al., 2020). Al aumentar la cantidad de recursos disponibles y accesibles, la escuela aumenta también su competencia para actuar sobre los factores de riesgo presentes en los entornos de desarrollo infantil, la capacidad de fortalecer los factores promotores del crecimiento infantil positivo y la facultad de responder de una forma más integral a las necesidades específicas de la diversidad de su alumnado.

» Detección e intervención escolar de barreras y facilitadores para el desarrollo infantil positivo de todos los alumnos. Esta indicación se refiere a la creación de entornos seguros, a través de la detección y eliminación de barreras físicas, actitudinales y sociales, para la promoción de ambientes escolares positivos y de apoyo en los que se potencien los factores que promueven la resiliencia y el bienestar infantil (Hinduja y Patchin, 2017; Lerner et al., 2015), a través del fomento de un clima escolar positivo que ayude al desarrollo personal y social de la diversidad del alumnado (Gaias, Lindstrom, White, Pettigrew y Dumka, 2019; Luengo-Kanacri et al., 2017). 
Para ello, es necesario realizar un análisis inicial acerca de todos los aspectos referentes al proceso de desarrollo infantil, el contexto en el que tiene lugar y las características de cada niño (OMS, 2001, 2007), con objeto de conocer los factores protectores o de riesgo presentes en cada nivel de desarrollo (Eichas et al., 2017; Souza et al., 2015), así como la planificación y puesta en marcha de programas educativos que tengan en cuenta los aspectos comunes y particulares de cada uno de los sistemas intervinientes (Bronfrenbrenner, 1979, 2002; Geldhof et al., 2014).

\section{»Atención a la diversidad desde métodos de salud pública} preventivos impulsados desde la escuela. Integrar recursos de salud y comportamiento pro-social dentro de la escuela, gestionados por servicios de alta calidad a los que puedan acceder todos los alumnos, resulta de gran relevancia para aquellas escuelas formadas por comunidades de alumnos que experimentan disparidades en el acceso a los servicios sociales emitidos por diferentes organismos públicos y privados (Anderson y Cardoza, 2016). En concreto, la promoción de la calidad de vida y desarrollo infantil positivo requiere de métodos de salud pública basados en la prevención, que pongan al servicio de la comunidad educativa prestaciones y recursos públicos que promuevan resultados personales significativos y prevengan de problemas a alumnos y familiares (Cummings et al., 2004). Para ello es necesario la planificación, organización e implementación de un modelo de salud pública para la prevención, centrado en el cambio de comportamientos a nivel poblacional, detección y manipulación de factores del contexto asociados al funcionamiento saludable y a los procesos de desarrollo positivo que mitigan la incidencia de trastornos e incrementan los resultados de salud de la población en general (Winslw, Sandler y Wolnick, 2005). La coordinación eficiente de escuelas e instituciones externas a ella, permite la puesta en marcha de intervenciones sistémicas para el apoyo universal de las necesidades de todos los agentes intervinientes en el desarrollo infantil. 
»Promoción del bienestar y funcionamiento saludable de la comunidad escolar desde la intervención sistémica. Para el desarrollo de intervenciones sistémicas, basadas en aproximaciones holísticas, se requiere definir bien las funciones de los sistemas intervinientes, tales como, el colegio, la familia o la comunidad (Hatzichristou, Issari, Lykitsakou, Lampropoulou y Dimitropoulou, (2011). Este tipo de intervenciones multinivel tienen el objetivo de promover un clima positivo y sentido de comunidad escolar, que nazca del ambiente creado entre estudiantes, familias, profesores y otros trabajadores escolares (Doll, Pfohl, y Yoon, 2010). Por tanto, para la provisión de servicios de calidad en el contexto escolar, no solo es necesario aunar el trabajo entre diferentes instituciones relacionadas con el desarrollo infantil, sino también mejorar la colaboración interna de todos los miembros de la comunidad escolar. Las intervenciones socio-ecológicas exitosas incluyen programas de varios años, llevados a cabo en interacción con otros sistemas comunitarios, que ponen en marcha estrategias centradas en la promoción de la salud en vez de la prevención de la enfermedad, involucrando para ello a todo el sistema escolar, lo que provoca cambios infantiles positivos en ambientes familiares y escolares (Greenberg, et al., 2003; Luengo-Kanacri et al., 2017). Dado que, la investigación ha detectado también la dificultad de la generalización de los resultados de las intervenciones escolares a otros ámbitos de desarrollo, por parte de poblaciones de alumnos de mayor edad (Joseph, 2015), se requiere el inicio de estas intervenciones preventivas a edades tempranas tal como se ha recomendado con anterioridad (Ten-Hove et al., 2018).

»Desarrollo de intervenciones sistémicas basadas en la evidencia científica, así como en la evaluación y reajuste permanente de sus procesos. Dadas las peculiaridades de cada comunidad escolar, además surge la obligación de hacer una evaluación inicial de necesidades y prioridades particulares de su contexto escolar (Booth, 2002, 2015), con la finalidad de ajustar las intervenciones 
multinivel a las características propias de su entorno, así como una evaluación final de la eficacia de las acciones realizadas, utilizando modelos, métodos e instrumentos basados en la evidencia científica previa (Hatzichristou, Lampropoulou y Lykitsakou, 2006). En este sentido, la investigación ha demostrado como las intervenciones basadas en procesos dinámicos a largo plazo, que vinculan la teoría con la práctica, la evaluación periódica de necesidades, el análisis e integración de nuevos elementos teóricos y metodológicos, la retroalimentación y el reajuste de los programas implementados, basado todo ello en el conocimiento empírico existente, impactan directamente sobre las dimensiones psicológicas de la comunidad escolar en su conjunto (Doll et al., 2010).

»Evolución del enfoque clásico de tratamiento psicológico de déficits individuales al fortalecimiento de las ecologías de las escuelas. En este enfoque sistémico el foco pasa del individuo al ambiente, centrando la intervención psicológica en objetivos de identificación y tratamiento de procesos que tienen lugar a nivel individual, familiar, escolar y comunitario (Hess, Short, y Hazel, 2012; Nastasi, Hart y Naser, 2020). Como ejemplo cabe citar el Modelo Escolar de Bienestar Comunitario, centrado en el cambio de las prácticas psicológicas escolares y prestación de servicios para la promoción de la resiliencia y el bienestar de la comunidad escolar (Hatzichristou, 2002). Para la implementación de este modelo se requiere una transición de las tareas tradicionales de clasificación, evaluación e intervención educativa a nivel individual, a la provisión de servicios psicológicos alternativos centrados en la sostenibilidad del sistema escolar y la satisfacción global de sus miembros (Booth, 2002, 2015; Muntaner et al., 2010). Al actuar como instituciones comunitarias las escuelas poseen una constelación única de oportunidades para la promoción del desarrollo infantil saludable. Sin embargo, para alcanzarlo necesitan desarrollar su capacidad intrínseca de nutrir los activos personales y recursos sociales que favorecen el crecimiento de la resiliencia de la 
comunidad escolar como una unidad propia (Pearrow et al., 2020). Estos programas se asientan en un sistema organizado de profesionales debidamente formados y equipados para la respuesta preventiva a las problemáticas presentes en las ecologías sociales de los más jóvenes. Tal y como se ha demostrado en esta tesis doctoral, un recurso esencial es el apoyo social, el cual se consigue a través de intervenciones dirigidas a la orientación de actitudes y respuestas positivas entre compañeros, maestros y resto de miembros de la comunidad educativa (Smith et al., 2017; UNICEF, 2013).

» Fomento de la inclusión, formación y participación activa de los docentes en las intervenciones sistémicas. Dentro del entorno escolar los educadores y profesionales escolares tienen la posibilidad y responsabilidad de implementar intervenciones universales para promover los factores asociados al bienestar y desarrollo positivo de todos sus alumnos (Smith et al., 2017). Una estrategia valida es apoyar el desarrollo de la resiliencia de los maestros (Van Rensburg, Theron, Rothmann, 2018), para que éstos incluyan en sus prácticas educativas el apoyo preventivo a sus alumnos, desarrollen una comunicación constructiva con ellos y sean proactivos hacia el cambio de paradigma educativo. En este sentido, la investigación resalta el impacto positivo que tiene en los resultados personales de los alumnos el hecho de que sean sus propios maestros quienes implementan los programas para el desarrollo infantil positivo dentro de sus aulas, en contraposición a cuando los realizan profesionales con profundo conocimiento en la materia pero ajenos a la escuela (Mackenzie y Williams, 2018).

» Implementación de programas escolares para el desarrollo infantil positivo desde un enfoque socio-ecológico. Los programas escolares para el desarrollo positivo se orientan a la adquisición de activos personales (habilidades personales y sociales, por ejemplo), a través del aumento de relaciones positivas, apoyos sociales y oportunidades que fortalecen y ayudan a los menores a florecer 
en sus entornos cercanos, así como a influir en ellos mejorándolos (Taylor, Oberle, Durlak y Weissberg, 2017). Existen una gran variedad de programas educativos orientados al bienestar y desarrollo infantil pleno que han demostrado el éxito de la intervención escolar desde una perspectiva sistémica (Belgrave et al., 2004; Eichas et al., 2017; Gresham et al., 2004; Jafar, 2018; Kremer et al., 2015; LuengoKanacri et al., 2017; Mahoney, Lord y Carryl, 2005b; Monjas, 2007; Pierce et al., 2010; Tebes et al., 2007). La finalidad general de estos programas es aumentar la contribución de los jóvenes a sus ecologías sociales, al mismo tiempo que se potencian sus activos y disminuye la probabilidad de comportamientos problemáticos que afectan a su desarrollo positivo (Geldhof et al., 2014). A continuación se describen tres de las múltiples aplicaciones terapeutas existentes en la literatura cientifica sobre desarrollo infantil positivo.

- El Let Art Unleash Great Happiness Time - LAUGH-Time (Pearrow et al., 2020). Es un programa que mezcla las técnicas de atención consciente del midnfulness con la expresión artística, a través de medios tecnológicos. Su objetivo es trabajar la concentración, la creatividad y el sentido de autocontrol con la finalidad de incrementar el bienestar y el desarrollo de la resiliencia infantil. Para ello los alumnos participan en un programa de actividades, durante un curso escolar, que involucra la tecnología, el arte y la atención plena dentro del aula. Los resultados iniciales del programa muestran su impacto sobre la motivación de los estudiantes hacia el aprendizaje y la mejora de los niveles de estado de ánimo y alegría en el conjunto de alumnos participantes.

- El Programa para la Promoción de la Salud Mental y el Aprendizaje PPMHL (Hatzichristou et al., 2011). Se trata de una intervención multinivel enfocada a la promoción del bienestar personal y aprendizaje de los alumnos, y al desarrollo del clima y sentido de comunidad escolar. Incluye un programa para el desarrollo de competencias personales socioemocionales, mejora de las 
relaciones personales, promoción de la resiliencia del aula. Así como métodos para el fomento de ambientes saludables entre alumnos, familiares y profesionales escolares. Los resultados muestran efectos significativamente positivos y beneficios en los diferentes niveles intervenidos. A nivel personal, los alumnos participantes mejoran la expresión de sentimientos, la comunicación y socialización en el aula, el conocimiento de sus fortalezas personales y la ejecución de las actividades académicas, con independencia de sus diferencias personales, sociales y/o culturales. A nivel sistémico, el PPMHL muestra potencial para producir mejoras en las dinámicas escolares que intervienen en el clima y sentido de comunidad escolar. Estos indicios de cambio son más evidentes conforme va aumentando el tiempo de aplicación del programa.

- El Programa de Futuros Resilientes (Raymond, Iasiello, Jarden y Kelly, 2018). Se trata de una intervención basada en el desarrollo de fortalezas, realizada desde un marco ecológico de psicología positiva y fundamentada en la evidencia científica multidisciplinar. Su objetivo es el desarrollo de habilidades para el bienestar y la resiliencia infantil, a través de métodos de enseñanza explícitos (realización de actividades) e implícitos (gestión de casos individuales), con la finalidad de reducir las desventajas entre iguales y fortalecer el compromiso de su contexto educativo. Los resultados iniciales muestran un efecto moderado, pero significativo, del programa en los resultados personales de los alumnos participantes, con diferencias significativas entre grupos específicos: mayores beneficios en chicos que en chicas y en el grupo de menores con posiciones iniciales más desfavorecidas, en relación a sus compañeros con posiciones más positivas. Dichas diferencias demarcan la necesidad de ampliar la investigación sobre los efectos específicos del programa en grupos de alumnos con condiciones diversas. 
»Flexibilidad de las intervenciones para actuar sobre las características de los diferentes niveles de los sistemas en los que intervienen. Las escuelas pueden incorporar este tipo de programas de prevención, estableciendo rutinas de participación que benefician al conjunto de los estudiantes. Sin embargo, dada la diversidad de contextos escolares, los componentes de los programas de prevención deben adaptase a las características específicas de los sistemas participantes (niño, aula, escuela, comunidad educativa). Así por ejemplo el LAUGH-Time, aunque es un programa orientado al grupo de clase, tiene la capacidad multimodal de dirigirse a la intervención individual cuando un alumno en particular experimenta alguna desregulación emocional, ayudándole a restaurar la calma y volver a participar en los procesos de aprendizaje del aula (Pearrow et al., 2020).

»Inclusión de la dimensión cultural para la comprensión de la diversidad del alumnado en las escuelas. Con objeto de comprender la diversidad humana de las escuelas, en este cambio de paradigma educativo enfocado a la promoción de factores asociados a la calidad de vida y desarrollo infantil positivo, se requiere incluir en el análisis socio-ecológico las distintas dimensiones intervinientes, incluida la dimensión cultural. Según Hatzichristou (2004) a nivel individual, la diversidad esta enlazada con las características personales de los alumnos (física, cognitiva, académica, personalidad, estilo de aprendizaje, intereses, etc.). A nivel familiar la diversidad se representa en las diferencias en el estatus socioeconómico, la estructura y el estilo familiar, así como en el ambiente parental. La diversidad referida a las escuelas incluye diferencias en el clima escolar, la comunicación, organización administrativa y las características comunitarias. Por último, a nivel de servicios, la diversidad se refiere al cambio en el enfoque de los servicios educativos ofrecidos, dirigiendo el foco hacia una visión cultural centrada en la comprensión de las necesidades universales de los alumnos y generación de respuestas específicas para 
aquellos con mayor necesidad. Este nuevo enfoque requiere adaptar la forma de implementar las intervenciones escolares, a través de programas escolares universales y selectivos, servicios de tratamiento individual, entre otros (Hatzichristou et al., 2006), a los distintos niveles en los que se interviene.

»Generalización de las intervenciones sistémicas para el desarrollo infantil positivo a diversos contextos socioecológicos. Los principios de intervención sistémica propuestos para el ámbito educativo pueden ser aplicables a diferentes contextos en los que tiene lugar la interacción del niño con su ambiente, tales como, el sistema social, comunitario o cultural. Teniendo en cuenta siempre las necesidades y características particulares de cada uno de ellos, y ajustando el diseño y la implementación de los programas a dichas peculiaridades (Taylor et al., 2017). Se basa en una perspectiva metacultural que atiende a la diversidad humana y sus necesidades comunes, centrada en las similitudes de las culturas y de los individuos, al tiempo que considera el potencial positivo de las competencias personales y las fortalezas del ambiente para promover el bienestar de los sistemas y su crecimiento sostenible (Lerner et al., 2009).

En resumen, en el ámbito escolar, las intervenciones sistémicas enfatizan las fortalezas personales, los procesos de resolución de problemas, la mejora de habilidades sociales y emocionales, la promoción de los distintos niveles sistémicos de resiliencia, el fomento de cambios contextuales que contribuyen al funcionamiento de la comunidad escolar (clima escolar, sentido de comunidad, bienestar y resiliencia del aula) como un entorno de vida saludable. (Doll et al., 2010). Este tipo de intervenciones proporcionan el contexto idóneo para la promoción de los factores asociados al bienestar infantil sostenibles a lo largo del tiempo (Oshri et al., 2017), permitiendo incorporar al sistema educativo los fundamentos e innovaciones de los constructos de calidad de vida, resiliencia y participación en actividades diversas, defendidos en esta tesis doctoral. Lo que se consigue enlazando la teoría, la investigación y la práctica educativa para proveer de servicios 
que incluyan la evaluación psicológica, la intervención preventiva, el asesoramiento y formación profesional, así como la gestión, supervisión y defensa de la calidad de vida y el desarrollo infantil pleno (Hatzichristou, 2004).

Aplicar a las escuelas el modelo teórico de calidad de vida y factores determinantes para el desarrollo de la diversidad del alumnado defendido en esta investigación, requiere un cambio paradigmático en los estándares teóricos y prácticos de educadores, líderes políticos y comunidad en general, así como en la ordenanza que regla actualmente el sistema educativo ordinario de nuestro país (Ley Orgánica 8, 2013). Desde el conocimiento generado en este trabajo de investigación se resalta la importancia de: a) incluir la aproximación sistémica (social, cultural, étnica y ecológica) a la evaluación y a la intervención psicológica en el ámbito escolar, b) hacer evolucionar los roles y funciones de los miembros de la escuela en las áreas de la investigación, la formación y la práctica educativa, y c) generar una aproximación ecológica a la formación de los profesionales docentes y de la identidad de la psicología en el ámbito escolar (Doll et al., 2010; Hess et al., 2012; Nastasi et al., 2020).

Utilizar el modelo de factores determinantes de la calidad de vida de alumnos con necesidades específicas de apoyo educativo y sin ellas, como marco conceptual para la identificación de los factores protectores potenciadores del desarrollo infantil positivo (Hamby, Grych y Banyard, 2018), requiere a su vez comprender las características y necesidades de niños desde una lente ecológica, es decir, de acuerdo con las raíces psicológicas positivas presentes en la interacción dinámica entre el niño y su ambiente. Lo que significa llegar a un enfoque de contenido que apunte a la consecución de resultados significativos en bienestar, resiliencia y comportamiento infantil saludable desde el fortalecimiento de los recursos ambientales presentes en sus entornos de desarrollo próximos (Durlak, Weissberg, Dymnicki, Taylor y Schellinger, 2011).

Estos cambios deben centrarse en el análisis de aquellos resultados personales que son significativos para los propios niños, así como en el 
impacto que los diferentes factores presentes en sus contextos de desarrollo tienen sobre las variaciones de estos resultados, dependiendo del efecto facilitador o limitador que estos factores ejercen sobre la interacción que cada niño mantiene con su medio ambiente. A continuación se presentan con más detalle algunas de las implicaciones prácticas que, a nivel individual, tienen los hallazgos de esta investigación en los resultados personales de los propios niños.

»Inclusión y participación activa del alumnado en los procesos educativos orientados a su desarrollo vital. Es necesario involucrar a los niños como expertos de su propia experiencia en la planificación e implementación de las prácticas educativas escolares (Rebekah, Walsh y Baird, 2016). Su inclusión en los procesos de organización y ejecución de programas para el desarrollo afecta positivamente al compromiso del niño en la realización de actividades (Nielsen, Mushin y Nielsen, 2017; Majnemer et al., 2010; Pearrow et al., 2020), e impacta sobre sus niveles de participación en actividades diversas (Everley y Macfadyen, 2015; Raymond et al., 2018), desarrollo de las fuentes de resiliencia (Edbom, et al., 2010; King et al., 2003; Imms et al., 2016b; Imms et al., 2017) y bienestar infantil (Almqvist et al., 2006; Bult et al., 2014; Shikako-Thomas et al., 2012). Para ello, y tal como se ha evidenciado en esta tesis, es preciso conocer qué experiencias de vida son importantes y significativas para ellos, qué factores y procesos contribuyen a su adaptación y bienestar (Oshri et al., 2017), así como en qué medida estos son similares o diferentes a los de la población infantil general u otras poblaciones específicas de niños.

\section{»Atención a las preferencias de participación infantil para el fomento del aprendizaje personal y cooperación social.} Aumentar el acceso a una amplia variedad de actividades basadas en el ocio y tiempo libre atendiendo a las preferencias informadas por los menores (ir en bicicleta, hacer deportes de equipo o individuales, recibir clases de arte, de música o de danza, etc.) (Bult et al., 2014; 
Kantomaa et al., 2011), abre vías significativas para el aprendizaje y mantenimiento de competencias personales y sociales, desarrollo de sentimientos de valía y autoeficacia, fomento de la interacción entre iguales y de vivencias compartidas de reciprocidad y confianza, así como la formación de grupos de amigos en los que los niños aumentan su capital social, referido a la riqueza de sus relaciones (Bandura, 1986; Mahoney, Larson y Eccles., 2005a; Rebekah et al., 2016).

»Fomento de las relaciones socio-emocionales entre los miembros de la comunidad educativa, en especial entre docentes y alumnos. Para incluir en el capital social del niño las relaciones con sus maestros, es necesario la interacción positiva del docente con sus alumnos. Para ello, se requiere que los profesionales de la educación conozcan las diferencias sociales y culturales que afectan a sus alumnos y familias, y cómo esta diversidad enriquece a las escuelas. Esto se consigue incluyendo en los currículos escolares: a) procesos de enseñanza basados en el compromiso, motivación y aprendizaje activo de los alumnos; b) cooperación con asociaciones familiares para la implicación familiar; c) servicios de prevención basados en la evidencia científica; d) programas adaptados a la diversidad del alumnado basados en el aprendizaje socio-emocional de la comunidad escolar, etc. (Macklem, 2014; Taylor Oberle, Durlak y Weissberg, 2017). En definitiva, involucrándose de forma activa en los procesos de cambio e innovación educativa defendidos a lo largo de este apartado.

»Aumento de la calidad de los entornos próximos de desarrollo desde la potenciación del apoyo social entre iguales. A nivel específico, dadas las diferencias halladas entre alumnos con NEAE y sin ellas en sus resultados personales de bienestar y resiliencia, se requiere trabajar sobre el aprovechamiento de aquellos activos y recursos que respondan a las necesidades personales y carencias sociales de cada alumno (Ponce-Meza, 2017). Para ello, se debe tener en cuenta la relevancia que la calidad de sus entornos próximos de desarrollo tiene sobre su crecimiento 
positivo (Camargo et al., 2012; Smith et al., 2017), lo que desde el paradigma socio-ecológico defendido se fundamenta en aumentar las relaciones positivas, los apoyos sociales y las oportunidades que fortalecen y ayudan a los menores a crecer entre iguales de forma saludable (Lerner et al., 2009; Snyder Hemmeter, ArtmanMeeker, Kinder, Pasia y McLaughlin, 2012; Taylor et al., 2017). En esta línea, la implementación de programas DP, como los presentados en esta investigación, los cuales buscan las vías que conectan a las personas con sus contextos, permiten la mejora de las fortalezas personales, así como la creación de entornos atractivos de apoyo que ofrezcan oportunidades para la interacción bidireccional y constructiva entre el niño su ambiente (Lerner et al., 2002, 2004; Lerner et al., 2015).

Acceso y disponibilidad en las escuelas de una amplia gama de actividades diversas, complementarias al currículo escolar, para facilitar la participación infantil de todos los alumnos. A continuación de presentan evidencias científicas acerca de los programas enfocados en la participación infantil, como ejemplo de intervenciones positivas que impactan significativamente en el bienestar y desarrollo infantil saludable:

- La disponibilidad en las escuelas de programas estructurados de participación en actividades de tipo físico está demostrando su efectividad en la consecución de resultados positivos en interacción social y desarrollo de habilidades sociales y de comunicación en poblaciones infantiles específicas, tales como los niños con trastorno del espectro autista (Jafar, 2018), con discapacidades físicas (Bult et al., 2011; Bult et al., 2014; Shikako-Thomas et al., 2008) y otras necesidades especiales (Di Marino, Tremblay, Khetani y Anaby, 2018).

- El acceso a actividades de tipo recreativo y extracurricular, desarrolladas como un servicio educativo relacionado a la escuela, favorece la calidad de vida de alumnos con necesidades especiales, que 
se refleja en sus niveles de bienestar físico, emocional, participación social e independencia (Diodati, 2018), así como la cohesión entre iguales en general (Oberle, Ji, Magee, Guhn, Schonert-Reichl y Gadermann, 2019).

- La participación de menores entre 8 y 14 años de edad en actividades artísticas y físicas como el circo, aumenta los niveles de bienestar psicológico, disfrute de la participación, socialización entre iguales y resiliencia infantil (Joseph, 2019).

- Incluir en los currículos escolares actividades de aprendizaje al aire libre, tal como, actividades deportivas, recreativas, artísticas, entre otras, impacta positivamente sobre el bienestar y desarrollo infantil de los alumnos. Con respecto a los resultados personales de los niños, la investigación ha evidenciado cómo realizar actividades al aire libre fomenta la salud física, mental y el bienestar general, el compromiso hacia la educación, aprendizaje permanente, la responsabilidad sobre el medio ambiente y la ciudadanía activa, reduce los problemas de conducta y los comportamientos antisociales, entre otras cualidades, potenciando de forma general el desarrollo infantil personal y social de sus participantes (Bragg, Wood, Barton y Pretty, 2015; Eigenschenk et al., 2019; Piccininni, Michaelson, Janssen, y Pickett 2018; Roberts, Hinds y Camic, 2019).

»Instrucción directa y explicita para el éxito de la participación y mejora de las interacciones sociales entre la diversidad infantil. Para el éxito de las intervenciones, la participación en este tipo de actividades y programas requiere a su vez la instrucción directa y explicita en poblaciones de niños con necesidades especiales (Barton, 2015; Nelson, McDonnell, Johnston, Crompton y Nelson, 2007; Rogers, 2000), así como la instrucción de sus iguales sin ellas, lo que conlleva tanto la participación significativa de todos ellos, como la adquisición y generalización de interacciones sociales positivas entre iguales (Buchter, 2020). Aunque un programa por sí solo no puede ofrecer todas las oportunidades de desarrollo y 
los apoyos que en general los jóvenes necesitan para crecer de forma positiva (Koller et al., 2017), sí ofrece vivencias y estrategias que los prepara para una vida futura significativa y de bienestar (Leman et al., 2017). Por tanto, la instrucción directa y explicita para la participación significativa en estos programas, supone una estrategia para combatir los efectos negativos que la falta de inclusión tiene el desarrollo potencial del niño, asociados a su vez al deterioro y aparición de nuevos problemas y barreras que condicionan el éxito de sus trayectorias de vida (Cacioppo, 2002; Gorter et al., 2011; Gresham et al., 2004).

Dado que, cuantos más recursos (claridad e implicación de los profesionales de la atención primaria, participación significativa en actividades diversas, apoyo de la comunidad escolar, relación positiva entre compañeros, etc.) interactúan solidariamente mayores son los resultados de desarrollo infantil positivo (Border, 2005), se hacen imprescindibles más esfuerzos comunitarios, que integren fórmulas políticas, educativas y sociales, dirigidos al progreso de una estructura organizativa que ofrezca servicios escolares de calidad. Estos servicios deben de estar unidos a una red social fuerte y a un apoyo administrativo comprometido, que favorezca la superación de barreras y la implementación exitosa de programas educativos centrados en la obtención de resultados personales significativos en la diversidad del alumnado (Durlak et al., 2011).

Con referencia a esta tesis doctoral, su investigación ha desvelado que atender a la resiliencia social de los niños en contextos sociales y escolares, a través de la modulación de su participación en actividades extraescolares de tipo formal e informal, tiene un efecto potenciador en el bienestar y la satisfacción vital que los menores perciben en dichos contextos de desarrollo (Koller et al., 2017, Lerner et al., 2015; Taylor et al., 2017). Según la UNESCO (2005) centrarse en la consecución de resultados personales significativos de bienestar, participación y resiliencia es una técnica de intervención que enfatiza el potencial y bienestar humano. Por lo que, conocer y comprender las vías que dan accesos al desarrollo infantil positivo sirve a los profesionales del campo de la educación de herramienta mediante 
la cual fomentar el bienestar personal y social de sus alumnos (Albertín et al., 2013; CIF-NJ, 2007; Mahoney et al., 2005a; Shikako.Thomas et al., 2012), a través de sus resultados personales significativos, tales como los evidenciados en este trabajo de investigación.

\subsection{Limitaciones y Pasos Futuros}

Pese a la potencialidad teórica y práctica de los resultados obtenidos en esta investigación, estos se deben interpretarse a la luz de algunas limitaciones.

Con respecto a la versión adapta de la escala de resiliencia CYRM-22 (Ruiz et al., en prensa), el reducido rango de edad de los participantes (de 10 a 12 años), el limitado tamaño muestral $(\mathrm{N}=374)$, la restringida representatividad española de la muestra (2 Comunidades Autónomas), así como el carácter semi-confirmatorio de los análisis factoriales realizados, limita la generalización de sus resultados a población infantil española. Estas limitaciones conllevan la necesidad de seguir investigando la validez de la escala con muestras más representativas de la población objeto de estudio, así como procedimientos estadísticos más robustos (Martínez-Arias, 2014).

Sin embargo, más allá de estas limitaciones, los primeros resultados de la CYRM-22 (Ruiz et al., en prensa) resultan de interés para la ampliación del conocimiento profesional acerca de la visión que el niño tiene sobre los recursos personales y ambientales que sus entornos de desarrollo próximo les ofrece para su crecimiento positivo, el cual tiene el potencial de facilitar la programación y desarrollo de intervenciones infantiles significativas para sus participantes.

Por su parte, las limitaciones más evidentes halladas en el estudio sobre el papel que las variables de tipo personal y ambienta juegan sobre los resultados personales de bienestar, resiliencia y participación de alumnos con NEAE y sin ellas, han sido el carácter voluntario de los participantes (alumnos, profesores y familiares) lo que limita nuevamente la generalidad de los resultados al resto de población infantil española. La deseabilidad social hallada en las respuestas dadas por los participantes adultos, debido en parte 
al carácter auto-administrado de los cuestionarios, lo cual ha conllevado una escasa variabilidad de respuesta con la consiguiente pérdida de información en el estudio de barreras y facilitadores para el bienestar y desarrollo infantil positivo. Así como, el uso de análisis estadístico de tipo no paramétrico para el contraste de los datos recopilados, con la posible pérdida de potencia estadística asociada a las técnicas no paramétricas.

Dadas estas limitaciones para investigaciones futuras se recomienda, por una parte, la obligatoriedad de la participación en el estudio de toda la comunidad educativa asumida por parte de la administración educativa, y el seguimiento de un evaluador especializado en el proceso de recogida de datos tanto en el grupo de niños, como en el de participantes adultos, además de la inclusión de respuestas de valencia positiva y negativa para controlar el efecto de la deseabilidad social. Estas medidas pueden aumentar a su vez la distribución normal de los datos recogidos y por tanto el uso de pruebas para el contraste de hipótesis más robustas como son las pruebas de tipo paramétrico (Martínez-Arias, 2014).

El tamaño muestral y procedimiento incidental seguido para la recogida de los datos, afecta también al último estudio de esta tesis, en el que se ha analizado las relaciones subyacentes que se establecen entre los valores de bienestar, resiliencia y participación infantil. En particular, el diseño trasversal de esta investigación compromete las conclusiones formuladas sobre las relaciones causales entre las variables analizadas, especialmente los efectos de moderación que la participación muestra en la asociación hallada entre la resiliencia social y el bienestar infantil.

Para investigaciones futuras en esta línea de investigación se recomienda el aumento del tamaño muestral para evitar la pérdida de información en el análisis de grupos y permita, a su vez, la integración de más factores en los modelos causales y condicionales analizados a la luz de la literatura científica en desarrollo infantil positivo. Así como, el estudio longitudinal de las supuestas relaciones entre constructos y variables, que posibilite el análisis de las variaciones entre todas ellas a lo largo del tiempo (Orosová et al., 2017), con la finalidad de ahondar en el conocimiento sobre las vías que 
dan lugar a trayectorias infantiles de vida que facilitan el desarrollo positivo y el bienestar de los menores, con independencia de sus condiciones de vida asociadas.

\subsection{Conclusiones}

A lo largo de esta investigación se ha abordado de forma pormenorizada el desarrollo positivo de niños en condiciones diversas de vida. Para ello se ha analizado su calidad de vida, resiliencia y participación en actividades de ocio y tiempo libre a partir de los resultados personales significativos obtenidos en estas variables. Dichos resultados han sido interpretados en esta tesis como aquellos activos y recursos que permiten al niño navegar con éxito y negociar con sus entornos de desarrollo próximos las vías que dan acceso a un desarrollo infantil positivo y a una vida de calidad.

A partir de esta tesis doctoral se ha evidenciado la relación que se establece entre los tres constructos de interés, así como el peso que otras variables personales, familiares y escolares tienen en su variabilidad, dando lugar a factores que actúan como barreras o facilitadores de los resultados personales de alumnos con NEAE y sin ellas.

A nivel práctico, los resultados obtenidos en esta investigación, comentados desde capítulo 5 hasta este último capítulo de conclusiones, sirven de guía y criterio para evaluar las estrategias de mejora que llevan a cabo los profesiones desarrollo infantil y juvenil desde diferentes ámbitos de acción. Así como, de herramientas válidas para el campo de los servicios educativos, sociales y comunitarios, con utilidad para reconocer y responder a las diversas necesidades infantiles y juveniles, permitiendo formular nuevas propuestas prácticas dirigidas a su bienestar y capacitación para la vida adulta. Todo ello desde una aproximación de la realidad basada en modelos sistémicos y socio-ecológicos de desarrollo humano, los cuales han sido profundamente fundamentados a lo largo de este trabajo de investigación.

En definitiva el desarrollo de esta tesis doctoral ha permitido alcanzar los objetivos propuestos, posibilitando nueva y mayor información sobre 
experiencias personales que ayudan a los niños a desarrollarse de forma plena y exitosa. El conocimiento científico generado a partir de este trabajo de investigación resulta válido para la elaboración y puesta en marcha de estrategias profesionales beneficiosas para el logro de resultados de vida positivos de niños en condiciones de vida diversas.

Se alienta a los profesionales implicados en el campo del desarrollo infantil a adoptar posturas proactivas dirigidas al cambio e innovación de la intervención infantil, basándose a lo largo de este proceso en los fundamentos científicos y empíricos actualmente vigentes. Todo ello orientado a la calidad de vida y desarrollo integral de todos los menores, como ciudadanos libres de pleno derecho de las sociedades de hoy y del mañana. 


Abellán, R. M., De Haro, R., y Escarbajal, A. (2010). Una aproximación a la educación inclusiva en España. Revista de educación inclusiva, 3(1) 149-164.

Abraham, C., Gregory, N., Wolf, L., y Pemberton, R. (2002). Self-esteem, stigma and community participation amongst people with learning difficulties living in the community. Journal of Community and Applied Social Psychology, 12(6), 430-443.

Acle, T. G., y Ordaz, V. G. (2010). Resiliencia y aptitudes sobresalientes en niños de zonas urbano-marginadas. Ideacción, 31, 288-299.

Acle, T.G., y Roque, M. P. (2013). Resiliencia materna, funcionamiento familiar y discapacidad intelectual de los hijos en un contexto marginal. Universitas Psychologica, 12(3), 811-820. doi: 10.11144/javeriana. UPSY12-3.rmff

Acle, T.G., Roque, M. P., Zacatelco, F., Lozada, R., y Martínez, L. (2007) Discapacidad y rezago escolar: Riesgos actuales. Acta Colombiana de Psicología, 10(2), 19-30.

Acosta, F., y Terigi, F. (2015). Experiencias de cambio en la escuela secundaria con foco en las políticas destinadas a la reinserción y permanencia de los jóvenes en la escuela en América Latina y en Europa. Madrid, España: Publicaciones EUROsoCIAL. Serie Estudios. Área Educación.

Adi, Y., Kiloran, A., Janmohamed, K., y Stewart-Brown, S. (2007). Systematic review of the effectiveness of interventions to promote mental wellbeing in primary schools-universal approaches which do not focus on violence and bullying. Londres, UK: National Institute for Clinical Excellence.

Adolfsson, M. (2011). Applying the ICF-CY to identify everyday life situations of children and youth with disabilities [Tesis Doctoral, Universidad de Jönköping]. https: / /www.diva-portal.org

Adolfsson, M., Malmqvist, J., Pless, M., y Granuld, M. (2011). Identifying child functioning from an ICF-CY perspective: Everyday life situations explored in measures of participation. Disability and Rehabilitation, 33(1314), 1230-1244. doi: 0.3109/09638288.2010.526163. 
Ager, A. (2013). Annual research review: resilience and child well-being, public policy implications. Journal of Child Psychology and Psychiatry, 54(4), 488-500. doi: 10.1111/jcpp. 12030

Aguirre, M. M. (2012). Factores contextuales y calidad de vida en las actividades de ocio de los jóvenes y adultos con discapacidades del desarrollo [Tesis Doctoral, Universidad de Salamanca]. https: / / gredos.usal.es

Ahern, N.R., Kiehl, E.M., Sole, M.L., y Byers, J. (2006). A review of instruments measuring resilience. Issues in Comprehensive Pediatric Nursing, 29(2), 103-125. doi: 10.1080/01460860600677643

Ainscow, M. (1999). Tendiendo la mano a todos los estudiantes: algunos retos y oportunidades. En M.A. Verdugo y F. B. Jordán de Urries (Eds.), Hacia una nueva concepción de la discapacidad (15-37). Salamanca, España: Amarú.

Albrecht, R. E. (2007). A model of self-transformative identity development in troubled adolescent youth [Tesis Doctoral, Universidad Internacional de Florida]. https: / / digitalcommons.fiu.edu

Allison, K. R. (1996). Predictors of inactivity: An analysis of the Ontario Health Survey. Revue Canadienne de Santé Publique, 87(5), 354-358.

Allison, K. R., Dwyer, J. J. M., Goldenberg, E., Fein, A., Yoshida, K. K., y Boutilier, M. (2005). Male adolescent's reasons for participating in physical activity, barriers to participation, and suggestions for increasing participation. Adolescense, 40, 155-170.

Almqvist, L., y Granlund, M. (2005). Participation in school environment of children and youth with disabilities: a person-oriented approach. Scandinavian Journal of Psychology, 46(3), 305-14. doi: 10.1111/j.14679450.2005.00460.x

Almqvist, L., Hellnas, P., Stefansson, M., y Granlund, M. (2006). "I can play!" Young children's perceptions of health. Pediatric Rehabilitation, 9, 275-284. doi: 10.1080/13638490500521303 
Álvarez, M., Castro, P., González-González, C., Álvarez, E., y Campo, M. A. (2016). Conductas disruptivas desde la óptica del docente: validación de una escala. Anales de Psicología, 32(3), 855-862. doi: 10.6018/ analesps.32.3.223251.

Alvord, M.A., Rich, B.A, y Berghorst, L. (2016). Resilience interventions. En J.C. Norcross, G.R. VandenBos, y D.K. Freedheim (Eds.), American Psychological Association Handbook of Clinical Psychology: Vol. 4 Psychopathology and Health (pp. 505-519). Washington D.C., EU: APA Books.

Amar, J., Kotliarenko, M., y Abello, R. (2003). Factores psicosociales asociados con la resiliencia en niños colombianos víctimas de la violencia intrafamiliar. Investigación y desarrollo, 11(1), 162-197.

American Association on Intellectual and Developmental Disabilities: AAIDD (2011). Discapacidad intelectual: definición, clasificación y sistemas de apoyo (11 Ed.). [Traducción de M. A. Verdugo]. Madrid, España: Alianza Editorial.

American Educational Research Association(AERA), American Psychological Association (APA), National Council on Measurement in Education, Joint Committee on Standards for Educational and Psychological Testing (NCEM). (2014). Standards for educational and psychological testing. Washington D.C., EU: AERA.

American Psychological Association: APA (2014). The road to resilience. Washington D.C., EU: American Psychological Association.

Anda R. F., Chapman D.P., Felitti V.J., Edwards V.E., Williamson D.F., Croft J.P., y Giles W.H. (2002). Adverse Childhood Experiences and Risk of Paternity in Teen Pregnancy. Obstetrics y Gynecology, 100, 37-45.

Anderson y Cardoza (2016). Mental health in schools: a hidden crisis affecting millions of students. Washington D.C., EU: NPR Ed. Recuperado de https: / / www.npr.org 
Andrews, F. M., y Withey, S. B. (1976). Social indicators of well-being: The development and measurement of perceptual indicators. NewYork, EU: Plenum.

Anyan, F., Worsley, L., y Hjemdal, O. (2017) Anxiety symptoms mediate the relationship between exposure to stressful negative life events and depressive symptoms: A conditional process modelling of the protective effects of resilience. Asian Journal of Psychiatry, 29, 41-48. doi: 10.1016/j. ajp. 2017.04.019

Arim, R.G., Frindlay, L.C., y Kohen, D.E. (2012). Participation in Physical Activity for Children with Neurodevelopmental Disorders. International Journal of Pediatrics. doi: 10.1155/2012/460384

Armstrong, M., Birnie-Lefcovitch, S., y Ungar, M. T. (2005). Pathways between social support, family well-being, quality of parenting, and child resilience: What we know. Journal of Child and Family Studies, 14(2), 269281. doi: 10.1007/s10826-005-5054-4

Asparauhov, T., y Muthén, B. (2009). Exploratory structural equation modeling. Structural Equation Modeling, 16(3), 397-438. doi: $10.1080 / 10705510903008204$

Arnaiz, P., Moresa, M., y Abellán, R. (2008). Indicadores de calidad para la atención a la diversidad del alumnado en la educación secundaria obligatoria. Educación y diversidad (2), 35-59. Recuperado de: https:// dialnet.unirioja.es/

Arrington, E. G., y Wilson, M. N. (2000). A re-examination of risk and resilience during adolescence: Incorporating culture and diversity. Journal ofChild and Family Studies, 9(2), 221-230. doi: 10.1023/ A:1009423106045

Ato, M., y Vallejo, G. (2011). Los efectos de terceras variables en la investigación psicológica. Anales de Psicología, 27, 550-561.

Axelsson, A.K., Granlund, M., y Wilder, J. (2013). Engagement in family activities: a quantitative, comparative study of children with profound intellectual and multiple disabilities and children with typical. Child: care health and development, 39(4), 523-534. doi: 10.1111/cch.12044. 
Aymerich, M., Berra, S., Guillamón, I., Herdman, M., Alonso, J., RavensSieberer, U., y Rajmil, L. (2005). Desarrollo de la versión en español del KIDSCREEN, un cuestionario de calidad de vida para la población infantil y adolescente. Gaceta Sanitaria, 19(2), 93-102.

Badia, M., y Longo, E. (2009). El ocio en las personas con discapacidad intelectual: participación y calidad de vida a través de las actividades de ocio. Siglo Cero, 40(2), 30-44.

Badia, M., Longo, E., Orgaz, M.B, y Gómez-Vela, M. (2013). The influence of participation in leisure activities on quality of life in spanish children and adolescents with cerebral palsy. Research in Developmental Disabilities, 34(9), 2864-2871. doi: 10.1016/j.ridd.2013.06.017

Badia M., Orgaz B. M., Verdugo M. A., Ullan A. M., y Martínez M. M. (2011) Personal factors and perceived barriers to participation in leisure activities for young and adults with developmental disabilities. Research in Developmental Disabilities, 32(6), 2055-2063. doi: 10.1016/j. ridd.2011.08.007

Badley, E. M. (2008). Enhancing the conceptual clarity of the activity and participation components of the International Classification of Functioning, Disability, and Health. Social Science \& Medicine, 66(11), 2335-2345. doi: 10.1016/j.socscimed.2008.01.026.

Baldwin, A.L., Baldwin, C.P., Kasser, T., Zax, M., Sameroff, A., y Seifer, R. (1993). Contextual risk and resiliency during late adolescence. Development and Psychopathology, 5(4), 741-761. doi: 10.1017/S095457940000626X

Banco Mundial (2006). Word Development Report 2007. Banco Mundial, Washington DC, EU.

Bandalos, D. L., y Finney, S. J. (2010). Factor Analysis: Exploratory and Confirmatory. En G. R. Hancock y R. O. Mueller (Eds.), Reviewer's guide to quantitative methods. New York, EU: Routledge. doi: 10.1080/00220671.2011.626376 
Bandura, A. (1977). Self-efficacy: Toward a unifying theory of behavioral change. Psychological Review, 84(2), 191-215.

Bandura, A. (1986). From thought to action: Mechanisms of personal agency. New Zealand Journal of Psychology, 15, 1-17.

Bandura, A. (1997). Self-efficacy: The exercise of control. New York, EU: W.H. Freeman.

Barber, B.K. (2008). Contrasting portraits of war: youths' varied experiences with political violence in Bosnia and Palestine. International Journal of BehavioralDevelopment,32(4),298-309.doi:10.1177/0165025408090972

Baron, R. M., y Kenny, D. A. (1986). The moderator mediator variable distinction in social psychological research-conceptual, strategic, and statistical considerations. Journal of Personality and Social Psychology, 51(6), 1173-1182.

Barton, E. (2015). Teaching generalized pretend play and related behaviors to young children with disabilities. Exceptional Children, 81(4), 489-506. doi.org/10.1177/0014402914563694

Bartone, P.T. (1995). A short hardiness scale. New York, EU: American Psychological Society.

Bartone, P.T. (2007). Test-retest reliability of the dispositional resilience scale-15, a brief hardiness scale. Psychological Report, 101(3), 943-944. doi: $10.2466 / \operatorname{pr} 0.101 .3 .943-944$

Bauer, R. (1966). Social Indicators. Cambridge: MIT Press.

Beckett, C., Maughan, B., Rutter, M., Castle, J., Colvert, E., Groothues, C., Sonuga-Barke, E. J. (2006). Do the effects of early severe deprivation on cognition persist into early adolescence? Findings from the English and Romanian Adoptees Study. Child Development, 77(3), 696-711. doi:10.1111/j.1467-8624.2006.00898.x 
Bedell, G., y Dumas, H.M. (2004). Social participation of children and youth with acquired brain injuries discharged from inpatient rehabilitation: a follow-up study. Brain Injury, 18, 65-82.

Beeghly, M., y Cicchetti, D. (1994). Child maltreatment, attachment, and the self-system: Emergence of an internal state lexicon in toddlers at high social risk. Development and Psychopathology, 6, 5-30.

Békaert, J., Masclet, G., y Caron, R. (2011). Les instruments de mesure de la résilience chez les adolescents ayant été confrontés à un traumatisme: une revue de la littérature [Measures of resilience in traumatized adolescents: A literature review]. Annales Médico-psychologiques, revue psychiatrique, 169(8), 510-516. doi: 10.1016/j.amp.2010.10.007

Ben-Arieh, A., Casas, F., Frønes, I., y Korbin, J.E. (2014) (Eds.). Handbook of child well-being:Theories, methods and policies in global perspective. Dortmund, Netherlands: Springer. doi: 10.1007/978-90-481-9063-8

Bentler, P. M., y Bonett, D. G. (1980). Significance tests and goodness of fit in the analysis of covariance structures. Psychological Bulletin, 88(3), 588606. doi: 10.1037/0033-2909.88.3.588

Blinde, E.M., y McCallister, S.G. (1998). Listening to the voices of students with physical disabilities. Journal of Physical Education, Recreation \& Dance, 69(6), 64-68.

Block, J. H., y Block, J. (1980). The role of ego-control and ego resiliency in the organization of behavior. En W. A. Collins (Ed.), Development of cognition, affect and social relations:The Minnesota symposia on child psychology (pp. 39-101). Hillsdale, NJ: Erlbaum.

Block, J., y Kremen, A.M. (1996). IQ and ego-resiliency: Conceptual and empirical connections and separateness. Journal of Personality and Social Psychology, 70(2), 349-361. 
Boer, A., Pijl, S-J., y Minnaert, A. (2012). Students' attitudes towards peers with disabilities: a review of the literature. International Journal of Disability, Development and Education, 59(4), 379-392. doi: $10.1080 / 1034912 X .2012 .723944$

Bonanno, G. A., Brewin, C.R., Kaniasty, K., y Greca, A.L. (2010). Weighing the Costs of Disaster: consequences, risks, and resilience in individuals, families and communities. Psychological Science in the Public Interest, 11(1), 1-49. doi: 10.1177/1529100610387086

Booth, T., y Ainscow. M. (2002). Guía para la evaluación y mejora de la educación inclusiva. [Trad. de Consorcio para la Educación inclusiva]. Madrid, España: Consorcio Universitario para la Educación Inclusiva.

Booth, T., y Ainscow, M. (2015). Guía para la Educación Inclusiva: Desarrollando el aprendizaje y la participación en los centros escolares ( $3^{\text {rd }} \mathrm{ed}$.). [Trad. de G. Echeita, Y. Muñoz, C. Simón y M. Sandoval]. Madrid, España: FUHEM y OEI.

Boothby, N., Strang, A., y Wessells M. (Eds.) (2006). A world turned upside down: Social ecological approaches to children in war zones. Bloomfield, CT: Kumarian Press. doi: 10.1093/jrs/fen018

Borthwick-Duffy, S.A. (1992). Quality of life and quality of care in mental retardation. En L. Rowitz (Ed.), Mental retardation in the year 2000 (5266). Berlin: Springer-Verlag.

Borthwick-Duffy, S. A. (1996). Evaluation and measurement of quality of life: Special considerations for persons with mental retardation. Quality of Life, 1, 105-119.

Bøttcher, L., y Dammeyer, J. (2013). Disability as a risk factor? Development of psychopathology in children with disabilities. Research in Developmental Disabilities, 34, 3607-3617. doi: 10.1016/j.ridd.2013.07.022

Bottrell, D. (2009). Understanding 'marginal' perspectives: Towards a social theory of resilience. Qualitative Social Work, 8(3), 321-340. doi: $10.1177 / 1473325009337840$ 
Bragg, R., Wood, C., Barton, J., y Pretty, J. (2015). Wellbeing benefits from natural environments rich in wildlife. North Wales, Bangor University: Wildlife Trust

Broder (2005). Resilience \& Vulnerability: Adaptation in the Context of Childhood Adversities. New York, EU: Cambridge University Press

Brodersen, E. (2013). The Child and Youth Resilience Measure in an adolescent offender population [Tesis Doctoral, Universidad de New Brunswick]. https: / / www.semanticscholar.org

Bronfenbrenner, U. (1979). The ecology of Human Development. Cambridge, Harvard University Press. [Bronfenbrenner, U. (2002). La ecología del desarrollo humano. Barcelona, España: Ediciones Paidós].

Bronfenbrenner, U. (1986). Ecology of the family as a context for human development: Research perspectives. Developmental Psychology, 22, 723742. doi: 10.1037/0012-1649.22.6.723

Bronfenbrenner, U. (1992). Ecological systems theory. En R. Vasta (Ed.), Six theories of child devepment: Revised formulations and current issues (pp. 187249). Londres, UK: JAI Press

Brooks, R. B. (1994). Children at risk: Fostering resilience and hope. American Journal of Orthopsychiatry, 64(4), 545-553.

Brooks, J. E. (2006). Strengthening resilience in children and youths: Maximizing opportunities in the schools. Children and Schools, 28(2), 6976. doi: $10.1093 / \mathrm{cs} / 28.2 .69$

Brown, A., y Croudace, T. (2015). Scoring and estimating score precision using multidimensional IRT. En S. P. Reise y Revicki, D. A. (Eds.), Handbook of Item Response Theory Modeling:Applications to Typical Performance Assessment (pp. 307-333). New York, EU: Taylor \& Francis. Recuperado de: http:/ /www.routledge.com/books/details/9781848729728 /

Brown J.H., Jean-Marie, G., y Beck, J. (2010). Resilience and risk competence in schools: theory/knowledge and international application in Project REWBOUND. Journal of drug education, 40(4), 331-359. 
Bryant, B., y Satorra, A. (2012) Principles and Practice of Scaled Difference Chi-Square Testing. Structural Equation Modeling, 19, 372-398. doi: $10.1080 / 10705511.2012 .687671$

Buchter, J. M. (2019). Large GroupVideo Modeling:Increasing Social Interactions in an Inclusive Head Start Classroom [Tesis Doctoral, Universidad de Nevada]. https: / / digitalscholarship.unlv.edu

Buckley, J. A., Ryser, G., Reid, R., y Epstein, M. H. (2006). Confirmatory factor analysis of the Behavioral and Emotional Rating Scale-2 (BERS2) Parent and Youth Rating Scales. Journal of Child and Family Studies, 15, 27-37. doi: 10.1007/s10826-005-9000-2

Bult, M. K., Verschuren, O., Jongmas, M. J., Lindeman, E., y Ketelaar, M. (2011). What influences participation in leisure activities of children and youth with physical disabilities? A systematic review. Research of Developmental Disabilities, 32(5), 1521-1529. doi: 10.1016/j. ridd. 2011.01 .045

Bult, M. K., Verschuren, O., Gorter, J. W., Jongmans, M. J., Piskur, B., y Ketelaar, M. (2010) Cross-cultural validation and psychometric evaluation of the Dutch language version of the Children's Assessment of Participation and Enjoyment (CAPE) in children with and without physical disabilities. Clinical Rehabilitation, 24(9), 843-853. doi:10.1177/0269215510367545

Bult, M., Verschuren, O., Lindeman, E., Jongmans, M., y Ketelaar, M. (2014). Do children participate in the activities they prefer? A comparison of children and youth with and without physical disabilities. Clinical Rehabilitation, 28(4), 388-396. doi: 10.1177/0269215513504314

Buttimer, J., y Tierney, E. (2005). Patterns of leisure and participation among adolescents with a mild intellectual disability. Journal of Intellectual Disabilities, 9(1), 1-18. 
Caballo, M.B., Caride, J. A., y Gradaílle, R. (2012). Entre los tiempos escolares y los tiempos de ocio: su incidencia en la vida cotidiana de los adolescentes que cursan la Educación Secundaria Obligatoria en España. Educar em Revista, 45, 37-56.

Cacioppo, J.T. (2002). Foundations in social neuroscience. Cambridge, MA:MIT Press.

Calderón, I. (2014). Educación y esperanza en las fronteras de la discapacidad. Madrid, España: CERMI.

Camargo-Ramos, C.M., y Pinzón-Villate, G.Y (2012). La promoción de la salud en la primera infancia: evolución del concepto y su aplicación en el contexto internacional y nacional. Revista de la Facultad de Medicina Universidad Nacional de Colombia, 60(1), 62-74.

Campbell, A., Converse, P., y Rodgers, E. (1976). The Quality of American Life: Perceptions, Evaluations and Satisfactions. New York, EU: Russel Sage Foundation.

Campbell-Sills L., y Stein M.B. (2007). Psychometric Analysis and Refinement of the Connor-Davidson Resilience Scale (CD-RISC): Validation of a 10-Item Measure of Resilience. Journal of Traumatic Stress, 20(6), 1019-1028. doi: 10.1002/jts.20271

Cantú-Martínez, P. C. (2015). Calidad de vida y sustentabilidad: una nueva ciudadanía. Ambiente y Desarrollo, 19(37), 09-21. Recuperado de: http: / / dx.doi.org/10.11144/Javeriana.ayd19-37.cvsn

Cardona, D., y Agudelo, H. (2005). Construcción cultural del concepto de calidad de vida. Revista facultad nacional de salud pública, 23(1), 79-90. Recuperado: http: / / www.redalyc.org/articulo. oa?id=12023108

Chen, X., DeSouza, A., Chen, H., y Wang, L. (2006). Reticent behavior and experiences in peer interactions in Chinese and Canadian children. Developmental Psychology, 42(4), 656-665. doi: 10.1037/00121649.42 .4 .656 
Cicchetti, D. (Ed.) (2016). Developmental psychopathology (vol. 4). Risk, resilience and intervention (3rd Edition). New York, EU: Wiley.

Clarke, M.T., Newton, C., Griffiths, T., Price, K., Lysley, A., y Petrides, K.V. (2011). Factors associated with the participation of children with complex communication needs. Research in developmental disabilities, 32(2), 774-780. doi: 10.1016/j.ridd.2010.11.002

Coastsworth, J. D., Sharp, E. H., Palen, L. A., Darling, N., Cumsille, P., y Ferrer-Wreder, L. (2006). Self-defining activities, expressive identity, and adolescent wellness. Applied Developmental Science, 10, 157-170. doi: $10.1207 /$ s1532480xads1003_5

Coates, J., y Vickerman, P. (2008). Let the children have their say: Children with special educational needs and their experiences of physical education - a review. Support for Learning, 23(4), 168-175.

Collin-Vézina, D., Coleman, K., Milne, L., Sell, J., y Daigneault, I. (2011). Trauma experiences, maltreatment-related impairments, and resilience among child welfare youth in residential care. International Journal of Mental Health and Addiction, 9, 577-589. doi:10.1007/s11469-0119323-8

Connors, C., y Stalker, K. (2007) Children's experiences of disability: pointers to a social model of childhood disability. Disability and Society, 22(1), 19-33. doi: 10.1080/09687590601056162

Connor, K. M., y Davidson, J. R. T. (2003). Development of a new resilience scale: The Connor-Davidson resilience scale (CD-RISC). Depression and Anxiety, 18(2), 76-82. doi: 10.1002/da.10113

Constantine, NA., y Benard, B. (2001). California Healthy Kids Survey Resilience Assessment Module: Technical report. Berkeley, CA: Public Health Institute. Recuperado de: http://ies.ed.gov/ncee/edlabs/regions/west/pdf/ REL_2007034.pdf 
Cornwall, A. (2008). Unpacking "Participation": Models, Meanings and Practices. Community Development Journal, 43(3), 269-283. doi: 10.1093/ $\mathrm{cdj} / \mathrm{bsn} 010$

Cortada de Kohan, N. (1999). Teorías psicométricas y construcción de tests. Buenos Aires, Argentina: Lugar Editorial.

Costello, A. B., y Osborne, J. W. (2005). Best practices in exploratory factor analysis: Four recommendations for getting the most from your analysis. Practical Assessment, Research \& Evaluation, 10(7). Recuperado de: http: / / pareonline.net/pdf/v10n7.pdf

Coster, W., Law, M., Bedell, G., Khetani, M., Cousins, M., y Teplicky, R. (2012). Development of the participation and environment measure for children and youth: conceptual basis. Disability and Rehabilitation, 34(3), 238-46. doi: 10.3109/09638288.2011.603017

Cowen, E. L., y Work, W. C. (1988). Resilient children, psychological wellness, and primary prevention. American Journal of Community Psychology, 16(4), 591-607.

Crawford, D., y Godbey, G. (1987). Reconceptualizing barriers to family leisure. Leisure Sciences, 9, 119-127.

Croll, P., y Moses, D. (2000). Special Needs in the Primary School: One in Five? ( $2^{\text {a }}$ ed. $)$. London: Cassell.

Cross, M., Gottfredson, D., Wilson, D., Rorie, M., y Connell, N. (2010) Implementation quality and positive experiences in after school programs. American Journal of Community Psychology, 45, 370-380.

Cross, T. (1998). Undertanding family resiliency from a relational world view. En I. Hamilton, E. A. McCubbin, A. I. Thompson, y J. E. Fromer (Eds.), Resiliency in Native American and immigrant families (pp. 143-158). Thousand Oasks, CA: Sage Publications.

Cummins, R.A. (1996). The domains of life satisfaction: An attempt to order chaos. Social Indicators Research, 38, 303-332. 
Cummins, R.A. (1997). Assessing quality of life for people with disabilities. En R.I. Brown (2 ${ }^{\mathrm{a}}$ Ed), Quality of Life for Handicapped People (pp. 116-150). Cheltenham, UK: StanleyThomas.

Cummins, R.A. (2000). Objective and subjective quality of life: an interactive model. Social Indicators Research, 52, 55-72. doi:10.1023/A:1007027822521

Cummins, R.A. (2005). Moving from the quality of life concept to a theory. Journal of Intellectual Disability Research, 49(10), 698-706. doi: $10.1111 / \mathrm{j} .1365-2788.2005 .00738 . \mathrm{x}$

Daigneault, I., Dion, J., Hébert, M., McDuff, P., y Collin-Vézina, D. (2013). Psychometric properties of the child and youth resilience measure (CYRM-28) among samples of French Canadian youth. Child Abuse \& Neglect, 37, 160-171. doi: 10.1016/j.chiabu.2012.06.004

Dahan-Oliel, N., Shikako-Thomas, K., y Majnemer, A. (2012). Quality of life and leisure participation in children with neurodevelopmental disabilities: a thematic analysis of the literature. Quality of Life Research:An International Journal of Quality of Life Aspects of Treatment, Care and Rehabilitation, 21(3), 427-439. doi: 10.1007/s11136-011-0063-9

Daigenault I., Dion J., Hébert M., McDuff P., y Collin-Vézina C. (2013). Psychometric properties of the Child and Youth Resilience Measure (CYRM-28) among samples of French Canadian youth. Child Abuse and Neglect, 37(2/3), 160-171. doi: 10.1016/j.chiabu.2012.06.004

Resilience Research Centre - RRC (2017). Resilience Research Centre RRC. Nova Scotia, Canada: Dalhousie University - Halifax. Recuperado de http: / / resilienceresearch.org/

Davis, E., Shelly, A., Waters, E., Boyd, R., Cook, K., y Davern, M. (2010). The impact of caring for a child with cerebral palsy: Quality of life for mothers and fathers. Child: Care, Health and Development, 36(1), 63-73. doi: 10.1111/j.1365-2214.2009.00989.x 
Davis, M. C., Luecken, L., y Lemery-Chalfant, K. (2009). Resilience in common life: Introduction to the special issue. Journal of Personality, 77(6), 1637-1644. doi:10.1111/j.14676494.2009.00595.x

Davidson, J. R. T., Payne, V. M., Connor, K. M., Foa, E. B., Rothbaum, B. O., Hertzberg, M. A.,y Weisler, R.H. (2005). Trauma, resilience, and saliostasis: Effects of treatment in post-traumatic stress disorder. International Clinical Psychopharmacology, 20(1), 43-48.

Davydov, D. M., Stewart, R., Ritchie, K., y Chaudieu, I. (2010). Resilience and mental health. Clinical Psychology Review, 30(5), 479-495. doi: 10.1016/j.cpr.2010.03.003

De Castro F., Allen-Leigh B., Katz G., Salvador-Carrulla L., y LazcanoPonce, E. (2013). Indicadores de bienestar y desarrollo infantil en México. Salud pública de México 55(2), 267-275.

De Civita, M., Regier, D., Alamgir, A. H., Anis, A. H., FitzGerald, M. J., y Marra, C. A. (2005). Evaluating health related quality-of-life studies in paediatric populations: Some conceptual, methodological and developmental considerations and recent applications. PharmacoEconomics, 23(7), 659-685.

De Inocencio, J., García-Consuegra, J., Merino, R., Calvo, I., García, J.J., y Ruperto, N. (2001). The European Spanish version of the Childhood Health Assessment Questionnaire (CHAQ) and the Child Health Questionnaire (CHQ). Clinical and Experimental Rheumatology 19(4), 141-1455.

De la Iglesia, M. B., Forteza, C., Rosselló, R., Verger, G., y Muntaner, J. J. (2012). Evaluación de la calidad de vida de alumnado con discapacidad en la escuela. Revista de Educación Inclusiva, 5(3), 33-51. Recuperado de: http: / /www.revistaeducacioninclusiva.es /

Departament for education and skills: DfES (2004). Removing Barriers to Achievement: The government's strategy for SEN. Nottingham, UK: DfES Publications. Recuperado de http: / / www.bexley.gov.uk/ 
Di Marino, E., Tremblay, S., Khetani, M., y Anaby, D. (2018). The effect of child, family and environmental factors on the participation of young children with disabilities. Disability and Health Journal, 11(1), 36-42. doi: $10.1016 /$ j.dhjo.2017.05.005

Diener, E. , Inglehart, R. , y Tay, L. (2013). Theory and validity of life satisfaction scales. Social Indicators Research, 112(3), 497-527. doi:10.1007/s11205012-0076-y

DiLorenzo, T.M., Stucky-Ropp, R.C., Vander Wal, J.S., y Gotham, H.J. (1998). Determinants of exercise among children. II. A longitudinal analysis. Preventive Medicine, 27, 470-477.

Diodati, M. R. (2017). Recreation as a related service: focusing on the quality of life of students with disabilities [Tesis Doctoral, Southern New Hampshire University]. https: / / academicarchive.snhu.edu

Ditterline, J., y Oakland, T. (2009). Relationship Between Adaptive Behavior and Impairment. En S. Glodstein, y J. Naglieri. Assessing Impairment. From Theory to Practice. New York, EU: Springer.

Doll, B., y Cummings, J. A. (2008). Best practices in population-based school mental health services. En A. Thomas y J. Grimes (Eds). Best practices in school psychologyV (pp. 1333-1347). Bethesda, EU: National Association of School Psychologists.

Doll, B., Pfohl, W., y Yoon, J.S. (2010). Handbook of Youth Prevention Science. New York, EU: Routledge. doi.10.4324/9780203866412

Domínguez-Lara, S. (2016). Evaluación de la confiabilidad del constructo mediante el Coeficiente $\mathrm{H}$ : breve revisión conceptual y aplicaciones. Psicología: Avances en la disciplina, 10(2), 87 - 94.

Donnon, T., y Hammond, W. (2007). A psychometric assessment of the self-reported youth resiliency assessing developmental strengths questionnaire. Psychological Reports, 100(3), 963-978. doi: 10.2466/ pr0.100.3.963-978 
Duggan, C.H., y Dijkers, M. (1999). Etiology, disablement, and quality of life: inter-personal violence versus other causes of spinal cord injury. Topics in Spinal Cord Injury Rehabilitation. 4, 65-85.

Dunn, L., Coster, W., Cohn, E., y Orsmond, G. (2009). Factors associated with participation of children with and without ADHD in household tasks. Physical and Occupational Therapy in Pediatrics, 29(3), 274-295.

Durlak, J. A., Weissberg, R. P., Dymnicki, A. B., Taylor, R. D., y Schellinger, K. B. (2011), The impact of enhancing students' social and emotional learning: A meta-analysis of school-based universal interventions. Child Development, 82, 405-432.

Earnshaw, V. A., Lang, S. M., Lippitt, M., Jin, H., y Chaudoir, S. R. (2015). HIV stigma and physical health symptoms: Do social support, adaptive coping, and/or identity centrality act as resilience resources? AIDS Behavior, 19, 41-49.

Echeita, G. (2013). Inclusión y exclusión educativa. De nuevo "voz y quebranto". REICE, Revista Electrónica Iberoamericana sobre Calidad, Eficacia y Cambio en Educación 6(2), 9-18.

Echeita, G. y Jiménez, D. (2007). Un estudio de casos sobre la situación académica, emocional y social de alumnos con n.e.e. asociadas a discapacidad intelectual en IES de la Comunidad de Madrid. Revista Española sobre Discapacidad Intelectual 38(2), 17-44.

Edwards, T. C., Huebner, C. E., Connell, F. A., y Patrick, D. L. (2002). Adolescent quality of life, part I: Conceptual and measurement model. Journal of Adolescence, 25(3), 275-286.

Echeita, G., Simón, C., Verdugo, M.A., Sandoval, M.; López, M., Calvo, I. y González, F. (2009). Paradojas y dilemas en el proceso de inclusión educativa en España. Revista de Educación, 349, 153-178. 
Edbom, T., Malmberg, K., Lichtenstein, P., Granlund, M., y Larsson J.O. (2010). High sense of coherence in adolescence is a protective factor in the longitudinal development of ADHD symptoms. Scandinavian Journal of Caring Sciences, 24(3), 541-547. doi: 10.1111/j.14716712.2009.00746.x

Eichas K., Montgomery, M.J., Meca, A., y Kurtines, W.M. (2017). Empowering Marginalized Youth: A Self-Transformative Intervention for Promoting Positive Youth Development. Child Development, 88(4), 11151124. doi: $10.1111 /$ cdev. 12866

Eigenschenk, B., Thomann, A., McClure, M., Davies, L., Gregory, M., Dettweiler, U., y Ingles E. (2019). Benefits of Outdoor Sports for Society. A Systematic Literature Review and Reflections on Evidence. International Journal of Environmental Research and Public Health, 16(6): 937 doi: 10.3390/ijerph16060937

Engel-Yeger B, y Hanna-Kasis A. (2010). The relationship between Developmental Co-ordination Disorders, child's perceived self-efficacy and preference to participate in daily activities. Child Care Health Development, 36(5), 670-677. doi: 10.1111/j.1365-2214.2010.01073.x

Engel-Yeger, B., Jarus, T., Anaby, D., y Law, M. (2009). Differences in patterns of participation between youths with cerebral palsy and typically developing peers. American Journal of Occupational Therapy, 63(1), 96-104.

Eggerman, M., y Panter-Brick' C. (2010). Suffering, hope, and entrapment: Resilience and cultural values in Afghanistan. Social Science y Medicine, 71(1/2), 71-83. doi: 10.1016/j.socscimed.2010.03.023

Erhart, M., Ottova, V., Gaspar, T., Nickel, J., Ravens-Sieberer, U., y the HBSC Positive Health Focus Group (2009). Measuring mental healthand well-being of school-children in 15 European countries: Results from the KIDSCREEN-10 Index. International Journal of Public Health, 54: doi $10.1007 / \mathrm{s} 00038-009-5407-7$ 
Eriksson, L. (2005). The relationship between school environment and participation for students with disabilities. Pediatric Rehabilitation, 8(2), 130-139.

Eriksson, L., Welander, J., y Granlund, M. (2007). Participation in Everyday School Activities For Children With and Without Disabilities. Journal of Developmental Physical Disabilities, 19(5), 485- 502. doi: 10.1007/s10882007-9065-5

Eriksson, L., y Granlund, M. (2004). Perceived participation: A comparison between students with disabilities and students without disabilities. Scandinavian Journal of Disability Research, 6(3), 206-225.

Eriksson, M., y Lindström, B. (2006). Antonovsky's sense of coherence scale and the relation with health: a systematic review. Journal of Epidemiology and Community Health 60(5), 376-381.

Etchebarne, I., O’Connell, M., y Roussos, A. (2008). Estudio de Mediadores y moderadores en la investigación en psicoterapia. Revista del Instituto de Investigaciones de la Facultad de Psicología. 13(1), 33-56.

Everley, S., y Macfadyen, T. (2015). I like playing on my trampoline; it makes me feel alive. Valuing physical activity: perceptions and meanings for children and implications for primary schools. Education 3-13, 45(2), 151-175.

Exenberger, S., y Juen, B. (2013). Well-Being, Resilience and Quality of Life from Children's Perspectives: A Contextualized Approach. New York, EU: Springer.

Farmer, C. (2012). Demystifying moderators and mediators in intellectual and developmental disabilities research: A primer and review of the literature. Journal of Intellectual Disability Research, 56, 1148-1160.

Fauconnier, J., Dickinson, H.O., Beckung, E., Marcelli, M., McManus, V., Michelsen, S.I., Parkes, J., Parkinson, K., Thyen, U., Arnaud, C., Colver, A. (2009). Participation in life situations of 8-12 year old children with cerebral palsy: cross-sectional European study. British medical journal, 338:b1458. doi:10.1136/bmj.b1458 
Felce, D. , y Perry, J. (1995). Quality of life: It's Definition and Measurement. Research in Developmental Disabilities, 16(1), 51-74

Fergus, S., y Zimmerman, M.A. (2005). Adolescent resilience: A framework for understanding healthy development in the face of risk. Annual Review Public Health, 26(1), 399-419. doi:10.1146/annurev. publhealth.26.021304.144357

Fernandes, L., Mendes, A., y Teixeira, A. A. C. (2012). A review essay of the measurement of child well-being. Social Indicators Research, 106(2), 239-257. doi: 10.1007/s11205-011-9814-9

Fernández-López, J.A., Fernández-Fidalgo, M., y Cieza, A. (2010). Los conceptos de calidad de vida, salud y bienestar analizados desde la perspectiva de la Clasificación Internacional del Funcionamiento (CIF). Revista Española de Salud Pública, 84(2), 169-184. Recuperado de: http: / / scielo.isciii.es/

Fernández-Mayoralas, F. G., y Rojo P. F. (2005). Calidad de vida y salud: planteamientos conceptuales y métodos de investigación. Territoris: Revista del Departament de Ciències de la Terra, 5, 117-135.

Ferrando, P. J., y Lorenzo-Seva, U. (2013). Unrestricted item factor analysis and some relations with item response theory. Technical Report. Tarragona, España: Departamento de Psicología, Universitat Rovira iVirgili. Recuperado de: psico.fcep.urv.es/utilitats/factor/documentation/technicalreport.pdf

Ferrando, P. J., y Lorenzo-Seva, U. (2014). El análisis factorial exploratorio de los ítems: algunas consideraciones adicionales. Anales de Psicología, 30(3), 1170-1175. doi:10.6018/analesps.30.3.199991

Ferrando, P. J., y Lorenzo-Seva, U. (2016). A note on improving EAP trait estimation in oblique factor-analytic and item response theory models. Psicológica, 37(2), 235-247.

Ferrando, P. J., y Lorenzo-Seva, U. (2017a). Program FACTOR at 10: origins, development and future directions. Psicothema, 29(2), 236-240. doi: $10.7334 /$ psicothema2016.304 
Ferrando, P. J., y Lorenzo-Seva, U. (2017b). Assessing the quality and appropriateness of factor solutions and factor socre estimates in exploratory ítem factor analysis. Educational and Psychological Measurement, 1-19. doi: 10.1177/0013164417719308

Ficapal-Cusí, P., Torrent-Sellens, P., Boada-Grau, J., y Hontangas-Beltrán, P. (2014). Job change without changing job? Exploring job crafting in Spain. Working Paper Series, WP14-005 [Online working paper]. Barcelona, España: Internet Interdisciplinary Institute, Universidad abierta de Catalunya. doi: 10.7238/in3wps.v0i0.2342

Fitzgerald, R., Taylor, R., y LaValle, I. (2003). National Adult Learning Survey (NALS) 2002. Nottingham, London: Department for Education and Skills.

Fleer, M., y Hedegaard, M. (2010). Children's Development as Participation in Everyday Practices across Different Institutions. Mind, Culture, and Activity, 17(2), 149-168. doi:10.1080/10749030903222760

Fletcher, D., y Sarkar, M. (2013). Psychological resilience: A review and critique of definitions, concepts, and theory. European Psychologist, 18(1), 12-23. doi:10.1027/1016-9040/a000124

Flórez, G., Aguado D., y Alcedo R. (2009). Revisión y análisis de los programas de cambio de actitudes hacia personas con discapacidad. Armario de Psicología Clínica y de la Salud. 5, 85-98.

Foro Mundial sobre la Educación (2000). Marco de Acción de Dakar. Educación para todos: cumplir nuestros compromisos comunes. Dakar, Senegal: Foro Mundial sobre la Educación.

Frazier, P., Tix, A., y Barron, K. (2004). Testing moderator and mediator effects in counseling psychology research. Journal of Counseling Psychology, 51, 115-134.

Friborg, O., Hjemdal, O., Rosenvinge, J. H., y Martinussen, M. (2003). A new rating scale for adult resilience: What are the central protective resources behind healthy adjustment? International Journal of Methods in Psychiatric Research, 12, 65-76 
Friedli, L. (2009). Mental health resilience and inequalities. Copenhague, Dinamarca: World Health Organization Regional Office for Europe.

Friedman, M.J. (2005). Toward a public mental health approach for survivors of terrorism. Journal of Aggression, Maltreatment and Trauma, 10 (1/2), 527539. doi:10.1300/J146v10n01_11

Forés, M. A., y Grané, O. J. (2012). La resiliencia en entornos socioeducativos. Madrid, España: Narcea.

Fuhs, M.W., Farran, D.C., y Nesbitt, K.T. (2013). Preschool classroom processes as predictors of children's cognitive self-regulation skills development. School Psychology Quarterly, 28(4), 347-359. doi: 10.1037/ spq0000031

Fundación Yehudi Menuhin España: FYME (2009). Memoria de Actividades 2009. Recuperado de http: / / fundacionyehudimenuhin.org/

Garbarino, J., y Ganzel, B. (2000). The human ecology of early risk. En J.P. Shonkoff y S.J. Meisels (Eds), Handbook of early intervention (pp. 76-93). Cambridge, UK: Cambridge University Press.

Gaias, L. M., Lindstrom J., S., White, R. M. B., Pettigrew, J., y Dumka, L. (2019). Positive School Climate as a Moderator of Violence Exposure for Colombian Adolescents. American Journal of Community Psychology, 63(1), 17-31

Gairín, J., y Rodríguez, D. (2011). Cambio y mejora de las organizaciones educativas. Revista educar 47(1), 31-50.

Garmezy, N. (1983). Stressors of childhood. En N. Garmezy \& M. Rutter (Eds.), Stress, coping, and development in children (pp. 43-84). New York, US: McGraw-Hill.

Garmezy, N. (1985). Stress-resistant children: The search for protective factors. En: Stevenson, J. E. (Ed.), Recent research in developmental psychopathology. Journal of Child Psychology and Psychiatry Book. (Suppl. 4; pp. 213-233). Oxford, UK: Pergamon Press. 
Garmezy, N. (1991). Resiliency and vulnerability to adverse developmental outcomes associated with poverty. American Behavioral Scientist, 34(4), 416-430.

Garmezy, N., Masten, A. S., y Tellegen, A. (1984). The study of stress and competence in children: A building block for developmental psychopathology. Child Development, 55(1), 97-111.

Garrote, A. (2017). Relationship between the social participation and social skills of pupils with an intellectual disability: A study in inclusive classrooms. Frontline Learning Research, 5(1), 25-40 doi: 10.14786/flr. v5il.266

Gaskin, J. (2016). Exploratory Factor Analysis (EFA). Statwiki. Recuperado de: http: / / statwiki.kolobkreations.com

Geldhof, G.J., Bowers E.P., Johnson S.K., Hershberg R.M., Hilliard L.J., y Lerner R.M. (2014). Relational developmental systems theories of positive youth development: methodological issues and implications. En: Molenaar P.C.M., Lerner R.M., Newell K.M. (Eds), Handbook of developmental systems theory and methodology (pp. 66-94). New York, US: Guilford.

Gilmore, L., Campbell, M., Shochet, I., y Roberts, C. (2013). Resiliency profiles of children with intellectual disability and their typically developing peers. Psychology in the Schools, 50, 1032-1043. doi:10.1002/ pits. 21728

Gómez, L.E., Verdugo, M.A., y Arias, B. (2010). Calidad de vida individual: avances en su conceptualización y retos emergentes en el ámbito de la discapacidad. Behavioral Psychology Psicología Conductual, 18(3), 453472. Recuperado de: https: / /www.researchgate.net/

Gómez, L.E., Verdugo, M.A., Arias, B., y Arias, V. (2011). A comparison of alternative models of individual quality of life for social service recipients. Social Indicators Research, 101(1), 109-126. doi:10.1007/s11205-0109639-y 
Gómez-Vela, M., y Sabeh, E. N. (2000). Calidad de vida. Evolución del concepto y su influencia en la investigación y la práctica. Salamanca, España: Instituto Universitario de Integración en la Comunidad (INICO). Recuperado de http: / /inico.usal.es/publicaciones/pdf/calidad.pdf

Gómez-Vela, M. (2007). La calidad de vida de alumnos con necesidades educativas especiales y sin ellas. Elaboración de un marco conceptual y un instrumento de evaluación. Educación y Diversidad, 1, 113-135.

Gómez-Vela, M., y Verdugo, M. A. (2004). Cuestionario de evaluación de calidad de vida de alumnos en educación secundaria obligatoria. Siglo Cero, 35(4), 212, 5-17.

Gómez-Vela, M., y Verdugo, M. A. (2006). La calidad de vida en la adolescencia: evaluación de jóvenes con discapacidad y sin ella. En M. A. Verdugo (Ed.), Cómo mejorar la calidad de vida de las personas con discapacidad. Instrumentos y estrategias de evaluación (77-102). Salamanca, España: Amarú.

Gómez-Vela, M., y Verdugo, M. A. (2009). Cuestionario de evaluación de la calidad de vida de alumnos adolescentes: manual de aplicación. Madrid, España: CEPE.

Gómez-Vela, M., Verdugo, M. A., y González-Gil, F. (2007). Calidad de Vida y autoconcepto en adolescentes con necesidades educativas especiales y sin ellas. Infancia y Aprendizaje, 30(4), 523-536.

González-Gil, F., Martín-Pastor, E., Poy, R. , y Jenaro, C. (2016). Percepciones del profesorado sobre la inclusión: estudio preliminar. Revista Electrónica Interuniversitaria de formación del profesorado, 19(3), 11-24. doi: 10.6018/ reifop.19.3.219321.

Göransson, K., Nilholm., C., y Karlsson (2011). Inclusive education in Sweden? A critical analysis. International Journal of Inclusive Education, 15(5), 541-555. doi:10.1080/13603110903165141 
Gorter, J.W., Stewart, D., y Woodbury-Smith, M. (2011).Youth in transition: care, health and development. Child: care, health and development 37(6), 757-763. doi: 10.1111/j.1365-2214.2011.01336.x.

Gottfredson, D., Cross, A. B., Wilson, D., Rorie, M., y Connell, N. (2010). Effects of participation in after-school programs for middle school students: A randomized trial. Journal of Research on Educational Effectiveness, 3(3), 282-313.

Granlund, M. (2009). Environmental dimension of participation related to ICF-CY. Paper presented at the Invited presentation MURINET meeting, Zürich, Switzerland.

Granlund, M. (2013). Participation-Challenges in conceptualization, measurement and intervention. Childcare, Health and Development, 39(4), 470-473. doi: 10.1111/cch. 12080

Granlund, M., Arvidsson, P., Niia, A., Björck-Åkesson, E., Simeonsson, R., Maxwell, G.,...Pless, M. (2012). Differentiating activity and participation of children and youth with disability in Sweden - a third qualifier in ICFCY? American Journal of Physical Medicine and Rehabilitation, 91(13-1), 84 96. doi: 10.1097/PHM.0b013e31823d5376

Greenberg, M.T., Weissberg, R. P., O’Brien, M. U., Zins, J. E., Fredericks, L., Resnik, H., y Elias, M. J. (2003). Enhancing school-based prevention and youth development through coordinated social, emotional, and academic learning. American Psychologist, 58(6-7), 466-474. doi: 10.1037/0003066X.58.6-7.466

Gresham, F.M., Cook, C.R., Crews, S.D., y Kern, L. (2004). Social skills training for children and youth with emotional and behavioral disorders: Validity considerations and future directions. Behavioral Disorders, 30, 32-46.

Grotberg, E. H. (1995). A guide to promoting resilience in children: Strengthening the human spirit. La Haya, Países Bajos: Bernard van Leer Foundation.

Grice, J. W. (2001). Computing and evaluating factor scores. Psychological Methods, 6, 430-450. doi: 10.1037//1082-989X.6.4.430 
Guariano, L. (2013). Mediación moderada, sensibilidad emocional y afrontamiento en el contexto del estrés. Pensamiento Psicológico, 11(1), 141-159.

Gutman, L.M., Sameroff,A.J., y Eccles, J.S. (2002).The academicachievement of African American students during early adolescence: an examination of multiple risk, promotive, and protective factors. American journal of community psychology, 30(3), 367-399. doi:10.1023/A:1015389103911

Haegele, J., y Sutherland, S. (2015) Perspectives of students with disabilities toward physical education: A qualitative inquiry review. Quest, 67(3), 255-273. doi:10.1080/00336297.2015.1050118

Hall, M.A., y Theron, L (2016). How school ecologies facilitate resilience among adolescents with intellectual disability: Guidelines for teachers. South African Journal of Education, 36(2), 1-13. doi:10.15700/saje. v36n2a1154

Hall, J., Sylva, K., Melhuish, E., Sammons, P., Siraj-Blatchford, I., y Taggart, B. (2009). The role of pre-school quality in promoting resilience in the cognitive development of young children. Oxford Review of Education, 35(3), 331-352. doi: 10.1080/03054980902934613

Hamby, S., Grych, J., y Banyard, V. (2018). Resilience portfolios and polystrengths: Identifying protective factors associated with thriving after adversity. Psychology of Violence, 8(2), 172-183. doi:10.1037/vio0000135

Hancock, G. R. (2001). Effect size, power, and sample size determination for structured means modeling and MIMIC approaches to between-groups hypothesis testing of means on a single latent construct. Psychometrika, 66, 373-388.

Hancock, G. R., y Mueller, R. O. (2000). Rethinking construct reliability within latent variable systems. En R. Cudek, S. H. C. duToit y D. F. Sorbom (Eds.), Structural equation modeling: Present and future (pp. 195216). Lincolnwood, IL: Scientific Software. 
Harvey, A.R., y Hill, R.B. (2004). Africentric youth and family rites of passage program: promoting resilience among at-risk African American youths. SocialWork, 49(1) 65-74.

Hatzichristou, C. (2002). A conceptual framework of the evolution of school psychology: transnational considerations of common phases and future perspectives. School Psychology International, 23, 266-282.

Hatzichristou, C. (2004). Alternative school psychological services: Development of a model linking theory, research, and service delivery. En N. M. Lambert, I Hylander y J. Sandoval (Eds). Consultee-centered consultation: Improving the quality of professional services in schools and community organizations (pp. 115-132) Mahwah, NJ: Lawrence Erlbaum.

Hatzichristou C., Issari, P., Lykitsakou K., Lampropoulou, A., y Dimitropoulou, P. (2011). The development of a multi-level model for crisis prevention and intervention in the Greek educational system. School Psychology International, 32(5), 464-483. doi:10.1177/0143034311402918

Hatzichristou, C., Lampropoulou, A., y Lykitsakou, K. (2006). Addressing cultural factors in development of system interventions. Journal of applied school psychology, 22(2), 103-126. doi: 10.1300/J370v22n02_06

Hess, R. S., Short, R. J., y Hazel, C. E. (2012). Comprehensive children's mental health services in schools and communities: A public health problem-solving model. New York, EU: Routledge.

Hinduja, S., y Patchin, J. W. (2017). Cultivating youth resilience to prevent bullying and cyberbullying victimization. Child Abuse y Neglect, 73, 51-62.

Hawkins, B.A. (1993). Leisure participation and life satisfaction of older adults with mental retardation and Down syndrome. En E. Sutton, A. R. Factor, B. A. Hawkins, T. Heller, y G. B. Seltzer (Eds.), Older adults with developmental disabilities: optimizing choice and change (pp. 141-153). Baltimore, US: Paul H. Brookers Publishing Co. 
Hawkins, J.D., Kosterman, R., Catalano, R.F., Hill, K.G., y Abbott, R.D. (2005). Promoting positive adult functioning through social development intervention in childhood: Long-term effects from the Seattle Social Development Project. Archives of pediatrics y adolescent medicine 159(1), 25-31. doi: 10.1001/archpedi.159.1.25

Hayes, A.F. (2013). Introduction to mediation, moderation, and conditional process analysis: A regression-based approach. New York, EU: The Guilford Press.

Heah, T., Case, T., McGuire, B., y Law, M. (2007). Successful participation: The lived experience among children with disabilities. Canadian Journal of Occupational Therapy, 74(1), 38-47.

Healy, S., Msetfi, R., y Gallagher, S. (2013). Happy and a bit Nervous': The experiences of children with autism in physical education. British Journal of Learning Disabilities, 41(3), 222-228

Hedegaard, M. (2009). Children's development from a cultural-historical approach: Children's activity in everyday local settings as foundation for their development. Mind, Culture, and Activity, 16, 64-82. doi: $10.1080 / 10749030802477374$

Henderson, N., y Milstein, M. (2003). Resiliencia en las escuelas. Buenos Aires: Editorial Paidós.

Henry, A. D. (2000). Pediatric interest profiles: Surveys of play for children and adolescents. San Antonio, TX: Therapy Skill Builders.

Heymann J, Hertzman C, Barer ML, Evans R, (Eds.) (2006). Healthier societies: from analysis to action. New York, EU: Oxford Press.

Highhouse, S., y Gillespie,J. Z. (2008). Do samples really matter that much? En C. E. Lance \& R. J. Vandenberg (Eds.), Statistical and methodological myths and urban legends: Received doctrine, verity, and fable in the organizational and social sciences (pp. 247-266). Mahwah, NJ: Erlbaum. 
Hjemdal, O., Friborg, O., Stiles, T.C., Martinussen, M., y Rosenvinge, J. (2006). A new rating scale for adolescent resilience. Grasping the central protective resources behind healthy development. Measurement and Evaluation in Counseling and Development 39(2), 84-96.

Hoelter, J.W. (1983). The analysis of covariance structures: Goodness-of-fit indices. Sociological Methods and Research, 11, 325-344.

Hogansen, J., Powers, K.M., Geenen, S., Gil-Kashiwabara, E., y Powers, L.E. (2008). Transition goals and experiences of females with disabilities: Youth, parents and professionals. Council for Exceptional Children, 74(2), 215-234.

Hollenweger, J., y Moretti, M. (2012). Using the International Classification of Functioning, Disability and Health Children and Youth version in education systems: a new approach to eligibility. American Journal of Physical Medicine \& Rehabilitation, 91(3), 97-102. doi:10.1097/ PHM.0b013e31823d5501

Holmbeck, G. N. (1997). Toward terminological, conceptual and statistical clarity in the study of mediators and moderators: Examples from the child-clinical and pediatric psychology literatures. Journal of Consulting and Clinical Psychology, 4, 599-610.

Holt, S., Buckley, H., yWhelan, S. (2008). The impact of exposure to domestic violence on children and young people: A review of the literature. Child Abuse y Neglect, 32(8), 797-810. doi:10.1016/j.chiabu.2008.02.004

Horn, J. L. (1965). A rationale and test for the number of factors in factor analysis. Psychometrika, 30, 179-185. doi: 10.1007/BF02289447

Hu, L., y Bentler, P.M. (1999). Cutoff criteria for fit indexes in covariance structure analysis: Conventional criteria versus new alternatives. Structural Equation Modeling, 6, 1-55. doi:10.1080/10705519909540118 
Huebner, E. S., y Hills, K. J. (2013). Assessment of life satisfaction with children and adolescents. En D. H. Saklofske, C. R. Reynolds, y V. Schwean (Eds.), Oxford handbook of psychological assessment of children and adolescents (773-787). Oxford University Press. doi:10.1093/97801997 96304.013 .0034

Hudziak, J., y Bartels, M. (2008). Genetic and environmental influences on wellness, resilience, and psychopathology: A family-based approach for promotion, prevention, and intervention. En J. J. Hudziak (Ed.), Developmental Psychopathology and Wellness (pp. 267-286). Washington D.C., EU: American Psychiatric Publishing.

Hurtes, K.P., y Allen, L.R. (2001). Measuring resiliency in youth: The resiliency attitudes and skills profile. Therapeutic Recreation Journal, 35(4), 333-347.

Idrees, B., y Ilyas, R. (2012). Discrimination and stigmatization of physically disabled student in a general educational environment in Pakistan: a case study. Academic Research International, 2(2), 622-626.

Imms, C., Adair, B., Keen, D., Ullenhang, A., Rosenbaum, P., y Granlund, M. (2016a). "Participation": a systematic review of language, definitions, and constructs used in intervention research with children with disabilities. Development Medicine \& Child Neurology, 58(1), 29-38. doi: 10.1111/ dmcn. 12932

Imms, C., Froude, E., Adair, B., y Shields, N. (2016b). A descriptive study of the participation of children and adolescents in activities outside school. BMC Pediatrics. doi:10.1186/s12887-016-0623-9

Imms, C., King, G., Majnemer, A., Avery, L., Chiarello, L., Palisano, R., Orlin, M., y Law, M. (2017). Leisure participation-preference congruence of children with cerebral palsy: a Children's Assessment of Participation and Enjoyment International Network descriptive study. Development Medicine \& Child Neurology, 59(4), 380-387. doi: 10.1111/ dmcn. 13302 
Imms, C., Reilly, S., Carlin, J., y Dodd, K. (2008). Diversity of participation in children with cerebral palsy. Developmental Medicine and Child Neurology, 50(5), 363-369. doi:10.1111/j.1469-8749.2008.02051.x

International Test Commission: ITC (2017). The ITC Guidelines for Translating and Adapting Tests ( $2^{a}$ ed.). International Journal of Testing, 18(2), 101-134. doi:10.1080/15305058.2017.1398166

IUNDA (2016). Estudio sobre la percepción de la infancia de la Cuidad de Madrid en relación a la satisfacción de sus necesidades y el conocimiento de sus derechos. Madrid: Instituto Universitario de Necesidades y Derechos de la Infancia y la Adolescencia.

Iwasaki, Y. (2007). Leisure and quality of life in an international and multicultural context: what are major pathways linking leisure to quality of life? Social Indicators Research, 82, 233-264. doi:10.1007/s11205-0069032-z

Jacelon, C. S. (1997). The trait and process of resilience. Journal of Advanced Nursing, 25(1), 123-129.

Jackson, E.L., y Searle, M. S. (1985). Recreation non-participation and barriers to participation: Concepts and models. Society and Leisure, 8(2), 693-707.

Jafar, A. (2018). The effectiveness of participation in sports program on social interactions among children with autism spectrum disorder [Tesis Doctoral, Universidad de Nuevo México]. https: / / www.researchgate.net

Jaramillo, L. (2007). Concepción de infancia. Zona Próxima, 8, 108-123.

Jarus T, Anaby D, Bart O, Engel-Yeger, B., y Law, M. (2010). Childhood participation in after-school activities: what is to be expected?. British Journal of Occupational Therapy, 73(8), 344 -350. doi: 10.4276/03080221 0X12813483277062

Joreskög, K. G. (1977). Factor analysis by least-squares and maximumlikelihood methods. En Enslein, K., Ralston, A., y Wilf, H. S. (Eds.), Statistical methods for digital computers. New York, EU: Wiley. 
Joseph, S. (2015). Positive psychology in practice: promoting human flourishing in work, health, education, and everyday life ( $\left.2^{\mathrm{a} E d}\right)$. New York, EU: Wiley.

Jurado, P. (2009). Calidad de vida y procesos educativos. Revista de Educación Inclusiva 2(2), 1-13.

Kahana, S. Y., Youngstrom, E. A., y Glutting, J. J. (2002). Factor and subtest discrepancies on the Differential Abilities Scales: Examining prevalence and validity in predicting academic achievement. Assessment, 9, 82-93.

Kantomaa, M.T., Purtsi, J., Taanila, A.M., Remes, J., Viholainen, H., Rintala, P.,...,Tammelin, T.H. (2011). Suspected motor problems and low preference for active play in childhood are associated with physical inactivity and low fitness in adolescence. PLoS ONE, 6(1), e14554, doi: 10.1371 /journal.pone.0014554.

Kaplan, H. B. (2002). Toward an understanding of resilience: A critical review of de fi notions and models. En M. D. Glantz y J. L. Johnson (Eds.), Resilience and development; positive life adaptations (pp. 17-83). . New York, EU: Springer. doi: 10.1007/0-306-47167-1_3

Kaplan, H. B. (2005). Understanding the concept of resilience. En S. Goldstein \& R. Brooks (Eds.), Handbook of resilience in children. NewYork, EU: Springer. doi:10.1007/0-306-48572-9_3

Khanlou, N., y Wray, R. (2014). A whole community approach toward child and youth resilience promotion: A review of resilience literature. International Journal of Mental Health \&Addiction, 12(1), 64-79. doi:10.1007/ s11469-013-9470-1

King, G. (2013). Perspectives on measuring participation: going forward. Child Care, Health and Development, 39(4), 466-469. doi: 10.1111/cch.12083

King, G., Law, M., Hanna, S., King, S., Hurley, P., Rosenbaum, P., Kertoy, M., y Petrenchik, T. (2006). Predictors of the leisure and recreation participation of children with physical disabilities: A structural equation modeling analysis. Children's Health Care, 35(3), 209-234. doi:10.1207/ s15326888chc3503_2 
King G. A., Law M., King S., Hurley P., Hanna S., y Kertoy M., (2007). Measuring children's participation in recreation and leisure activities: Construct validation of the CAPE and PAC. Child: Care, Health and Development, 33, 28-39.

King, G., Law, M., King, S., Hurley, P., Rosenbaum, P., Hanna, S., Kertoy, M. y Young N (2004). Children's assessment of participation and enjoyment (CAPE) and preferences for activities of children (PAC). San Antonio, TX: Harcourt Assessment.

King, G., Law, M., King, S., Rosenbaum, P., Kertoy, M. K., y Young, N.L. (2003). A conceptual model of the factors affecting the recreation and leisure participation of children with disabilities. Physical and Occupational Therapy in Pediatrics, 23(1), 63-90.

King, G., Law, M., King, S., Rosenbaum, P., Kertoy, M. K., y Young, N. L. (2009). Un modelo conceptual de los factores que afectan a la participación en las actividades de ocio y recreo de los niños con discapacidades. Siglo Cero, 40(2), 5-29.

King, G., Law, M., Petrenchik, T., y Hurley, P. (2013). Psychosocial determinants of out of school activity participation for children with and without physical disabilities. Physical \& Occupational Therapy in Pediatrics, 33(4), 384 404. doi: 10.3109/01942638.2013.791915

Kim-Cohen, J., y Turkewitz, R. (2012). Resilience and measured geneenvironment interactions. Development and Psychopathology, 24(4), 1297 1306 doi: 10.1017/S0954579412000715.

Kirby, P., y Bryson, S. (2002). Measuring the magic. Evaluating and researching young people's participation in public decision making. London, UK: CarnegieYoung People Iniciative. Recuperado de: https: / / www. yacwa.org.au/ 
Kleinert, H. L., Miracle, S., y Sheppard-Jones, K. (2007). Including students with moderate and severe intellectual disabilities in school extracurricular and community recreation activities. Intellectual and Developmental Disabilities, 45(1), 46-55.

Knight, C., Ballatti, J., Haase, M., y Henderson, L. (2010). Preservice teacher stressors and their reactions to those stressors: Resilient responses. Paper presented at the Australian Teacher Education Association Conference, Townsville, QLD, Australia.

Kolbe, L., Kann, L., Everett, S., y Hannan, C. (1997)Frameworks to inform the development of US adolescent health indicators for the 21 st century. Promotion Education, 4, 30-36.

Koller, S.H., y Verma, S. (2017). Commentary on cross-cultural perspectives on positive youth development with implications for intervention research. Child development, 88(4), 1178-1182. doi: 10.1111/cdev.12873

Kowalchuk, K., y Crompton, S. (2009). Social participation of children with disabilities. Canadian Social Trends, 88, 63-72.

Kraemer, H.C., Wilson, G.T., Fairburn, C.G., y Agras, W.S. (2002). Mediators and moderators of treatment effects in randomized clinical trials. Archives of General Psychiatry. 59(10), 877-883.

Kramer, J. M., Olsen, S., Mermelstein, M., Balcells, A., y Liljenquist, K. (2012). Youth with disabilities' perspectives of the environment and participation: A qualitative meta-synthesis. Child: Care, Health and Development, 38(6), 763-777. doi: 10.1111/j.1365-2214.2012.01365.x

Kremer, K.P., Maynard, B.R., Polanin, J.R., Vaughn, M.G., y Sarteschi, C.M. (2015). Effects of After-School Programs with At-Risk Youth on Attendance and Externalizing Behaviors: A Systematic Review and MetaAnalysis. Journal of Youth and Adolescent, 44(3), 616-636. doi: 10.1007/ s10964-014-0226-4

Lamb, V.L., y Land, K.C. (2014).Methodologies used in the construction of composite child well-being indices. En A. Ben-Arieh, F. Casas, I. Frønes, y 
J.E. Korbin (Eds.). Handbook of child well-being:Theories, methods and policies in global perspective (2739-2755). Dortmund, Netherlands: Springer. doi 10.1007/978-90-481-9063-8

Landgraf, J. M., Abetz, L., y Ware, J. E. (1996). Child Health Questionnaire (CHQ): A user's manual. Boston, MA:The Health Institute, New England Medical Center.

Laws, G., y Kelly, E. (2005).The attitudes and friendship intentions of children in United Kingdom mainstream schools towards peers with physical or intellectual disabilities. International Journal of Disability, Development and Education, 52(2), 79-99 doi:10.1080/10349120500086298

Law, M., King, G., King, S., Kertoy, M., Hurley, P., Rosenbaum, P., yYoung, N., (2006). Patterns of participation in recreational and leisure activities among children with complex physical disabilities. Developmental Medicine and Child Neurology, 48(5), 337-342.

Law, M., Petrenchik, T., King, G., y Hurley, P. (2007). Perceived environmental barriers to recreational, community, and school participation for children and youth with physical disabilities. Archives of Physical Medicine \& Rehabilitation, 88(12), 1636-1642.

LeBuffe, P., Shapiro, V., y Naglieri, J. (2005). Devereux student strengths assessment (DESSA) user's manual. Lewisville, N.C.: KPress. Recuperado de:https://www.kaplanco.com/content/products/ DESSAIntroduction.pdf

Lee, T.Y., Cheung, C.K., y Kwong, W.M. (2012) Resilience as a Positive Youth Development Construct: A Conceptual Review. The ScientificWorld Journal, doi:10.1100/2012/390450

Lee, T. Y., Kwong, W. M., Cheung, C. K., Ungar, M., y Cheung, M. Y. L. (2010). Children's resilience-related beliefs as a predictor of positive child development in the face of adversities: implications for interventions to enhance children's quality of life. Social Indicators Research, 95(3), 437453. doi:10.1007/s11205-009-9530-x 
Leffert, N., Benson, P. L., Scales, P. C., Sharma, A., Drake, D., y Blyth, D. A. (1998). Developmental assets: Measurement and prediction of risk behaviors among adolescents. Applied Developmental Science, 2, 209-230. doi:10.1207/s1532480xads0204_4

Leman, P.J., Smith, E.P., Petersen A.C., y SRCD Ethnic-Racial Issues and International Committees (2017). Introduction to the Special Section of Child Development en Positive Youth Development in Diverse and Global Contexts. Child development, 88(4), 1039-1044. doi: 10.1111/cdev. 12860

Lerner, J.V., Phelps, E., Forman, Y., y Bowers, E.P. (2009). Positive youth development. In R.M. Lerner, \& L. Steinberg (Eds.), Handbook of Adolescent Psychology:Vol. 1. Individual bases of adolescent development ( $3^{\mathrm{a}} \mathrm{ed}$., pp. 524-558). Hoboken, NJ: Wiley.

Lerner, R. M. (1984). On the nature of human plasticity. New York, EU: Cambridge University Press.

Lerner, R. M. (2002). Concepts and theories of human development ( $3^{\mathrm{a}}$ ed.). Mahwah, NJ: Erlbaum.

Lerner, R. M. (2004). Liberty: Thriving and civic engagement among America's youth. Thousand Oaks, CA: Sage.

Lerner, R. M. (2006). Resilience as an attribute of the developmental system. Annals of the New York Academy of Sciences, 1094, 40-51.

Lerner, R. M., Lerner, J. V., Bowers, E. P., y Geldhof, G. J. (2015). Positive youth development and relational-developmental-systems. En W. F. Overton \& P. C. M. Molenaar (Eds.), \& R. M. Lerner (Series Ed.), Theory and method: Vol. 1. Handbook of child psychology and developmental science (Chap. 16, 7th ed., pp. 607-651). New York, EU: Wiley.

Lerner, R., y Overton, W. F. (2008). Exemplifying the integrations of the Relational Developmental System: Synthesizing theory, research, and application to promote positive development and social justice. Journal of Adolescent Research, 23(3), 245-255. doi:10.1177/0743558408314385 
Lévy-Mangin, J. P., y Varela-Mallou, J. (2006). Modelización con estructuras de covarianzas en ciencias sociales. Temas esenciales, avanzados y aportaciones especiales. Madrid, España: Gesbiblo.

Lewin, K. (1951). Defining the "field at a given time". En D. Cartwright (Ed.), Field theory in social science (pp. 43-59). New York, EU: Harper \& Brothers.

Ley orgánica de ordenación general del sistema educativo (LOGSE) (Ley Orgánica 1/1990, 3 de octubre). Boletín Oficial del Estado, n ${ }^{\circ} 238$, 1990, 4 de octubre.

Ley orgánica de educación (LOE) (Ley Orgánica 2/2006, 3 de mayo). Boletín Oficial del Estado, $\mathrm{n}^{\circ}$ 106, 2006, 4 de mayo.

Ley orgánica para la mejora de la calidad educativa (LOMCE) (Ley Orgánica 8/2013, 9 de diciembre). Boletín Oficial del Estado, nº 295, 2013, 10 de diciembre.

Lickenbrock, D.M., Ekas, N.V., y Whitman, T.L. (2011). Feeling good, feeling bad: Influences of maternal perceptions of the child and marital adjustment on well-being in mothers of children with an autism spectrum disorder. Journal of autism and developmental disorders 41(7), 848-858. doi: 10.1007/s10803-010-0986-y

Liebel, M. (2004). A will of their own: Cross-cultural perspectives on working children. London, UK: Zed Books.

Liebenberg, L., Ungar, M., y Van de Vijver, F. R. R. (2012). Validation of the Child and Youth Resilience Measure-28 (CYRM-28) Among Canadian Youth with Complex Needs. Research on Social Work Practice, 22(2), 219226.

Lloret-Segura, S., Ferreres-Traver, A., Hernández-Baeza, A., y Tomás-Marco, I. (2014). Exploratory Item Factor Analysis: A practical guide revised and up-dated. Anales de Psicología, 30(3), 1151-1169. doi: 10.6018/ analesps.30.3.199361 
Lloret-Segura, S., Ferreres, A., Hernández, A., y Tomás, I. (2017). The exploratory factor analysis of items: guided analysis based on empirical data and software. Anales de Psicología, 33(2), 417-432. doi: 10.6018/ analesps.33.2.270211

Longo, E., y Badia, M. (2009). La participación en las actividades de ocio en los niños y adolescentes con parálisis cerebral. Siglo Cero, 40(4), 79-93. Longo, E., Badia, M., y Orgaz, M.B. (2012). Participación y calidad de vida en los niños y adolescentes con parálisis cerebral (tesis doctoral). Universidad de Salamanca, España.

Longo, E., Badia, M., y Orgaz, M.B. (2013). Patterns and predictors of participation in leisure activities outside of school in children and adolescents with Cerebral Palsy. Research in developmental disabilities, 34(1), 266-275. doi: 10.1016/j.ridd.2012.08.017

Longo, E., Badia, M., Orgaz, B., y Verdugo, M. A. (2012). Cross-cultural validation of the Children's Assessment of Participation and Enjoyment (CAPE) in Spain. Child: Care, Health and Development, 40(2), 231-241. doi: $10.1111 /$ cch. 12012

Lorenzo-Seva, U. (1999). Promin: A method for oblique factor rotation. Multivariate Behavioral Research, 34(3), 347-356. doi: 10.1207/ S15327906MBR3403_3

Lorenzo-Seva, U., y Ferrando, P. J. (2006). FACTOR: a computer program to fit the exploratory Factor Analysis model. Behavioral Research Methods, Instruments y Computers, 38(1), 88-91.

Lorenzo-Seva, U., y Ferrando, P. J. (2013). FACTOR 9.2 A Comprehensive Program for Fitting Exploratory and Semiconfirmatory Factor Analysis and IRT Models. Applied Psychological Measurement, 37, 497-498.

Lorenzo-Seva, U., Kiers, H.A.L., y Ten Berge, J.M.F. (2002). Techniques for oblique factor rotation of two or more loading matrices to a mixture of simple structure and optimal agreement. British Journal of Mathematical and Statistical Psychology, 55, 337-360. doi:10.1348/000711002760554624 
Luengo-Kanacri, B. P., Eisenberg, N., Thartori, E., Pastorelli, C., UribeTirado, L. M., Gerbino M., y Caprara, G. V. (2017). Longitudinal relations among positivity, perceived positive school climate, and prosocial behavior in Colombian adolescents. Child Dev., 88(4), 1100-1114. doi: 10.1111/cdev. 12863

Luján-Tangarife, J. A., y Cardona-Arias, J. A. (2015). Construcción y validación de escalas de medición en salud: revisión de propiedades psicométricas. Archivos de medicina, 11, 3:1. doi: 10.3823/1251

Luthar, S. S. (1999). Poverty and children's adjustment (vol.41). Thousand Oaks, CA: Sage.

Luthar, S.S. (2006). Resilience in development: A synthesis of research across five decades. En D. Cicchetti y D.J. Cohen (Eds.), Developmental Psychopathology: Risk, Disorder, and Adaptation. New York, EU: Wiley.

Luthar, S., y Brown, P. (2007). Maximizing resilience through diverse levels of inquiry: Prevailing paradigms, possibilities and priorities for the future. Development and Psychopathology, 19(3), 931-955. doi: 10.1017/ S0954579407000454

Luthar, S. S., y Cicchetti, D. (2000a). The construct of resilience: Implications for interventions and social policies. Development and Psychopathology, 12(4), 857-885. doi:10.1017/S0954579400004156

Luthar, S. S., Cicchetti, D., y Becker, B. (2000b). The construct of resilience: A critical evaluation and guidelines for future work. Child Development, 71(3), 543-562. doi:10.1111/14678624.00164

Luthar, S. S., y Zelazo, L. B. (2003). Research on resilience: An integrative review. En S. S. Luthar (Ed.), Resilience and vulnerability: Adaptation in the context of childhood adversities (pp. 510-549). Cambridge: Cambridge University Press doi:10.1017/CBO9780511615788.023

Luthar, S. S., y Zigler, E. (1991). Vulnerability and competence: A review of research on resilience in childhood. American Journal of Orthopsychiatry, 61(1), 6-22. 
Luthar, S. S., y Zigler, E. (1992). Intelligence and social competence among high-risk adolescents. Development and Psychopathology, 4(2), 287-299. doi: $10.1017 /$ S0954579400000158

Lynam, T., De Jong,W., Sheil, D., Kusumanto, T., y Evans, K. (2007). A review of tools for incorporating community knowledge, preferences, and values into decision making in natural resources management. Ecology and Society 12(1): 5. Recuperado de:http://www.ecologyandsociety. org/vol12/iss1/art5/

Mackenzie, K., yWilliams, C. (2018). Universal, school-based interventions to promote mental and emotional well-being: what is being done in the UK and does it work? A systematic review. Mental Health Research, BMJ Open 2018;8:e022560. doi: 10.1136/bmjopen-2018-022560

Macklem, G. (2014). Preventive mental health at school: Evidence-based services for students. Nueva York, EU: Springer. doi: 10.1007/978-1-4614-8609-1

Mactavish, J., Schleien, S., y Tabourne, C. (1997). Patterns of family recreation in families that include children with a developmental disability. Journal of Leisure Research, 29(1), 21-46.

Mahoney, J. L., Larson, R. W., y Eccles J. S. (2005a). Organized activities as contexts of development: extracurricular activities, after-school and community programs Mahwah, NJ: Erlbaum.

Mahoney, J.L., Lord, J.H., y Carryl, E. (2005b). An ecological analysis of after-school program participation and the development of academic performance and motivational attributes for disadvantaged children. Child Development, 76(4), 811-825.

Mahoney, J. L., y Bergman, L. R. (2002). Conceptual and methodological considerations in a developmental approach to the study of positive adaptation. Applied Developmental Psychology, 23(2), 195-217. doi: 10.1016/S0193-3973(02)00104-1 
MajnemerA., Shevell M. , Law M., Birnbaum R., Chilingaryan G., Rosenbaum P., y Poulin C. (2008). Participation and enjoyment of leisure activities in school-aged children with cerebral palsy. Developmental Medicine and Child Neurology, 50, 751-758. doi:10.1111/j.1469-8749.2008.03068.x

Majnemer, A., Shikako-Thomas, K., Chokron, N., Law, M., Shevell, M., Poulin, C., y Rosenbaum, P. (2010).Leisure activity preferences for 6- to 12-year-old children with cerebral palsy. Developmental Medicine \& Child Neurology, 52(2), 167-173. doi: 10.1111/j.1469-8749.2009.03393.x

Mancini, M.C., Coster, W.J., Trombly, C.A., y Heeren, T.C. (2000). Predicting elementary school participation in children with disabilities. Archives of Physical Medicine and Rehabilitation, 81, 339-347

Mardia, K.V. (1970). Measures of multivariate skewness and kurtosis with applications. Biometrika, 57, 519-530.

Marsh, H. W., Hau, K. T., y Wen, Z. (2004). In search of golden rules: Comment on hypothesis-testing approaches to setting cutoff values for fit indexes and dangers in overgeneralizing $\mathrm{Hu}$ and Bentler's (1999) findings. Structural equation modeling, 11(3), 320-341. doi:10.1207/ s15328007sem1103_2

Martínez-Arias, M. R., Hernández-Lloreda, M. V., y Hernández-Lloreda, M. J. (2014). Psicometría (1 $1^{\mathrm{a}}$ ed.). Madrid, España: Alianza Editorial.

Mash, E. J., y Wolfe, D. A. (2019). Abnormal child psychology (7th., ed.). Boston, MA: Cengage Learning.

Masten, A. S. (2001). Ordinary magic: Resilience processes in development. American Psychologist, 56(3), 227-238.

Masten, A. S. (2007). Resilience in developing systems: Progress and promise as the fourth wave rises. Development and Psychopathology, 19(3), 921-930.

Masten, A. S., Best, K. M., y Garmezy, N. (1990). Resilience and development: Contributions from the study of children who overcome adversity. Development and Psychopathology, 2(4), 425-444. doi:10.1017/ S095457940000581 
Masten, A. S., y Coatsworth, J. D. (1998). The development of competence in favorable and unfavorable environments: Lessons from research on successful children. American Psychologist, 53(2), 205-220.

Masten, A.S., y Powell, J.L. (2003). A resilience framework for research, policy, and practice. En S. S. Luthar (Ed), Resilience and vulnerability: Adaptation in the context of childhood adversities, (pp. 1-25). New York, EU: Cambridge University Press. doi: 10.1017/CBO9780511615788.003

Masten, W., y Wright, M. O. (2009). Resilience over the lifespan. En J. W. Reich (Ed.), Handbook of adult resilience (pp. 213-237). New York, EU: Guilford Publications. doi:10.1080/17439760.2011.614836

Matza, L. S., Swensed, A. R., Flood, E. M., Secnik, K., y Leidy, N. K. (2004). Assessment of health-related quality of life in children: Review of conceptual, methodological, and regulatory issues. Value in Health, 7(1), 79-92.

Maxwell, G. (2012). Bringing more to participation [Tesis Doctoral, Jönköping University]. http://hj.diva-portal.org

Maxwell, G., Alves, I., y Granlund, M. (2012) Participation and environmental aspects in education and the ICF and the ICF-CY: findings from a systematic literature review. Developmental Neurorehabilitation, 15(1), 63-78. doi: 10.3109/17518423.2011.633108

McDonald, R. P. (1999). Test theory:A unified approach. Mahwah, NJ: Lawrence Erlbaum Associates.

McWilliam, R., y Casey, A.M. (2008). Engagement of Every Child in the Preschool Classroom. Baltimore, MD: Paul Brookes.

Michel, G., Bisegger, C. Fuhr, D.C., Abel, T., y Kidscreen-Group (2009). Age and gener differences in health-related quality of life of children and adolescents in Europe: a multilevel analysis. Quality of Life Research, 18(9), 1147-1157. doi: 10.1007/s11136-009-9538-3 
Ministerio de Educación, Cultura y Deporte: MECD (2015). Revisión Nacional 2015 de la Educación para Todos: España. UNESCO. Recuperado de: unesdoc.unesco.org/

Ministerio de Educación, Cultura y Deporte: MECD (2017a). Estadísticas de las enseñanzas no universitarias. Alumnado con Necesidad Específica de Apoyo Educativo. Curso 2015-2016. Recuperado de: https: / /www.mecd.gob.es / $\mathrm{dms} / \mathrm{mecd} /$ servicios.../Necesidades.../Nota-Resumen.pdf

Ministerio de Educación, Cultura y Deporte: MECD (2017b). Datos y Cifras. Curso escolar 2016-2017. Recuperado de: https://www.mecd.gob.es/ servicios-al.../datos-cifras/Datosycifras1617esp.pdf

Ministerio de Educación, Cultura y Deporte: MECD (2019). Datos y Cifras. Curso escolar 2019-2020. Recuperado de: https://www.educacionyfp. gob.es / dam / jcr:b998eea 2-76c0-4466-946e-965698e9498d/ datosycifras1920esp.pdf

Ministerio de Educación, Política Social y Deporte: MEPSYD (2008). III y IV Informe de Aplicación de la Convención sobre los Derechos del Niño en España. Recuperado de http: / /www.observatoriodelainfancia.msssi.gob.es/

Ministerio de Sanidad, Servicios Sociales e Igualdad: MSSSI (2013). II PENIA: Plan Estratégico Nacional de Infancia y Adolescencia 2013-2016. Recuperado http: / /www.bienestaryproteccioninfantil.es/

Ministerio de Trabajo y Asuntos sociales: MTAS (2006). I PENIA: Plan Estratégico Nacional de Infancia y Adolescencia 2006-2009. Recuperado de http: / /www.bienestaryproteccioninfantil.es/

Missiuna, C., Moll, S., Law, M., King, S., y King, G. (2006). Mysteries and mazes: Parents' experiences of children with developmental coordination disorder. Canadian Journal of Occupational Therapy, 73(1), 7-1.

Monjas, Ma I. (2004). Programa de enseñanza de habilidades de interacción social (PEHIS) para niños y adolescentes ( $1^{\mathrm{a}} \mathrm{ed} ., 7^{\mathrm{a}}$ imp.). Madrid, España: CEPE.

Monjas, M ${ }^{\mathrm{a}}$ I. (Dir.) (2007). Cómo promover la convivencia:Programa de Asertividad y Habilidades Sociales (PAHS). Madrid, España: CEPE. 
Monjas, Ma I., y González, B. (2000). Las habilidades sociales en el currículo. Madrid: Ministerio de Educación, Cultura y Deporte. Centro de Investigación y Documentación Educativa (CIDE).

Montoya, N. E., Restrepo, A., Duque, L. F., y Ungar, M. (2011). Predicting resilient adolescents and youths: validation of screening test in Colombia. Issues in Comprehensive Pediatric Nursing, 34(4), 167-88. doi: 10.3109/01460862.2011.619400

Morata-Ramírez, M. A., Holgado-Tello, F. P., Barbero-García, I., y Méndez, G. (2015). Análisis factorial confirmatorio. Recomendaciones sobre mínimos cuadrados no ponderados en función del error típico I de jicuadrado y RMSEA. Acción Psicológica, 12(1), 79-90. doi:10.5944/ ap. 12.1 .14362

Morley, D., Bailey, R., Tan, J., y Cooke, B. (2005). Inclusive Physical Education: teachers' views of including pupils with Special Educational Needs and/or disabilities in Physical Education. European Physical Education Review, 11(1), 84-107.

Muntaner, J. J. (2010). De la integración a la inclusión: un nuevo modelo educativo. En Arnaiz, P.; Hurtado, Ma . D. y Soto, F. J. (Coords.) 25 Años de Integración Escolar en España: Tecnología e Inclusión en el ámbito educativo, laboral y comunitario. Murcia, España: Consejería de Educación, Formación y Empleo.

Muntaner, J.J. (2013). Calidad de vida en la escuela inclusiva. Revista Iberoamericana de Educación, 63, 35-49. Recuperado de: rieoei.org/ rie63a02.pdf

Muntaner, J.J., Forteza, D., Rosselló, M.R., Verger, S., y De la Iglesia, B. (2010). Estándares e indicadores para analizar la calidad de vida del alumnado con discapacidad durante su proceso educativo. Palma de Mallorca, España: Edicions UIB. 
Muñiz, J., Elosua, P., y Hambleton, R. (2013). Directrices para la traducción y adaptación de los test: Segunda edición. Psicothema, 25(2), 151-157. doi: $10.7334 /$ psicothema2013.24

Muñoz Silva, A. (2005). La familia como contexto de desarrollo infantil, dimensiones de análisis relevantes para la intervención educativa y social. Portularia, 2(5), 147-163.

Muthén, B., y Kaplan, D. A. (1992). Comparison of some methodologies for the factor-analysis of non-normal Likert variables: A note on the size of the model. British Journal of Mathematical and Statistical Psychology, 45(1), 19-30. doi: 10.1111/j.2044-8317.1992.tb00975.x

Nava-Galán, M. G. (2012). La calidad de vida: Análisis multidimensional. Enfermería Neurológica 11(3), 129-137. Recuperado de: http://www. medigraphic.com/

Naglieri, J.A., y LeBuffe, P.A. ( 2005). Measuring resilience in children. En S. Goldstein y R. Brooks (Eds.), Handbook of resilience (pp. 107-124). New York, EU: Kluwer.

Nastasi, B. K., Hart, S. N., y Naser, S. C. (2020). International handbook on child rights and school psychology. Cham, Switzerland: Springer. doi:10.1007/978-3-030-37119-7

Navarro-Barba, J. (coord.) (2011). Diversidad, calidad y equidad educativas. Murcia, España: Consejería de Educación, Formación y Empleo.

Neldner, K., Mushin, I., y Nielsen, M. (2017). Young children's tool innovation across culture: affordance visibility matters. Cognition, 168, 335-343. doi: 10.1016/j.cognition.2017.07.015

Nelson, C., McDonnell, A. P., Johnston, S. S., Crompton, A., y Nelson, A. R. (2007). Keys to play: A strategy to increase the social interactions of young children with autism and their typically developing peers. Education and Training in Developmental Disabilities, 42, 165-181. 
Noreau, L., y Boschen, K. (2010). Intersection of participation and environmental factors: a complex interactive process. Archives of Physical Medicine and Rehabilitation, 91(9), 44-53. doi: 10.1016/j. apmr.2009.10.037

Noreau, L., Lepage, C., Boissiere, L., Picard, R., Fougeyrol- las, P., Mathieu, J.,...Nadeau, L. (2007). Measuring participation in children with disabilities using the Assessment of Life Habits. Developmental Medicine and Child Neurology, 49(9), 666-671.

Nordström, I. (2011). Inclusion and participation in peer relations. Scandinavian Journal of Disability Research, 13(1), 71-87. doi:10.1080/15017411003711775

Nunnally, J. C., y Bernstein, I. H. (1994). Psychometric theory (3rd ed.). New York, EU: McGraw-Hill.

Oberle, E., Ji, X. R., Magee, C., Guhn, M., Schonert-Reichl, K. A., y Gadermann, A. M. (2019). Extracurricular activity profiles and wellbeing in middle childhood: A population-level study. PLoS One 14(7):e0218488. doi: 10.1371 /journal.pone.0218488

O’Dougherty-Wright, M., Masten, A.S., Northwood, A., y Hubbard, J.J. (1997). Long-term effects of massive trauma: Developmental and psychobiological perspectives. En D. Cicchetti, y S.L. Toth, (Eds.), Rochester Symposium on Developmental Psychopathology: vol. 8. Developmental perspectives on trauma (pp. 181-225). Rochester, US: University of Rochester Press.

Oliver, M. (1998). ¿Una sociología de la discapacidad o una sociología discapacitada? En L. Barton (Comp.). Discapacidad y sociedad (pp. 34-58). Madrid, España: Morata.

Oliver, M. (2004). If I had a hammer: The social model in action. En J. Swain, S. French, C. Barnes y C. Thomas (Eds.). Disabling barriers, enabling environments. ( ${ }^{\circ}$ Ed.) (7-12). London, UK: Sage. doi: $10.1080 / 09687599466780121$ 
Olsson, C.A., Bond, L., Burns, J.M., Vella-Brodrick, D.A., y Sawyer, S.M. (2003). Adolescent resilience: a concept analysis. Journal Adolescence, 26(1), 1-11.

OMS (2001). Clasificación Internacional del Funcionamiento, de la Discapacidad y de la Salud: CIF. Madrid: IMSERSO, OMS y OPS. Recuperado de: http: / / www.imserso.es/

OMS (2004). De la teoría a la práctica: indicadores de salud ambiental infantil : implementación de una iniciativa lanzada en la Cumbre Mundial sobre el Desarrollo Sostenible . Ginebra, Suiza: OMS. http://www.who.int/iris/ handle/10665/43053

OMS (2005). Informe sobre la salud en el mundo 2005. ¡Cada madre y cada niño contarán! Ginebra, Suiza: OMS.

OMS (2007). Clasificación Internacional del Funcionamiento, de la Discapacidad y de la Salud - Niños y Jóvenes: CIF-NJ. Madrid: IMSERSO, OMS y OPS. Recuperado de: http: / /www.imserso.es/

Orlin, M. N., Palisano, R. J., Chiarello, L. A., Kang, L.-J., Polansky, M., Almasri, N., y Maggs,J. (2010). Participation in home, extracurricular, and community activities among children and young people with cerebral palsy. Developmental Medicine and Child Neurology, 52, 160-166. doi: 10.1111/j.1469-8749.2009.03363.x

Organización Mundial de la Salud y UNICEF (2013). El desarrollo del niño en la primera infancia y la discapacidad: un documento de debate. Ginebra, Suiza: Organización Mundial de la Salud (OMS). http://www.who.int/iris/ handle/10665/78590

Organization for Economic Co-operation and Development: OCDE (2006). Assessing scientific, reading and mathematical literacy: A framework for PISA 2006. Paris, Francia: OCDE.

Organization of Economic Co-operation and Development: OCDE (2007). PISA 2006: Science competencies for tomorrow's world (vol. 1: Analysis). Paris, España: OCDE. 
Orosová, O., Benka, J., y Bavol’ár, J. (2017). Individual and psychosocial factors of mental health indicators among Slovak university students. Človek a spoločnost', 20(3), 15-29.

Oshri,A., Tropple,T.A., y Carlson, M.W. (2017). Positive youth development and resilience: Growth patterns of social skills among youth investigated for maltreatment. Child Development 88(4) 1087-1099. doi: 10.1111/ cdev. 12865

Ossa, C., Quintana, I., y Mendoza, R. (2015). Construyendo un modelo de calidad de vida escolar. En Saavedra et al. (Ed.): Resiliencia y calidad de vida. La Psicología Educacional en diálogo con otras disciplinas (pp. 95-107). Talca, Chile: Universidad Católica del Maule.

Palisano, R. J., Chiarello, L.A., Orlin, M., Oeffinger, D., Polansky, M., Maggs, J.,...Children's Activity and Participation Group. (2011). Determinants of intensity of participation in leisure and recreational activities by children with cerebral palsy. Developmental Medicine and Child Neurology, 53(2), 142-149. doi: 10.1111/j.1469-8749.2010.03819.x

Panter-Brick, C. (2002). Street children, human rights and public health: a critique and future considerations. Annual Review Anthropology, 31, 147171 Recuperado de: http://www.jstor.org/stable/4132875

Panter-Brick, C. (2014). Health, Risk, and Resilience: Interdisciplinary Concepts and Applications. Annual Review Anthropology, 43, 431-48 doi: 10.1146/annurev-anthro-102313-025944

Panter-Brick, C., y Eggerman, M. (2012). Understanding culture, resilience, and mental health:The production of hope. En M. Ungar (Ed.), The social ecology of resilience: $A$ handbook of theory and practice (pp. 369-386). New York, EU: Springer. doi: 10.1007/978-1-4614-0586-3_29

Panter-Brick, C., Eggerman, M., yTomlinson, M. (2014). How might global health master deadly sins and strive for greater virtues? Global Health Action, 7 doi: 10.3402/gha.v7.23411 
Panter-Brick, C., y Fuentes, A. (Eds.) (2010). Health, Risk, and Adversity. New York, EU: Berghahn Books. doi: 10.1017/S0021932009990459

Panter-Brick, C., Hadfield, K., Dajani, R., Eggerman, M., Ager, A., y Ungar, M. (2017). Resilience in context: a brief and culturally grounded measure for syrian refugee and Jordanian host-community adolescent. Child development, 89(5):1803-1820. doi: 10.1111/cdev.12868

Park, N., y Peterson, C. (2006). Character strengths and happiness among young children: context analysis of parental descriptions. Journal of Happiness Studies, 7, 323-341. doi:10.1007/s10902-005-3648-6

Passmore, A., y French, D. (2003). The nature of leisure in adolescence: A focus group study. British Journal of Occupational Therapy, 66 (9), 419-426.

Payot, A., y Barrington, K.J. (2011). The quality of life of young children and infants with chronic medical problems: review of the literature. Current Problems in Pediatric and Adolescent Health Care, 41(4), 91-101. doi: 10.1016/j.cppeds.2010.10.008

Perenboom, R.J., y Chorus, A.M. (2003). Measuring participation according to the International Classification of Functioning, Disability and Health (ICF). Disability \& Rehabilitation, 25(11-12), 577-587.

Pearrow, M., y Jones, J. (2020). School-based behavioral health services: A public health model for prevention. En C. Maykel y M. A. Bray (Eds.), Applying psychology in the schools. Promoting mind-body health in schools: Interventions for mental health professionals (pp. 45-60). Washington D. C., EU: American Psychological Association. doi:10.1037/0000157-004

Peters, R. D. (2005). A community-based approach to promoting resilience in young children, their families, and their neighborhoods. En R. D. Peters, B. Leadbeater, y R. J. McMahon (Eds.), Resilience in children, families, and communities: Linking context to practice and policy (pp. 157-176). New York, EU: Kluwer. doi:10.1007/0-387-23824-7_10 
Peterson, C., y Park, N. (2011). Character strengths and virtues: Their role in well-being. En S.I. Donaldson, M. Csikszentmihaly, y J. Nakamura (Eds.), Applied Positive Psychology. Improving Everyday Life, Health, Schools, Work and Society (pp. 49-62). Nueva York, NY: Routledge.

Phelps, E., Balsano, A. B., Fay, K., Peltz, J. S., Zimmerman, S. M., Lerner, R. M., y Lerner, J. V. (2007). Nuances in early adolescent developmental trajectories of positive and of problematic / risk behaviors: Findings from the 4-H study of positive youth development. North American Clinics of Child and Adolescent Psychiatry, 16, 473-496.

Phillips, R. L., Olds, T., Boshoff, K., y Lane, A. E. (2013). Measuring activity and participation in children and adolescents with disabilities: A literature review of available instruments. Australian Occupational Therapy Journal, 60(4), 288-300. doi:10.1111/1440-1630.12055

Piccininni, C., Michaelson, V., Janssen, I., y Pickett, W. (2018). Outdoor play and nature connectedness as potential correlates of internalized mental health symptoms among Canadian adolescents. Preventive medicine, 112, 168-175.

Pierce, K.M., Bolt, D.M., y Vandell, D.L. (2010). Specific features of afterschool program quality: Associations with children's functioning in middle childhood. American Journal of Community Psychology, 45, 381-393.

Piña-López (2015). Un análisis crítico del concepto de resiliencia en psicología. Anales de Psicología, 31(3), 751-758. Recuperado de: https: / / www.researchgate.net/

PNUD (2009). Informe sobre desarrollo humano 2009. Superando barreras: movilidad y desarrollo humanos. New York, EU: Programa de las Naciones Unidas para el Desarrollo.

Belgrave, F.Z., Reed, M. C., Plybon, L.E., y Corneille, M. (2004). The impact of a culturally enhanced drug prevention program on drug and alcohol refusal efficacy among urban African American girl. Journal of Drug Education, 34, 267-279. 
Polk, L. V. (1997). Toward a middle-range theory of resilience. Advances in Nursing Science, 19(3), 1-13.

Ponce-Cisternas, F. P. (2015). Análisis exploratorio de modelos de ecuaciones estructurales sobre la escala de resiliencia de Connor y Davidson (CDRISC) en Chile y España. Salud y Sociedad, 6(3), 238-247. doi: 10.22199/ S07187475.2015.0003.00004

Ponce-Meza, J. (2017). Atención temprana en niños con trastornos del neurodesarrollo. Propósitos y Representaciones, 5(1), 403-422 http:// dx.doi.org/10.20511/pyr2017.v5n1.154

Prince-Embury, S. (2006). Resiliency Scales for Children and Adolescents: Profiles of personal strengths. San Antonio, TX: Harcourt Assessments.

Prince-Embury, S. (2008). The Resiliency Scales for Children and Adolescents, Psychological Symptoms, and Clinical Status in Adolescents. Canadian Journal of School Psychology, 23, 41-56. doi:10.1177/0829573508316592

Prince-Embury, S. (2014). Review of Resilience Conceptual and Assessment Issues. En Prince-Embury S. y Saklofske D. H.(Eds.), Resilience Interventions for Youth in Diverse Populations (pp. 13-23). New York, EU: Springer. doi: 10.1007/978-1-4939-0542-3_2

Prince-Embury, S., y Saklofske, D. H. (Eds.). (2013). Resilience in children, adolescents, and adults: Translating research into practice. New York, EU: Springer. doi: 10.1177/0734282913151684

Prince-Embury S., Saklofske D. (2014). Resilience interventions for youth in diverse populations. New York, EU: Springer.

Quiceno, J. M., y Vinaccia, S. (2013). Calidad de vida relacionada con la salud infantil una aproximación desde la enfermedad crónica. Psychologia: avances de la disciplina, 7(2), 69-86. 
Rajmil, L., Serra-Sutton, V., Fernández-López, J. A., Berra, S., Aymerich, M., Cieza, A., Ferrer, M., Bullinger, M., y Raven-Sieberer, U. (2004). Versión española del cuestionario alemán de calidad de vida relacionada con la salud en población infantil y de adolescentes: el Kindl. Anales de Pediatría, 60, 514-521. doi: 10.1016/S1695-4033(04)78320-4

Rapley, M. (2003). Quality of life research: A critical introduction. London, UK: Sage. Recuperado de: https: / / books.google.es

Rashid, T., Anjum, A., Chu, R., Stevanovski, S., Zanjani, A., y Lennox, C. (2014). Strength based resilience: Integrating risk and resources towards holistic well-being. En G.A. Fava y C. Ruini (Eds.), Increasing psychological well-being in clinical and educational settings (153-176). New York, EU: Springer. doi: 10.1007/978-94-017-8669-0_10

Ravens-Sieberer, U., Auquier, P., Erhart, M., Gosch, A., Rajmil, L., Bruil, J., Power, M., Duer, W., Cloetta, B., Czemy, L., Mazur, J., Czimbalmos, A., Tountas, Y., Hagquist, C., Kilroe, J., y European Kidscreen Group (2007). The KIDSCREEN-27 quality of life measure for children and adolescents: psychometric results from a cross-cultural survey in 13 European countries. Quality of Life Research, 16, 1347-56. doi: 10.1007/ s1 1136-007-9240-2

Ravens-Sieberer, U., y Bullinger, M. (1998). Assessing health-related quality of life in chronically ill children with the German KINDL: First psychometric and content analytical results. Quality of Life Research, 7, 339-407. doi: 10.1023/a:1008853819715

Ravens-Sieberer, U., Devine, J., Bevans, K., Riley, A.W., Moon, J., Salsman, J. M., y Forrest, C. B. (2014a). Subjective well-being measures for children were developed within the PROMIS project: Presentation of first results. Journal of Clinical Epidemiology, 67, 207-218. doi:10.1016/j. jclinepi.2013.08.018 
Ravens-Sieberer, U, Erhart, M., Rajmil, L. Herdman, M. Auquier, P., Bruil., J., Power, M., Duer, W., Abel, T., Czemy, L., Mazur, J., Czimbalmos, A., Tountas, Y., Hagguist, C., Kilroe, J., y European KIDSCREEN Group (2010). Reliability, construct validity and criterion validity of the KIDSCREEN-10 score: A short measure for children and adolescents' well-being and health-related quality of life. Quality of Life Research, 19(10) 1487-1500. doi: 10.1007/s11136-010-9706-5

Ravens-Sieberer, U., Erhart, M., Wille, N., Wetzel, R., Nickel, J., y Bullinger, M. (2006). Generic health-related quality-of-life assessment in children and adolescents: Methodological considerations. PharmacoEconomics, 24(2), 1199-1220.

Ravens-Sieberer, U., Gosch, A. , Rajmil, L., Erhart, M., Bruil, J., Dür, W., Auquier, P., Poder, M., Abel, T., Czemy, L ., Mazur, J., Czimbalmos, A., Tountas, Y., Hagquist, C., Kilroe, J., y Grupo europeo KIDSCREEN. (2005). KIDSCREEN-52 medida de la calidad de vida de los niños y adolescentes. Revisión de Expertos de Farmacoeconomía y Resultados de Investigación, 5(3), 353-364.

Ravens-Sieberer, U., Gosch, A., Rajmil, L., Erhart, M., Bruil, J., Power, M., Duer, W. Auquier, P., Cloetta, B., Czemy, L., Mazur, J., Czimbalmos, A., Tountas, Y., Hagquist, C., Kilroe, J., y KIDSCREEN Group (2008). The KIDSCREEN-52 quality of life measure for children and adolescents: Psychometric results from a cross-cultural survey in 13 European countries. Value in Health, 11(4), 645-658. doi: 10.1111/j.15244733.2007.00291

Ravens-Sieberer, U., Herdman, M., Devine, J., Otto, C., Bullinger, M., Rose, M., y Klasen, F. (2014b). The European KIDSCREEN approach to measure quality of life and well-being in children: development, current application, and future advances. Qual Life Res, 23(3), 791-803. doi: $10.1007 / \mathrm{s} 11136-013-0428-3$ 
Raymond, I. J., Iasiello, M., Jarden, A., y Kelly, D. M. (2018). Resilient futures: An individual and system-level approach to improve the wellbeing and resilience of disadvantaged young Australians. Translational Issues in Psychological Science, 4(3), 228-244. doi:10.1037/tps0000169

Ravens-Sieberer, U., Karow, A., Barthel, D. , y Klasen (2014c). How to assess quality of life in child and adolescent psychiatry. Dialogues in Clinical Neuroscience, 16(2), 147-158.

Reckase, M. (2009). Multidimensional Item Response Theory. New York, EU: Springer.

Reed, R.V., Fazel, M., Jones, L., Panter-Brick, C., y Stein, A. (2012). Mental health of displaced and refugee children resettled in low-income and middle-income countries: risk and protective factors. Lancet, 379(9812), 250-265. doi: 10.1016/S0140-6736(11)60050-0

Rebekah, G., Walsh, R., y Baird, K. (2016). Connection special objects and congruence: the perspectives of young children from disadvantage communities on participation in early childhood education settings. Early Child Development and Care, 188(2), 1-14.

Reise, S. R., Cook, K. F., y Moore, T. M. (2015). Evaluating the impact of multidimensionality on unidimensional item response theory model parameters. En S. P. Reise y D. A. Revicki (Eds.), Handbook of item response theory modeling: Applications to typical performance assessment (pp. 13-40). New York, EU: Routledge.

Reynolds, C.R., y Kamphaus, R.W. (2004). Behavior assessment system for children ( $2^{\mathrm{a}}$ ed.). Circle Pines, MN: American Guidance Service. doi: $10.1177 / 15345084070320020301$

Resilience Research Centre - RRC (2009). The Child and Youth Resilience Measure-28: User Manual. Halifax, NS: Dalhousie University. Recuperado de http: / / resilienceresearch.org / 
Resilience Research Centre - RRC (2017). Child and youth resilience measure \& adult resilience measure. Halifax, NS: Dalhousie University. Recuperado de http: / / resilienceresearch.org/

Resilience Research Centre - RRC (2018). CYRM/ARM RESEARCH TOOL. Halifax, NS: Dalhousie University. Recuperado de: http://cyrm. resilienceresearch.org/

Richardson, G. E. (2002). The metatheory of resilience and resiliency. Journal of Clinical Psychology, 58(3), 307-321. doi:10.1002/jclp. 10020

Risdal, D., y Singer, G. H. S. (2004). Marital Adjustment in Parents of Children with Disabilities: A Historical Review and Meta-Analysis. Research \& Practice for Persons with Severe Disabilities, 29, 95-103. doi:10.2511/ rpsd.29.2.95

Roberts, A., Hinds, J., y Camic, P. M. (2019). Nature activities and wellbeing in children and young people: a systematic literature review. Journal of adventure education and outdoor learning doi:10.1080/14729679.2019.16 60195

Rogers, S. J. (2000). Interventions that facilitate socialization in children with autism. Journal of Autism and Developmental Disorders, 30, 399-409. doi: 10.1023/A:1005543321840

Rodriguez, A., Reise, S. P., y Haviland, M. G. (2016). Evaluating bifactor models: calculating and interpreting statistical indices. Psychological Methods, 21(2), 137-150.

Rodríguez, G., Pérez, F., Gázquez, L., y Rodríguez, R. (2013). Propuesta de estudio sobre la influencia del estilo educativo parental en el nivel de adaptación e inteligencia emocional de menores en riesgo social. En Pérez, F. M. (Ed.), Variables psicológicas y educativas para la intervención en el ámbito escolar (pp. 339-344). Almería, España: Asociación Universitaria de Educación y Psicología.

Rodríguez-Jaume, M. J. (2000). Modelo socio-demográficos:Atlas social de la ciudad de Alicante [Tesis Doctoral, Universidad de Alicante]. https: / / rua.ua.es 
Roisman, G.I. (2005). Conceptual clarifications in the study of resilience. American Psychologist, 60(3), 264-265. doi:10.1037/0003-066X.60.3.264

Roizen, M., Rodriguez, S., Bauer, G., Medin, G., Bevilaqua, S., Varni, J.W., y Dussel, V. (2008). Initial validation of the Argentinean Spanish version of the PedsQL ${ }^{\mathrm{TM}}$ 4.0TM 4.0 Generic Core scales in children and adolescents with chronic diseases; acceptability and comprehensibility in low income settings. Health Qual Life Outcomes, 6:59. doi:10.1186/14777525-6-59

Rosenberg, L., y Bart, O. (2016). Different pathways to children's enjoyment of participation in daily activities. Scandinavian Journal of Occupational Therapy, 23(5), 366-373. doi:10.3109/11038128.2015.1130169

Rosenberg, L., Bart, O., Ratzon, N. Z., y Jarus, T. (2012). Personal and environmental factors predict participation of children with and without mild developmental disabilities. Journal of Child and Family Studies, 22, 658-671. doi:10.1007/s10826-012-9619-8.

Rosenblum, S., Sachs, D., y Schreuer, N. (2010). Reliability and validity of the children's leisure assessment scale. American Journal of Occupational Therapy, 64(4), 633-641.

Runswick-Cole, K., y Goodley, D. (2013). Resilience: A disability studies and community psychology approach. Social and Personality Psychology Compass, 7(2), 67-78. doi: 10.1111/spc3.12012

Rutter, M. (1987). Psychosocial resilience and protective mechanisms [special report]. American Journal of Orthopsychiatry, 57(3), 316-331. doi: 10.1111/j.1939-0025.1987.tb03541.x

Rutter, M. (1999). Resilience Concepts and Findings: Implications for Family Therapy. Journal of Family Therapy, 21(2), 119-144. doi: 10.1111/14676427.00108

Rutter M. (2012). Resilience as a dynamic concept. Development Psychopathology, 24(2), 335-44. doi: 10.1017/S0954579412000028 
Ruvalcaba-Romero N.A., Gallegos-Guajardo, J., y Villegas-Guinea J.G. (2014). Validación de la escala de resiliencia para adolescentes (READ) en México. Journal of Behavior, Health y Social Issues, 6(2), 21-34. doi:10.5460/jbhsi.v6.2.41180

Sabeh, E. (2003). Desarrollo y aplicación de un modelo de calidad de vida en niños de escolaridad primaria. En F. Gonzalez, M. I. Calvo y M. A. Verdugo (Coords.), Últimos avances en intervención en el ámbito educativo. Actas V congreso internacional de educación (125-132). Salamanca, España: INICO.

Sabeh, E., Verdugo, M. A., y Prieto, G. (2006). Dimensiones e indicadores de la calidad de vida en la infancia. En M. A. Verdugo (Ed.), Cómo mejorar la calidad de vida de las personas con discapacidad. Instrumentos y estrategias de evaluación (61-76). Salamanca, España: Amarú.

Sabeh, E., Verdugo, M. A., Prieto, G., y Contini, E. (2009). Cuestionarios de evaluación de la calidad de vida en la infancia. Madrid, España: CEPE.

Sacks, G., y Kern, L. (2008). A comparison of quality of life variables for students with emotional and behavioural disorders and students without disabilities. Journal of Behavioral Education, 17(1), 111-127. doi:10.1007/ s10864-007-9052-Z

Samejima, F. (1969). Estimation of latent ability using a response pattern of graded scores. Psychometrika Monograph Supplement, 34(4, Pt. 2), 100.

Sameroff, A., Gutman, L.M., y Peck, S.C. (2003). Adaptation among youth facing multiple risks: prospective research findings. En S. S. Luthar (Ed.), Resilience and Vulnerability: Adaptation in the Context of Childhood (pp. 364-391). New York, EU: Cambridge University Press. doi:10.1017/ CBO9780511615788.017

Sameroff, A.J., y Fiese, B.H. (1990). Transactional regulation and early intervention. En S.J. Meisels y J.P. Shonkoff (Eds.). Handbook of early childhood intervention (pp.119-149). Cambridge: Cambridge University Press. 
Sanchez-Herrero, S. A. (2008). La importancia de la perspectiva de género en la psicología del ocio. Anales de Psicología, 24(1), 64-76.

Sanders, J., Munford, R., Thimasarn-Anwar, T., y Liebenberg, L. (2015). Validation of the Child and Youth Resilience Measure (CYRM-28) on a Sample of At-risk New Zealand Youth. Research on Social Work Practice, 27(7), 827-840. doi:10.1177/1049731515614102

Sandler, I. N. (2001). Quality and ecology of adversity as common mediators of risk and resilience. American Journal of Community Psychology, 29(1), 19 - 63 doi:10.1023/A:1005237110505

Snyder, P., Hemmeter, M. L., Artman-Meeker, K., Kinder, K., Pasia, C., y McLaughlin, T. (2012). Characterizing key features of the early childhood professional development literature. Infants and young children, 25(3), 188-212.

Scales, P. C., Benson, P. L., Roehlkepartain, E. C., Hintz, N. R., Sullivan, T. K., y Mannes, M. (2001). The role of neighborhood and community in building developmental assets for children and youth: A national study of social norms among American adults. Journal of Community Psychology, 29, 703-727. doi: 10.1002/jcop. 1044

Schalock R. L. (2005). Introduction and overview to the special issue. Journal of Intellectual Disability Research, 49(9), 695-698. doi: 10.1111/j.13652788.2005.00737.x

Schalock. R. L., Bonham, G. S., yVerdugo. M.A. (2008). The conceptualization and measurement of quality of life: Implications for program planning and evaluation in the field of intellectual disabilities. Evaluation and Program Planning, 31(2), 181-190. doi: 10.1016/j.evalprogplan.2008.02.001

Schalock, R. L, Gardner, J., y Bradley, V. (2007). Quality of life for persons with intellectual and other developmental disabilities: Applications across individuals, organizations, communities and systems. Washington D.C., EU: American. 
Schalock, R. L., y Verdugo, M.A. (2002). Handbook on quality of life for human service Practitioners. Washington, DC: American Association on Mental Retardation.

Schalock, R.L. y Verdugo, M.A. (2003). Calidad de Vida. Manual para profesionales de la educación, salud y servicios sociales. Madrid, España: Alianza.

Schalock, R. L., y Verdugo, M.A. (2006). Revisión actualizada del concepto de calidad de vida. En M.A. Verdugo (Ed), Cómo mejorar la calidad de vida de las personas con discapacidad: instrumentos y estrategias de evaluación (2942). Salamanca, España: Amarú Ediciones.

Schalock, R. L., y Verdugo, M. A. (2013a). The transformation of disabilities organizations. Intellectual and Developmental Disabilities, 51(4), 273-286. doi: 10.1352/1934-9556-51.4.273

Schalock, R. L., y Verdugo, M. A. (2013b). La respuesta del futuro: organizaciones en innovación. En M. A. Verdugo, R. L. Schalock (Coord.) Discapacidad e Inclusión: Manual para la Docencia (495-511). Salamanca, España: Amarú Ediciones.

Schalock, R.L., Verdugo, M. A., Bonham, G., Fantova, F., y Van-Loon, J. (2008). Enhancing personal outcomes: organizational strategies, guidelines and examples. Journal of Policy in Intellectual Disabilities, 5(1), 18-28. doi: 10.1111/j.1741-1130.2007.00135.x

Schalock, R.L. Verdugo, M.A., Gómez, L.E., y Reinders, H.S. (2016a). Moving us toward a theory of individual quality of life. American Journal of Intellectual and Developmental Disabilities, 121, 1-12. doi: 10.1352/19447558-121.1.1

Schalock, R. L., Verdugo, M. A., Jenaro, C., Wang, M., Wehmeyer, M., $\mathrm{Xu}$, J., y Lachapelle, Y. (2005). Cross-cultural study of quality of life indicators. American Journal on Mental Retardation, 110, 298-311.

Schalock, R. L., Verdugo, M.A., y Lee, T. (2016b). A systematic approach to an organization's sustainability. Evaluation and Program Planning, 56, 56-63. doi:10.1016/j.evalprogplan.2016.03.005 
Schalock, R. L., Verdugo, M. A., y van Loon, J. (2018). Understanding organization transformation in evaluation and program planning. Evaluation and Program Planning, 67, 53-60.

Schmitt, T.A. (2011). Current methodological considerations in exploratory and confirmatory factor analysis. Journal of psychoeducational assessment, 29(4), 304-321. doi: 10.1177/0734282911406653

Schoon I. (Ed.) (2006). Risk and Resilience: Adaptation in Changing Times. Cambridge, UK: Cambridge University Press. doi:10.1017/ CBO9780511490132

Schoon, I., Bynner, J., Joshi, H., Parsons, S., Wiggins, R.D., y Sacker, A. (2002). The influence of context, timing and duration of risk experiences for the passage from childhood to early adulthood. Child Development, 73(5), 1486-1504. doi: 10.1111/1467-8624.00485

Schreuer, N., Sachs, D., y Rosenblum, S. (2014). Participation in leisure activities: differences between children with and without physical disabilities. Research in Developmental Disabilities, 35(1), 223-33. doi: 10.1016/j.ridd.2013.10.001

Schuntermann, M.F. (2005). The implementation of the International Classification of Functioning, Disability and Health in Germany: experiences and problems. International Journal of Rehabilitation Research, 28(2), 93-102.

Schwarz, G. (1978). Estimating the dimension of a model. Annals of Statistics, 6, $461-464$.

Seccombe, K. (2002). "Beating the odds" versus "changing the odds": poverty, resilience, and family policy. Journal of Marriage and Family, 64(2), 384 394. doi: 10.1111/j.1741-3737.2002.00384.x

Seligman, E. P., Ernst, M., Gillham, J., Reivich, K., y Linkins, M. (2009). Positive education: positive psychology and classroominterventions. Oxford Review of Education, 35(3), 293-311. doi:10.1080/03054980902934563 
Sen, A. (1993). Capability and Well-being. En M. Nussbaum y A. Sen (eds.) The Quality of Life. Oxford, England: Clarendon Press. [Trad. de R. Reyes, En Nussbaum y Sen (Eds.). La calidad de vida ( $3^{\text {rd }}$ reimpresión). México: Fondo de Cultura Económica, 2002].

Serra-Sutton, V. (2006). Desarrollo de la versión española del Child Health and Illness Profile para medir el estado de salud percibido en la adolescencia (tesis doctoral). Universidad Autónoma de Barcelona, España.

Shek, D.T.L. (2005). Perceived parental control processes, parent-child relational qualities, and psychological well-being in Chinese adolescents with and without economic disadvantage. Journal of Genetic Psychology, 166(2), 171-189 doi:10.3200/GNTP.166.2.171-18

Shernoff, D.J., y Schmidt, J.A. (2008). Further evidence of an engagementachievement paradox among U.S. high school students. Journal of Youth and Adolescence, 37(5), 564-580. doi:10.1007/s10964-007-9241-z

Shields, N., Synnot, A., y Kearns, C. (2015). The extent, context and experience of participation in out-of-school activities among children with disability. Research in Developmental Disabilities, 47, 165-174. doi: 10.1016/j.ridd.2015.09.007

Shikako-Thomas, K., Dahan-Oliel, N., Shevell, M., Law, M., Birnbaum, R., Rosenbaum,...Majnemer, A. (2012). Play and be happy? Leisure participation and quality of life in school-aged children with cerebral palsy. International Journal of Pediatrics. doi:10.1155/2012/38728

Shikako-Thomas, K., Majnemer, A., Law, M., y Lach, L. (2008). Determinants of participation in leisure activities in children and youth with cerebral palsy: Systematic review. Physical and Occupational Therapy in Pediatrics, 28(2), 155-170.

Shimoni, M., Engel-Yeger, B., y Tirosh, E. (2010). Participation in leisure activities among boys with attention deficit hyperactivity disorder. Research in Developmental Disabilities, 31(6), 1234-1239. doi: 10.1016/j. ridd.2010.07.022 
Shochet, I.M., Dadds, M.R., Holland, D., Whitefield, K., Harnett, P.H., y Osgarby, S.M. (2001). The efficacy of a universal school-based program to prevent adolescent depression. Journal Clinical Child Psychology, 30(3), 303-315. doi:10.1207/S15374424JCCP3003

Shoshani, A., y Slone, M. (2013). Middle school transition from the strengths perspective: young adolescents' character strengths, subjective wellbeing, and school adjustment. Journal of happiness studies, 14(4), 11631181.

Shoshani, A., y Slone, M. (2017). Positive Education for Young Children: Effects of a Positive Psychology Intervention for Preschool Children on Subjective Well Being and Learning Behaviors. Frontiers in Psychology, doi: 10.3389/fpsyg. 2017.01866

Siméoni, M.C., Auquier, P., Antoniotte, S., Sapin, C., y San Marco, J.L. (2000). Validation of a French health-related quality of life intrument for adolescents: The VSP-A. Qual Life Res, 9, 393-403.

Simón-Saiz, M. J., Fuentes-Chacón, R. M., Garrido-Abejar, M., SerranoParra, M. D., Larrañaga-Rubio, E. yYubero-Jiménez, S. (2018). Influence of resilience on health-related quality of life in adolescents. Enfermería Clínica, 28(5), 283-291.

Simpkins, S. D., Vest, A. E., y Becnel, J. N. (2010). Participating in sport and music activities in adolescence: The role of activity participation and motivational beliefs during elementary school. Journal of Youth and Adolescence, 39, 1368-1386. doi:10.1007/s10964-009-9448-2

Síndic de Greuges (2014). Informe sobre los derechos del niño. 25 años de la convención: principales retos pendientes, 2014. Barcelona, España: Síndic de Greuges de Catalunya. Recuperado de http://www.sindic.cat/

Simeonsson, R. J., Carlson, D., Huntington, G. S., McMillen, J. S., y Brent, J. L. (2001). Students with disabilities: a national survey of participation in school activities. Disability and Rehabilitation, 23(2), 49-63. 
Simpkins, S.D., Ripke, M., Huston, A.C., y Eccles, J.S. (2005). Predicting participation and outcomes in out-of-school activities: similarities and differences across social ecologies. New DirYouth Development, 105(10-11), 51-69.

Skinner, D., Matthews, S., y Burton, L. (2005). Combining ethnography and GIS technology to examine constructions of developmental opportunities in contexts of poverty and disability. En T. S. Weisner (Ed.), Discovering successful pathways in children's development (pp.223-239). Chicago, IL: The University of Chicago Press. doi: 10.1111/j.1548-1352.2010.01123.x

Sloper, P., Knussen, C., Turner, S., y Cunningham, C. (1991). Factors related to stress and satisfaction with life in families of children with Down's Syndrome. Journal of Child Psychology and Psychiatry, 32(4), 655-676.

Smith, A., y Stirling, A. (2010). The politics of social-ecological resilience and sustainable socio-technical transitions. Ecology and Society, 15(1), 11. Recuperado de: http: / / www.ecologyandsociety.org/vol15/iss1/art11/

Smith,V., y Schonert-Reichl, K.A. (2013). Contextual facilitators: Resilience, sense of coherence, and hope. In G. M. Ronen and P. L. Rosenbaum (Eds.), Life quality outcomes in children and young people with neurological and developmental conditions (120-135). London, UK: MacKeith Press.

Smith E.P., Witherspoon D.P., y Osgood D.W. (2017). Positive youth development among diverse racial-ethnic children: quality afterschool contexts as developmental assets. Child development, 88(4), 1063-1078. doi: $10.1111 /$ cdev. 12870

Smith, J. S. (2006). Similarities and differences in students' and parents' perceptions of the transition from middle school to high school. RMLE Online, 29(10), 1-9. doi: 10.1080/19404476.2006.11462033

Snyder, F. J., y Flay, B. R. (2012). Positive youth development. En P. Brown, M. W. Corrigan, \& A. Higgins-D’ Alessandro (Eds.), Handbook of prosocial education (pp. 415-443). Lanham, MD: Rowman \& Little-eld Publishing Group. 
Solans, M., Pane, S., Estrada, M. -D., Serra-Sutton, V., Berra, S., Herdman, M., Aloson, J., y Rajmil, L. (2008). Health-related quality of life measurement of children and adolescents: A systematic review of generic and disease-specific instruments. Value in Health, 11(4), 742-764. doi:10.1111/j.1524-4733.2007.00293.x

Solis, J. (2003). Re-thinking illegality as a violence against, not by Mexican immigrants, children, and youth. Journal of Social Issues, 59(1), 15-33. doi: $10.1111 / 1540-4560.00002$

Southwick, S.M., Bonanno, G.A., Masten, A.S., Panter-Brick, C., y Yehuda R. (2014) Resilience definitions, theory, and challenger: interdisciplinary perspectives. European Journal Psychotraumatology, 1; 5 doi:10.3402/ejpt. v5.25338

Souza, J. M. y Verissimo, R. M. (2015). Child development: analysis of a new concept. Revista Latino-Americana de Enfermagem, 23(6), 1097-1104. doi: 10.1590/0104-1169.0462.2654

Spencer-Cavaliere, N., y Watkinson, E. J. (2010). Inclusion understood from the perspectives of children with disability. Adapted Physical Activity Quarterly, 27(4), 275-293.

Stucki, G. (2005). International Classification of Functioning, Disability, and Health (ICF): A promising framework and classification for rehabilitation medicine. American Journal of Physical Medicine \& Rehabilitation, 84(10), 733-740.

Summers, J., Larkin, D., y Dewey, D. (2008). Activities of daily living in children with developmental coordination disorder: Dressing, personal hygiene and eating skills. Human, Movement Science, 27(2), 215-229. doi: 10.1016/j.humov.2008.02.002

Sun, J., y Stewart, D. (2007). Development of population-based resilience measures in the primary school setting. Health Education, 7(6), 575-599. 
Tamm M., y Skär L. (2000). How I play: Roles and relations in the play situations of children with restricted mobility. Scandinavian Journal of Occupational Therapy, 7, 174-182. doi:0.1080/110381200300008715

Taylor, L. R. (2005). Dangerous trade-offs: The behavioral ecology of child labor and prostitution in rural northern Thailand. Current Anthropology, 46(3), 411-423. Recuperado de: www.journals.uchicago.edu/

Taylor, R. D., Oberle, E., Durlak, J. A., y Weissberg, R. P. (2017). Promoting positive youth development through school-based social and emotional learning interventions: A meta-analysis of follow-up effects. Child Development, 88, 1156-1171. doi: 10.1111/cdev.12864

Tebes, J.K., Feinn, R., Vanderploeg, J.J., Chinman, M.J., Shepard J., Brabham T.,...Connell, C. (2007). Impact of a positive youth development program in urban after-school settings on the prevention of adolescent substance use. Journal of Adolescent Health, 41(3), 239-247.

Tempski, P., Santos, I.S., Mayer, F.B., Enns, S.C., Perotta, B., Paro, M.S., Gannam, S., Peleias, M., Garcia, L.V., Baldassin, S., Guimaraes, K.B., Silva, N.R., Navarro da Cruz, M.T., Tofoli, L., Silveira, S.P., y Martins, M.A (2015) Relationship among Medical Student Resilience, Educational Environment and Quality of Life. PLoS ONE 10(6). doi:10.1371/journal. pone. 0131535

Ten Berger, J.M.F. (1977). Orthogonal Procrustes rotation for two or more matrices. Psychometrika, 42, 267-276.

Ten-Hove, J., y Rosenbaum, P (2018). The concept of resilience in childhood disability: Does the International Classification of Functioning, Disability and Health help us?. Child: care, health and development, 44(5), 730-735. doi: $10.1111 /$ cch. 12590

Thomaes, S. Sedikides, C., van den Bos N., Hutteman R., y Reijntjes A. (2017). Happy To Be “Me?” Authenticity, Psychological Need Satisfaction, and Subjective Well-Being in Adolescence. Child Development, 88(4), 1045-1056. doi: 10.1111/cdev. 12867. 
Thurstone, L. L. (1935). The vectors of the mind. Chicago, US: University of Chicago Press.

Tiet, Q. Q., Bird, H. R., Davies, M., Hoven, C., Cohen, P., Jensen, P., y Goodman, S. (1998). Adverse life events and resilience. Journal of the American Academy of Child and Adolescent Psychiatry, 37, 1191-1200. doi:10.1097/00004583-199811000-00020

Timmerman, M. E., y Lorenzo-Seva, U. (2011). Dimensionality assessment of ordered polytomous items with parallel analysis. Psychological Methods, 16(2), 209-220. doi:10.1037/a0023353

Tisdall, E. K. M., y Riddell, S. (2006). Policies on special needs education: competing strategies and discourses. European Journal of Special Needs Education, 21(4), 363-379. doi:10.1080/08856250600956154

Tonon, G (2009). Los estudios sobre calidad de vida y la perspectiva de la Psicología Positiva. Psicodebate, Psicología, Cultura y Sociedad, 10, 73-81. Recuperado de: https: / / dspace.palermo.edu/

Trompetter, H. R., Bohlmeijer, E. T., Lamers, S. M. A., y Schreurs, K. M. G. (2016). Positive Psychological Wellbeing Is Required for Online Self-Help Acceptance and Commitment Therapy for Chronic Pain to be Effective. Frontiers in Psychology, doi: 10.3389/fpsyg.2016.00353

Turnbull, H., Turnbull., A., Wehmeyer, M., y Park, J. (2006). A quality of life framework for special education outcomes. Remedial and special education, 24(2), 67-74.

UNESCO (1985). Reflections on the future development of education. Paris, Francia: UNESCO

UNESCO (1994): Declaración de Salamanca y Marco de Acción sobre Necesidades Educativas Especiales. Salamanca, España: UNESCO.

UNESCO. (2000). The Dakar Framework for Action. Education for All: Meeting our Collective Commitments. Dakar, Senegal: UNESCO. 
UNESCO (2005): Guidelines for inclusion: ensuring access to education for all. París, Francia: UNESCO.

UNESCO (2006). Convención internacional sobre los derechos de las personas con discapacidad. New York, EU: UNESCO.

UNESCO (2010). Conferencia mundial sobre atención y educación de la primera infancia (AEPI): construir la riqueza de las naciones, documento conceptual. Moscú, Rusia: UNESCO.

Ungar, M. (2004). A constructionist discourse on resilience: Multiple contexts, multiple realities among at-risk children and youth. Youth and Society, 35(3), 341-365. doi:10.1177/0044118X03257030

Ungar, M. (2008). Resilience across cultures. British Journal of SocialWork, 38 , 218-235. doi: 10.1093/bjsw/bcl343

Ungar M. (2011). The social ecology of resilience: Addressing contextual and cultural ambiguity of a nascent construct. American Journal of Orthopsychiatry, 81(1), 1-17. doi:10.1111/j.1939-0025.2010.01067.x

Ungar, M. (Ed.) (2012). Social Ecologies and Their Contribution to Resilience: A Handbook of Theory and Practice. En The Social Ecology of Resilience (pp. 13-31). New York, EU: Springer.

Ungar, M. (2015a). Resilience and culture: A social ecological process model of positive adaptation. En L. Theron, L. Liebenberg, \& M. Ungar (Eds.), Youth Resilience and Culture(s): Commonalities and complexities. London, UK: Springer. doi:10.1111/1467-8624

Ungar, M. (2015b). Practitioner Review: Diagnosing childhood resilience: A systemic approach to the diagnosis of adaptation in adverse social ecologies. Journal of Child Psychology and Psychiatry, 56(1), 4-17. doi: $10.1111 /$ jcpp. 12306

Ungar, M. (2015c). Working with children and youth with complex needs: 20 skills to build resilience. New York, EU: Routledge. 
Ungar, M. (2016). The child and youth resilience measure (CYRM): Child Version. Nueva Escocia, Canadá: RRC. Recuperado de: www.resilienceresearch. org

Ungar, M., Brown, M., Liebenberg, L., Othman, R., Kwong, W. M., Armstrong, M., y Gilgun, J. (2007). Unique pathways to resilience across cultures. Adolescence, 42(166), 287-310. Recuerpado de: https: / /www. researchgate.net

Ungar, M., y Liebenberg, L. (2005). The International Resilience Project: A mixed methods approach to the study of resilience across cultures. En M. Ungar (ed.), Handbook for working with children and youth: Pathways to Resilience across cultures and contexts (pp. 211-226). Thousand Oaks, CA: Sage Publications. doi: 10.4135/9781412976312.n13

Ungar, M., y Liebenberg, L. (2009). Cross-cultural consultation leading to the development of a valid measure of youth resilience: the international resilience project. Studia Psychologica, 51(2-3), 259-269.

Ungar, M., y Liebenberg, L. (2011). Assessing resilience across cultures using mixed methods: Construction of the Child and Youth Resilience Measure. Journal of Mixed Methods Research, 5(2), 126-149. doi: $10.1177 / 1558689811400607$

Ungar, M., y Liebenberg, L. (2013). A measure of resilience with contextual sensitivity-The CYRM-28: exploring the tension between homogeneity and heterogeneity in resilience theory and research. En Prince-Embury, S. y Saklofske, D.H. (eds.). Resilience in Children, Adolescent, and Adults: Translating Research into Practice. NewYork, EU: Springer Series on Human Exceptionality.

Ungar, M., Liebenberg, L., Boothroyd, R., Kwong, W.M., Lee, T. Y., Leblanc, J., Duque, L., y Maknach, A. (2008). The study of youth resilience across cultures: Lessons from a pilot study of measurement development. Research in Human Development, 5(3), 166-180. 
Ungar, M., Theron, L., y Didkowsky, N. (2011). Adolescents' precocious and developmentally appropriate contributions to their families' wellbeing and resilience in five countries. Family Relations, 60(2), 231-246.

UNICEF (2006). Estado mundial de la infancia. La mujer y la infancia: el doble dividendo de la igualdad de género. Nueva York, EU: UNICEF.

UNICEF (2013). Estado mundial de la infancia: niñas y niños con discapacidad. NewYork, NY: Fondo de las Naciones Unidas para la Infancia. Recuperado de: https://www.unicef.org/spanish/sowc2013/files/SPANISH_ SOWC2013_Lo_res.pdf

UNICEF (2011). Fostering Resilience, Protecting Children: UNICEF in Humanitarian Action. New York, EU: UNICEF. Recuperado de: https: / / www.unicef.org/hac2011/hac_lead.html

UNICEF (2012). Estado mundial de la infancia: niñas y niños en mundo urbano. New York, NY: UNICEF. Recuperado de: https: //www.unicef. org/spanish/sowc2012/pdfs/SOW C\%202012\%20Executive\%20 Summary\%20LoRes\%20PDF_SP_03132012.pdf

UNICEF (2015). Una oportunidad justa para cada niño. Fondo de las Naciones Unidas para la Infancia. New York, EU: UNICEF. Recuperado de: https://www.unicef.org/about/execboard/files/A_fair_chance_for_ every_child_SPANISH_15June15v1.pdf

UNICEF (2016). Estado mundial de la infancia. Una oportunidad para cada niño. New York, EU: UNICEF. Recuperado de https: / / www.unicef.org / spanish/sowc2016/

UNICEF Comité Español (2014). La infancia en España 2014. El valor social de los niños: hacia un Pacto de Estado por la Infancia, 2014. Madrid, España: UNICEF.

United Nations (1989). United Nations Convention on the Rights of the Child (UNCRC). Geneva, Suiza: ONU.

Uriarte, J.D. (2006). Construir la resiliencia en la escuela. Revista de Psicodidáctica, 11(1), 7-24. 
Urbina, C., Simon, C., y Echeita, G. (2011). Concepciones de los profesores acerca de las conductas disruptivas: análisis a partir de un marco inclusivo. Infancia y Aprendizaje, 34(2), 205-217.

Urquijo, M. (2014). La teoría de las capacidades en Amartya Sen. Revista Edetania, 46, 63-80. Recuperado de: https://dialnet.unirioja.es/

Urzúa M, A., y Caqueo-Urízar, A. (2012). Calidad de vida: Una revisión teórica del concepto. Terapia psicológica, 30(1), 61-71. doi:10.4067/ S0718-48082012000100006

Urzúa, M. A, Caqueo-Urízar A, Albornoz B. N, y Jara S. C. (2013). Calidad de vida en la infancia: estudio comparativo entre una zona rural y urbana en el norte de Chile. Revista chilena de pediatría, 84, 276-284.

Van de Vijver, F., y Poortinga, Y. (2005). Conceptual and methodological issues in adapting tests. En R. Hambleton, P. Merenda y S. Spielberger (Eds.), Adapting educational and psychological tests for cross-cultural assessment (pp. 39-63). Filadepfia, NJ: Lawrence Erlbaum Associates.

Van Loon, J. H. M., Bonham, G. S., Peterson, D. D., Schalock, R. L., Claes, C., y Decramer, A. E. M. (2013). The use of evidence-based outcomes in systems and organizations providing services and supports to persons with intellectual disability. Evaluation and Program Planning, 36(1), 80-87. doi:10.1016/j.evalprogplan.2012.08.002

Van Naarden Braun, K., Yeargin-Allsopp, M., y Lollar, D. (2006). Factors associated with leisure activity among young adults with developmental disabilities. Research in Developmental Disabilities, 27, 567-583.

Van Rensburg, A., Theron, L., y Rothmann, S. (2018) Adolescent perceptions of resilience-promoting resources: The South African Pathways to Resilience Study. South African Journal of Psychology 48(1), 73-85. doi:10.1177/0081246317700757 
Vanistendael, S. (2005). La resiliencia: desde una inspiración hacia cambios prácticos. En II Congreso Internacional de los trastornos del comportamiento en niños y adolescentes, Madrid: España. Recuperado de https://www. obelen.es/upload/262D.pdf

Varni, J.W., Seid, M., y Rode, C. A. (1999). The PedsQL: Measurement model for the pediatric quality of life inventory. Medical Care, 37(3), 126139.

Veit, C., y Ware, J. (1983). The structure of psychological distress and wellbeing in general populations. Journal of Consulting and Clinical Psychology, 51, 730-742.

Verdugo, M.A. (2006). Como mejorar la calidad de vida de las personas con discapacidad. Salamanca, España: Amarú Ediciones.

Verdugo, M.A. (2009). El cambio educativo desde una perspectiva de calidad de vida. Monográfico. Revista de Educación, 349, 23-43.

Verdugo, M.A. (2011). La atención a la diversidad del alumnado: valores, derechos y calidad de vida. En Juan Navarro (Coord.) Diversidad, Calidad y Equidad Educativas, (1-13). Murcia, España: Consejería de Educación, Formación y Empleo. Recuperado de: https: / /www.researchgate.net/

Verdugo, M. A., y Sabeh, E. N. (2002). Evaluación de la percepción de calidad de vida en la infancia. Psicothema, 14(1), 86-91.

Verdugo, M. A., y Schalock, R. L. (2013a). El cambio en las organizaciones de discapacidad. Estrategias para superar los retos y hacerlo realidad. Madrid, España: Alianza.

Verdugo, M.A., y Schalock, R. (Eds.) (2013b). Discapacidad e Inclusión: manual para la docencia. Salamanca, España: Amarú Ediciones.

Verdugo, M. A., Schalock, R. L., Arias, B., Gómez, L. E., y Jordán de Urríes, F. B. (2013c) Calidad de vida. En M. A. Verdugo, R. L. Schalock (Coord.) Discapacidad e Inclusión: Manual para la Docencia (pp. 443461). Salamanca, España: Amarú Ediciones. 
Verdugo, M.A., Vicente, E., Fernández-Pulido, R., Gómez-Vela, M., Wehmeyer, L., y Guillén, V.M. (2015). A psychometric evaluation of the ARC-INICO Self-Determination Scale for adolescent with intelectual disabilities. International Journal of Clinical and Health Psychology, 15, 149159. doi: 10.1016/j.ijchp.2015.03.001

Vezub, L. F. (2007). La formación y el desarrollo professional docente frente a los nuevos desafíos de la escolaridad. Revista de Curriculum y Formación del Profesorado 11(1), 1-23.

Vidal, F., y Mota, R. (2008). Encuesta de Infancia en España 2008. Madrid: Fundación SM y Universidad Pontificia Comillas. Recuperado de: http: / / www.grupo-sm.com/

Viguer-Seguí, P. y Serra-Desfilis, E. (2008). Nivel socioeconómico y calidad del entorno familiar en la infancia. Cadernos de Psicopedagogía, 7(12), 00.

Vygotsky, L. S. (1978). Mind in society: The development of higher psychological processes (M. Cole, V. John-Steiner, S. Scribner,y E. Souberman, Eds. y Trans.). Cambridge, UK: Harvard University Press.

Wagnild, G.M., y Young, H.M. (1993). Development and psychometric evaluation of the resilience scale. Journal of Nursing Measurement 1(2), 165178.

Wald, J., Taylor, S., Asmundson, G. J., Jang, K. L., y Stapleton, J. (2006). Literature review of concepts: Psychological resiliency. Vancouver, Canada: British Columbia University Recuperado de: www.dtic.mil/dtic/tr/fulltext/ u2 /a472961.pdf

Wallander, J.L., y Koot, H.M. (2016). Quality of life in children: A critical examination of concepts, approaches, issues, and future directions. Clinical Psychology Review, 45, 131-145. doi: 10.1016/j.cpr.2015.11.007

Walsh, F. (2006). Strengthening family resilience ( $2^{\text {a }}$ ed.). NewYork, NY: Guilford. doi: 10.1080/01926180701290867 
Wang, M., Schalock, R. L., Verdugo, M. A., y Jenaro, C. (2010). Examining the factor structure and hierarchical nature of the quality of life construct. American Journal on Intellectual and Developmental Disabilities, 115(3), 218233. doi: 10.1352/1944-7558-115.3.218

Watkinson, E.J., Dwyer, S.A., y Nielsen, A.B. (2005). Children theorize about reasons for recess engagement: Does expectancy value theory apply? Adapted Physical Activity Quarterly, 22(2), 179-197.

Wehmeyer, M. L. (1992). Self-determination and the education of students with mental retardation. Education and Training in Mental Retardation, 27, 302-314.

Wehmeyer M. L. (1997). Self-determination as an educational outcome: A definitional framework and implications for intervention. Journal of Developmental and Physical Disabilities, 9(3), 175-209. doi:10.1023/A:1024981820074

Wehmeyer, M.L. (2009). Autodeterminación y la tercera generación de prácticas de inclusión. Revista de educación, 149, 45-67.

Wehmeyer, M.L., Buntinx, W., Lachapelle, Y., Luckasson, R., Schalock, R. L., Verdugo, M. A., Borthwick-Duffy, S.,... Yeager, M. H. (2008). El constructo de discapacidad intelectual y su relación con el funcionamiento humano. Revista Española sobre Discapacidad Intelectual SIGLO CERO, 39(3), $5-18$.

Wells, R., y Schwebel, A. (1987). Chronically ill children and their mothers: Predictors of resilience and vulnerability to hospitalization and surgical stress. Journal of Developmental and Behavioral Pediatrics, 8, 83-89.

Werner, E. E. (1971). The children of Kauai:A longitudinal study from the prenatal period to age ten. Honolulu, HI: University of Hawaii Press.

Werner, E. E. (1992). The children of Kauai: Resiliency and recovery in adolescence and adulthood. Journal of Adolescent Health, 13(4), 262-268. doi:10.1016/1054-139X(92)90157-7 
Werner, E. E., y Smith, R. S. (1982). Vulnerable but not invincible: A longitudinal study of resilient children and youth. New York, EU: McGraw Hill.

Werner, E. E., y Smith, R. S. (2004). Journeys from childhood to midlife: risk, resilience, and recovery. Pediatrics, 114(2): 492. doi: 10.1542/ peds.114.2.492

Wilkes, S., Cordier, R., Bundy, A., Docking, K., y Munro, N. (2011). A play-based intervention for children with ADHD: A pilot study. Australian Occupational Therapy Journal, 58(4), 231-240. doi: 10.1111/j.14401630.2011.00928.x

Windle, G. (2011). What is resilience? A review and concept analysis. Reviews in Clinical Gerontology, 21(2), 152-169. doi:10.1017/S0959259810000420

Windle, G., Bennett, K.M., y Noyes, J. (2011). A methodological review of resilience measurement scales. Health Qual Life Outcomes, 9(1):8. doi:10.1186/1477-7525-9-8

Winslow, B.E., Sandler, I.N., y Wolnick, A.S. (2005). Building resilience in all children: A public health approach, En Goldstein, S. y Brooks, R.B. Handbook of resilience in children (pp. 337-356). New York, EU: Kluwer Academic/Plenum Publishers.

World Health Organization (1948). Constitution of theWorld Health Organization. New York, EU: WHO. Recuperado de: http://apps. who. int/gb/

World Health Organization (1995). The World Health Organization Quality of life assessment (WHOQOL): position paper from the World Health Organization. Social Science Medicine, 41(10), 1.403-1.409. Recuperado de: http: / /www.sciencedirect.com/

World Health Organization (2004 ${ }^{a}$ Prevention of mental disorders: Effective interventions and policy options, Summary Report. Ginebra, Suiza:WHO.

World Health Organization (2004b). Promoting mental health: Concepts, emerging evidence, practice: summary report. Ginebra, Suiza:WHO. 
Wolfensberger, W. (1972). Normalization: the principles of normalization in human services. Toronto, Canadá: National Institute of Mental Retardation.

Wolff, S. (1995). The concept of resilience. The Australian and New Zealand Journal of Psychiatry, 29(4), 565-574. doi:10.3109/00048679509064968

Wright, M. O., y Masten, A. S. (1997). Vulnerability and resilience in young children. En J. S. Greenspan, S.Weider, y J. Osofsky (Eds.), Handbook of Child and Adolescent Psychiatry and Preschooler Development and Syndromes (pp. 202-224). New York, EU: Wiley.

Wyman, P.A. (2003). Emerging perspectives on context specificity of children's adaptation and resilience: Evidence from a decade of research with urban children in adversity. En S. S. Luthar (Ed.), Resilience and vulnerability: Adaptation in the context of childhood adversities (pp. 293-317). Cambridge, UK: Cambridge University Press. doi:10.1017/CBO9780511615788.014

Wyman, P. A., Cowen, E. L., Work, W. C., Raoof, A., Gribble, P. A., Parker, G. R., y Wannon, M.(1992). Interviews with children who experienced major life stress: Family and child attributes that predict resilient outcomes. Journal of the American Academy of Child and Adolescent Psychiatry, 31(5), 904 910. doi:10.1097/00004583-199209000-00019

Yalon-Chamovitz, S., Mano, T., Jarus, T., y Weinblatt, N. (2006). Leisure activities during school break among children with learning disabilities: preference vs performance. British Journal of Learning Disabilities, 34(1), 42-48. doi: 10.1111/j.1468-3156.2005.00335.x

Yang-Wallentin, F., Jöreskog, K. G., y Luo, H. (2010). Confirmatory factor analysis of ordinal variables with misspecified models. Structural Equation Modeling, 17(3), 392-423. doi:10.1080/10705511.2010.489003

Young, A., Green, E., y Rogers, K. (2008) Resilience and deaf children: a literature review. Deafness Education International, 10(1), 40-55. doi: $10.1002 /$ dei. 234

Zolkoski, S.M., y Bullock, L.M. (2012). Resilience in children and young: a review. Children and Youth Services Review 34(12), 2295-2303. doi: 10.1016/j.childyouth.2012.08.009 



FACTORES DETERMINANTES DE LA CALIDAD DE VIDA DE ALUMNOS CON NECESIDADES ESPECÍFICAS DE APOYO EDUCATIVO Y SIN ELLAS

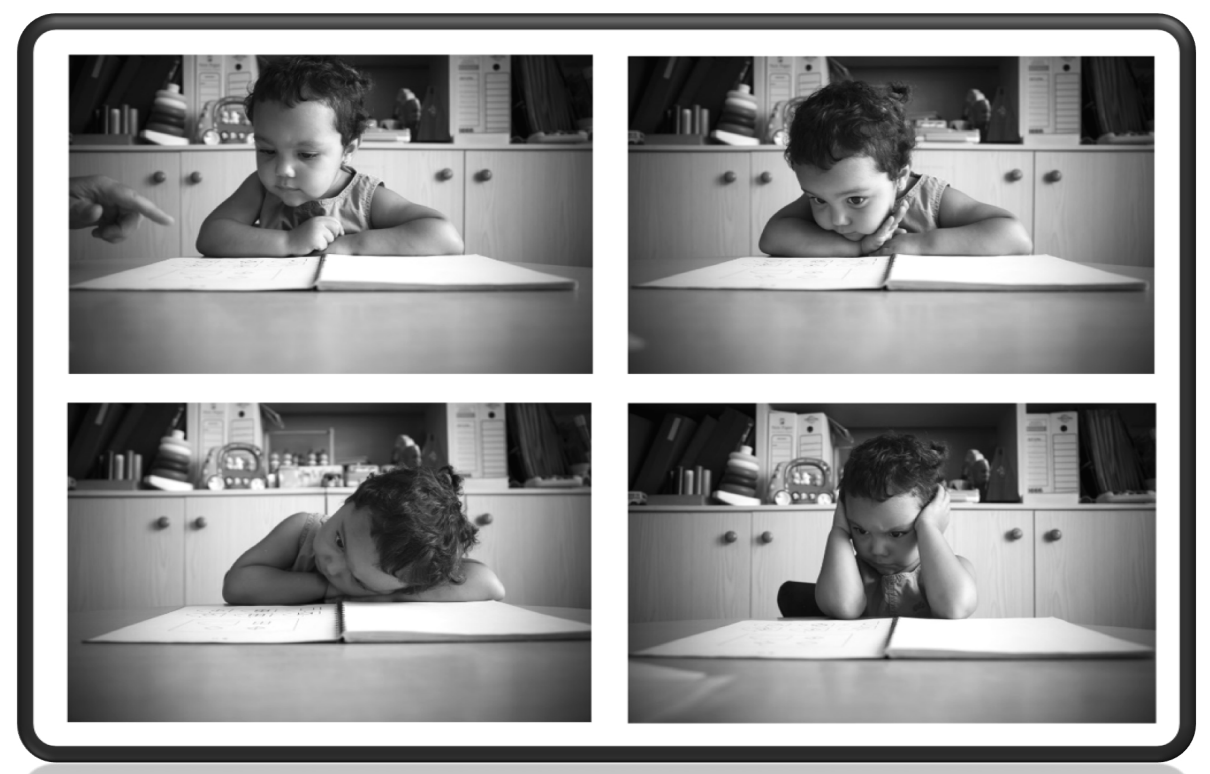

Aprendiendo en atención temprana Autor: Manuel López Francés 


\section{ALUMNO}

POR FAVOR, RESPONDE LAS SIGUIENTES PREGUNTAS

\begin{tabular}{|c|c|c|c|c|}
\hline \multicolumn{5}{|c|}{ DATOS PERSONALES } \\
\hline $\begin{array}{l}\text { Género } \\
\text { (señala con una "X") }\end{array}$ & \multicolumn{2}{|c|}{ Masculino } & \multicolumn{2}{|c|}{ Femenino } \\
\hline Fecha de Nacimiento & \multicolumn{2}{|l|}{ Día } & es & Año \\
\hline \multicolumn{5}{|l|}{ Lugar de Nacimiento } \\
\hline \multicolumn{5}{|l|}{$\begin{array}{l}\text { Ciudad o Pueblo } \\
\text { en el que vives }\end{array}$} \\
\hline \multicolumn{5}{|l|}{ Nombre de tu Barrio } \\
\hline $\begin{array}{l}\text { ¿Has vivido siempre en } \\
\text { España? (si la respuesta } \\
\text { es "NO”, dinos cuánto } \\
\text { tiempo llevas en España) }\end{array}$ & \multicolumn{2}{|c|}{ SI } & \multicolumn{2}{|c|}{$\begin{array}{c}\text { NO } \\
\text { ¿Desde cuándo } \\
\text { vives en España? }\end{array}$} \\
\hline $\begin{array}{l}\text { Curso } \\
\text { (señala con una "X") }\end{array}$ & $\begin{array}{c}4^{\circ} \\
\text { Primaria }\end{array}$ & $\begin{array}{c}5^{\circ} \\
\text { Primaria }\end{array}$ & $\begin{array}{c}6^{\circ} \\
\text { Primaria }\end{array}$ & Otro: \\
\hline \multicolumn{5}{|l|}{$\begin{array}{l}\text { ¿Cuántos hermanos } \\
\text { sois? (incluido tú) }\end{array}$} \\
\hline \multicolumn{5}{|l|}{$\begin{array}{l}\text { Qué lugar ocupas } \\
\text { entre tus hermanos }\end{array}$} \\
\hline ¿Trabaja tu madre? & \multicolumn{2}{|c|}{ SI } & \multicolumn{2}{|c|}{ NO } \\
\hline \multicolumn{5}{|l|}{ Profesión de tu madre } \\
\hline ¿Trabaja tu padre? & \multicolumn{2}{|c|}{ SI } & \multicolumn{2}{|c|}{ NO } \\
\hline Profesión de tu padre & & & & \\
\hline
\end{tabular}




\section{INFORMACIÓN SOBRE TU COLEGIO}

En mi clase se trabaja...: (señala con una cruz las que "SI" hacéis en clase)

En clase...:

(señala con una cruz las cosas que "SI" hay en tu colegio)

Los profesores nos preguntan qué pensamos acerca de...: (señala con una cruz las cosas que "SI" hay en tu colegio)

\section{Por las tardes hago actividades} extraescolares en el cole: (señala con una cruz las cosas que "SI" hay en tu colegio) en grupos

por parejas

de forma individual

Hacemos asambleas, debates, etc.

Los profesores nos escuchan con atención

Los profesores toman en serio nuestras opiniones

las materias que vemos en las asignaturas

Los controles y exámenes

Los deberes

Los compañeros con dificultades en su aprendizaje

Mi propia forma de aprender

Inglés

Fútbol

Karate, judo, etc.

Gimnasia rítmica

Apoyo escolar (matemáticas, lengua, etc.)

Informática

Manualidades

Otras:

SI

NO 


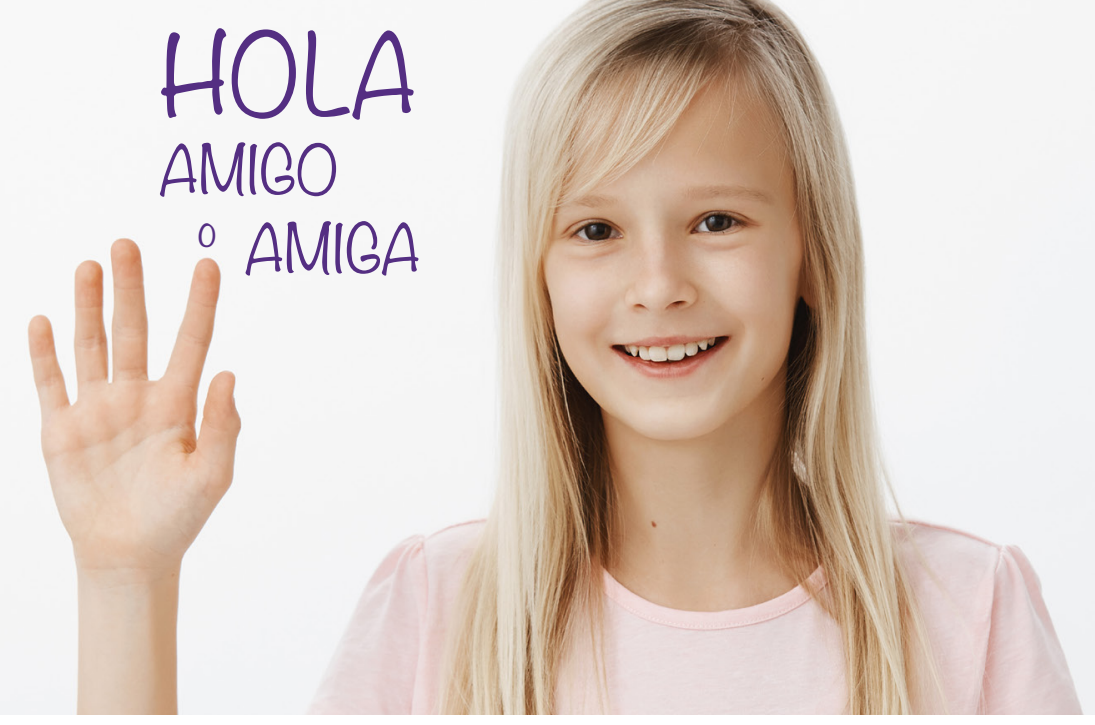

\section{La escala CYRM-28}

Nos gustaría saber qué piensas sobre algunos aspectos de ti mismo, tu familia, tu comunidad y las personas que te rodean, por eso te vamos hacer algunas preguntas. No hay respuestas buenas ni malas. Lo importante es que nos digas lo que piensas y sientes de verdad. Adwe respondas es privado y no se lo contaremos a nadie.

»Por favor, lee despacio cada frase

»Piensa cómo te sientes

» Elige una respuesta y márcala con una cruz

\section{POR EJEMPLO}

Si crees que tus amigos piensan que CASI SIEMPRE eres simpático, marca con una cruz la respuesta "Casi siempre”, de este modo:

\begin{tabular}{|l|l|l|l|l|}
\hline $\begin{array}{l}\text { Mis amigos piensan } \\
\text { que soy simpático }\end{array}$ & Nunca & Casi nunca & $\begin{array}{c}\text { Algunas } \\
\text { veces }\end{array}$ & $\begin{array}{c}\text { Casi } \\
\text { siempre }\end{array}$
\end{tabular} Siempre




\section{¡Adelante! \\ Acuérdate de responder a todas las preguntas}

\section{¡Nos vemos al final!}

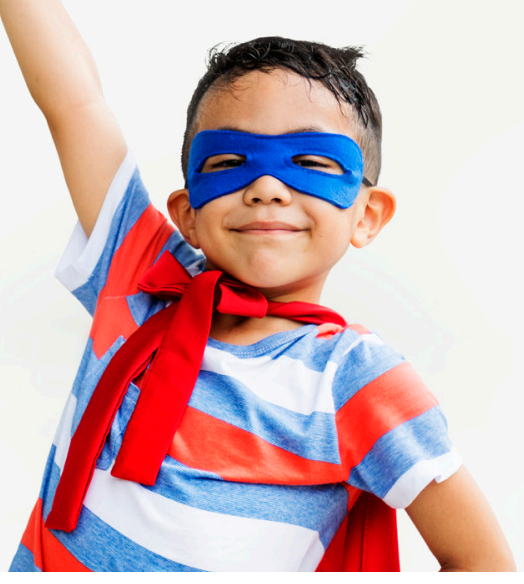

\begin{tabular}{|c|c|c|c|c|c|}
\hline PREGUNTAS & & & PESPUES & TAS & \\
\hline 1. Termino los deberes del cole & Nunca & $\begin{array}{l}\text { Casi } \\
\text { nunca }\end{array}$ & $\begin{array}{c}\text { Algunas } \\
\text { veces }\end{array}$ & $\begin{array}{c}\text { Casi } \\
\text { siempre }\end{array}$ & Siempre \\
\hline $\begin{array}{l}\text { 2. Ayudo a la gente con la que vivo (por } \\
\text { ejemplo, pongo la mesa en casa) }\end{array}$ & Nunca & $\begin{array}{c}\text { Casi } \\
\text { nunca }\end{array}$ & $\begin{array}{l}\text { Algunas } \\
\text { veces }\end{array}$ & $\begin{array}{l}\text { Casi } \\
\text { siempre }\end{array}$ & Siempre \\
\hline 3. Para mí es importante ir a la escuela & Nada & Poco & Algo & Bastante & Mucho \\
\hline $\begin{array}{l}\text { 4. Mis padres saben qué pienso y cómo } \\
\text { me siento (si estoy preocupado, triste, } \\
\text { feliz...) }\end{array}$ & Nunca & $\begin{array}{c}\text { Casi } \\
\text { nunca }\end{array}$ & $\begin{array}{l}\text { Algunas } \\
\text { veces }\end{array}$ & $\begin{array}{l}\text { Casi } \\
\text { siempre }\end{array}$ & Siempre \\
\hline $\begin{array}{l}\text { 5. Hay personas a las que admiro (por } \\
\text { ejemplo mis padres, hermanos, depor- } \\
\text { tistas, etc.) }\end{array}$ & Nada & Poco & Algo & Bastante & Mucho \\
\hline $\begin{array}{l}\text { 6. Respeto las normas de casa o del } \\
\text { cole (por ejemplo no tiro cosas al suelo, } \\
\text { no pongo los pies en la mesa) }\end{array}$ & Nunca & $\begin{array}{c}\text { Casi } \\
\text { nunca }\end{array}$ & $\begin{array}{l}\text { Algunas } \\
\text { veces }\end{array}$ & $\begin{array}{c}\text { Casi } \\
\text { siempre }\end{array}$ & Siempre \\
\hline $\begin{array}{l}\text { 7. Por norma general hay comida en } \\
\text { casa (para desayunar, comer, cenar) }\end{array}$ & Nunca & $\begin{array}{c}\text { Casi } \\
\text { nunca }\end{array}$ & $\begin{array}{l}\text { Algunas } \\
\text { veces }\end{array}$ & $\begin{array}{l}\text { Casi } \\
\text { siempre }\end{array}$ & Siempre \\
\hline 8. Mi familia se preocupa por mí & Nada & Poco & Algo & Bastante & Mucho \\
\hline 9. Creer en dios me hace sentir seguro & Nada & Poco & Algo & Bastante & Mucho \\
\hline $\begin{array}{l}\text { 10. Disfruto de las costumbres de } \\
\text { mi cultura (disfrazarse en carnaval, } \\
\text { ir a fiestas populares de mi ciudad o } \\
\text { pueblo, etc.) }\end{array}$ & Nada & Poco & Algo & Bastante & Mucho \\
\hline $\begin{array}{l}\text { 11. Tengo amigos que están a mi lado } \\
\text { en los momentos difíciles (cuando estoy } \\
\text { enfermo, cuando tengo un problema en } \\
\text { casa o en el cole, por ejemplo) }\end{array}$ & Nunca & $\begin{array}{c}\text { Casi } \\
\text { nunca }\end{array}$ & $\begin{array}{l}\text { Algunas } \\
\text { veces }\end{array}$ & $\begin{array}{l}\text { Casi } \\
\text { siempre }\end{array}$ & Siempre \\
\hline $\begin{array}{l}\text { 12. Hablo con mi familia sobre cómo } \\
\text { me siento (por ejemplo, si tengo un } \\
\text { problema en el cole con un maestro o } \\
\text { compañero) }\end{array}$ & Nunca & $\begin{array}{c}\text { Casi } \\
\text { nunca }\end{array}$ & $\begin{array}{l}\text { Algunas } \\
\text { veces }\end{array}$ & $\begin{array}{l}\text { Casi } \\
\text { siempre }\end{array}$ & Siempre \\
\hline
\end{tabular}




\begin{tabular}{|c|c|c|c|c|c|}
\hline $\begin{array}{l}\text { 13. En el cole tengo oportunidad de } \\
\text { demostrar que soy responsable (ir } \\
\text { hacer fotocopias, ser el capitán de un } \\
\text { grupo, etc.) }\end{array}$ & Nunca & $\begin{array}{c}\text { Casi } \\
\text { nunca }\end{array}$ & $\begin{array}{c}\text { Algunas } \\
\text { veces }\end{array}$ & $\begin{array}{c}\text { Casi } \\
\text { siempre }\end{array}$ & Siempre \\
\hline $\begin{array}{l}\text { 14. Sé a quién pedir ayuda cuando lo } \\
\text { necesito (si tengo una duda en clase, } \\
\text { por ejemplo) }\end{array}$ & Nunca & $\begin{array}{c}\text { Casi } \\
\text { nunca }\end{array}$ & $\begin{array}{c}\text { Algunas } \\
\text { veces }\end{array}$ & $\begin{array}{c}\text { Casi } \\
\text { siempre }\end{array}$ & Siempre \\
\hline $\begin{array}{l}\text { 15. Mis compañeros piensan que es } \\
\text { divertido estar conmigo }\end{array}$ & Nada & Poco & Algo & Bastante & Mucho \\
\hline $\begin{array}{l}\text { 16. En casa tengo la oportunidad de } \\
\text { demostrar que soy responsable (por } \\
\text { ejemplo, ordenar y limpiar mi cuarto, ir } \\
\text { a comprar al supermercado solo) }\end{array}$ & Nunca & $\begin{array}{c}\text { Casi } \\
\text { nunca }\end{array}$ & $\begin{array}{l}\text { Algunas } \\
\text { veces }\end{array}$ & $\begin{array}{l}\text { Casi } \\
\text { siempre }\end{array}$ & Siempre \\
\hline $\begin{array}{l}\text { 17. Mi familia está conmigo en los mo- } \\
\text { mentos difíciles (cuando estoy enfermo, } \\
\text { por ejemplo) }\end{array}$ & Nunca & $\begin{array}{c}\text { Casi } \\
\text { nunca }\end{array}$ & $\begin{array}{l}\text { Algunas } \\
\text { veces }\end{array}$ & $\begin{array}{l}\text { Casi } \\
\text { siempre }\end{array}$ & Siempre \\
\hline $\begin{array}{l}\text { 18. Participo en actividades religiosas } \\
\text { (dar religión, ir a catequesis, el rama- } \\
\text { dán, por ejemplo) }\end{array}$ & Nunca & $\begin{array}{c}\text { Casi } \\
\text { nunca }\end{array}$ & $\begin{array}{c}\text { Algunas } \\
\text { veces }\end{array}$ & $\begin{array}{c}\text { Casi } \\
\text { siempre }\end{array}$ & Siempre \\
\hline $\begin{array}{l}\text { 19. Me gusta cómo me tratan las } \\
\text { demás personas (compañeros, vecinos, } \\
\text { etc.) }\end{array}$ & Nunca & $\begin{array}{c}\text { Casi } \\
\text { nunca }\end{array}$ & $\begin{array}{c}\text { Algunas } \\
\text { veces }\end{array}$ & $\begin{array}{c}\text { Casi } \\
\text { siempre }\end{array}$ & Siempre \\
\hline $\begin{array}{l}\text { 20. Creo que es importante ayudar } \\
\text { a los demás (abrirle la puerta a una per- } \\
\text { sona mayor, ayudar a compañeros más } \\
\text { pequeños, por ejemplo) }\end{array}$ & Nada & Poco & Algo & Bastante & Mucho \\
\hline $\begin{array}{l}\text { 21. Tengo amigos que me apoyan y } \\
\text { ayudan cuando lo necesito (compañe- } \\
\text { ros de clase, vecinos de casa, amigos } \\
\text { del barrio, por ejemplo) }\end{array}$ & Nunca & $\begin{array}{c}\text { Casi } \\
\text { nunca }\end{array}$ & $\begin{array}{l}\text { Algunas } \\
\text { veces }\end{array}$ & $\begin{array}{l}\text { Casi } \\
\text { siempre }\end{array}$ & Siempre \\
\hline $\begin{array}{l}\text { 22. Sé que es lo que no se me da } \\
\text { bien (las matemáticas, el dibujo, hacer } \\
\text { amigos, etc.) }\end{array}$ & Nunca & $\begin{array}{c}\text { Casi } \\
\text { nunca }\end{array}$ & $\begin{array}{l}\text { Algunas } \\
\text { veces }\end{array}$ & $\begin{array}{l}\text { Casi } \\
\text { siempre }\end{array}$ & Siempre \\
\hline $\begin{array}{l}\text { 23. Hago actividades extraescolares } \\
\text { (deporte, clases de inglés, conservato- } \\
\text { rio de música, por ejemplo) }\end{array}$ & Nunca & $\begin{array}{c}\text { Casi } \\
\text { nunca }\end{array}$ & $\begin{array}{c}\text { Algunas } \\
\text { veces }\end{array}$ & $\begin{array}{l}\text { Casi } \\
\text { siempre }\end{array}$ & Siempre \\
\hline $\begin{array}{l}\text { 24. Cuando tengo un problema normal- } \\
\text { mente puedo solucionarlo sin hacerme } \\
\text { daño y sin hacérselo a otros (por ejem- } \\
\text { plo, sin pelearme, sin dejar que me in- } \\
\text { sulten, etc.) }\end{array}$ & Nunca & $\begin{array}{c}\text { Casi } \\
\text { nunca }\end{array}$ & $\begin{array}{c}\text { Algunas } \\
\text { veces }\end{array}$ & $\begin{array}{c}\text { Casi } \\
\text { siempre }\end{array}$ & Siempre \\
\hline $\begin{array}{l}\text { 25. Cuando estoy con mi familia no } \\
\text { tengo miedo, me siento seguro }\end{array}$ & Nunca & $\begin{array}{c}\text { Casi } \\
\text { nunca }\end{array}$ & $\begin{array}{c}\text { Algunas } \\
\text { veces }\end{array}$ & $\begin{array}{c}\text { Casi } \\
\text { siempre }\end{array}$ & Siempre \\
\hline $\begin{array}{l}\text { 26. Me divierto cuando hacemos fiestas } \\
\text { familiares o en el barrio (navidad, cum- } \\
\text { pleaños, etc.) }\end{array}$ & Nunca & $\begin{array}{c}\text { Casi } \\
\text { nunca }\end{array}$ & $\begin{array}{l}\text { Algunas } \\
\text { veces }\end{array}$ & $\begin{array}{l}\text { Casi } \\
\text { siempre }\end{array}$ & Siempre \\
\hline
\end{tabular}




\begin{tabular}{|c|c|c|c|c|c|}
\hline $\begin{array}{l}\text { 27. Sé encontrar solución a mis dificulta- } \\
\text { des (por ejemplo, si me da miedo el as- } \\
\text { censor subo por las escaleras, si no sé } \\
\text { nadar muy bien juego donde hago pie) }\end{array}$ & Nunca & $\begin{array}{c}\text { Casi } \\
\text { nunca }\end{array}$ & $\begin{array}{c}\text { Algunas } \\
\text { veces }\end{array}$ & $\begin{array}{c}\text { Casi } \\
\text { siempre }\end{array}$ & Siempre \\
\hline $\begin{array}{l}\text { 28. Mis maestros piensa que soy listo/ } \\
\text { inteligente }\end{array}$ & Nada & Poco & Algo & Bastante & Mucho \\
\hline $\begin{array}{l}\text { 29. Doy abrazos a la gente que quiero } \\
\text { (mi padres, hermanos, abuelos, ami- } \\
\text { gos, etc.) }\end{array}$ & Nunca & $\begin{array}{c}\text { Casi } \\
\text { nunca }\end{array}$ & $\begin{array}{l}\text { Algunas } \\
\text { veces }\end{array}$ & $\begin{array}{c}\text { Casi } \\
\text { siempre }\end{array}$ & Siempre \\
\hline $\begin{array}{l}\text { 30. Me da vergüenza que los demás } \\
\text { sepan cómo me siento (por ejemplo, } \\
\text { que sepan que estoy triste, enfadado, } \\
\text { o que me gusta una chica o un chico, } \\
\text { etc.) }\end{array}$ & Nada & Poco & Algo & Bastante & Mucho \\
\hline $\begin{array}{l}\text { 31. Pienso en lo que me gustaría ser } \\
\text { de mayor (maestro, bombero, pintor, } \\
\text { camarero, etc.) }\end{array}$ & Nunca & $\begin{array}{c}\text { Casi } \\
\text { nunca }\end{array}$ & $\begin{array}{c}\text { Algunas } \\
\text { veces }\end{array}$ & $\begin{array}{c}\text { Casi } \\
\text { siempre }\end{array}$ & Siempre \\
\hline $\begin{array}{l}\text { 32. Mi familia confía en mí (por ejemplo, } \\
\text { me creen cuando les cuento las cosas } \\
\text { del cole, me dejan ir a las excursiones } \\
\text { con mis compañeros, etc.) }\end{array}$ & Nunca & $\begin{array}{c}\text { Casi } \\
\text { nunca }\end{array}$ & $\begin{array}{l}\text { Algunas } \\
\text { veces }\end{array}$ & $\begin{array}{l}\text { Casi } \\
\text { siempre }\end{array}$ & Siempre \\
\hline $\begin{array}{l}\text { 33. Soy capaz de conseguir lo que } \\
\text { me propongo (por ejemplo, aprender } \\
\text { a nadar, aprender inglés, hablar en } \\
\text { público, etc.) }\end{array}$ & Nunca & $\begin{array}{c}\text { Casi } \\
\text { nunca }\end{array}$ & $\begin{array}{l}\text { Algunas } \\
\text { veces }\end{array}$ & $\begin{array}{l}\text { Casi } \\
\text { siempre }\end{array}$ & Siempre \\
\hline $\begin{array}{l}\text { 34. Tengo un grupo de amigos en la } \\
\text { escuela }\end{array}$ & Nada & Poco & Algo & Bastante & Mucho \\
\hline $\begin{array}{l}\text { 35. En general sé cuáles son las cosas } \\
\text { que mejor hago (jugar al futbol, pintar, } \\
\text { cantar, leer, etc.) }\end{array}$ & Nunca & $\begin{array}{c}\text { Casi } \\
\text { nunca }\end{array}$ & $\begin{array}{c}\text { Algunas } \\
\text { veces }\end{array}$ & $\begin{array}{c}\text { Casi } \\
\text { siempre }\end{array}$ & Siempre \\
\hline $\begin{array}{l}\text { 36. Me gusta cómo soy con los demás } \\
\text { (familia, compañeros, maestros, etc.) }\end{array}$ & Nada & Poco & Algo & Bastante & Mucho \\
\hline $\begin{array}{l}\text { 37. ¿Me siento orgulloso } \\
\text { de ser de (país en el que } \\
\text { vives }\end{array}$ & Nada & Poco & Algo & Bastante & Mucho \\
\hline $\begin{array}{l}\text { 38. Estoy orgulloso de la cultura de mi } \\
\text { familia (cultura es cuando un grupo de } \\
\text { personas comparte una lengua, creen- } \\
\text { cias, tradiciones y costumbres propias) }\end{array}$ & Nada & Poco & Algo & Bastante & Mucho \\
\hline
\end{tabular}


Las siguientes preguntas cambian un poquito.

Por favor, presta atención

¡Ánimo, ya queda menos!
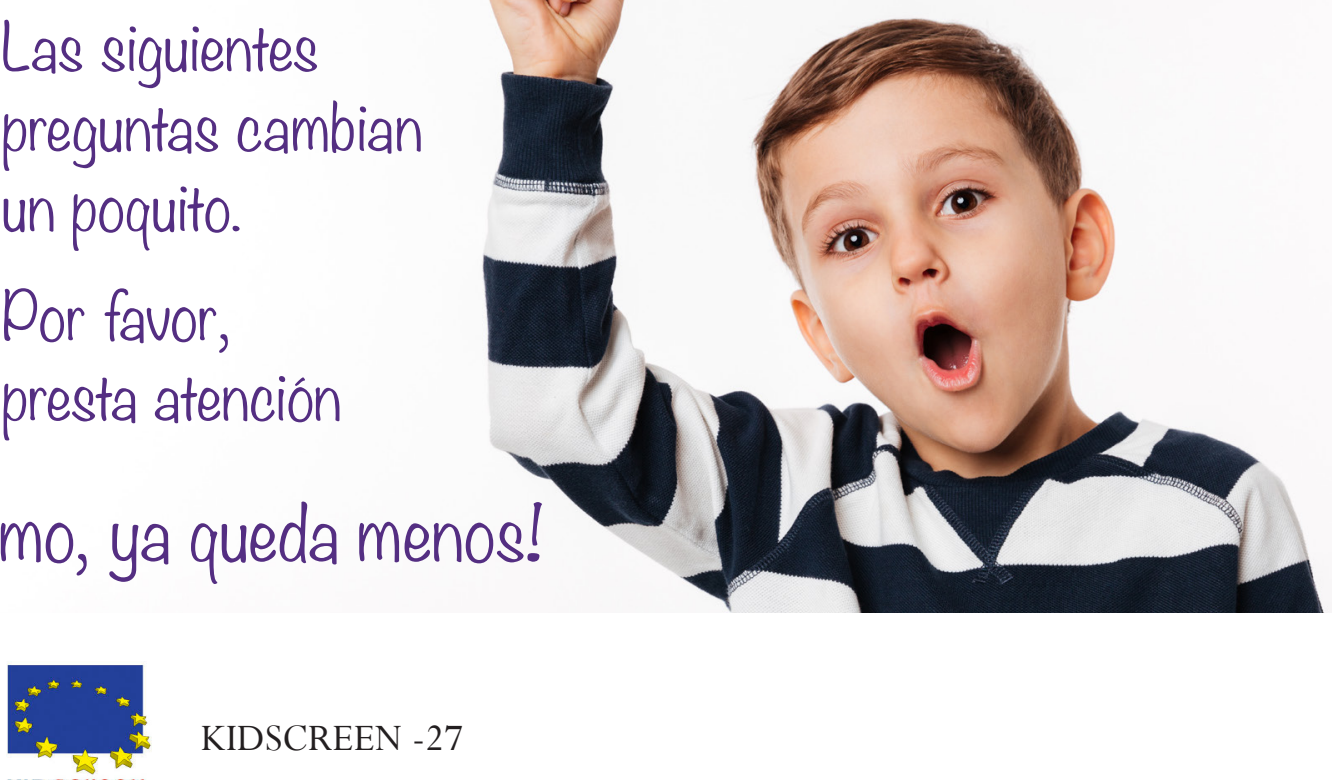

KIDSCREEN -27

¿Cómo estás? ¿Cómo te sientes? Ahora, esto es lo que queremos saber sobre ti.

Por favor, lee cada pregunta atentamente. Antes de responder piensa en la última semana, es decir, los últimos siete días. ¿Cuál es la respuesta que primero se te ocurre? Escoge la opción que creas te describe mejor y márcala con una cruz.

Recuerda: Esto no es un examen. No hay respuestas correctas o incorrectas. Pero es importante que contestes todas las preguntas que puedas y que podamos ver con claridad las cruces.

Ejemplo: Si la última semana te has sentido alegre CASI SIMEPRE, haz una cruz en la casilla de 5 ó 6 días.

\begin{tabular}{|c|c|c|c|c|c|}
\hline \multicolumn{2}{|c|}{ Piensa en la última semana... } & \multirow[b]{2}{*}{$\begin{array}{c}\text { CASI } \\
\text { NUNCA }\end{array}$} & \multirow[b]{2}{*}{$\begin{array}{c}\text { ALGUNAS } \\
\text { VECES }\end{array}$} & \multirow[b]{2}{*}{$\begin{array}{c}\text { CASI } \\
\text { SIEMPRE }\end{array}$} & \multirow[b]{2}{*}{ SIEMPRE } \\
\hline & NUNCA & & & & \\
\hline ¿Te has sentido alegre? & $\begin{array}{l}\text { Ningún } \\
\text { día }\end{array}$ & 1 ó 2 días & 3 ó 4 días & & Los 7 días \\
\hline
\end{tabular}



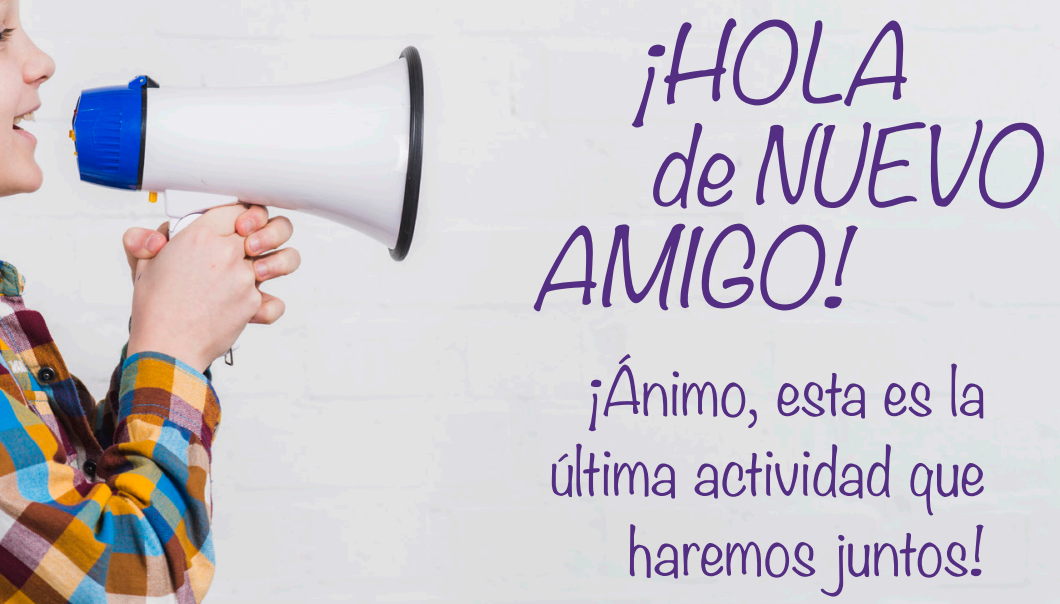

\section{CAPE / PAC-Versión Española}

Esta vez se presentaran una serie de actividades que los niños de tu edad hacen para divertirse fuera del horario escolar.

Si tú también has hecho esta actividad marca "SI" en la primera casilla y responde a las siguientes preguntas (¿Cuántas veces?; ¿Con quién?; ¿Dónde?; ¿Cuánto has disfrutado?; y ¿Cómo de preferida era para ti?)

\section{Ejemplo:}

\begin{tabular}{|c|c|c|c|c|c|c|c|}
\hline & 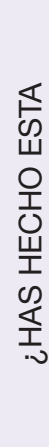 & 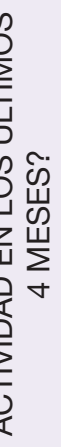 & 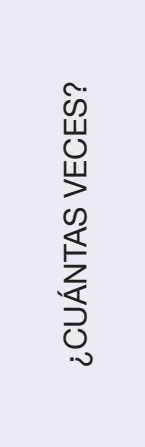 & 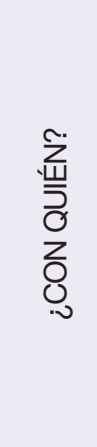 & 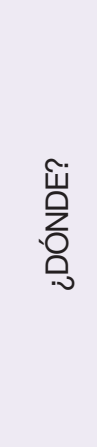 & 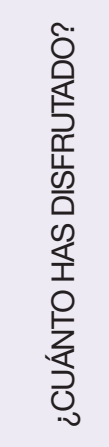 & 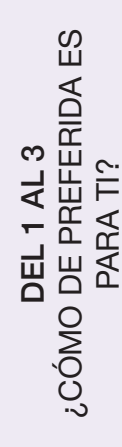 \\
\hline $\begin{array}{l}\text { Ir al parque de } \\
\text { atracciones }\end{array}$ & $\mathrm{SI}$ & NO & & & & & \\
\hline $\begin{array}{l}\text { Jugar a la pelota } \\
\text { en la calle }\end{array}$ & $\mathrm{SI}$ & NO & $\begin{array}{l}\text { 4) dos-tres } \\
\text { veces al mes }\end{array}$ & $\begin{array}{l}\text { 4) Con } \\
\text { amigos }\end{array}$ & $\begin{array}{l}\text { 3) En tu } \\
\text { barrio }\end{array}$ & 4) Mucho & 2 \\
\hline
\end{tabular}

No te preocupes, completaremos juntos el cuestionario. Es importante que preguntes todas las dudas que tengas a medida que vayamos haciendo la tarea. 

ANEXO 2

Cuestionario evaluación familias 



\section{CUESTIONARIO PARA PADRES}

Por favor, responda a las siguientes preguntas referentes a los contextos familiar, social y educativo de su hijo.

La información proporcionada será tratada con total y absoluta confidencialidad.

1.- Información familiar

\begin{tabular}{|c|c|}
\hline \multicolumn{2}{|c|}{ PADRE } \\
\hline Edad & \\
\hline \multirow{6}{*}{ Nivel educativo } & Sin estudios formales \\
\hline & Educación Primaria (o equivalente) \\
\hline & Educación Secundaria (o equivalente) \\
\hline & Bachillerato (o equivalente) \\
\hline & Formación profesional \\
\hline & Estudios Universitarios \\
\hline \multirow{5}{*}{ Ocupación laboral } & Autónomo \\
\hline & Empleado \\
\hline & A tiempo parcial \\
\hline & A tiempo completo \\
\hline & Desempleado \\
\hline
\end{tabular}




\section{MADRE}

\begin{tabular}{|c|c|}
\hline Edad & \\
\hline \multirow{6}{*}{ Nivel educativo } & Sin estudios formales \\
\hline & Educación Primaria (o equivalente) \\
\hline & Educación Secundaria (o equivalente) \\
\hline & Bachillerato (o equivalente) \\
\hline & Formación profesional \\
\hline & Estudios Universitarios \\
\hline \multirow{5}{*}{ Ocupación laboral } & Autónoma \\
\hline & Empleada \\
\hline & A tiempo parcial \\
\hline & A tiempo completo \\
\hline & Desempleada \\
\hline
\end{tabular}

\begin{tabular}{|c|c|}
\hline \multirow{4}{*}{ Ingresos familiares } & Menos de $9.000 € /$ año \\
\hline & De 9.000 a 17.000 €/año \\
\hline & De 17.000 a 30.000 €/año \\
\hline & Más de $30.000 € /$ año \\
\hline
\end{tabular}

Número de hijos

Lugar que ocupa su hijo entre los hermanos 


\begin{tabular}{|l|l|l|}
\hline \multicolumn{2}{|c|}{$\begin{array}{c}\text { Cuántos miembros conviven en la vivienda } \\
\text { (incluyendo su hijo) }\end{array}$} \\
\hline \multirow{4}{*}{ ¿Quiénes son? (señale con X) } & Padre \\
\cline { 2 - 3 } & & Pareja madre \\
\cline { 2 - 3 } & & Madre \\
\cline { 2 - 3 } & & Pareja padre \\
\cline { 2 - 3 } & & Hermanos \\
\cline { 2 - 3 } & & Medios hermanos \\
\cline { 2 - 3 } & & Abuelos \\
\cline { 2 - 2 } & & Tíos \\
\hline & & Otros: \\
\hline
\end{tabular}

2.- Información sobre el cuidado y atenciones específicas del hijo

\begin{tabular}{|l|l|}
\hline \multicolumn{2}{|c|}{ ¿Quién se ocupa del cuidado habitual del niño? } \\
\hline \multirow{2}{*}{ Recibe rehabilitación } & $\mathrm{SI}$ \\
\hline De qué tipo & $\mathrm{NO}$ \\
\hline Dónde & \\
\hline \multirow{2}{*}{ Quién lo cubre } & Seguridad social \\
\hline & Seguro privado \\
\hline
\end{tabular}

¿Pertenecen a alguna asociación de personas con discapacidad o entidad?

(Si la respuesta es "SI" indique cuál)

¿Reciben FORMACIÓN sobre el cuidado y/o atención que debe proporcionar a su hijo?

(Si la respuesta es "SI" indique cuál)

¿Reciben INFORMACIÓN sobre el cuidado y/o atención que debe proporcionar a su hijo? (Si la respuesta es "SI" indique cuál) 
¿Reciben servicios de respiro?

(Si la respuesta es "SI" indique cuál)

¿Dispone de suficiente información sobre métodos de actuación, prestaciones económicas, etc. para la crianza de su hijo?

Dispone su hijo de un transporte adaptado para llegar al centro

\begin{tabular}{|l|l|}
\hline & SI \\
\hline & NO \\
\hline & SI \\
\hline & Público \\
\hline & Privado \\
\hline & NO \\
\hline
\end{tabular}

Entre los siguientes, señale: 1) los apoyos que necesita su hijo, 2) si lo recibe o no y 3 ) quien se lo proporciona (puede marcar varias)

\begin{tabular}{|l|l|l|}
\hline \multirow{2}{*}{ ¿Lo neyo emocional } \\
\hline \multirow{2}{*}{ ¿Lo recibe? } & & $\mathrm{SI}$ \\
\cline { 2 - 3 } & & $\mathrm{NO}$ \\
\hline \multirow{4}{*}{ ¿Quién se lo proporciona? } & & $\mathrm{SI}$ \\
\cline { 2 - 3 } & & $\mathrm{NO}$ \\
\cline { 2 - 3 } & & Familia \\
\cline { 2 - 3 } & & Maestros \\
\cline { 2 - 3 } & & Compañeros \\
\hline & & Otros familiares \\
\hline & & amigos \\
\hline & & Otros profesionales \\
\hline Apoyo académico & & Otros: \\
\hline \multirow{2}{*}{ ¿Lo necesita? } & & SI \\
\hline \multirow{2}{*}{ ¿Lo recibe? } & & NO \\
\hline
\end{tabular}




\begin{tabular}{|c|c|}
\hline \multirow{7}{*}{ ¿Quién se lo proporciona? } & Familia \\
\hline & Maestros \\
\hline & Compañeros \\
\hline & Otros familiares \\
\hline & amigos \\
\hline & Otros profesionales \\
\hline & Otros: \\
\hline \multicolumn{2}{|c|}{ Apoyo físico } \\
\hline \multirow{2}{*}{ ¿Lo necesita? } & SI \\
\hline & NO \\
\hline \multirow{2}{*}{ ¿Lo recibe? } & SI \\
\hline & NO \\
\hline \multirow{7}{*}{ ¿Quién se lo proporciona? } & Familia \\
\hline & Maestros \\
\hline & Compañeros \\
\hline & Otros familiares \\
\hline & Amigos \\
\hline & Otros profesionales \\
\hline & Otros: \\
\hline \multicolumn{2}{|c|}{ Otros apoyos (especificar cuál): } \\
\hline \multirow{2}{*}{ ¿Lo necesita? } & SI \\
\hline & NO \\
\hline \multirow{2}{*}{ ¿Lo recibe? } & $\mathrm{SI}$ \\
\hline & NO \\
\hline \multirow{7}{*}{ ¿Quién se lo proporciona? } & Familia \\
\hline & Maestros \\
\hline & Compañeros \\
\hline & Otros familiares \\
\hline & Amigos \\
\hline & Otros profesionales \\
\hline & Otros: \\
\hline
\end{tabular}


En general, cómo describiría la actitud

de las siguientes personas hacia su hijo:

\begin{tabular}{|l|l|l|}
\hline \multirow{2}{*}{ Los miembros de la familia } \\
\hline \multirow{4}{*}{ En casa } & & Actitud positiva \\
\cline { 2 - 3 } & & Indiferencia \\
\cline { 2 - 3 } & & Actitud negativa \\
\hline \multirow{4}{*}{ En lugares públicos } & & Actitud positiva \\
\hline \multirow{4}{*}{ Oos profesores } & Indiferencia \\
\hline \multirow{3}{*}{ Otros alumnos } & Actitud negativa \\
\hline & & Actitud positiva \\
\cline { 2 - 3 } & & Indiferencia \\
\cline { 2 - 3 } & & Actitud negativa \\
\hline & & Actitud positiva \\
\cline { 2 - 3 } & & Indiferencia \\
\cline { 2 - 3 } & & Actitud negativa \\
\hline
\end{tabular}

\begin{tabular}{l|l|l|}
\hline $\begin{array}{l}\text { ¿Existe colaboración entre la } \\
\text { familia y el colegio para favorecer } \\
\text { el desarrollo educativo de su } \\
\text { hijo? }\end{array}$ & SI \\
\cline { 2 - 2 } $\begin{array}{l}\text { ¿Pertenecen al AMPA del } \\
\text { colegio? }\end{array}$ & $\mathrm{NO}$ \\
\hline \multirow{2}{*}{ ¿Pertenecen al Consejo Escolar? } & $\mathrm{SI}$ \\
\cline { 2 - 2 } & $\mathrm{NO}$ \\
\hline \multirow{2}{*}{ ¿Asisten a ...? } & $\mathrm{SI}$ \\
\hline & $\mathrm{NO}$ \\
\cline { 2 - 2 } & Reuniones escolares \\
\cline { 2 - 2 } & Tutorías escolares \\
\hline & $\begin{array}{l}\text { Actos públicos escolares (fiestas de } \\
\text { navidad, fin de curso, por ejemplo) }\end{array}$ \\
\hline
\end{tabular}

Asiste su hijo a...

Excursiones escolares en horario escolar

Excursiones de varios días de duración

SI

NO

SI

NO 
Excursiones fuera de su ciudad o localidad

\begin{tabular}{|c|c|}
\hline & SI \\
\hline & NO \\
\hline
\end{tabular}

\section{En general, cómo valoraría su nivel de satisfacción respecto a los siguientes aspectos:}

Formación de los profesionales para atender al cuidado y educación de su hijo

\begin{tabular}{|l}
\hline \\
Información que recibe desde el centro escolar sobre \\
el proceso y evolución educativa de su hijo
\end{tabular}

\begin{tabular}{|l|l|}
\hline & \\
\hline & \\
\hline
\end{tabular}

Muy satisfecho

Satisfecho

Apoyos escolares recibidos para el aprendizaje y desarrollo educativo, personal y social del niño

\begin{tabular}{|c|c|}
\hline & \\
\hline & Insatisfecho \\
\hline & Muy satisfecho \\
\hline & Satisfecho \\
\hline & Poco satisfecho \\
\hline & Insatisfecho \\
\hline & Muy satisfecho \\
\hline Las actitudes de los compañeros y alumnos del cen- & Satisfecho \\
\hline tro escolar hacia su hijo & Poco satisfecho \\
\hline & Insatisfecho \\
\hline & Muy satisfecho \\
\hline Apoyos que fomentan la inclusión de su hijo en todos & Satisfecho \\
\hline los contextos (escuela, barrio, etc.) & Poco satisfecho \\
\hline & Insatisfecho \\
\hline
\end{tabular}


Escriba en este apartado cualquier otra cuestión o información que crea de interés para el proceso educativo de su hijo y no se haya contemplado en el cuestionario:

\section{Ya ha terminado}

¡Gracias por su colaboración! 
ANEXO 3

Cuestionario evaluación docentes 



\section{CUESTIONARIO PARA PROFESORES}

Por favor, responda las siguientes preguntas referentes a su formación profesional, al alumno y su entorno.

La información proporcionada será tratada con total y absoluta confidencialidad.

Datos del Centro

Nombre del centro educativo

Tipo de centro educativo

(señale con una $X$ )

Público

Concertado

Privado

\section{Datos del Profesional}

\begin{tabular}{|c|c|}
\hline \multirow{7}{*}{$\begin{array}{l}\text { Formación } \\
\text { (señale con una } X \text { ) }\end{array}$} & Maestro de Educación Primaria \\
\hline & Profesor de Secundaria \\
\hline & Psicólogo, Psicopedagogo \\
\hline & Maestro de Educación Especial \\
\hline & Maestro de Audición y Lenguaje \\
\hline & Trabajador Social \\
\hline & Otro. Indicar cuál: \\
\hline Año de la finalización de la carrera & Años de actividad docente \\
\hline \multicolumn{2}{|c|}{$\begin{array}{l}\text { Formación sobre atención a la diversidad del alumnado } \\
\qquad(\text { breve descripción) }\end{array}$} \\
\hline
\end{tabular}




\begin{tabular}{|l|l|l|}
\hline \multirow{2}{*}{$\begin{array}{l}\text { Relación con el alumno } \\
\text { (señale con una X) }\end{array}$} & Tutor \\
\cline { 2 - 2 } & & Apoyo \\
\cline { 2 - 2 } & & Psicólogo, Psicopedagogo \\
\cline { 2 - 2 } & & Maestro de Educación Especial \\
\cline { 2 - 2 } & Maestro de Audición y Lenguaje \\
\cline { 2 - 2 } & Otro. Indicar cuál: \\
\hline Desde cuándo conoce al alumno & \\
\hline $\begin{array}{l}\text { Ratio profesor-alumno } \\
\text { (en la clase del alumno evaluado) }\end{array}$ & \\
\hline
\end{tabular}

\section{2.- Datos del Alumno}

\begin{tabular}{|c|c|c|c|c|}
\hline Código & & & & \\
\hline Género & Varón & Mujer & Edad & Curso \\
\hline
\end{tabular}

\section{2.- Datos escolares del Alumno}

\begin{tabular}{|l|l|l|}
\hline \multirow{4}{*}{$\begin{array}{l}\text { Tipo de escolarización } \\
\text { del alumno } \\
\text { (señale con una } X)\end{array}$} & Centro ordinario \\
\cline { 2 - 2 } & & Centro ordinario de atención preferente \\
\cline { 2 - 2 } & & Centro de educación especial \\
\cline { 2 - 2 } & Aula sustitutoria \\
\cline { 2 - 2 } & Escolarización combinada \\
\hline
\end{tabular}

\begin{tabular}{|l|l|l|}
\hline $\begin{array}{l}\text { Alumno con Necesidades Específicas } \\
\text { de Apoyo Educativo (ACNEAE) }\end{array}$ & SI & NO \\
\hline
\end{tabular}

\begin{tabular}{|l|l|}
\hline \multicolumn{2}{|c|}{ Si has señalado “SI”, indique grupo (señale con una $X$ ) } \\
\hline & ACNEE: Alumnado con Necesidades Educativas Especiales \\
\hline & ANCE: Alumnado con Necesidades de Compensación Educativa \\
\hline & ALTAS CAPACIDADES INTELECTUALES \\
\hline & ALTERACIONES DE LA COMUNICACIÓN Y DEL LENGUAJE \\
\hline & DIFICULTADES ESPECÍFICAS DE APRENDIZAJE \\
\hline & CAPACIDAD INTELECTUAL LÍMITE \\
\hline
\end{tabular}


Si ha señalado el grupo acnee (alumnado con necesidades educativas especiales), señale subgrupo

\begin{tabular}{|c|c|}
\hline TIPOLOGÍA & CATEGORÍA (SUBGRUPO) \\
\hline \multirow{2}{*}{ Discapacidad Física } & Físico Motórico \\
\hline & Físico No Motórico \\
\hline \multirow{4}{*}{ Discapacidad Psíquica } & Psíquico Leve \\
\hline & Psíquico Moderado \\
\hline & Psíquico Grave \\
\hline & Psíquico Profundo \\
\hline \multicolumn{2}{|l|}{$\mathbf{C l}$} \\
\hline \multicolumn{2}{|l|}{$\begin{array}{l}\text { Prueba de evaluación del CI } \\
\text { (si se dispone de la información) }\end{array}$} \\
\hline \multicolumn{2}{|l|}{$\begin{array}{l}\text { Fecha de la aplicación } \\
\text { (si se dispone de la información) }\end{array}$} \\
\hline \multirow{3}{*}{ Discapacidad Auditiva } & Hipoacusia Media \\
\hline & Hipoacusia Severa \\
\hline & Hipoacusia Profunda \\
\hline \multirow{2}{*}{ Discapacidad Visual } & Deficiencia Visual \\
\hline & Ceguera \\
\hline \multirow{5}{*}{ Trastorno General del Desarrollo } & Trastorno Autista \\
\hline & Trastorno de Rett \\
\hline & Trastorno de Asperger \\
\hline & Trastorno Desintegrativo Infantil \\
\hline & $\begin{array}{l}\text { Trastorno Generalizado del } \\
\text { Desarrollo no Especificado }\end{array}$ \\
\hline $\begin{array}{l}\text { Trastornos Graves de la } \\
\text { Personalidad }\end{array}$ & $\begin{array}{l}\text { Trastornos Graves de la } \\
\text { Personalidad }\end{array}$ \\
\hline \multirow{4}{*}{$\begin{array}{l}\text { Trastornos por Déficit de } \\
\text { Atención y Comportamiento } \\
\text { Perturbador }\end{array}$} & $\begin{array}{l}\text { Trastorno por Déficit de Atención } \\
\text { con Hiperactividad }\end{array}$ \\
\hline & Trastorno Disocial \\
\hline & Trastorno Negativista Desafiante \\
\hline & $\begin{array}{l}\text { Trastorno de Comportamiento } \\
\text { Perturbador no Especificado }\end{array}$ \\
\hline
\end{tabular}


Si ha señalado el grupo ance (alumnado con necesidades de compensación educativa) señale subgrupo

\begin{tabular}{|c|c|}
\hline \multicolumn{2}{|r|}{ CATEGORÍA (SUBGRUPO) } \\
\hline \multirow{2}{*}{ Inmigrantes } & $\begin{array}{l}\text { Incorporación Tardía al Sistema Educativo } \\
\text { Español: Desconocimiento del Idioma }\end{array}$ \\
\hline & $\begin{array}{l}\text { Incorporación Tardía al Sistema Educativo } \\
\text { Español: Desfase Curricular }\end{array}$ \\
\hline $\begin{array}{l}\text { Especiales Condiciones } \\
\text { Personales }\end{array}$ & Hospitalización / Convalecencia Prolongada \\
\hline \multirow{5}{*}{$\begin{array}{l}\text { Especiales Condiciones } \\
\text { Geográficas, Sociales y } \\
\text { Culturales }\end{array}$} & Minorías \\
\hline & Ambiente Desfavorecido \\
\hline & Exclusión Social o Marginalidad \\
\hline & Temporeros / Feriantes \\
\hline & Aislamiento Geográfico \\
\hline
\end{tabular}

Si ha señalado el grupo alteraciones de la comunicación y del lenguaje, señale subgrupo

\begin{tabular}{|l|l|l|}
\hline \multicolumn{2}{|c|}{ TIPOLOGíA } & \multicolumn{1}{|c|}{ CATEGORÍA } \\
\hline \multirow{4}{*}{$\begin{array}{l}\text { Trastornos de } \\
\text { Comunicación } \\
\text { del Lenguaje }\end{array}$} & & Afasia \\
\cline { 2 - 3 } & & Disfasia \\
\cline { 2 - 3 } & & MutismoSelectivo \\
\cline { 2 - 3 } & & Disartria \\
\cline { 2 - 3 } & & Disglosia \\
\cline { 2 - 3 } & & Disfemia \\
\hline \multirow{2}{*}{ Otros } & & Retraso Simple del Lenguaje \\
\hline & & Dislalia \\
\hline
\end{tabular}


Si ha señalado el grupo altas capacidades intelectuales, señale subgrupo

\begin{tabular}{|l|l|}
\hline \multicolumn{2}{|c|}{ TIPOLOGíA (SUBGRUPO) } \\
\hline & Superdotación Intelectual \\
\hline & Talento Simple o Complejo \\
\hline & Precocidad Intelectual \\
\hline
\end{tabular}

SI HA SEÑALADO EL GRUPO DIFICULTADES ESPECÍFICAS DE APRENDIZAJE, SEÑALE SUBGRUPO

\begin{tabular}{|l|l|}
\hline \multicolumn{2}{|l|}{ TIPOLOGÍA (SUBGRUPO) } \\
\hline & Dislexia \\
\hline & Disortografía \\
\hline & Discalculia \\
\hline & Lectoescritura \\
\hline
\end{tabular}

\section{Apoyos}

\begin{tabular}{|l|l|l|}
\hline \multicolumn{2}{|c|}{ Apoyos que recibe } & No Horas semanales \\
\hline & Apoyo de PT (pedagogía-terapéutica) & \\
\hline Apoyos de AL (logopedas) & \\
\hline Educación Compensatoria & \\
\hline Apoyo de iguales y compañeros & \\
\hline $\begin{array}{l}\text { Apoyos con TIC } \\
\text { (tecnologías de la información y la comunicación) }\end{array}$ & \\
\hline & Otros (especificar): & \\
\hline
\end{tabular}


4. Otros datos del alumno:

\begin{tabular}{|l|l|l|}
\hline \multicolumn{1}{|c|}{ Problemas de comportamientos asociados } & SI & NO \\
\hline \multirow{5}{*}{$\begin{array}{l}\text { Si la respuesta es SI, } \\
\text { indicar cuáles }\end{array}$} & $\begin{array}{l}\text { Comportamientos autodestructivos } \\
\text { (autolesiones, conductas de pica, } \\
\text { intento de suicidio,...) }\end{array}$ \\
\cline { 2 - 4 } & $\begin{array}{l}\text { Comportamientos hetero-destructivos } \\
\text { (lesiones a otros, destrucción de la } \\
\text { propiedad, robos,...) }\end{array}$ \\
\cline { 2 - 4 } & $\begin{array}{l}\text { Comportamientos sexual inapropiado } \\
\text { (agresiones sexuales, conductas } \\
\text { sexuales no agresivas pero inapropiadas...) }\end{array}$ \\
\cline { 2 - 4 } & $\begin{array}{l}\text { Otros (rabietas, absentismo escolar, abu- } \\
\text { so de sustancias, o trastornos de } \\
\text { salud mental...) } \\
\text { Indicar cuáles _ }\end{array}$ \\
\hline
\end{tabular}

\begin{tabular}{|c|c|c|c|}
\hline \multicolumn{2}{|c|}{ Problemas de salud asociados } & SI & NO \\
\hline \multirow{4}{*}{$\begin{array}{l}\text { Si la respuesta es SI, } \\
\text { indicar cuáles }\end{array}$} & \multicolumn{3}{|l|}{ Cuidados respiratorios } \\
\hline & \multicolumn{3}{|l|}{ Asistencia en la alimentación } \\
\hline & \multicolumn{3}{|l|}{ Cuidados de la piel } \\
\hline & \multicolumn{3}{|c|}{ Otros, Indicar cuál } \\
\hline
\end{tabular}


5. Datos del centro educativo:

Señale con una $X$ los servicios de los que dispone el centro para la supresión de barreras arquitectónicas y fomento de la inclusión educativa

\begin{tabular}{|c|}
\hline Transporte escolar adaptado \\
\hline $\begin{array}{l}\text { Rampas adaptadas } \\
\text { (anchura, inclinación de la pendiente, goma antideslizante, etc.) }\end{array}$ \\
\hline $\begin{array}{l}\text { Puertas adaptadas } \\
\text { (anchura, peso, mecanismos facilitadores para su apertura, etc.) }\end{array}$ \\
\hline Ascensor adaptado (amplitud, barras de apoyo, etc.) \\
\hline $\begin{array}{l}\text { Aseos adaptados (amplitud, barras de apoyo, cisterna accesible, suelo } \\
\text { antideslizante, picaporte adaptado, lavabo adaptado, etc.) }\end{array}$ \\
\hline $\begin{array}{l}\text { Pasillos adaptados } \\
\text { (amplitud, esquinas redondeadas, barandillas junto a las escaleras, etc.) }\end{array}$ \\
\hline $\begin{array}{l}\text { Carteles con información e imágenes para indicar el comedor, el gimna- } \\
\text { sio, la secretaría, las aulas, etc. }\end{array}$ \\
\hline $\begin{array}{l}\text { Aulas adaptadas } \\
\text { (entrada accesible, amplitud, mobiliario específico y adaptado, etc.) }\end{array}$ \\
\hline $\begin{array}{l}\text { Materiales escolares adaptados (soportes, atriles, tijeras especiales, } \\
\text { férulas postulares, adaptaciones para el teclado del ordenador, sistemas } \\
\text { aumentativos y alternativos de comunicación, etc.) }\end{array}$ \\
\hline $\begin{array}{l}\text { Materiales curriculares adaptados } \\
\text { (libros de texto, audiovisuales, multimedia, etc.) }\end{array}$ \\
\hline Recursos TIC (pizarra digital, aula 2.0., internet, redes, etc.) \\
\hline $\begin{array}{l}\text { Patio (accesibilidad, amplitud, división de espacios, suelo antideslizante, } \\
\text { fuente adaptada, etc.) }\end{array}$ \\
\hline Comedor escolar \\
\hline $\begin{array}{l}\text { Comedor escolar adaptado } \\
\text { (entrada accesible, amplitud, mobiliario específico, etc.) }\end{array}$ \\
\hline $\begin{array}{l}\text { Personal educativo especializado } \\
\text { (logopedas, pedagogos, psicólogos, fisioterapeutas, etc.) }\end{array}$ \\
\hline $\begin{array}{l}\text { Personal colaborador (educadores, monitores, voluntarios, miembros } \\
\text { de la comunidad participan en el proyecto educativo del centro, etc.) }\end{array}$ \\
\hline
\end{tabular}


Cómo describiría la actitud de las siguientes personas hacia el alumno

\section{El personal docente del centro}

\begin{tabular}{|c|c|}
\hline \multirow{3}{*}{ En clase } & Actitud positiva \\
\hline & Indiferencia \\
\hline & Actitud negativa \\
\hline \multirow{3}{*}{ Fuera de clase } & Actitud positiva \\
\hline & Indiferencia \\
\hline & Actitud negativa \\
\hline \multicolumn{2}{|l|}{ Otros alumnos } \\
\hline \multirow{3}{*}{ En clase } & Actitud positiva \\
\hline & Indiferencia \\
\hline & Actitud negativa \\
\hline \multirow{3}{*}{ Fuera de clase } & Actitud positiva \\
\hline & Indiferencia \\
\hline & Actitud negativa \\
\hline
\end{tabular}

Responda de forma sincera a las siguientes cuestiones. Sus respuestas

servirán para conocer mejor la realidad del centro, las barreras y facilitadores

de éste para una educación integral de los alumnos.

PIENSE EN EL ALUMNO AL QUE VA DIRIGIDA LA EVALUACIÓN y

responda a las preguntas que correspondan haciendo referencia a la

actuación del centro educativo con respecto a este alumno en cuestión.

Valore la colaboración entre el personal docente del centro y la familia

\begin{tabular}{|l|l|}
\hline Frecuente \\
\hline & Ocasional \\
\hline Infrecuente \\
\hline Totalmente de Acuerdo \\
\hline De Acuerdo \\
\hline Desacuerdo \\
\hline $\begin{array}{l}\text { Totalmente en } \\
\text { Desacuerdo }\end{array}$ \\
\hline
\end{tabular}




\begin{tabular}{|c|c|}
\hline \multirow{4}{*}{$\begin{array}{l}\text { El logro del alumno se valora en relación } \\
\text { a sus propias posibilidades en vez de en } \\
\text { comparación con el logro académicos de } \\
\text { otros alumnos }\end{array}$} & Totalmente de Acuerdo \\
\hline & De Acuerdo \\
\hline & Desacuerdo \\
\hline & $\begin{array}{l}\text { Totalmente en } \\
\text { Desacuerdo }\end{array}$ \\
\hline \multirow{4}{*}{$\begin{array}{l}\text { El profesorado hace uso de nuevos } \\
\text { materiales y recursos para el fomento del } \\
\text { aprendizaje y la participación escolar del } \\
\text { alumno (por ejemplo, plataformas intranet, } \\
\text { sistemas aumentativos y alternativos de } \\
\text { comunicación (SAACs), etc.) }\end{array}$} & Totalmente de Acuerdo \\
\hline & De Acuerdo \\
\hline & Desacuerdo \\
\hline & $\begin{array}{l}\text { Totalmente en } \\
\text { Desacuerdo }\end{array}$ \\
\hline \multirow{4}{*}{$\begin{array}{l}\text { Se tiene en cuenta las diferencias, la } \\
\text { heterogeneidad entre los estudiantes (por } \\
\text { ejemplo, los diferentes estilos de aprendizaje } \\
\text { del alumnado, sus motivaciones, etc.) }\end{array}$} & Totalmente de Acuerdo \\
\hline & De Acuerdo \\
\hline & Desacuerdo \\
\hline & $\begin{array}{l}\text { Totalmente en } \\
\text { Desacuerdo }\end{array}$ \\
\hline \multirow{4}{*}{$\begin{array}{l}\text { El profesorado trabaja colaborativamente (en } \\
\text { equipos o compartiendo aula) para introducir } \\
\text { mejoras pedagógicas que permitan el éxito } \\
\text { del alumno }\end{array}$} & Totalmente de Acuerdo \\
\hline & De Acuerdo \\
\hline & Desacuerdo \\
\hline & $\begin{array}{l}\text { Totalmente en } \\
\text { Desacuerdo }\end{array}$ \\
\hline \multirow{2}{*}{$\begin{array}{l}\text { Participa el centro en proyectos de } \\
\text { innovación y mejora docente }\end{array}$} & SI \\
\hline & NO \\
\hline \multirow{2}{*}{$\begin{array}{l}\text { Participa el profesorado en cursos para } \\
\text { mejorar su formación profesional (por } \\
\text { ejemplo, curso de aprendizaje colaborativo } \\
\text { basado en proyectos, etc.) }\end{array}$} & SI \\
\hline & NO \\
\hline \multirow{2}{*}{$\begin{array}{l}\text { Reciben información actualizada sobre } \\
\text { Inclusión Educativa y Atención a la } \\
\text { Diversidad (por ejemplo, buenas prácticas } \\
\text { docentes relacionadas con las respuesta } \\
\text { educativa a ACNEAEs) }\end{array}$} & SI \\
\hline & NO \\
\hline \multirow{2}{*}{$\begin{array}{l}\text { Los informes de evaluación psicopedagógica } \\
\text { dan directrices claras sobre los apoyos } \\
\text { educativos específicos que necesita el } \\
\text { alumno para aumentar su participación } \\
\text { curricular y social }\end{array}$} & SI \\
\hline & NO \\
\hline
\end{tabular}




\begin{tabular}{|c|c|}
\hline \multirow{2}{*}{$\begin{array}{l}\text { Se llevan a cabo proyectos para la preven- } \\
\text { ción y/o reducción del bulling escolar en } \\
\text { los que se implica a todos los estudiantes y } \\
\text { docentes del centro }\end{array}$} & SI \\
\hline & NO \\
\hline \multirow{4}{*}{$\begin{array}{l}\text { Se implica activamente al alumno en su } \\
\text { propio aprendizaje (por ejemplo, suscitando } \\
\text { el deseo por aprender o la capacidad de } \\
\text { autoevaluación en el alumnado) }\end{array}$} & Totalmente de Acuerdo \\
\hline & De Acuerdo \\
\hline & Desacuerdo \\
\hline & $\begin{array}{l}\text { Totalmente en } \\
\text { Desacuerdo }\end{array}$ \\
\hline \multirow{4}{*}{$\begin{array}{l}\text { Los docentes de aula y los docentes de } \\
\text { apoyo comparten el trabajo con estudiantes } \\
\text { de forma individual, en grupos y con toda la } \\
\text { clase }\end{array}$} & Totalmente de Acuerdo \\
\hline & De Acuerdo \\
\hline & Desacuerdo \\
\hline & $\begin{array}{l}\text { Totalmente en } \\
\text { Desacuerdo }\end{array}$ \\
\hline \multirow{4}{*}{$\begin{array}{l}\text { Se estimula al alumno con independencia de } \\
\text { su rendimiento académico o su discapacidad } \\
\text { para que participe en las excursiones y viajes } \\
\text { escolares }\end{array}$} & Totalmente de Acuerdo \\
\hline & De Acuerdo \\
\hline & Desacuerdo \\
\hline & $\begin{array}{l}\text { Totalmente en } \\
\text { Desacuerdo }\end{array}$ \\
\hline \multirow{3}{*}{$\begin{array}{l}\text { Se aprovechan los recursos de la comunidad } \\
\text { para el desarrollo educativo de los estu- } \\
\text { diantes (recursos familiares, profesionales } \\
\text { de otros ámbitos como las asociaciones, } \\
\text { infraestructuras deportivas y culturales, etc.) }\end{array}$} & Frecuentemente \\
\hline & Ocasionalmente \\
\hline & Infrecuentemente \\
\hline \multirow{4}{*}{$\begin{array}{l}\text { Se evita el uso de estereotipos, etiquetas, } \\
\text { etc., para referirse al estudiante (por ejemplo, } \\
\text { "Jorge no habla porque es autista") }\end{array}$} & Totalmente de Acuerdo \\
\hline & De Acuerdo \\
\hline & Desacuerdo \\
\hline & $\begin{array}{l}\text { Totalmente en } \\
\text { Desacuerdo }\end{array}$ \\
\hline
\end{tabular}


Registre en el siguiente apartado aquellas cuestiones o información sobre la educación del alumno, su propia formación docente, la política y clima del centro, etc., que no se hayan tenido en cuenta y considere usted relevantes:

\section{Ya ha terminado}

¡Gracias por su colaboración! 
